José Roberto Marques

Aplicação da Transformada de Hilbert-Huang na Análise das Vibrações dos Motores de Indução de Máquinas Ferramentas

Tese apresentada à Escola Politécnica da Universidade de São Paulo como parte dos requisitos para a obtenção do título de Doutor em Ciências

Área de concentração: Engenharia Elétrica Sistemas de Potência.

Orientador: Prof. Dr. José Roberto Cardoso

São Paulo

2013 
José Roberto Marques

Aplicação da Transformada de Hilbert-Huang na Análise das Vibrações dos Motores de Indução de Máquinas Ferramentas

Tese apresentada à Escola Politécnica da Universidade de São Paulo como parte dos requisitos para a obtenção do título de Doutor em Ciências

Área de concentração: Engenharia Elétrica Sistemas de Potência.

Orientador: Prof. Dr. José Roberto Cardoso

São Paulo 
Este exemplar foi revisado e corrigido em relação à versão original, sob responsabilidade única do autor e com a anuência de seu orientador.

São Paulo, 02 de julho de 2013.

Assinatura do autor

Assinatura do orientador

FICHA CATALOGRÁFICA

Marques, José Roberto

Aplicação da transformada de Hilbert-Huang na análise das vibrações dos motores de indução de máquinas-ferramenta /

J.R. Marques. -- versão corr. -- São Paulo, 2013.

$332 \mathrm{p}$.

Tese (Doutorado) - Escola Politécnica da Universidade de São Paulo. Departamento de Engenharia de Energia e Automação Elétricas.

1.Processamento de sinais 2.Motores de indução 3.Maquinas-ferramenta 4.Transformada de Hilbert-Huang I.Universidade de São Paulo. Escola Politécnica. Departamento de Engenharia de Energia e Automação Elétricas II.t. 
Dedicatória 
Agradecimentos

A Deus por todas as bênçãos, as que vi e que não vi.

À Regina que mantém uma alegria vívida, paciência perene e disposição ímpar mesmo diante dos meus piores dias. Você foi o esteio deste trabalho, sem o qual nada se realizaria.

À Mayara por ser o meu projeto de continuidade.

À minha mãe Maria Inês e a meu pai Faride (in memorian) por seu apoio e incentivo.

Ao prof. Dr. José Roberto Cardoso, pela orientação e amizade, pelo apoio na solicitação dos softwares e incentivo para as superações dos problemas que surgiram ao longo desta jornada. Ao meu caro amigo fica uma dívida de gratidão que se perpetuará no tempo.

A profa. Dra. Izabel Fernanda Machado que me recebeu no departamento de Engenharia Mecatrônica da Escola Politécnica da USP, acompanhou todos os testes realizados em máquina ferramenta, discutiu os resultados comigo e enfim deu todo o suporte que necessitei na área de engenharia mecânica. Sua orientação foi imprescindível.

À meus caros colegas MSc. Patricia Alves Barbosa e MSc. Marcelo Bertolete Carneiro pelo suporte nos testes realizados na máquina ferramenta.

Aos funcionários do Laboratório de Máquinas Operatrizes do Departamento de Engenharia Mecatrônica e Sistemas Mecânicos da Escola Politécnica da USP pela ajuda e disposição na preparação dos testes.

Á todos que de uma forma ou outra contribuíram para a realização deste trabalho. 
Resumo

Este trabalho tem seu foco na monitoração dos processos de usinagem das máquinas ferramentas sem a utilização de sensores dedicados à medição direta das grandezas mecânicas envolvidas no processo de usinagem em si. Assim sendo, optou-se por um método de medição indireta utilizando um estimador de potência e torque baseado nas grandezas elétricas na entrada de energia do motor de indução da máquina ferramenta.

O núcleo central do trabalho consiste na medição de processos de usinagem utilizando um dinamômetro de alta precisão próprio para máquina ferramenta para obter os valores médios e os modos de vibração do processo máquina ferramenta-usinagem e fazer a confrontação com os mesmos dados obtidos pelo estimador de torque.

A pesquisa realizada utilizou ferramentas clássicas de processamento de sinais, como é o caso da FFT, assim como duas poderosas ferramentas atuais, a transformada de wavelet (WT) e a transformada de Hilbert-Huang (HHT). Em adição foi utilizado um processo de otimização para a determinação dos parâmetros do motor de indução "on-line" baseado em uma metaheurística denominada busca de harmonia (Harmony Search - HS)

Palavras-chave: Parâmetros do motor de indução, Máquina ferramenta, Torno, busca de harmonia, Transformada Rápida de Fourier, Transformada de HilbertHuang, Transformada de wavelet, vibrações em maquinas ferramentas, trepidações em máquinas ferramentas 
Abstract

This work focuses on monitoring the machining processes in machine tools without the use of dedicated transducers to directly measure mechanicals quantities of the machining process. The approached method used the option of measuring the power and torque through a estimator based in the electrical quantities in the input of the induction motor used by machine tool.

The core of the work consists in the measuring the mechanical processes of machining using a high precision dynamometer specified to machine tool to get the average values of mechanical quantities and the vibration modes of the set machine tool-machining process, the objective is to compare the same data group got from dynamometer and estimator.

The research data was based on classical analysis tool such as Fourier transform (FFT) and on modern powerful tools such as wavelet transforms (WT) and Hilbert-Huang transform (HHT). To refine the measuring process of average values of torque and power using the induction motor a method to estimates the motor parameters was added based on an optimization method named harmony search (HS).

Keywords: Induction motor parameters, machine tool, lathe, harmony search, Fast Fourier Transform (FFT), wavelet transform (WT), Hilbert-Huang Transform (HHT), machine tool vibrations, machine tool chattering 
1.1 Relação entre os principais processos de Usinagem 33

1.2 Os esforços de usinagem presentes no processo de torneamento ..... 35

1.3 Efeitos relacionados a potência no processo de usinagem ................. 36

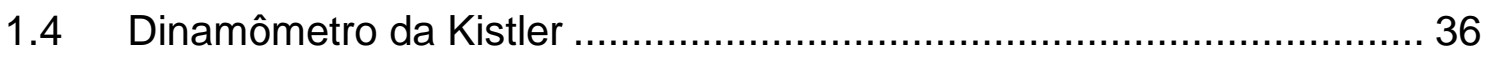

2.1 O posicionamento das bobinas do estator e os vetores espaciais ....... 42

2.2 Efeitos das transformações de Park das coordenadas generalizadas . 47

2.3 Estimador do torque e dos fluxos concatenados do estator ................ 50

2.4 método do sistema adaptativo com modelo de referência...................... 52

2.5 Efeito do Fator de desequilíbrio de fase sobre o torque em função do VUF . 55

2.6 Simulação da forma de onda do torque e efeito do desequilíbrio de fase 55

2.7 Esquema geral de acionamento de um torno mecânico simples... 57

2.8 Modelagem de desbalanceamento rotativo com 1 grau de liberdade... 58

2.9 Resposta de frequência de um sistema rotativo desbalanceado.......... 59

2.10 Perfil esperado para a força de corte para o caso ideal ........................ 61

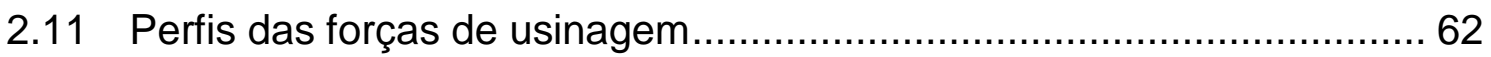

2.12 Árvore de decomposição de um sinal em três níveis da WT ................. 65

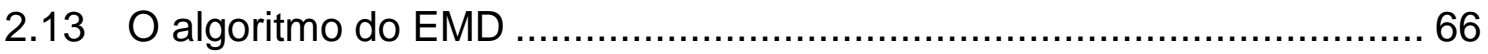

2.14 Relação entre as categorias de sinais e as ferramentas de análise ...... 68

2.15 Composição da função analítica ..................................................... 71

$2.16 \mathrm{O}$ espectro de frequências do sinal $\mathrm{x}(\mathrm{t})$ e sua função analítica $z(\mathrm{t}) \quad \ldots . .72$ 
2.17 Processamento do sinal $x(t)$ para a obtenção da função analítica......... 73

2.18 Obtenção do sinal analítico a partir da FFT ....................................... 73

2.19 Processo de improvisação do algoritmo HS ....................................... 76

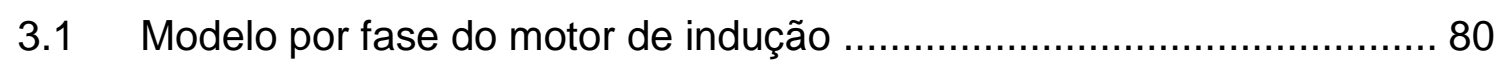

3.2 Resistência do estator em função da corrente eficaz do estator ............ 81

3.3 Estimador da derivada do fluxo de referência do estator ........................ 82

3.4 Parâmetros Ls, Lr, Lm e $\sigma$ obtidos em função do carregamento ............ 83

3.5 Esquema de estimação dos parâmetros x1, x2 e x3 …….................... 83

3.6 Estimador da derivada do fluxo concatenado de referência do rotor ... 84

3.7 de Rr em função do carregamento do motor ..................................... 86

3.8 Comparação entre a corrente rms medida e calculada ......................... 87

3.9 Erro entre os valores eficazes das correntes medida e calculada ......... 87

3.10 Correntes eficazes de fase medida no estator e estimada no rotor ........ 88

3.11 Comportamento do escorregamento em função do valor eficaz............. 88

3.12 Estimador de torque e potência efetiva na carga.................................. 89

3.13 Estimador do torque líquido na carga .............................................. 90

3.14 Comportamento das perdas no núcleo mais perdas rotacionais ........... 91

3.15 Comportamento das potências medida e estimada na carga ............... 91

3.16 Erro porcentual da potência estimada em relação a potência medida . 92

3.17 Potências medida e estimada ............................................................ 92

3.18 Torque estimado e medido .............................................................. 93

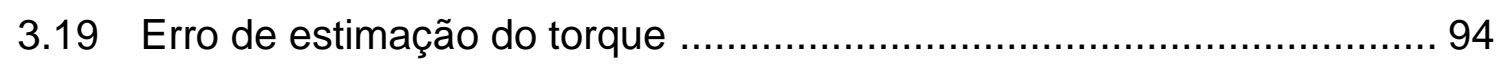

3.20 Velocidades medida e estimada ……………............................... 95

3.21 Erro de velocidade em função do carregamento porcentual ................. 95

3.22 Velocidades medida e estimada em radianos ..................................... 96

3.23 Erro de velocidade em função do carregamento porcentual...................96 
3.24 Esquema operacional do setup experimental

3.25 Esquema do sistema de aquisição com os sensores de tensão e corrente 98

3.26 Conexão do sistema de aquisição de dados do motor de indução ........ 99

3.27 Dinamômetro estacionário Kistler 9441B montado na torre do torno .. 100

3.28 Diagrama com todas as etapas do processo implementado 101

3.29 Comportamento da resistência do estator 101

3.30 Curvas de torque do dinamômetro 102

3.31 Potencia ativa na entrada do motor, potência de corte medida 105

3.32 Correntes eficazes medida e calculada com os parâmetros. 105

3.33 Potência mecânica estimada e ajustada. 106

3.34 As potência medida e estimada 107

3.35 Erro porcentual AM função das profundidades dos passe 107

3.36 Torques estimado e medido e (b) porcentual de erro 108

4.1 Perfil das forças da UCP de $0,5 \mathrm{~mm}$ 111

4.2 Perfil das três forças na região com dinamômetro em vazio 112

4.3 Espectro da força passiva em vazio 112

4.4 Espectro da força de avanço em vazio 113

4.5 Espectro da força de corte em vazio 113

4.6 Gráfico das forças de corte e de avanço com UCP de $0,5 \mathrm{~mm}$ 114

4.7 Diagrama espectral da força de corte para UCP de $0,5 \mathrm{~mm}$ 115

4.8 Espectro da região de baixas frequências da UCP de 0,5mm............ 115

4.9 Estimativa da composição do sinal modulado de $8 \mathrm{~Hz}$........................ 116

4.10 Espectro da região altas frequências do dinamômetro Kistler .............. 116

4.11 Espectro da força de avanço da UCP de 0,5mm 117 
4.12 Espectro da força de avanço para a UCP de $0,5 \mathrm{~mm}$ em baixas frequências

4.13 Detalhe parcial do espectro da força de corte

4.14 Espectro da força de avanço para a UCP de $0,5 \mathrm{~mm}$

4.15 Região de maior concentração de energia nas frequências mais altas

4.16 Perfil das forças de usinagem para passe de $1,0 \mathrm{~mm}$

4.17 Gráfico das forças de corte e de avanço com UCP de 1,0 mm

4.18 Espectro da força de corte na região de usinagem

4.19 Espectro contínuo (a) e de linhas (b) correspondente ao espectro da figura 4.18

4.20 O espectro de linhas do detalhamento da figura 4.19(b)

4.21 Espectro contínuo e de linhas da região entre $150 \mathrm{~Hz}$ e $200 \mathrm{~Hz}$

4.22 Espectro contínuo e de linhas da região entre $300 \mathrm{~Hz}$ e $350 \mathrm{~Hz}$

4.23 Espectro completo da força de avanço para a situação de UCP de $1,0 \mathrm{~mm}$

4.24 Espectro contínuo e de linhas da região entre $150 \mathrm{~Hz}$ e $225 \mathrm{~Hz}$ 125

4.25 Espectro Espectro contínuo (a) e de linhas (b) da região entre $325 \mathrm{~Hz}$ e $375 \mathrm{~Hz}$. 126

4.26 Perfil das forças de UCP de $1,5 \mathrm{~mm}$. 127

4.27 Gráfico das forças de corte e de avanço do teste com UCP de $1,5 \mathrm{~mm}$

4.28 Espectro da força de corte na região de usinagem 128

4.29 Espectro contínuo e de linhas correspondente ao espectro da figura 4.28

4.30 Espectro de linhas da parcela de frequencias mais baixas do espectro

4.31 Espectro contínuo (a) e de linhas (b) da região entre $150 \mathrm{~Hz}$ e $220 \mathrm{~Hz} 129$

4.32 Espectro da força de avanço na região de usinagem .......................... 130

4.33 Espectro contínuo (a) e de linhas (b) da região entre $\mathrm{OHz}$ e $25 \mathrm{~Hz} \ldots \ldots . .131$ 
4.34 Espectro de linhas de duas regiões de baixa frequencia da força de avanço

4.35 Espectro da região entre $150 \mathrm{~Hz}$ e $250 \mathrm{~Hz}$ para UCP de $1,5 \mathrm{~mm}$ 132

4.36 Perfil ideal da força de corte para o caso de corte interrompido 133

4.37 Estimação da forma de onda até a 10 ${ }^{\mathrm{a}}$ harmônicam 134

4.38 Forças de corte, de avanço e passiva com $\mathrm{Cl}$ e $0,5 \mathrm{~mm}$ 134

4.39 Espectro da força de corte do sinal mostrado na figura 4.38(b) ......... 135

4.40 Detalhes do espectro da figura 4.39 135

4.41 Detalhe do sinal de força de corte interrompido para UCP de $0,5 \mathrm{~mm} 136$ 4.42 Espectro da força de corte com as frequências das oscilações dominantes.

4.43 Espectro da força de avanço para o caso de UCP de $0,5 \mathrm{~mm}$ 137

4.44 Espectro parcial da força de avanço com as oscilações dominantes .. 138

4.45 Perfil detalhado da força de avanço para a situação de Cl e UCP de $0,5 \mathrm{~mm}$

4.46 Espectro da força de avanço das frequências entre $20 \mathrm{~Hz}$ e $200 \mathrm{~Hz} \ldots 139$

4.47 Espectro parcial da força de avanço das frequências entre $200 \mathrm{~Hz}$ e $400 \mathrm{~Hz}$ 140

4.48 Perfil do conjunto das três forças para Cl e UCP de 1,0mm .............. 140

4.49 Espectro total da força de corte para o caso de Cl e UCP de 1,0m .... 141

4.50 Efeito do $\mathrm{Cl}$ sobre a força de corte ................................................ 141

4.51 Espectro da força de corte da região entre $0 \mathrm{~Hz}$ e $25 \mathrm{~Hz}$.................... 142

4.52 Espectro contínuo da força de corte da região entre $25 \mathrm{~Hz}$ e $100 \mathrm{~Hz}$... 142

4.53 Espectro da força de avanço com Cl e UCP de 1,0mm 143

4.54 Espectro contínuo da força de avanço na região entre $0 \mathrm{~Hz}$ e $25 \mathrm{~Hz} \ldots . .144$

4.55 Perfil do conjunto das três forças para usinagem com Cl e UCP de $1,5 \mathrm{~mm}$ 144

4.56 Espectro total da força de corte para $\mathrm{Cl}$ e UCP de $1,5 \mathrm{~mm}$ 145 
4.57 Efeito do $\mathrm{Cl}$ sobre a força de corte para a UCP de $1,5 \mathrm{~mm} \ldots \ldots \ldots \ldots \ldots \ldots . . . .145$

4.58 Espectro da região entre $\mathrm{OHz}$ e $25 \mathrm{~Hz}$ para $\mathrm{Cl}$ e UCP de $1,5 \mathrm{~mm} \ldots \ldots . .146$

4.59 Espectro contínuo da força de corte na região entre $\mathrm{OHz}$ e $100 \mathrm{~Hz} \ldots . .146$

4.60 Espectro da força de avanço da usinagem com Cl e UCP de 1,5mm . 147

4.61 Detalhe da força de avanço com $\mathrm{Cl}$ e de $1,5 \mathrm{~mm}$............................ 148

4.62 Espectro da força de avanço na região entre $0 \mathrm{~Hz}$ e $25 \mathrm{~Hz} \ldots \ldots \ldots \ldots \ldots \ldots . . . . .148$

4.63 Espectro contínuo da força de avanço na região entre $0 \mathrm{~Hz}$ e $25 \mathrm{~Hz} \ldots . .149$

4.64 Acomodação oscilante da força de avanço ...................................... 149

4.65 Modelo matemático do porta fermenta na operação de usinagem ....... 150

4.66 Força de corte com Cl e UCP de 1,0mm ......................................... 151

5.1 Perfis das forças de corte medidas pelo dinamômetro Kistler ............ 154

5.2 Espectro do sinal do dinamômetro Kistler com ucp de 0,5mm ............ 157

5.3 Inversão de fase do sinal analítico da primeira IMF ............................ 157

5.4 Espectros locais de algumas componentes mais evidentes ............... 158

5.5 Espectros locais referentes as IMF-2(a) e IMF-3(b) .......................... 159

5.6 Parcela de baixas frequências do espectro da força de corte ............. 159

5.7 Espectro da região detectada pela HHT nas IMFs 3 e $4 \ldots \ldots \ldots \ldots \ldots \ldots . . . . . . .160$

5.8 Frequências das IMF-1 (a) e IMF-2 (b) em função do tempo .............. 161

5.9 Módulos das IMF-1 (a) e IMF-2 (b) em função do tempo...................... 161

5.10 Espectro da região detectada pela HHT nas IMFs 3 e 4 ................... 161

5.11 Frequências das IMF-3 (a) e IMF-4 (b) em função do tempo ............... 162

5.12 Módulos das IMF-3 (a) e IMF-4 (b) em função do tempo..................... 162

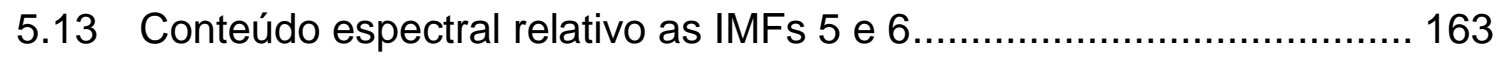

5.14 Frequências das IMF-5 (a) e IMF-6 (b) em função do tempo ............... 163

5.15 Módulos das IMF-5 (a) e IMF-6 (b) em função do tempo....................... 164

5.16 Espectro total dos dados da figura 5-1(b) (passe de 1,0mm) ............ 165

5.17 Regiões espectrais com oscilações estacionárias relevantes .............. 165 
5.18 Frequência (a) e módulo (b) da IMF-1 …….................................... 166

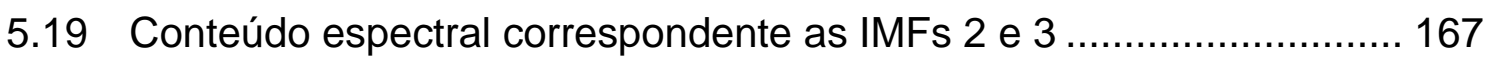

5.20 Frequência (a) e módulo (c) da IMF-2, frequência (b) e módulo (d) da

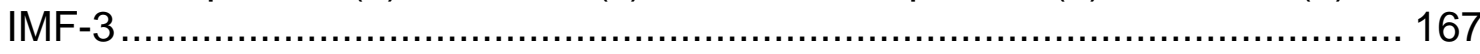

5.21 Espectro parcial das componentes relacionadas as IMFs 4 e $5 \ldots \ldots \ldots . .168$

5.22 Frequência (a) e módulo(b), da IMF-4 …….................................. 168

5.23 Frequência (a) e módulo(b), da IMF-5 ………............................... 169

5.24 Perfil da força de corte no passe de 1,0mm de profundidade.............. 169

5.25 Espectro completo dos sinais da força de corte do dinamômetro......... 170

5.26 Espectros parciais com as componentes dominantes locais ............... 170

5.27 Frequência (a) e módulo(b), da IMF-1 do passe contínuo de 1,5mm .. 171

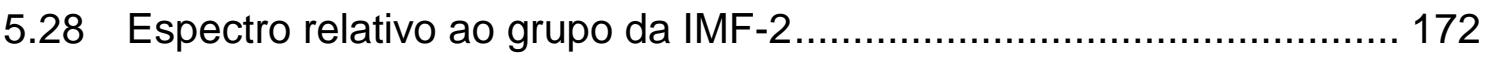

5.29 Frequência (a) e módulo(b), da IMF-2 do passe contínuo de 1,5mm .. 172

5.30 Espectro parcial das baixas frequências ......................................... 173

5.31 Frequências relativas as IMF-3 (a) e IMF-4 (b) ............................... 173

5.32 Módulos relativos as IMF-3 (a) e IMF-4 (b) ....................................... 174

5.33 Perfis das forças de corte para os passes de $0,5 \mathrm{~mm}(\mathrm{a}), 1,0 \mathrm{~mm}(\mathrm{~b}) \mathrm{e}$

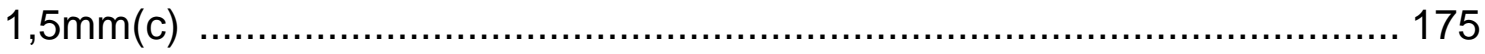

5.34 Forma da onda representativa da usinagem com corte interrompido. 176

5.35 Portadora relativa a trepidação (a) e modulante da força de corte (b) 177

5.36 Sinal modulado (a) e espectro do sinal modulado ............................. 177

5.37 Espectro da operação com Cl com passe de 0,5 mm ….................... 178

5.38 Espectro da usinagem com Cl e UCP de 0,5mm ............................ 179

5.39 Módulo da IMF-5 (a) e frequência da IMF-5 (b) ............................... 180

5.40 Módulo da IMF-4 (a) e frequência da IMF-4 (b) ............................... 181

5.41 Espectros da IMF-4 (a) e da IMF-5 (b) com Cl e UCP de 0,5mm....... 182

5.42 Relação entre os valores médios das forças de corte e a frequência

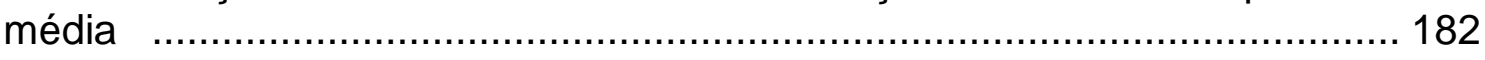

5.43 Espectro do sinal do dinamômetro para a situação de Cl e UCP de $1,0 \mathrm{~mm}$ 
5.44 Composição da IMF-5.

5.45 Módulo da IMF-5 (a) e frequência da IMF-5 (b) 184

5.46 Relação entre os valores médios das forças de corte e a frequência média

5.47 Espectro do sinal do dinamômetro para de $\mathrm{Cl}$ e ucp de $1,5 \mathrm{~mm}$ 186

5.48 Espectro do sinal do dinamômetro para de $\mathrm{Cl}$ e ucp de $1,5 \mathrm{~mm}$ 186

5.49 Módulo da IMF-2 (a) e frequência da IMF-2 (b) 187

5.50 Módulo da IMF-3 (a) e frequência da IMF-3 (b) 188

5.51 Módulo da IMF-4 (a) e frequência da IMF-4 (b) 188

5.52 Módulo da IMF-5 (a) e frequência da IMF-5 (b) 189

5.53 Relação entre os valores médios das forças de corte e a frequência média 189

5.54 Estrutura de decodificação do sinal pela wavelet utilizada 190

5.55 Coef. de aproximação 4 e a superposição com UCP de $0,5 \mathrm{~mm}$ 191

5.56 Coef. de aproximação 4 (a) e a superposição com UCP de 1,0mm .... 191

5.57 Coef. de aproximação 4 (a) e a superposição com UCP de 1,5mm .... 192

5.58 Os sinais da IMF-1 da força de corte e seu espectro (a) e (c) e os sinais de detalhe cD1 seu espectro em (b) e (d) 193

5.59 Os sinais da IMF-2 da força de corte e seu espectro (a) e (c) e os sinais de detalhe cD2 e seu espectro em (b) e (d) 194

5.60 Os sinais da IMF-3 da força de corte e seu espectro (a) e (c) e os sinais de detalhe $\mathrm{cD} 3$ e seu espectro em (b) e (d) respectivamente. 195

5.61 Os sinais da IMF-4 da força de corte e seu espectro (a) e (c) e os sinais de detalhe cD4 e seu espectro em (b) e (d). 196

5.62 Os sinais da IMF-5 da força de corte e seu espectro (a) e (c) e os sinais de detalhe cD5 e seu espectro em (b) e (d)

5.63 Os sinais da IMF-6 da força de corte e seu espectro (a) e (c) e os sinais de detalhe cD6 e seu espectro em (b) e (d). 198

5.64 As IMFs 4 (a), (c) e (e) e 5 (b), (d) e (f) e os módulos, fases e frequências de seus respectivos sinais analíticos. 
5.65 As IMFs 4 (a), (c) e (e) e 5 (b), (d) e (f) e os módulos, fases e frequências de seus respectivos sinais analíticos

6.1 Perfis de torque eletromagnético estimados .................................. 206

6.2 Espectro dos dados de torque do estimador). ............................ 208

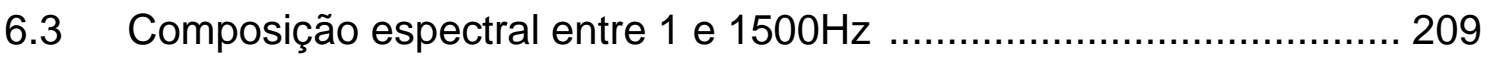

6.4 Detalhes do espectro da figura $6.3 \mathrm{com}$ as componentes estacionárias de origem elétrica

6.5 Espectros parciais com as componentes correspondentes as IMFs. 210

6.6 Frequência instantânea (a) e módulo (b) relativos a componente de $360 \mathrm{~Hz}$.

6.7 Frequência instantânea (a) e módulo (b) relativos a componente de $120 \mathrm{~Hz}$

6.8 Espectro total do sinal do módulo do torque eletromagnético fornecido pelo motor de indução com o torno realizando UCP de $0,5 \mathrm{~mm}$ 213

6.9 Espectros do torque estimado na condição de passe de $0,5 \mathrm{~mm}$ para o caso das frequências de $360 \mathrm{~Hz}$ (a) e $120 \mathrm{~Hz}$ (b)

6.10 Espectros do torque estimado das componentes de baixas frequências para a situação de passe de com profundidade de corte de $0,5 \mathrm{~mm}$ e a associação com as IMFs da tabela

6.11 Espectro de frequências do sinal obtido pelo estimador de torque com a máquina ferramenta executando passe de $1,0 \mathrm{~mm}$ 216

6.12 Espectros do torque estimado na condição de passe de 1,0mm

enfatizando a componente de $360 \mathrm{~Hz}$ (a) e a componente de $120 \mathrm{~Hz}$ (b) ...... 216

6.13 Espectros do torque estimado na condição de passe de 1,0mm para as componentes de baixas frequências do torque

6.14 Frequências instantâneas do torque estimado na condição de passe de $1,0 \mathrm{~mm}$ para as componentes de baixas frequências do torque 218

6.15 Composição espectral entre 1 e 1500Hz (sem a componente média) 219

6.16 16 Espectros do torque estimado na condição de passe de $1,5 \mathrm{~mm}$ enfatizando a componente de $360 \mathrm{~Hz}$ (a) e a componente de $120 \mathrm{~Hz}$ (b) ...... 219 
6.17 Espectros do torque estimado na condição de passe de $1,5 \mathrm{~mm}$ para as componentes de baixas frequências do torque estimado

6.18 Parcela do espectro de baixa frequência do torque estimado correspondente a IMF-7

6.19 Decomposição dos sinais da figura 6-19 em função do tempo com a frequência em (a) e o módulo em (b).

6.20 Parcela do espectro de baixa frequência correspondente a IMF-6...... 222

6.21 Frequência (a) e módulo (b) correspondentes ao espectro da figura 6-21 e a IMF-7 222

6.22 Tarugo utilizado para a usinagem com corte interrompido 223

6.23 Perfis dos sinais do estimador de torque para usinagem com Cl e UCP de $0,5 \mathrm{~mm}(\mathrm{a}), 1,0 \mathrm{~mm}$ (b) $1,5 \mathrm{~mm}$ (c) . 224

6.24 Espectro do torque estimado na região pesquisada sem a componente contínua para enfatizar os sinais vibratórios 224

6.25 Figura 6-25 Espectro de baixa frequência do corte interrompido de $0,5 \mathrm{~mm}$ abaixo de $100 \mathrm{~Hz}$ (a) e abaixo de $30 \mathrm{~Hz}$ (b)

6.26 Detalhe do espectro do torque estimado com uma oscilação dominante local próxima a $1680 \mathrm{~Hz}$ (a) também detectada na IMF 2 cujo módulo é mostrado em (b) 226

6.27 Frequência (a) e módulo (b) do sinal analítico da IMF 5 com UCP de $0,5 \mathrm{~mm} \mathrm{e} \mathrm{Cl}$ 227

6.28 Espectro entre 1 e $1500 \mathrm{~Hz}$ com a máquina ferramenta usinando com $\mathrm{Cl}$ e UCP de $1,0 \mathrm{~mm}$ 228

6.29 Detalhes da região de baixas frequências do espectro e suas respectivas IMFs 228

6.30 Espectro do sinal do torque estimado com a máquina ferramenta executando $\mathrm{Cl}$ e UCP de $1,5 \mathrm{~mm}$. 230

6.31 Espectro das baixas frequências (a) e seu detalhe com as componentes abaixo de $30 \mathrm{~Hz}$ e as IMFs correspondente 230 
6.32 Módulo (a) e fase (b) da HHT da IMF-5

6.33 Módulo (a) e fase (b) da HHT da IMF-6. 231

6.34 Coef. de aproximação cA7 (a) e de detalhe cD7 (b) com o torno em vazio 233

6.35 Frequência (a) e módulo (b) em função do tempo do sinal analítico da IMF-6 juntamente com a IMF-5 com o torno em vazio

6.36 Coef. de aproximação cA7 (a) e de detalhe CD7 (b) do torno com corte contínuo e passe de $1,5 \mathrm{~mm}$ 234

6.37 37 Frequência (a) e módulo (b) em função do tempo do sinal analítico da IMF-5 com o torno executando passe contínuo de $1,5 \mathrm{~mm}$ 234

6.38 Coef. de aproximação cA7 (a) e de detalhe cD7 (b) com o torno operando com passe interrompido de $1,5 \mathrm{~mm}$ 235

6.39 Frequência (a) e módulo (b) em função do tempo do sinal analítico da IMF-5 com o torno executando corte interrompido de $1,5 \mathrm{~mm}$

6.40 Comportamento do módulo espectral das componentes de frequências acima de $30 \mathrm{~Hz}$ em (a) e abaixo de $31,5 \mathrm{~Hz}$ (b) 236

6.41 O sinal de frequência do sinal analítico da IMF-3 (a) e o sinal de frequência do sinal analítico da IMF-7 do estimador de torque

6.42 O sinal do módulo do sinal analítico da IMF-3 (a) e o sinal do módulo do sinal analítico da IMF-7 do estimador de torque. 238

6.43 O sinal do módulo do sinal analítico da IMF-3 (a) e o sinal do módulo do sinal analítico da IMF-7 do estimador de torque.

6.44 Rugosidades na superfície de uma peça usinada provocada pelas vibrações do módulo da força de corte 
2.1 Desequilíbrio das tensões de fase e porcentual de VUF gerado .......... 54

2.2 Comparação entre as transformadas em geral...................................... 67

3.1 Resistência em função da corrente eficaz de fase ............................. 80

3.2 Grandezas elétricas medidas na entrada do motor ............................ 100

3.3 Parâmetros obtidos com o algoritmo de HS .................................... 102

4.1 Forças médias do dinamômetro em vazio ......................................... 111

4.2 Forças médias do dinamômetro com passe de $0,5 \mathrm{~mm}$...................... 114

4.3 Forças médias do dinamômetro com passe de 1,0 mm ........................ 120

4.4 Forças médias do dinamômetro com passe de 1,5mm ...................... 126

5.1 Características da HHT do sinal de torque com corte contínuo e

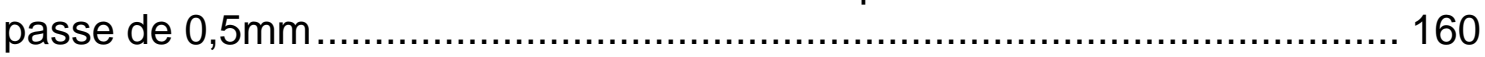

5.2 Características da HHT do sinal de torque com corte contínuo e passe de $1,0 \mathrm{~mm}$ 166

5.3 Características da HHT do sinal de torque com corte contínuo e passe de $1,5 \mathrm{~mm}$

5.4 Relação entre as componentes encontradas no processo de usinagem e no processo de modulação

5.5 Características da HHT do sinal de torque com corte interrompido e passe de $0,5 \mathrm{~mm}$ 180

5.6 Características da HHT do sinal de torque com corte interrompido e passe de $0,5 \mathrm{~mm}$.

5.7 Características da HHT do sinal de torque com corte interrompido e passe de $1,5 \mathrm{~mm}$.

6.1 Características da HHT do sinal de torque em vazio 
6.2 Características da HHT do sinal de torque com corte contínuo e passe de $0,5 \mathrm{~mm}$

6.3 Características da HHT do sinal de torque com corte contínuo e passe de $1,0 \mathrm{~mm}$

6.4 Características da HHT do sinal de torque com corte contínuo e passe de $1,5 \mathrm{~mm}$

6.5 Características da HHT do sinal de torque com corte interrompido e passe de $0,5 \mathrm{~mm}$.

6.6 Características da HHT do sinal de torque com corte interrompido e passe de $1,0 \mathrm{~mm}$

6.7 Características da HHT do sinal de torque com corte interrompido e passe de $1,5 \mathrm{~mm}$ 
cA Coeficiente de aproximação

CA Corrente alternada

CC Corrente contínua

CD Coeficiente de detalhe

$\mathrm{Cl}$ Corte Interrompido

E/S Entrada e Saída

EMD Empirical Mode of Decomposition

FFT Fast Fourer Transform

HHT Hilbert-Huang Transform

HM Harmony Memory

HS Harmony Search

IMF Intrinsic Mode Function (FMI)

MIT Motor de Indução Trifásico

MRAS Model Reference Adaptive System

UCP Usinagem Com Profundidade

VUF Voltage Unbalance Factor

WT Wavelet Transform 


\begin{tabular}{|c|c|}
\hline$\omega_{r}$ & Velocidade angular do rotor do MIT \\
\hline$\omega_{s}$ & Velocidade angular sincrona do MIT \\
\hline$\omega_{k}$ & Velocidade angular do MIT em um referencial arbitrário \\
\hline$\omega(t)$ & Frequência angular do sinal analítico \\
\hline$\sigma$ & Fator de dispersão do fluxo concatenado do estator \\
\hline$\lambda_{s(s)}$ & Vetor espacial fluxo concatenado do estator na referência do estator \\
\hline$\lambda_{r(s)}$ & Vetor espacial fluxo concatenado do rotor na referência do estator \\
\hline$\lambda_{d s(s)}$ & Fluxo concatenado de eixo direto do estator na referência do estator \\
\hline $\begin{array}{l}\lambda_{q s(s)} \\
\text { estator }\end{array}$ & Fluxo concatenado de eixo de quadratura do estator na referência do \\
\hline$\psi(t)$ & Fase do sinal analítico \\
\hline$\xi$ & Fator de amortecimento do sistema mecânico \\
\hline$\theta_{s}$ & Posição angular do campo síncrono do estator \\
\hline$\theta_{r}$ & Posição angular do rotor do MIT \\
\hline$\psi_{m, n}(t)$ & Wavelet mãe \\
\hline$F^{-1}\{\}$ & Transformada inversa de Fourier \\
\hline$F_{C}$ & Força média de corte na aresta da ferramenta de usinagem \\
\hline$F_{f}$ & Força média de avanço da ferramenta de usinagem \\
\hline$F_{S}$ & Frequência de amostragem \\
\hline$F_{\text {trans }}$ & Força transmitida \\
\hline$L_{l r}$ & Reatância de dispersão do rotor referida ao estator \\
\hline
\end{tabular}


$L_{l s} \quad$ Reatância de dispersão do estator referida ao estator

$L_{m} \quad$ Reatância de magnetização

$L_{r} \quad$ Reatância do rotor referida ao estator

$L_{s} \quad$ Reatância do estator referida ao estator

$P_{0} \quad$ Potência de vazio do MIT

$P_{0} \quad$ Potência de vazio do torno com tração do carro principal

$P_{1} \quad$ Número de polos do MIT

Paresta Potência na aresta da ferramenta de usinagem

$P_{e} \quad$ Potência elétrica transmitida entre dois circuitos

$P_{m e c} \quad$ Potência no eixo do rotor

$R_{r} \quad$ Resistência do rotor referida ao estator

$R_{S} \quad$ Resistência do estator

$R_{\text {usin }} \quad$ Raio médio de usinagem

$T_{e m} \quad$ Torque eletromagnético no rotor

$T_{f} \quad$ Transmissibilidade de força

$T_{r} \quad$ Constante de tempo do rotor

$f_{\text {corte }}(t) \quad$ Força de corte instantânea em função do tempo

$f_{\text {osc }} \quad$ Frequência de oscilação

$m_{0} \quad$ Massa equivalente de desbalanceamento de um sistema rotativo

$v_{c} \quad$ Velocidade média de corte da ferramenta de usinagem

$v_{f} \quad$ Velocidade média de avanço da ferramenta de usinagem

$\hat{x}(t) \quad$ Transformada de Hilbert do sinal analítico

$x^{\prime} \quad$ Vetor de harmonia do algoritmo HS

$x_{a j} \quad$ Variável ajustável

$x_{\text {ref }} \quad$ Variável de referência

$\boldsymbol{i}_{x(s)} \quad$ Vetor espacial corrente da fase $\mathrm{x}$ na referência fixada no estator 


$\begin{array}{ll}\boldsymbol{v}_{x(s)} & \text { Vetor espacial tensão da fase } \mathrm{x} \text { na referência fixada no estator } \\ B & \text { Atrito viscoso } \\ J & \text { Momento de inércia } \\ \mathrm{P} & \text { Valor principal de Cauchy } \\ A(t) & \text { Módulo do sinal analítico } \\ F\{\} & \text { Transformada de Fourier de uma função } \\ H\{\} & \text { Transformada de Hilbert de uma função } \\ X(\omega) & \text { Transformada de Fourier da parte real do sinal } \\ Z(\omega) & \text { Transformada de Fourier do sinal analítico } \\ c & \text { Coeficiente de atrito viscoso do amortecedor equivalente } \\ d & \text { Distância equivalente do desequilíbrio de massa } \\ j & \text { Número imaginário }(\sqrt{-1}) \\ k & \text { Coeficiente elástico equivalente de um sistema mecânico } \\ r & \text { Raio de rotação } \\ s & \text { Fator de escorregamento do MIT } \\ s(t) & \text { Sinal em função do tempo } \\ x(t) & \text { Deslocamento longitudinal das massas do torno } \\ x(t) & \text { Parte real do sinal analítico }\end{array}$


Sumário

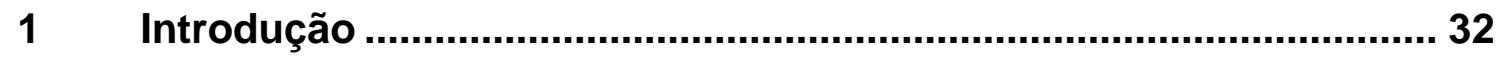

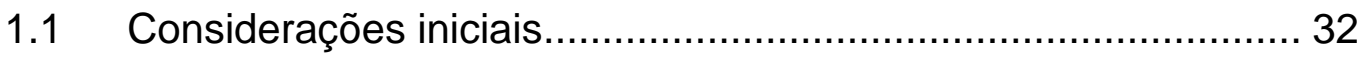

1.2 Objetivos, motivação e contribuições do trabalho ................. 37

1.3 Organização deste trabalho ................................................ 38

1.4 Publicação relativas ao trabalho .................................................39

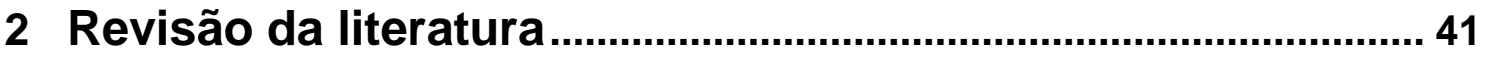

2.1 Os motores de indução trifásicos (MIT) ………....................... 41

2.1.1 Estimação dos fluxos estatóricos e torque nos MIT ..... 48

2.1.2 Estimação da velocidade dos MIT sem sensor

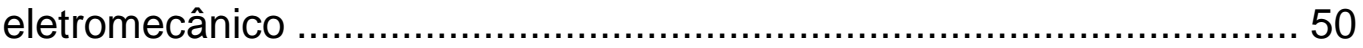

2.1.3 Os sinais da alimentação elétrica dos MIT ....................... 51

2.1.4 O efeito do desequilíbrio de fase nos MIT ...................... 52

2.2 Vibrações nos sistemas mecânicos ………………………...... 55 
2.2.1 Análise do comportamento vibratório da máquina

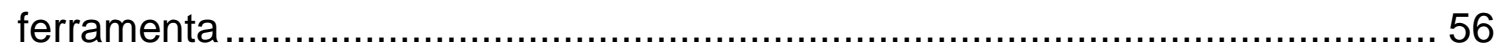

2.2.2 Oscilações da máquina ferramenta …………………...... 56

2.2.3 A monitoração das vibrações.......................................... 62

2.2.4 O método da transformada de Fourier (FFT) .................. 63

2.2.5 O método da transformada de wavelet............................. 64

2.2.6 O método da transformada de Hilbert-Huang ....................66 66

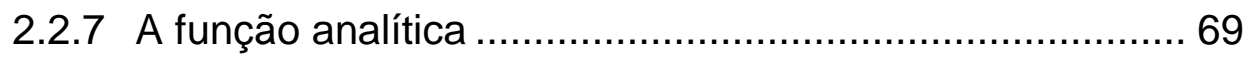

2.2.8 Obtenção da função analítica utilizando a FFT................. 73

$2.3 \quad$ Metaheuristicas.....................................................................................

2.3.1 O algoritmo de busca de harmonia (HS) ……................ 75

2.3.2 A implementação do algoritmo HS ................................ 75

2.4 Conclusões da revisão da literatura ........................................... 77

3 Estimação da potência e torque na carga de um motor de indução com base nas quantidades elétricas medidas em sua entrada de energia .78

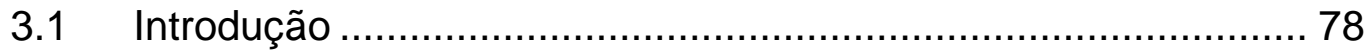

3.2 A obtenção dos parâmetros do motor de indução (1 ${ }^{\circ}$ Estágio) .. 80

3.3 A obtenção dos parâmetros do motor de indução (2ํㅡ Estágio) .. 84

3.4 Verificação da consistência dos valores obtidos com base nas correntes de fase medida e calculada utilizando os parâmetros estimados..... 86

3.5 Comparação entre as potências medidas e estimadas............... 89

3.6 A estimação de torque ……………………....................... 93

3.7 A estimação de velocidade …………………........................ 93

3.7.1 Primeiro método de estimação de velocidade .................. 94 
3.7.2 Segundo método de estimação de velocidade 94

3.8 O setup experimental ......................................................... 96

3.9 Aplicando o método à máquina ferramenta............................... 98

3.9.1 Os parâmetros do motor de indução do torno ................. 100

3.9.2 Análise do comportamento da potência......................... 104

3.9.3 Análise do comportamento da potência.......................... 106

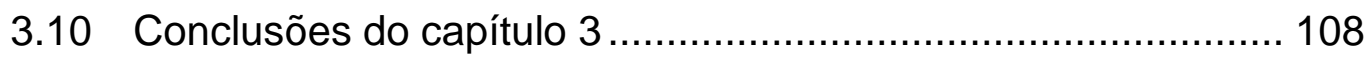

4 Análise das vibrações de uma máquina ferramenta utilizando os dados de um dinamômetro Kistler com a transformada de Fourier ........ 110

4.1 Teste com dinamômetro Kistler em operação de corte contínuo 110

4.1.1 O perfil da ucp de $0,5 \mathrm{~mm}$

4.1.1.1 Análise da região sem a ação de usinagem (em vazio) 111

4.1.1.2 Análise da força de corte ................................. 115

4.1.1.3 Análise da força de avanço................................ 117

4.1.2 Análise da ucp de $1,0 \mathrm{~mm}$........................................ 120

4.1.2.1 Análise da força de corte .................................. 122

4.1.2.2 Análise da força de avanço............................... 124

4.1.3 Análise da ucp de 1,5mm ......................................... 126

4.1.3.1 Análise da força de corte ............................... 128

4.1.3.2 Análise da força de avanço................................ 130

4.2 Análise dos sinais de força obtidos pelo dinamômetro Kistler em operações de usinagem de corte interrompido $(\mathrm{Cl})$ 133

4.2.1 Análise da força de corte da ucp de $0,5 \mathrm{~mm}$ 134 
4.2.2 Análise da força de avanço da ucp de $0,5 \mathrm{~mm}$

4.2.3 Análise da força de corte da ucp de $1,0 \mathrm{~mm}$................... 140

4.2.4 Análise da força de avanço da ucp de 1,0mm ............... 143

4.2.5 Análise da força de corte da ucp de 1,5mm ................. 143

4.2.6 Análise da força de avanço com UCP de 1,5mm .......... 147

4.3 Modelagem do sistema do porta-ferramentas........................ 150

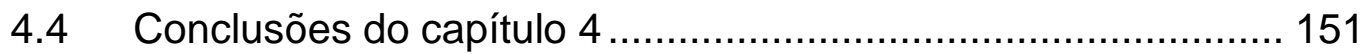

5 Análise das vibrações de uma máquina ferramenta utilizando os dados de um dinamômetro Kistler com a HHT e a WT

5.1 Estratégias utilizadas para a análise dos sinais do dinamômetro 153

5.1.1 A organização geral dos resultados 155

5.2 Relações entre o espectro (FFT) e a HHT dos dados do dinamômetro 156

5.2.1 Usinagem com corte contínuo e UCP de 0,5mm 156

5.2.2 Usinagem com corte contínuo e passe de 1,0mm 164

5.2.3 Usinagem com corte contínuo e passe de $1,5 \mathrm{~mm}$ 169

5.3 Análise espectral e com a HHT da operação de usinagem com Cl 174

5.3.1 A usinagem com $\mathrm{Cl}$ como um fenômeno de modulação com amplitude modulada (AM) 175

5.3.2 Análise espectral (FFT) e com a HHT da operação de $\mathrm{Cl}$ com UCP de $0,5 \mathrm{~mm}$ 179

5.3.3 Análise espectral (FFT) com a HHT da operação com Cl e UCP de $1,0 \mathrm{~mm}$ 182

5.3.4 Análise espectral (FFT) com a HHT da operação com Cl e UCP de $1,5 \mathrm{~mm}$ 185 
5.4 Análise pela aplicação da transformada de wavelet

5.4.1 A WT do sinal de corte contínuo com UCP de 0,5mm.. 190

5.4.2 Wavelet do sinal de corte contínuo com passe de 1,0mm

5.4.3 A WT do sinal de corte contínuo com passe de 1,5mm.. 192

5.5 A transformada de wavelet e o EMD 192

5.6 As relações entre a HT e as IMFs obtidas pelo EMD 200

5.7 Conclusões do capítulo 5 201

6 A análise dos dados de torque do estimador de torque utilizando a HHT e a WT 205

6.1 Estratégias utilizadas para a análise dos sinais do estimador de torque 205

6.1.1 A determinação experimental da frequência máxima ..... 207

6.2 Relações entre o espectro e a HHT do torque eletromagnético estimado 207

6.2.1 Caso 1: Torno operando em vazio com tração do carro longitudinal 207

6.2.2 Caso 2: Torno com UCP de 0,5mm contínua ................. 213

2.2.3 Caso 3: Torno com UCP de 1,0mm contínua ................. 215

2.2.4 Caso 4: Torno com UCP de 1,5mm contínua ................. 218

6.3 Máquina ferramenta operando com usinagem de $\mathrm{Cl}$................ 223

6.3.1 Caso 1: Torno com Cl e UCP de 0,5mm ...................... 223

6.3.2 Caso 2: Torno com Cl e UCP de 1,0mm ….................... 228

6.3.3 Caso 3: Torno com Cl e UCP de 1,5mm ……….......... 229

6.4 Análise do cenário pela aplicação a WT .................................. 232

6.5 O comportamento das componentes estacionárias em função do carregamento 236 
6.6 Comparação entre os sinais de usinagem observados pela HHT nos dados do dinamômetro e do estimador de torque 237

6.7 Conclusões do capítulo 6 239

\section{Conclusões Finais}

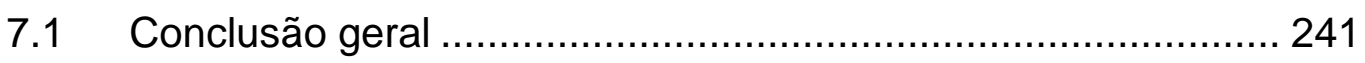

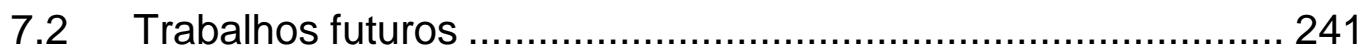

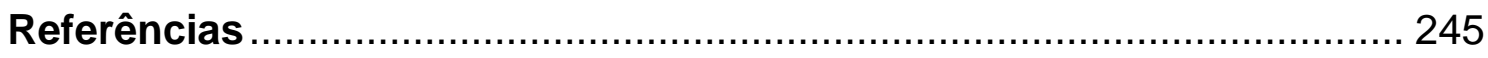

\section{Apêndice A}

A1 Fases do sinal analítico em vazio............................................ 249

A2 Frequências do sinal analítico em vazio................................... 250

A3 Módulos do sinal analítico em vazio........................................ 252

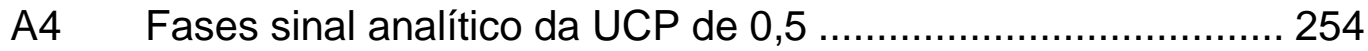

A5 Frequências do sinal analítico da UCP de $0,5 \mathrm{~mm}$................... 255

A6 Módulos do sinal analítico com UCP de 0,5mm ..................... 256

A7 Fases do sinal analítico com UCP de 1,0mm......................... 258

A8 Frequências sinal analítico com UCP de 1,0mm.................... 259

A9 Módulos do sinal analítico com UCP de 1,0 mm ...................... 260

A10 Fases do sinal analítico com UCP de 1,5mm........................ 262

A11 Frequências do sinal analítico com UCP de 1,5mm ................. 263

A12 Módulos do sinal analítico com UCP de 1,5mm ..................... 264

A14 Fases do sinal analítico de Cl com UCP de 0,5mm ................ 266

A15 Frequências do sinal analítico de Cl com UCP de $0,5 \mathrm{~mm}$....... 267

A16 Módulos do sinal analítico de Cl com UCP de 0,5mm ............. 269

A17 Fases do sinal analítico de Cl com UCP de 1,0mm ................. 271

A18 Frequências do sinal analítico de Cl com UCP de 1,0mm ....... 272 
A19 Módulos do sinal analítico de Cl com UCP de 1,0mm ............. 274

A20 Fases do sinal analítico de Cl com UCP de 1,5mm ................ 276

A21 Frequências do sinal analítico de $\mathrm{Cl}$ com UCP de $1,5 \mathrm{~mm}$...... 277

A22 Módulos do sinal analítico de Cl com UCP de 1,5mm ........... 279

\section{Apêndice B Dinamômetro}

B1- Fases do sinal analítico com UCP de 0,5mm............................ 281

B2- Frequências do sinal analítico com UCP de 0,5 mm.................... 282

B3- Módulos do sinal analítico com UCP de 0,5mm ......................... 283

B4- Fases do sinal analítico com UCP de 1,0mm............................ 284

B5- Frequências do sinal analítico com UCP de 1,0mm................... 285

B6- Módulos do sinal analítico com UCP de 1,0 mm ......................... 286

B7- Fases do sinal analítico com UCP de 1,5mm............................ 287

B8- Frequências do sinal analítico com UCP de 1,5mm.................... 288

B9- Módulos do sinal analítico com UCP de 1,5mm .......................... 289

B10- Fases do sinal analítico de Cl com UCP de 0,5mm .................. 291

B11- Frequências do sinal analítico de Cl com UCP de 0,5mm ......... 292

B12- Módulos do sinal analítico de Cl com UCP de 0,5mm ............... 293

B13- Fases do sinal analítico de Cl com UCP de 1,0mm ...................294

B14-Frequências do sinal analítico de Cl com UCP de 1,0mm .......... 295

B15-Módulos do sinal analítico de Cl com UCP de 1,0mm ................ 296

B16- Fases do sinal analítico de Cl com UCP de 1,5mm .................. 298

B17- Frequências do sinal analítico de Cl com UCP de 1,5mm ......... 299

B18- Módulos do sinal analítico de $\mathrm{Cl}$ com UCP de 1,5mm ............... 300

\section{Apêndice C}

C1- As IMFs dos dados do estimador de torque para UCP de $0,5 \mathrm{~mm}$ 302

C2- As IMFs dos dados do estimador de torque para UCP de $1,0 \mathrm{~mm}$ 
C3- As IMFs dos dados do estimador de torque para UCP de $1,5 \mathrm{~mm}$ 304

C4- As IMFs dos dados do estimador de torque para Cl e UCP de $0,5 \mathrm{~mm}$ 305

C5- As IMFs dos dados do estimador de torque para Cl e UCP de $1,0 \mathrm{~mm}$ 306

C6- As IMFs dos dados do estimador de torque para Cl e UCP de $1,0 \mathrm{~mm}$

\section{Apêndice D}

D1- As IMFs dos dados do dinamômetro Kistler com UCP de 0,5mm 308

D2- As IMFs dos dados do dinamômetro Kistler com UCP de 1,0mm 309

D3- As IMFs dos dados do dinamômetro Kistler com UCP de 1,5mm 310

D4- As IMFs dos dados do dinamômetro Kistler com Cl e UCP de $0,5 \mathrm{~mm}$

D5- As IMFs dos dados do dinamômetro Kistler com Cl e UCP de $1,0 \mathrm{~mm}$

D6- As IMFs dos dados do dinamômetro Kistler com Cl e UCP de $1,5 \mathrm{~mm}$

Apêndice $E$

E1- Coef. de aproximação - Torno operando em vazio 314

E2- Coef. de aproximação - Torno operando com UCP de 0,5mm..... 315

E3- Coef. de aproximação - Torno operando com UCP de 1,0mm..... 316

E4- Coef. de aproximação - Torno operando com UCP de 1,5mm..... 317

E5- Coef. de aproximação - Torno operando com Cl e UCP de 0,5mm

E6- Coef. de aproximação - Torno operando com Cl e UCP de 1,0mm

E7- Coef. de aproximação - Torno operando com Cl e UCP de 0,5mm 320

\section{Apêndice F}

F1- Coef. de aproximação - Torno operando com UCP de 0,5mm ..... 321 
F2- Coef. de detalhe - Torno operando com UCP de 0,5mm.

F3- Coef. de aproximação - Torno operando com UCP de 1,0mm ..... 323

F4- Coef. de detalhe - Torno operando com UCP de 1,0mm.............. 324

F5- Coef. de aproximação - Torno operando com UCP de 1,5mm ..... 325

F6- Coef. de detalhe - Torno operando com UCP de 1,5mm............. 326

F7- Coef. de aproximação - Torno operando com Cl e UCP de 0,5mm

F8- Coef. de detalhe - Torno operando com Cl e UCP de 0,5mm ...... 328

F9- Coef. de aproximação - Torno operando com Cl e UCP de 1,0mm

F10- Coef. de detalhe - Torno operando com Cl e UCP de 1,0mm .... 330

F11- Coef. de detalhe - Torno operando com Cl e UCP de 1,5mm .... 331

F12- Coef. de detalhe - Torno operando com Cl e UCP de 1,5mm .... 332 


\subsection{Considerações iniciais}

A alta competitividade em vários setores das atividades humanas tem conduzido as pesquisas, em vários setores, à busca de otimização de métodos e sistemas, e isso ocorre principalmente no setor industrial onde as máquinas de manufatura, de todos os tipos, desempenham um processo crucial na competitividade e ganhos de produção.

Os processos de usinagem são realizados por diversos tipos de máquinas ferramentas, as quais são definidas pela sua capacidade de realização de processos de usinagem específicos. Embora os processos realizados por essas máquinas tenham uma similaridade no seu comportamento em relação a operação de usinagem em si, elas diferem no modo como realizam suas tarefas. Esse trabalho focaliza a utilização de tornos mecânicos horizontais devido a uma gama bastante grande de utilização dessas máquinas no mercado de manufatura mecânica como é mostrado no gráfico da figura 1.1 (TÖNSHOFF et al., 1994).

Entre os aspectos que exigem operações relativas a produtividade e desempenho operacional, é fundamental que a máquina ferramenta tenha um alto grau de confiabilidade em todos seus componentes, passando, nesse aspecto, por todos os elementos mecânicas que a compõem assim como pelos 
elementos elétricos e dentre mos mesmos o de maior importância que seu motor de acionamento.

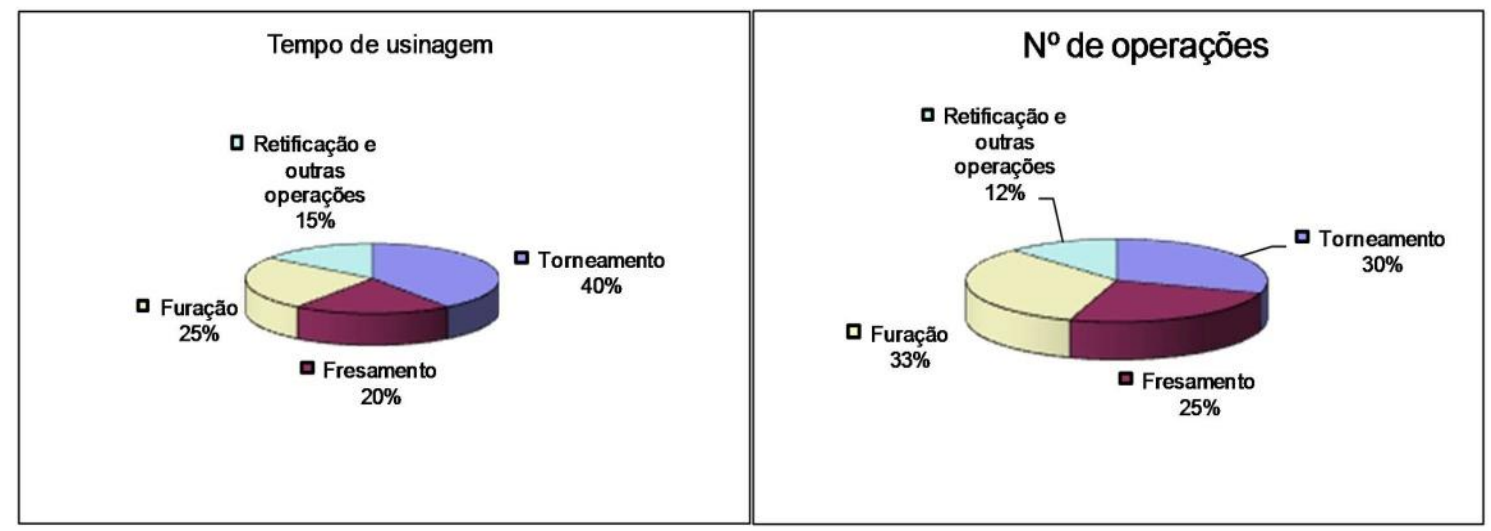

Figura 1.1 Relação entre os principais processos de Usinagem (TÖNSHOFF et al., 1994)

Em máquinas de manufatura antigas o emprego de motores de corrente contínua (CC) era praticamente obrigatório, uma vez que o mesmo, na sua forma com campo paralelo, apresentava excelentes características de controle, linearidade e facilidade de operação em regiões estendidas de velocidade (SEN, 1981). Embora os motores de corrente contínua fossem excelentes em vários aspectos eles também apresentavam problemas de robustez mecânica devido ao seu anel comutador além de baixa confiabilidade operacional, custo inicial e de manutenção.

Por sua vez, os motores de indução trifásicos (MIT) apresentavam um cenário oposto aos motores de corrente contínua com rotor em gaiola de esquilo, eram muito confiáveis, de construção relativamente simples e por isso de menor custo, mas suas opções de velocidade estavam basicamente limitadas as frequências da rede elétrica, sendo que, sua versão, mais controlável com rotor bobinado, ficava muito próxima, em termos de confiabilidade, dos motores de corrente contínua.

As características de confiabilidade operacional e durabilidade levaram os MIT para a indústria de máquinas ferramentas onde os mesmos são utilizados em uma enorme gama de aplicações relativas as mesmas, cujos processos podem ser classificados como processos de corte (torneamento, 
fresamento e furação), processos abrasivos (retificação) e processos não tradicionais (elétricos, ópticos e químicos) (Kalpakjian, 2000).

Embora a evolução dos sistemas de acionamento tenham introduzido muitas melhorias no controle das máquinas ferramentas utilizando os métodos sofisticados de controle tais como o método de acionamento escalar, o acionamento por orientação de campo (FOC - Field Oriented Control) e o controle de torque direto (DCT - Direct Torque Control) em conjunto com métodos de controle numérico, a determinação precisa das condições de corte permanecem difíceis e um operador de máquina ferramenta experimentado ainda produz melhores resultados que um sistema de automatização da máquina (Jeong, Y.; Cho, D., 2002).

A teoria dos vetores espaciais possibilitou enormes avanços na aplicação dos motores de indução. A sua aplicação por Joetten em seu trabalho sobre o controle e medição de quantidades mecânicas com base nas quantidades elétricas medidas na entrada de alimentação do MIT (JOETTEN, MAEDER, 1983), permitiu a Schauder a concepção da orientação de campo sem a necessidade de um transdutor de velocidade (SCHAUDER, 1992).

Sobre as bases teóricas mencionadas acima foram concebidos métodos de estimação de torque sobre os quais escreveram Vas e Trzynadlowski (Vas,1993) e (TRZYNADLOWSKI, 1994),

Vas discute profundamente um estimador de torque sem sensor para operações com frequência da tensão de alimentação do motor acima de $3 \mathrm{~Hz}$ (Vas,1993), que constituiu a base do sistema de aquisição realizado neste trabalho e através do qual se realizou toda a parcela experimental correspondente ao circuito de aquisição usado no trabalho.

O trabalho realizado por uma máquina ferramenta é basicamente uma operação de transformação da potência elétrica colocada pelo motor na entrada do sistema mecânico, onde uma parcela da potência é utilizada para ativar os processos mecânicos da operação da máquina ferramenta em si e a parcela restante é utilizada no trabalho de usinagem. 
A figura 1.2 evidencia as forças componentes mecânicas que fazem parte dos processos de usinagem em uma máquina ferramenta com operação de torneamento e são definidas como força de avanço $(F f)$, força passiva $(F p)$ e força de corte $\left(F_{c}\right)$, cujo efeito resultante final é a força de usinagem $(F)$. (Machado et al., 2009).

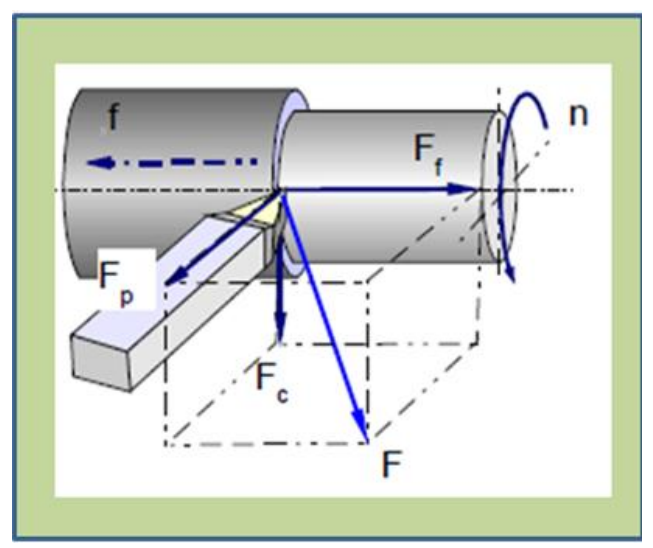

Figura 1.2 Os esforços de usinagem presentes no processo de torneamento.

Os trabalhos de MANNAN, (MANNAN, BROMS,1989), Huh (Huh, Kim, 1999), Dimla (DIMLA, DIMLA, 2000), JEONG (JEONG, CHO, 2002) e outros procuram fazer a estimação das forças de usinagem, notadamente a força de corte que supera em muito as outras duas forças de usinagem, com base nas quantidades elétricas aplicadas ao motor como a potência (Huh, Kim, 1999) ou a corrente de regime estacionário (JEONG, CHO, 2002).

Entre os objetivos desejados por cada autor podemos citar o de determinar $\mathrm{o}$ torque e a potência aplicados no processo de usinagem (MANNAN, BROMS,1989), ou o comportamento dos transitórios que ocorrem na usinagem (Huh, Kim, 1999) que usa a força de corte estimada para operar também o controle da mesma.

A figura 1.3 indica como o processo de transformação da energia de entrada contribui para a ocorrência da potência média de corte, que se traduz em força média de corte ou de regime na aresta da ferramenta, assim como na variação dos estados de corte da ferramenta de usinagem que perde afiação e exigem mais esforço na realização da tarefa de corte e também nas forças componentes vibratórias associadas ao corte inclusive as trepidações que 
podem ser destrutivas para a ferramenta e provocam danos na superfície usinada que dependendo do ponto da ação de usinagem, podem levar a perda da peça inteira.

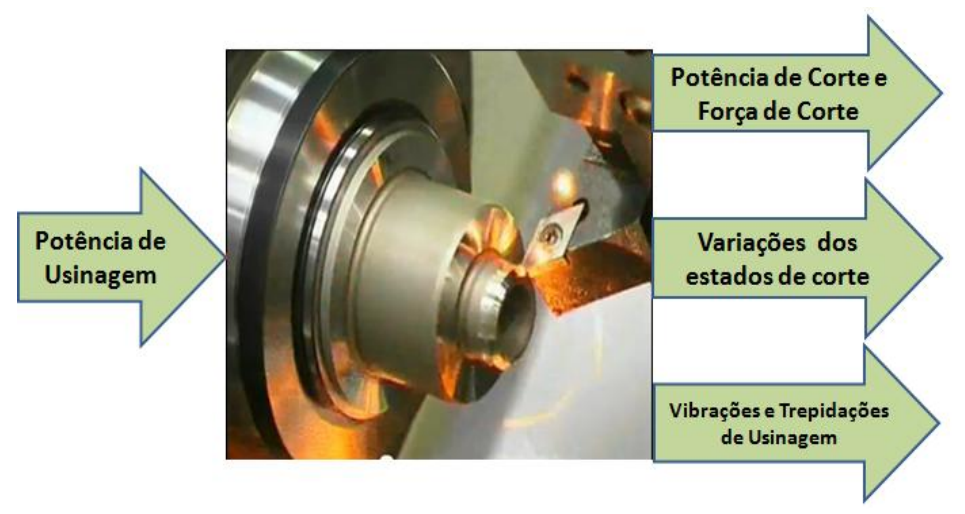

Figura 1.3 Efeitos relacionados à potência no processo de usinagem

Se de por um lado os pesquisadores estão procurando desenvolver métodos para a detecção de fenômenos associados a usinagem, a indústria de equipamentos de teste também tem procurado oferecer soluções que contemplem as questões discutidas, assim a empresa sueca Kistler desenvolveu um sistema de medição de esforços para máquinas ferramentas em geral e um determinado tipo para tornos. Em linhas gerais o sistema é mostrado na figura 1.4 e foi utilizado como suporte na verificação de consistência de dados nesse trabalho.
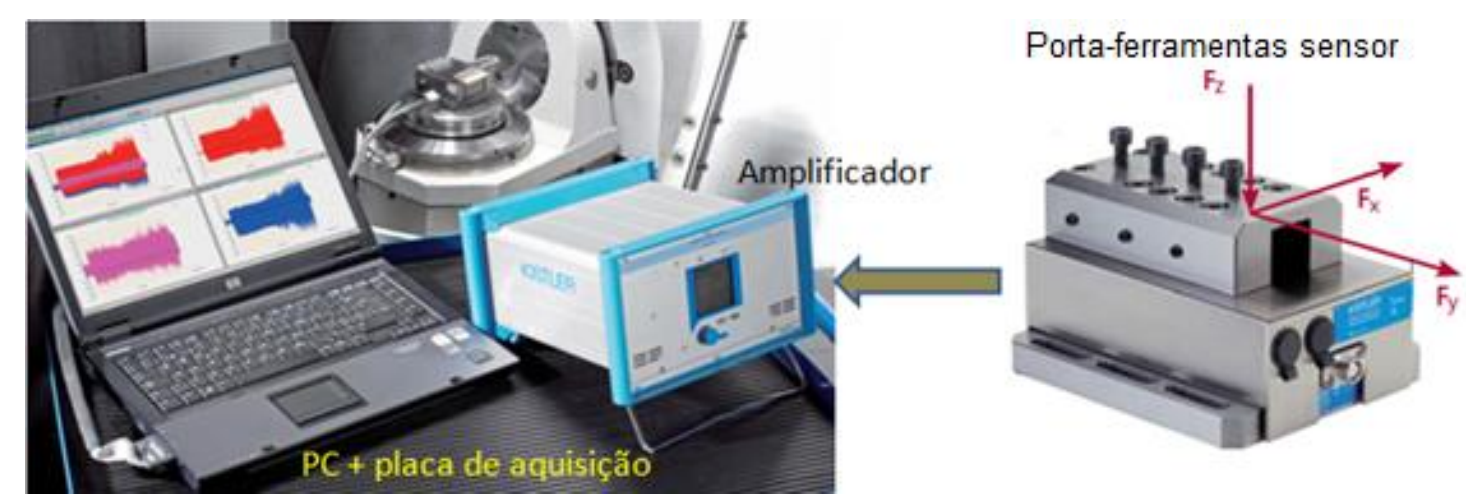

Figura 1.4

Figura 1.4 Dinamômetro da Kistler (KISTLER GROUP, 2009) 


\subsection{Objetivos, motivação e contribuições do trabalho}

Da seção anterior, pode-se observar a preocupação dos pesquisadores na obtenção de meios para a avaliação dos efeitos que ocorrem nos sistemas de usinagem, desde a potência utilizada na aresta da ferramenta até os fenômenos vibratórios envolvidos no próprio sistema de usinagem.

O princípio deste projeto ocorreu devido às observações realizadas por um grupo de pesquisadores do Laboratório de Fenômenos de Superfície da Escola Politécnica da USP na empresa Aços Villares de Pindamonhangaba onde o setor de usinagem de cilindros de laminação necessitava de um método de otimização e monitoramento para uso no sistema de torneamento dos cilindros. As características da seção de fábrica responsável pela usinagem e manutenção dos cilindros eram:

- Máquinas-ferramentas antigas utilizando um único MIT, ligado diretamente à rede de energia.

- Impossibilidade de adaptação de sensores de qualquer tipo na máquina ferramenta devido ao tamanho e dificuldade de colocação dos cilindros no torno usando pontes rolantes.

- Confiabilidade baixa de manutenção da integridade dos sensores em um ambiente mecanicamente muito agressivo.

Com as características citadas acima, o grupo precisava de um método "invisível" com capacidade de fazer suas tarefas sem perturbar o ambiente de fabricação dos cilindros, assim uma solução que pareceu muito interessante foi utilizar um método de monitoração do processo de usinagem baseado nos dados obtidos na alimentação do MIT da máquina ferramenta.

As escolhas para a realização do processo levam a argumentações fundamentais tanto dentro da engenharia elétrica como da engenharia mecânica, quais sejam:

- Com que grau de precisão é possível estimar o valor da potência média na aresta da ferramenta de corte com base na potência medida na entrada do motor? 
- Qual é a faixa de passagem ou resposta de frequência do motor e do conjunto associado da máquina ferramenta incluindo a própria peça em usinagem?

- É possível separar o ruído associado inerentemente à rede elétrica e aos mecanismos da máquina ferramenta das vibrações que ocorrem no processo de usinagem?

Uma vez definidos os objetivos mencionados, o próximo passo foi realizar um estudo de caso do qual este trabalho é resultante onde foram estabelecidos os seguintes procedimentos:

- Escolha de um torno com formatação tecnológica antiga do Laboratório de Máquinas Operatrizes do Departamento de Engenharia Mecatrônica e Sistemas Mecânicos juntamente com um dinamômetro Kistler do Laboratório de Fenômenos de Superfície também do Departamento de Engenharia Mecatrônica e Sistemas Mecânicos da Escola Politécnica da Universidade de São Paulo.

- Construção de um estimador de torque baseado no estimador estudado por Vas (Vas, 1993).

- Realizar medições simultâneas com o estimador de torque e 0 dinamômetro Kistler para confrontação de resultados.

Para finalizar a etapa de análise foi decidido que os dados passariam por dois métodos de análise procurando-se estabelecer uma relação entre ambos. O primeiro baseado na transformada rápida de Fourier (FFT - Fast Fourier Transform) para detectar as componentes estacionárias e o segundo baseado na transformada de Hilbert-Huang (HHT - Hilbert-Huang Transform) que permite a detecção de sinais lineares e não lineares sendo em alguns aspectos superior a Transformada de Wavelet, porém não faz parte do escopo deste trabalho uma comparação entre as duas transformadas (HUANG, 2005).

\subsection{Organização deste trabalho}

Este primeiro capítulo apresentou os objetivos, as abordagens, alguns questionamentos e as principais contribuições deste trabalho. 
O capítulo 2 apresenta uma revisão da literatura, abordando os principais aspectos da operação dos MIT no modo vetorial, a estimação do torque, o método de otimização baseado na metaheurística Busca de Harmonia (HS - Harmony Search) que é utilizada para obtenção dos parâmetros do MIT e a HHT.

O capítulo 3 apresenta o método de estimação do torque médio com base nas quantidades elétricas medidas na entrada do MIT.

O capítulo 4 apresenta uma análise dos sinais de força de corte e força de avanço do dinamômetro tanto no domínio da frequência quanto do tempo procurando detectar as principais componentes vibratórias estacionárias com base na análise espectral via FFT.

O capítulo 5 faz uma abordagem dos dados da força de corte do dinamômetro procurando estabelecer uma relação entre as componentes estacionárias obtidas pela FFT e o agrupamento de componentes inseridos na fase do sinal analítico, assim como dos sinais de módulo instantâneo e frequência instantânea do sinal que constituem a base formadora da HHT. Ao final do capítulo procurou-se estabelecer um critério de consistência utilizando a transformada de wavelet.

O capítulo 6 apresenta uma análise das relações entre a FFT e a HHT dos dados obtidos pelo estimador de torque utilizando os dados relativos às mesmas operações utilizadas para a obtenção dos dados do dinamômetro. Aqui também a transformada de wavelet foi utilizada como elemento verificador de consistência de dados.

O capítulo 7 apresenta um quadro geral dos capítulos 3, 4, 5 e 6 com as indicações das seções que definem as conclusões parciais de cada capítulo e finalmente indica algumas propostas de continuidade do trabalho.

\subsection{Publicações relativas ao trabalho}

\subsubsection{Congressos científicos}


Marques, J. R., Machado, I. F., Cardoso, J. R., Induction Motor Parameter Determination Using the Harmony Search Algorithm to Power, Torque and Speed Estimation, The $38^{\text {th }}$ Annual Conference of the IEEE Electronics Society, IECON 2012, p. 1835-1840, October 2012, Montreal, Canada

\subsubsection{Publicação em revista}

"The Use of the Hilbert-Huang Transform in the Analysis of Machining Vibration Processes of Machines Tools", Marques, J.R, Machado, I. F.; Cardoso, J. R.; Barbosa, P. A.; Transactions on Industrial Electronics (IEEE) (submetido) 


\subsection{Os motores de indução trifásicos (MIT)}

O desenvolvimento da teoria vetorial dos motores de indução realizada por Braschke para o modelo direto e Hasse para o modelo indireto, permitiu uma grande simplificação na modelagem da máquina de indução, com a transformação das variáveis das coordenadas trifásicas naturais para um modelo bifásico, mais simples para simular e utilizar em aplicações práticas (BLASCHKE,1980) (HASSE,1972) .

A modelagem vetorial assume que a força magnetomotriz da máquina se desloca rotativamente sobre o plano complexo e o caso de uma máquina simples de dois polos pode ser representada com o eixo do motor fixado na origem de um eixo $z$ perpendicular ao plano de observação e os enrolamentos do estator distribuídos espacialmente como mostrado na figura 2.1.

Neste plano as bobinas do estator de dois polos podem ser consideradas como fixadas fisicamente como mostra a figura 2.1 , onde a bobina da fase $\boldsymbol{a}$ está na posição $0^{\circ}$, a bobina da fase $\boldsymbol{b}$ a $120^{\circ}$ e a bobina $\boldsymbol{c}$ a $240^{\circ}$, assim as correntes trifásicas que percorrem estas bobinas, em sua associação com a força magnetomotriz que geram, podem ser consideradas vetores espaciais de correntes, embora em si mesmas, as correntes sejam fisicamente grandezas escalares. Esta abstração também se aplica às tensões 
e fluxos concatenados, de modo que passamos, em função da disposição física dos enrolamentos, a tratar componentes escalares como vetoriais, sem perda de coerência nesta abstração que é modelada matematicamente pelas expressões (2.1) (VITHAYATHIL, 1995; LEONHARD, 1996).

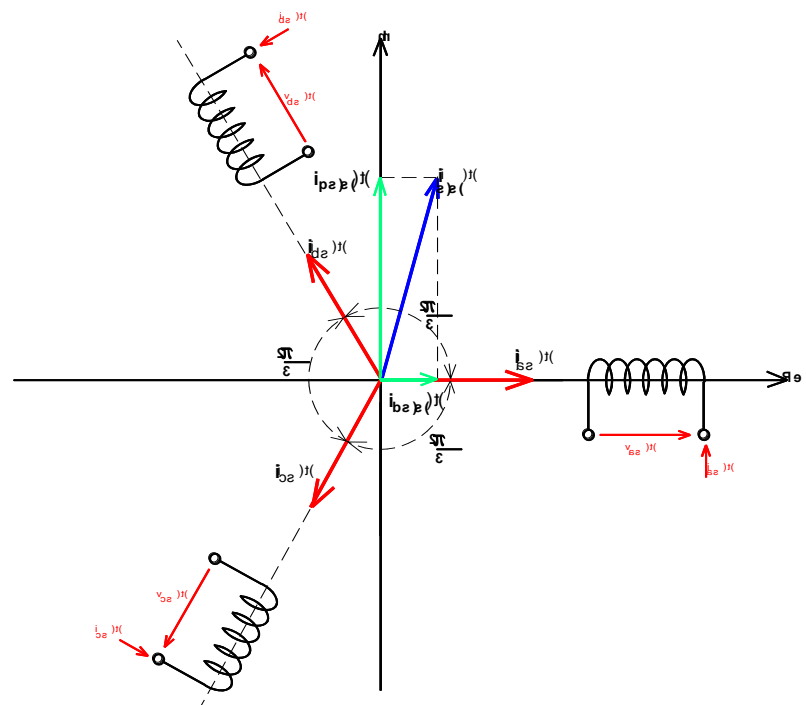

Figura 2.1 O posicionamento das bobinas do estator e os vetores espaciais gerados pelas mesmas.

$$
\begin{aligned}
& \mathbf{i}_{a s}(t)=\sqrt{2} I_{S} \cos (\omega t+\varphi) e^{j 0} \\
& \mathbf{i}_{b s}(t)=\sqrt{2} I_{S} \cos (\omega t+\varphi) e^{j\left(\frac{2 \pi}{3}\right)} \\
& \mathbf{i}_{c S}(t)=\sqrt{2} I_{S} \cos (\omega t+\varphi) e^{j\left(\frac{4 \pi}{3}\right)}
\end{aligned}
$$

Onde $\mathbf{i}_{a s}(t)$ é o vetor espacial corrente da fase $\mathbf{a}$ do estator nas coordenadas fixadas no estator, $\mathbf{i}_{b s}(t)$ é o vetor espacial corrente da fase $\boldsymbol{b}$ do estator nas coordenadas fixadas no próprio estator e $\mathbf{i}_{c s}(t)$ é o vetor espacial corrente da fase $\boldsymbol{c}$ do estator nas coordenadas fixadas no mesmo. Como as expressões (2.1) mostram claramente, os módulos dos vetores espaciais variam no tempo, mas suas direções angulares definidas por $e^{j \theta}$ tem posição fixa, que no caso corresponde as coordenadas fixadas no estator da máquina. O vetor espacial resultante do estator é dado por (2.2a) o mesmo recebe um (s) indicativo do sistema de referência utilizado.

$$
\mathbf{i}_{S(s)}(t)=\mathbf{i}_{a s}(t)+\mathbf{i}_{b s}(t)+\mathbf{i}_{c S}(t)=\frac{3}{2} \sqrt{2} I_{S} e^{j(\omega t+\varphi)}
$$


Como o vetor é descrito no plano de Argand, é natural que ele possa ser decomposto em uma expressão complexa na forma da equação (2.2b) (VITHAYATHIL, 1995; LEONHARD, 1996).

$$
\mathbf{i}_{s(s)}(t)=i_{d s(s)}+j i_{q s(s)}
$$

Onde os índices $d(s)$ e $q(s)$ indicam a componente de eixo direto e a componente do eixo de quadratura, ambas referidas às coordenadas fixadas no estator. Esta técnica permite escrever a expressão (2.2b) na forma de duas equações separadas uma no eixo direto e outra no eixo de quadratura como indicado em (2.3). Esta técnica é geralmente denominada transformada de Clarke.

$$
\begin{aligned}
& i_{d s(s)}=i_{a s}-\frac{i_{b s}+i_{c s}}{2} \\
& i_{q s(s)}=\frac{\sqrt{3}}{2}\left(i_{b s}-i_{c s}\right)
\end{aligned}
$$

Onde $i_{d s}$ é a corrente do estator de eixo direto e $i_{q s}$ é a corrente do estator de eixo de quadratura. O raciocínio utilizado para a descrição das correntes em termos de vetores espaciais também é válido para a descrição das tensões e fluxos concatenados do motor e as expressões gerais para a transformação tomam a forma da expressão (2.4) ( ANDERSON,1973).

$$
\left[\begin{array}{c}
x_{d(s)} \\
x_{q(s)} \\
x_{0}
\end{array}\right]=\left[\begin{array}{ccc}
1 & \frac{-1}{2} & \frac{-1}{2} \\
0 & \frac{\sqrt{3}}{2} & \frac{-\sqrt{3}}{2} \\
\frac{1}{3} & \frac{1}{3} & \frac{1}{3}
\end{array}\right]\left[\begin{array}{c}
x_{a s} \\
x_{b s} \\
x_{c s}
\end{array}\right]
$$

Onde os índices $d(s), q(s)$ e 0 referem-se as variáveis transformadas nos eixos direto, de quadratura fixados na referência do estator e sequência zero respectivamente, enquanto os índices as, bs e cs indicam as coordenadas naturais trifásicas das variáveis correspondentes.

Uma observação da expressão (2.2a) mostra que o vetor espacial sofre o efeito de um produto por $3 / 2$, assim como é necessário preservar as quantidades transformadas, modifica-se (2.4) de modo a normalizar o fator que modifica as quantidades originais como mostra a expressão (2.5) (BARRET, 
1982; TRZYNADLOWSKI, 1994; LEONHARD, 1996). Essas modificações alteram as energias associadas com cada variável transformada, de modo que quando forem utilizadas as expressões de potência ou torque, deve-se cuidar para fazer as compensações nos fatores de transformação. .

$$
\left[\begin{array}{c}
x_{d(s)} \\
x_{q(s)} \\
x_{0}
\end{array}\right]=\frac{2}{3}\left[\begin{array}{ccc}
1 & \frac{-1}{2} & \frac{-1}{2} \\
0 & \frac{\sqrt{3}}{2} & \frac{-\sqrt{3}}{2} \\
\frac{1}{2} & \frac{1}{2} & \frac{1}{2}
\end{array}\right]\left[\begin{array}{c}
x_{a s} \\
x_{b s} \\
x_{c s}
\end{array}\right]
$$

A transformação de Clarke permite a redução do número de variáveis, mas sua referência é fixada nas coordenadas do estator. Esta transformação pode ser reduzida se considerarmos que a fonte de alimentação do motor é simétrica e equilibrada como é o caso geral dos inversores de frequência utilizados em sistemas de acionamento e no caso particular de redes elétricas de boa qualidade, permitindo que as componentes de sequência zero sejam nulas. O que redefine a expressão (2.5) para a forma (2.6) (TRZYNADLOWSKI, 1994).

$$
\left[\begin{array}{l}
x_{d(s)} \\
x_{q(s)}
\end{array}\right]=\frac{2}{3}\left[\begin{array}{ccc}
1 & -1 / 2 & -1 / 2 \\
0 & \sqrt{3} / 2 & -\sqrt{3} / 2
\end{array}\right]\left[\begin{array}{l}
x_{a s} \\
x_{b s} \\
x_{c s}
\end{array}\right]
$$

Uma transformação fundamental, quando se trata de controle vetorial por orientação de campo, que permite a transformação das variáveis das coordenadas fixadas no estator para coordenadas fixadas em qualquer referencial desejado geralmente é denominada transformada de Park e sua expressão é mostrada em (2.7) (TRZYNADLOWSKI, 1994; LEONHARD, 1996).

$$
\left[\begin{array}{l}
x_{d(k)} \\
x_{q(k)}
\end{array}\right]=\left[\begin{array}{cc}
\cos \left(\omega_{k} t\right) & \operatorname{sen}\left(\omega_{k} t\right) \\
-\operatorname{sen}\left(\omega_{k} t\right) & \cos \left(\omega_{k} t\right)
\end{array}\right]\left[\begin{array}{l}
x_{d(s)} \\
x_{q(s)}
\end{array}\right]
$$

Onde o índice entre parênteses $(k)$ define o referencial desejado, no caso (k) define um referencial arbitrário, portanto se a transformação desejada for para o referencia do estator $\omega_{k}=0$, se for para o referencial sincronizado com a rede ou fonte trifásica de alimentação do motor, $\omega_{k}=\omega_{s}=2 \pi f_{s}$, onde $f_{s}$ 
é a frequência da fonte de alimentação trifásica, se for para o referencial do rotor, $\omega_{k}=\omega_{r}$, onde $\omega_{r}$ é a velocidade do rotor em radianos por segundo.

As transformadas de Clarke e Park podem ser unificadas de modo a se ter uma única transformada, que nem sempre é conveniente em termos práticos, mas que demonstra a generalização do sistema de transformadas utilizados em máquinas elétricas. A relação (2.8) mostra esta transformada generalizada aplicada a um referencial arbitrário (BARRET, 1982).

$$
\left[\begin{array}{c}
x_{d(k)} \\
x_{q(k)} \\
x_{0}
\end{array}\right]=\frac{2}{3}\left[\begin{array}{ccc}
\cos \left(\omega_{k} t\right) & \cos \left(\omega_{k} t-\frac{2 \pi}{3}\right) & \cos \left(\omega_{k} t-\frac{4 \pi}{3}\right) \\
\operatorname{sen}\left(\omega_{k} t\right) & \operatorname{sen}\left(\omega_{k} t-\frac{2 \pi}{3}\right) & \operatorname{sen}\left(\omega_{k} t-\frac{4 \pi}{3}\right) \\
\frac{1}{2} & \frac{1}{2} & \frac{1}{2}
\end{array}\right]\left[\begin{array}{l}
x_{a s} \\
x_{b s} \\
x_{c s}
\end{array}\right]
$$

Utilizando as transformações descritas anteriormente, pode-se estabelecer relações entre as variáveis sob análise em qualquer referencial desejado, assim utilizando a transformação de Park obtemos a expressão do vetor espacial tensão do estator nas coordenadas arbitrárias dadas pelas expressões (2.7) e (2.8) (KAZMIERKOWSKI, 1994; TRZYNADLOWSKI, 1994; LEONHARD, 1996), onde (2.9) é o vetor espacial tensão do estator,

$$
\boldsymbol{v}_{S(k)}=R_{S} \boldsymbol{i}_{S(k)}+\frac{d \lambda_{S(k)}}{d t}+j \omega_{k} \lambda_{s(k)}
$$

e (2.10) é o vetor espacial tensão do rotor.

$$
\boldsymbol{v}_{r(k)}=R_{r} \boldsymbol{i}_{r(k)}+\frac{d \lambda_{r(k)}}{d t}+j\left(\omega_{k}-\frac{P_{1}}{2} \omega_{r}\right) \lambda_{r(k)}
$$

De modo explícito $v_{s(k)}$ é a tensão do estator nas coordenadas arbitrárias, $i_{s(k)}$ é a corrente do estator nas coordenadas arbitrárias, $\lambda_{s(k)}$ é 0 fluxo concatenado do estator nas coordenadas arbitrárias, $\omega_{k}$ é a velocidade das componentes elétricas nas coordenadas arbitrárias, $v_{r(k)}$ é a tensão do rotor referida ao estator nas coordenadas arbitrárias, $i_{r(k)}$ é a corrente do rotor referida ao estator nas coordenadas arbitrárias, $\lambda_{r(k)}$ é o fluxo concatenado do rotor referido ao estator nas coordenadas arbitrárias, $\omega_{r}$ é a velocidade do eixo do rotor e $P_{1}$ é o número de polos da motor de indução. 
Fixando o modelo nas coordenadas de referência do estator $\left(\omega_{k}=0\right)$, e fixando a tensão do rotor em zero, para o caso do motor de indução com rotor em gaiola, obtemos as relações (2.11) e (2.12) (KAZMIERKOWSKI, 1994; TRZYNADLOWSKI, 1994):

$$
\begin{aligned}
& \boldsymbol{v}_{s(s)}=R_{s} \boldsymbol{i}_{s(s)}+\frac{d \lambda_{S(s)}}{d t} \\
& \boldsymbol{v}_{r(s)}=\mathbf{0}=R_{r} \boldsymbol{i}_{r(s)}+\frac{d \lambda_{r(s)}}{d t}-j \frac{P_{1}}{2} \boldsymbol{\omega}_{r} \lambda_{r(s)}
\end{aligned}
$$

As relações entre os fluxos concatenados do estator e do rotor com as correntes nos mesmos é indicada em (2.13a) e (2.13b) (KAZMIERKOWSKI, 1994)

$$
\begin{aligned}
& \lambda_{s(s)}=L_{s} \boldsymbol{i}_{s(s)}+L_{m} \boldsymbol{i}_{r(s)} \\
& \lambda_{r(s)}=L_{r} \boldsymbol{i}_{r(s)}+L_{m} \boldsymbol{i}_{s(s)}
\end{aligned}
$$

Onde $L_{s}=L_{l s}+L_{m}$, sendo $L_{l s}$ a indutância de dispersão do estator e $L_{m}$ a indutância mútua da máquina e $L_{r}=L_{l r}+L_{m}$ onde $L_{l r}$ é a indutância de dispersão do rotor.

A separação das partes real e imaginária das variáveis elétricas das equações na forma indicada em (2.2), (2.9), (2.10a) e (2.10b) juntamente com as relações (2.6) permite a obtenção das relações (2.14) a (2.16).

$$
\begin{aligned}
& \boldsymbol{v}_{s(s)}=v_{d s(s)}+j v_{q s(s)} \\
& \boldsymbol{i}_{s(s)}=i_{d s(s)}+j i_{q s(s)} \\
& \lambda_{s(s)}=\lambda_{d s(s)}+j \lambda_{q s(s)}
\end{aligned}
$$

Onde $v_{d s(s)}$ é a tensão de eixo direto do estator nas coordenadas fixadas no estator, $v_{q s(s)}$ é a tensão de eixo de quadratura do estator nas mesmas coordenadas, $i_{d s(s)}$ é a corrente de eixo direto do estator nas coordenadas fixadas no estator, $i_{q s(s)}$ é a corrente de quadratura nas mesmas coordenadas, $\lambda_{d s(s)}$ é o fluxo concatenado de eixo direto do estator nas mesmas coordenadas 
e $\lambda_{q s(s)}$ é o fluxo concatenado de eixo de quadratura do estator nas mesmas coordenadas.

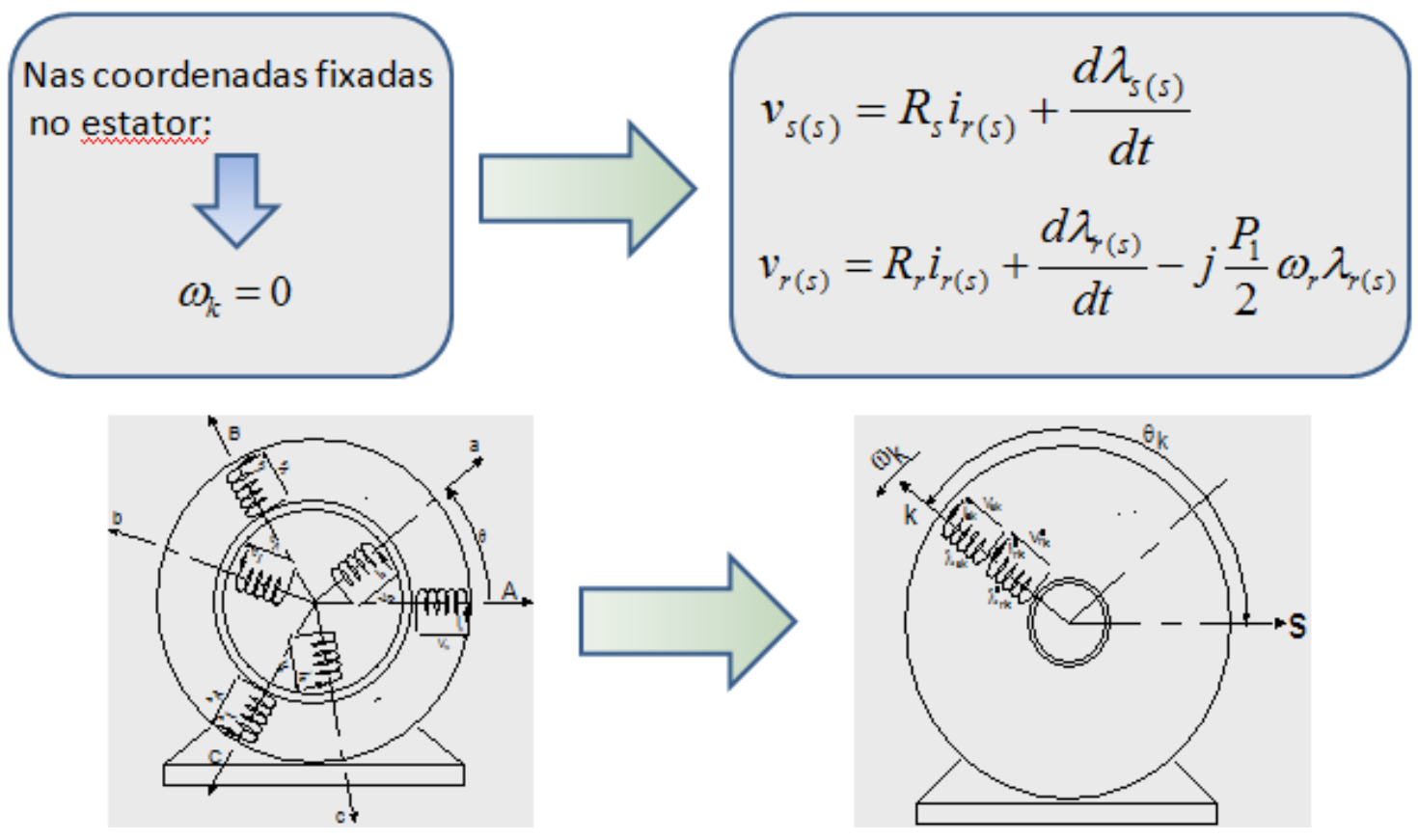

Figura 2.2 Efeitos das transformações de Park das coordenadas generalizadas para as coordenadas fixadas no estator.

As relações (2.14) a (2.16) e seus desenvolvimentos, formam a base para a construção de um estimador dos fluxos concatenados do estator cuja expressão é indicada em (2.17a) e (2.17b) (KAZMIERKOWSKI, 1994; TRZYNADLOWSKI, 1994; LEONHARD, 1996).

$$
\begin{gathered}
\frac{d \lambda_{d s(s)}}{d t}=v_{d s(s)}-R_{s} i_{d s(s)} \\
\frac{d \lambda_{q s(s)}}{d t}=v_{q s(s)}-R_{s} i_{q s(s)}
\end{gathered}
$$

Os limites do uso da expressões (2.17a) e (2.17b) na construção de um estimador de torque e fluxos concatenado do estator decorre da dificuldade para a construção de integradores práticos em baixas frequência, portanto esse estimador não lida bem com baixas frequências ficando limitado à operações com frequências acima de 3Hz (JOTTEN; MAEDER, 1983). 


\subsubsection{Estimação dos fluxos estatóricos e torque nos MIT}

Barret faz uma incursão interessante considerando o balanço de energia na máquina com o estator fixado como gerador de energia e o rotor como receptor. Com isso tem-se a estimativa da potência transferida entre os dois circuitos nas coordenadas naturais dada pela expressão (2.18) (BARRET, 1982).

$$
P_{e}=v_{a s} i_{a s}+v_{b s} i_{b s}+v_{c s} i_{c s}-v_{a r} i_{a r}-v_{b r} i_{b r}-v_{c r} i_{c r}
$$

A aplicação da transformada de Park (2.7) em (2.18) nas coordenadas fixadas no estator resulta a expressão (2.19).

$$
P_{e}=\frac{3}{2}\left(v_{d s(s)} i_{d s(s)}+v_{q S(s)} i_{q S(s)}+2 v_{0 s} i_{0 s}-v_{d r(s)} i_{d r(s)}-v_{q r(s)} i_{q r(s)}-2 v_{0 r} i_{0 r}\right)
$$

Onde os índices $d s(s), q s(s)$ e $0 s$ indicam componentes direta, de quadratura e zero do estator respectivamente e $\operatorname{dr}(s), \operatorname{qr}(s)$, e or as componentes de eixo direto, de quadratura e zero do rotor, respectivamente nas coordenadas fixadas no estator. Substituindo as componentes de (2.14) a (2.16) e incorporando os termos de sequência zero das relações pertinentes, não demonstradas aqui, mas de definição clara com o emprego da relação (2.8), obtemos a equação (2.20) (BARRET, 1982).

$$
\begin{aligned}
P_{e}=\frac{3}{2}\left[-i_{d s}\right. & \left.\frac{d \lambda_{d s(s)}}{d t}-i_{q s} \frac{d \lambda_{q s(s)}}{d t}-2 i_{0 s} \frac{d \lambda_{0 s}}{d t} i_{d r}-\frac{d \lambda_{d r(s)}}{d t}-i_{q r} \frac{d \lambda_{q r(s)}}{d t}-2 i_{0 r} \frac{d \lambda_{0 r}}{d t}\right] \\
& +\frac{3}{2}\left[\left(\lambda_{d s(s)} i_{q s(s)}-\lambda_{q s(s)} i_{d s(s}\right) \frac{d \theta_{s}}{d t}+\left(\lambda_{d r(s)} i_{q r(s)}-\lambda_{q r(s)} i_{d r(s)}\right) \frac{d \theta_{r}}{d t}\right] \\
& +\frac{3}{2}\left[R_{s}\left(i_{d s(s)}^{2}+i_{q s(s)}^{2}+2 i_{0 s}^{2}\right)+R_{r}\left(i_{d r(s)}^{2}+i_{q r(s)}^{2}+2 i_{0 r}^{2}\right)\right]
\end{aligned}
$$

O primeiro colchete de (2.20) representa a energia armazenada nos campos magnéticos por unidade de tempo ou potência reativa do motor, o terceiro colchete representa a dissipação de potência da máquina por efeito Joule nos enrolamentos estatóricos e rotóricos. O colchete central corresponde 
a potência transferida entre o estator e o rotor, ou seja, a potência transferida ao eixo do rotor do motor. Como a expressão (2.20) é de balanço de energia o segundo parênteses do colchete central corresponde a uma reação ao efeito do primeiro, ou seja eles tem sinais trocados, assim podemos escrever a relação (2.21)(BARRET, 1982).

$$
P_{m e c}=\frac{3}{2}\left(\lambda_{d s} i_{q s}-\lambda_{q s} i_{d s}\right)\left(\frac{d \theta_{s}}{d t}-\frac{d \theta_{r}}{d t}\right)
$$

Como a diferença entre as derivadas corresponde a diferença entre o deslocamento angular do estator, na velocidade síncrona do campo girante e o deslocamento angular das componentes rotóricas que estão escorregando em relação ao primeiro, temos nesta diferença a velocidade do rotor da máquina, que pode ser escrita na forma (2.22).

$$
\omega_{r}=\frac{d \theta_{s}}{d t}-\frac{d \theta_{r}}{d t}
$$

Se o número de polos for levado em conta a expressão (2.22) fica com a forma (2.23).

$$
\omega_{r}=\frac{2}{P_{1}}\left(\frac{d \theta_{s}}{d t}-\frac{d \theta_{r}}{d t}\right)
$$

Utilizando as mesmas relações e mais a relação entre a potência mecânica e a velocidade do rotor podemos escrever a equação (2.24) do torque eletromagnético transferido para o rotor (KAZMIERKOWSKI, 1994; TRZYNADLOWSKI, 1994; LEONHARD, 1996).

$$
T_{e m}=\frac{P_{m e c}}{\omega_{r}}=\frac{3 P_{1}}{4}\left(\lambda_{d s} i_{q s}-\lambda_{q s} i_{d s}\right)
$$

O esquema de obtenção deste torque juntamente com os fluxos concatenados do estator e suas derivadas é mostrado na figura 2.3 (ONG, 1998). 


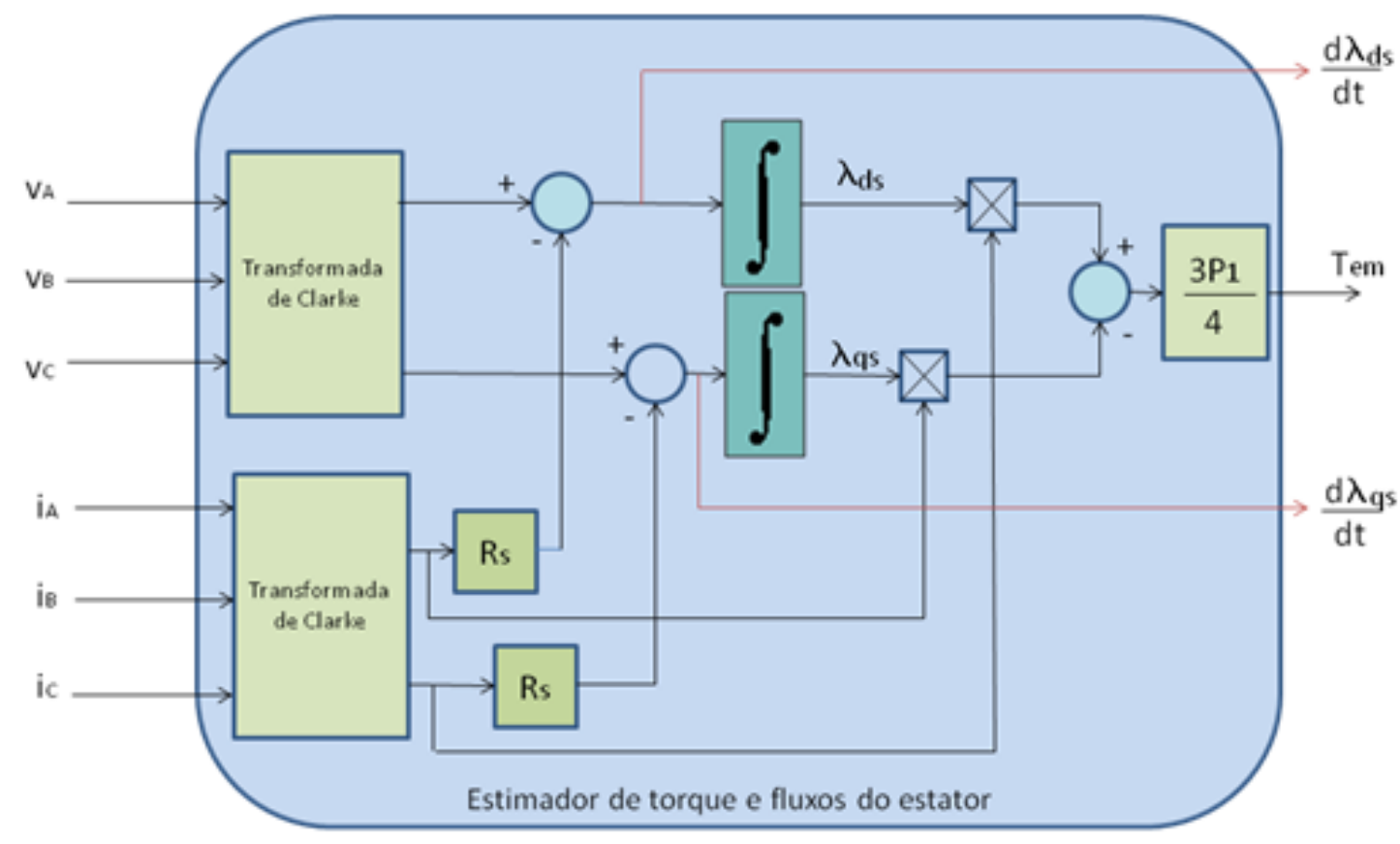

Figura 2.3 Estimador do torque e dos fluxos concatenados do estator

\subsubsection{Estimação da velocidade dos MIT sem sensor eletromecânico}

Schauder faz um trabalho seminal, usando sistemas adaptativos para a determinação da velocidade do motor de indução sem sensor eletromecânico. Seu trabalho leva em consideração os fluxos concatenados do rotor, obtidos com base nos fluxos concatenados do estator, utilizando as expressões (2.10), (2.11), (2.15) e (2.16) em suas formas escalares, admitindo o conhecimento dos parâmetros, para obter, via um mecanismo de adaptação, a velocidade real do motor (SCHAUDER, 1992).

Em sua exposição, Schauder considera que a relação $L_{m} / L_{r}$ é desnecessária, pois ela se encaixaria automaticamente no processo de adaptação, uma vez que é um parâmetro multiplicador de todas as relações relativas aos fluxos concatenados. Com isso as expressões relacionadas a tensão aplicada ao motor tem a forma das expressões (2.25) e (2.26) (SCHAUDER, 1992). Todas as variáveis são assumidas implicitamente como função do tempo.

$$
\frac{d\left(\frac{L_{m}}{L_{r}} \lambda_{d r(s)}\right)}{d t}=v_{d s(s)}-\left(R_{s} i_{d s(s)}+\sigma L_{s} \frac{d i_{d s(s)}}{d t}\right)
$$




$$
\frac{d\left(\frac{L_{m}}{L_{r}} \lambda_{q r(s)}\right)}{d t}=v_{q s(s)}-\left(R_{s} i_{q s(s)}+\sigma L_{s} \frac{d i_{q s(s)}}{d t}\right)
$$

$\mathrm{E}$ as expressões da parte de velocidade tem a forma indicada nas expressões (2.27) e (2.28) (SCHAUDER, 1992).

$$
\begin{aligned}
& \frac{d\left(\frac{L_{m}}{L_{r}} \lambda_{d r}\right)}{d t}=-\frac{L_{m}}{L_{r}} \frac{1}{\tau_{r}} \lambda_{d r}-\frac{P_{1}}{2} \frac{L_{m}}{L_{r}} \omega_{r} \lambda_{q r}+\frac{L_{m}^{2}}{L_{r} \tau_{r}} i_{d s} \\
& \frac{d\left(\frac{L_{m}}{L_{r}} \lambda_{q r}\right)}{d t}=-\frac{L_{m}}{L_{r}} \frac{1}{\tau_{r}} \lambda_{q r}+\frac{P_{1}}{2} \frac{L_{m}}{L_{r}} \omega_{r} \lambda_{d r}+\frac{L_{m}^{2}}{L_{r} \tau_{r}} i_{q s}
\end{aligned}
$$

Em seu artigo sobre metodologia de medição de velocidade sem sensor, cujo esquema é mostrado na figura 2.4, Schaulder utilizou as equações (2.25) e (2.26) como referência, já que as mesmas não levam em conta a velocidade, comparando os fluxos concatenados do rotor com as expressões dadas por (2.27) e (2.28) utilizando um mecanismo de adaptação de velocidade do tipo MRAS (Model Reference Adaptive System), para determinar a velocidade por estimação (SCHAUDER, 1992).

\subsubsection{Os sinais da alimentação elétrica dos MIT}

A alimentação dos motores de indução trifásicos pode ocorrer diretamente da rede elétrica, ou através de inversores de frequência variável, ambos casos tem seus prós e seus contras, mas a flexibilidade conferida aos sistemas de controle dos motores de indução trifásicos pelos inversores de frequência associado a durabilidade dos motores de indução, tornaram este modo de acionamento praticamente absoluto em todas as áreas de aplicações (BOSE, 2009), mas ainda existem situações onde o motor opera conectado diretamente a rede elétrica trifásica e este é o caso de muitas máquinas ferramentas utilizadas na indústria, muitas vezes devido ao porte das aplicações e em outras situações devido a operacionalidades específicas.

A literatura técnica é profícua sobre os efeitos dos rolamentos defeituosos nas "assinaturas" ou perfis das correntes de fase. Entre vários trabalhos estão os de Thomson e Weidong que utilizam várias técnicas para detectar os defeitos dos rolamentos e do próprio motor (THOMSON et al, 1999), (WEIDONG,MEHEFSKE, 2006). Mehala trata em detalhe de vários 
métodos de processamento digital de sinais para a detecção de falhas no MITs (MEHALA.2010).

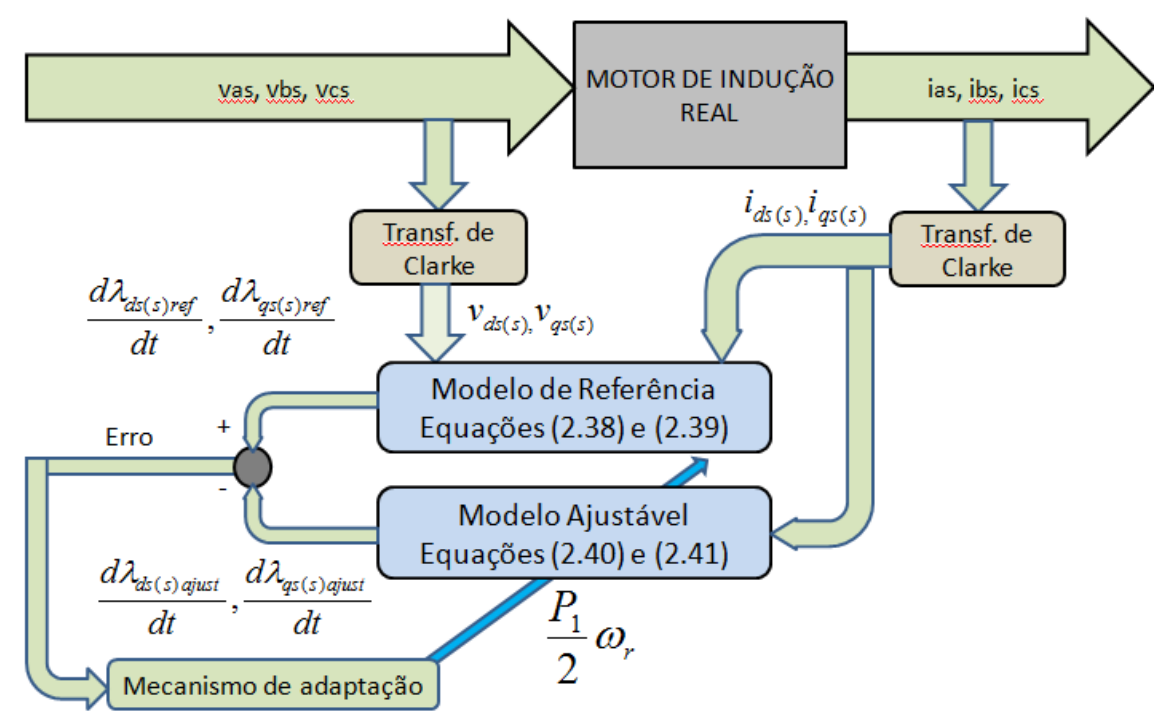

Figura 2.4 O método do sistema adaptativo com modelo de referência (MRAS, Model

Reference Adaptive System) de adaptação de velocidade (SCHAUDER, 1992)

Além dos aspectos relacionados acima, o efeito da qualidade da energia elétrica que alimenta o motor também produz efeitos de modulação na tensão e corrente de alimentação do motor, contribuindo assim em alguns aspectos para seu perfil de corrente (DUGAN et al, 2012), potência e torque (SILVA, 2006). Uma alimentação elétrica de qualidade supõe que a rede elétrica tenha um grau de desequilíbrio mínimo (DUGAN ET al, 2012).

\subsubsection{O efeito do desequilíbrio de fase nos MIT}

O desequilíbrio das tensões de fase causam efeitos adversos no equipamento elétrico da rede incluindo os motores de indução, uma vez que um pequeno desequilíbrio das tensões pode causar um pronunciado desequilíbrio das correntes de fase (MULJADI; SCHIFER; LIPO, 1985; LEE, 1989). Sob condições desequilibradas, os sistemas de potência impõem mais perdas por aquecimento e são menos estáveis devido ao desbalanceamento das fases, já que em condições equilibradas a resposta do sistema à transferências emergenciais de energia é mais rápida (BROADWATER; KHAN, 
SHAALAN, LEE, 1993). O efeito do desequilíbrio de tensão também pode provocar sérios defeitos em motores de indução e equipamentos de eletrônica de potência, tais como conversores e sistemas de acionamento de velocidade ajustáveis.

O desequilíbrio de tensão em porcentagem é definido pela National Electrical Manufacturers Association (NEMA) no Standard Publications número MG 1-1993 (NEMA. MG 1-1993) pela expressão (2.29):

$$
\% \text { Desequilíbrio }=\frac{\text { Desvio máximo da média }}{\text { Média das tensões de linha }} \times 100
$$

Deve-se notar que a norma NEMA utiliza as tensões de linha ao invés das tensões de fase. Quando as tensões de fase são utilizadas, o desequilíbrio entre os ângulos de fase não são refletidos na porcentagem de desequilíbrio, portanto as tensões de fase raramente são utilizadas para calcular 0 desequilíbrio de tensão.

Um outro índice utilizado em padrões europeus (IEC) indicam o grau de desequilíbrio e o fator de desequilíbrio de tensão (VUF - Voltage Unbalance Factor) que é a razão entre as tensões de sequência negativa e de sequência positiva, representadas pela expressão (2.30) (MASWOOD, JOOS, ZIOGAS, LINDSEY, 1991)

$$
V U F \%=\frac{V_{2}}{V_{1}} \times 100
$$

Onde $V_{1}$ e $V_{2}$ são os valores das tensões de sequência positiva $e$ negativa, respectivamente, e podem ser obtidas com a utilização da teoria das componentes simétricas (JOUANNE, BANERJEE, 2001).

EBADI simula o efeito do desequilíbrio das tensões de fase sobre um motor de indução a partir do Fator de Desequilíbrio de Fase (VUF) acentuando que além de um torque constante na carga, ocorre o efeito estacionário de uma componente de segunda harmônica. Como o estudo é de simulação, somente o efeito desta componente é considerado, a tabela 2.1 indica os valores considerados na simulação . (EBADI, MIRZAIE, GHOLAMIAN, 2011) 
O efeito desse desequilíbrio de tensão sobre o torque do motor pode ser dividido entre um torque contínuo e um torque flutuante com componentes de segunda harmônica como mostram os gráficos das figuras 2.5(a) e (b) ambos em função do fator de desequilíbrio de fase. (EBADI, MIRZAIE, GHOLAMIAN, 2011)

Tabela 2.1. Desequilíbrio das tensões de fase e porcentual de VUF gerado

\begin{tabular}{|c|c|c|c|c|c|c|c|}
\hline VUF\% & 1 & 2 & 3 & 4 & 5 & 6 & 7 \\
\hline $\mathrm{Va}(\mathrm{V})$ & $223.19 \angle 0$ & $226.99 \angle 0$ & $230.79 \angle 0$ & $234.59 \angle 0$ & $238.39 \angle 0$ & $242.19 \angle 0$ & $245.99 \angle 0$ \\
\hline $\mathrm{Vb}(\mathrm{V})$ & $219.39 \angle 240$ & $219.39 \angle 240$ & $219.39 \angle 240$ & $219.39 \angle 240$ & $219.39 \angle 240$ & $219.39 \angle 240$ & $219.39 \angle 240$ \\
\hline $\mathrm{V} \mathrm{c}(\mathrm{V})$ & $215.59 \angle 120$ & $211.79 \angle 120$ & $207.99 \angle 120$ & $204.19 \angle 120$ & $200.39 \angle 120$ & $196.59 \angle 120$ & $192.78<120$ \\
\hline $\mathrm{V}+(\mathrm{V})$ & 219.39 & 219.39 & 219.39 & 219.39 & 219.39 & 219.39 & 219.39 \\
\hline $\mathrm{V}-(\mathrm{V})$ & 2.193 & 4.387 & 6.581 & 8.775 & 10.969 & 13.163 & 15.374 \\
\hline
\end{tabular}

O mesmo estudo mostra os efeitos deste desequilíbrio sobre o torque do motor e seu comportamento espectral, como é mostrado na figura $2.6 \mathrm{com}$ VUF de $6 \%$. Percebe-se que o efeito da componente de segunda harmônica no torque é bastante pronunciado, com mais da metade da parte constante do valor do torque. O efeito desta trepidação de $100 \mathrm{~Hz}$ no estudo realizado gera trepidações indesejáveis no processo sob acionamento, além de provocar efeitos de aquecimento e outras perdas devido aos efeitos vibratórios, nas partes mecânicas do sistema. O gráfico do espectro da simulação mostrada na figura 2.6 indica também o efeito das componentes relacionadas com os dentes das ranhuras de acondicionamento das bobinas do estator gerando componentes bastante amortecidas em frequência que vão de aproximadamente $560 \mathrm{~Hz}$ para cima (EBADI, MIRZAIE, GHOLAMIAN, 2011) .

Não é recomendada a operação de motores de indução para situações acima de $2 \%$ de desequilíbrio de fase, caso isso seja necessário, deve-se diminuir a potência da aplicação. Para casos de desequilíbrio acima de 5\% a incidência de falha do motor aumenta bastante.

Com vista à aplicação desejada neste trabalho, o efeito do desequilíbrio de fase é um efeito estacionário, como mostra a figura 2.5, e portanto passível detecção pela FFT. 


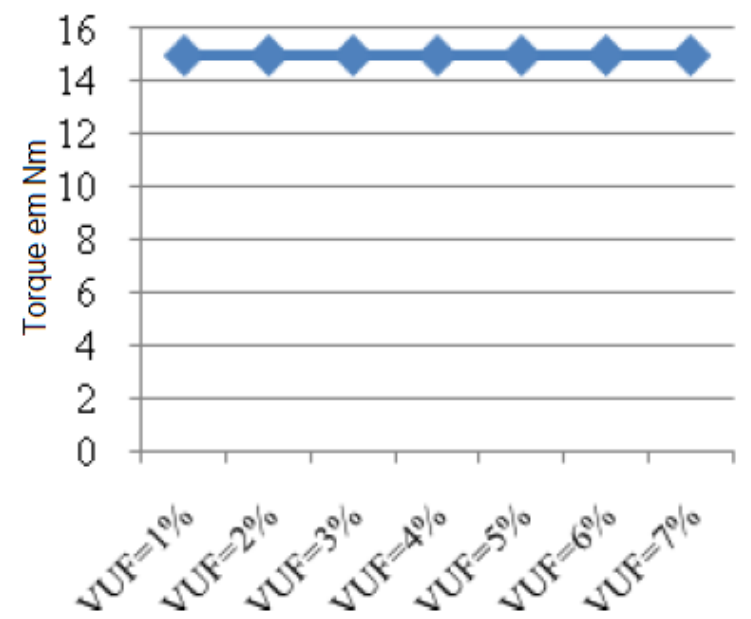

(a)
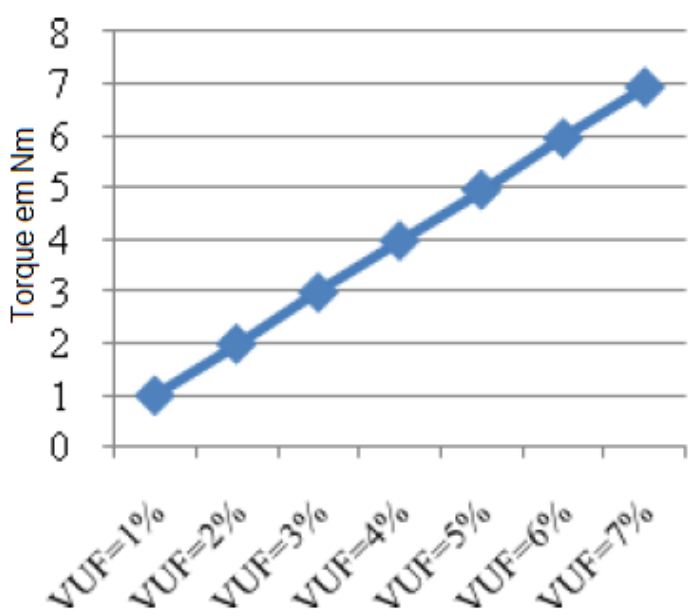

(b)

Figura 2.5 Efeito do Fator de desequilíbrio de fase sobre o torque em função do VUF a) Fundamental e (b) 2ª harmônica (EBADI, MIRZAIE, GHOLAMIAN, 2011)
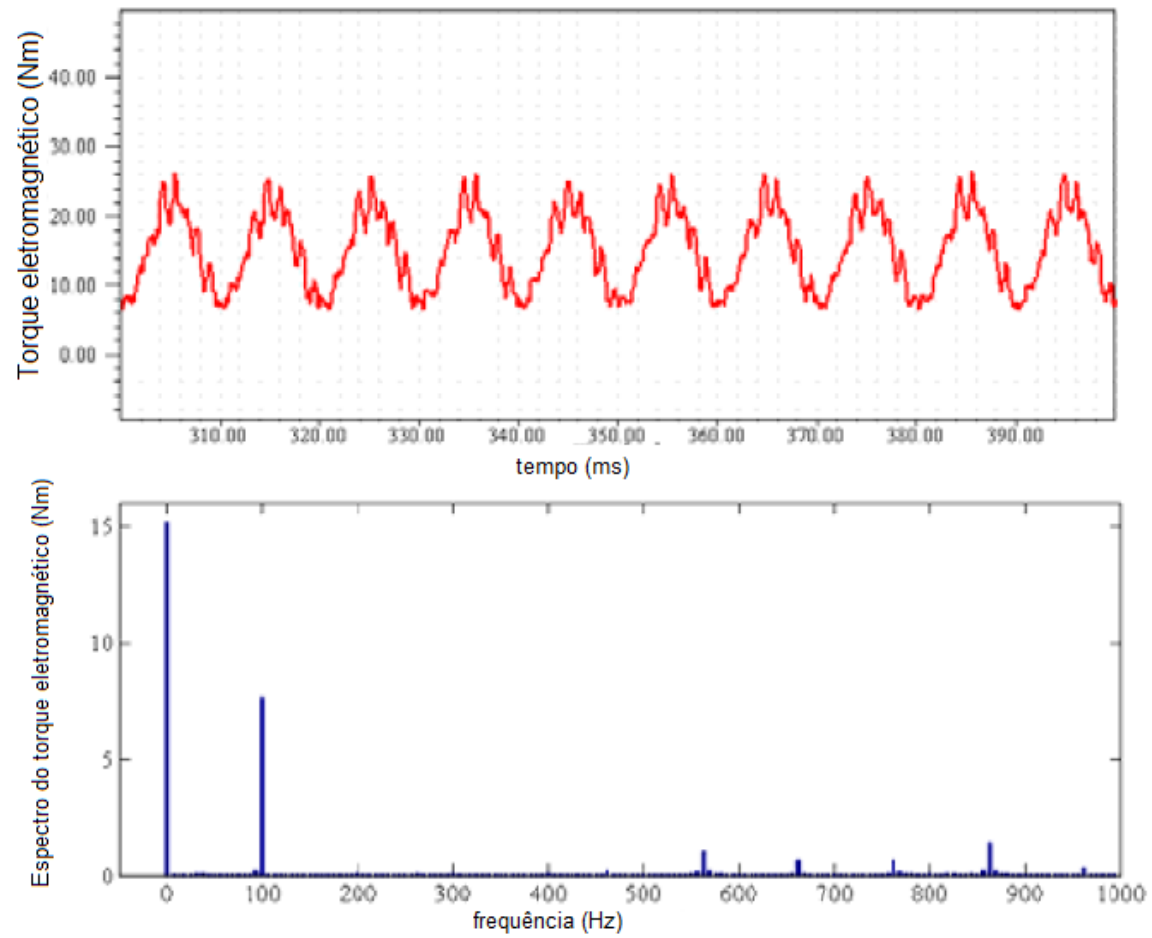

Figura 2.6 Simulação da forma de onda do torque e efeito do desequilíbrio de fase para a condição de VUF de $6 \%$ e o espectro correspondente para redes de $50 \mathrm{~Hz}$ (EBADI, MIRZAIE, GHOLAMIAN, 2011)

\subsection{Vibrações nos sistemas mecânicos}

Os sistemas das máquinas ferramentas são constituídos de vários elementos mecanicamente acoplados, que por natureza tem sua própria 
frequência vibratória natural, porém quando o conjunto mecânico é aplicado a uma tarefa específica, como é o caso de torneamento, o conjunto das vibrações presentes no sistema mecânico pode gerar fenômenos de trepidação que modificam o comportamento da ferramenta durante a usinagem da peça gerando com isso, no melhor caso, má formação da superfície usinada e refugo da peça, destruição da ferramenta de corte e no pior caso falha de componentes mecânicos da máquina ferramenta paralisando a produção. Este cenário indica que a monitoração das vibrações nos processos de usinagem são fundamentais para (SILVA, C., 2007):

- Monitoração de vibrações para avaliação de desempenho.

- Monitoração da vida útil da ferramenta de corte

- Controle e supressão de trepidações

- Proteção operacional da máquina ferramenta

\subsubsection{Análise do comportamento vibratório da máquina-ferramenta}

O conjunto de componentes que constituem uma máquina ferramenta, quando em movimento, apresenta oscilações livres em algumas frequências, principalmente a parte relacionada as correias, que por terem um comprimento longo e massa relativamente grande, operam como cordas vibrantes que induzem oscilações que dependem da velocidade de operação da máquina (RAO, 2009).

A influência das correias no perfil de corrente é similar ao das barras quebradas, porém a especificidade da aplicação de correias em tornos mostra que as bandas laterais produzidas por suas oscilações, embora também estacionárias, estão relacionadas com a velocidade de operação do processo de usinagem da máquina ferramenta (RAO, 2009), enquanto que as barras quebradas geram bandas laterais fixas, que tem relação com o carregamento e portanto com o escorregamento do rotor (MEHALA, 2010).

\subsubsection{Oscilações da máquina-ferramenta}

Existem muitos fenômenos elétricos e mecânicos que produzem oscilações em máquinas ferramentas, desde problemas com engrenagens defeituosas, com dentes quebrados, defeitos em mancais e rolamentos da 
própria máquina, além de problemas no motor de indução que pode estar com barras do rotor de gaiola quebradas, curtos parciais nos enrolamentos do estator. Admitindo que a máquina ferramenta não sofra dos problemas mencionados, seu maior problema, devido ao tempo e modo de uso, é o desbalanceamento das massas que a constituem.

A figura 2.7 mostra o esquema de um torno mecânico acionado por um MIT, o conjunto de componentes mecânicos do torno apresenta uma distribuição complexa de massas rotativas, nem sempre balanceadas. A presença de desbalanceamentos provocam componentes oscilatórias nas operações realizadas pela máquina. $O$ modelo simples considerando apenas um grau de liberdade para estudo de desbalanceamentos para um torno é mostrado na figura 2.8. (YANG, 2005).

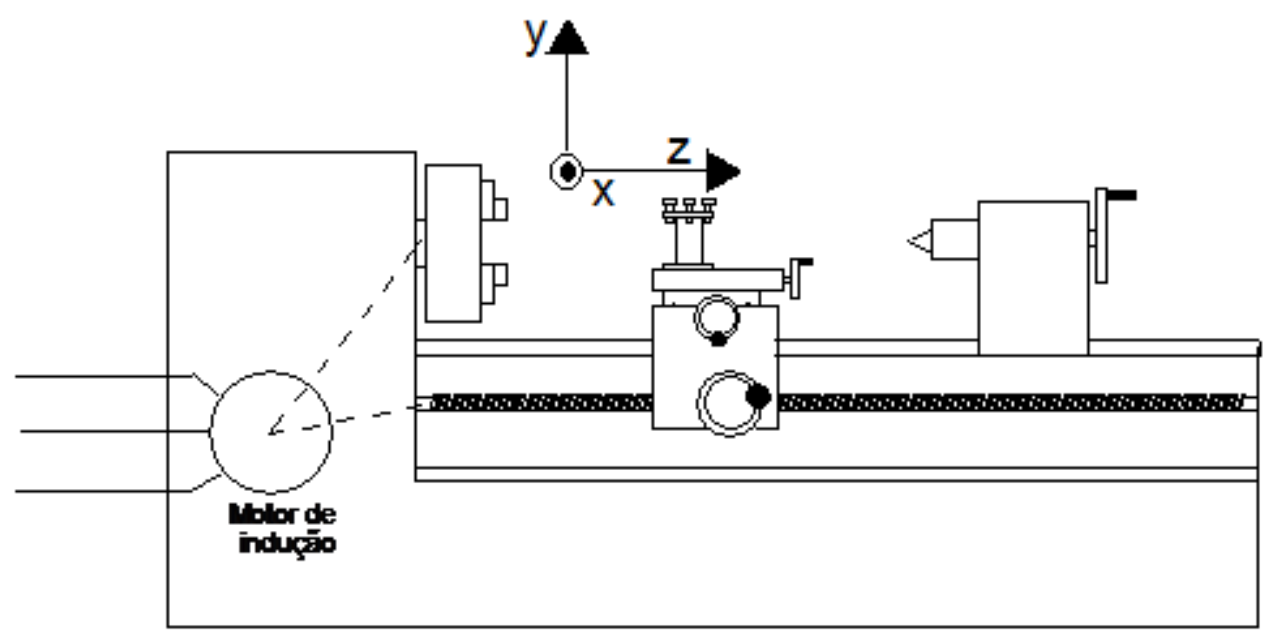

Figura 2.7 Esquema geral de acionamento de um torno mecânico simples.

A modelagem leva em conta apenas o deslocamento vertical, ou de eixo y da máquina onde ocorre a ação da força de corte nas operações de usinagem, que via de regra, é muito maior que as forças de avanço e passiva (STEMMER, 2007) .

A modelagem do sistema da figura 2.8 , onde $\omega$ é a velocidade angular da massa desbalanceada mo, a massa total do sistema é $m, d$ é a distância equivalente da massa desbalanceada, $k$ é o coeficiente de elasticidade da mola equivalente do sistema e $c$ o coeficiente de atrito viscoso do amortecedor. Se $x(t)$ é 0 
deslocamento de um grau de liberdade do sistema, o modelo matemático do sistema é dado pela expressão (2.31) (YANG,2005).

$$
m \frac{d^{2} x(t)}{d t}+c \frac{d x(t)}{d t}+k x(t)=m_{o} d \omega^{2} \operatorname{sen}(\omega t)
$$

Cuja solução de regime é dada em (2.32).

$$
x_{\text {regime }}(t)=X \operatorname{sen}(\omega t+\phi)
$$

Onde a magnitude e a fase são dadas por (2.33).

$$
\begin{aligned}
& X=\frac{m_{0} d \omega^{2}}{\sqrt{\left(k-m \omega^{2}\right)^{2}+c^{2} \omega^{2}}}=\frac{m_{0} d}{m} \frac{r^{2}}{\sqrt{\left(1-r^{2}\right)^{2}+4 \xi^{2} r^{2}}} \\
& \phi=-\operatorname{arctg}\left(\frac{c \omega}{k-m \omega^{2}}\right)=\operatorname{arctg} \frac{2 \xi r}{1+r^{2}}
\end{aligned}
$$

Com $r=\omega / \omega_{n}$ sendo $\omega_{n}=\sqrt{k / m}$ a frequência de rotação natural ou de ressonância mecânica e $\xi=c / 2 \sqrt{m k}$ a taxa de amortecimento do sistema mecânico.

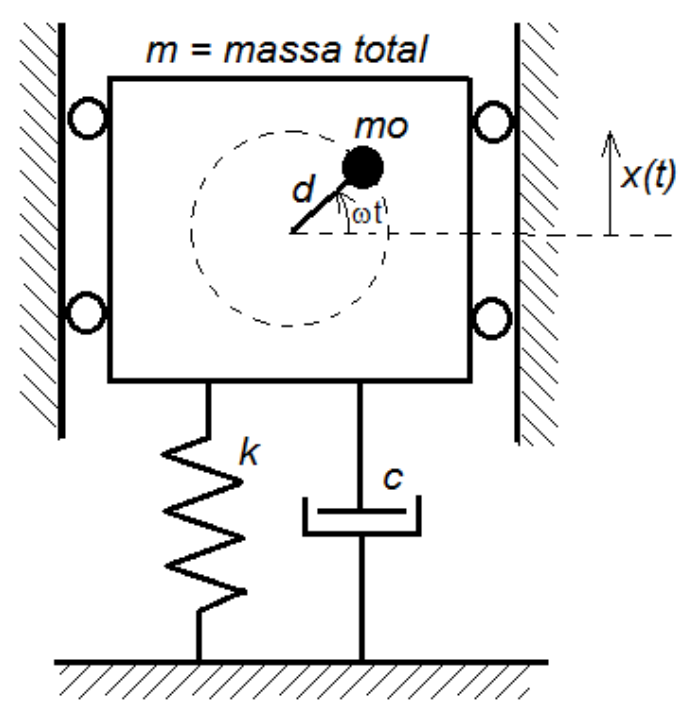

Figura 2.8 Modelagem de desbalanceamento rotativo com um grau de liberdade.

A força transmitida para as bases de sustentação do conjunto mecânico devido ao desbalanceamento é dada na expressão (2.34).

$$
F_{\text {transm }}=k X \operatorname{sen}(\omega t+\phi)+c \omega X \cos (\omega t+\phi)
$$


Onde X é dado pela expressão definida em (2.32a). A magnitude da força transmitida é dada por $F_{T}=X \sqrt{k^{2}+c^{2} \omega^{2}}$. A transmissibilidade de força $T_{f}$ é a razão entre a magnitude da força transmitida e a força de excitação causada pelo desbalanceamento rotativo como indica a expressão (2.35).

$$
T_{f}=\frac{F_{t}}{m_{0} d \omega^{2}}=\frac{\sqrt{1+4 \xi^{2} r^{2}}}{\sqrt{\left(1-r^{2}\right)+4 \xi^{2} r^{2}}}
$$

A transmissibilidade de força é utilizada em isolação de vibração das estruturas e máquina (YANG, 2005), como esta força se propaga pelos meios mecânicos para a fundação dos sistemas, ela passa pelos sensores de força e torque alocados entre esses pontos da estruturas e máquinas.
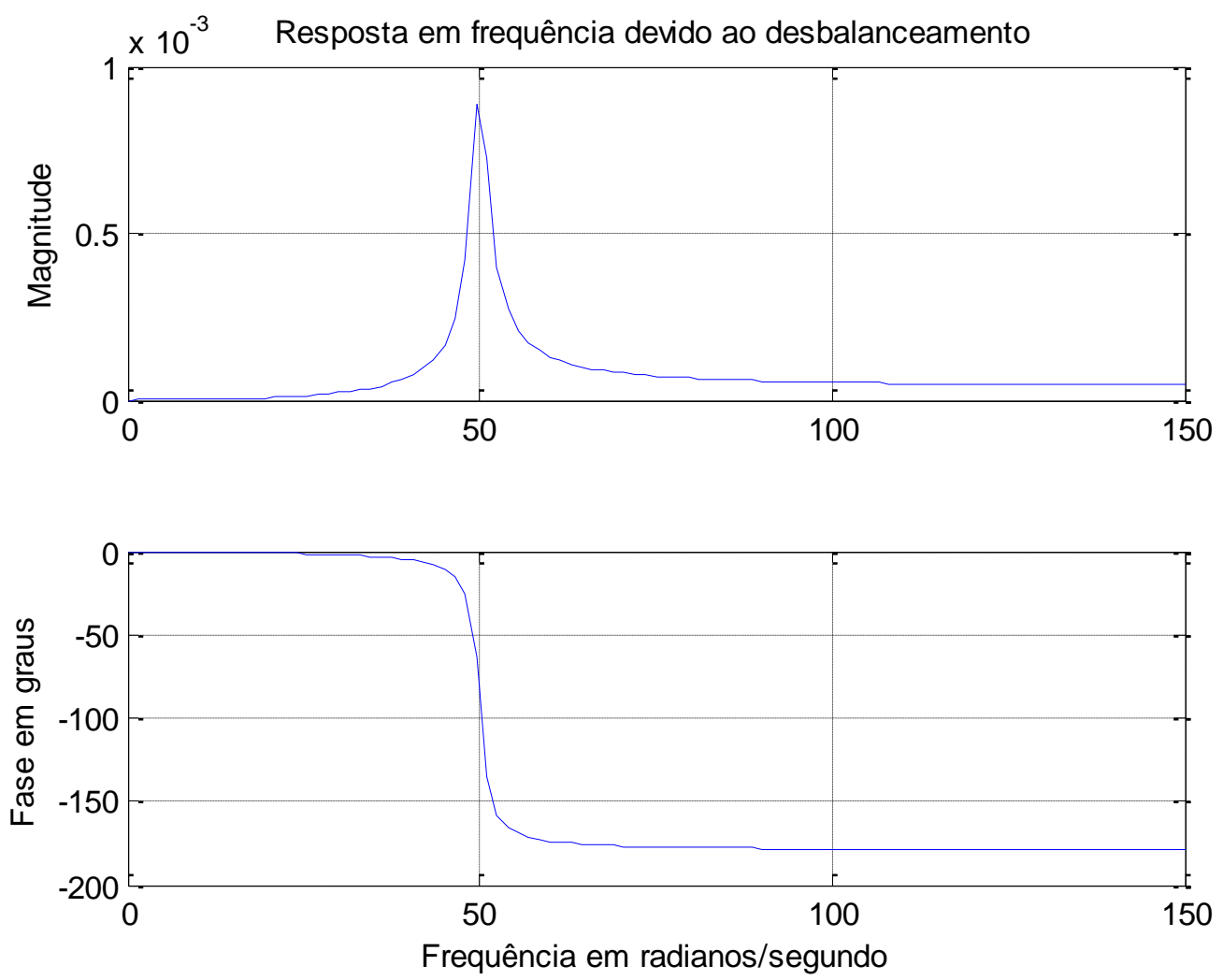

Figura 2.9 Resposta de frequência de um sistema rotativo desbalanceado

A figura 2.9 mostra o efeito do desbalanceamento de massas de um sistema com rotor de $250 \mathrm{~kg}, k=625000 \mathrm{~N} / \mathrm{m}, \xi=0,02$ e um desbalanceamento de $m_{0} d=0,01 \mathrm{~kg} / \mathrm{m}$ (YANG, 2005). 
As forças e consequentemente os torques envolvidos no processo de usinagem são influenciados pelos parâmetros relacionados com o processo de formação de cavaco, ou seja (ANDREASEN, LE CHIFFRE, 1993):

- Material da peça

- Geometria da ferramenta

- Fluído de corte

- Profundidade de corte

- Velocidade de avanço

- Velocidade de corte

A figura 2.10 mostra a relação entre as forças de corte dinâmica e estática, sendo que, a potência de corte associada a esta última, é muito superior as potências utilizadas para o avanço e para manter a ferramenta estática que é o caso da força passiva. Essas condições são fundamentais para considerarmos apenas um grau de liberdade nos estudos dos modos presentes nas operações de usinagem.

Em termos de valor médio, a potência aplicada à aresta da ferramenta em um processo de usinagem é dada pela expressão (2.36).

$$
P_{\text {aresta }}=\frac{F_{c} v_{c}}{60}+\frac{F_{f} v_{f}}{60000}[W]
$$

Onde $F c$ é a força de corte, $v c$ é a velocidade de corte, Ff é a força de avanço e $v f$ a velocidade de avanço, com as forças dadas em Newton e as velocidades em metros/minuto (STEMMER, 2007).

A figura 2.10 mostra o comportamento esperado para a força de corte em um processo de usinagem e correspondem a um comportamento similar ao do torque, já que a relação entre essas duas quantidades corresponde ao raio médio da peça em usinagem. As oscilações presentes na parte dinâmica da força de corte contém informações relevantes sobre os parâmetros mencionados acima (SILVA, 2007). 


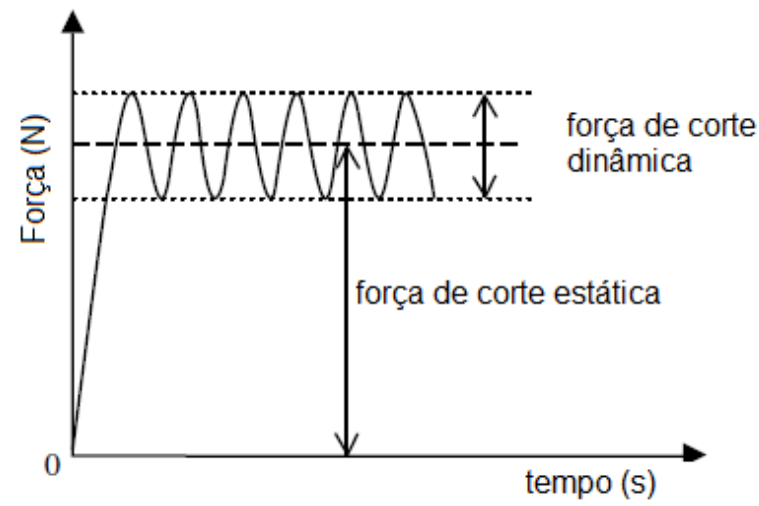

Figura 2.10 Perfil esperado para a força de corte para o caso ideal (Silva, 2007)

As oscilações presentes na operação de usinagem, principalmente devido ao efeito do corte podem ser utilizadas para a determinação do desgaste da ferramenta, porém uma das principais dificuldades na monitoração do desgaste da ferramenta em função das vibrações é a identificação da faixa de frequências que é influenciada pelo desgaste da ferramenta, visto que o processo de usinagem acarreta vários mecanismos de produção de vibrações que não estão relacionadas com o desgaste da ferramenta. A faixa de frequências das vibrações produzidas durante o processo ordinário de usinagem caem entre 0 e $10 \mathrm{KHz}$ (SILVA, 2007). Disso conclui-se que a faixa de frequências sensível ao desgaste da ferramenta depende inteiramente do tipo de operação de usinagem e deve ser determinada para cada caso individualmente. Existem duas importantes frequências de vibrações presentes no processo usinagem (ANDREASEN, LE CHIFFRE, 1993; SILVA, 2007) :

a) A frequência natural do porta-ferramenta e seus componentes

b) A frequência de formação de cavacos

O projeto diferenciado de um porta-ferramenta, assim como testes dinâmicos são utilizados, para a identificação de suas propriedades e isso permite condições mais adequadas para a investigação da frequência de quebra de cavaco. 


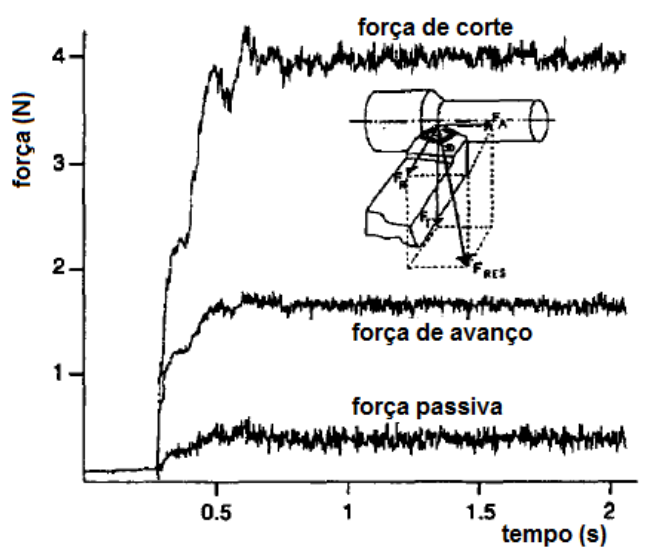

Figura 2.11 Perfis das forças de usinagem (ANDREASEN, LE CHIFFRE, 1993)

A figura 2.11 mostra os perfis das forças envolvidas no processo de usinagem em caso real, onde nota-se que a força de corte supera bastante as forças de avanço e passiva, nota-se também o ruído oscilatório que superpõe os valores médios dessas forças e que correspondem a força de corte dinâmica.

\subsubsection{A monitoração das vibrações}

Como já verificado nas seções anteriores, as máquinas elétricas na aplicação de acionamento de máquinas ferramentas, em bom estado operacional e sem o uso de inversores de frequência, estão sujeitas a uma série de processos vibratórios originários de várias fontes, entre as quais podemos citar (Silva, 2007):

- Vibrações e trepidações produzidas pelo processo de usinagem, que podem ser ou não estacionárias, mas em geral não tem correlação harmônica com a frequência operacional da rede elétrica (ANDREASEN, LE CHIFRE, 1993).

- Vibrações originárias das interfaces mecânicas entre o processo de usinagem e a máquina elétrica, que em geral são estacionárias, mas não guardam correlação harmônica com a frequência da rede elétrica e podem ser oriundas de componentes defeituosos, tais como rolamentos, mancais, engrenagens com defeito com dentes quebrados, etc (Nehala, 2010). 
- Oscilações originárias no desequilíbrio da fonte de energia trifásica, que são estacionárias e guardam correlação harmônica com a frequência da rede elétrica (EBADI ET AL, 2011).

Estas vibrações podem ser analisadas através de uma série de ferramentas de processamento digital de sinais de uso geral, cada uma das quais tem seus pontos fortes e seus pontos fracos. As ferramentas mais utilizadas, em geral, são:

a) Transformada de Fourier (FFT - Fast Fourier Transform)

b) A Transformada de Wavelet (WVT)

\subsubsection{O método da transformada de Fourier (FFT)}

O método da transformada de Fourier, através de seu algoritmo FFT é o método mais empregado na determinação das componentes de frequência de um sinal, uma vez que transforma os sinais diretamente para o domínio da frequência e o tempo é eliminado matematicamente no processo de transformação e todas componentes do sinal são analisadas apenas no domínio da frequência. Essa característica da transformada de Fourier é muito útil na identificação de sinais estacionários, nos quais a frequência não varia no tempo e consequentemente corresponde a força do algoritmo FFT na análise dos sinais (GOSWAMI, CHAN, 2011).

Como o algoritmo calcula os valores real e imaginário do sinal de entrada, denominando de $s(t)$ o sinal de entrada e $S(\omega)$ sua transformada de Fourier o módulo do espectro de frequências do sinal de entrada é dado pela expressão (2.37) (GOSWAMI, CHAN, 2011).

$$
|S(\omega)|=\frac{\text { Magnitude }|F F T(s(t))|}{N}=\frac{\sqrt{\operatorname{real} \mid F F T\left(\left.s(t)\right|^{2}+\operatorname{imag} \mid F F T\left(\left.s(t)\right|^{2}\right.\right.}}{N}
$$

e o espectro de fases é dado por (2.37). 


$$
\text { Espectro de fases em radianos }=\text { Fase }\left(F F T(s(t))=\operatorname{arctg} \frac{\operatorname{imag}[F F T(s(t))]}{\operatorname{real}[F F T(s(t))]}\right.
$$

Os valores da magnitude podem ser obtidos em decibéis utilizando a expressão $\left.S(f)\right|_{d B}=20 \log _{10}|S(f)|$ que algumas vezes é conveniente para salientar algumas frequências menos evidentes.

O espectro de fases retorna as mesmas entre $-\pi e \pi$, cuja oscilação entre estes valores pode camuflar alguns aspectos importantes da fase, por isso é comum utilizar um software com possibilidade de "retificar" o sinal de fase, o programa MatLab possui a função unwrap que realiza esta tarefa (HALSEMAN, LITTLEFIELD, 2003) .

Em geral os algoritmos retornam o espectro em função de seu valor de pico, da frequência de amostragem e do número de pontos $N$ do sinal adquirido. Portanto, para que haja uma representação real do sinal na grandeza desejada é necessário multiplicar o arranjo retornado pelo algoritmo (Por exemplo o FFT do MatLab) pelo fator $F_{S} / N$ que ajusta a amplitude do espectro de saída do sinal de entrada e coloca a frequência em seu devido lugar. Considerando que o limite da frequência de amostragem de Nyquist, o espectro do sinal ficará entre 0 e $F_{S} / 2$, com a segunda parte de $F_{S} / 2$ a $F_{S}$ espelhando a primeira parte. (GOSWAMI, CHAN, 2011).

A transformada de Fourier, mesmo com suas limitações para sinais estacionários, ainda encontra muitas aplicações, principalmente como ferramenta complementar de outros tipos de análises de uso mais abrangentes. Roy utiliza a FFT juntamente com a transformada de Wavelet para a análise de vibrações em motores de indução (ROY et al, 2005), Huang utiliza uma versão modificada (all-phase) da FFT para obter o diagnóstico de motores de indução.

\subsubsection{O método da transformada de wavelet}

A transformada de wavelet é um processo de filtragem de multiestágios, ou de decomposição multiescala, no qual um sinal discreto sofre um processo 
de convolução com um filtro passa baixas e um passa altas, resultando em dois vetores de coeficientes, um de coeficientes de aproximação cA1 e outro de coeficientes de detalhe $\mathrm{CD} 1$. Os coeficientes de aproximação representam os componentes de alta escala e baixa frequência do sinal, enquanto que os coeficientes de detalhes representam os componentes de baixa escala e alta frequência do sinal. A transformada empacotada de wavelet (WPT - Wavelet Packet Transform), foi originalmente introduzida por Coifman como uma generalização da análise tempo-frequência da transformada de wavelet. $O$ WPT permite, não apenas, a aproximação em um determinado nível, mas também dos detalhes. Isto resulta em uma base ampla e flexível para a análise das informações contidas no sinal (FAN, ZUO, 2006).

O principal conceito na análise de wavelets é a representação da função original como uma superposição de funções básicas de wavelets. A partir de uma wavelet mãe $\psi_{m, n}(t)$, uma família de funções bases ortonormais pode ser obtida através de dilatações e translações da variável independente $(t)$, de acordo com (2.38).

$$
\psi_{m, n}(t)=2^{-m / 2} \psi\left(2^{-m} t-n\right)
$$

Onde $m$ e $n$ são inteiros. Este processo de dilatação implica em uma transformação do sinal original em outra em um espaço vetorial que possui uma resolução diferente. Similarmente, o processo translacional transforma a função em uma outra, em um espaço vetorial com uma posição distinta. O sinal $\mathrm{s}(\mathrm{t})$ pode ser decomposto pela equação (2.39).

$$
s(t)=\sum_{m, n} c_{n, m} \psi_{n, m}(t)
$$

Com isto, $m$ é um parâmetro de escala e $n$ é uma localização no tempo. A decomposição pela WPT resulta na árvore mostrada na figura 2.12 para três níveis.

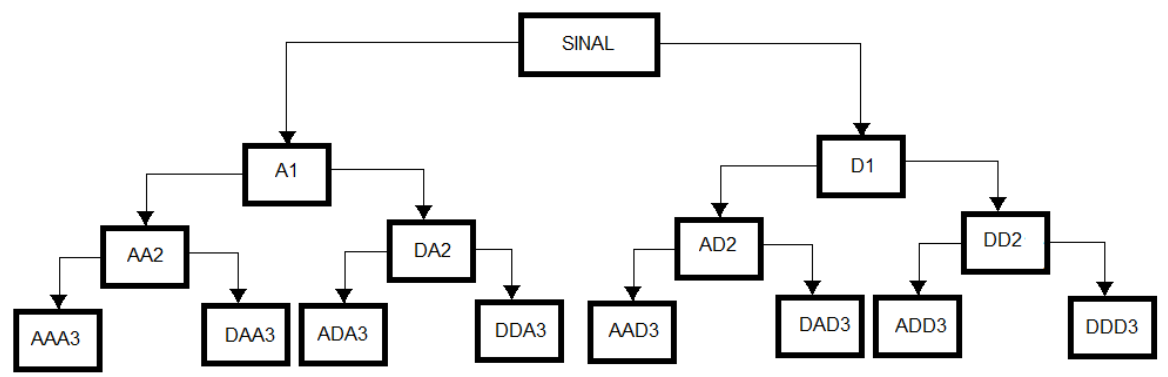

Figura 2.12 Árvore de decomposição de um sinal em três níveis da WT 
Dentre muitas aplicações de wavelets em análise de vibrações, Rucka propõe um método de detecção de defeitos em barras utilizando o método da transformada de wavelet baseado nos modos de vibrações altos (RUCKA, 2011); Al-Badour propõe uma metodologia para analise de vibrações em máquinas rotativas utilizando a análise de tempo-frequência e técnicas de wavelet (AL-BADOUR et al, 2011); GOSWAMl apresenta em uma série de aplicações utilizando wavelets, indo de métodos de identificação de perfis de vibrações de rolamentos defeituosos a problemas de fronteiras (GOSWAMI., CHAN.,2011); Roy faz análise de vibrações em máquinas de indução utilizando a transformada de wavelet (ROY et al, 2005).

\subsubsection{O método da transformada de Hilbert-Huang}

Recentemente, Huang introduziu um método de processamento de sinais que permite a separação de componentes dos mesmos baseados em interpolação cúbica (método com splines) e extração de valores médios. $O$ método, denominado Modo de Decomposição Empírico (EMD) faz a separação dos sinais utilizando uma metodologia denominada "peneiramento" e cada componente retirada do sinal é denominada "Função de Modo Intrínseco" ou FMI. O algoritmo da EMD é mostrado na figura 2.13.

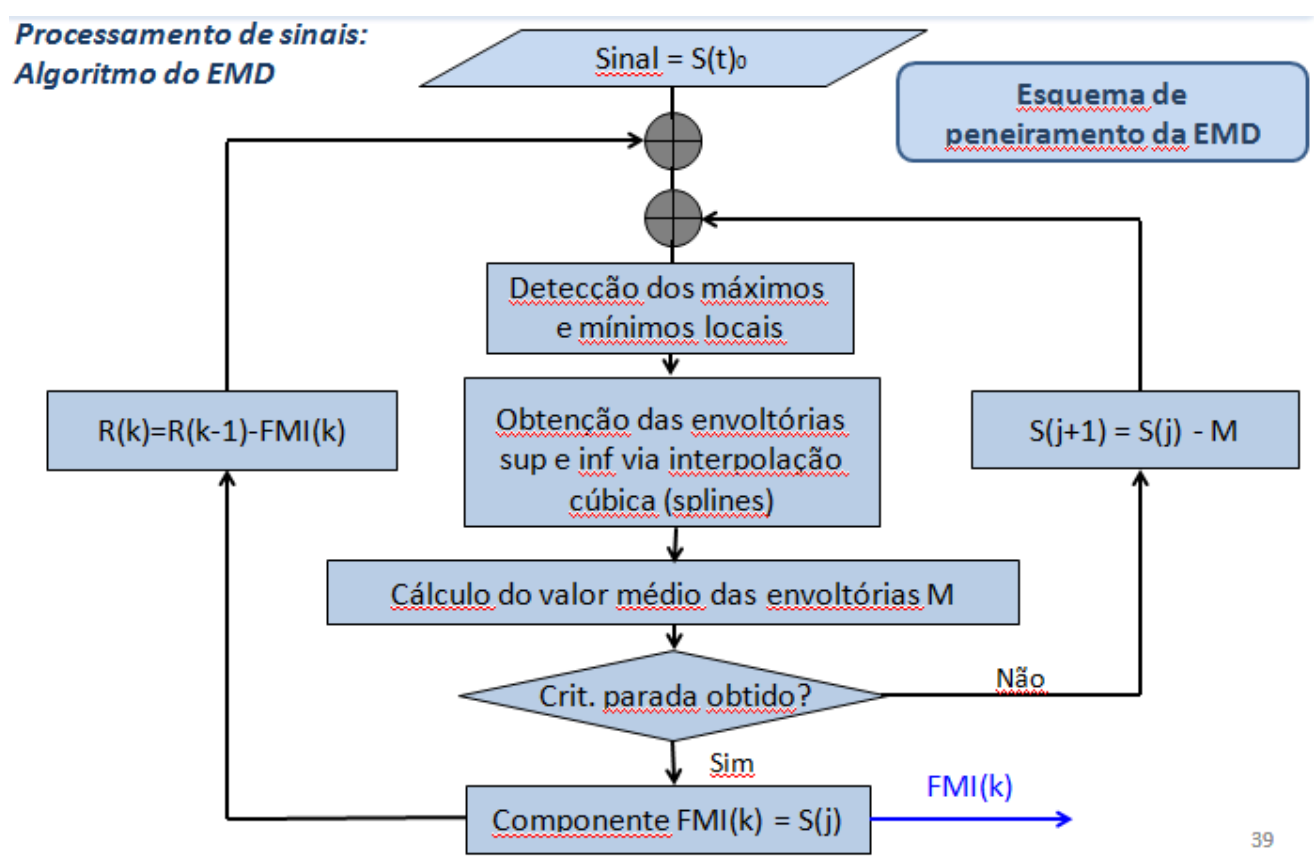

Figura $2.13 \mathrm{O}$ algoritmo do EMD 
O método básico de extração de cada função de modo intrínseco (FMI) é realizado detectando-se os valores dos picos superiores e inferiores do sinal, seguido da aplicação de método de interpolação cúbica, que gera uma envoltória superior para os valores de pico superiores e uma envoltória inferior relacionada aos valores de pico inferiores. No passo seguinte uma função correspondente ao valor médio pontual entre as duas envoltórias é obtido, o sinal resultante dessa média passa por um critério de parada simplificado onde o número de picos pode diferir no máximo de um em relação ao número de cruzamentos por zero, quando isso ocorre obtém-se uma função de modo intrínseco (RILLING, 2007).

Tabela 2.2 Comparação entre as transformadas em geral

\begin{tabular}{|l|l|l|l|}
\hline & Fourier & Wavelet & Hilbert-Huang \\
\hline Base & A priori & A priori & Adaptativa \\
\hline Frequência & $\begin{array}{l}\text { Convolução global - } \\
\text { Incerteza }\end{array}$ & $\begin{array}{l}\text { Convolução local } \\
\text { incerteza }\end{array}$ & $\begin{array}{l}\text { Diferenciação local - } \\
\text { certeza }\end{array}$ \\
\hline Apresentação & Energia-frequência & $\begin{array}{l}\text { Energia tempo - } \\
\text { frequência }\end{array}$ & $\begin{array}{l}\text { Energia tempo- } \\
\text { frequência }\end{array}$ \\
\hline Sinal não linear & Não & Não & Sim \\
\hline $\begin{array}{l}\text { Não } \\
\text { estacionariedade }\end{array}$ & Não & Sim & Sim \\
\hline $\begin{array}{l}\text { Característica de } \\
\text { extração }\end{array}$ & Não & Sim & Sim \\
\hline Base teórica & Teoria completa & Teoria completa & Empírica \\
\hline
\end{tabular}

No caso do critério de parada não ser obtido, extrai-se do sinal atualmente em análise, a função correspondente ao valor médio pontual. $O$ sinal correspondente a essa diferença é então submetido novamente a entrada do algoritmo na busca de uma das IMFs que compõem o sinal. Nesse aspecto o método é perfeitamente adaptativo, uma vez que ele se ajusta, via processo de splines. A tabela 2.4 mostra a relação entre as transformadas de Fourier, wavelet e Hilbert-Huang.

Após a aplicação do EMD, obtém-s a série temporal $X(t)$ que pode se expressa em temos das funções de modo intrínseco (IMF) obtidas como mostra a expressão (2.41) (HUANG, ATTOH-OKINE, 2005).

$$
X(t)=\sum_{k=1}^{n} S_{k}(t)+r_{n}(t)
$$


Onde $S_{j}(t)$ é a jésima $\mathrm{FMI}$ e $r_{n}(t)$ é o resíduo que pode ser um sinal variável dando uma tendência da média, ou uma constante.

Obtendo-se a transformada de Hilbert de cada IMF $S_{j}(t)$ como indica (2.42).

$$
D_{k}(t)=\frac{1}{\pi} P \int \frac{S_{j}(\tau)}{t-\tau} d \tau
$$

Onde $P$ indica o valor principal de Cauchy, obtém-se a forma de uma função analítica indicada na expressão (2.42) (HUANG, ATTOH-OKINE, 2005)

$$
Z_{k}(t)=S_{k}(t)+j D_{k}(t)=A_{k}(t) e^{j \theta_{k}(t)}
$$

A frequência instantânea da IMF é dada pela expressão (2.44):

$$
\omega_{k}(t)=\frac{d \theta_{k}(t)}{d t}
$$

Assim $X(t)$ pode ser expressa em termos de (2.45).

$$
X(t)=\operatorname{Re}\left\{\sum_{k=1}^{n} A_{k}(t) e^{j \theta_{k}(t)}\right\}+r_{n}(t)
$$

Desta análise conclui-se que dependendo da natureza do sinal uma determinada transformada pode ser uma ferramenta mais atraente para a aplicação. A figura 2.14, mostra os sinais e suas categorias e as ferramentas mais adequadas para sua análise.

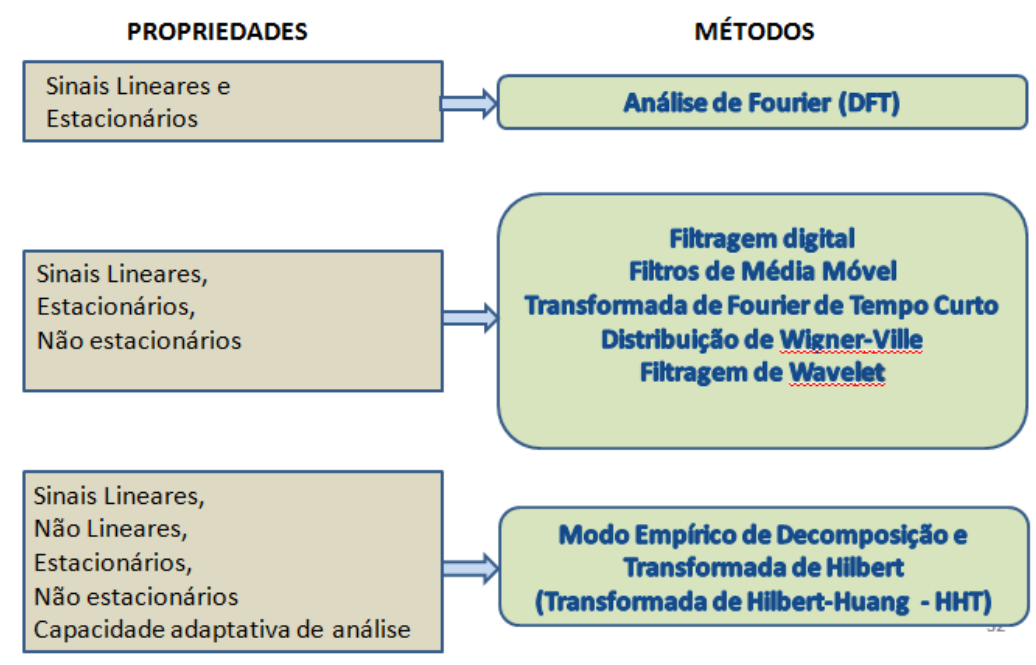

Figura 2.14 Relação entre as categorias de sinais e as ferramentas de análise mais adequadas para sua análise. 


\subsubsection{A função analítica}

O uso da função analítica é fundamental para a concentração da energia do sinal no espectro positivo evitando com isso o efeito de não causalidade existente de modo intrínseco na transformada de Fourier.

Seja $x(\mathrm{t})$ um sinal obtido de um sistema físico para monitoração ou controle, a função analítica relacionada ao mesmo é dada pela expressão (2.46).

$$
f\{x(t)\}=\{x(t)+j y(t) \mid y(t)>0, x(t), y(t) \in \mathbb{R}\}
$$

Onde $y(t)=\mathcal{H}\{x(t)\}$ é a transformada de Hilbert que descreve uma relação entre os valores da parte real e da parte imaginária, ou seja, se $f(z)$ é analítica no plano Imaginário com $z>0$ e $u(t)=\operatorname{Re}\{f(t)+j 0\}$, então $\operatorname{Im}\{f(t)+$ $j 0=H u(t)$, onde $H\{u t\}$ indica a transformada de Hilbert da função $u(t)$, se a transformada de Hilbert existir.

A transformada de Hilbert do sinal $x(t)$ é obtida pela expressão (2.47) (FELDMAN, 2011).

$$
y(t)=\frac{1}{\pi} P \int_{-\infty}^{\infty} \frac{x(\tau)}{t-\tau} d \tau
$$

Uma vez que (2.47) é uma integral de convolução, a transformada pode ser escrita na forma da expressão (2.48) (Feldman, 2011):

$$
y(t)=\frac{1}{\pi t} * x(t)
$$

Como a transformada de Fourier de $\frac{1}{\pi t}$ é conhecida temos (2.49).

$$
F\left\{\frac{1}{\pi t}\right\}=-j \operatorname{sgn}(\omega)
$$

A transformada de Fourier da convolução pode ser escrita na forma da expressão (2.50).

$$
F\{y(t)\}=-j \operatorname{sgn}(\omega) X(\omega)
$$


Com isso o sinal analítico no domínio da frequência é obtido por (2.51) (FELDMAN, 2011).

$$
Z(\omega)=X(\omega)+j(-j \operatorname{sgn}(\omega) X(\omega))
$$

Um dos métodos para a obtenção da transformada de Hilbert é descrito por Marple e é realizado utilizando a própria transformada de Fourier, o que torna muita pratica a sua obtenção (MARPLE, 1999; HAHN, 2000).

Outro detalhe fundamental é que a obtenção da transformada de Hilbert utilizando a transformada de Fourier é dada por (2.53):

$$
H\{x(t)\}=-j \operatorname{sgn}(\omega) X(\omega)
$$

E sua inversa é dada por (2.54).

$$
\hat{x}(t)=F^{-1}\{-j \operatorname{sgn}(\omega) X(\omega)\}
$$

Com essa relação podemos obter a transformada de Hilbert de uma função $x(t)$, utilizando um algoritmo que permita a obtenção da transformada de Fourier do mesmo sinal (a FFT, por exemplo).

Com isso teremos o sinal analítico em função do tempo (2.55) (FELDMAN, 2011).

$$
z(t)=x(t)+j \hat{x}(t)=A(t) e^{j \psi(t)}
$$

A figura 2.15 mostra a relação entre as variáveis que compõem a função analítica para um sinal cosenoidal $x(t)=\cos (\omega t)$, cuja transformada de Hilbert é $H\{x(t)\}=\operatorname{sen}(\omega t)$ formando a função analítica $z(t)=\cos (\omega t)+j \operatorname{sen}(\omega t)$. Ao fundo vemos o plano complexo ou pano de fases onde fica explícito a transformação polar retangular.

O sinal analítico concentra toda a energia do sinal original no espectro positivo do mesmo, recuperando com isso, a causalidade inexistente quando da aplicação da transformada de Fourier, isso é mostrado na figura 2.16 onde o sinal resultando concentra-se no semieixo positivo de $\omega$ dobrando seus valores no plano real. 


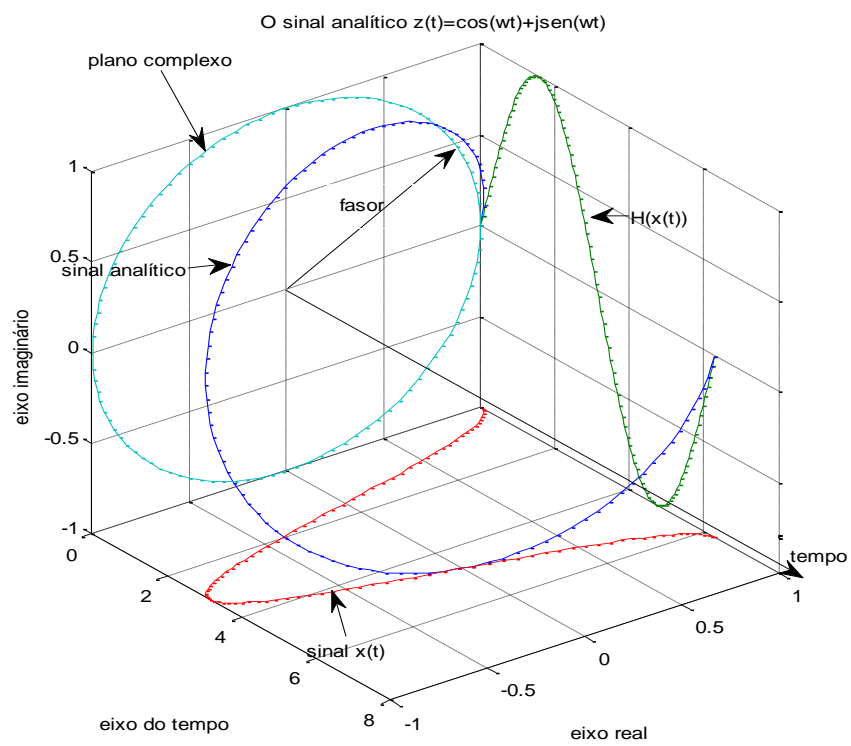

Figura 2.15 - Composição da função analítica

De forma similar à transformada de wavelet, a transformada de Hilbert, mantém de forma coerente, a informação da frequência do sinal sob investigação sem prescindir do tempo, utilizando para obter a frequência, a derivada da fase do sinal. De forma geral pode-se escrever a expressão (2.56):

$$
\log (z(t)=\log (A(t))+j \psi(t)
$$

Onde a amplitude instantânea $\mathrm{A}(\mathrm{t})$ pode ser determinada a partir de (2.56).

$$
A(t)= \pm|z(t)|= \pm \sqrt{x^{2}(t)+\hat{x}^{2}(t)}= \pm e^{R e|\ln (z(t))|}
$$

E a fase instantânea do sinal de (2.58).

$$
\psi(t)=\arctan \left(\frac{\hat{x}(t)}{x(t)}\right)=\operatorname{Im}|\ln (z(t))|
$$




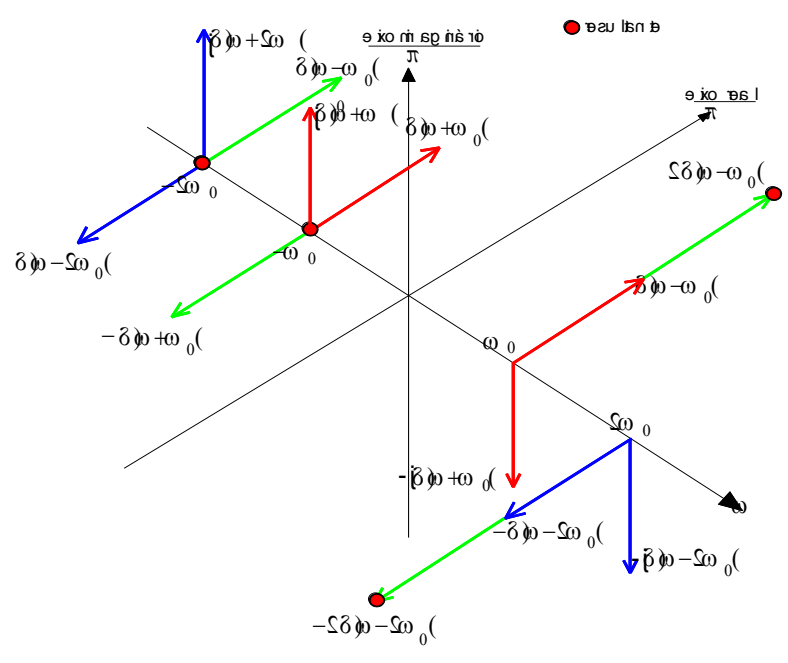

Figura 2.16 - $O$ espectro de frequências do sinal $x(t)$ e sua função analítica $z(t)$

Consequentemente a frequência instantânea do sinal é obtida diretamente da derivada da fase, da forma indicada em (2.58).

$$
\omega(t)=\frac{d \psi(t)}{d t}
$$

A frequência instantânea $\omega(t)$ mede a taxa de variação e a direção da rotação de um fasor no plano complexo. Em casos de operação com sinal mono-harmônico, a envoltória e a frequência instantânea são constantes e a fase aumenta linearmente com o tempo, porém para o caso geral a frequência instantânea de um sinal é uma variável no tempo. Além disso, a frequência instantânea pode mudar de sinal em alguns intervalos de tempo, o que indica mudança de rotação do fasor do sentido anti-horário para horário. A frequência instantânea sempre tem um significado físico simples e claro, já que ela não é nada mais que a taxa de variação da velocidade da rotação de um fasor. No domínio do tempo uma frequência instantânea negativa corresponde a inversão na tendência do sinal de fase, ou seja, a fase é decrescente no tempo na região onde a frequência torna-se negativa (FELDMAN, 2011) .

A frequência instantânea pode ser obtida derivando-se diretamente o arco tangente do ângulo de fase, através de (2.60).

$$
\omega(t)=\frac{d \psi(t)}{d t}=\frac{d}{d t}\left(\arctan \left(\frac{\hat{x}(t)}{x(t)}\right)\right)
$$

De onde obtemos, 


$$
\omega(t)=\frac{x(t) x^{\prime}(t)-x^{\prime}(t) \hat{x}(t)}{A^{2}(t)}=\operatorname{Im}\left(\frac{z^{\prime}(t)}{z(t)}\right)
$$

A função analítica ou sinal analítico permite que obtenhamos a amplitude e a fase variáveis no tempo de um sinal. A figura 2.17 ilustra o processo.

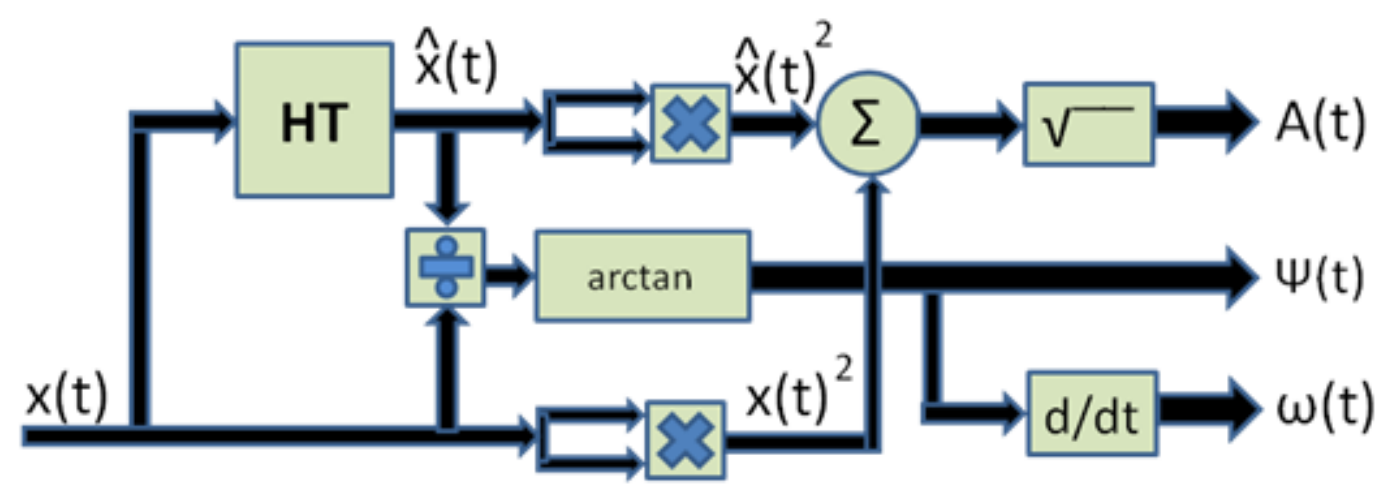

Figura 2.17 Processamento do sinal x(t) para a obtenção da função analítica

\subsubsection{Obtenção da função analítica utilizando a FFT}

Marple discute em seu trabalho um método para a determinação da função analítica com base no algoritmo FFT, o método utiliza o fato de que a função analítica não possui frequências negativas, ou seja ela é naturalmente causal (MARPLE, 1999).

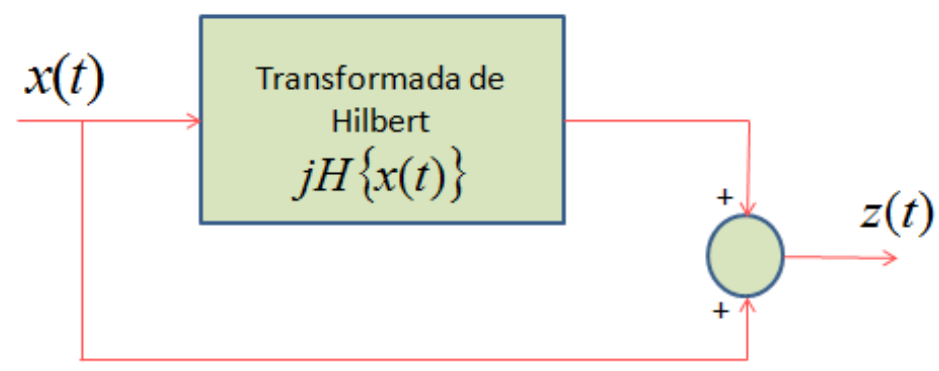

Obtenção da função analítica no MatLab (Marple, 1999)

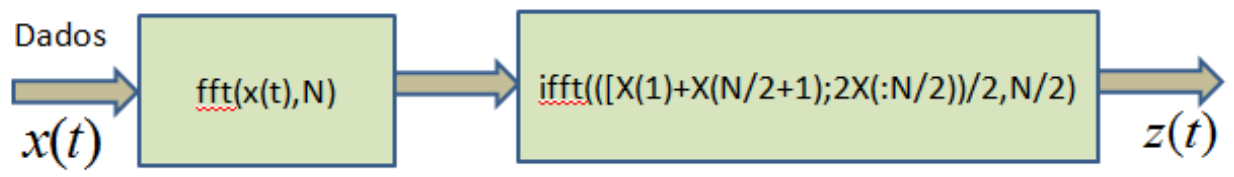

Figura 2.18 Obtenção do sinal analítico a partir da FFT. 


\subsection{Metaheuristicas}

As metaheurísticas tem como precursor os algoritmos genéticos e os algoritmos bio-inspirados e fazem parte de um campo de pesquisa literalmente em processo de evolução dos métodos numéricos (YANG, 2008).

\subsubsection{O algoritmo de busca de harmonia (HS)}

HS é um método de otimização, o que obviamente nos leva a condição de identificação da natureza do problema ao qual desejamos aplicá-lo. Um problema de otimização, irrestrito, de objetivo único e multivariável pode se descrito por (GEEM,2009).

$$
{ }_{x}^{\min } f(\boldsymbol{x})
$$

Onde $f$ é a função objetivo (ou de custo) a ser minimizada pela variação do vetor de decisão $\boldsymbol{x}=\left(x_{1}, \ldots ., x_{n}\right)^{T}$.

O algoritmo de busca de harmonia foi inspirado na improvisação dos músicos de Jazz, especificamente no processo pelo qual os músicos, embora nunca tenham tocado juntos antes, rapidamente refinam suas improvisações individuais através de variações até obterem uma harmonia estética.

Metaforicamente, cada músico corresponde a um atributo de uma solução candidata dentro do domínio do problema, enquanto que o tom e a faixa de frequência de cada instrumento, correspondem aos limites e restrições das variáveis do problema. A harmonia entre os músicos é vista como uma solução candidata completa em dado tempo, enquanto que a apreciação estética da harmonia pela audiência representa a função de custo específica do problema. Os músicos perseguem a harmonia todo o tempo, através de pequenas variações e improvisações que representam melhorias estéticas ou otimização da função de custo (Brownlee, 2011).

A forma como o algoritmo de HS manuseia os agentes de intensificação e diversificação dão um indicativo do porque 0 algoritmo de HS é provavelmente uma metaheurística de sucesso (YANG, 2008).

No algoritmo de HS a diversificação é controlada essencialmente pelo ajuste do tom (pitch) e pela aleatorização, ou seja neste caso existem dois 
subcomponentes para a diversificação, o que pode ser um dos motivos para a alta eficiência do algoritmo de HS. O primeiro subcomponente que gera um novo tom via aleatorização seria no mínimo do mesmo nível de eficiência que os dos outros algoritmos que manuseiam a aleatorização, contudo o subcomponente adicional da diversificação da HS é a operação de ajuste do tom executada com a probabilidade $r_{p a}$ (taxa de consideração) . $O$ ajuste do tom é realizado dentro de uma determinada banda passante. Uma pequena quantidade é adicionada ou subtraída a um tom existente (ou solução) armazenada na memória de harmonia (HM).

Essencialmente, o ajuste do tom é um processo de refinamento das soluções locais. Tanto a taxa de consideração quanto 0 ajuste do tom asseguram que as boas soluções locais sejam retidas enquanto a aleatorização faz o algoritmo explorar o espaço de busca global efetivamente. A sutileza está no fato do algoritmo HS operar em uma diversificação controlada no entorno das boas soluções. A aleatorização permite uma exploração do espaço de busca completo de forma eficiente.

A intensificação do algoritmo HS é representada pela taxa de aceitação da memória de harmonia raccept. Uma aceitação de harmonia alta significa que as boas soluções da história/memória são igualmente selecionadas ou herdadas. Isto corresponde a um certo grau de elitismo Obviamente se a taxa de aceitação for muito baixa, as soluções convergirão mais lentamente. (GEEM, 2009)

\subsubsection{A implementação do algoritmo HS}

A implementação do algoritmo de HS é composta de cinco passos (GEEM:2009)

\section{Passo1: Inicialização do problema e parâmetros.}

$$
\text { Minimizar } \mathrm{f}(\mathrm{x}) \text {, sujeita a } x_{i} \in X_{i}, \mathrm{i}=1,2, \ldots, \mathrm{N}
$$

Onde $f(x)$ é a função objetivo ou função de custo a ser minimizada, $x$ é o grupo (orquestra) de variáveis de decisão, $\mathrm{N}$ é o número de variáveis de decisão (número de instrumentos) e $X i$ é o conjunto de todas as faixas de solução 
possíveis de cada variável de decisão (faixa de frequências (tons) de cada instrumento).

\section{Passo 2: Inicialização da memória de harmonia.}

A memória de harmonia (HM) é a localização de memória onde todos os vetores solução e os correspondentes valores das funções objetivo são armazenados. Neste passo, a matriz HM é preenchida com vetores solução gerados aleatoriamente dentro das faixas de restrições definidas no passo1.

\section{Passo3: Improvisação de uma nova harmonia}

Um novo vetor de harmonia $x^{\prime}=\left(x_{1}^{\prime}, x_{2}^{\prime}, \ldots, x_{N}^{\prime}\right)$, é gerado baseado em três regras que são: consideração de memória, ajuste de tom e seleção aleatória.

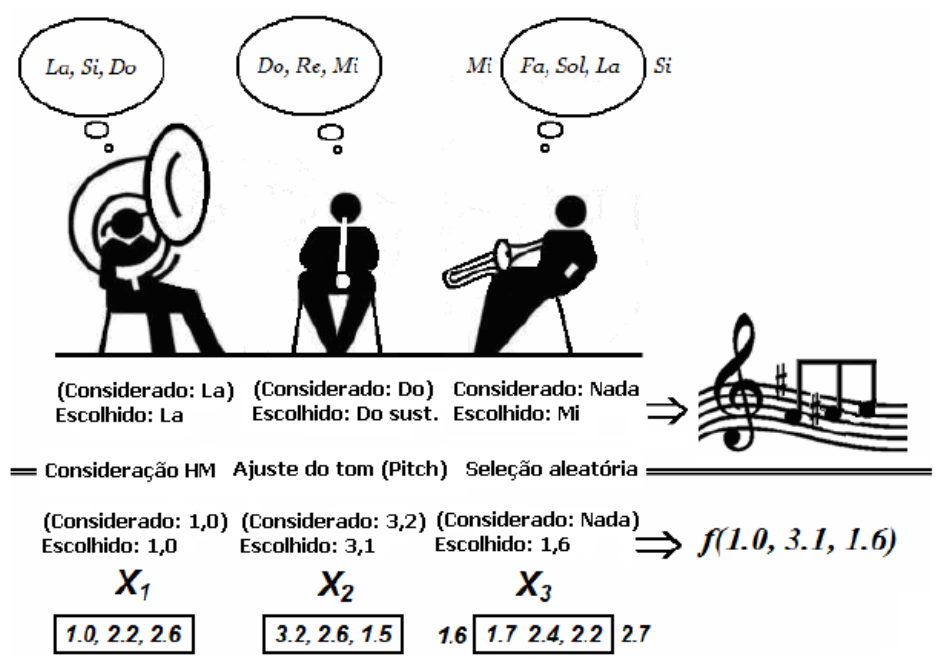

Figura 2.19 Processo de improvisação do algoritmo HS (GEEM, 2009)

O valor de uma variável de decisão pode ser selecionado a partir dos valores armazenados na memória de harmonia $(\mathrm{HM})$ com probabilidade correspondente a taxa de consideração da HM (HMCR). Este valor pode ser ajustado posteriormente pela movimentação para um valor vizinho do valor selecionado da HM com probabilidade da taxa de ajuste do tom (PAR), ou ele pode ser selecionado aleatoriamente a partir do conjunto de todos os valores candidatos sem nenhuma consideração com os valores já armazenados na HM, com probabilidade (1-HMCR). O processo de improvisação da HS é mostrado na figura 2.19. 


\section{Passo4: Atualização da HM}

Se o novo vetor de decisão, fornecer um valor melhor para a função de custo, o mesmo é incluído na HM e a pior harmonia é descartada.

\section{Passo5: Verificação do critério de término.}

Se o critério de término for obtido, ou seja, o número máximo de improvisações for atingido, os cálculos são terminados, de outro modo os passos 3 a 5 devem ser repetidos.

\subsection{Conclusões da revisão da literatura}

Nesta revisão abordamos o suporte matemático para a construção de um estimador de torque para o motor de indução e discutimos suas limitações práticas.

Foi abordado também um método para estimação dos parâmetros do motor de indução com característica de obtenção dos parâmetros "in loco", para aplicação em ambientes industriais sem condição de paralisação de máquinas ferramentas por tempo prolongado.

Para suportar a técnica de determinação paramétrica discutiu-se a aplicação de um método de otimização metaheurístico, denominado de Busca de Harmonia. 
Estimação da potência e torque na carga de um motor de indução com base nas quantidades elétricas medidas em sua entrada de energia

\subsection{Introdução}

Um dos motivos iniciais para realização deste trabalho era a possibilidade de utilizar o próprio motor de indução de acionamento de uma máquina ferramenta, especificamente um torno, para obter informações sobre a potência e o torque na aresta de corte da ferramenta utilizada no processo de usinagem de um MIT acionado diretamente da rede elétrica.

A medição da potência ativa na entrada de energia do MIT é uma tarefa simples e pode ser realizada on-line, a questão é quanto dessa potência é efetivamente aplicada na aresta de corte da ferramenta?

A resposta à questão acima depende de qual é a precisão desejada, ou qual é a precisão possível. O caso estudado admitia que a máquina ferramenta estava em uso e não podia parar, exceto para testes e manutenções de curta duração, a solução deveria ser "transparente" ao operador e robusta o suficiente para suportar a usinagem de peças de grande dimensões, cujas manobras de inserção e retirada colocariam em risco quaisquer sensores adicionais ao sistema da máquina. 
A solução encontrada baseou-se no trabalho de Schauder sobre um método adaptativo de obtenção da velocidade do motor sem sensor mecânico (SCHAUDER, 1992), onde a adição de um sensor de velocidade ao problema enfrentado originalmente por Schauder, permitia a obtenção de todos os parâmetros do MIT exceto a resistência do estator, que deveria ser medida diretamente nos terminais da máquina de indução. $O$ método também foi utilizado por Marques em um sistema de autocomissionamento de motores de indução (MARQUES, 2004).

Joetten propôs um método para a estimação de velocidade baseado nas quantidades elétricas nos terminais da máquina de indução que foi o ponto de partida do trabalho de Schauder e em ambos os métodos eram dependentes do conhecimento dos parâmetros do motor de indução (JOETTEN,1983).

O método de determinação dos parâmetros do MIT proposto neste trabalho depende do conhecimento inicial do valor da resistência por fase do estator do MIT, que sofre variações com a temperatura do motor, as quais são dependentes do carregamento do mesmo, ou seja dependem da tarefa de usinagem em curso.

Lee propõe um método de estimação on-line do valor da resistência do estator onde seu valor demonstrando que a mesma é dependente de alguns parâmetros do motor, mas que seu valor em condições de regime é bastante estável o são as condições de usinagem, que em geral, comporta ciclos bastante estáveis, uma sugestão é trabalhar com uma tabela de valores de Rs em função da corrente do estator, isso diminui o erro de estimação da potência na aresta da ferramenta (LEE et al, 2002).

As condições necessárias para a estimação da potência útil da máquina ferramenta na aresta da ferramenta são:

- O motor de indução deve estar eletricamente e mecanicamente em boas condições.

- A máquina ferramenta deve estar mecanicamente em boas condições também. 
- Os parâmetros do motor de indução mostrados na figura 3.1 devem ser conhecidos em toda a faixa operacional.

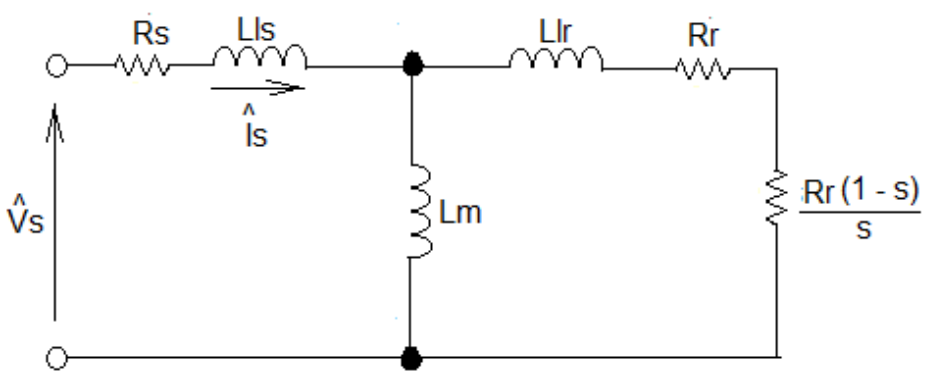

Figura 3.1 Modelo por fase do motor de indução

\subsection{A obtenção dos parâmetros do motor de indução (10 Estágio)}

Os parâmetros do motor de indução foram obtidos em dois estágios, o primeiro utilizou o modelo vetorial das equações das derivadas do fluxo concatenado do estator referidas ao estator. A equação vetorial do enrolamento do estator foi utilizado como referência, admitindo-se como conhecida a resistência do enrolamento estatórico e a equação da derivada do fluxo estatórico relacionada aos componentes rotóricos foi utilizada como equação ajustável.

A resistência por fase do estator, de acordo como o modelo usual do motor mostrado na figura 3.1 foi obtido experimentalmente aplicando-se a corrente nominal do motor e esperando a estabilização térmica e seu valor $\mathrm{R}_{\mathrm{s}}=0,445 \Omega$. A tabela 3.1 mostra o comportamento da resistência em função da corrente eficaz de fase.

Tabela 3.1: Resistência em função da corrente eficaz de fase

\begin{tabular}{|l|l|l|l|l|l|l|l|l|l|l|l|}
\hline $\begin{array}{l}\text { Corrente eficaz } \\
\text { de fase }(\mathrm{A})\end{array}$ & 0 & 1,4 & 2,8 & 4,2 & 5,6 & 7 & 8,4 & 9,8 & 11,2 & 12,6 & 14 \\
\hline $\begin{array}{l}\text { Resistência do } \\
\text { estator }(\Omega)\end{array}$ & 0,27 & 0,304 & 0,339 & 0,347 & 0,352 & 0,365 & 0,376 & 0,385 & 0,392 & 0,399 & 0,405 \\
\hline
\end{tabular}

A equação vetorial de referência do primeiro estágio de estimação paramétrica é dada pela expressão (3.1): 


$$
\frac{d \lambda_{s(s) r e f}}{d t}=v_{s(s)}-R_{s} i_{s(s)}
$$

Onde o índice s(s) indica variável do estator $s$ referida ao estator (s) e $\lambda_{s(s) r e f}$ é vetor o fluxo concatenado de referência do estator, $\boldsymbol{v}_{\boldsymbol{s}(\boldsymbol{s})}$ é o vetor tensão do estator e $\boldsymbol{i}_{\boldsymbol{s}(\boldsymbol{s})}$ é o vetor corrente do estator.

A resistência do estator varia com a temperatura do motor, que está relacionada com a temperatura ambiente e com a corrente eficaz que circula no estator. A figura 3.2 relaciona o valor da resistência do estator em função do carregamento para a condição de temperatura ambiente de $25^{\circ}$ Celsius.

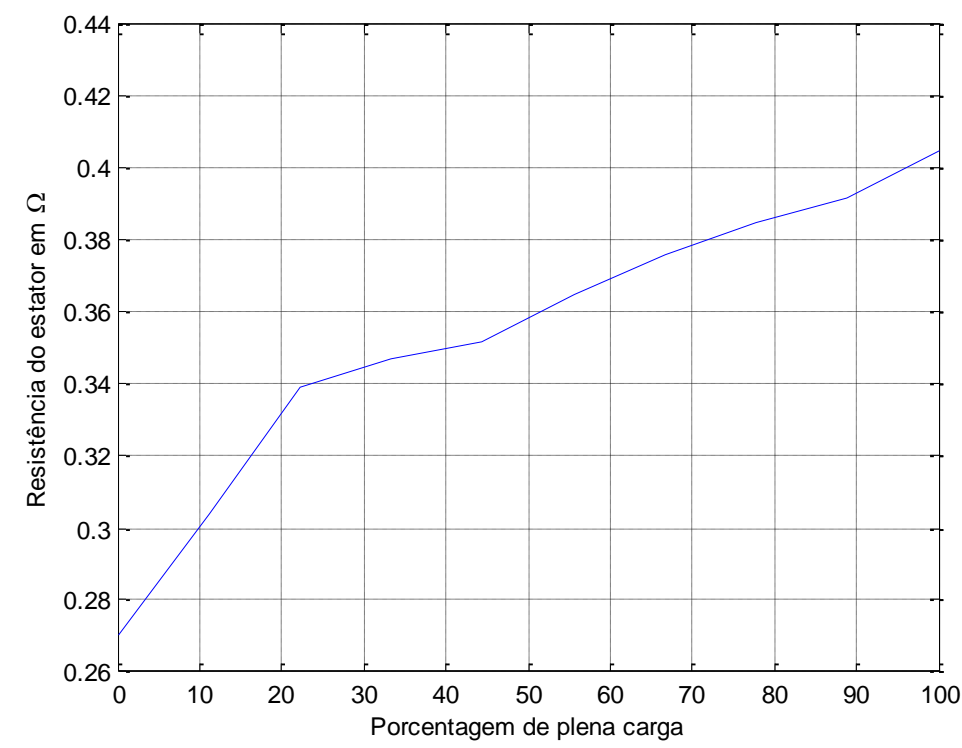

Figura 3.2 Resistência do estator em função da corrente eficaz do estator

Com o motor operando em estrela com tensão de linha de 220Vef, o valor eficaz nominal da derivada do fluxo por fase é $120,8 \mathrm{~V} / \mathrm{s}$, o valor eficaz da corrente com a máquina em vazio $6 \mathrm{~A}$. O estimador da derivada fluxo de referência do estator é mostrado na figura 3.3. 


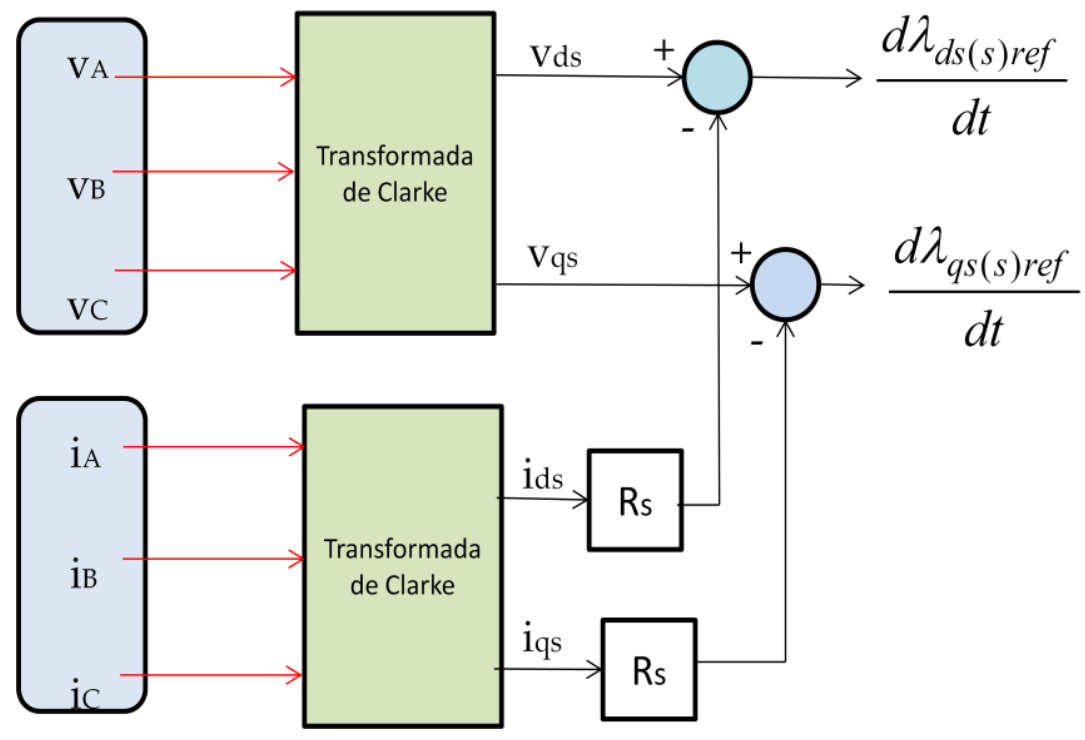

Figura 3.3 Estimador da derivada do fluxo de referência do estator na referência do estator.

O vetor da derivada do fluxo ajustável do estator utilizando as componentes relativas ao rotor é:

$$
\frac{d \lambda_{s(s) a d j}}{d t}=-x_{1} \lambda_{s(s) a d j}+j \frac{P_{1}}{2} \omega_{r} \lambda_{r(s) a d j}+x_{2}\left(\frac{d i_{s(s)}}{d t}-j \frac{P_{1}}{2} \omega_{r} i_{s(s)}\right)+x_{3} i_{s(s)}
$$

Onde $\lambda_{\boldsymbol{s}(\boldsymbol{s}) \boldsymbol{a d j}}$ é o vetor fluxo concatenado ajustável do estator, $\omega_{r}$ é a velocidade do rotor, $P_{1}$ é o número de polos do motor, $x_{1}, x_{2}$ e $x_{3}$ correspondem aos parâmetros que se deseja determinar.

Utilizando as expressões (3.1) e (3.2) com o conhecimento do valor da resistência do estator e da velocidade do motor na situação de regime definida pela carga, podemos estimar os valores dos parâmetros constante de tempo do rotor $\tau_{r}$, indutância do estator $L_{s}$ e coeficiente total de dispersão do fluxo do concatenado do estator $\sigma$ em função da carga o que é mostrado no gráfico da figura 3.4 . 


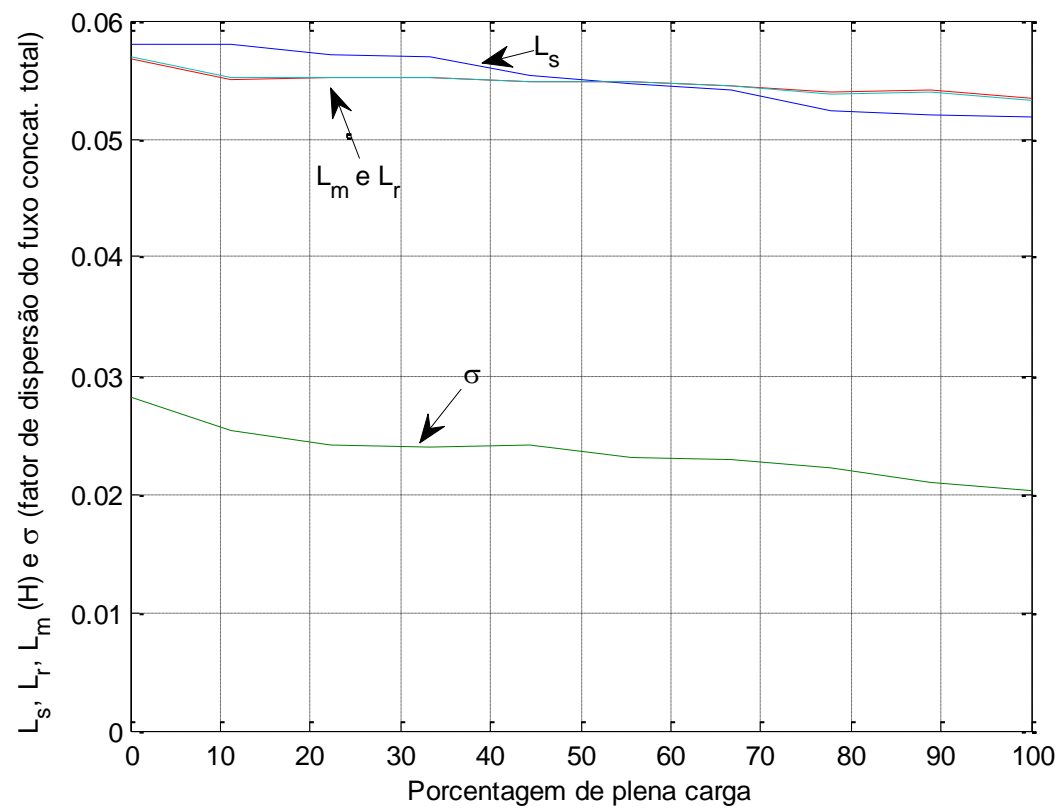

Figura 3.4 Parâmetros Ls, Lr, Lm e $\sigma$ (total leakage) obtidos em função do carregamento.

Aplicando-se a transformada de Clarke nas expressões (3.1) e (3.2) todos os valores ficam relacionados aos eixos direto e de quadratura.

O método de otimização utilizado para realizar a determinação dos parâmetros definidos por $x 1, x 2$ e $x 3$ é o algoritmo de busca de harmonia e o esquema é mostrado na figura 3.5.

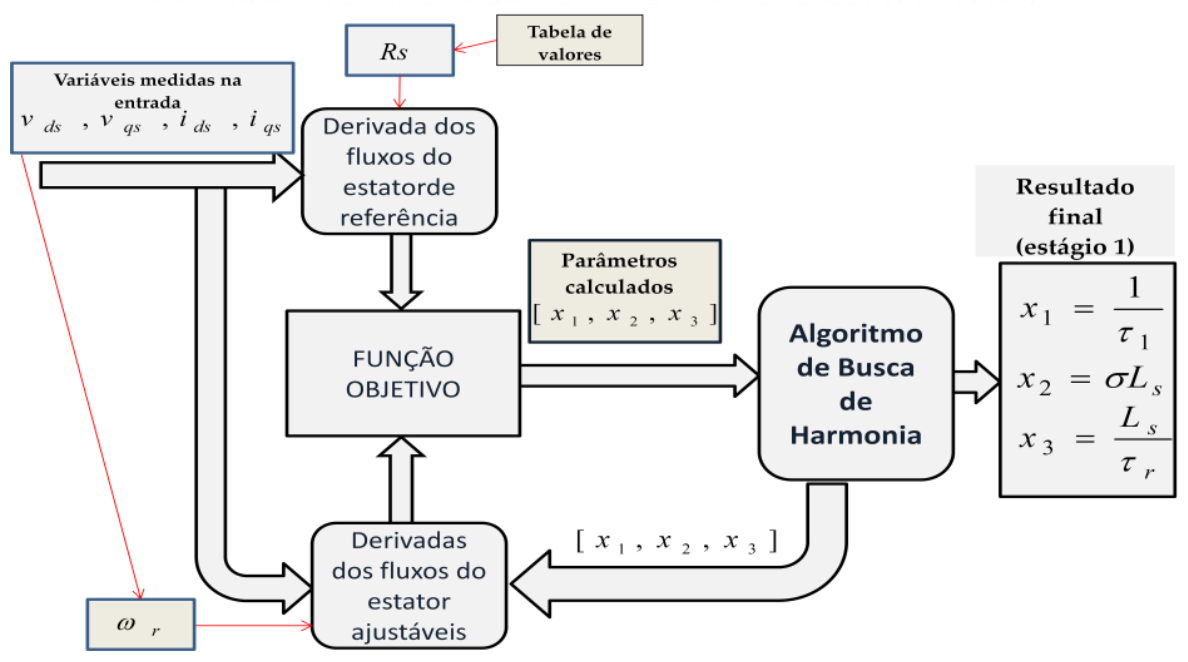

Figura 3.5 - Esquema de estimação dos parâmetros x1, x2 e x3 usando o algoritmo de Busca de Harmonia 


\subsection{A obtenção dos parâmetros do motor de indução (2º Estágio)}

Com base nas derivadas dos fluxos concatenados do rotor na referência do estator podemos escrever as seguintes equações vetoriais.

$$
\frac{L_{m}}{L_{r}} \frac{d \lambda_{r(s) r e f}}{d t}=v_{s(s)}-R_{s} i_{s(s)}-\sigma L_{s} \frac{d i_{s(s)}}{d t}
$$

Onde $\lambda_{r(s) r e f}$ é o vetor fluxo concatenado de referência do rotor, $L_{m}$ é a indutância de magnetização e $L_{r}$ é a indutância do rotor.

O estimador utilizado para a equação (3.3) é mostrado na figura 3.6.

A expressão do vetor da derivada do fluxo concatenado ajustável do rotor na referência do estator é dada na equação (3.4).

$$
\frac{L_{m}}{L_{r}} \frac{d \lambda_{r(s) a d j}}{d t}=x_{4}\left(\frac{\lambda_{r(s) a d j}}{\tau_{r}}+j \frac{P_{1}}{2} \omega_{r} \lambda_{r(s) a d j}\right)+x_{5} i_{s(s)}
$$

As equações (3.5 a) e (3.5b) mostram a relação entre os parâmetros e as variáveis auxiliares utilizadas na solução do problema.

$$
\begin{aligned}
\tau_{r}=\frac{1}{x_{1}} & L_{s}=\frac{x_{3}}{x_{1}} & \sigma=\frac{x_{2} x_{1}}{x_{3}} \\
L_{m}=\frac{x_{5}}{x_{1} x_{4}} & L_{r}=\frac{x_{5}}{x_{1} x_{4}^{2}} & R_{r}=\frac{x_{5}}{x_{4}^{2}}
\end{aligned}
$$

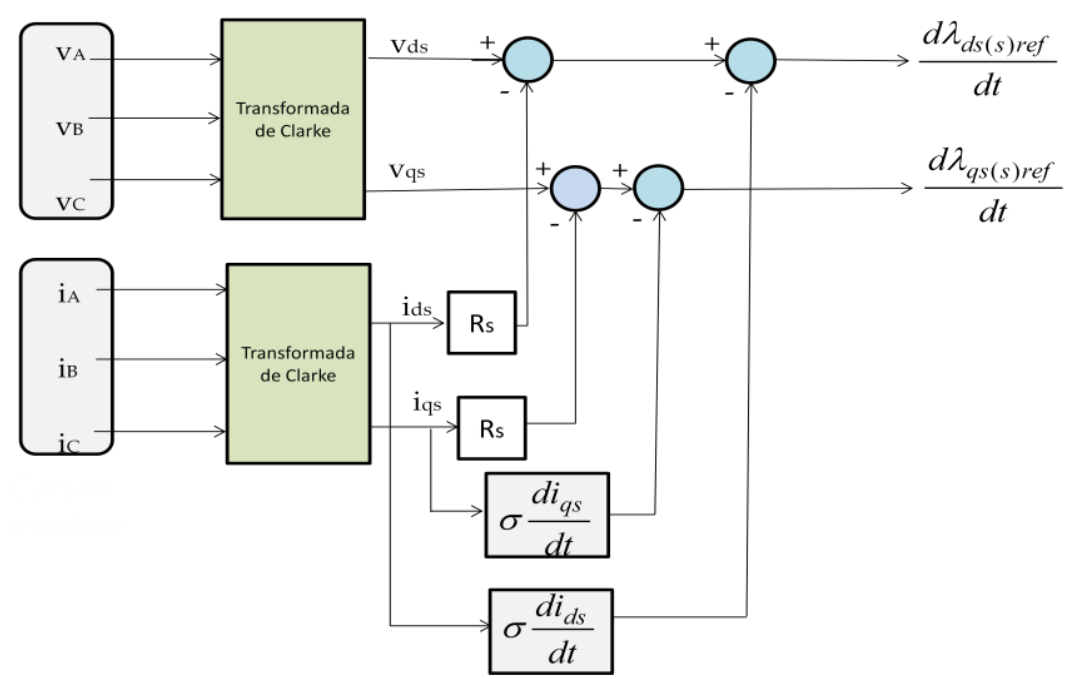

Figura 3.6 Estimador da derivada do fluxo concatenado de referência do rotor na referencia do estator

Esses parâmetros variam com o carregamento do motor. 
Devido à proximidade entre os valores de Lm e Lr utilizados no processo acima, e ao fato do artifício de se embutir nos parâmetros do processo o termo $L m / L r$, geralmente se utiliza a relação $L r=L s$, que é um procedimento usual nos ensaios de motores elétricos.

Esta situação modifica a expressão (3.4) na forma indicada na expressão (3.4) em que $\lambda_{r m(s) a d j}=\left(\frac{L_{m}}{L_{r}}\right) \lambda_{r(s) a d j}$ onde $x_{6}=L_{m}^{2} / \tau_{r}$, como 0 $\tau_{r}=1 / x_{1}$ e foi determinado no $1^{\circ}$ estágio obtem assim o valor $L_{m}=\sqrt{x_{1} x_{6}}$.

$$
\frac{d \lambda_{r m(s) a d j}}{d t}=\left(\frac{\lambda_{r m(s) a d j}}{\tau_{r}}+j \frac{P_{1}}{2} \omega_{r} \lambda_{r m(s) a d j}\right)+x_{6} i_{s(s)}
$$

Da mesma forma que no caso do estágio 1, utilizou o algoritmo de Busca de Harmonia para o cálculo do parâmetros desta fase e o resultado é mostrado na figura 3.7 .

A variação de Rr é mostrada na figura 3.7 onde pode-se verificar que no modelo utilizado, $\mathrm{Rr}$ em regiões de carregamento leve parece menor que em regiões de plena carga, isso deve-se ao modelo utilizado no qual os parâmetros do motor não são fixos, mas variam com o carregamento do motor o que fica mais acentuado em regiões de baixo carregamento onde 0 escorregamento é menor e propicia um aumento também na incerteza do conhecimento do resistor $\mathrm{Rr}$, mas de qualquer modo $\mathrm{Rr}$ tem um aumento aparente nas regiões de menor escorregamento onde o carregamento do motor é menor como mostra a figura 3.7. 


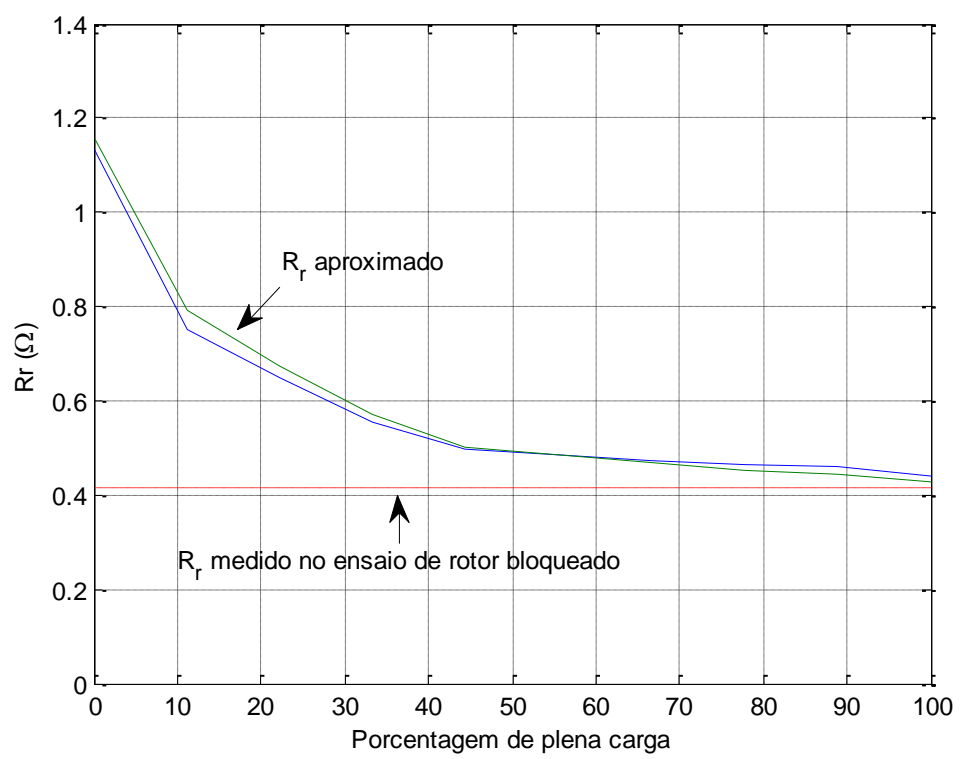

Figura 3.7 Variação de Rr em função do carregamento do motor

A figura 3.7 mostra também que se assumirmos que $L r=L s$, o que é um procedimento normal em ensaios de motores, os valores de $\mathrm{Rr}$ não se alteram significativamente.

\subsection{Verificação da consistência dos valores obtidos com base nas correntes de fase medida e calculada utilizando os parâmetros estimados}

A verificação de consistência dos valores paramétricos levantados pode ser verificada contra os valores de previsão teórica segundo a qual a corrente eficaz por fase do motor é dada pela equação dada em (3.7) (TRZYNADLOWSKI, 1994).

$$
I_{S_{-} \text {calculado }}=\left|I_{S_{-} \text {calculado }}\right|=\frac{\left|\widehat{V}_{S}\right|}{\left|R_{S}+j X_{l s}+\frac{j X_{m}\left(\frac{R_{S}}{S}+j X_{l r}\right)}{\frac{R_{S}}{S}+j\left(X_{m}+X_{l r}\right)}\right|}
$$

Utilizando os valores paramétricos ponto a ponto da carga podemos calcular as correntes de fase experimental e teórica ou calculada, assim podemos construir o gráfico da figura 3.8. 


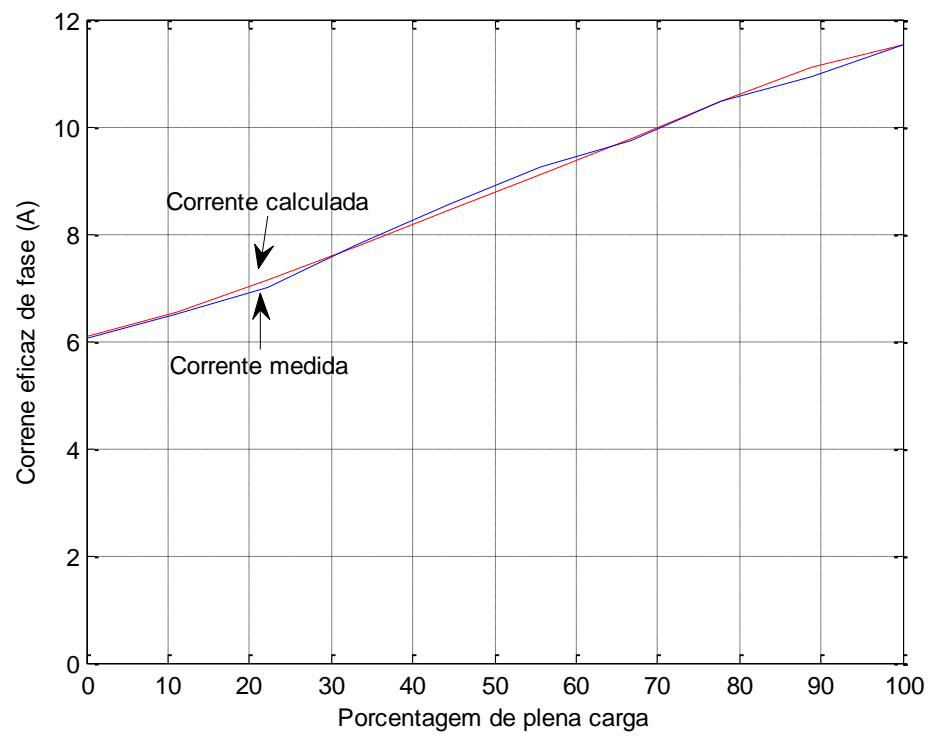

Figura 3.8 Comparação entre a corrente rms medida em uma das fases e a corrente de fase calculada.

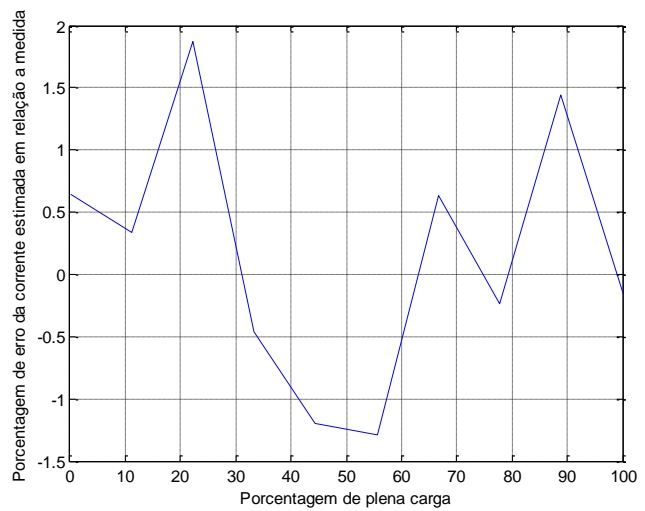

Figura 3.9 Erro entre os valores eficazes das correntes medido e calculado.

A figura 3.9 mostra o erro porcentual entre os valores eficazes das correntes medida e calculada utilizando como referência o valor medido. Notase que o erro para mais é inferior a 2,5\% e para menos é ainda menor.

A figura 3.10 mostra a relação entre a corrente eficaz medida no estator e a corrente de fase estimada no rotor. 


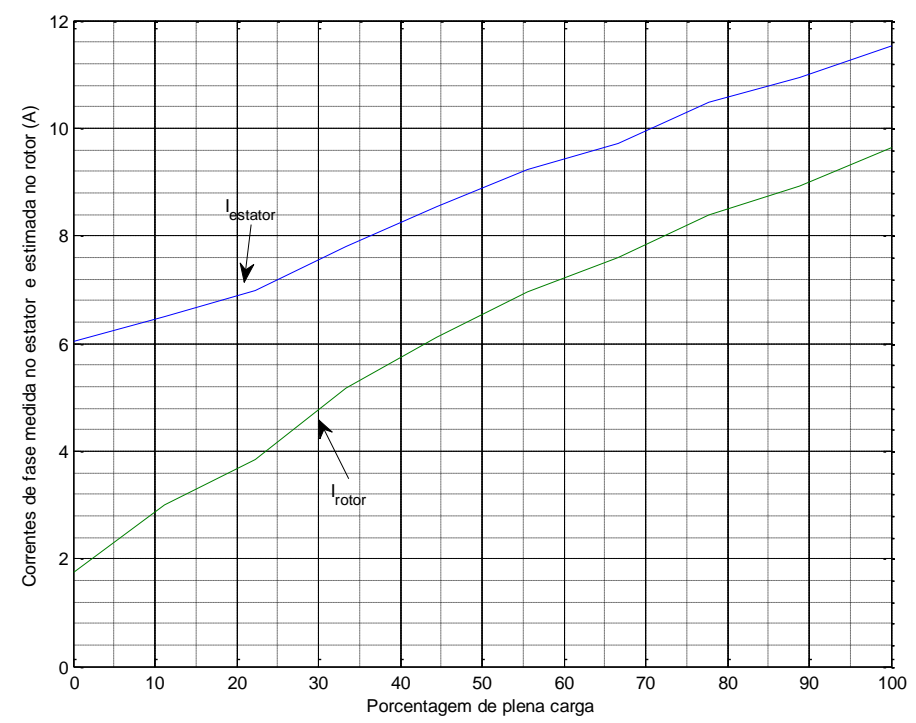

Figura 3.10 Correntes eficazes de fase medida no estator e estimada no rotor.

A figura 3.11(a) mostra o comportamento do escorregamento em função da corrente eficaz na carga enquanto que a figura 3.11(b) mostra o comportamento da relação $\mathrm{Rr} / \mathrm{s}$ com relação ao escorregamento.

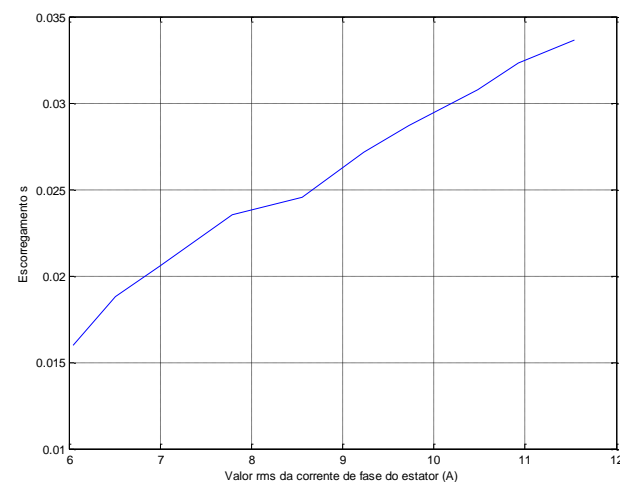

(a)

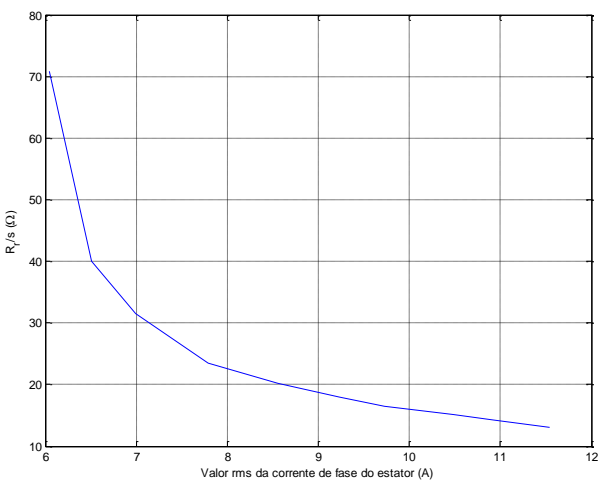

(b)

Figuras 3.11 Comportamento do escorregamento em função do valor eficaz da corrente do estator (a) e da relação $\mathrm{Rr} / \mathrm{s}$ em relação ao valor eficaz da corrente o estator.

A estimação da corrente rotórica foi feita utilizando a equação (3.8) com base efetiva na corrente medida no estator (TRZYNADLOWSKI, 1994).

$$
I_{r_{-} \text {calculada }}=\left|\frac{-I_{S_{-} \text {calculada }} * j X_{m}}{\frac{R_{r}}{s}+j\left(X_{m}+X_{l r}\right)}\right|
$$




\subsection{Comparação entre as potências medidas e estimadas}

O estimador mostrado na figura 3.12 foi utilizado para a estimação do torque eletromagnético do motor e com a inserção da velocidade medida do rotor permitiu também a estimação da potência entregue pelo motor para a carga.

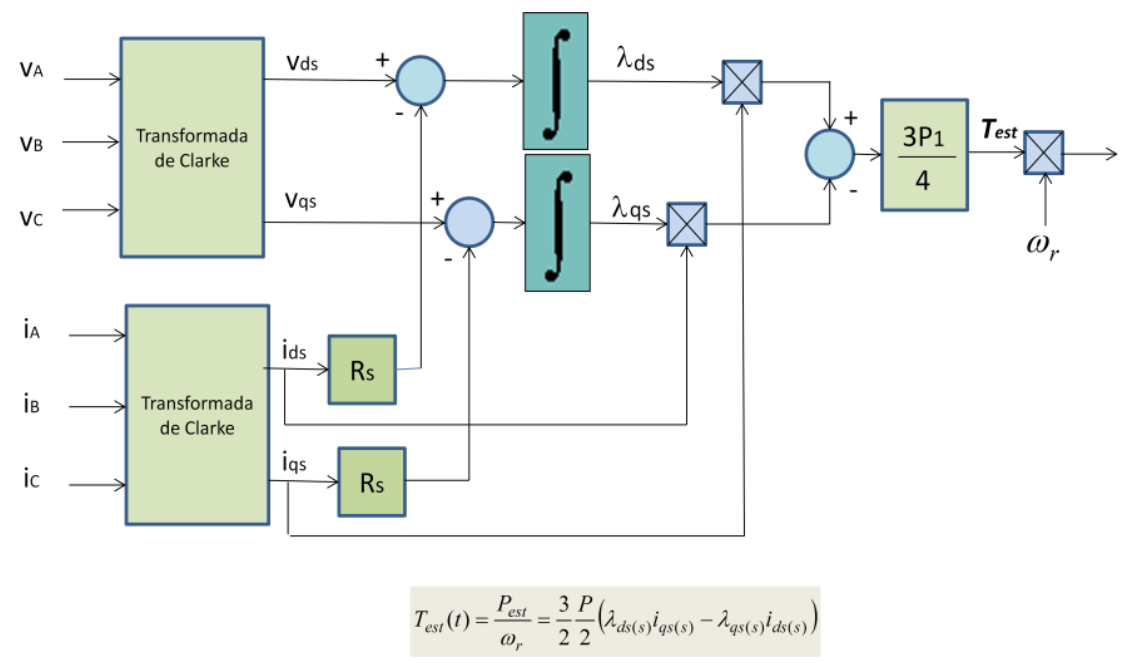

Figura 3.12 Estimador de torque e potência efetiva na carga (VAS, 1993)

Com a utilização do estimador juntamente com o conhecimento das correntes eficazes do estator e do rotor é possível determinar ou estimar o comportamento das perdas do motor.

O gráfico da figura 3.13 mostra o método utilizado para estimar as perdas do núcleo, adicionadas às perdas rotacionais da máquina.

A figura 3.14 mostra o gráfico do comportamento da potência P0 (perdas no núcleo mais perdas rotacionais) e as perdas no cobre do estator e na resistência do rotor. Nota-se que enquanto ocorre um aumento progressivo em relação ao carregamento das potências nas resistências do estator e do rotor, o comportamento das perdas no núcleo adicionadas as perdas rotacionais não têm uma tendência generalizada de aumento no inicio da faixa de carregamento, mas diminuído aproximadamente no centro da mesma voltando a aumentar no final da faixa, porém observa-se que essas perdas são relativamente constantes, pois variam entre $525 \mathrm{~W}$ e $565 \mathrm{~W}$, ou seja variam em cerca de $40 \mathrm{~W}$ na faixa toda, o que corresponde a aproximadamente $7,5 \%$ do valor da potência mínima quando motor opera em vazio. Se consideramos a 
potência total em vazio o erro cai para $6,8 \%$ das perdas,e se considerarmos a potência máxima das perdas do motor o erro cai para $4,8 \%$. Se levamos em conta a potência máxima útil da máquina o erro vai para 1,16\% e no meio da faixa operacional (carregamento de $50 \%$ ) o erro fica em torno de $1,6 \%$.

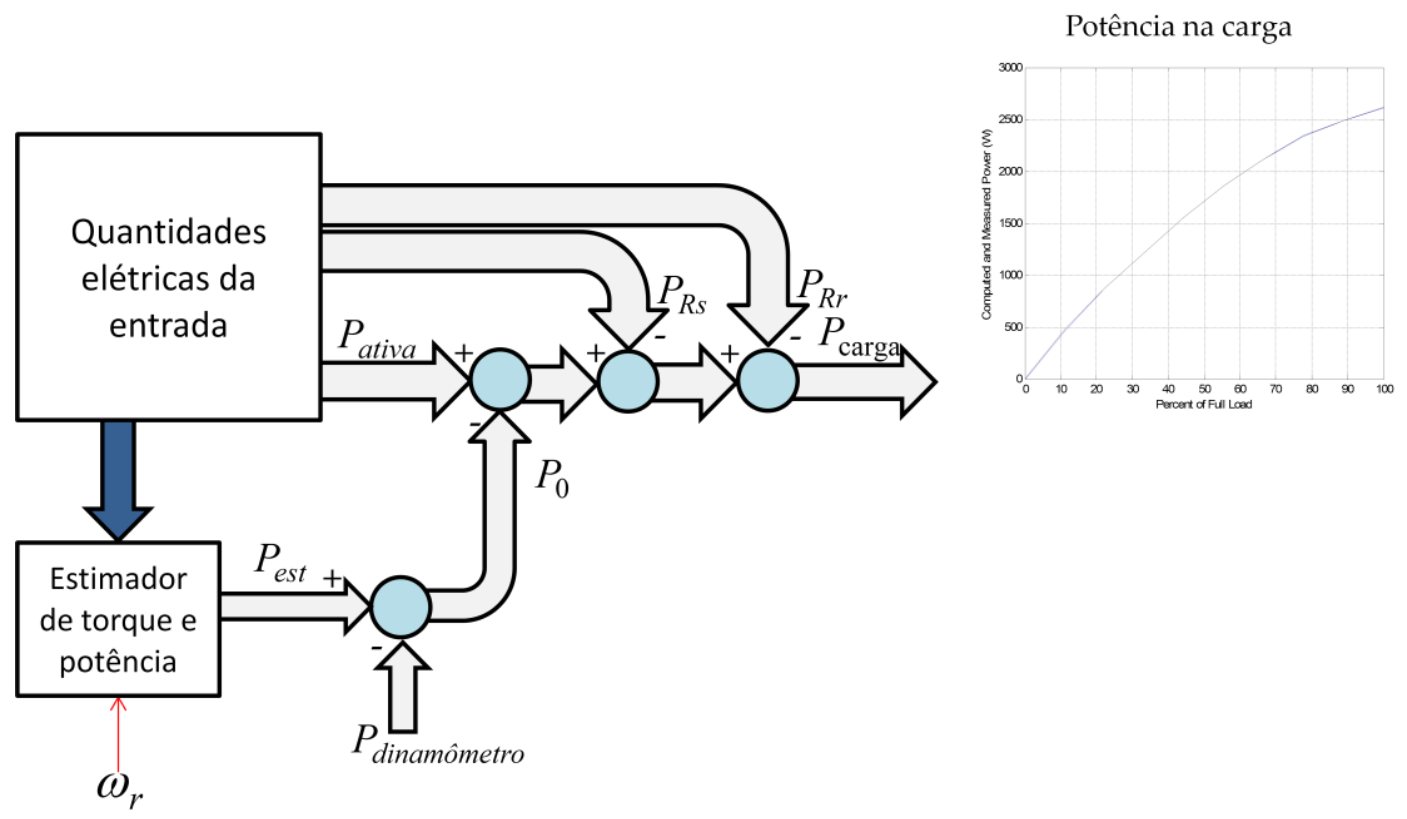

Figura 3.13 Estimador do torque líquido na carga e também das perdas no núcleo mais perdas rotacionais indicadas por P0 nesta figura.

A potência líquida na carga que foi medida diretamente utilizando 0 dinamômetro. Em uma primeira abordagem a potência liquida na carga foi obtida a partir da potência estimada pelo estimador da figura 3.12 levando em consideração as perdas rotacionais e do núcleo em sua forma distribuída em toda a faixa de carregamento e denominada POdistrib. nas expressões (3.9) e (3.10). 


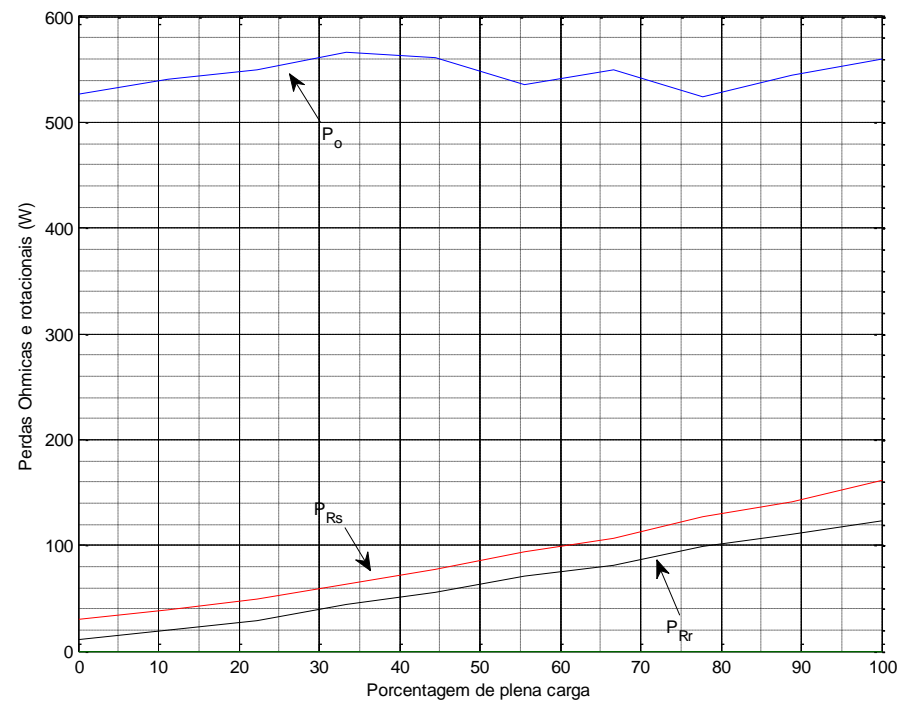

Figura 3.14 Comportamento das perdas no núcleo mais perdas rotacionais (superior) na resistência do estator (intermediária) e do rotor (inferior).

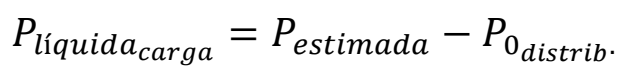

A mesma potência estimada pode ser obtida a partir da potência ativa na entrada da máquina descontando todas as potências perdidas ao longo do fluxo de potência como mostra a figura 3.14 e numericamente relacionada pela equação (3.10).

$$
P_{\text {liquida }}^{\text {carga }}=P_{\text {ativa }}-\left(P_{R s}+P_{R r}+P_{\text {0distrib. }}\right)
$$

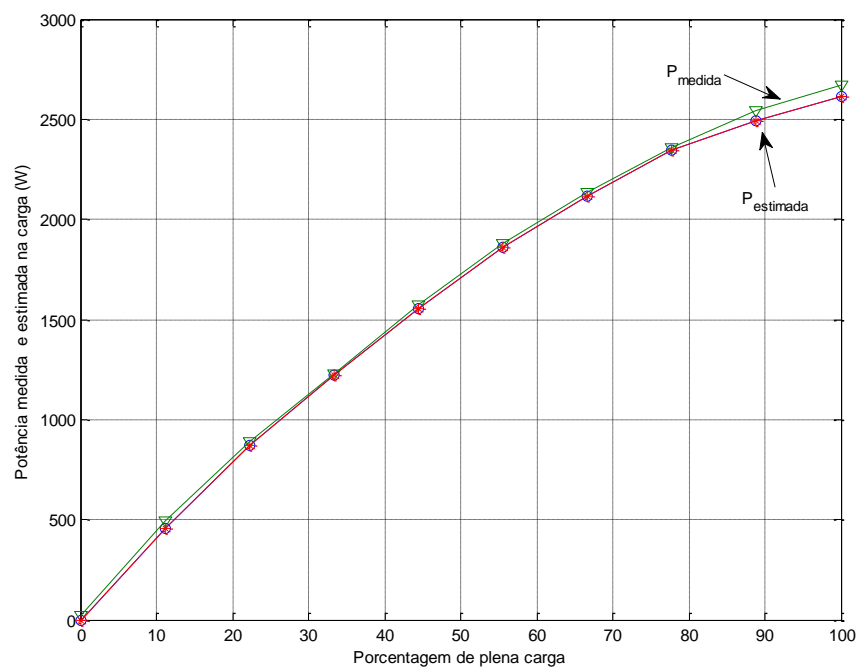

Figura 3.15 Comportamento das potências medida e estimada na carga em função da porcentagem de carregamento de plena carga baseada na equação (3.10). 


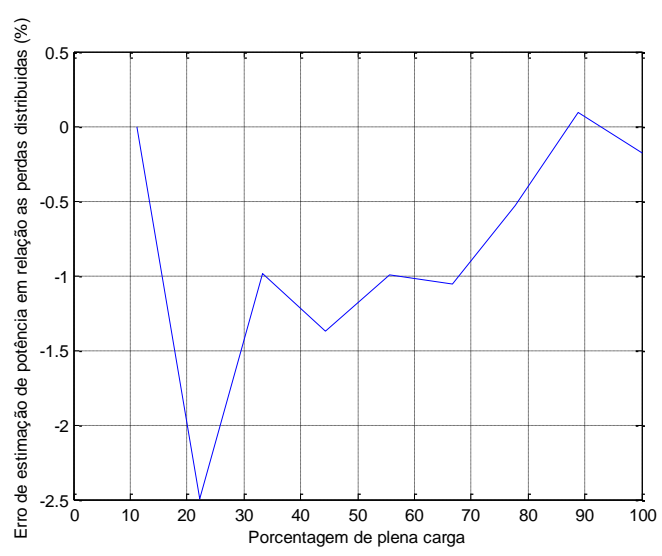

(a)

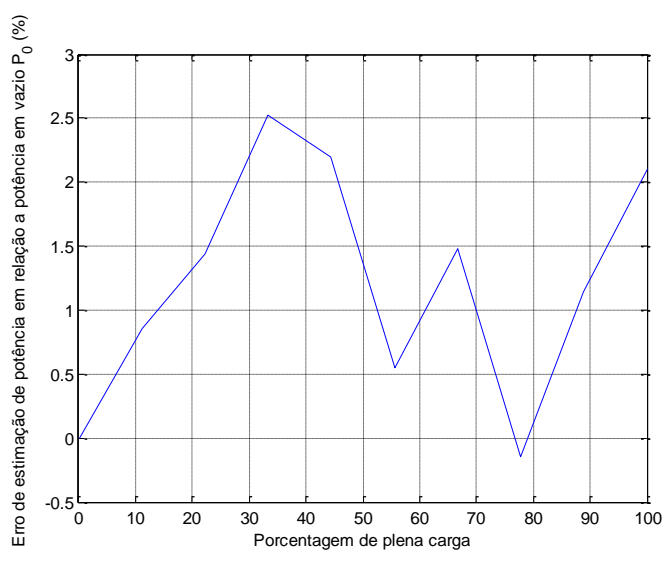

(b)

Figura 3.16 Erro porcentual da potência estimada em relação a potência medida tomando como deslocamento (off-set) as perdas distribuídas (a) e o mesmo erro tomando como deslocamento (off-set) a perda em vazio inicial P0 (b).

A figura 3.15 mostra o comportamento da potência líquida medida e estimada utilizando a equação (3.10) na carga..

Em um processo prático é impossível o conhecimento da potência Podistrib., assim é comum a fixação da potência em vazio, descontando a perda em $R$ s e admitindo como nula a perda e $R r$ como o total das perdas rotacionais somadas as perdas do núcleo denominada aqui $P_{0}$, a figura 3.17 mostra o efeito desta consideração e o erro em relação ao valor da potência medida é mostrado na figura 3.17 .

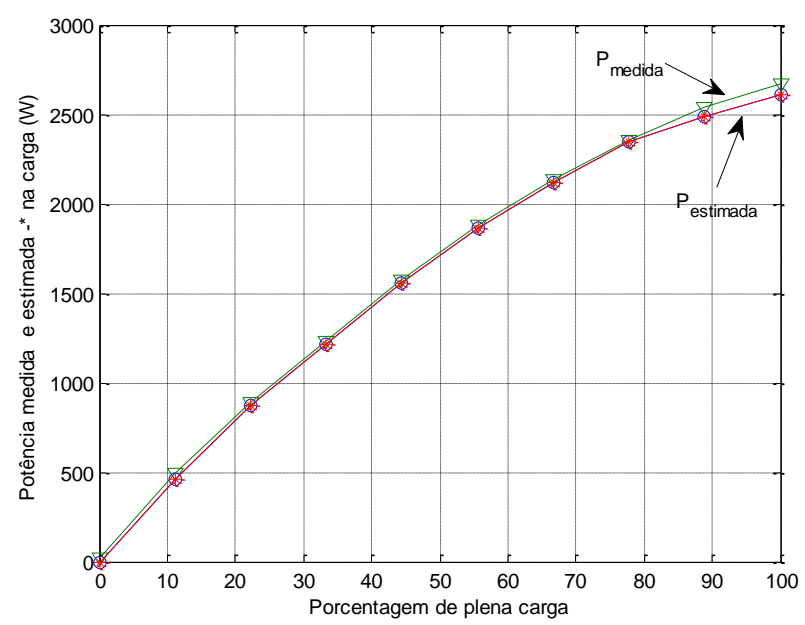

Figura 3.17 Potências medida e estimada, esta última considerando apenas a perdas rotacionais e no núcleo do motor de indução em vazio $(P 0)$. 
Em termos gerais é possível obter a potência na carga a partir da potência ativa medida no terminais do motor de indução, do parâmetro Rs medido inicialmente e do valor de $R r$ é estimado utilizando o algoritmo de Busca de Harmonia.

\subsection{A estimação de torque}

O torque fornecido pelo motor de indução foi medido via dinamômetro e estimado pelo estimador mostrado nas figuras 3.12 sendo que o gráfico da figura 3.18 mostra as duas curvas. Neste caso o erro máximo do torque estimado em relação ao torque medido foi menor que $-3,5 \%$ e de todas as quantidades estimadas, esta foi a que mostrou maior desvio em relação ao valor medido.

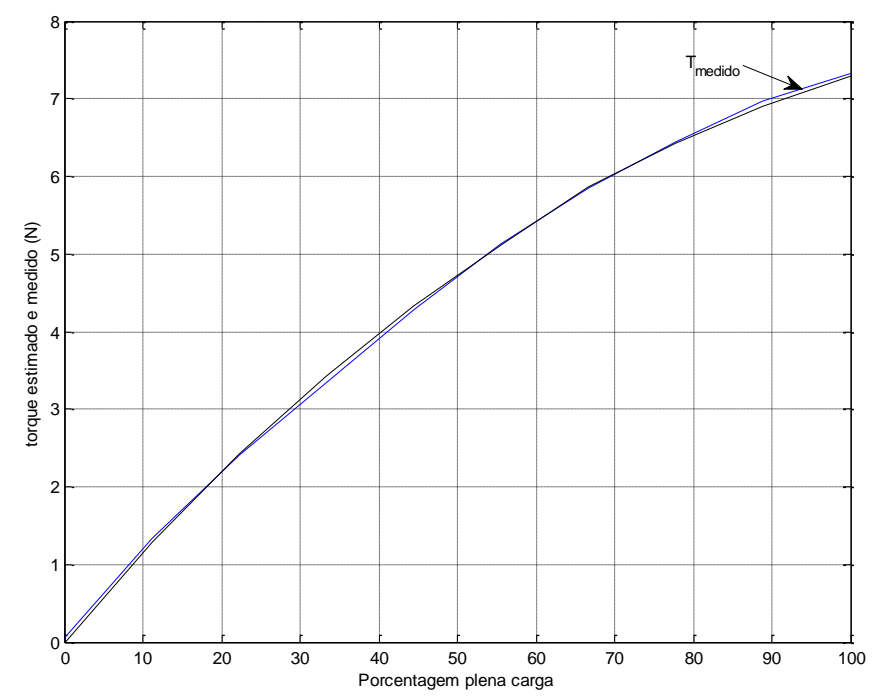

Figura 3.18 Torque estimado e medido

A figura 3.19 mostra o erro porcentual do torque estimado em relação ao torque medido.

\subsection{A estimação de velocidade}

Uma vez que a potência e o torque do motor tenham sido estimados, nada impede que a velocidade do mesmo também seja estimada. 


\section{7 .1 Primeiro método de estimação de velocidade}

Se o valor da velocidade síncrona da fonte de alimentação trifásica $\omega_{s}$ for conhecida e geralmente o é, mesmo com acionamento via inversor de frequência, a velocidade do eixo do rotor pode ser estimada a partir da expressão (3.11).

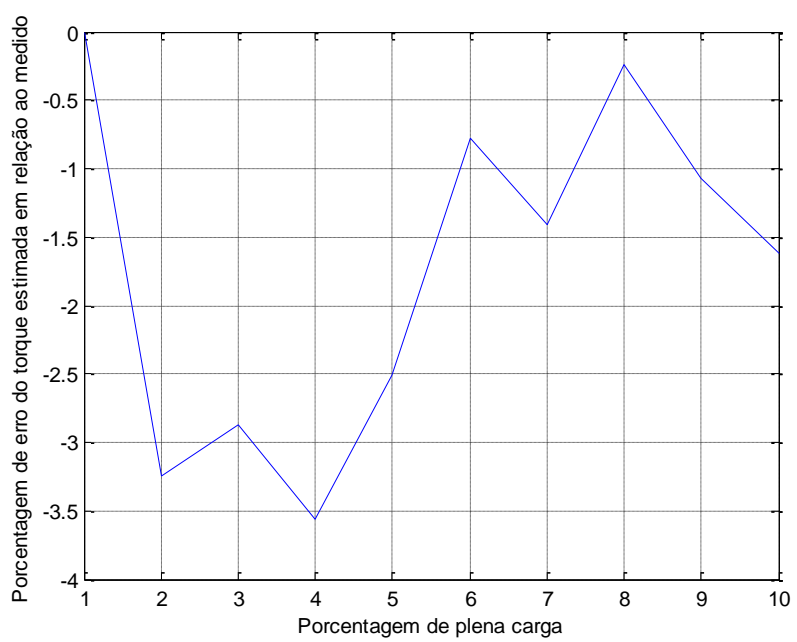

Figura 3.19 Erro de estimação do torque mostrando que na região de menor carregamento ocorre um erro maior em torno de $-3,5 \%$

$$
\omega_{r_{-} e s t}=\frac{2}{P_{1}}\left(\omega_{s}-\frac{\left|3 R_{r} I_{I_{-} \text {calculado }}^{2}\right|}{T_{e s t}}\right)
$$

O gráfico relativo a esta expressão comparado com a velocidade medida por um tacômetro é mostrado na figura 3.20 e o erro relativo baseado na velocidade medida é mostrado na figura 3.21. Nota-se de 3.21 que o erro é maior no extremo inferior quando a máquina opera com carregamento leve, ficando menor na meia faixa e aumentando gradativamente a medida que a mesma é carregada, mas por este método o erro absoluto máximo é menor que $0,4 \%$.

\subsection{Segundo método de estimação de velocidade}

Um outro método de estimação da velocidade a partir de valores já estimados, pode ser obtido a partir da expressa (3.12).

$$
\omega_{r_{-} e s t}=\frac{2}{P_{1}} \frac{P_{a t i v a}-\left(P_{R S}+P_{R r}+P_{0}\right)}{T_{e s t}}
$$




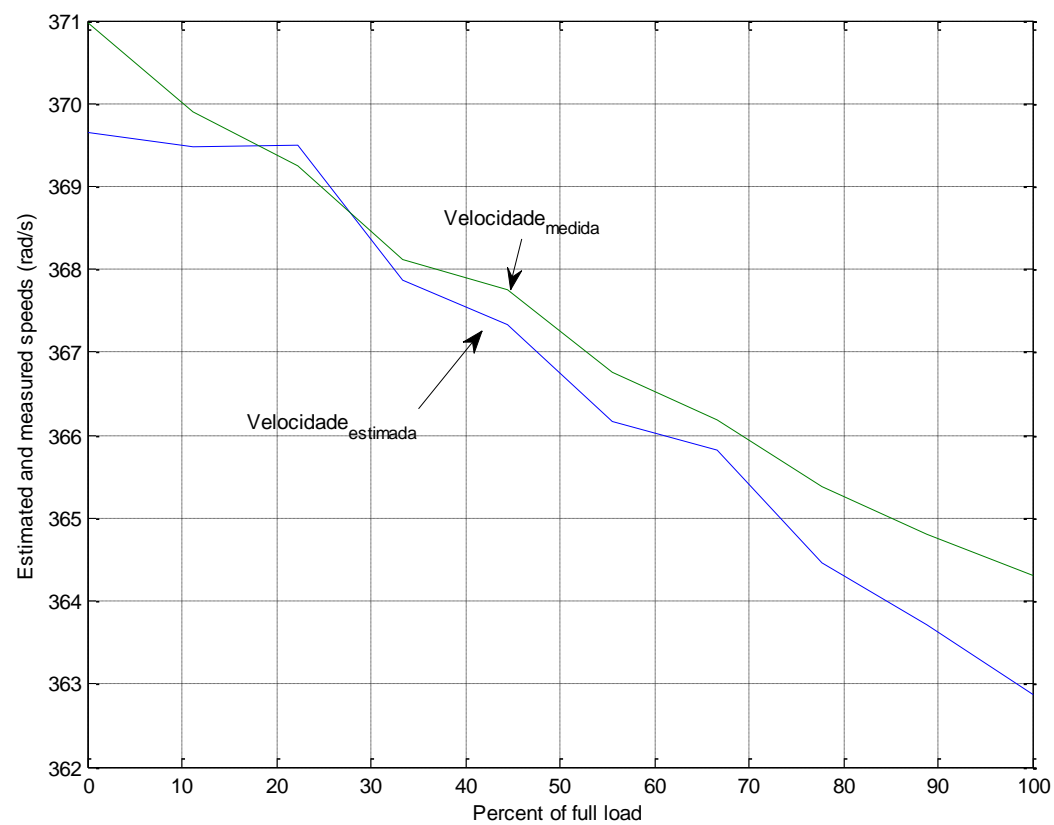

Figura 3.20 Velocidades medida e estimada em radianos em função do porcentual de carregamento da máquina utilizando a expressão (3.11) para uma máquina de 2 polos $\left(P_{1}=2\right)$.

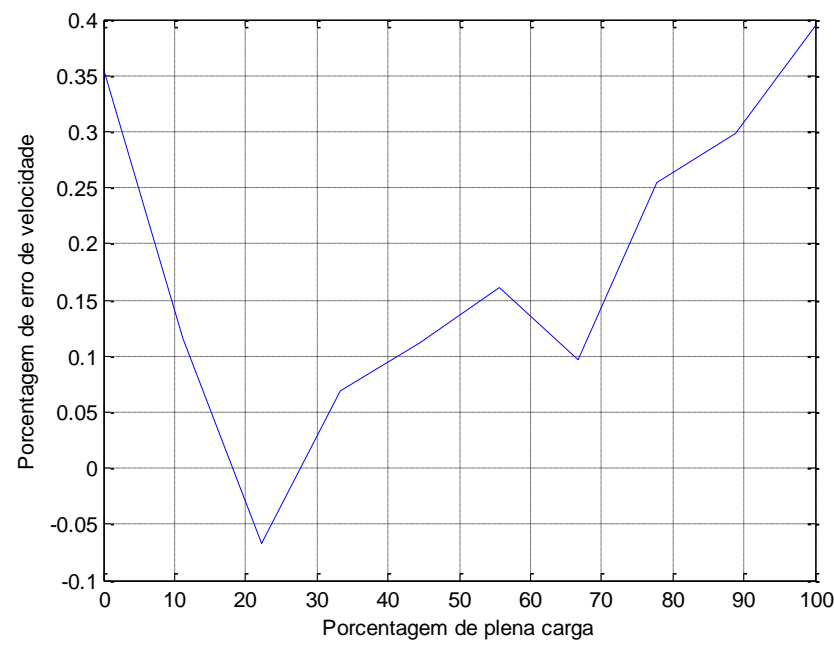

Figura 3.21 Erro de velocidade em função do carregamento porcentual do motor de indução utilizando o primeiro método.

Neste caso o erro é um pouco maior, principalmente na região de carregamento menor como mostra a figura 3.22 e se acentua também no carregamento pleno. 


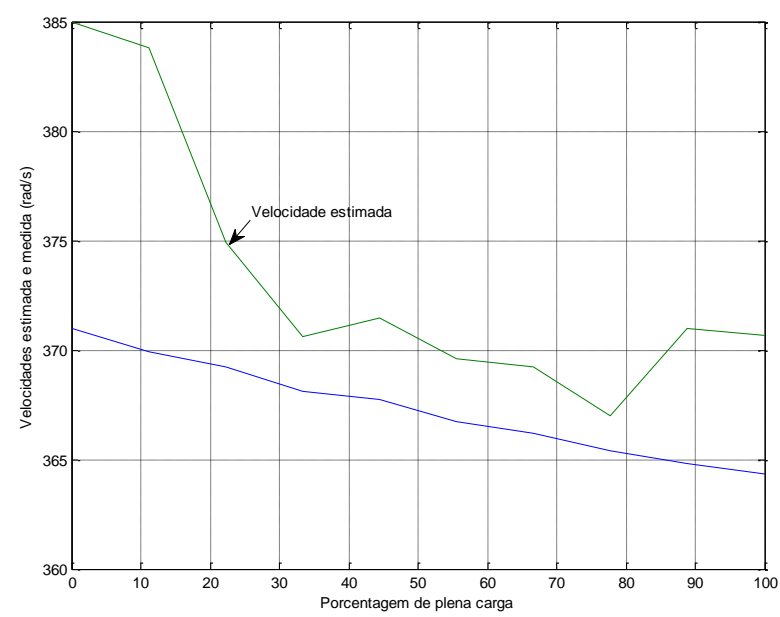

Figura 3.22 Velocidades medida e estimada em radianos em função do porcentual de carregamento da máquina utilizando a expressão (3.12) para uma máquina de 2 polos $\left(P_{1}=2\right)$.

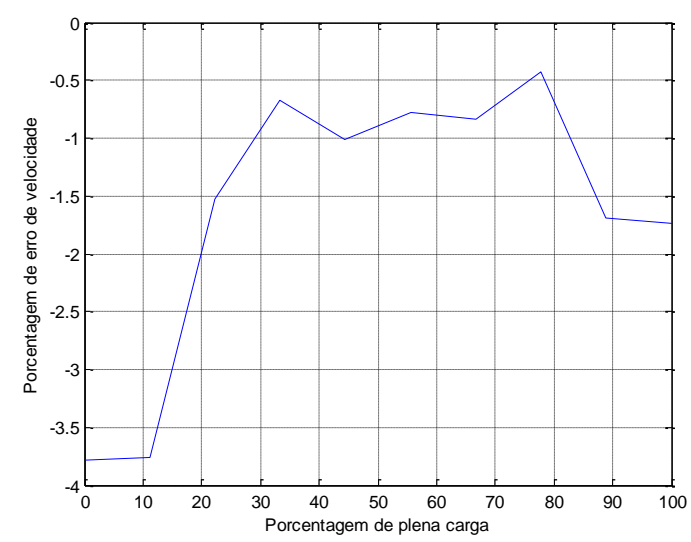

Figura 3.23 Erro de velocidade em função do carregamento porcentual do motor de indução utilizando o segundo método.

O gráfico da figura 3.23 mostra o erro de velocidade para a estimação utilizando a expressão (3.12), neste gráfico fica evidente o deslocamento da estimação tanto na região de carregamento leve como na de carregamento pleno. O erro absoluto máximo no caso é menor que $2 \%$ que muito maior que $0,35 \%$ obtido com o método anterior.

\subsection{0 setup experimental}

Todos os experimentos relativos a esta fase inicial de testes foram realizados no laboratório de máquinas elétricas da universidade de Mogi das 
Cruzes e o setup consistiu de uma máquina de corrente contínua utilizada como dinamômetro acionada por um motor de indução de 2 polos ligada em $Y$ com tensão de linha de $220 \mathrm{~V}$. O funcionamento do setup é mostrado na figura 3.24.

A interface consistiu de sensores de tensão do tipo LEM-LV-20P para operação até 500Vrms e sensores de corrente LEM-HXS-20NP para operação com até 20Arms.

O condicionamento dos sinais foi feito com o amplificador operacional LT1014 ultra-low offset voltage e todas as compensações e ajustes foram realizadas por software com consistência verificada por um multímetro FLUKE $87 \mathrm{~V}$ true-rms. O esquema do sistema de aquisição é mostrado na figura 3.25.

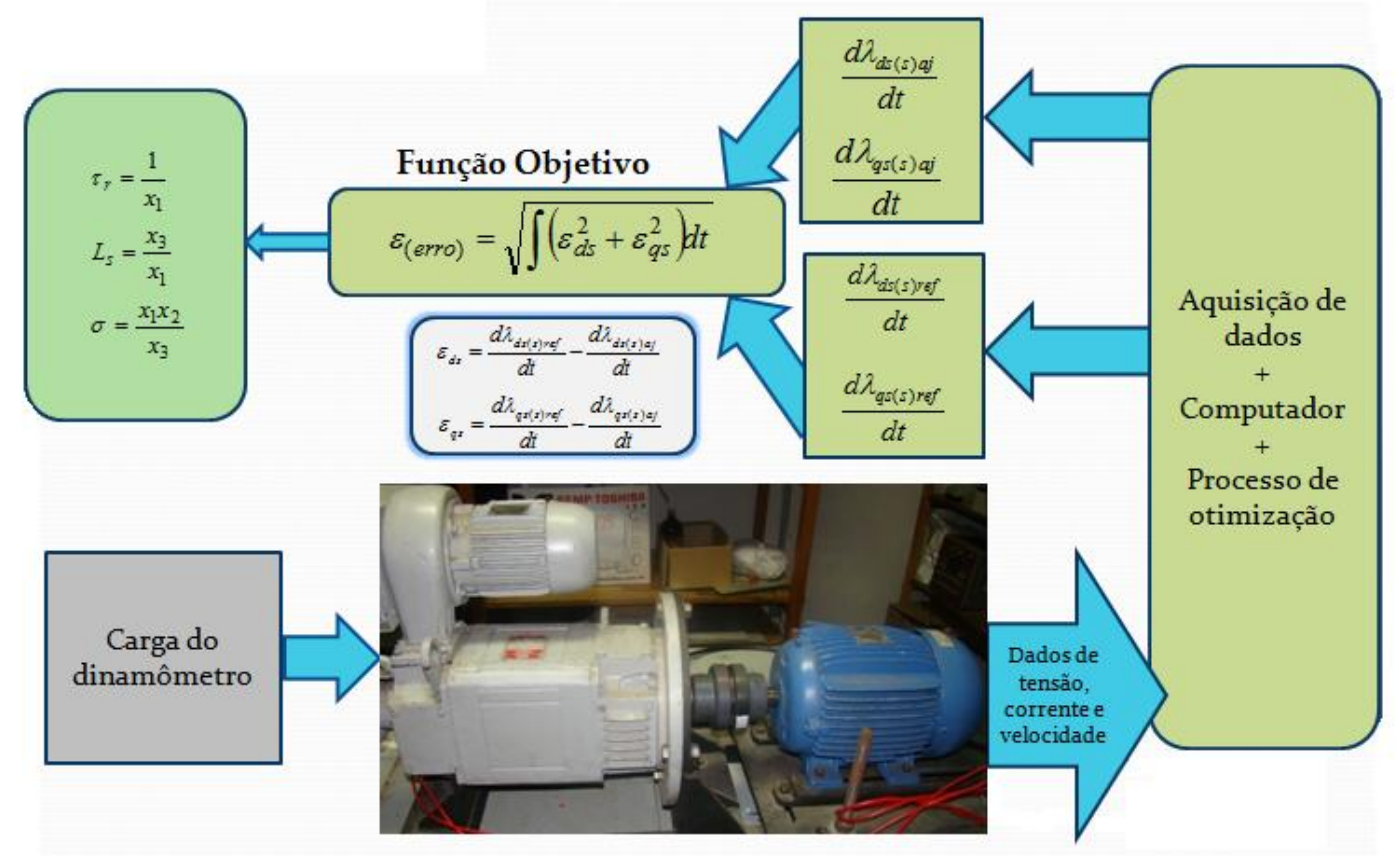

Figura 3.24 Esquema operacional do setup experimental com indicação do carregamento do dinamômetro e o fluxo dos dados para processamento das derivadas dos fluxos de referência e fluxos ajustáveis contra a função objetivo especificada utilizando o algoritmo de Busca de Harmonia (Harmony Search). 


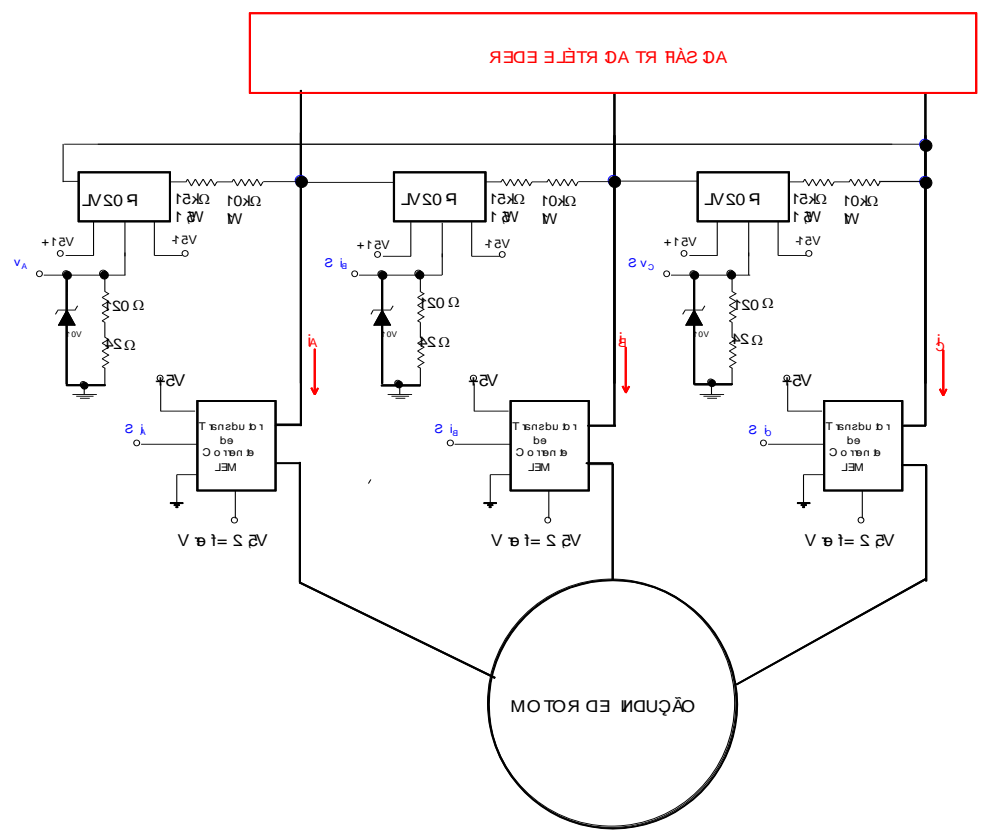

Figura 3.25 Esquema do sistema de aquisição com os sensores de tensão e corrente da LEM.

O sistema de aquisição de dados consistiu de um data acquisition do tipo NI-6210USB da National Instruments, com resolução de 16bits e velocidade de $250 \mathrm{ks} / \mathrm{s}$ independente do número de canais. No processamento dos dados foi utilizada a taxa de aquisição de $20 \mathrm{ks} / \mathrm{s}$ que é 20 vezes maior que o sistema de aquisição utilizado pelo dinamômetro Kistler. A conexão tanto do setup experimental da UMC quanto ao torno do Laboratório de Fenômenos de Superfície (LFS) da escola de engenharia mecânica da Escola Politécnica da USP é basicamente o mesmo, sendo a conexão ao torno é mostrada na figura 3.26 .

\subsection{Aplicando o método à máquina ferramenta}

A parte experimental relacionada com um processo de usinagem em um torno foi realizada no Laboratório de Fenômenos de Superfície (LFS) da escola de engenharia mecânica da Escola Politécnica da USP e consistiu do uso de um torno de médio porte com um dinamômetro estacionário Kistler do tipo 9441B com faixa de medição de 0 a $30 \mathrm{kN}$ montado na torre do torno como mostrado na foto da figura 3.27(a) conectado a um sistema de condicionamento e processamento do sinal mostrado na figura 3.27(b). 


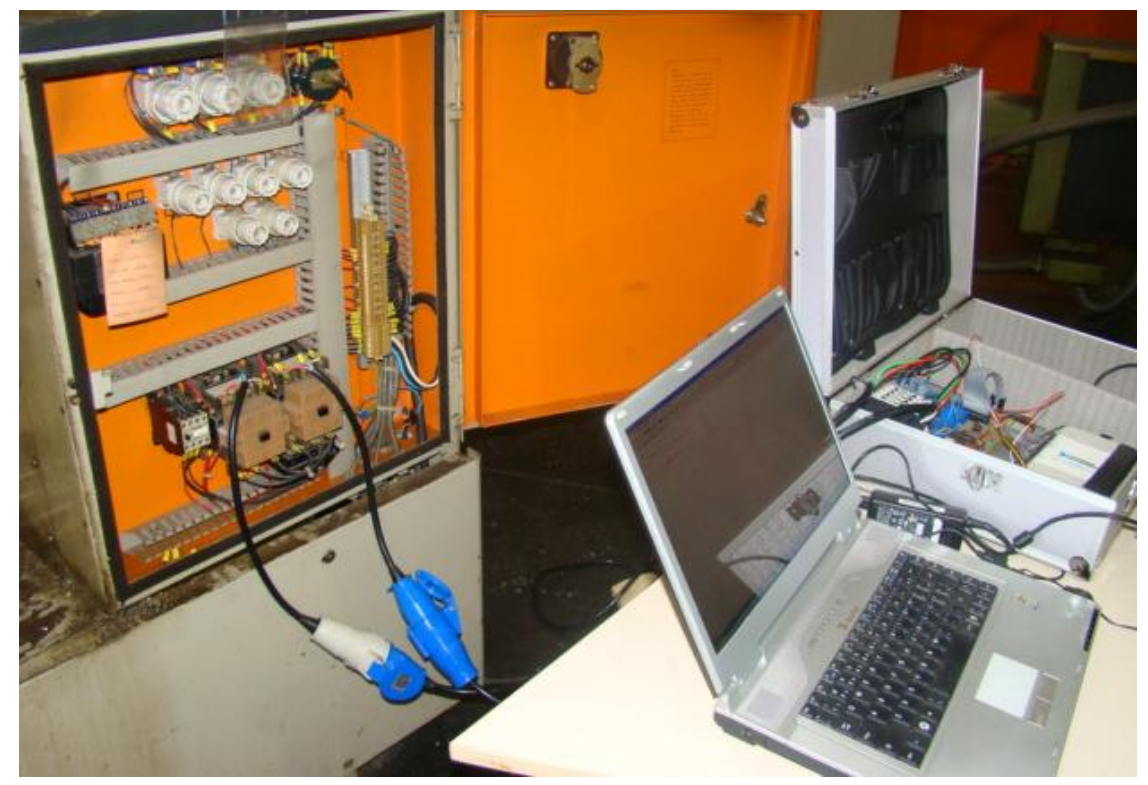

Figura 3.26 Conexão do sistema de aquisição de dados do motor de indução ao sistema de acionamento do torno do LFS.

As características do sistema de aquisição do dinamômetro Kistler são :

a) Resolução de 16 bits.

b) Taxa de amostragem máxima de 1000 amostras/segundo.

c) Programa de processamento de aquisição Kistler com exportação para planilha Excel da Microsoft.

Os ensaios realizados com corte contínuo na máquina ferramenta foram em número de três, com passes de profundidade $0,5 \mathrm{~mm}, 1,0 \mathrm{~mm}$ e $1,5 \mathrm{~mm}$, é importante salientar que neste caso não houve condição de obter os dados completos do motor em toda a região de carga, mas em três condições pontuais dentro da faixa operacional da máquina ferramenta, procurou-se manter uma peça com diâmetro de $39,9 \mathrm{~mm}$, a velocidade do eixo árvore do torno foi medido diretamente por um tacômetro conectado ao próprio eixo árvore e as forças de corte, de avanço e passiva foram medidas pelo dinamômetro Kistler. 


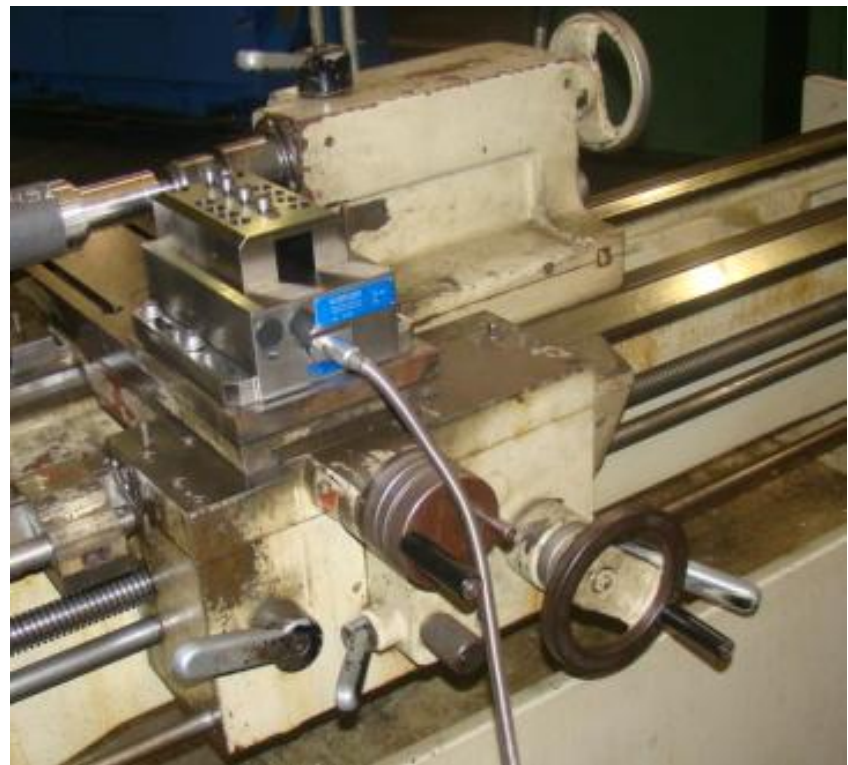

(a)

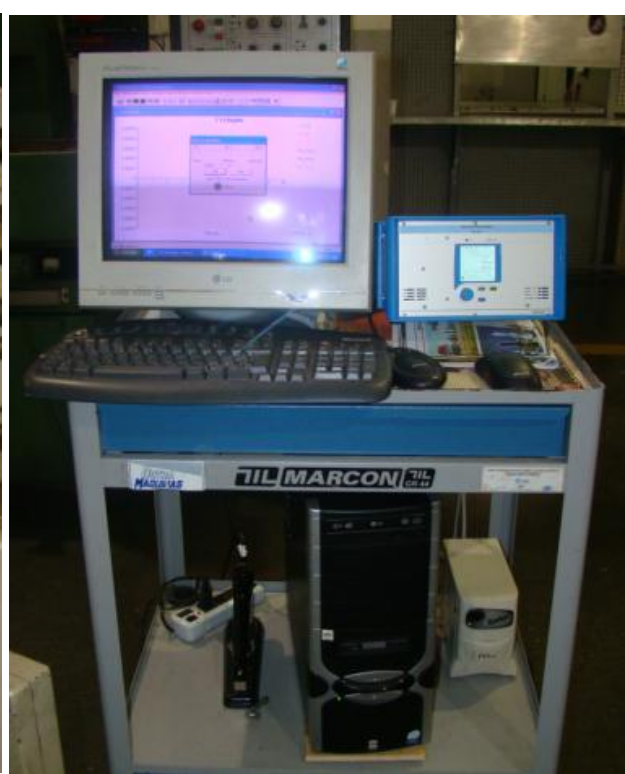

(b)

Figura 3.27 A parte experimental com usinagem montada em um torno do LFS. (a) Dinamômetro estacionário Kistler 9441B montado na torre do torno e (b) Amplificador e sistema de aquisição de dados.

\subsubsection{Os parâmetros do motor de indução do torno}

Para a obtenção dos parâmetros do motor de indução do torno foi aplicado o método mostrado na figura 3.24 onde a usinagem no torno foi realizada com passes de profundidade constante como já mencionado e o sensor das quantidades elétricas na entrado do motor de indução juntamente com o dinamômetro Kistler obtiveram os dados mostrados na tabela 3.2

Tabela 3.2 Grandezas elétricas medidas na entrada do motor

\begin{tabular}{|l|r|r|r|r|}
\hline passe & vazio & $0,5 \mathrm{~mm}$ & $1,0 \mathrm{~mm}$ & $1,5 \mathrm{~mm}$ \\
\hline Vs(rms) (V) & 131,4 & 131,0 & 131,0 & 130,5 \\
\hline Is(rms) (A) & 8,56 & 8,8 & 9,07 & 9,4 \\
\hline Paparente (VA) & 3353,8 & 3452,3 & 3561,7 & 3689,8 \\
\hline Pativa (W) & 1092,8 & 1254,3 & 1483,2 & 1794,3 \\
\hline Força de corte (N) & 6,9 & 255,56 & 424,94 & 672,9 \\
\hline Torque estimado(Nm) & 5,9 & 7,13 & 8,37 & 10,074 \\
\hline Vel. Arvore (rad/s) & 49,632 & 49,582 & 49,555 & 49,482 \\
\hline Fator potência & 0,356 & 0,363 & 0,416 & 0,486 \\
\hline
\end{tabular}




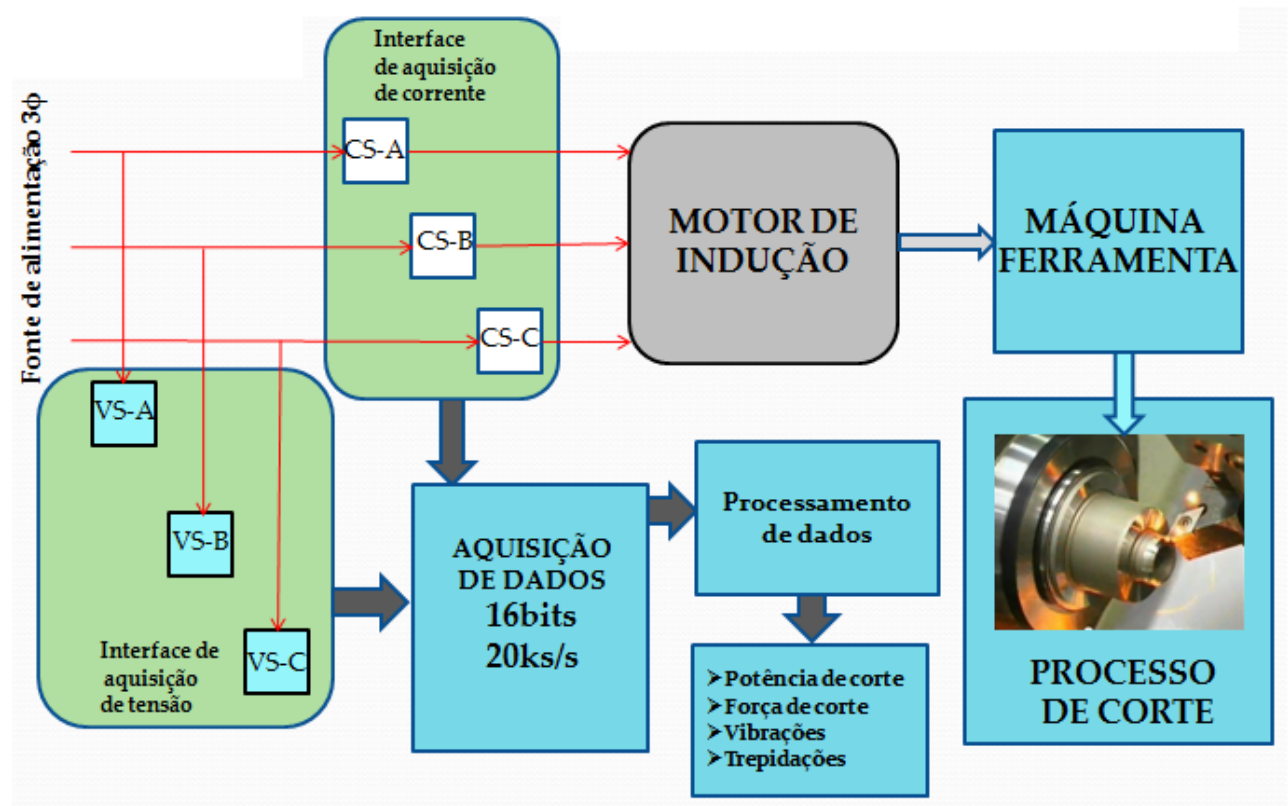

Figura 3.28 Diagrama com a representação de todas as etapas do processo implementado.

Os valores da resistência do estator da máquina foram medidos em cada caso com Rs $=0,4 \Omega$, Rs $=0,43 \Omega$, Rs $=0,47 \Omega$ e Rs $=0,51 \Omega$ para as condições de vazio, $0,5 \mathrm{~mm}, 1,0 \mathrm{~mm}$ e $1,5 \mathrm{~mm}$ respectivamente. O gráfico da figura 3.29 mostra a relação entre a resistência do estator e as corrente eficazes de fase.

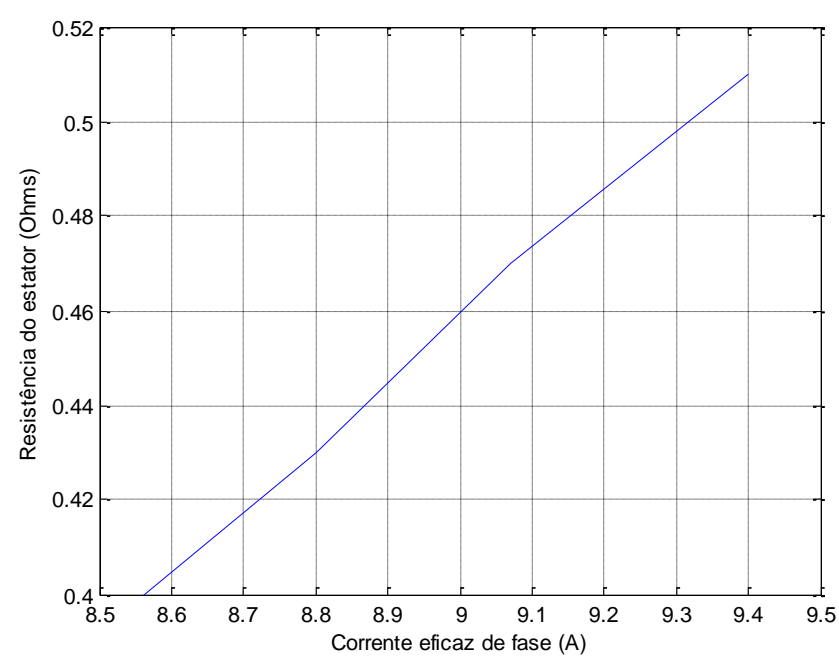

Figura3.29 Comportamento da resistência do estator em função da corrente eficaz de fase a temperatura externa de $24^{\circ} \mathrm{C}$.

Os dados elétricos relativos aos valores instantâneos de tensões e correntes foram obtidos e permitiram a obtensão dos fluxos, suas derivadas 
assim como as correntes instantâneas e suas derivadas e a aplicação das transformadas de Clake permitiram a obtenção das variáveis escalares de eixos direto e de quadratura e assim a aplicação do algoritmo de busca de harmonia de onde obteve-se a tabela 3.3

Tabela 3.3 Parâmetros obtidos com o algoritmo de HS

\begin{tabular}{|c|c|c|c|c|c|c|c|}
\hline $\begin{array}{c}\text { Profundidade } \\
\text { de corte } \\
\text { (passe) }\end{array}$ & $\boldsymbol{x}_{\mathbf{1}}=\frac{\mathbf{1}}{\boldsymbol{\tau}_{\boldsymbol{r}}}$ & $\boldsymbol{x}_{\mathbf{2}}=\boldsymbol{\sigma} \boldsymbol{L}_{\boldsymbol{s}}$ & $\boldsymbol{x}_{\mathbf{3}}=\frac{\boldsymbol{L}_{\boldsymbol{s}}}{\boldsymbol{\tau}_{\boldsymbol{r}}}$ & $\boldsymbol{L}_{\boldsymbol{s}}(\boldsymbol{H})$ & $\boldsymbol{\sigma}$ & $\begin{array}{c}\boldsymbol{R}_{r_{-} \text {aprox }}(\mathbf{\Omega}) \\
\left(\boldsymbol{L}_{\boldsymbol{r}}=\boldsymbol{L}_{\boldsymbol{s}}\right)\end{array}$ & $\mathbf{L m ( \mathbf { H } )}$ \\
\hline Vazio & 4,0536 & 0,00121 & 0,1832 & 0,0452 & 0,0268 & 0,183 & 0,0429 \\
\hline $0,5 \mathrm{~mm}$ & 4,4735 & 0,00109 & 0,1931 & 0,04317 & 0,0223 & 0,193 & 0,0414 \\
\hline $1,0 \mathrm{~mm}$ & 4,7945 & 0,00127 & 0,1777 & 0,04426 & 0,0288 & 0,177 & 0,03995 \\
\hline $1,5 \mathrm{~mm}$ & 3,2610 & 0,00118 & 0,1355 & 0,4156 & 0,0284 & 0,135 & 0,0416 \\
\hline
\end{tabular}

A figura 3.30 mostra os torques medidos na árvore do torno e o torque estimado pelo dinamômetro Kistler montado na torre do torno. O cálculo do torque relativo a força de corte medida pelo dinamômetro Kistler foi realizado considerando o diâmetro da peça presa na placa do torno com $39,9 \mathrm{~mm}$ de diâmetro e portanto com raio de 19,95mm com três profundidades de corte bem definidas. O raio médio de corte ou raio de usinagem em metros é obtido da expressão (3.12).

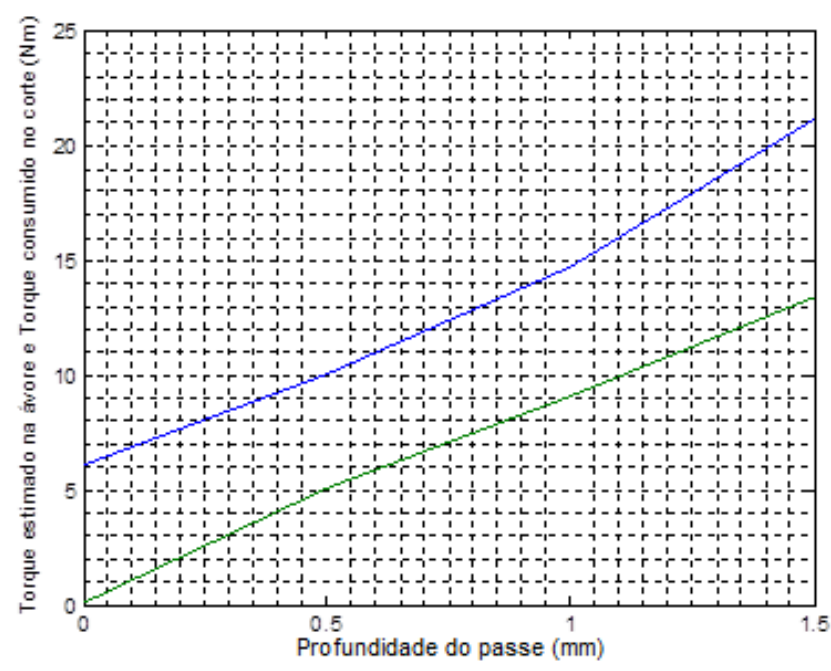

Figura 3.30 - Curvas de torque do dinamômetro (inferior) e do estimador de torque baseado nas quantidades elétricas do motor (superior) 


$$
R_{\text {usin }}=2 \pi\left(R_{\text {peça }}-\frac{p_{\text {passe }}}{2}\right)
$$

Onde $R_{\text {peça }}$ é o raio da peça em usinagem e $p_{\text {passe }}$ é a profundidade do passe na operação de usinagem.

A velocidade da árvore $v_{\text {árvore }}$ em metros por minuto foi medida por um tacômetro Hohner de fundo de escala de 10V/4000rpm que indica que a velocidade de corte na aresta da ferramenta pode ser obtida pela expressão (3.13).

$$
v_{\text {corte }}=2 \pi R_{\text {usin }} V_{\text {taco }} \frac{4000}{10}
$$

Onde $V_{\text {taco }}$ é a tensão medida pelo tacômetro do eixo árvore em volts. Com isso a potência de corte na aresta da ferramenta em kW é dada pela expressão (3.14) (STEMMER, 2005).

$$
P_{\text {corte }}=\frac{F_{\text {corte }} v_{\text {corte }}}{60000}
$$

Onde $F_{\text {corte }}$ é a força de corte medida diretamente pelo dinamômetro Kistler em Newtons, a figura 3.30 mostra a curva de torque do dinamômetro e a curva de torque do estimador de torque baseado nas quantidades elétricas do motor

A relação estatística entre as duas curvas de torque mostram que a correlação entre ambas é bastante forte como mostram as figuras de correlação abaixo.

$$
\begin{aligned}
& R=\left[\begin{array}{cc}
1.000000000000000 & 0.989673084799116 \\
0.989673084799116 & 1.000000000000000
\end{array}\right] \\
& P=\left[\begin{array}{cc}
1.000000000000000 & 0.010326915200884 \\
0.010326915200884 & 1.000000000000000
\end{array}\right]
\end{aligned}
$$

Os valores $\mathrm{P}$ de teste da hipótese de nenhuma correlação mostram que há uma forte correlação entre os valores obtidos $(R=0,99)$ já que $P(i, j)$ é quase 5 vezes menor que 0,05 que é um valor de teste de correlação $R(i, j)$ significativo. A análise realizada acima mostra uma correlação muito forte entre a função relacionada ao torque medido diretamente na peça pelo dinamômetro Kistler e o torque estimado pelo estimador de torque da figura 3.12 . 


\subsubsection{Análise do comportamento da potência}

Na figura 3.30, a potência consumida pelo torno foi obtida a partir do torque estimado pelo estimador de torque da figura 3.12 utilizando um fator de multiplicação relativo ao sistema de redução de velocidade entre o eixo do motor e o eixo árvore. A velocidade da árvore foi medida diretamente por um tacômetro acoplado a mesma. Admitindo que o estimador de torque estime 0 torque efetivo entregue ao processo de acionamento do torno mais usinagem, podemos inferir, já que a potência de corte está sendo medida pelo dinamômetro, que a potência consumida pelo sistema mecânico do torno, somada a potência consumida pelos atritos de movimento do carro no barramento principal pode ser obtida pela relação (3.15).

$$
P_{\text {torno }}=k \omega_{\text {árvore }} T_{\text {estimado }}-\omega_{\text {árvore }} R_{\text {usin }} F_{\text {corte }}
$$

Onde $\omega_{\text {arvore }}$ é a velocidade angular do eixo árvore do torno, $F_{\text {corte }}$ é a força de corte medida pelo dinamômetro Kistler, $R_{u s i n}$ é o raio médio de usinagem da peça no torno dada por (3.12) e $k$ é o fator de transmissão de velocidade entre o eixo do motor e o eixo árvore $(k=3,78)$. É importante observar que $\omega_{\text {arvore }} R_{\text {usin }} F_{\text {corte }}$ medida em Watts, corresponde a $P=$ vcorteFcorte/60000 dada em kW com vcorte estipulada em metros/min.

A figura 3.31 mostra também a potência ativa medida nos terminais do motor, além do comportamento da potência relativa ao sistema do torno no extremo direito da mesma onde o aumento do passe leva também a um aumento da potência no sistema mecânico provavelmente devido ao aumento do atrito do carro longitudinal sobre o barramento principal do torno. Como é possível observar, a potência absorvida pelos sistemas mecânicos do torno é praticamente constante até o passe de $1 \mathrm{~mm}$ de profundidade, mas sofre um aumento relativamente substancial quando o passe é de $1,5 \mathrm{~mm}$ de profundidade, o que demonstra que não há uma proporcionalidade no consumo de potência do torno pelo menos nesta região de menor carregamento do motor, já que a situação de carregamento entre $0,5 \mathrm{~mm}$ e $1,0 \mathrm{~mm}$ gera uma inclinação muito mais discreta na curva de potência. 


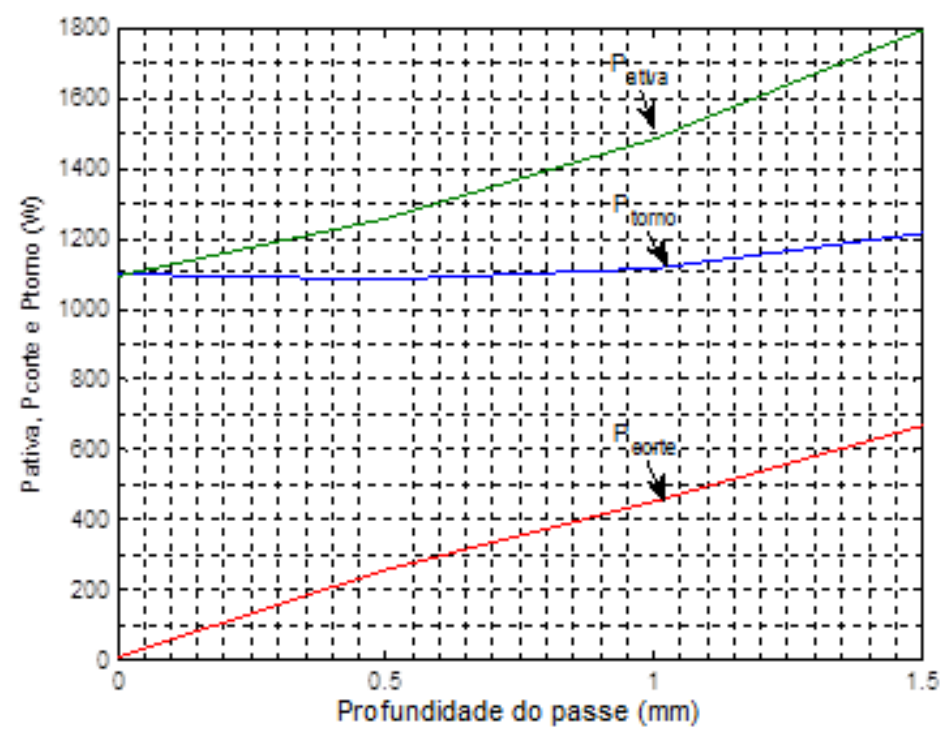

Figura 3.31 Potencia ativa na entrada do motor, potência de corte medida indiretamente pelo dinamômetro e Potência estimada de consumo do torno.

A corrente de equivalentes de fase (linha) medida e estimada utilizando os parâmetros obtidos pelo método aqui utilizado e a expressão (3.7) são mostradas na figura 3.32 em função da profundidade do passe realizado na máquina ferramenta, aqui o erro máximo ocorre com o passe maior e chega a aproximadamente $12 \%$..

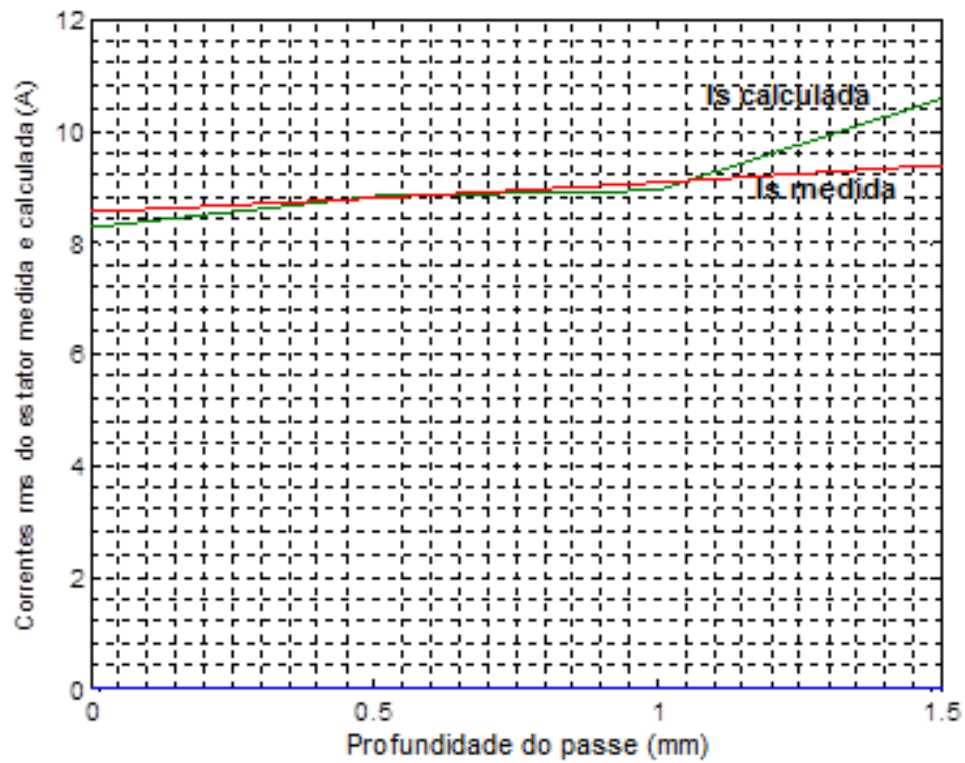

Figura 3.32 - Correntes eficazes medida e calculada utilizando os parâmetros determinados pelo processo descrito. 


\subsubsection{A aplicação do método na previsão da força de corte e potência de corte na aresta da ferramenta no processo de usinagem}

Com base na informação obtida no processo de análise é possível fazer algumas previsões da potência e força de usinagem.

Os parâmetros medidos e estimados permitem calcular a potência mecânica entregue pela rede para o motor, desprezando as perdas no ferro da máquina, estimamos a potência mecânica fornecida pelo motor pela expressão (3.16).

$$
P_{m e c}=P_{a t i v a}-\left(P_{R s}+P_{R r}\right)
$$

Observa-se que esta potência tem um comportamento linear exceto com relação ao seu porto de operação em vazio. Aplicando o método de regressão linear a todos os ponto, exceto ao de operação em vazio, obtemos uma potência mecânica ajustada, o que é mostrado na figura 3.33 .

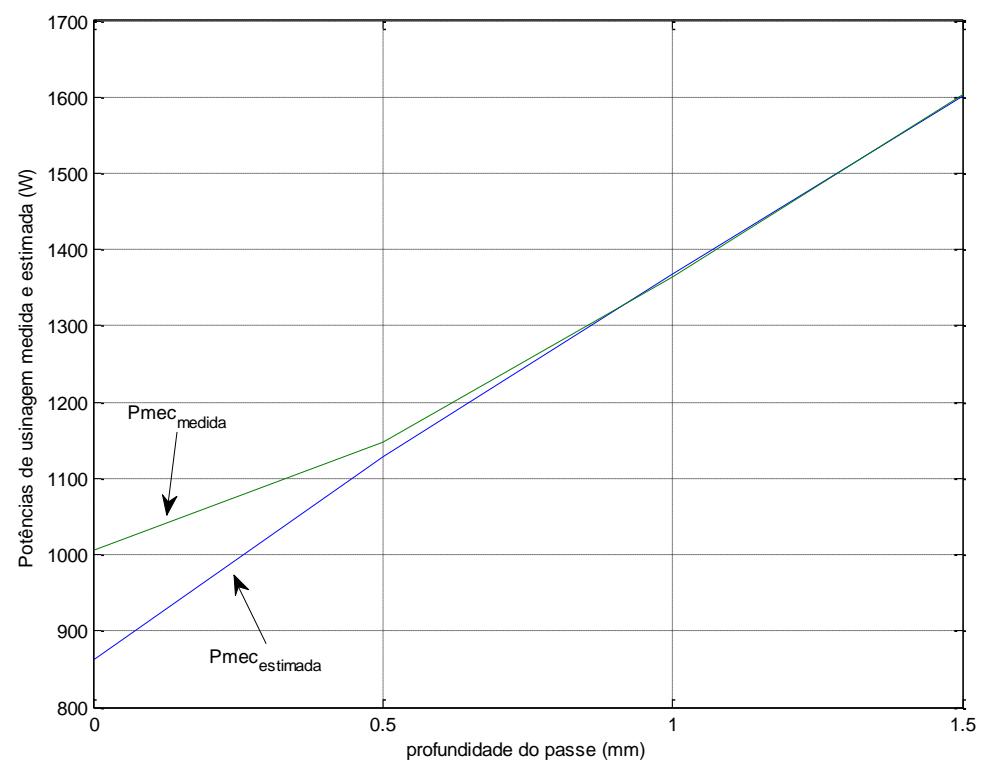

Figura 3.33 Potência mecânica estimada e ajustada

Utilizando o ponto de passagem pela origem como potência consumida pelos mecânicos do torno adicionados com as perdas rotacionais do motor e da máquina ferramenta, podemos escrever a expressão (3.17). 


$$
P_{\text {est }} \text { usinagem }=P_{\text {mec } a j}-P_{m e c_{-} a j_{-} 0}
$$

A comparação entre as potência medidas pelo dinamômetro e a potência estimada pode ser vista na figura 3.34.

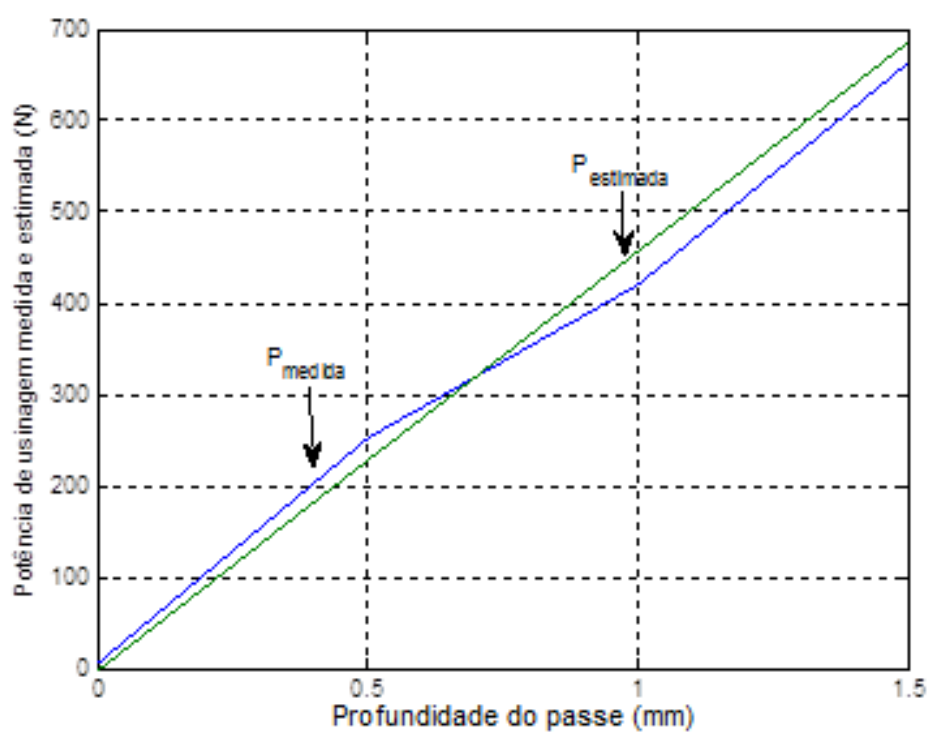

Figura 3.34 As potência medida e estimada

A figura 3.35 mostra porcentual de erro em função do carregamento.

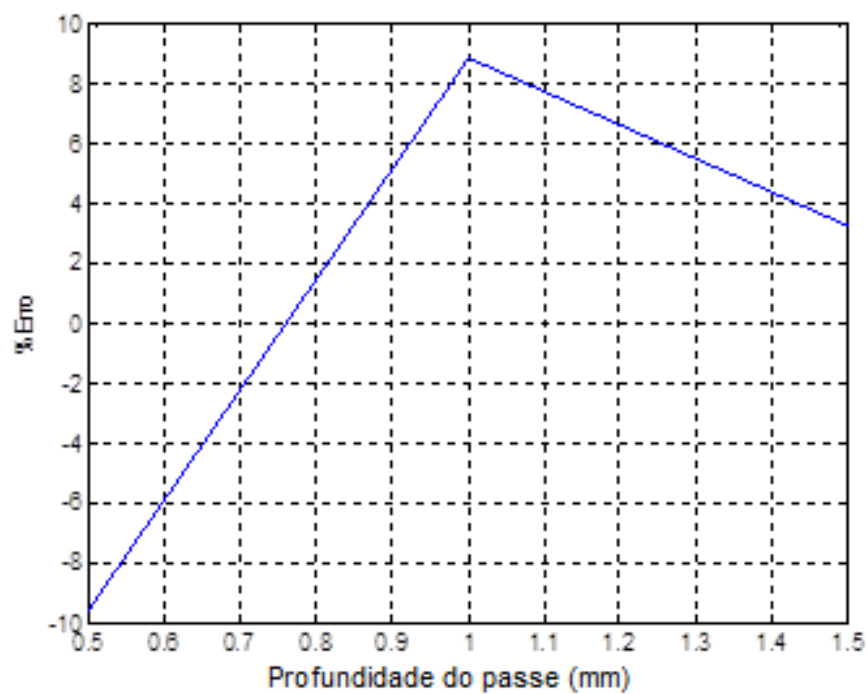

Figura 3.35 Erro porcentual AM função das profundidades dos passe.

As figuras 3.36 (a) e (b) correspondem as mesmas situações analisadas acima, porem considerando a resistência do rotor zero. 


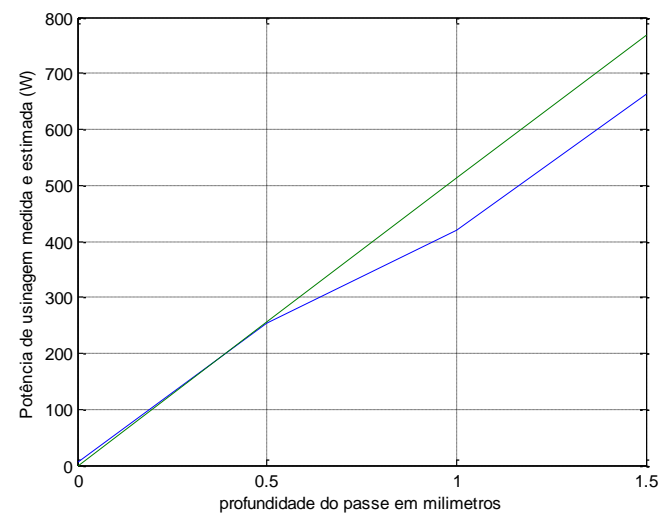

(a)

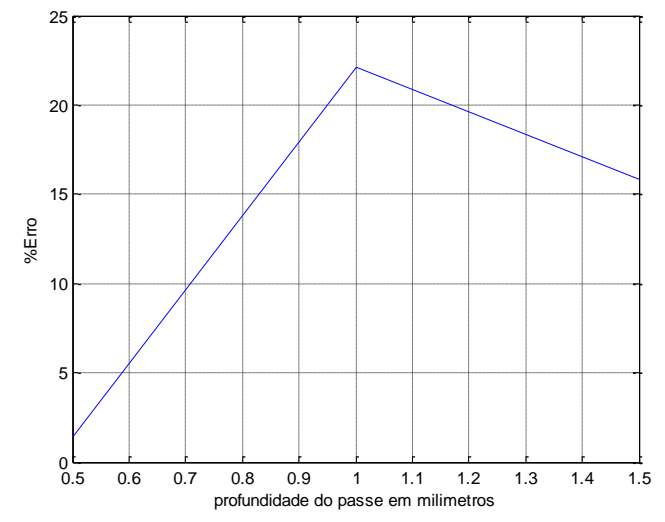

(b)

Figura3.36 (a)Torques estimado (superior) e medido (inferior) e (b) porcentual de erro, as duas situações resultaram de se considerar $R r=0$.

A força de corte pode ser obtida diretamente da relação (3.18).

$$
F_{\text {corte }}=\frac{P_{\text {est_usinagem }}}{R_{\text {usin }} \omega_{\text {arvore }}}
$$

\subsection{Conclusões do capítulo 3}

No capítulo 3 foram apresentados dois testes com motores de indução buscando a estimação do torque com os seguintes resultados:

a) O primeiro estudo foi realizado em uma bancada dinamométrica com maior rigor experimental e o MIT sofreu carregamento de $100 \%$ de modo que toda a faixa de operação do motor foi explorada, os parâmetros do motor foram obtidos por um método baseado na teoria dos vetores espaciais com o uso de um algoritmo de otimização que é uma evolução do método dos algoritmos genéticos. Constatou-se que as perdas rotacionais do motor são relativamente constantes e as perdas Joules em Rs e Rr que são quadráticas devem ser conhecidas para diminuir o erro de estimação do torque e consequentemente da potência na carga. O método permite estimar a velocidade do MIT com precisão bastante razoável, com as seguintes conclusões:

- Erro absoluto máximo de estimação de potência menor que 2,5\%.

- Erro absoluto máximo de estimação torque menor 3,6\%.

- Erro máximo de estimação velocidade menor que $0,4 \%$ no melhor método. 
De onde se conclui que o método é razoavelmente bom em laboratório.

b) O segundo estudo foi realizado utilizando um torno no LFS da engenharia mecânica da POLI/USP e o estudo resumiu-se a trabalhar com três profundidades de passe o que contrasta com a situação anterior onde utilizou-se 10 posições distribuídas até $100 \%$ de carregamento, neste caso o motor trabalhou muito pouco carregado, o fator de potência máximo não chegou a 0,5 e a potência máxima medida na entrada do motor foi de aproximadamente $1,8 \mathrm{~kW}$ com para um motor de $8 \mathrm{CV}(5,9 \mathrm{~kW})$. Aplicou-se a mesma metodologia para a determinação dos parâmetros e as principais constatações foram:

- Na faixa de carregamento utilizada as perdas rotacionais são relativamente constantes, o que é similar ao primeiro caso, mas esta é uma constatação quase pontual devido ao pequeno carregamento do MIT.

- Dentro da faixa de erro de estimação de potência com relação a potência medida no dinamômetro Kistler o erro absoluto máximo é menor que $10 \%$

- Quando Rr é desprezado e apenas Rs é levado em consideração nas mesmas condições que o caso anterior, o erro absoluto máximo na faixa de potência estimada é maior que $20 \%$.

De onde se obtém uma das respostas para as perguntas iniciais do capítulo 1, é possível estimar a potência de corte na aresta da ferramenta de corte, utilizando medições de tensão e corrente na entrada de energia do MIT com o auxílio de um sistema de processamento, com um erro máximo menor que $10 \%$, mas os resultados obtidos em laboratório indicam que esta precisão pode ser bastante melhorada. 
Análise das vibrações de uma máquina ferramenta utilizando os dados de um dinamômetro Kistler com a transformada de Fourier

As vibrações oriundas do processo de usinagem decorrem de uma multiplicidade de processos com origens na própria máquina ferramenta, no porta-ferramenta, no processo de usinagem em si e em outras condições inerentes ao material que compõe a peça, comprimento da mesma, profundidade do passe de usinagem, ângulo de corte da ferramenta, etc.

A análise realizada neste trabalho é do tipo operacional, uma vez que esta parte do trabalho está baseada em experimentações realizadas na própria máquina ferramenta, que ao contrário do método modal pressupõe um estudo mais generalizado. Os testes realizados foram do tipo contínuo e interrompido e as análises foram realizadas utilizando a transformada de Fourier (FFT).

\subsection{Teste com dinamômetro Kistler em operação de corte contínuo}

O material utilizado em todos os testes deste capítulo foi uma barra cilíndrica de aço 52100 com diâmetro nominal de $39,9 \mathrm{~mm}$ nas seguintes condições de corte:

- Taxa de amostragem $=1000$ amostras por segundo, dados de 16 bits.

- Velocidade de corte $(\mathrm{Vc})=70,54 \mathrm{~m} / \mathrm{mm}$

- Velocidade nominal do eixo árvore $(\mathrm{Nar})=450 \mathrm{rpm}$

- Velocidade de avanço da ferramenta $(\mathrm{Vf})=46,8 \mathrm{~mm} / \mathrm{min}$ 
- Avanço da ferramenta $(\mathrm{f})=0,104 \mathrm{~mm} /$ volta

- A profundidade de corte foi fixada nos valores $0,5 \mathrm{~mm}, 1,0 \mathrm{~mm}$ e $1,5 \mathrm{~mm}$.

\subsubsection{O perfil da usinagem com passe de $0,5 \mathrm{~mm}$ de profundidade}

\subsubsection{Análise da região sem a ação de usinagem (em vazio)}

A figura 4.1 mostra o perfil das forças de corte, de avanço e passiva para o caso de usinagem com passe de profundidade de $0,5 \mathrm{~mm}$ entre os tempos de $2,8 \mathrm{~s}$ a $11 \mathrm{~s}$ aproximadamente, sendo que as regiões entre 0 s e $2,8 \mathrm{~s}$ e $11 \mathrm{~s}$ e $14 \mathrm{~s}$ exibem o perfil das forças vistas pelo dinamômetro em vazio.

Como a operação em vazio traduz um comportamento oscilatório natural da própria máquina ferramenta, foi realizada nestas regiões uma análise espectral com a finalidade de detectar oscilações que possam estar presentes também nas regiões onde ocorrem usinagens.

Os valores médios das três forças nas regiões em vazio são mostrados na tabela 4.1

Tabela 4.1 Forças médias do dinamômetro em vazio

\begin{tabular}{|l|c|}
\hline Força de corte (vazio) & $6,09 \mathrm{~N}$ \\
\hline Força de avanço (vazio) & $14,12 \mathrm{~N}$ \\
\hline Força passiva (vazio) & $14,66 \mathrm{~N}$ \\
\hline
\end{tabular}

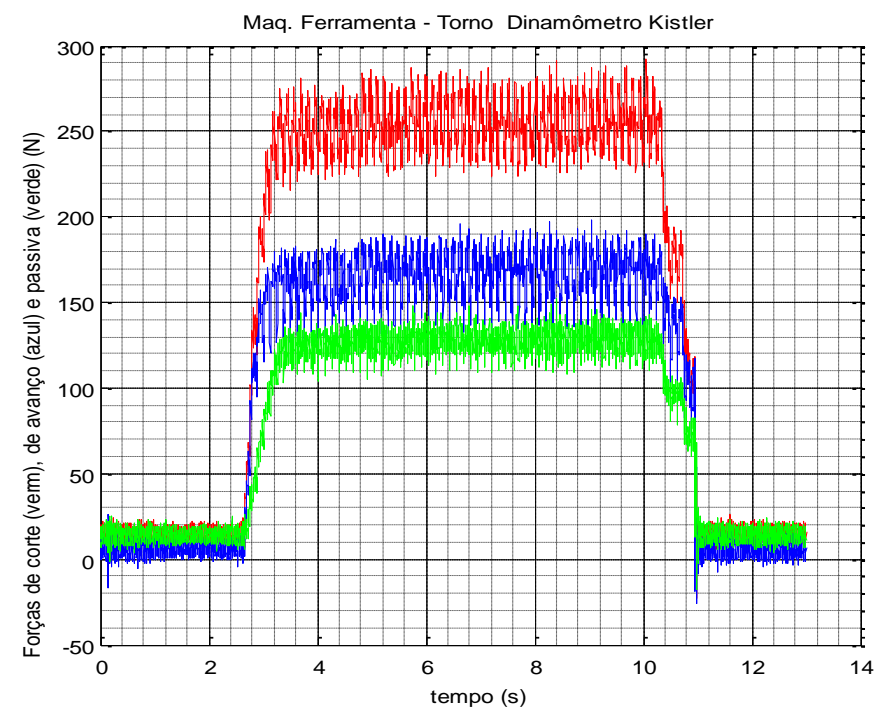

Figura 4.1 Perfil das forças da UCP de 0,5mm 
A figura 4.2 mostra o perfil dos sinais gerados pelo dinamômetro Kistler na região em que o mesmo opera em vazio, sem o efeito de qualquer usinagem. Já as figuras 4.3, 4.4 e 4.5 mostram os espectros das três forças na região em vazio obtidas para efeito comparativo com as oscilações na região de usinagem.

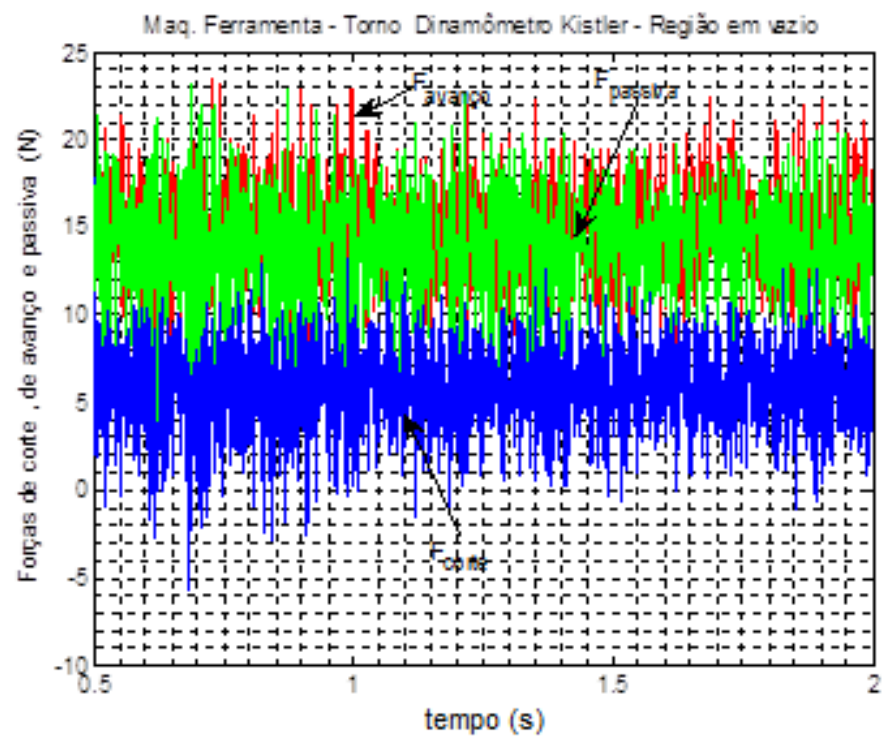

Figura 4.2 Perfil das três forças na região com dinamômetro em vazio.

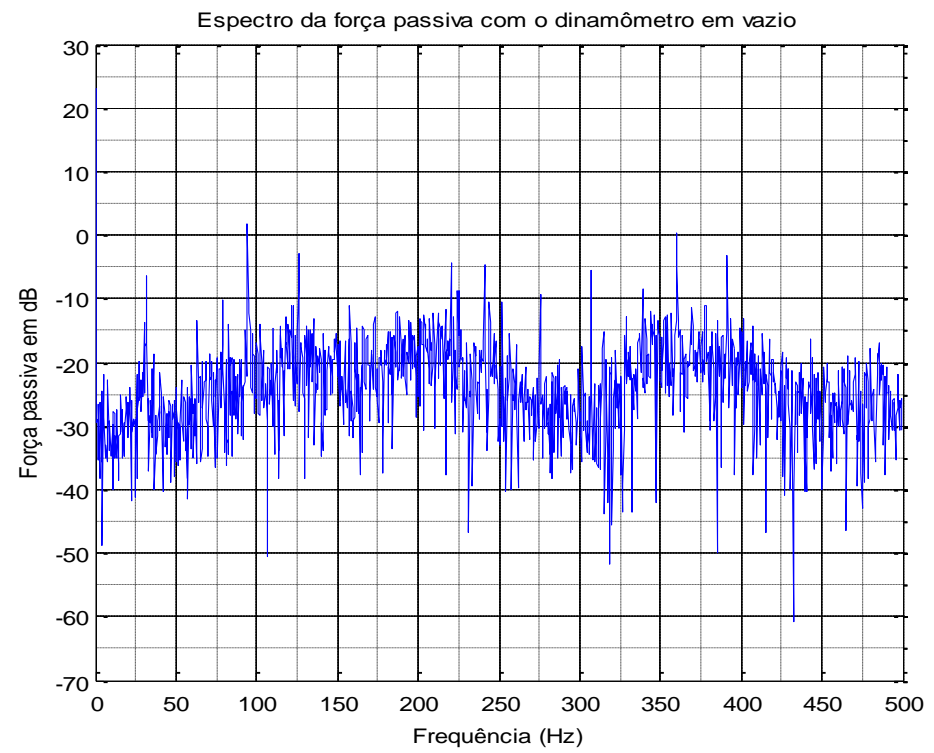

Figura 4.3 Espectro da força passiva em vazio 


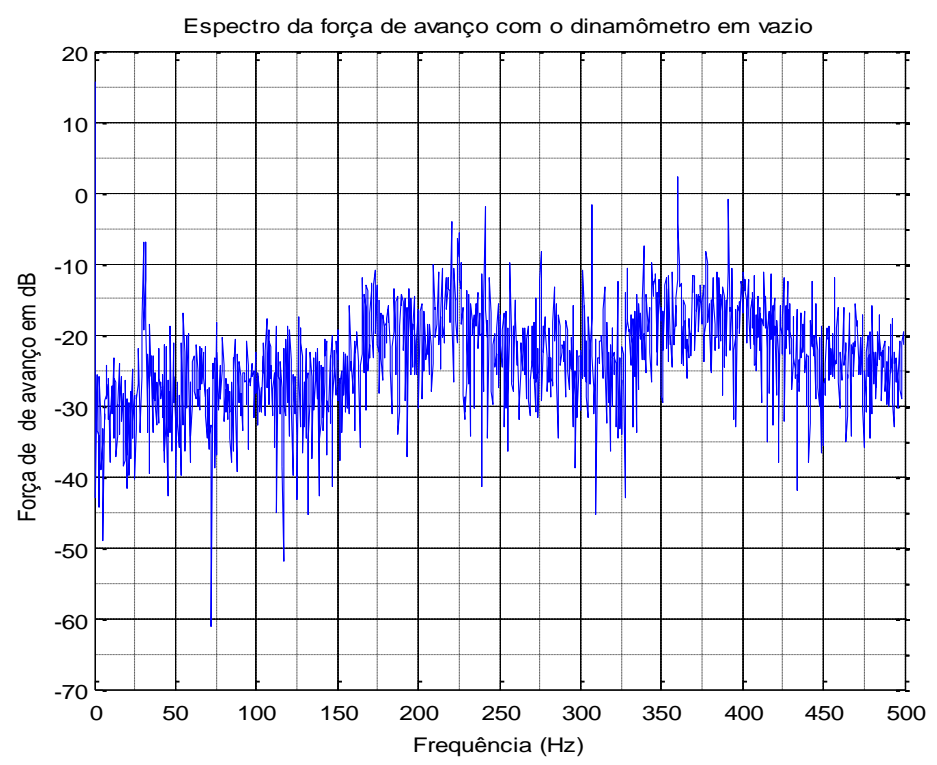

Figura 4.4 Espectro da força de avanço em vazio,

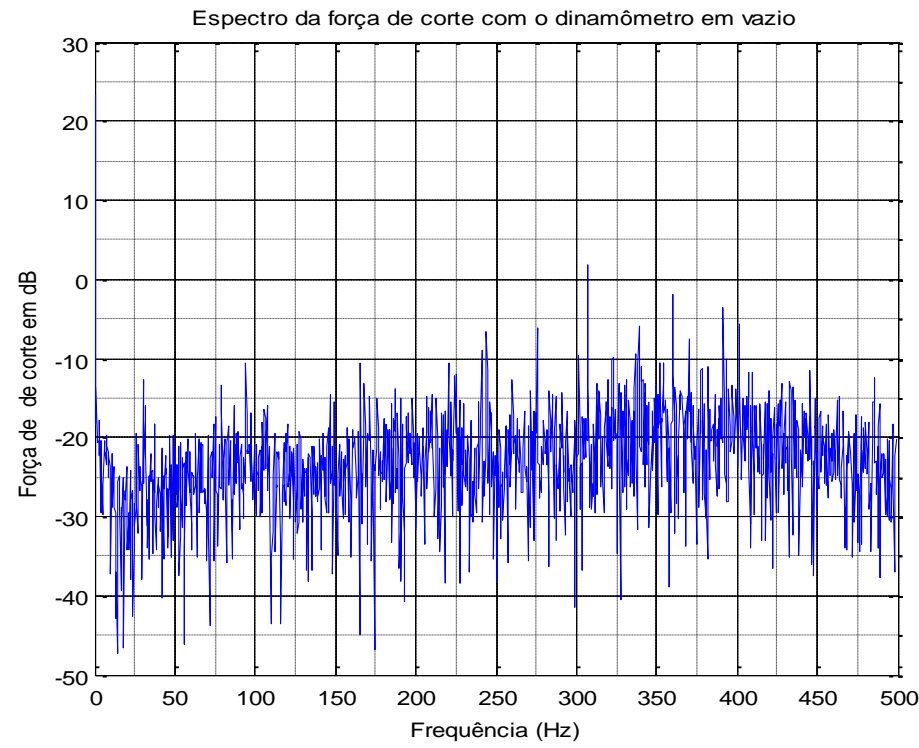

Figura 4.5 Espectro da força de corte em vazio

Os gráficos das figuras 4.3, 4.4 e 4.5 foram obtidos com o carro da máquina ferramenta em movimento e portanto exibem um comportamento vibratório similar ao de um acelerômetro de três eixos fixados no carro longitudinal da máquina.

A região de usinagem mostrada na figura 4.1 mostra que ocorrem efeitos vibratórios bastante diferenciados nas forças de corte e de avanço, que apresentam uma oscilação de baixa frequência evidente, em relação a força 
passiva, cuja distribuição espectral é mais uniforme ao longo da região de usinagem. A tabela 4.2 mostra os valores médios e o torque médio de corte na região de usinagem.

Tabela 4.2 Forças médias do dinamômetro com passe de $0,5 \mathrm{~mm}$

\begin{tabular}{|l|l|}
\hline Força de corte & $255,56 \mathrm{~N}$ \\
\hline Força de avanço & $168,19 \mathrm{~N}$ \\
\hline Força passiva & $128,16 \mathrm{~N}$ \\
\hline Torque de corte & $6,376 \mathrm{Nm}$ \\
\hline
\end{tabular}

A figura 4.6 mostra uma parte efetiva da região de usinagem, que ocorre entre os períodos de 4 a 9s, que é a região que foi utilizada para a análise dos espectros das forças que atuam sobre o dinamômetro. O comportamento oscilatório das forças de corte e de avanço é evidente na própria figura 4.6

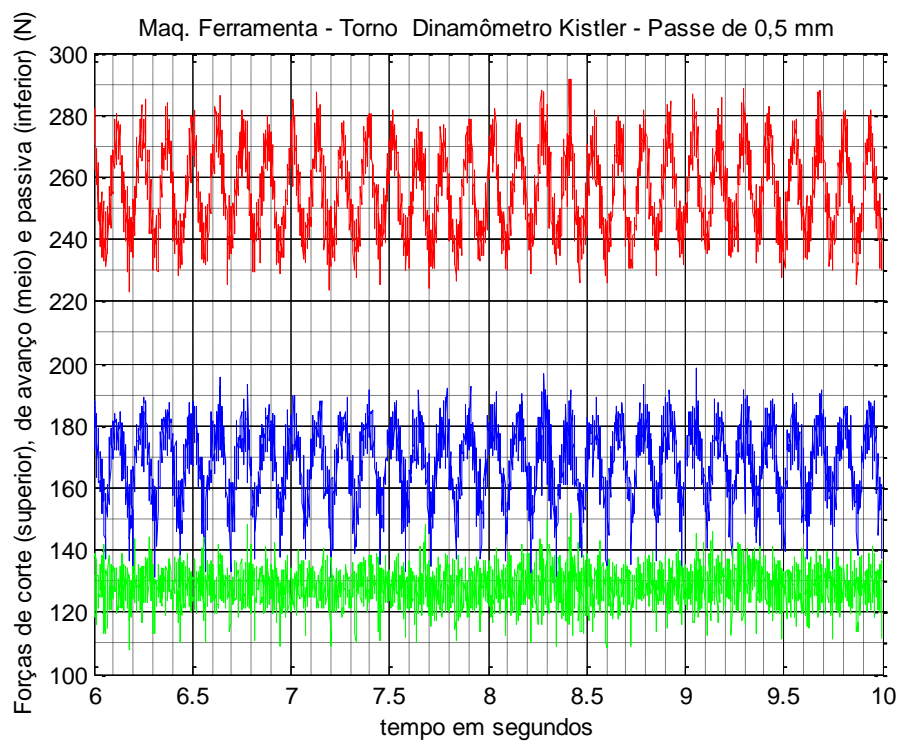

Figura 4.6 Gráfico das forças de corte (superior) e de avanço (inferior) do teste na região de UCP de $0,5 \mathrm{~mm}$.

Observa-se que o torno tem uma vibração de baixa frequência por volta de $8 \mathrm{~Hz}$, observa-se também do espectro que os três eixos vibram com várias componentes, mas existe um componente de $360 \mathrm{~Hz}$ em todos os eixos que predomina na forçam de avanço, em termos oscilatórios, mas esta presente também com magnitude razoável nos outros dois eixos. 


\subsubsection{Análise da força de corte}

A análise espectral da força de corte da figura 4.6 é mostrada na figura 4.7, onde ficam evidentes duas frequências dominantes cujos entornos têm os detalhes mostrados nas figuras 4.8, 4.9, 4.10 e 4.11 .

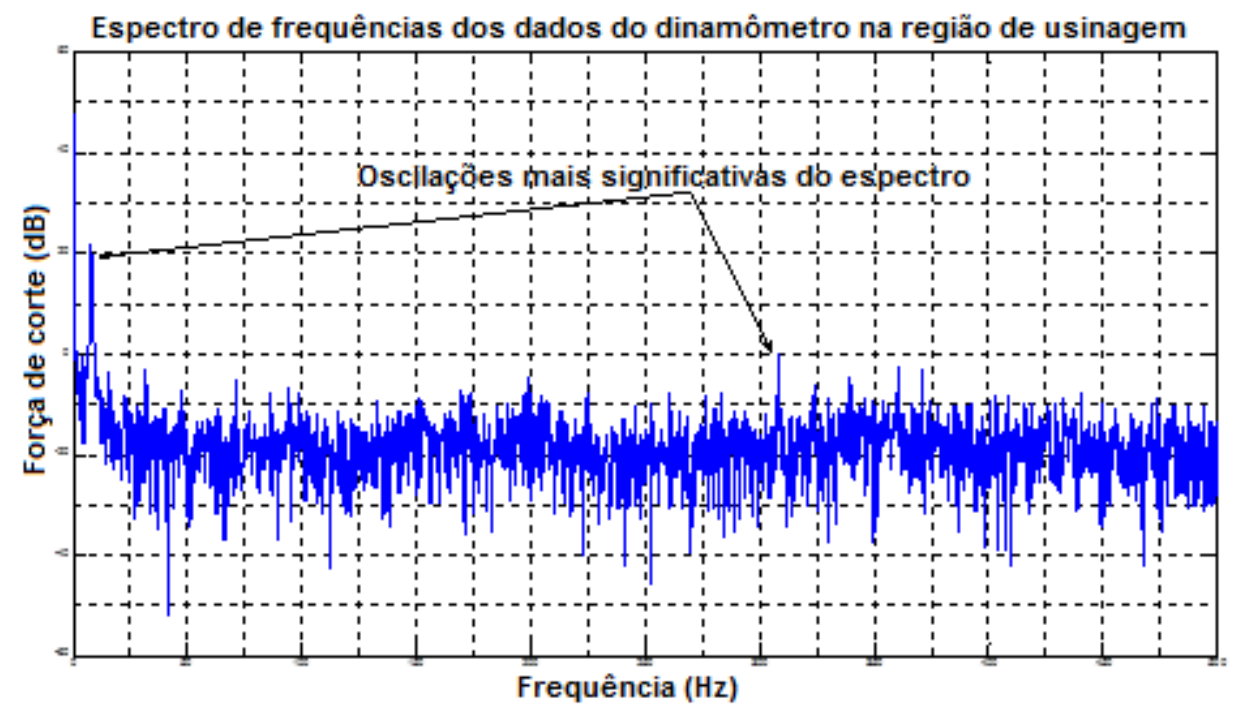

Figura 4.7 Diagrama espectral da força de corte para o caso da UCP de $0,5 \mathrm{~mm}$

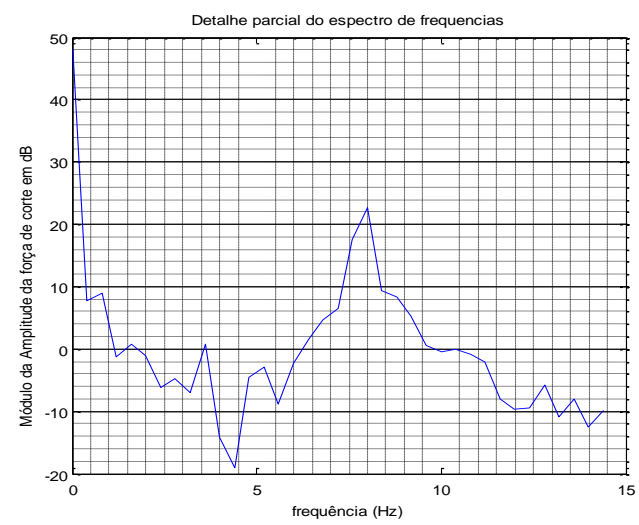

(a)

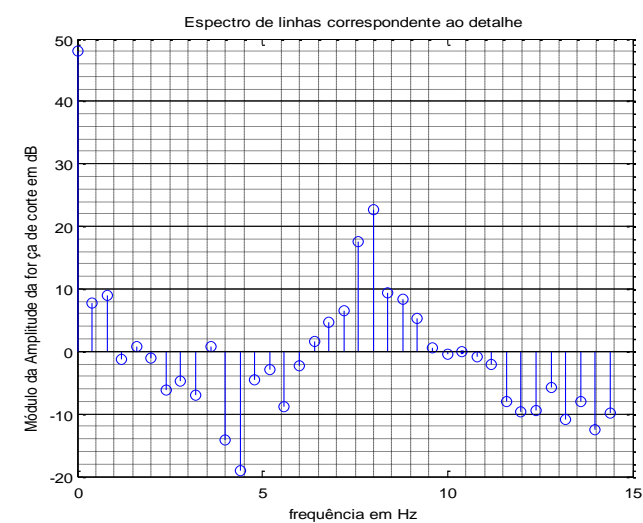

(b)

Figura 4.8 Espectro contínuo (a) e de linhas (b) da região de baixas frequências da UCP de $0,5 \mathrm{~mm}$.

Uma parcela do espectro contínuo e de linhas é mostrado nas figuras 4.8(a) e 4.8(b) respectivamente, onde a existência de componentes no entorno de uma componente central de $8 \mathrm{~Hz}$ demonstra que existem componentes 
periódicas nesta região do espectro com frequência central de $8 \mathrm{~Hz}$ e lóbulos laterais irregulares com espaçamento de $0,4 \mathrm{~Hz}$ o que demonstra uma oscilação periódica com múltiplas componentes harmônicas com provável modulação por amplitude modulada (AM). A figura 4.9 mostra um sinal estimativo relacionado com o espectro da figura 4.8. A estimação indica uma modulação de baixa frequência da ordem de $1,8 \mathrm{~Hz}$ também mostrada nas figuras 4.8 , juntamente com uma frequência de cerca de $0,9 \mathrm{~Hz}$ também correlata a esta última. Ao que tudo indica são essas componentes que modulam a frequência central de $8 \mathrm{~Hz}$ gerando suas bandas laterais em um efeito multiplicador.

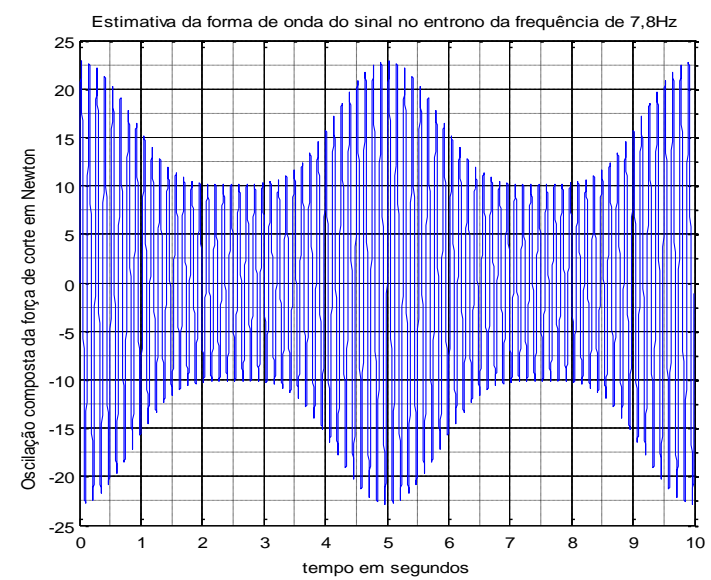

Figura 4.9 Estimativa da composição do sinal modulado de $8 \mathrm{~Hz}$ mostrado na figura 4.8(b).

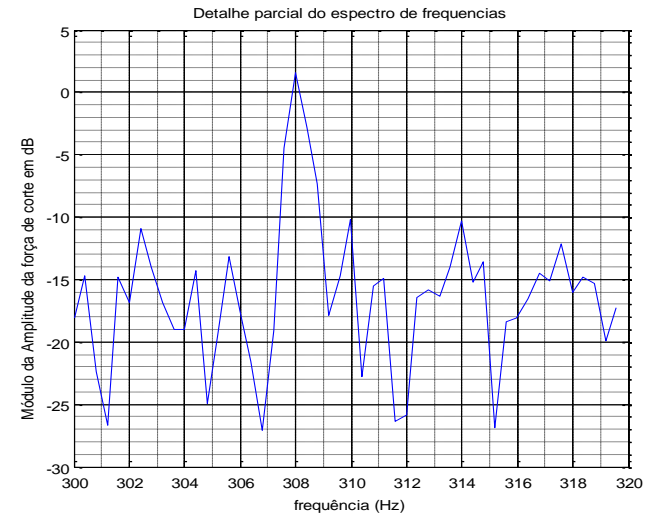

(a)

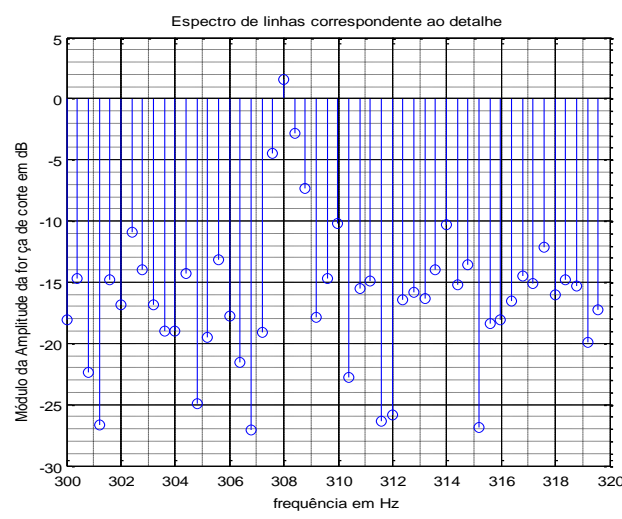

(b)

Figura 4.10 Espectro contínuo (a) e de linhas (b) da região de frequências mais altas do espectro do dinamômetro Kistler 
Ocorre uma oscilação significativa aparentemente mono harmônica próximo a frequência de $308 \mathrm{~Hz}$ como se vê na figura 4.10 , mas sua magnitude é bastante pequena o que a torna pouco relevante.

\subsubsection{Análise da força de avanço}

Objetivando a generalização da análise do comportamento das duas principais forças que interagem no comportamento da força de usinagem, realizou-se também, uma análise da força de avanço obtida com 0 dinamômetro Kistler, embora seja notório que esta força reflete muito pouco na potência absorvida pela operação de usinagem da máquina ferramenta. $A$ figura 4.11 mostra o espectro da força de avanço para o caso de corte com profundidade de $0,5 \mathrm{~mm}$.

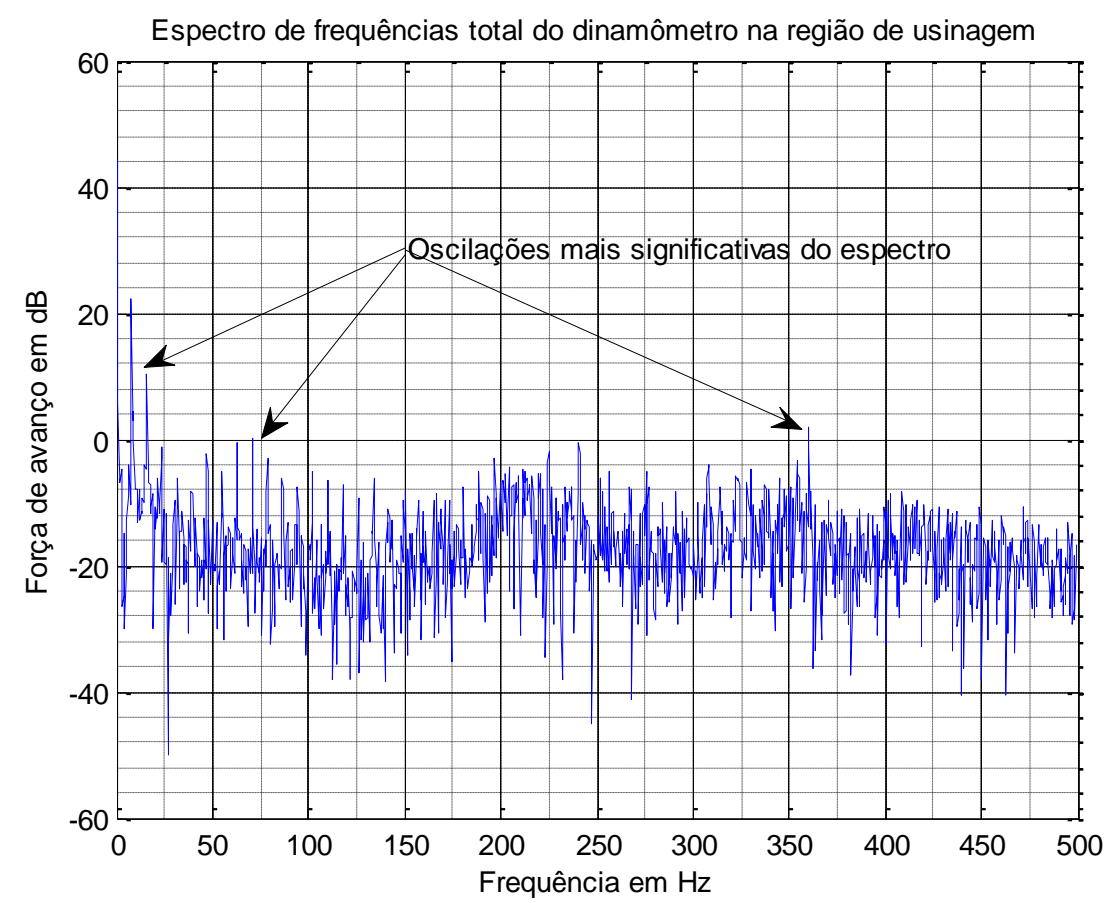

Figura 4.11 Espectro da força de avanço da UCP de 0,5mm.

$\mathrm{Na}$ figura 4.11, observa-se que o conteúdo oscilatório da força de avanço é superior ao da força de corte, isso decorre, além do efeito de usinagem em si, dos vários elementos utilizados na transmissão de força entre o elemento motriz da máquina e o carro longitudinal, que embora não tenham ação direta sobre a força de avanço medida pelo dinamômetro, tem ação 
indireta na interação da operação de deslocamento do carro longitudinal no qual se situa a máquina ferramenta e no qual refletem as ações de todos os mecanismos que ativam o movimento longitudinal da máquina ferramenta.

As figuras 4.12 (a) e (b) mostram as componentes do espectro contínuo e de linha, respectivamente da força de avanço na região de frequências mais baixas do espectro, que é similar ao obtido no espectro da frequência de corte, com exceção de uma componente mono harmônica próximo a $16 \mathrm{~Hz}$ e uma composição harmônica menor no entorno da frequência de $8 \mathrm{~Hz}$.

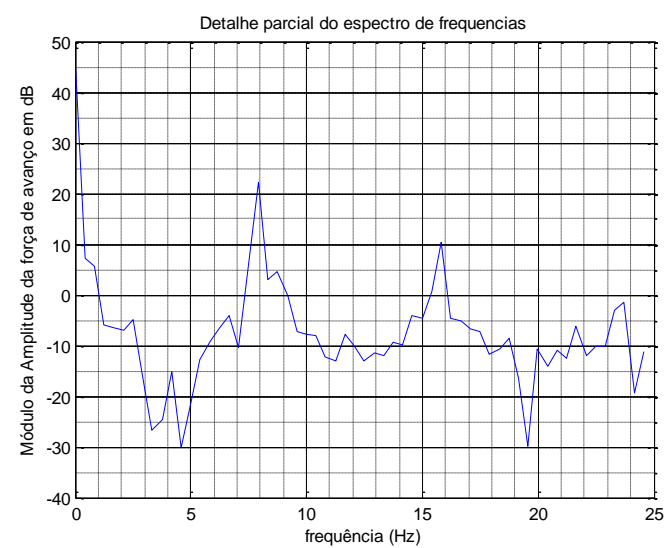

(a)

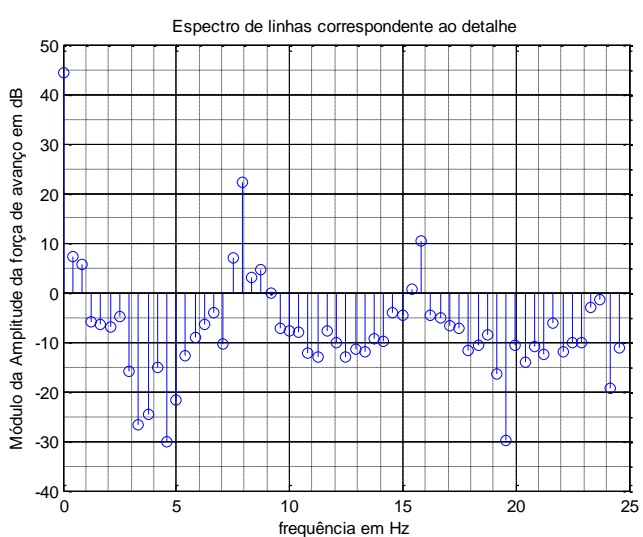

(b)

Figura 4.12 Espectro contínuo (a) e de linhas (b) da força de avanço para a UCP de $0,5 \mathrm{~mm}$ em baixas frequências.

A figura 4.13 exibe um grupo de componentes de maior energia no entorno de $47 \mathrm{~Hz}$, embora a amplitude das componentes deste entorno não seja a de maior amplitude, o conjunto apresenta uma composição mais consistente com amplitude próxima a -2dB, e é mostrado no círculo vermelho da figura 413. O espectro apresenta outras componentes na mesma região, mas com menor energia e estão relacionadas com os mecanismos da máquina ferramenta, já que o espectro da força de corte na região correlata não mostra esses efeitos. 


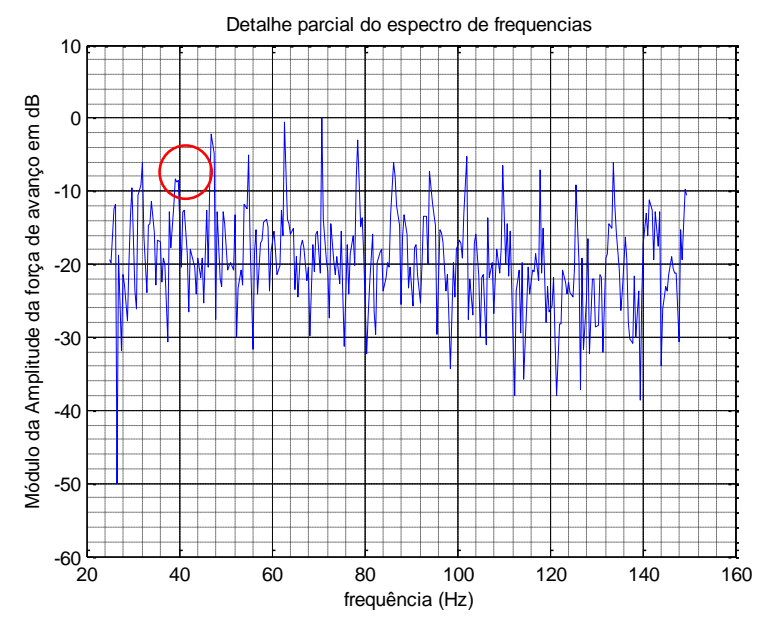

Figura 4.13 Detalhe parcial do espectro da força de corte mostrando uma concentração de energia no entorno das frequências $40 \mathrm{~Hz}$ a $66 \mathrm{~Hz}$.

As figuras 4.14 (a) e (b) mostram que ocorre uma componente mono harmônica na frequência de $360 \mathrm{~Hz}$. Componentes nesta frequência estão relacionadas com o batimento entre a $5^{\mathrm{a}}$ e a $7^{\mathrm{a}}$ harmônica geradas pelo motor de indução da máquina ferramenta, isso é detectado com maior detalhe pelo estimador de torque mencionado no capítulo 3 desse trabalho.

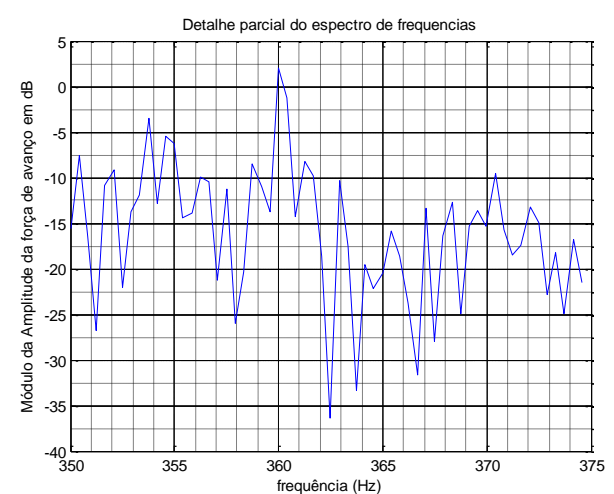

(a)

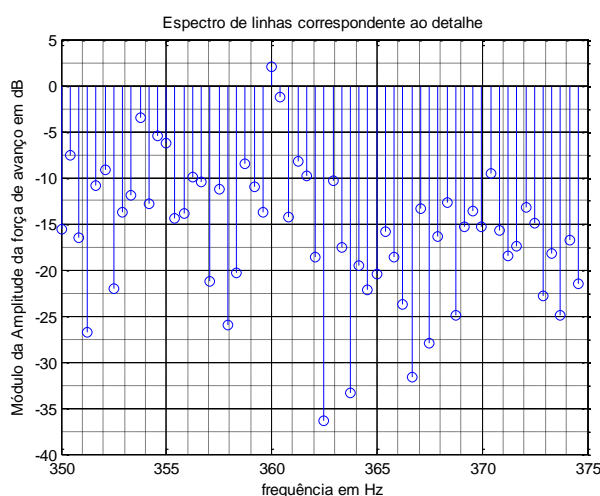

(b)

Figura 4.14 Espectro contínuo (a) e de linhas (b) da força de avanço para a usinagem com profundidade de $0,5 \mathrm{~mm}$ nas frequências mais altas.

A figura 4.15 mostra que, embora de baixa intensidade ou baixa quantidade de energia (Teorema de Parseval), existe uma concentração de maior energia nas regiões do espectro de frequências mais altas entre $190 \mathrm{~Hz}$ e $240 \mathrm{~Hz}$. 


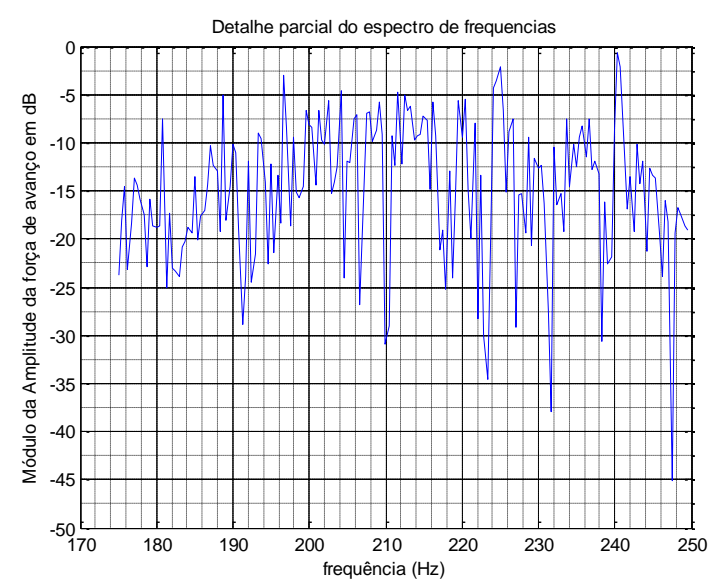

Figura 4.15 Região de maior concentração de energia nas frequências mais altas do espectro.

\subsubsection{Análise da UCP de $1,0 \mathrm{~mm}$}

Este teste foi realizado com um período de tempo de usinagem um pouco menor que os outros (5s), o perfil obtido para as três forças obtidas é mostrado na figura 4.16 e os valores médios dessas três forças e o torque médio de corte efetivo no eixo árvore na região efetiva de usinagem são dados na tabela 4.3. A partir da figura 4.8 é possível observar que a saída da ferramenta do processo de corte foi relativamente lenta gerando um pequeno patamar no final da operação de usinagem, esse fato não representou efeito algum no processo de análise uma vez que a região de sinal escolhida para a realização da mesma situa-se na região central onde o efeito da operação de usinagem é mais regular.

Tabela 4.3 Forças médias do dinamômetro com passe de $1,0 \mathrm{~mm}$

\begin{tabular}{|l|c|}
\hline Força de corte & $457,94 \mathrm{~N}$ \\
\hline Força de avanço & $315,86 \mathrm{~N}$ \\
\hline Força passiva & $134,46 \mathrm{~N}$ \\
\hline Torque de corte & $11,42 \mathrm{Nm}$ \\
\hline
\end{tabular}

A relação entre solicitações de forças nos dois testes demonstra que 0 aumento da força passiva, no segundo teste é de apenas $4,7 \%$, enquanto que da força de avanço é $87,8 \%$ e na força de corte $79,2 \%$, o que mostra que nesta 
situação o aumento da força de avanço é ligeiramente maior que o da força de corte.

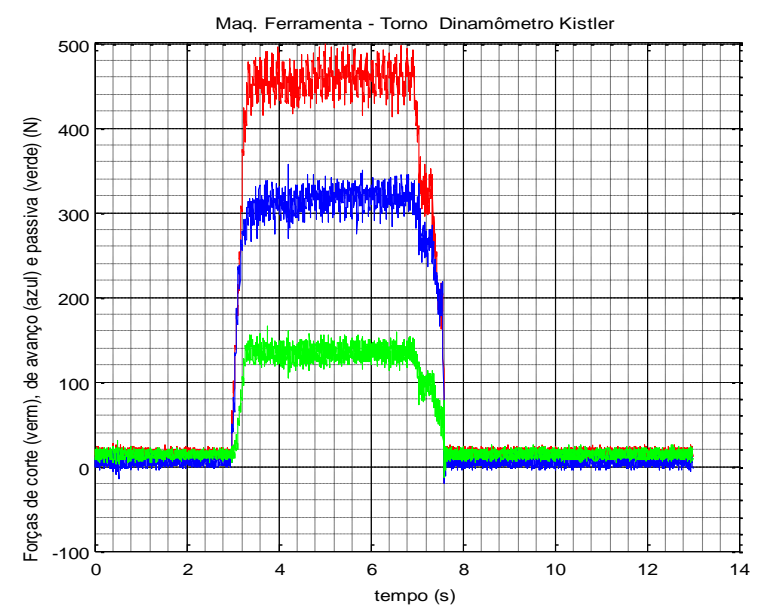

Figura 4.16 Perfil das forças de usinagem para passe de 1,0mm.

A figura 4.17 mostra a região de usinagem útil entre $4 \mathrm{~s}$ e $6,5 \mathrm{~s}$ do perfil mostrado na figura 4.17 e pode-se notar claramente o efeito oscilatório de baixa frequência de aproximadamente $8 \mathrm{~Hz}$ que superpõe os valores médios das forças de corte e de avanço.

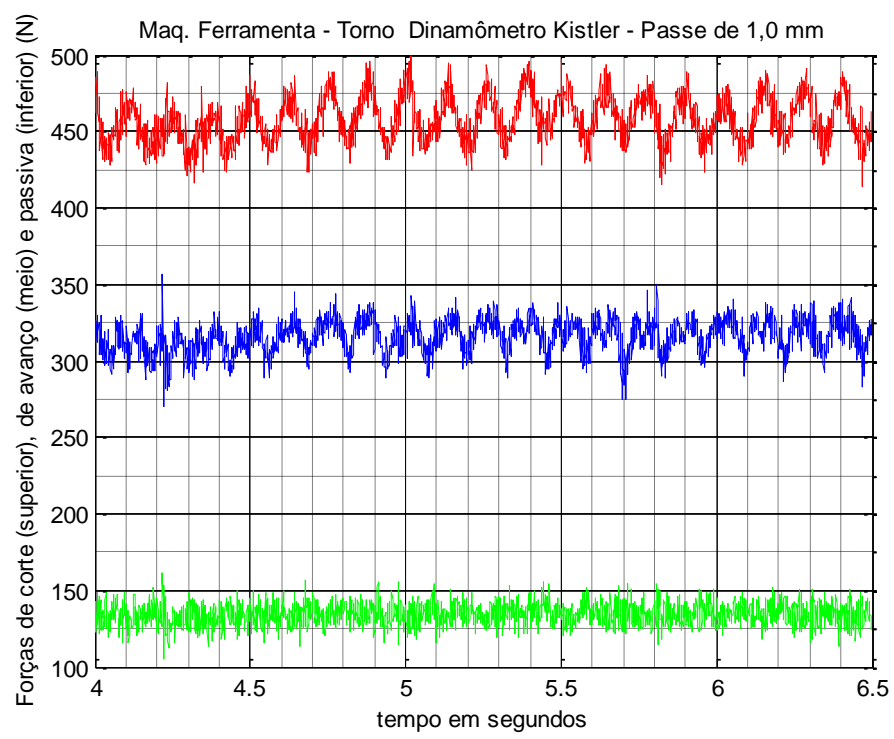

Figura 4.17 Gráfico das forças de corte (superior) e de avanço (inferior) do teste na região de usinagem com profundidade de $1,0 \mathrm{~mm}$. 


\subsubsection{Análise da força de corte}

A análise espectral da força de corte, mostrada na figura 4.18 indica, que além da força de corte média, cujo valor aproximado no gráfico é de $53 \mathrm{~dB}$, que corresponde a $458 \mathrm{~N}$, a existência de uma oscilação estacionária dominante de aproximadamente $8 \mathrm{~Hz}$ e $22 \mathrm{~dB}(12 \mathrm{~N})$ no perfil da força de corte, como este fenomeno já foi observado no caso do corte com profundidade de $0,5 \mathrm{~mm}$, a primeira conjectura sobre a origem do fenomeno, é a de que se trata de uma oscilação natural do sistema porta-ferramenta-usinagem.

Uma análise mais pormenorizada das componentes espectrais de baixas frequências permite a observação da composição dessas componentes para uma comparação com o mesmo efeito observado na usinagem com profundidade de $0,5 \mathrm{~mm}$. As figuras $4, .19$ (a) e 4.19 (b) mostram os espectros contínuo e de linhas desta região do espectro.

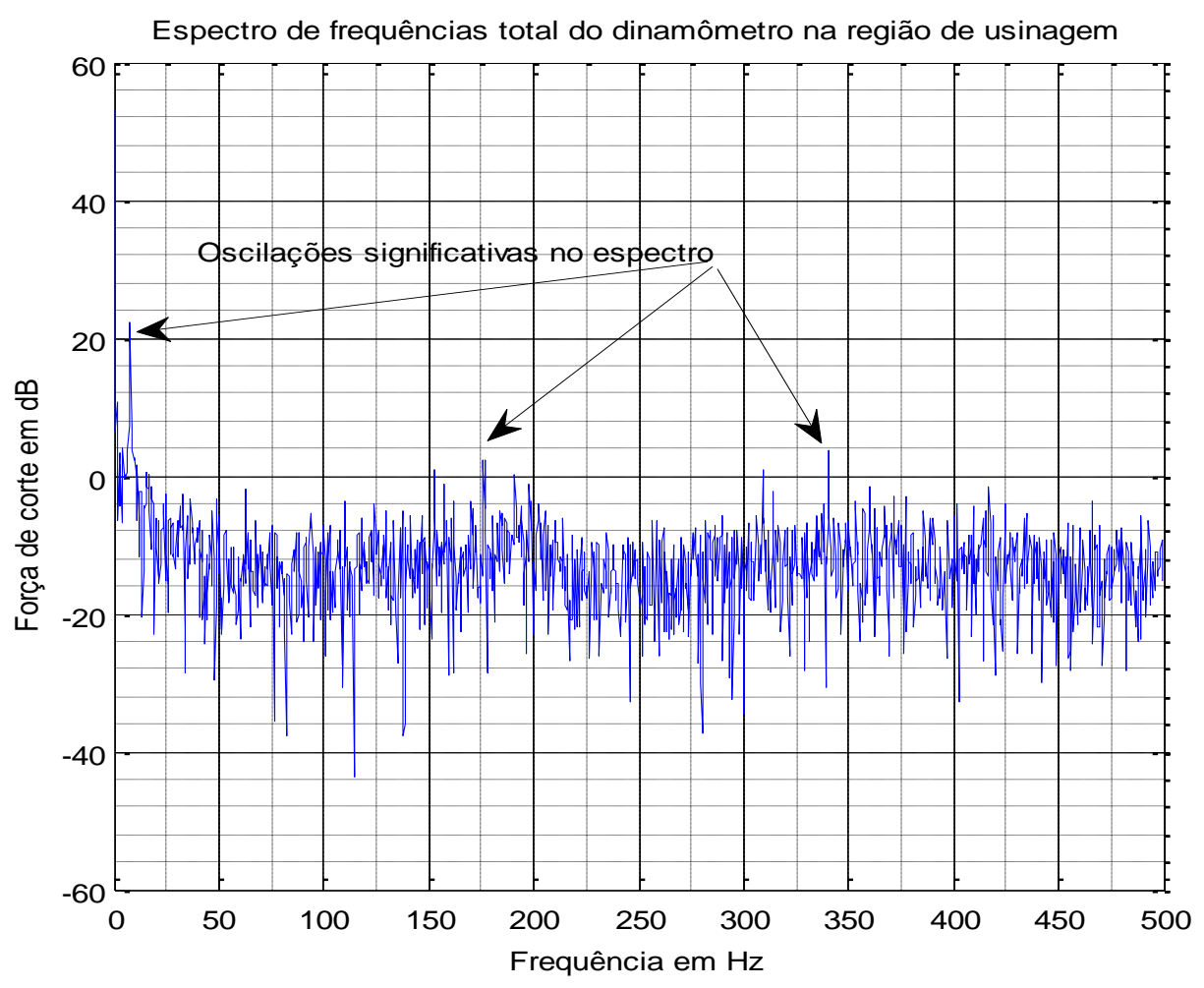

Figura 4.18 Espectro da força de corte na região de usinagem 


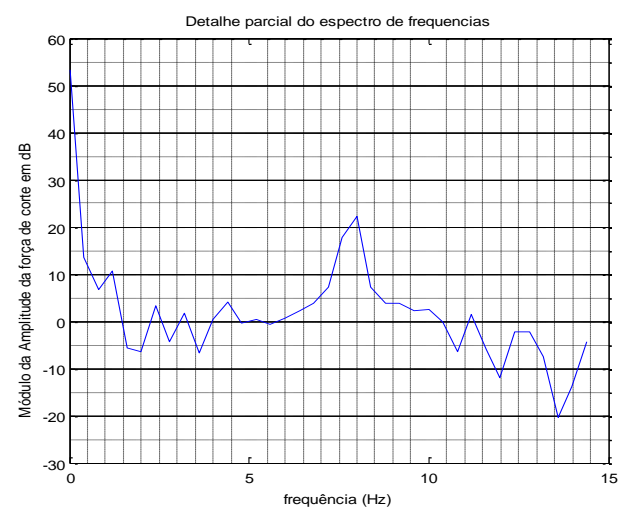

(a)

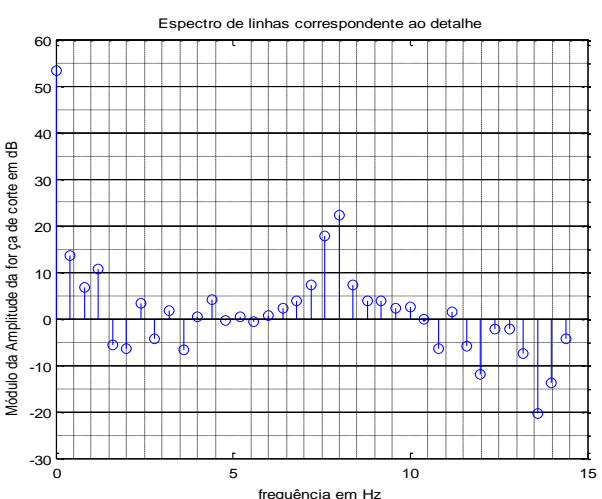

(b)

Figura 4.19 Espectro contínuo (a) e de linhas (b) correspondente ao espectro da figura 4.18 com detalhes das componentes de frequências mais baixas.

As figuras 4.20(a) e 4.20(b) mostram os detalhes das componentes do espectro de linhas da figura 4.21(b) onde na parte de frequências mais baixas mostrada na figura 4.21 (a) observa-se três componentes de $14 \mathrm{~dB}$ e $0,4 \mathrm{~Hz}$, $12 \mathrm{db}$ e $0,8 \mathrm{~Hz}$ e $11 \mathrm{~dB}$ e $1,2 \mathrm{~Hz}$.

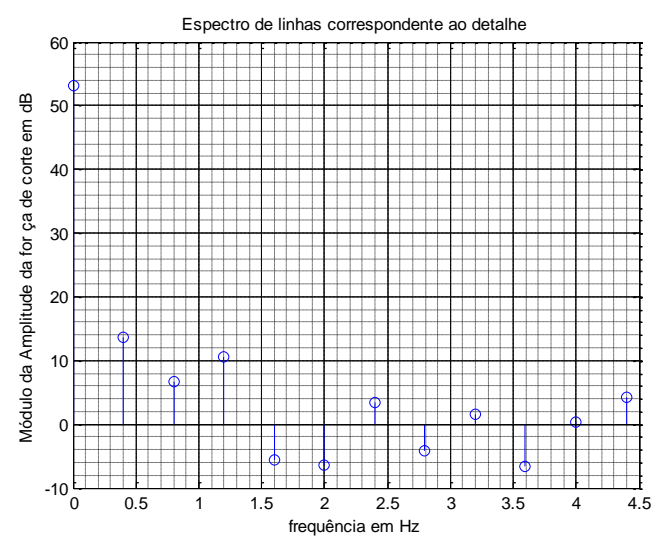

(a)

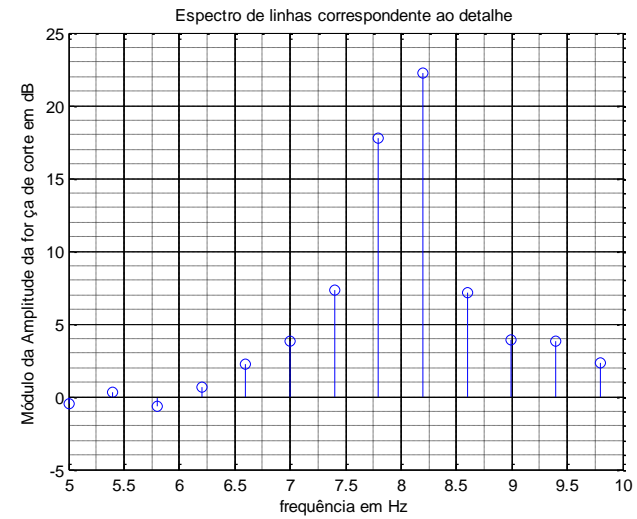

(b)

Figura 4.20 O espectro de linhas correspondente ao detalhamento de componentes do espectro mostrado na figura 4.19(b).

A composição espectral demonstra que a oscilação no entorno da frequência de $8 \mathrm{~Hz}$ não é mono harmônica, portanto trata-se, pelo menos em termos estacionários, de uma oscilação com formato de uma série temporal com um formato que, matematicamente pode ser modelado por:

$$
S_{c}(t)=\left(12,6+\sum_{n=1}^{N} k_{n} \cos (2 \pi n \Delta f t)\right) \cos (2 \pi 7,8 t)
$$


Onde $\Delta f$ é a distância entre a portadora e a componente lateral no espectro de frequência modulada, 12,6 é a amplitude da componente de $7,8 \mathrm{~Hz}$ e $k_{n}$ é a amplitude das componentes laterais.

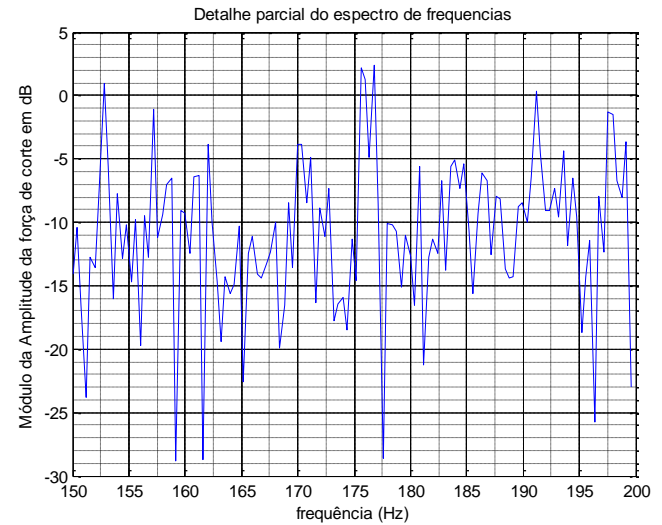

(a)

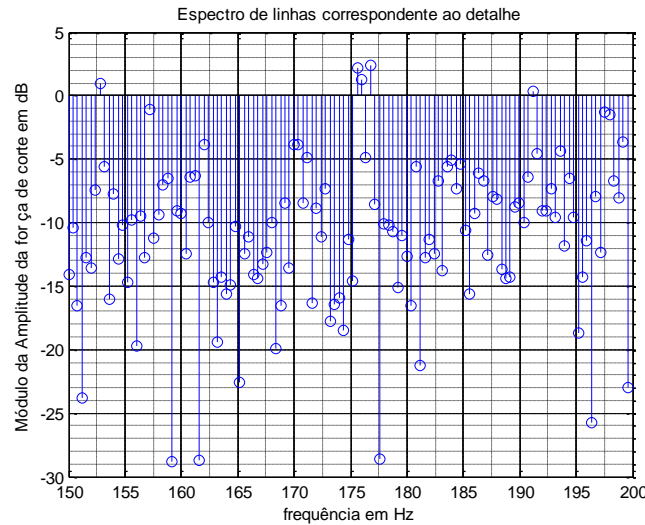

(b)

Figura 4.21 Espectro contínuo (a) e de linhas (b) da região entre $150 \mathrm{~Hz}$ e $200 \mathrm{~Hz}$ onde ocorre uma oscilação mais significativa no espectro.

As figuras 4.21(a) e 4.21(b) mostram detalhes do espectro próximos a frequência de $176 \mathrm{~Hz}$, onde se pode observar que existem oscilações com composição harmônica composta por três componentes.

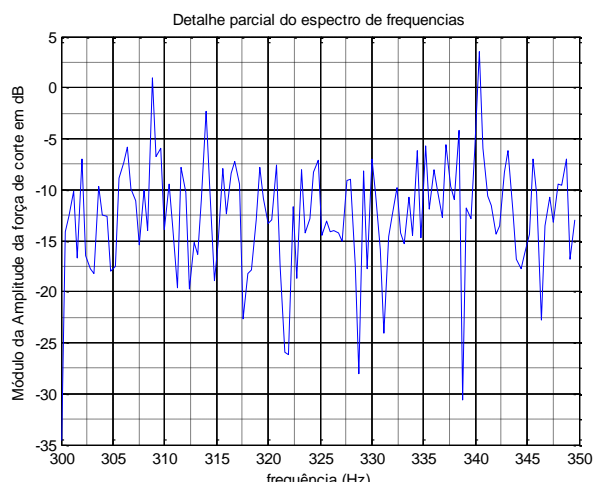

(a)

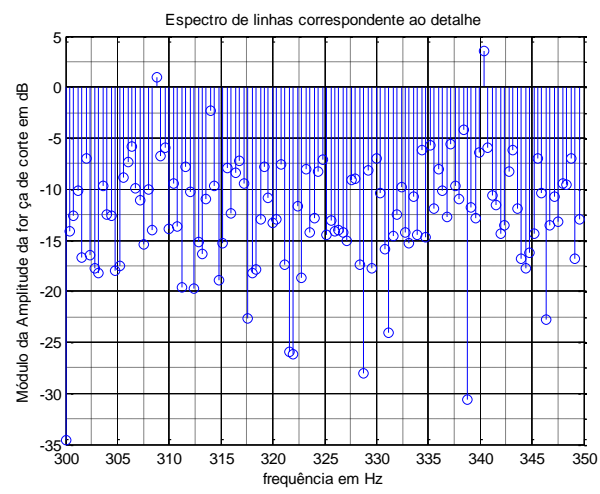

(b)

Figura 4.22 Espectro contínuo (a) e de linhas (b) da região entre $300 \mathrm{~Hz}$ e $350 \mathrm{~Hz}$ onde ocorre outra oscilação significativa no espectro.

\subsubsection{Análise da força de avanço}

A figura 4.23 mostra o espectro completo da força de avanço para a situação de corte com profundidade de $1,0 \mathrm{~mm}$. O que se observa na figura é 
que ocorre um deslocamento do conjunto de frequências entre $200 \mathrm{~Hz}$ e $225 \mathrm{~Hz}$ (observado na figura 4.11) para a esquerda, ocupando uma região com frequência centrada em aproximadamente $200 \mathrm{~Hz}$, a direção do deslocamento é mostrado por uma seta na figura 4.23 .

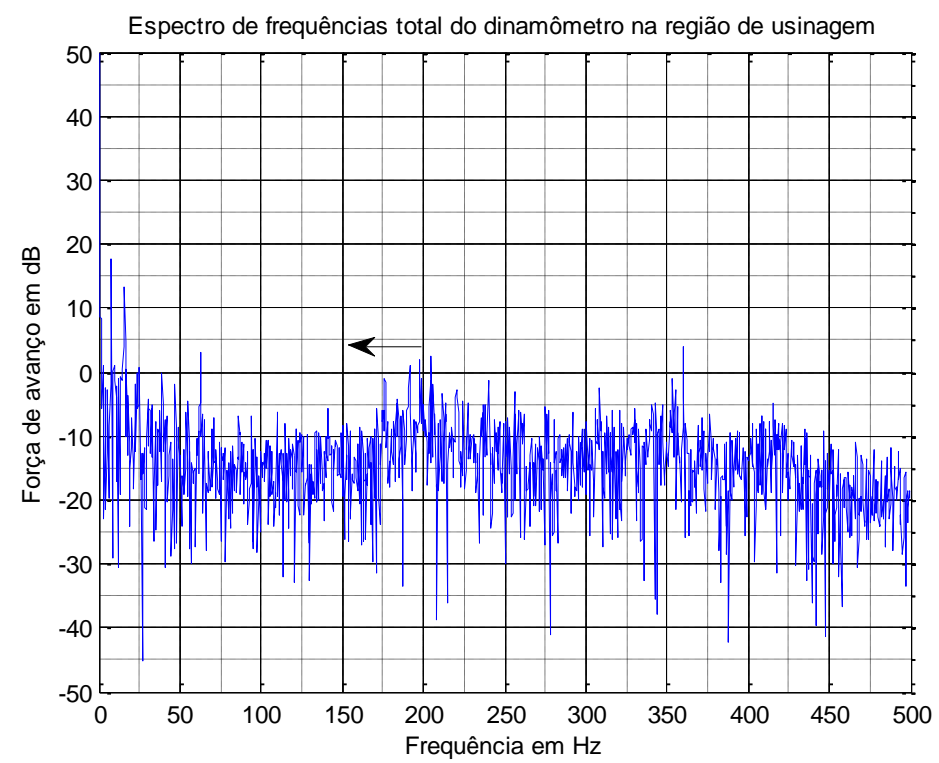

Figura 4.23 Espectro completo da força de avanço para a situação de UCP de 1,0mm

Um outro detalhe do espectro da figura 4.24 é o aparecimento ou concentração de energia na região entre $150 \mathrm{~Hz}$ e $225 \mathrm{~Hz}$ como é mostrado nas figuras 4.24(a) e (b). A composição harmônica é relativamente simples

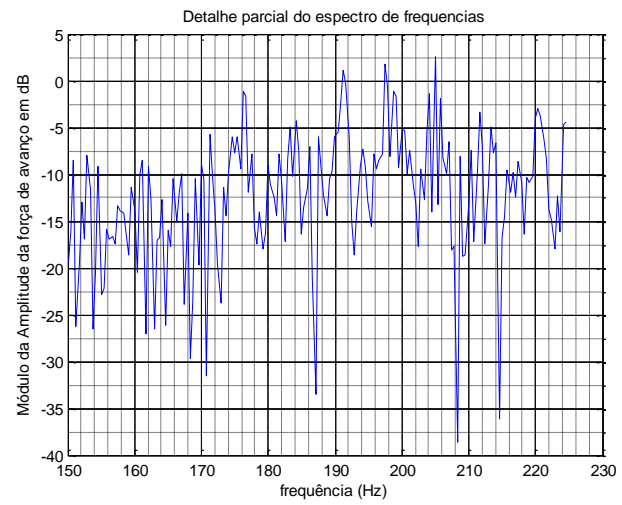

(a)

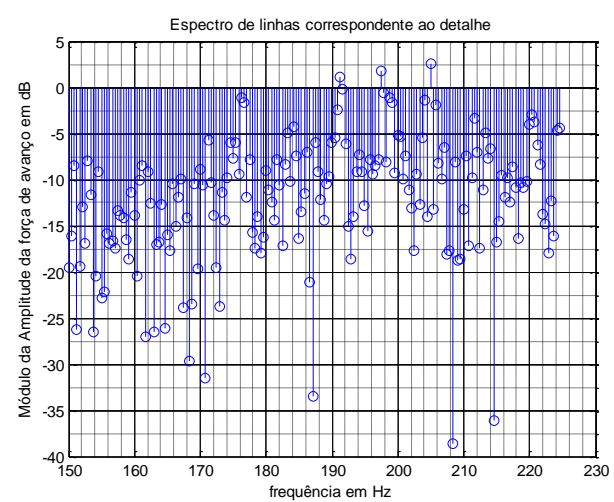

(b)

Figura 4.24 Espectro contínuo (a) e de linhas (b) da região entre $150 \mathrm{~Hz}$ e $225 \mathrm{~Hz}$ da força de avanço. 


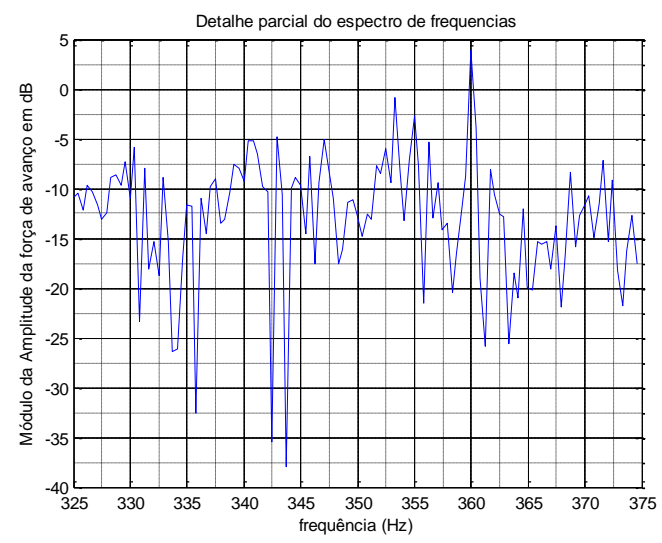

(a)

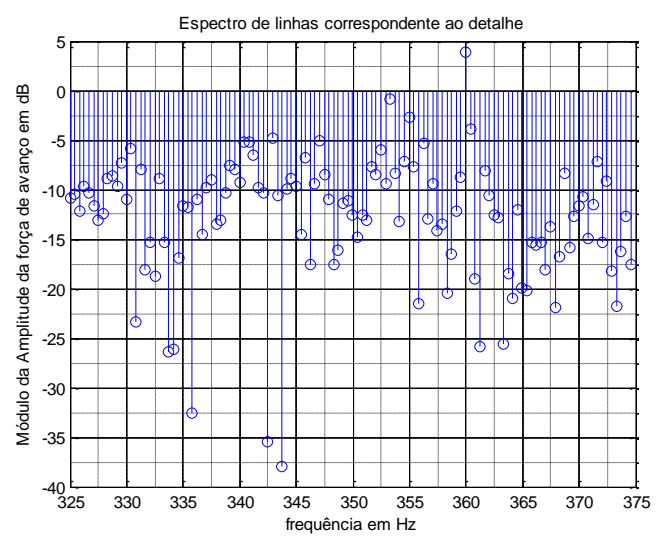

(b)

Figura 4.25 Espectro contínuo (a) e de linhas (b) da região entre $325 \mathrm{~Hz}$ e $375 \mathrm{~Hz}$ da força de avanço.

A análise do espectro da força de avanço do caso de corte com profundidade de $1,0 \mathrm{~mm}$ com relação ao caso de corte de $0,5 \mathrm{~mm}$ mostra que ocorre uma concentração de energia em algumas frequências e manutenção da energia em outras frequências como é o caso da componente de $360 \mathrm{~Hz}$ mostrada nas figuras 4.25 (a) e (b). Esta componente tem origem elétrica nas 5aㅡ e 7a harmônicas da corrente de alimentação do motor de indução.

\subsubsection{Análise da UCP de 1,5mm}

Este teste foi realizado com um período de tempo de usinagem um pouco maior que $8 \mathrm{~s}$, o perfil obtido para as três forças obtidas é mostrado na figura 4.26 e os valores médios dessas três forças e o torque médio de corte efetivo no eixo árvore na região efetiva de usinagem são dados na tabela 4.3. A partir da figura 4.26 é possível observar uma perturbação nas forças passiva e de corte medidas pelo dinamômetro um pouco antes do início da operação de usinagem, mas que não se reflete na força de avanço e consequentemente está relacionada ao processo de manuseio da máquina ferramenta.

Tabela 4.4 Forças médias do dinamômetro com passe de $1,5 \mathrm{~mm}$

\begin{tabular}{|l|c|}
\hline Força de corte & $672.90 \mathrm{~N}$ \\
\hline Força de avanço & $471.76 \mathrm{~N}$ \\
\hline Força passiva & $137.85 \mathrm{~N}$ \\
\hline Torque de corte & $13,42 \mathrm{Nm}$ \\
\hline
\end{tabular}




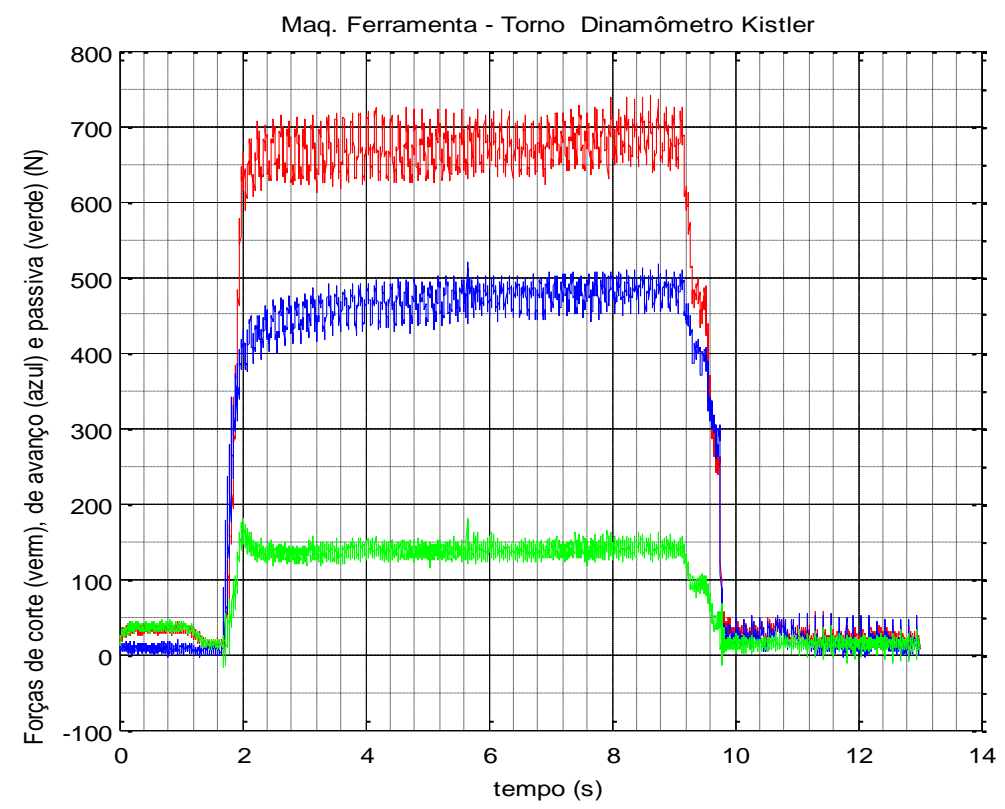

Figura 4.26 Perfil das forças de UCP de $1,5 \mathrm{~mm}$

A figura 4.27 ilustra a região útil de usinagem entre 3 s e 9s do perfil mostrado na figura 4.26 e pode-se notar claramente o efeito oscilatório de baixa frequência de $7,8 \mathrm{~Hz}$ que superpõe os valores médios das forças de corte e de avanço.

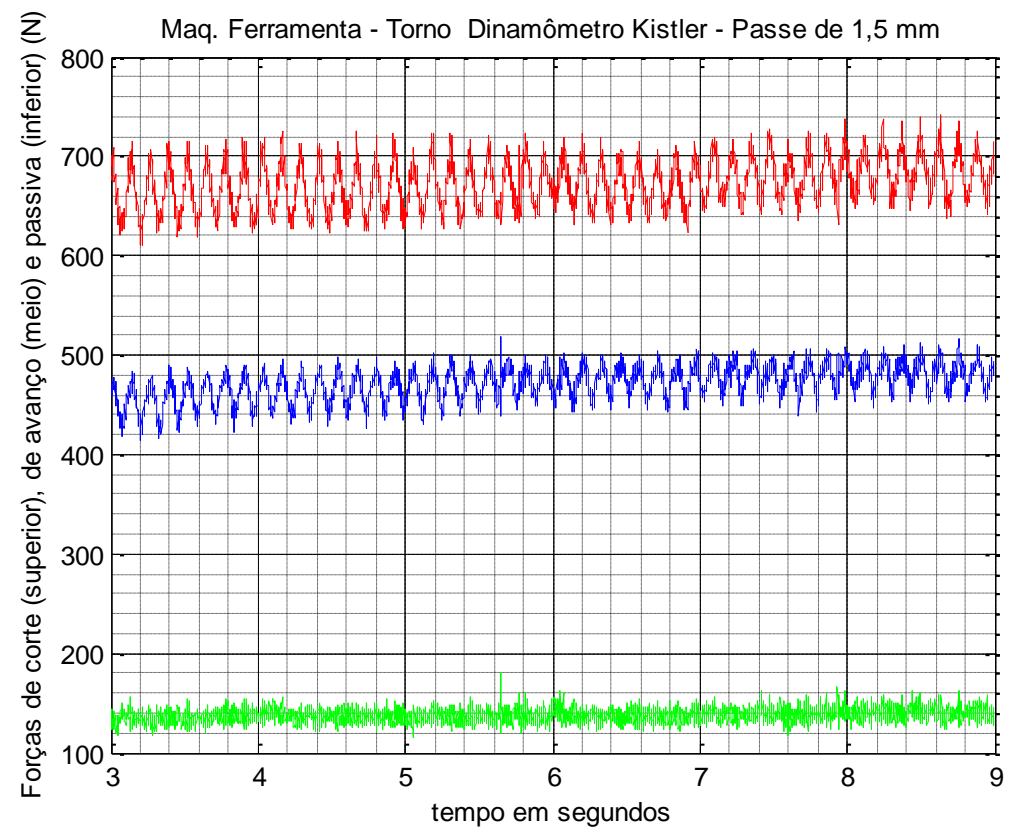

Figura 4.27 Gráfico das forças de corte (superior) e de avanço (inferior) do teste na região de UCP de $1,5 \mathrm{~mm}$. 


\subsubsection{Análise da força de corte}

A figura 4.28 mostra o espectro completo da força de corte para o passe com profundidade de $1,5 \mathrm{~mm}$ obtido com o dinamômetro Kistler operando com uma taxa de aquisição de 1000 amostras por segundo e dados de 16 bits.

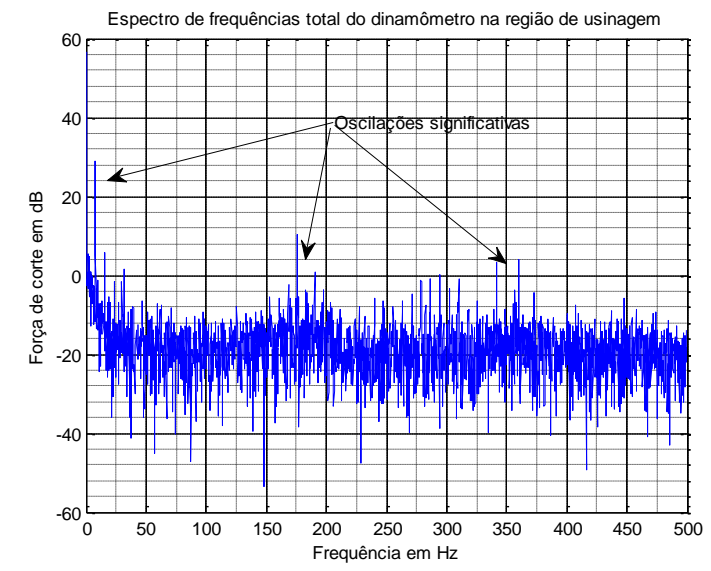

Figura 4.28 Espectro da força de corte na região de usinagem

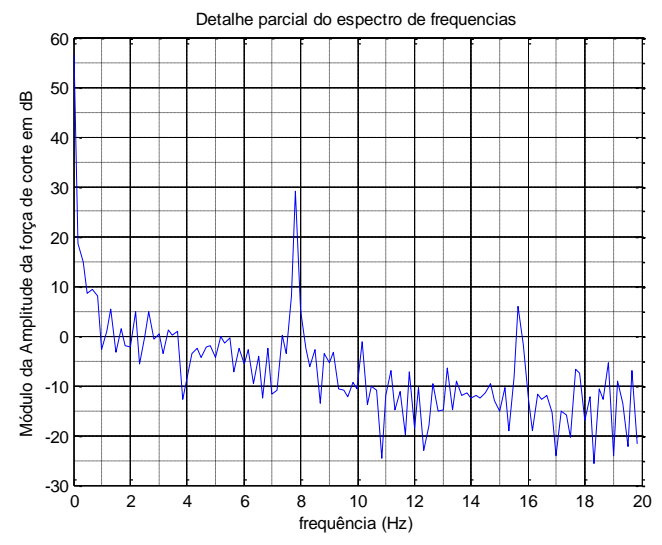

(a)

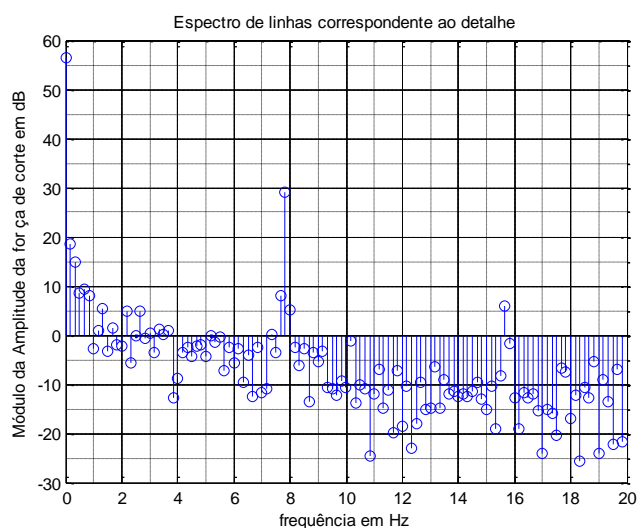

(b)

Figura 4.29 Espectro contínuo (a) e de linhas (b) correspondente ao espectro da figura $4.28 \mathrm{com}$ detalhes das componentes de frequências mais baixas.

As figuras 4.29(a) e 4.29(b) mostram os detalhes das componentes do espectro da figura 4.28 onde, em comparação com o espectro da força de corte com passe de profundidade de $1,0 \mathrm{~mm}$, ocorre um estreitamento da banda do sinal no entorno da frequência de $8 \mathrm{~Hz}$, ao mesmo tempo que um alargamento da banda frequências mais baixas indo até $3 \mathrm{~Hz}$.

A figura 4.30(a) mostra que o aumento da força de corte provoca um aumento de componentes vibratórias de baixa frequência inexistentes nas 
condições de corte anteriores. Já a figura 4.30(b) mostra que ocorre um deslocamento da componente no entorno de $8 \mathrm{~Hz}$ para caindo para $7,6 \mathrm{~Hz}$ e 0 aparecimento de uma componente harmônica próximo a $15,7 \mathrm{~Hz}$ de amplitude aproximada de $2 \mathrm{~N}$

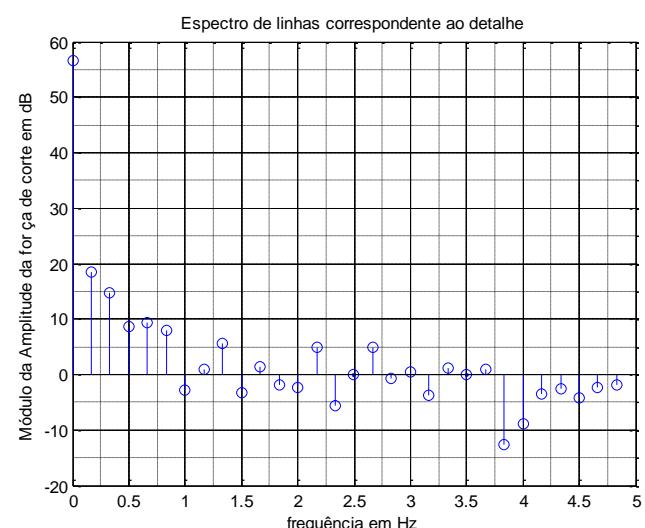

(a)

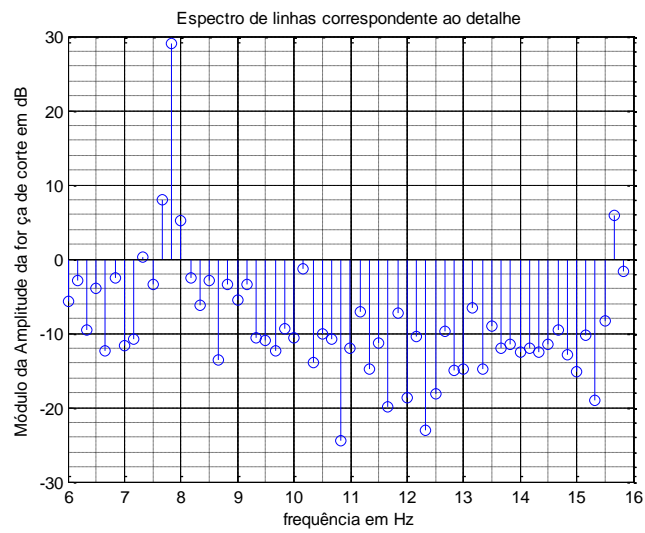

(b)

Figura 4.30 Espectro de linhas da parcela de frequencias mais baixas do espectro (a) e espectro de linhas das componentes no entorno da frequencia de $7,6 \mathrm{~Hz}$ (b)

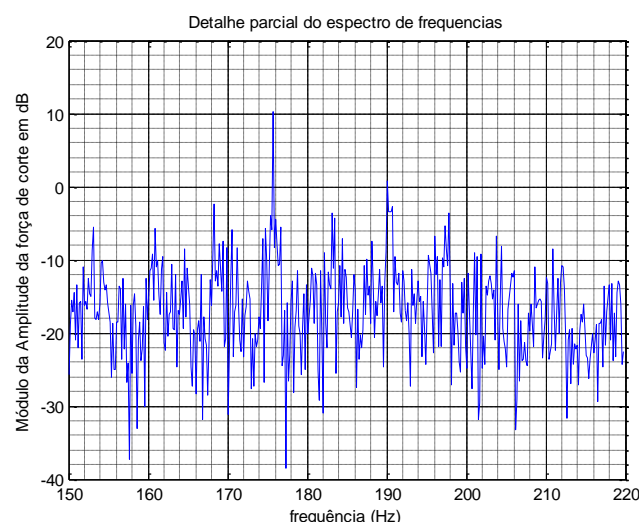

(a)

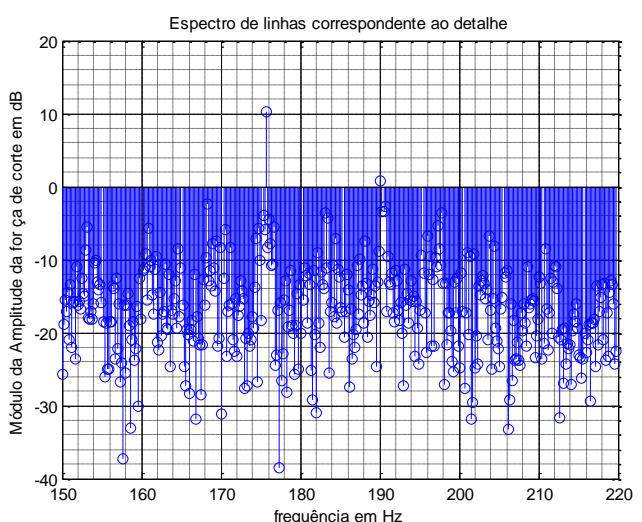

(b)

Figura 4.31 Espectro contínuo (a) e de linhas (b) da região entre $150 \mathrm{~Hz}$ e $220 \mathrm{~Hz}$

O espectro mostrado na figura 4.28 apresenta uma concentração de energia nas componentes no entorno de $175 \mathrm{~Hz}$ que já apareceu sem muita ênfase no espectro da força de corte com profundidade de $0,5 \mathrm{~mm}$, tornou-se um pouco mais evidente no caso do espectro da força de corte de $1,0 \mathrm{~mm}$ e assumiu um aspecto mais característico no espectro da força de corte de $1,5 \mathrm{~mm}$. No primeiro caso o espectro aparenta ter uma maior densidade de 
energia próximo a $200 \mathrm{~Hz}$, mas nos dois outros há uma evidente caracterização do espectro em torno de $170 \mathrm{~Hz}$ com uma relativamente pronunciada componente de força em aproximadamente $176 \mathrm{~Hz}$ como aparecem nas figuras $4.31(a)$ e 4.31 (b).

\subsubsection{Análise da força de avanço}

A figura 4.32 mostra o espectro contínuo do sinal da força de avanço em toda a região de operação do dinamômetro Kistler, nota-se do espectro que os mesmos fenômenos oscilatórios ocorridos nas outras análises, se repetem com maior ou menor intensidade, ou se mantém no mesmo nível como é o caso da componente de $360 \mathrm{~Hz}$ oriunda do sistema de acionamento elétrico da máquina ferramenta. Outra observação importante é o fato de algumas componentes de maior energia na região de $200 \mathrm{~Hz}$ na situação de corte com profundidade de $1,0 \mathrm{~mm}$, novamente aparentarem deslocar para a esquerda com uma oscilação dominante de aproximadamente $175 \mathrm{~Hz}$.

As figuras 4.33(a) e 4.33(b) mostram o comportamento das componentes oscilatórias na região de frequências mais baixas do espectro obtido pelo dinamômetro onde a onipresente componente de aproximadamente $8 \mathrm{~Hz}$ domina o cenário do espectro nesta região.

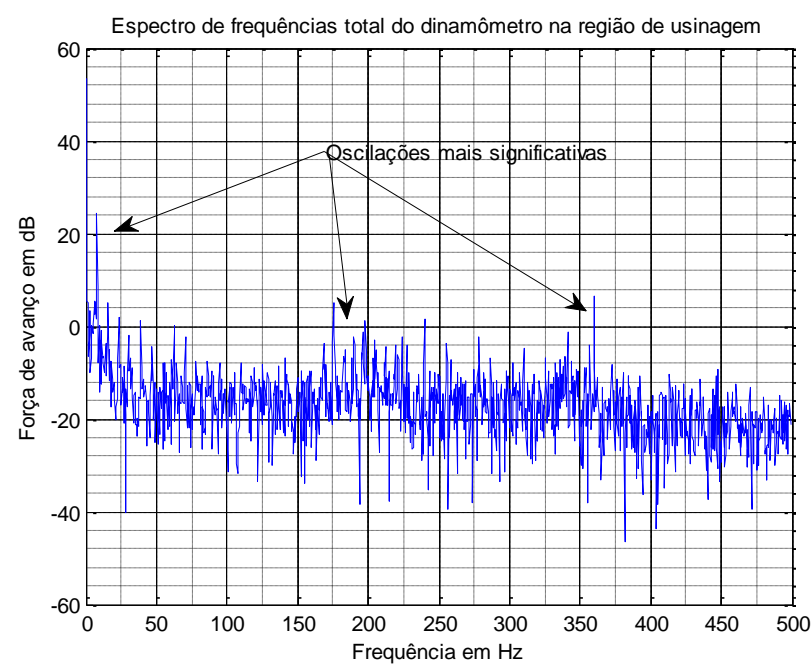

Figura 4.32 Espectro da força de avanço na região de usinagem 


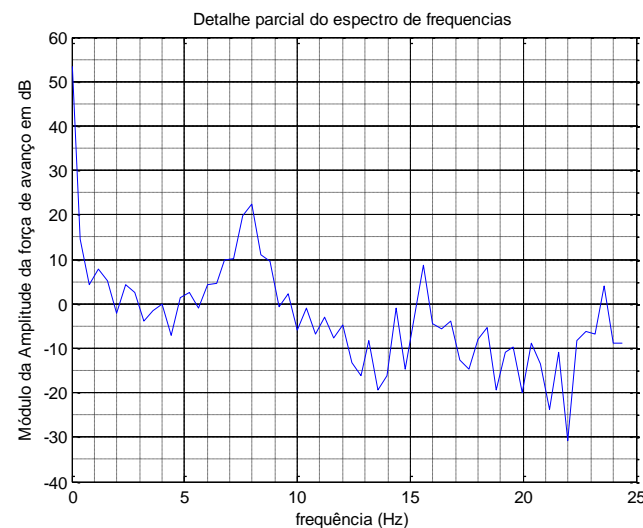

(a)

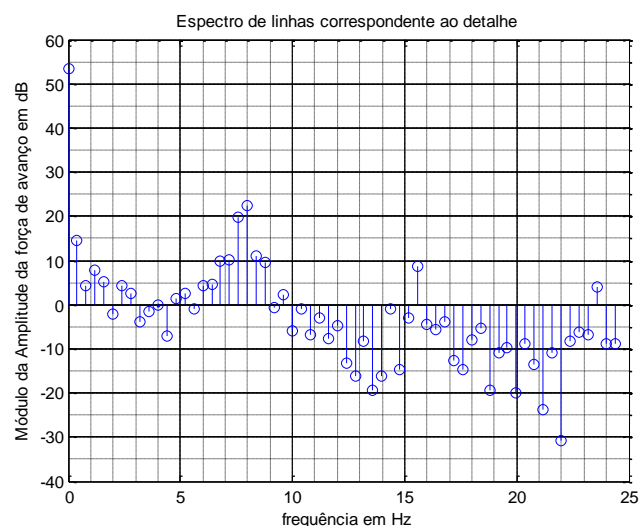

(b)

Figura 4.33 Espectro contínuo (a) e de linhas (b) da região entre $0 \mathrm{~Hz}$ e $25 \mathrm{~Hz}$

Os espectros das figuras 4.33 (a) e (b) sugerem o agrupamento de algumas componentes de muito baixa frequência na região do espectro entre a frequência da componente média e $2,5 \mathrm{~Hz}$ que indica a presença de uma componente composta (não harmônica) de baixa frequencia no processo de avanço do carro longitudinal, esse detalhe é mostrado na figura 4.34.

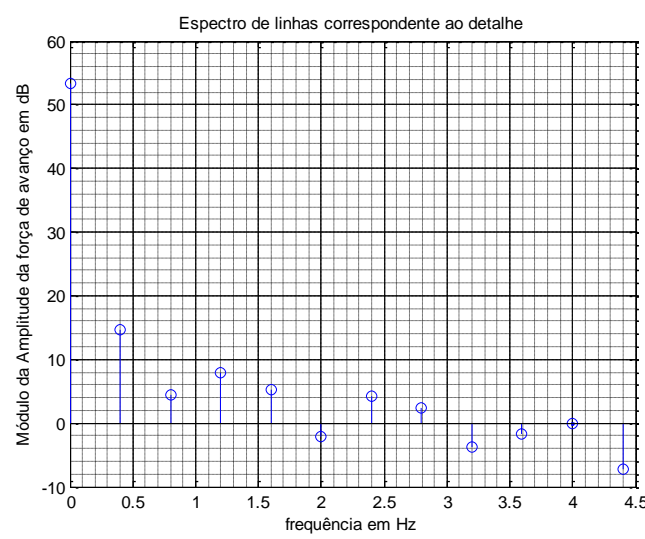

(a)

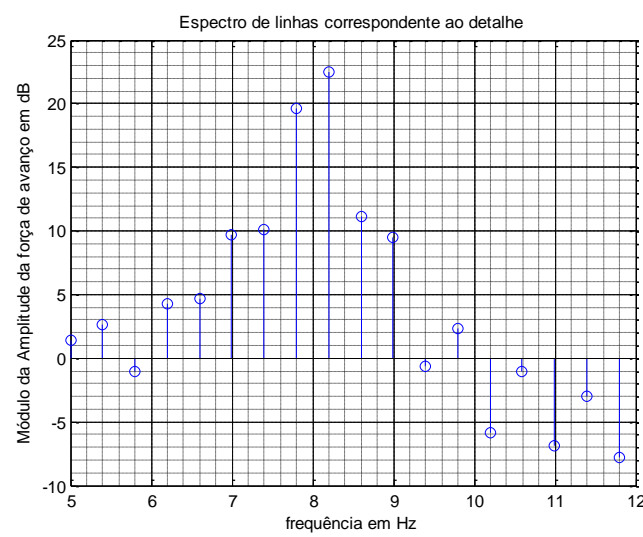

(b)

Figura 4.34 Espectro de linhas de duas regiões de baixa frequencia da força de avanço

As figuras 4.35 (a) e (b) mostram os espectros contínuo e de linhas respectivamente, relacionados a parte do espectro entre $150 \mathrm{~Hz}$ e $250 \mathrm{~Hz}$ que é uma região de concentração de componentes que indica a existência de um processo mecânico do sistema da máquina ferramenta ou de do sistema de usinagem presentes na região. É importante salientar que não se espera a existência de componentes estacionárias decorrentes do sistema de 
acionamento elétrico nesta região. Observa-se, inclusive, ocorre o deslocamento das componentes para cada situação de esforço de corte do sistema da máquina ferramenta.

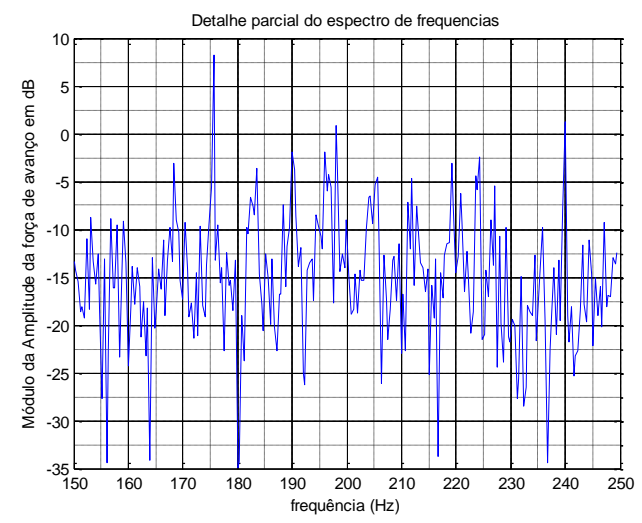

(a)

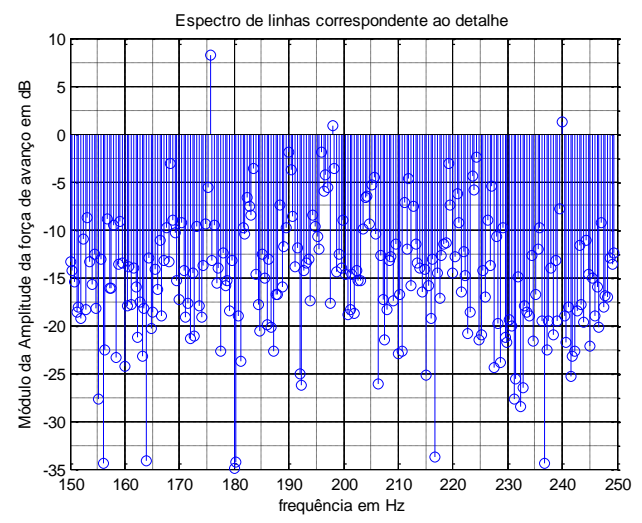

(b)

Figura 4.35 Espectro contínuo (a) e de linhas (b) da região entre $150 \mathrm{~Hz}$ e $250 \mathrm{~Hz}$ para UCP de $1,5 \mathrm{~mm}$

A figuras 4.36(a) e (b) mostram uma parte do espectro onde aparece uma componente estácionária já observada em outros espectros da força de avanço e está relacionada ao acionamentro elétrico do sistema da máquina ferramenta.

\subsection{Análise dos sinais de força obtidos pelo dinamômetro Kistler em operações de usinagem de corte interrompido (Cl)}

Além de finalidades puramente metalúrgicas, os testes com corte interrompido, no contexto aqui aplicado, permitem que obtenhamos informações sobre a resposta de frequência do sistema dinamométrico para posterior comparação com o processo de aquisição baseado no sistema de acionamento da máquina ferramenta.

Os testes de usinagem com corte interrompido foram realizados utilizando um toróide de $39,9 \mathrm{~mm}$ de diâmetro, com dois rasgos simétricos, semelhantes a chavetas, de $10 \mathrm{~mm}$ de largura e $15 \mathrm{~mm}$ de profundidade. Com esta geometria é possível fazer uma previsão do comportamento aproximado das forças de corte e de avanço em termos de comportamento oscilatório. 
A velocidade da placa da máquina ferramenta, medida diretamente no eixo árvore é de 473,30 rpm que equivale a 49,56 rad/s, levando se em conta esses dados, a geometria da peça com duas chavetas simétricas de $10 \mathrm{~mm}$ de largura e o valor médio da força de corte $(316,22 \mathrm{~N})$ baseada no modelo do perfil ideal de força ilustrado na figura 4.36 , podemos esboçar um modelo matemático preliminar para o estudo dos possíveis resultados do ensaio com corte interrompido. A frequência angular do sinal é $\omega_{\text {chaveta }}=2 * 49,56=99,12$ $\mathrm{rad} / \mathrm{s}$.

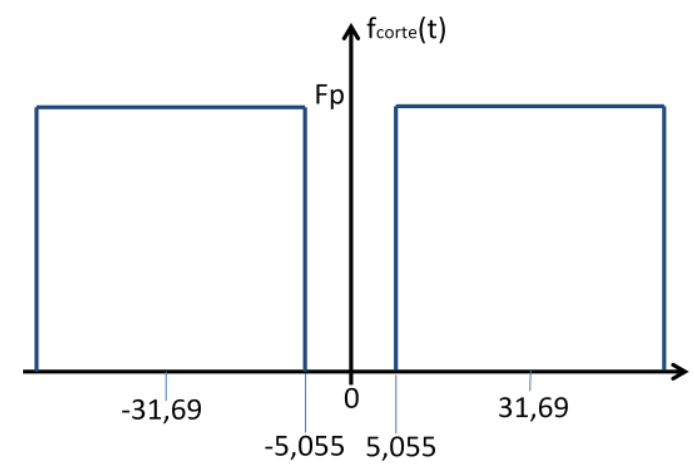

Figura 4.36 Modelo do perfil ideal de comportamento da força de corte (e de avanço) para o caso de corte interrompido.

Utilizando o valor médio obtida dos dados da figura $4.38(179,15 \mathrm{~N})$ e a relação $F_{p}=0,84 F_{\text {cortemedia }}$ pode-se escrever, utilizando a análise de Fourier da figura 4.36:

$$
\begin{array}{rl}
f_{\text {corte }}(t)=1 & 79,15 \\
& +213,6\{-0,3035 \cos (99,12 t)-0,27 \cos (198,2 t) \\
& -0,297 \cos (297,6 t)-0,1499 \cos (396,48 t)-0,161 \cos (495,6 t) \\
& +0,0166 \cos (594,92 t)+0,0342 \cos (693,84 t) \\
& +0,0584 \cos (792,96 t)+0,0712 \cos (892,08 t)+0,0589 \cos (991,2 t) \\
& +\cdots\}
\end{array}
$$

A figura 4.37(a) mostra o perfil simulado pela expressão acima e a figura 4.37(b) mostra o espectro de linhas do mesmo. Como esperado ocorre uma componente fundamental de $15,77 \mathrm{~Hz}$, porem o espectro do sinal real mostra algo mais que isso como se verificará a seguir. 


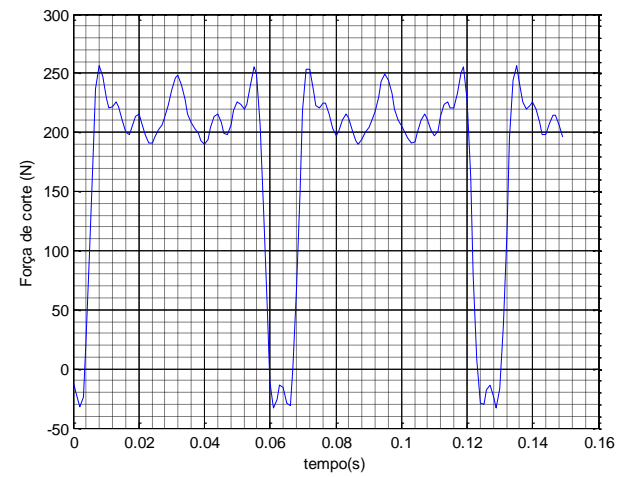

(a)

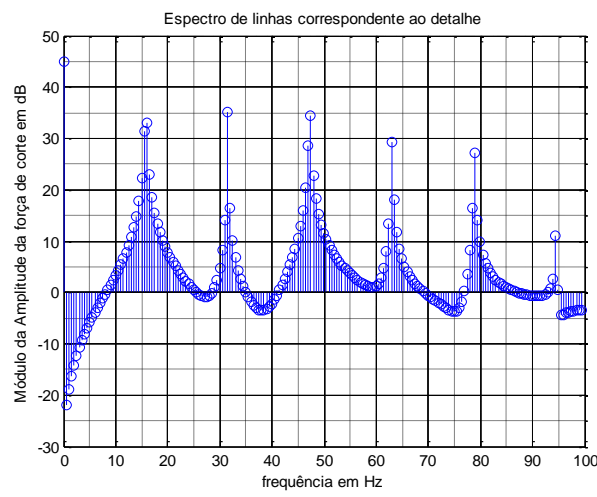

(b)

Figura 4.37 Estimação da forma de onda até a 10ª harmônicam (a) e espectro de linhas esperado (b) na região entre $0 \mathrm{~Hz}$ e $100 \mathrm{~Hz}$.

\subsubsection{Análise da força de corte da UCP de 0,5mm}

A figura 4.38 mostra o perfil da usinagem com corte interrompido das três forças medidas pelo dinamômetro Kistler para a situação de usinagem com profundidade de $0,5 \mathrm{~mm}$.

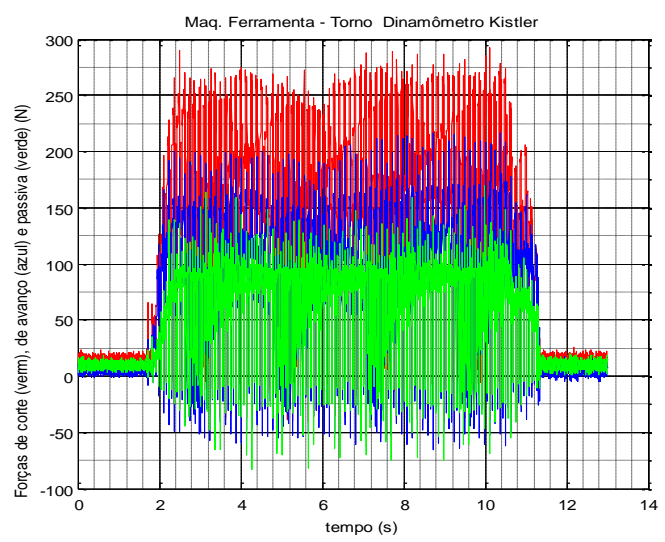

(a)

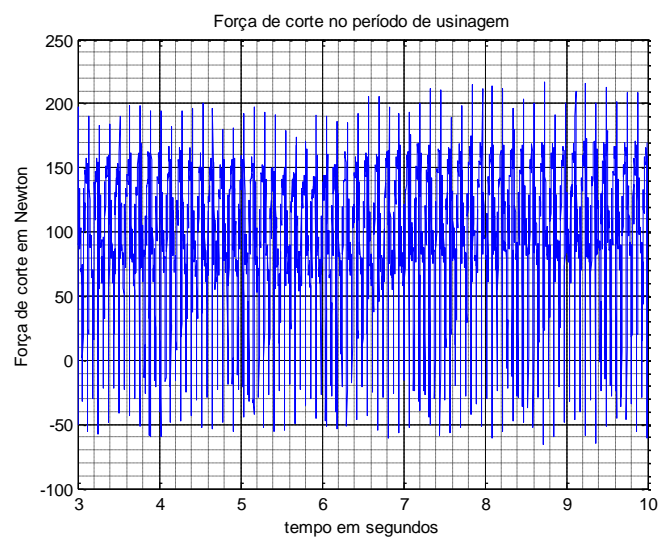

(b)

Figura 4.38 Perfil das forças de corte, de avanço e passiva (a) e somente da força de corte (b) na situação de usinagem com $\mathrm{Cl}$ e UCP de $0,5 \mathrm{~mm}$

A figura 4.38 (a) mostra o perfil da usinagem com corte interrompido das três forças medidas pelo dinamômetro Kistler para a situação de usinagem com profundidade de 0,5m enquanto que a figura 4.38(b) mostra somente a força de corte na região de usinagem efetiva. $O$ espectro relativo ao sinal da figura 
4.38(b) é mostrado na figura 4.39 e como era esperado, o espectro apresenta um rico conteúdo harmônico.

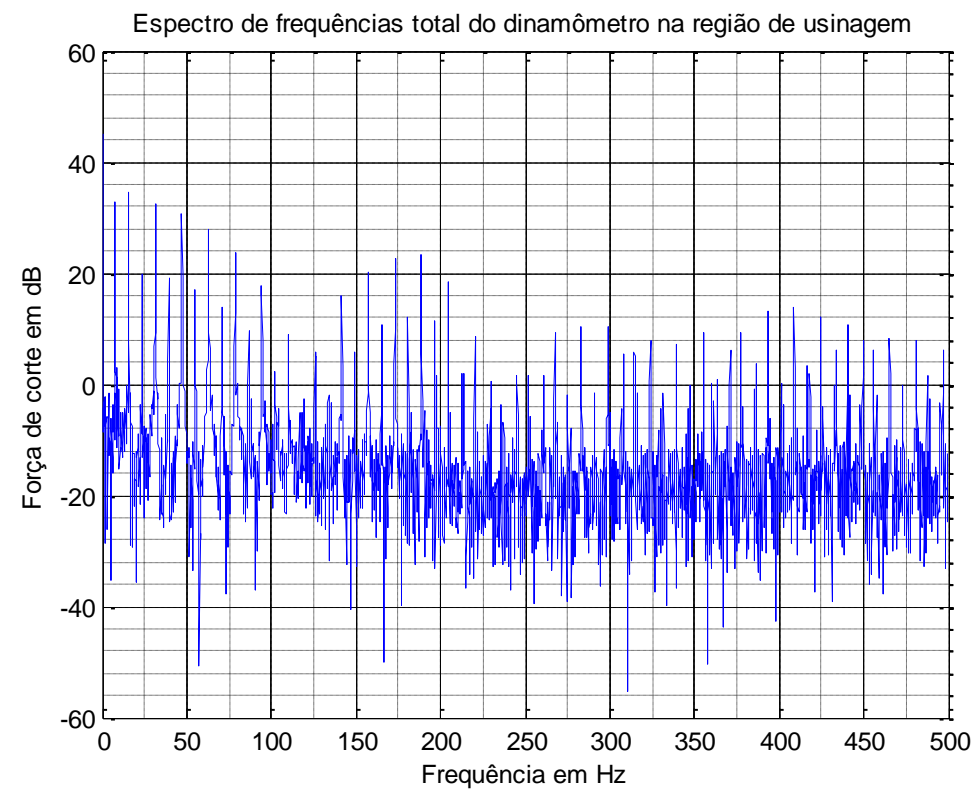

Figura 4.39 Espectro da força de corte do sinal mostrado na figura 4.38(b)

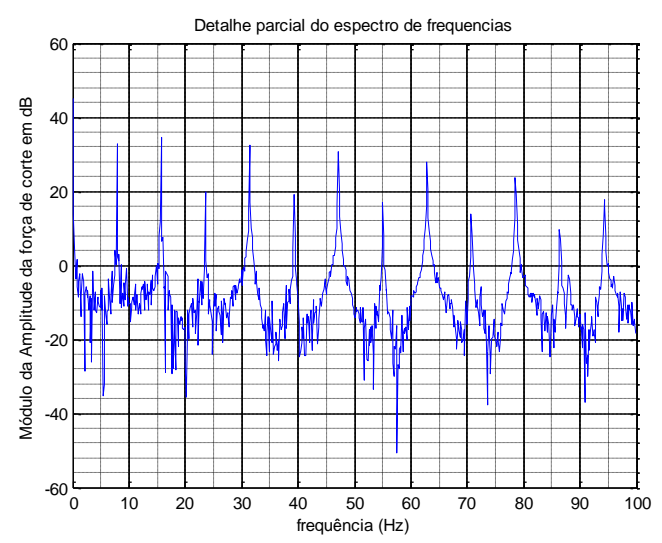

(a)

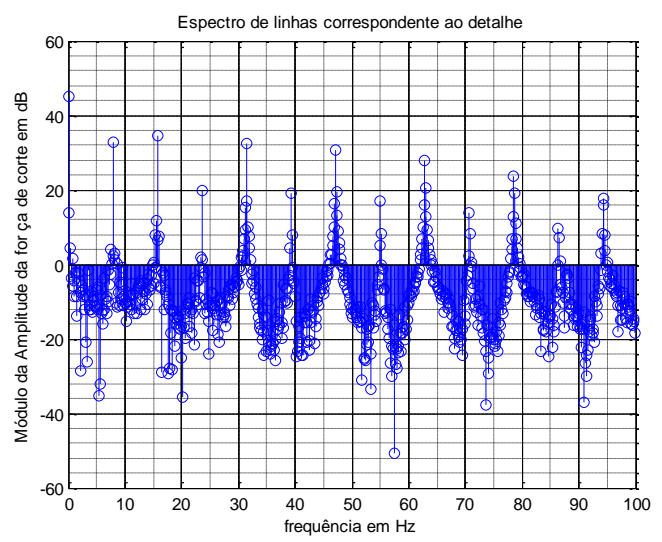

(b)

Figura 4.40 Detalhes do espectro da figura 4.39 mostrando uma componente não esperada com fundamental em aproximadamente $24 \mathrm{~Hz}$.

O espectro mostrado na figura 4.39 diverge em alguns aspectos do espectro esperado mostrado na figura 4.37(b), uma vez que alem das harmônicas relativas à frequência fundamental de $15,77 \mathrm{~Hz}$, existem componentes intermediárias alem da sempre presente componente de aproximadamente $8 \mathrm{~Hz}$ também existentes nas situações de corte contínuo. A explicação para essas componentes está presente na força de reação do portaferramentas e da própria ferramenta que na situação de acomodação durante o 
intervalo das chavetas no corte interrompido, libera a energia de seu retorno elástico no próprio sistema do porta-ferramentas gerando com isso uma componente vibratória no próprio sistema do porta-ferramentas como é possível verificar na figura 4.41. Observa-se que esta energia é menor do a absorvida na entrada da ferramenta em corte, porque está não exibe um conteúdo oscilatório livre, mas sim um conteúdo oscilatório forçado pela presença da usinagem que está entrando em operação.

As figuras 4.42(a) e (b) mostram o espectro de frequências fundamentais dominantes na parte das frequências mais baixas do espectro. A frequência de aproximadamente $8 \mathrm{~Hz}$ é a mesma detectada nas condições de corte contínuo, a frequência de $15,77 \mathrm{~Hz}$ já era esperada a partir do modelo matemático do sinal enquanto que a frequência de $23,6 \mathrm{~Hz}$ corresponde a força de reação do porta-ferramentas por ocasião de sua liberação súbita no intervalo em que a ferramenta se encontra dentro dos rasgos de chaveta da peça em usinagem.

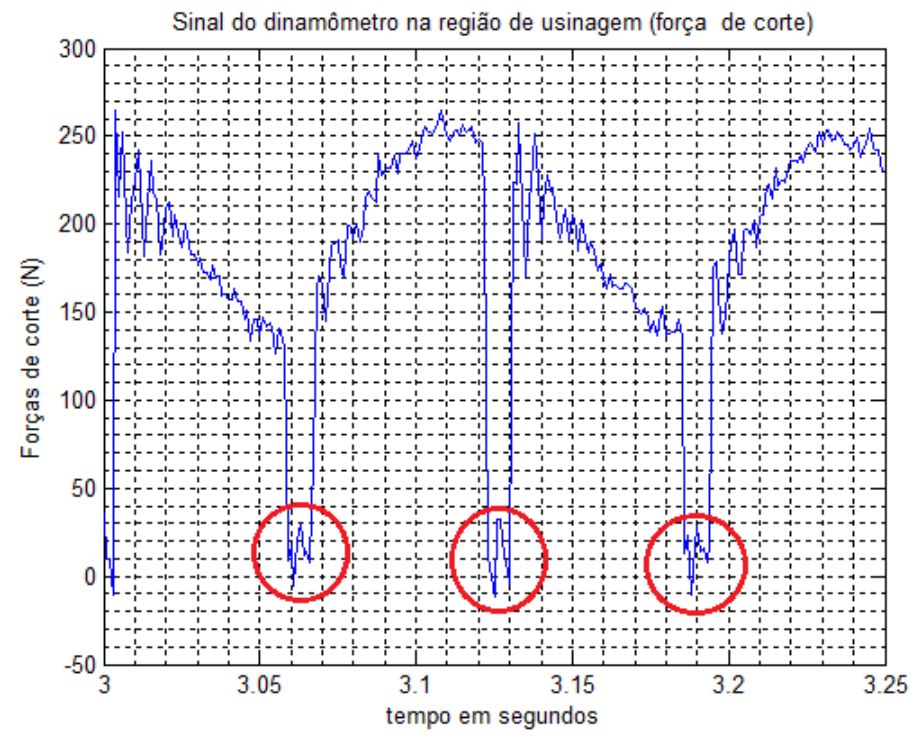

Figura 4.41 Detalhe do sinal de força de corte para o caso de profundidade de $0,5 \mathrm{~mm}$ mostrando a oscilação de acomodação no intervalo da chaveta do corte interrompido, observa-se também a componente de $7,8 \mathrm{~Hz}$ na parte superior. 


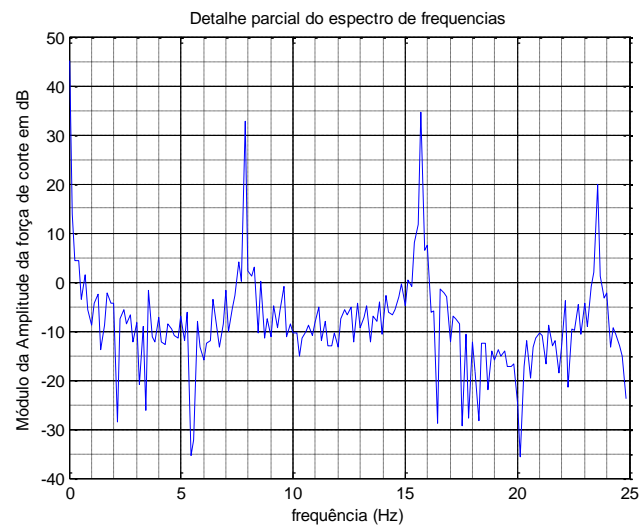

(a)

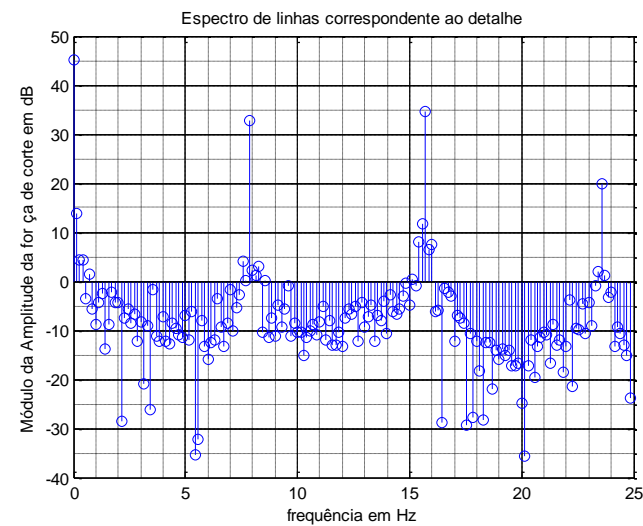

(b)

Figura 4.42 Espectro parcial contínuo (a) e de linhas (b) da força de corte mostrando as frequências das oscilações dominantes

\subsubsection{Análise da força de avanço da UCP de $0,5 \mathrm{~mm}$}

A figura 4.43 mostra o espectro da força de avanço para o caso de corte com profundidade de $0,5 \mathrm{~mm}$. O espectro é bastante similar ao relativo a força de corte mostrado no figura 4.39 a menos da amplitude algo maior em dB no caso anterior.

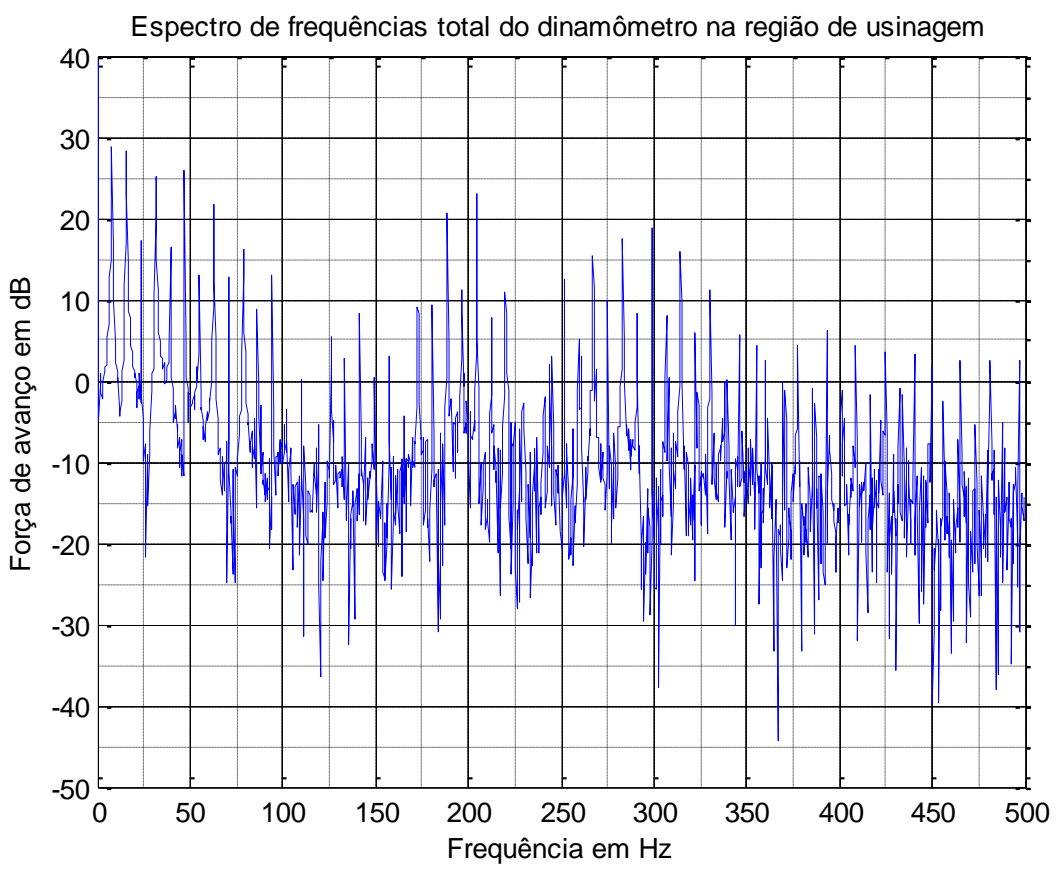

Figura 4.43 Espectro da força de avanço para o caso de UCP de $0,5 \mathrm{~mm}$ 


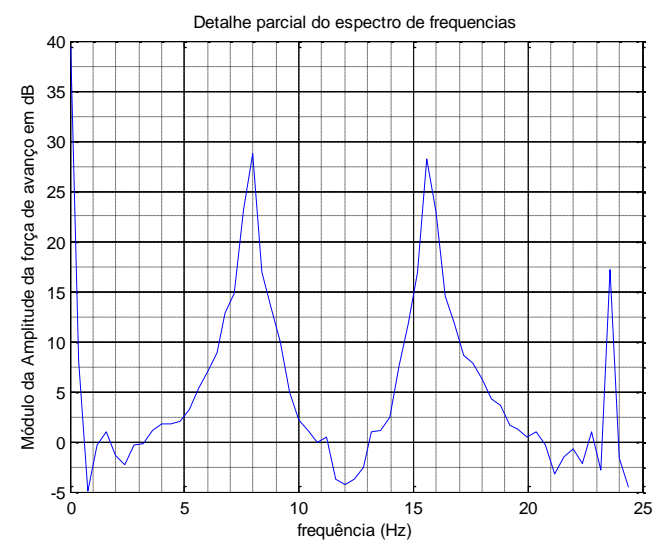

(a)

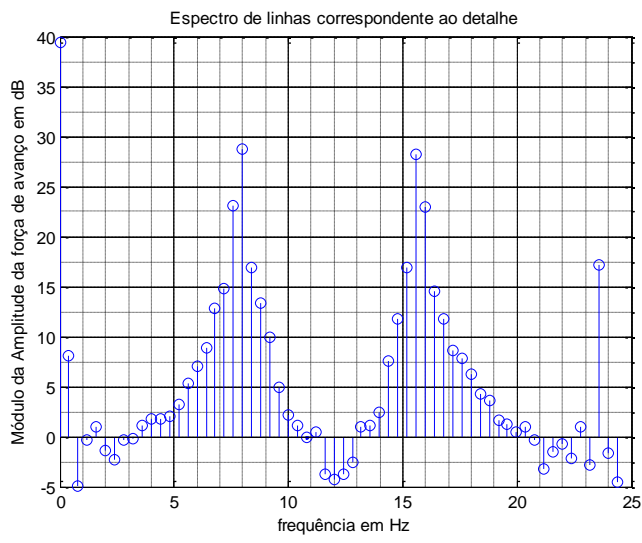

(b)

Figura 4.44 Espectro parcial contínuo (a) e de linhas (b) da força de avanço mostrando as frequências das oscilações dominantes

Em comparação com a força de corte do espectro das componentes da força de avanço, estas apresentam um sinal com uma largura de banda maior, mas as frequência espectrais dominantes são as mesmas já detectadas na ocasião da análise do caso anterior. Uma observação do sinal da força de avanço em função do tempo é o conteúdo harmônico da acomodação, mostrado entre $3,12 \mathrm{~s}$ e $3,13 \mathrm{~s}$ da figura 4.45 , onde o efeito de liberação da energia armazenada no eixo x relativa a força de avanço é fortemente oscilatório, mais que o da força de corte, isso aumenta a banda relacionada com a frequência central de $23,6 \mathrm{~Hz}$ observada tanto no caso da força de corte como no da força de avanço. Outro aspecto relevante é a oscilação subamortecida presente entre os instantes 3,13 s e 3,15 s que, também justifica o aumento da banda em torno do sinal de $15,77 \mathrm{~Hz}$ e suas componentes harmônicas.

O espectro do sinal obtido na usinagem com corte interrompido é bastante mais ruidoso que o com corte contínuo, a situação interrompida gera componentes harmônicas significativas por toda a região do espectro entre $\mathrm{OHz}$ e $500 \mathrm{~Hz}$ muitas com amplitudes superior a 1 Newton, isso dificulta a busca por frequências especiais no espectro, mas é possível verificar no espectro mostrado nas figuras 4.46 (a) e (b) a presença de uma frequência oriunda do sistema de acionamento em $360 \mathrm{~Hz}$ embora de pequena amplitude e isso 
somente é possível no espectro da força de avanço, não sendo detectável no espectro da força de corte.

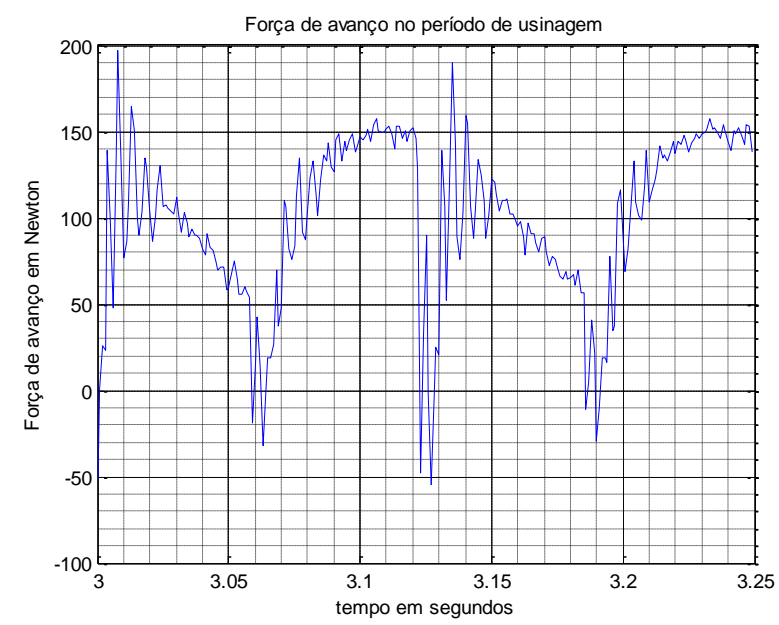

Figura 4.45 Perfil mais detalhado da força de avanço para a situação de corte interrompido e UCP de $0,5 \mathrm{~mm}$

As figuras 4.46 (a) e (b) evidenciam situações de reforço e cancelamento harmônico de algumas componentes em conformidade com a previsão teórica do início da seção 4.2 do presente capítulo, onde as figuras 4.46 mostram que as componentes próximas a $120 \mathrm{~Hz}$ tem magnitude inferior as das outras regiões do espectro, o que corresponde a $5^{\underline{a}}, 6^{\underline{a}}$ e $7^{\underline{a}}$ harmônicas da previsão teórica, sem levarmos em conta o efeito de acomodação do sistema ferramenta/porta-ferramenta que influenciam esta mesma situação devido a sua proximidade do fenômeno.

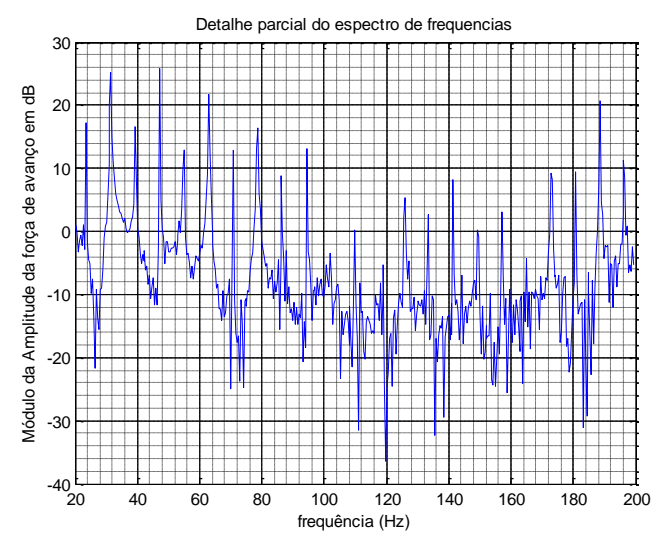

(a)

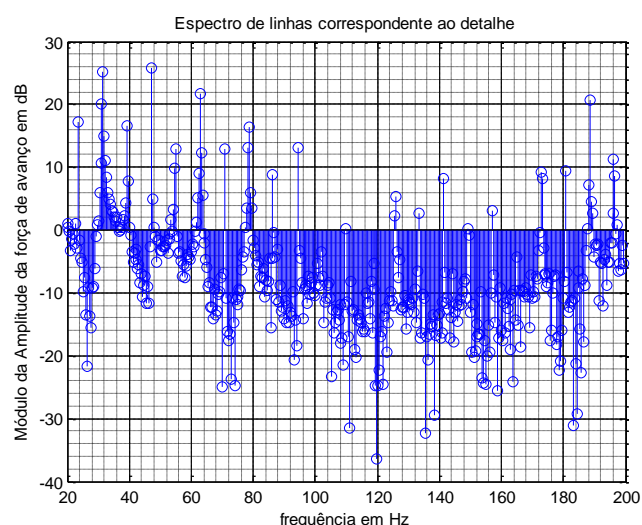

(b)

Figura 4.46 Espectro parcial contínuo (a) e de linhas (b) da força de avanço das frequências entre $20 \mathrm{~Hz}$ e $200 \mathrm{~Hz}$. 


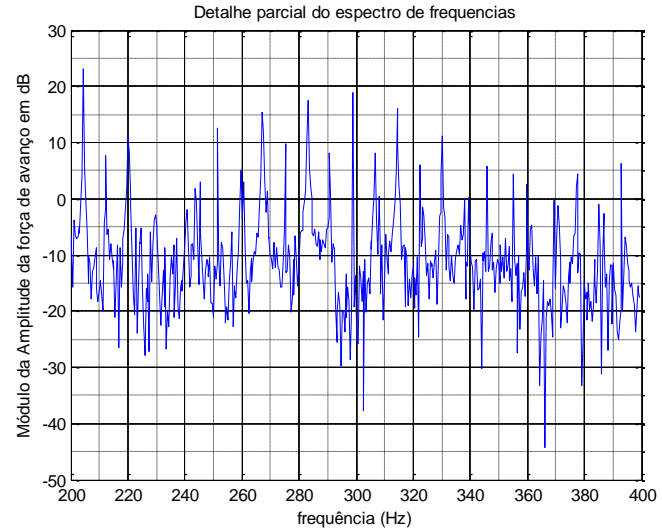

(a)

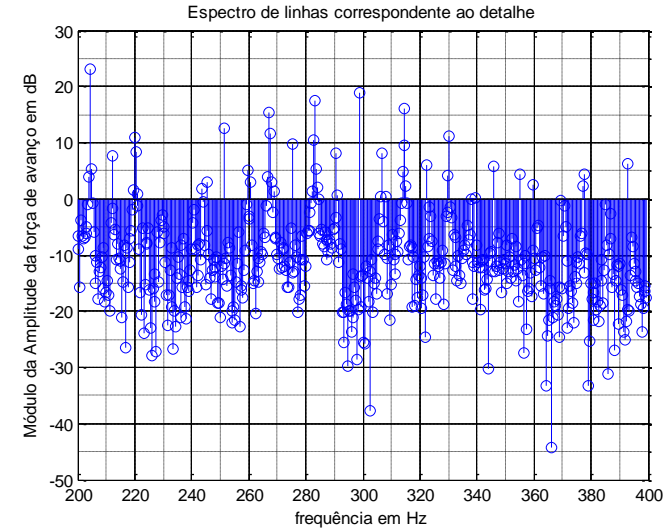

(b)

Figura 4.47 Espectro parcial contínuo (a) e de linhas (b) da força de avanço das frequências entre $200 \mathrm{~Hz}$ e $400 \mathrm{~Hz}$.

\subsubsection{Análise da força de corte da ucp de 1,0mm}

A figura 4.48(a) mostra o perfil das três forças componentes da força de usinagem em todo o período de aquisição de dados e as figura 4.48(b) mostra apenas a força de corte durante o período efetivo de usinagem.

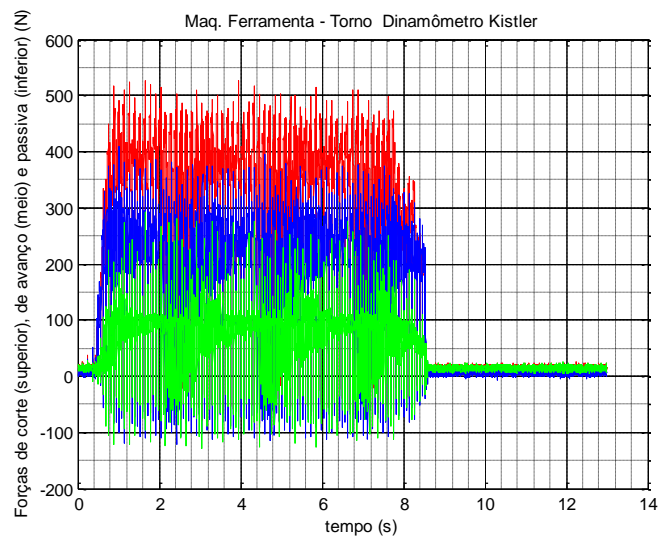

(a)

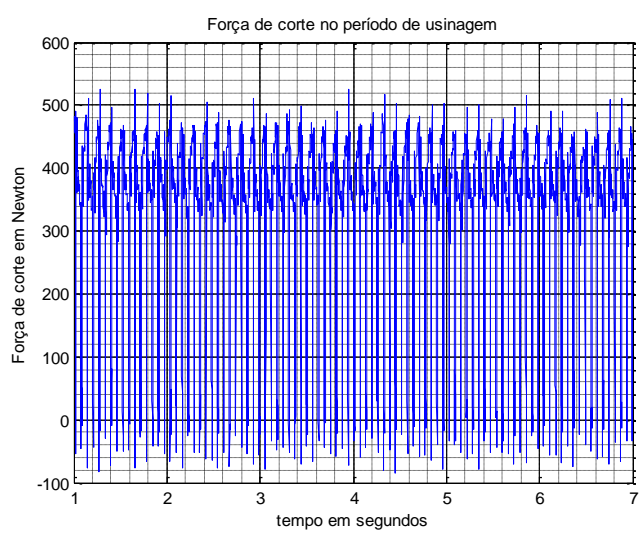

(b)

Figura 4.48 Perfil do conjunto das três forças (a) e somente da força de corte durante operação efetiva de usinagem (b) para usinagem com Cl e UCP de 1,0mm

O conteúdo oscilatório produzido pela operação de corte interrompido é bastante ruidoso, como já foi visto para o caso de usinagem com passe de profundidade de $0,5 \mathrm{~mm}$, isso se repete para o caso de usinagem de $1,0 \mathrm{~mm}$ com um grau mais acentuado devido ao aumento das solicitações de esforços. 
A figura 4.49 mostra o espectro total observado na força de corte para o caso de passe com profundidade de $1,0 \mathrm{~mm}$ e o padrão observado na figura 4.39 relativa ao caso de passe de $0,5 \mathrm{~mm}$ se repete aqui de forma mais acentuada.

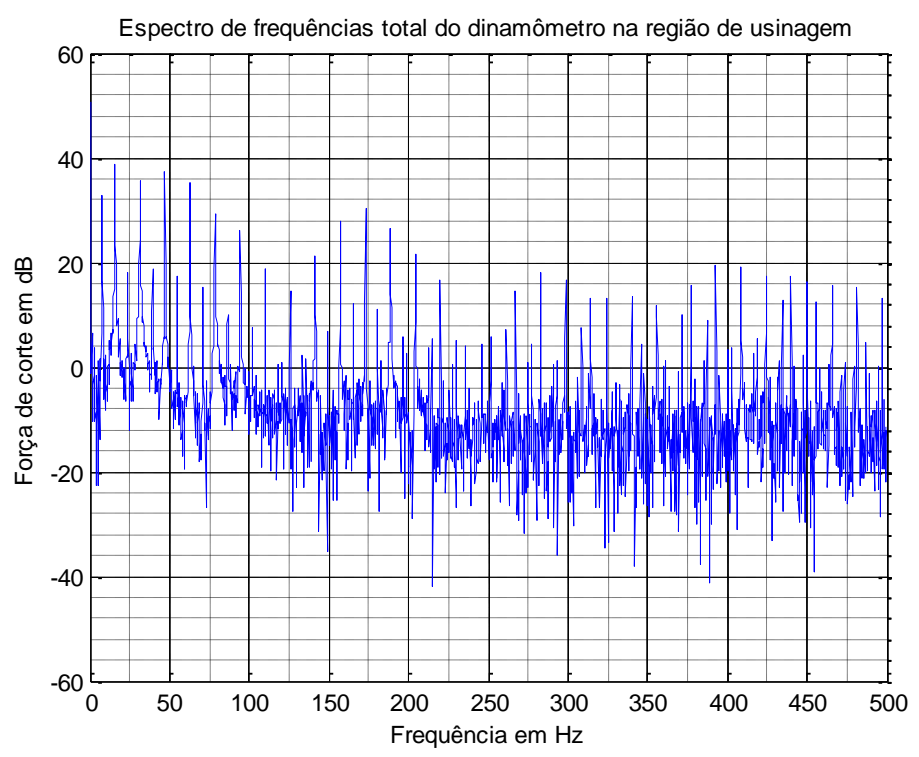

Figura 4.49 Espectro total da força de corte para o caso de Cl e UCP de 1,0m

A figura 4.50 mostra 0 efeito do corte interrompido para o caso de usinagem com passe de $1,0 \mathrm{~mm}$ onde fica evidente a presença da oscilação de aproximadamente $8 \mathrm{~Hz}$ na parte superior da figura e o efeito de acomodação de forças na parte inferior onde ocorre uma oscilação de curta duração com o dobro da frequência definida no corte interrompido.

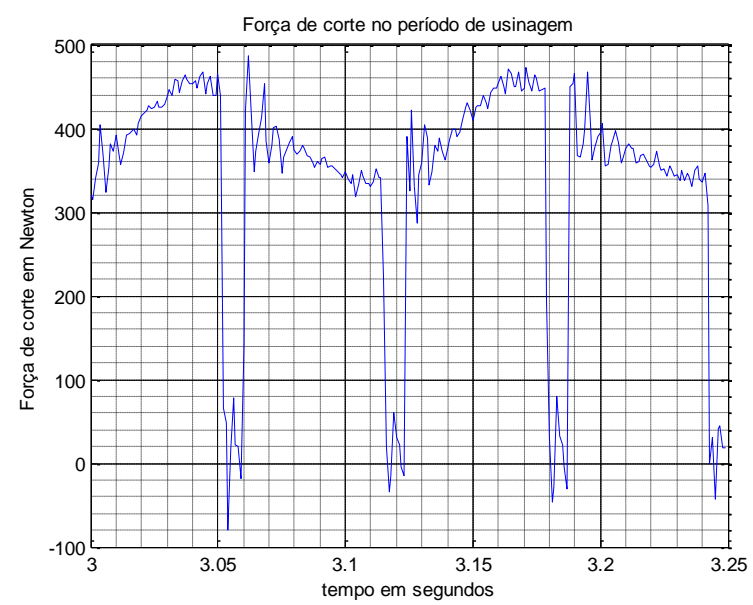

Figura 4.50 Efeito do Cl sobre a força de corte 


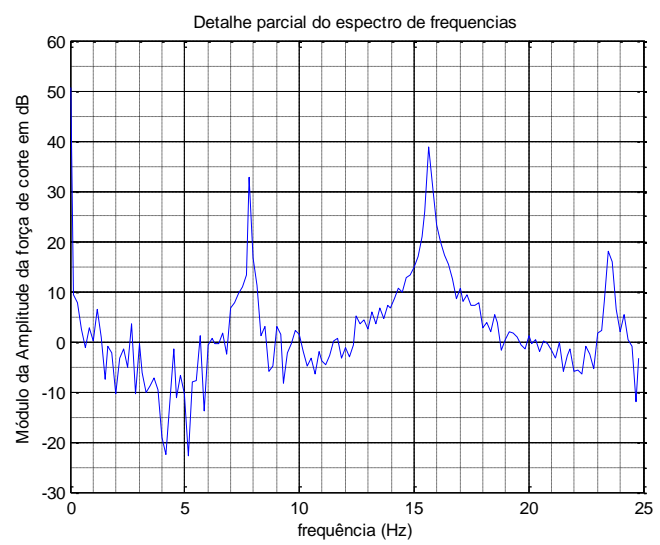

(a)

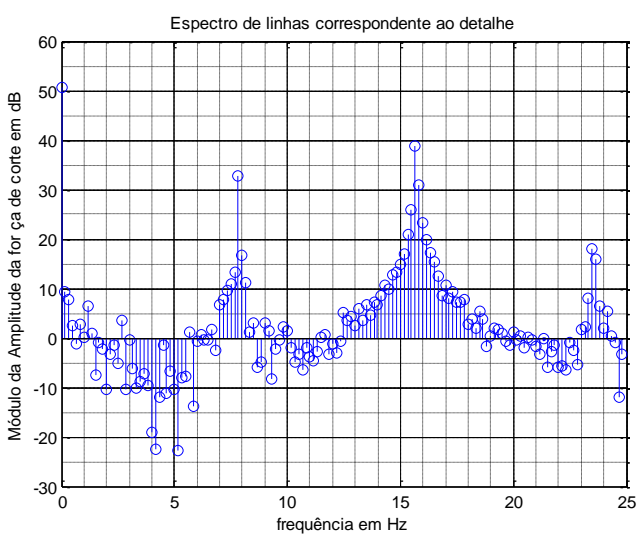

(b)

Figura 4.51 (a) Espectro contínuo da força de corte da região entre $0 \mathrm{~Hz}$ e $25 \mathrm{~Hz}$ (b)Espectro de linhas da mesma região.

A figura 4.51 mostra o espectro de linhas da região de baixa frequência da força de corte onde, observa-se a manutenção da banda do sinal próximo a $8 \mathrm{~Hz}$, com ligeira queda na componente central como já ocorreu no caso de corte contínuo na mesma situação. Por outro lado observa-se também um alargamento da banda do sinal cuja componente central é $15,77 \mathrm{~Hz}$ que é induzido pelo efeito de corte interrompido o que indica um aumento na energia efetiva do sinal, o que era esperado em função do maior esforço para a realização desta usinagem, este efeito também é observado na componente de 23,6 Hz uma vez que a devolução da energia armazenada na flexão da ferramenta e seu suporte, é maior nesta condição de usinagem.

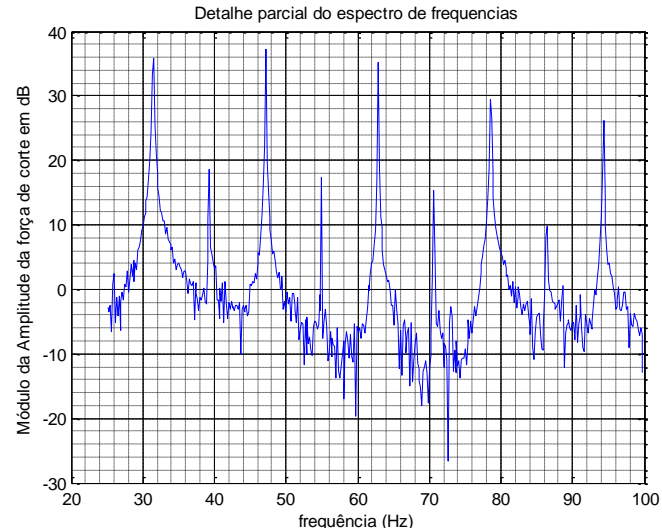

(a)

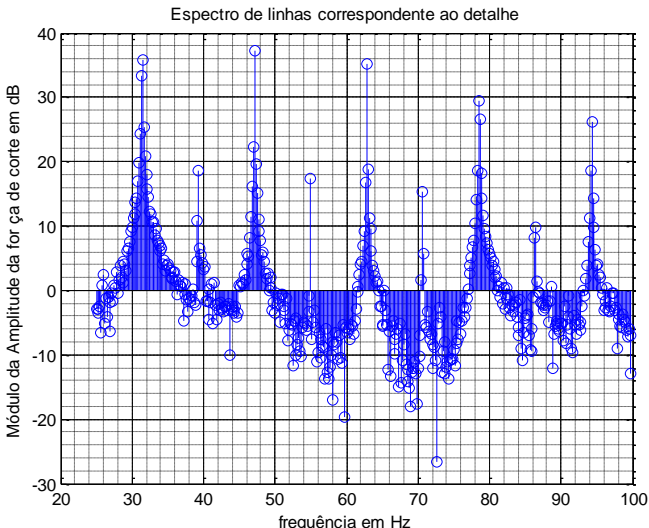

(b)

Figura 4.52 (a)Espectro contínuo da força de corte da região entre $25 \mathrm{~Hz}$ e $100 \mathrm{~Hz}$ (b)Espectro de linhas da mesma região. 
A figura 4.52 apenas ratifica o que foi observado na figura anterior com relação ao aumento da banda relativa as componentes harmônicas derivada do efeito de corte interrompido.

\subsubsection{Análise da força de avanço da UCP de 1,0mm}

A figura 4.53 mostra o espectro total da força de avanço obtida com o dinamômetro Kistler na condição de corte interrompido e passe com profundidade de $1,0 \mathrm{~mm}$, o efeito ruidoso do corte interrompido não permite a observação das nuances características do corte em regime contínuo, portanto as similaridades dos espectros de ambas as forças somente é alterado por suas próprias magnitudes sem muitas alterações em seus perfis.

Como evidenciado na figura 4.53 que mostra a oscilação de acomodação em regime de força de avanço, a oscilação presente no processo aparece nítida no espectro correspondente a lateralidade da frequência dominante de $15,77 \mathrm{~Hz}$ mostrada nas figuras 4.54 (a) e (b).

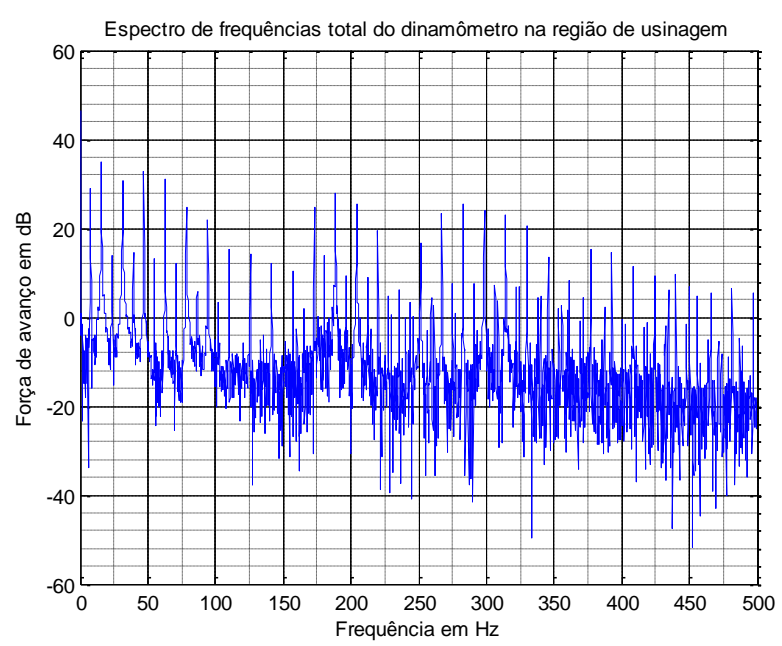

Figura 4.53 Espectro da força de avanço com Cl e UCP de 1,0mm

\subsubsection{Análise da força de corte da UCP de 1,5mm}

A figura 4.55(a) mostra o perfil das três forças componentes da força de usinagem em todo o período de aquisição de dados e as figura 4.47 (b) mostra apenas a força de corte durante o período efetivo de usinagem. 


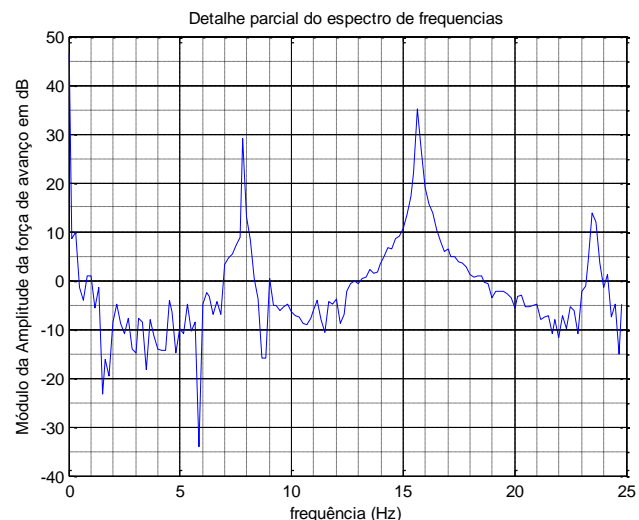

(a)

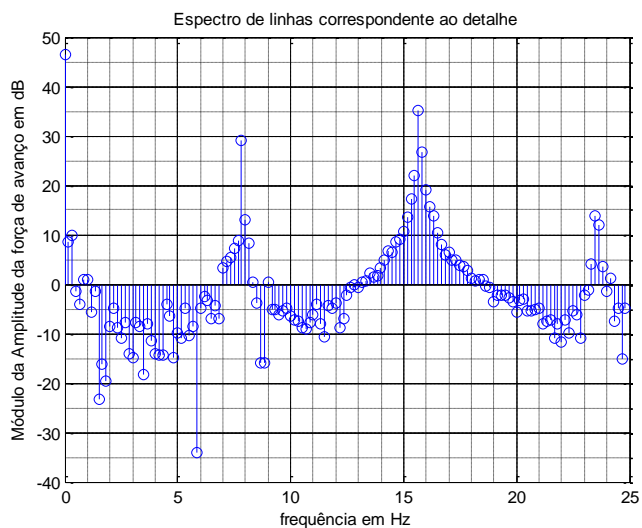

(b)

Figura 4.54 (a)Espectro contínuo da força de avanço na região entre $0 \mathrm{~Hz}$ e $25 \mathrm{~Hz}$ (b)Espectro de linhas da mesma região.
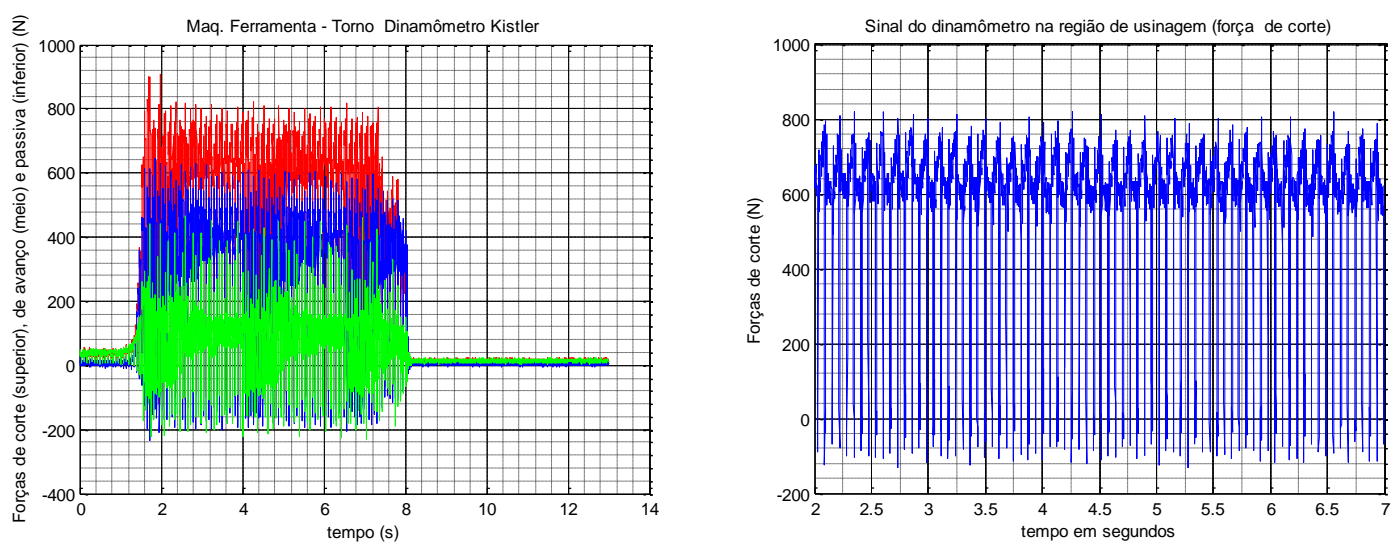

Figura 4.55 Perfil do conjunto das três forças (a) e somente da força de corte durante operação efetiva de usinagem (b) para usinagem com Cl e UCP de 1,5mm

A figura 4.56 mostra o espectro total da força de corte para a condição de usinagem com corte interrompido e $1,5 \mathrm{~mm}$ de profundidade de corte. $\mathrm{O}$ espectro é similar, a menos de sua magnitude aos outros espectros de mesma natureza já discutidos. A figura 4.57 mostra o efeito do corte interrompido para o caso de usinagem com passe de $1,5 \mathrm{~mm}$ onde, novamente fica evidente a presença da oscilação de aproximadamente $8 \mathrm{~Hz}$ na parte superior da figura e 0 efeito de acomodação de forças na parte inferior onde ocorre uma oscilação de curta duração com o dobro da frequência definida no corte interrompido, alem de oscilação na entrada de esforço de corte antes da acomodação na condição contínua na qual predomina a baixa frequência de aproximadamente $8 \mathrm{~Hz}$. 


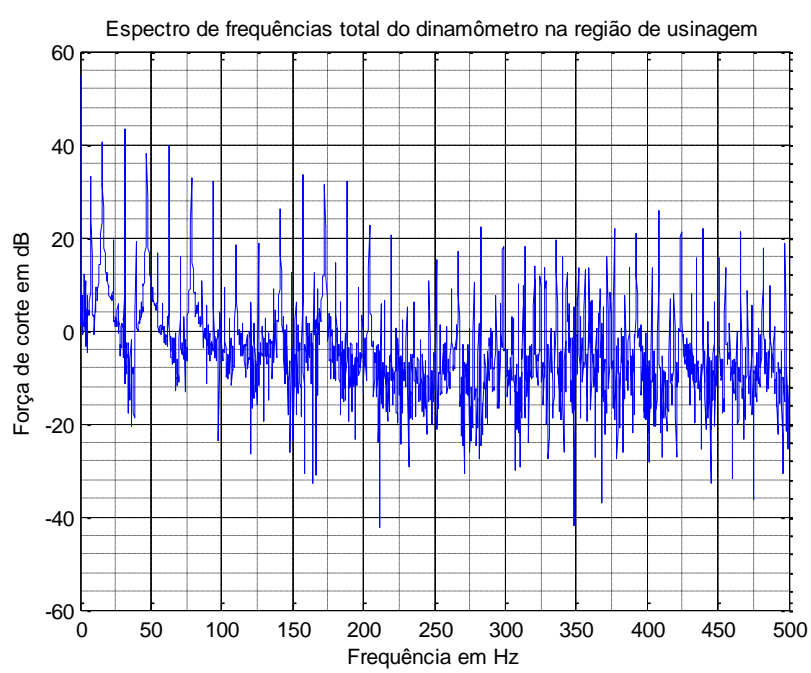

Figura 4.56 Espectro total da força de corte para Cl e UCP de $1,5 \mathrm{~mm}$

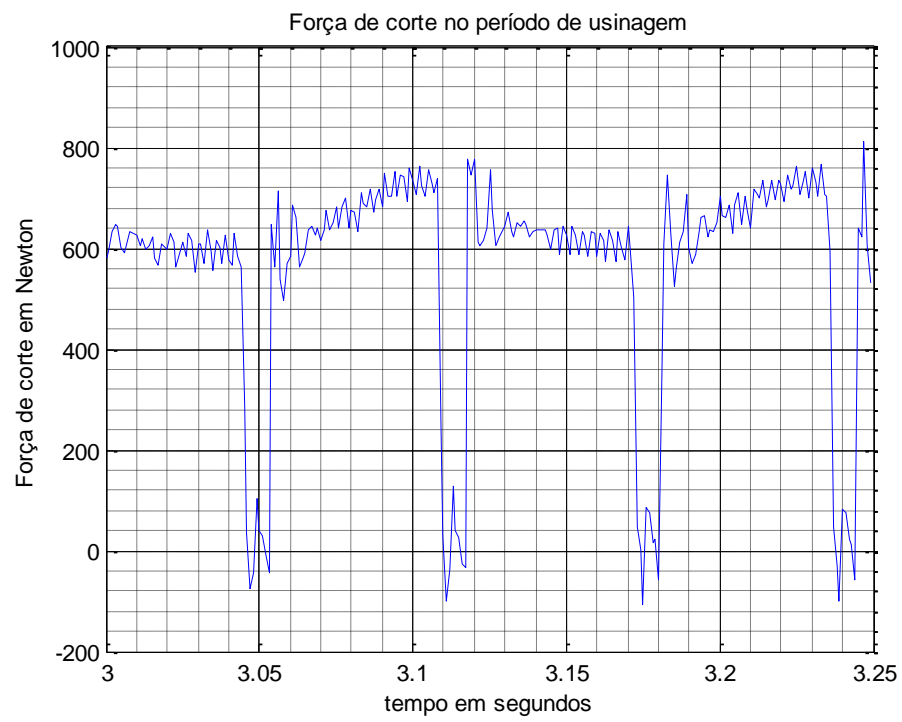

Figura 4.57 Efeito do Cl sobre a força de corte para a UCP de 1,5mm

Observa-se na figura 4.57 que a aumento da profundidade de corte exige um tempo maior de acomodação do sistema da ferramenta/portaferramenta, o que pode ser diretamente observado pelo, novo alargamento da banda lateral em torno da frequência dominante de $15,77 \mathrm{~Hz}$ e pode ser observado na figura 4.58 . 


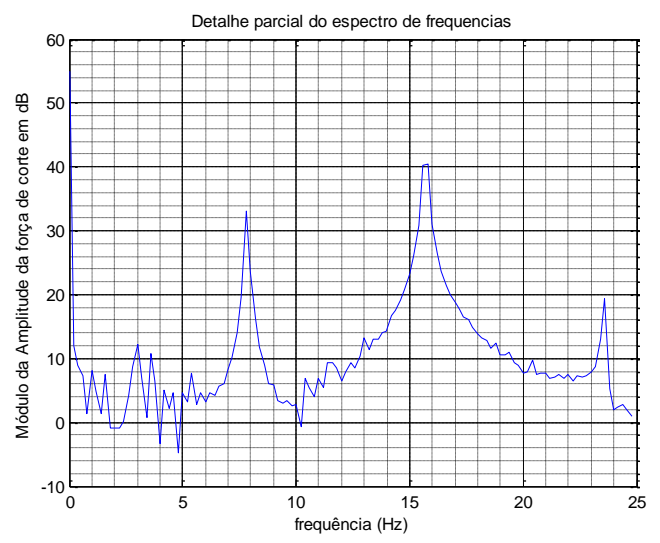

(a)

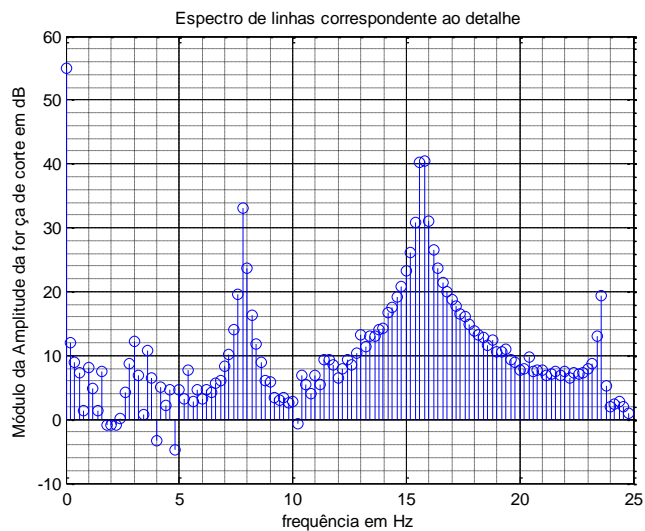

(b)

Figura 4.58 (a)Espectro contínuo da região entre $0 \mathrm{~Hz}$ e $25 \mathrm{~Hz}$ (b)Espectro de linhas da mesma região para $\mathrm{Cl}$ e UCP de $1,5 \mathrm{~mm}$.

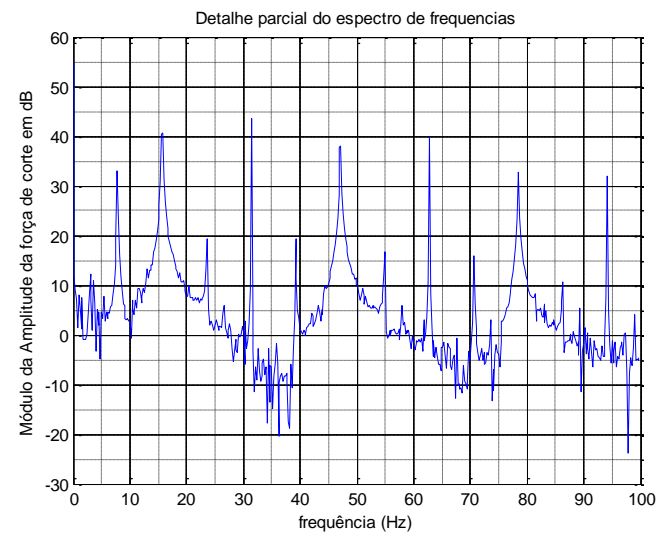

(a)

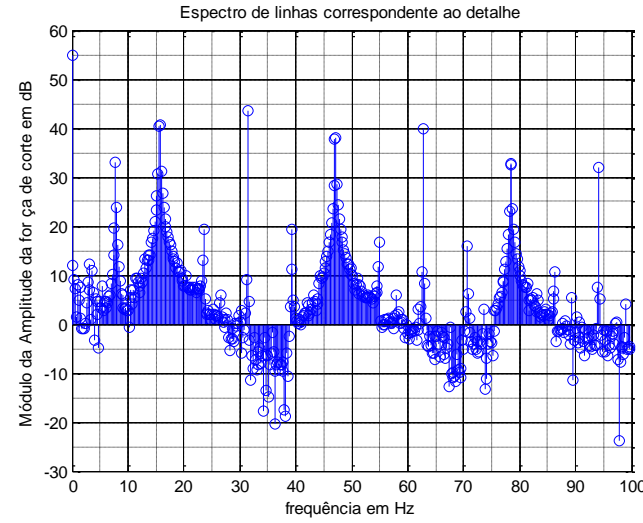

(b)

Figura 4.59 (a)Espectro contínuo da força de corte na região entre $0 \mathrm{~Hz}$ e $100 \mathrm{~Hz}$ (b)Espectro de linhas da mesma região.

As figuras 4.59 (a) e (b) apresentam um efeito interessante quanto as energias associadas ao fenômeno de corte interrompido nesta situação de passe com profundidade de $1,5 \mathrm{~mm}$, como já foi obervado anteriormente, ocorre um alargamento das bandas laterais da componente fundamental, mas por outro lado cancelamentos harmônicos concentram mais energias em algumas componentes harmônicas associadas a frequência da oscilação dominante, assim, enquanto a componente dominante tem aproximadamente $41 \mathrm{~dB}$, a componente relativa a segunda harmônica tem magnitude $47 \mathrm{~dB}$ e isso ocorre com todas as componentes pares que tem maior energia concentrada em seus valores centrais enquanto que as componentes ímpares apresentam uma maior banda lateral distribuindo aí suas energias. 


\subsubsection{Análise da força de avanço com UCP de $1,5 \mathrm{~mm}$}

A figura 4.61 mostra o espectro total da força de avanço obtida com o dinamômetro Kistler na condição de corte interrompido e passe com profundidade de $1,5 \mathrm{~mm}$.

O detalhe da força de avanço da figura 4.62mostra que a mesma não tem tempo para chegar a um valor de acomodação entre a saída e entrada de corte dentro do rasgo de chaveta, que é outro indicativo do aumento das bandas laterais das componentes pares do espectro como mostram as figuras 4.63 (a) e (b) o que é confirmado pelo espectro de faixa mais ampla mostrado nas figuras 4.64 (a) e (b).

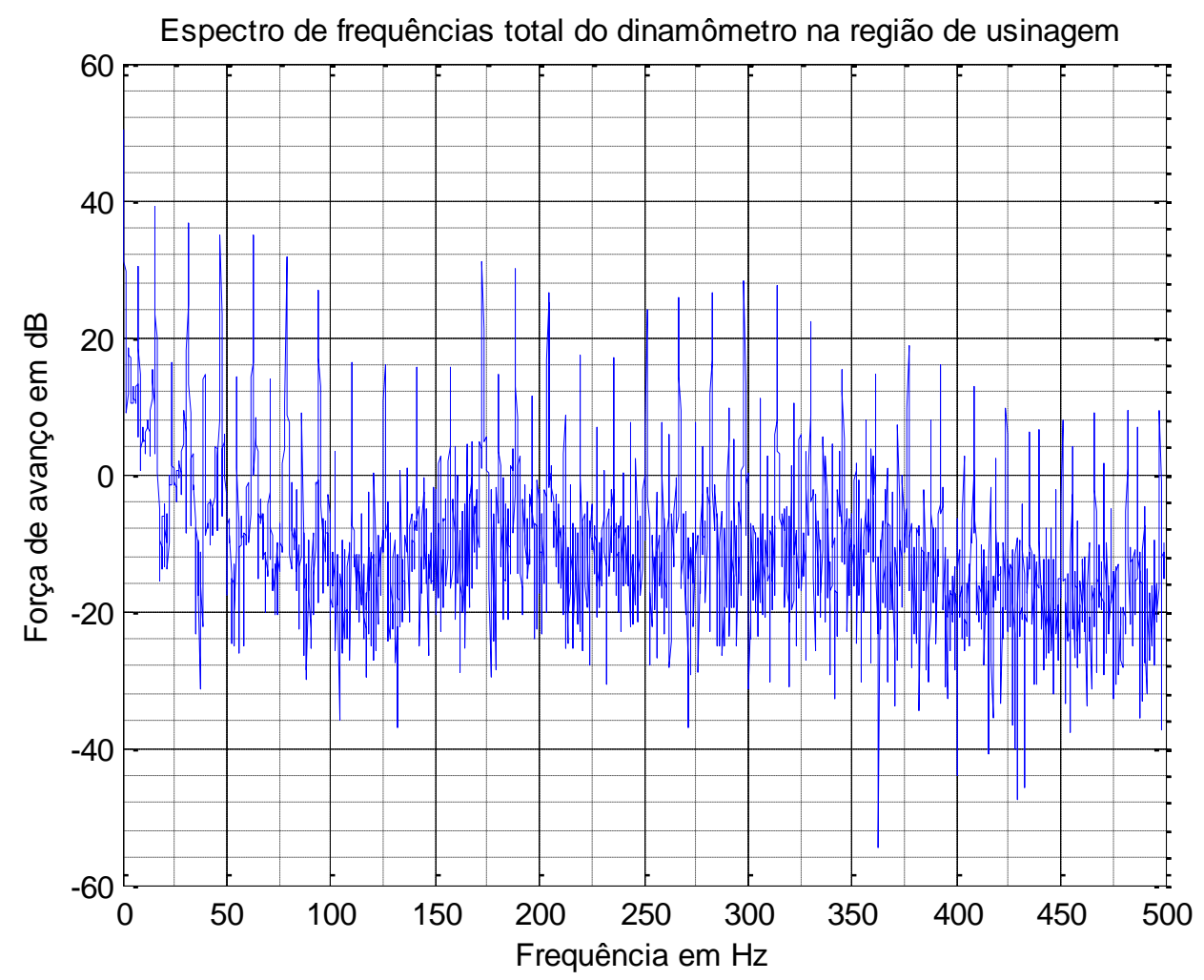

Figura 4.60 Espectro da força de avanço da usinagem com Cl e UCP de 1,5mm 


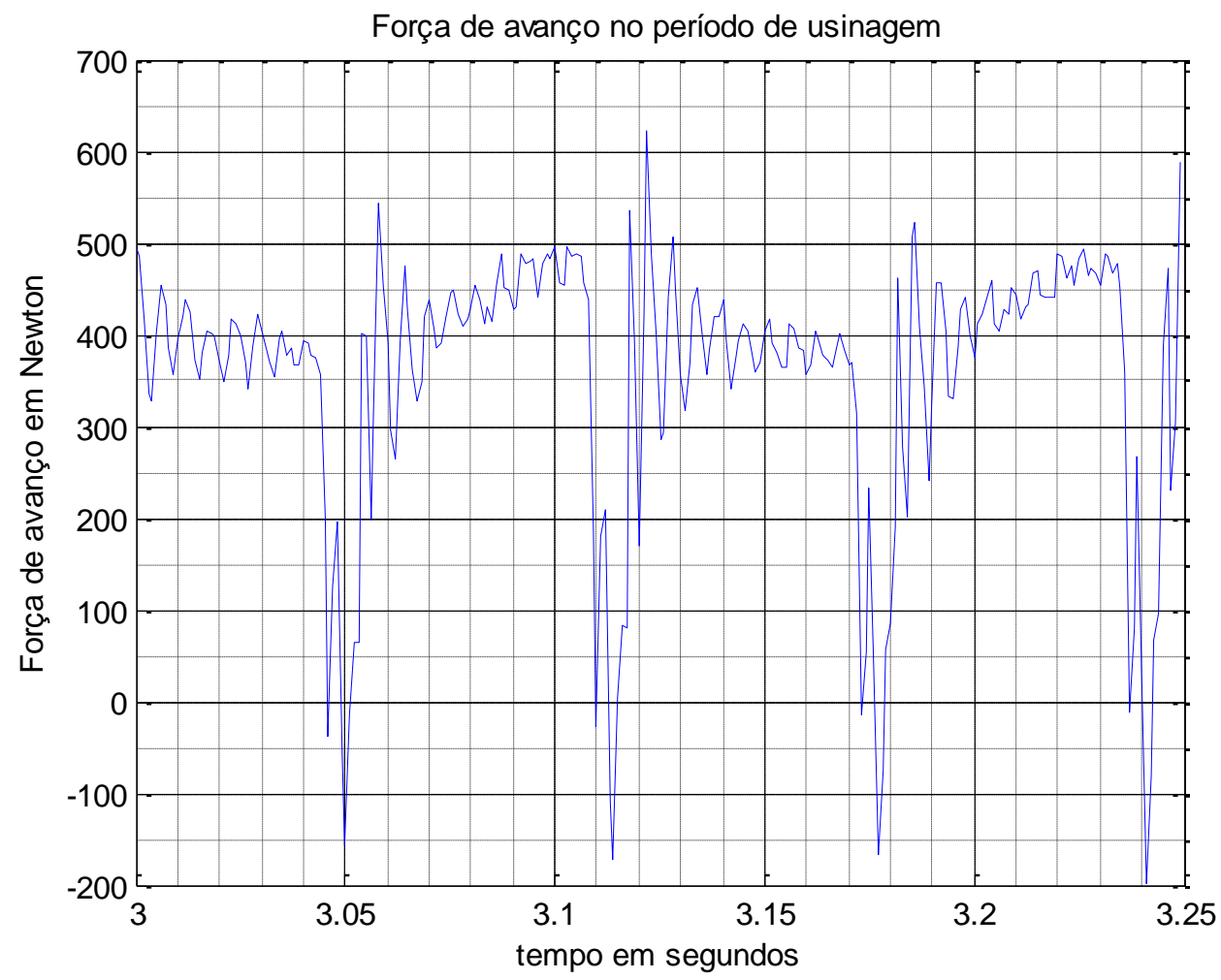

Figura 4.61 Detalhe da força de avanço com Cl e UCP de 1,5 mm

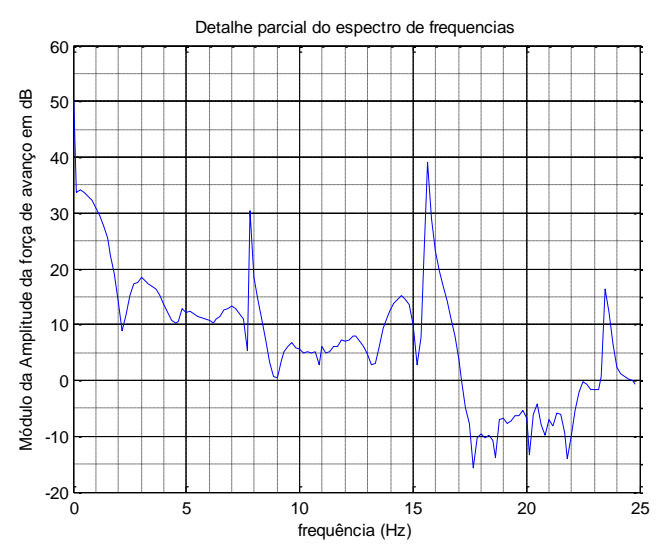

(a)

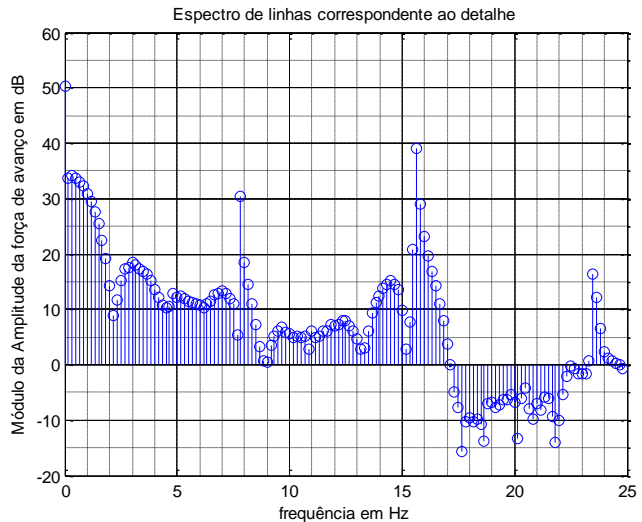

(b)

Figura 4.62 (a)Espectro contínuo da força de avanço na região entre $0 \mathrm{~Hz}$ e $25 \mathrm{~Hz}$ (b)Espectro de linhas da mesma região da força de avanço com Cl e UCP de 1,5mm. 


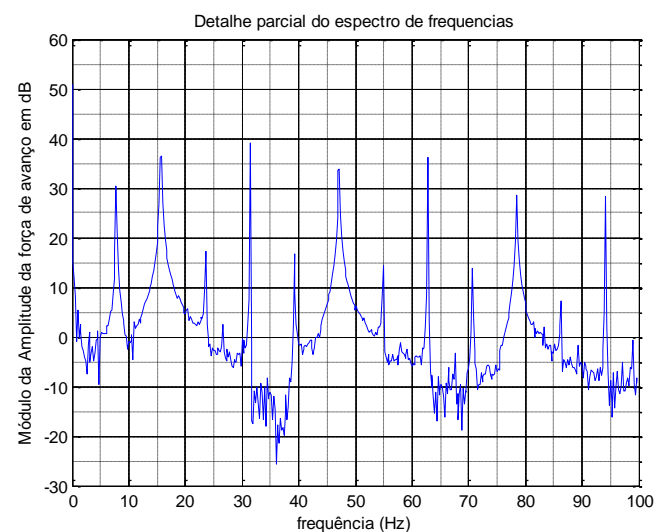

(a)

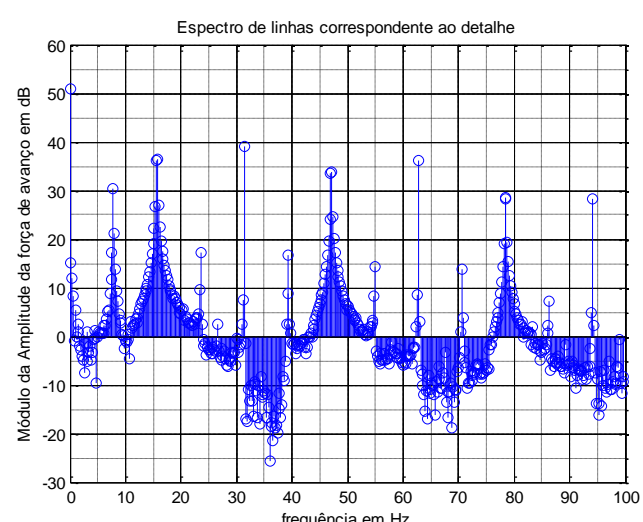

(b)

Figura 4.63 (a)Espectro contínuo da força de avanço na região entre $0 \mathrm{~Hz}$ e $25 \mathrm{~Hz}$ (b)Espectro de linhas da mesma região da força de avanço com Cl e UCP de 1,5mm.

Uma análise mais acurada da oscilação de entrada em corte da força de avanço permite estabelecer um período aproximado de 5,75ms para a componente oscilante amortecida que é mostrada na figura 4.64(a). Isto indica que deve haver uma componente oscilante de boa amplitude próximo a $174 \mathrm{~Hz}$, o que é comprovado na figura $4.64(\mathrm{~b})$ as distorções relacionadas a baixa frequência de amostragem do processo provoca componentes laterais na figura.

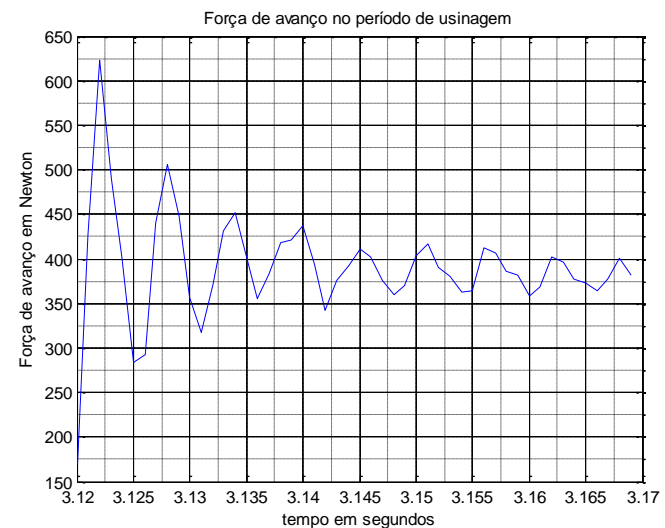

(a)

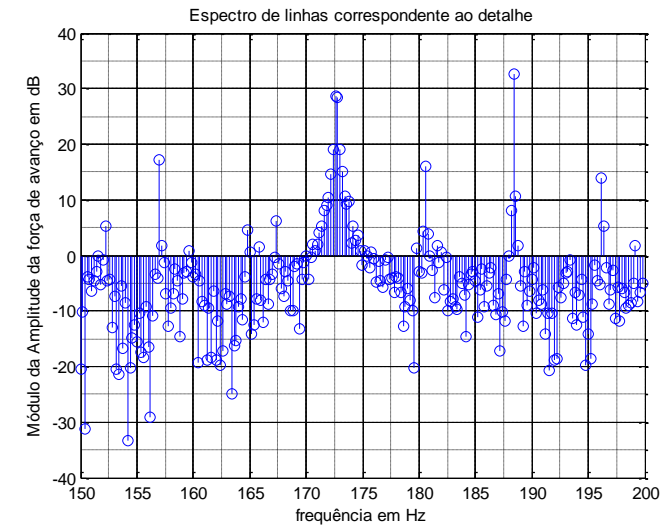

(b)

Figura 4.64 (a) Acomodação oscilante da força de avanço e a região relacionada com a mesma no espectro de frequências (b)

Observa-se na figura 4.65(a) que ocorrem aproximadamente 9 picos oscilatórios entre 3,12 e 3,15s de modo que podemos calcular, por inspeção da 
figura 4.65(a) a componente relativa a esta oscilação embora ela não seja estacionária:

$$
f_{o s c}=\frac{9}{3,17-3,12}=180 \mathrm{~Hz}
$$

Que é um valor próximo a $172 \mathrm{~Hz}$ é importante verificar que esta componente é não estacionária, a FFT acusa sua presença porque ela aparece periodicamente no corte interrompido e esta ação de periodicidade é detectada.

\subsection{Modelagem do sistema do porta-ferramentas}

Se considerarmos o sistema ferramenta mais porta-ferramentas com massa na forma mostrada na figura 4.66, podemos utilizar os dados da figura 4.67para obter um valor aproximado do tempo de subida da força de corte e o tempo relativo de pico para calcular os coeficientes do efeito mola e do amortecedor equivalente associado ao sistema. Da figura 4.67 obtemos o valor aproximado do tempo de subida $t_{r}=0,02 s$ e 0 valor do pico relativo $M_{p}=$ $\frac{420-350}{350}=0,2$, de onde calculamos o fator de amortecimento $\zeta=0,397$, a frequência amortecida $\omega_{d}=157,08 \mathrm{rad} / \mathrm{s}$ e a frequência natural não amortecida $\omega_{n}=144,2 \mathrm{rad} / \mathrm{s}$ e desses valores, utilizando as expressões deduzidas no capítulo 2.2.2, calculamos os coeficientes da mola $k=m_{p f f} \omega_{n}^{2}=$ $m_{p f f} 157,08^{2}$ e do amortecedor $c=2 \zeta \sqrt{m_{p f f} k}$.

Onde $m_{p f f}$ é a massa do porta-ferramentas mais a massa da ferramenta.

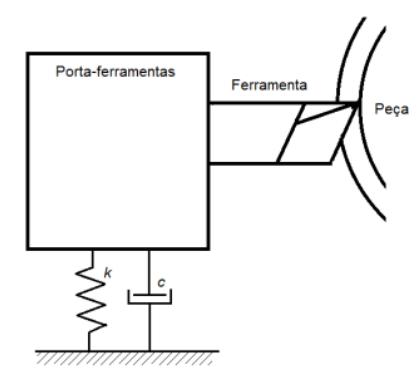

Figura 4.65 Modelo matemático do porta-ferramenta na operação de usinagem 


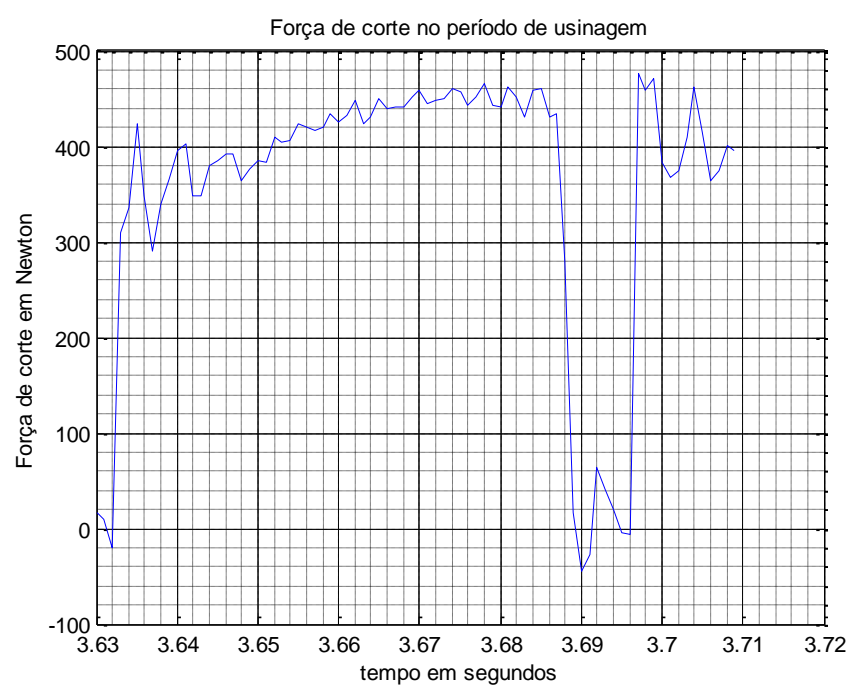

Figura 4.66 Força de corte com Cl e UCP de 1,0mm

Os valores não foram efetivamente calculados em função do carro principal de uma máquina antiga não ter rigidez estacionária grande o sufiente para considerarmos o mesmo sem movimento, esta condição nos obrigaria a incorporar a massa do carro a $m_{p f f}$ o que é pouco prático.

Disso conclui-se que a medição da transmissibilidade de força $T_{f}$ entre o porta-ferramentas e o carro longitudinal fica prejudicada nesta aplicação.

\subsection{Conclusões do capítulo 4}

Neste capítulo foi desenvolvida um a série de análises espectrais das operações realizadas com o dinamômetro Kistler onde se destaca:

1. Inicialmente o dinamômetro é utilizado como acelerômetro com a máquina em vazio e capta uma forte oscilação estacionária em torno de $8 \mathrm{~Hz}$ assim como uma oscilação de $360 \mathrm{~Hz}$ presente com mais ênfase na força de avanço.

2. Nos passes contínuos nas várias profundidades a vibração de $7,8 \mathrm{~Hz}$ se mantém, mas seus de lóbulos laterais são contínuos com indício de oscilações periodicamente não estacionárias em seu entorno.

3. Em algumas situações com passe contínuo algumas componentes de dominantes locais do espectro se deslocam discretamente para a 
esquerda e se aglutinam devido a resposta forçada do conjunto mecânico.

4. Não se observa efeitos do desequilíbrio de fase da rede elétrica sobre as forças, mas observa-se, na maioria dos casos de corte contínuo, uma pequena componente de $360 \mathrm{~Hz}$ resultante dos efeitos da $5^{\underline{a}}$ e $7^{\text {a }}$ harmônicas presentes na corrente do motor. Deve-se observar que 0 motor está pouco carregado utilizando apenas uma pequena fração de sua potência nominal. Isso já foi observado no capítulo 3 deste trabalho, em casos de maior carregamento este efeito deve desaparecer ou tornar-se irrelevante.

5. Na situação de corte interrompido a presença da interrupção gera uma componente caracterizada com uma série temporal com frequência de aproximadamente $15,8 \mathrm{~Hz}$, que "coincidentemente" é o dobro da frequência de oscilação natural já observada no item 1. Isto gera uma modulação em amplitude da componente de $15,8 \mathrm{~Hz}$ pela componente de $7,8 \mathrm{~Hz}$.

6. A "coincidência" do item 5 está relacionada a velocidade de operação do eixo árvore do torno, o qual tem associado a si um desbalanceamento de massas e a operação de corte interrompido ocorre exatamente com o dobro da frequência relativa a esta velocidade.

7. O perfil do sinal de corte interrompido permite a determinação da frequência de oscilação natural e do fator de amortecimento do conjunto mecânico associado a ferramenta $e$ ao porta-ferramenta. A determinação do fator de elasticidade $\boldsymbol{k}$ e do coeficiente de atrito viscoso $\boldsymbol{c}$ do amortecedor equivalente do conjunto mecânico, só não foi possível porque isso depende da massa do carro principal do torno cuja pesagem foi impraticável.

8. O perfil das operações de corte interrompido exibem uma componente não estacionária associada a frequência de corte interrompido que somente é detectada pela FFT devido a periodicidade do corte interrompido. Uma análise desta componente somente é possível utilizando métodos não estacionários como a transformada de wavelet ou a transformada de Hilbert-Huang. 
Análise das vibrações de uma máquina ferramenta utilizando os dados de um dinamômetro Kistler com a HHT e a WT

\subsection{Estratégias utilizadas para a análise dos sinais do dinamômetro}

As figuras 5.1 (a) a (c) exibem os perfis dos torques estimados em várias situações operacionais da máquina ferramenta em ensaios de corte contínuo partindo da situação em vazio e entrando em contato com a peça a ser usinada, o que é indicado pela mudança do nível da força de corte, aumentando quase que bruscamente ou diminuindo da mesma forma.

Os perfis exibidos nas figuras 5-1 (a) a (c), estão relacionados com esforços realizados pela máquina ferramenta para usinar um tarugo de $39,9 \mathrm{~mm}$ de diâmetro que já havia sido pré-usinado, o material do tarugo era de aço 52100 e a usinagem neste caso foi realizada em regime de corte contínuo com velocidade média de avanço da ferramenta de $100 \mathrm{~m} / \mathrm{min}$. A ferramenta utilizada para a usinagem era de metal duro, nova e estava fixada com um ângulo de corte de $90^{\circ}$ em relação a peça em usinagem.

Os ensaios foram projetados para a realização de passes com $0,5 \mathrm{~mm}$, $1,0 \mathrm{~mm}$ e $1,5 \mathrm{~mm}$ progressivamente com duração total de 10 segundos, embora 
o teste efetivo seja realizado em 6 segundos de operação de usinagem, o sincronismo com o sistema de aquisição foi realizado manualmente.

O objetivo do ensaio é obter os modos vibratórios da máquina ferramenta via dinamômetro para posterior comparação com as mesmas medições realizadas com o estimador de torque e verificar a confiabilidade deste último como instrumento de medição de forças de corte e vibrações do sistema máquina ferramenta $x$ processo de usinagem.

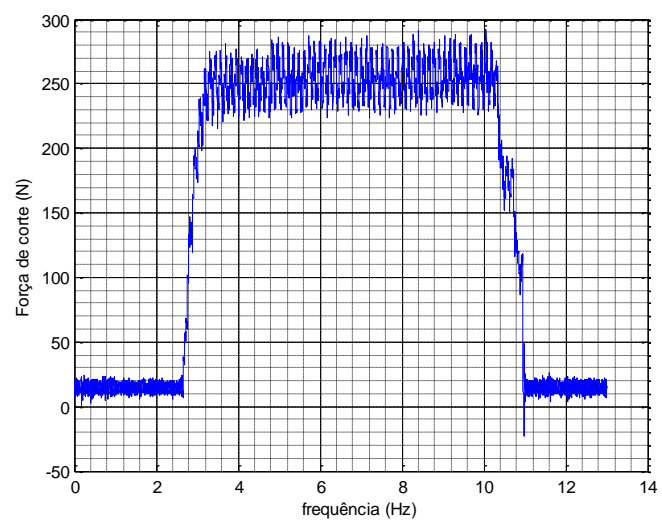

(a)

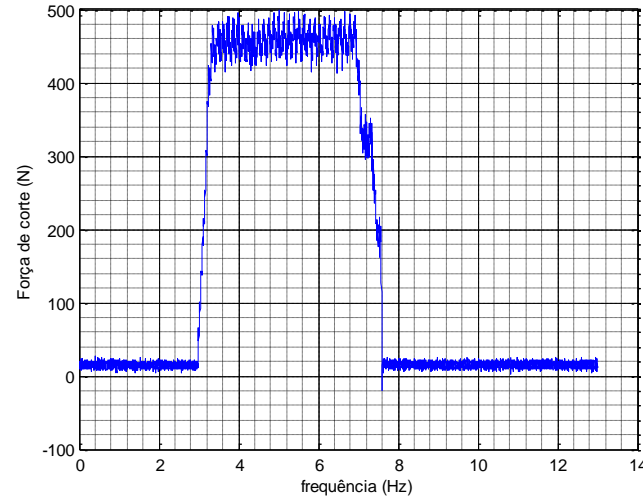

(b)

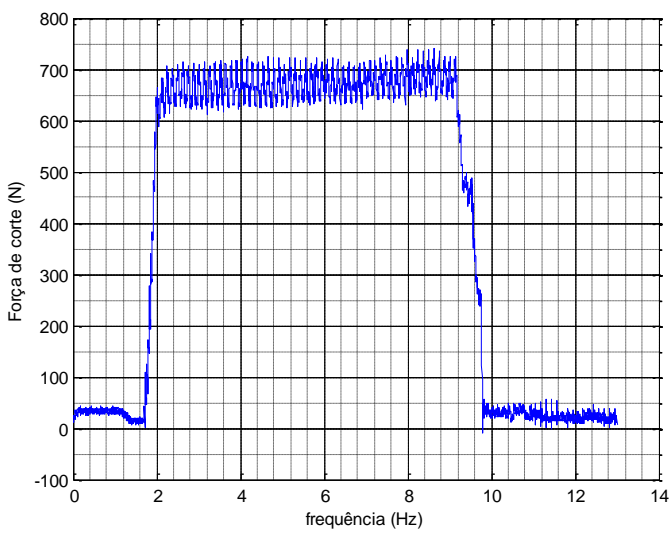

(c)

Figura 5-1 Perfis das forças de corte medidas pelo dinamômetro Kistler para as condições de carregamento da máquina ferramenta operando com corte contínuo e passe de $0,5 \mathrm{~mm}$ de profundidade (a), passe de $1,0 \mathrm{~mm}$ de profundidade (b), passe de $1,5 \mathrm{~mm}$ de profundidade(c).

Todas as situações mencionadas são analisadas utilizando a transformada de Fourier, tomada como referência para o estudo das oscilações 
estacionárias e a transformada de Hilbert-Huang, buscando informações mais detalhadas da operação de usinagem dentro do cenário experimental efetuado.

Alguns aspectos práticos relevantes da HHT se relacionam ao modo como a mesma funciona utilizando as interpolações polinomiais, ou splines para definir as envoltórias superior e inferior do sinal sob análise. O método exige a existência de pontos de picos positivos e negativos no processo, o que torna-se problemático quando as componentes de alta frequência do sinal são retirados, nas primeiras etapas do processo de peneiramento.

Quando o sinal peneirado passa a ser processado em suas componentes de baixas frequências ocorre naturalmente uma diminuição dos sinais de pico, que são nulos para sinais contínuos no tempo, o que elimina definitivamente o uso das splines e consequentemente leva o processo da HHT a um limite natural, isso é acentuado em sistemas de aquisição de dados com frequência de amostragem baixa, como é o caso do dinamômetro Kistler utilizado nesse trabalho, cuja taxa de amostragem máxima é $1000 \mathrm{~Hz}$.

A aplicação do métodos da HHT realizada neste trabalho a partir dos dados obtidos pelo dinamômetro Kistler, permite a obtenção de 6 a 9 funções de modo implícito (IMF), o que não incorpora o valor médio, já que a frequência do mesmo é zero, o que é de se esperar, já que a transformada de Hilbert (HT) de um valor contínuo é zero.

Outra observação que se faz necessária é a taxa de amostragem máxima do dinamômetro Kistler que foi utilizada nos experimentos, isso indica que o método de obtenção da função analítica, e mesmo a FFT, suporta uma frequência máxima de $500 \mathrm{~Hz}$, com isso as componentes significativas serão menores que $500 \mathrm{~Hz}$.

\subsubsection{A organização geral dos resultados}

Para definir melhor os dados apresentados na forma de gráficos, cujo volume tornou-se significativo neste trabalho, tais gráficos foram colocados nos apêndices A, B, C, D, E, F e G da seguinte forma: 
1. O apêndice A contém os gráficos relativos aos módulos, fases e frequências instantâneas das funções analíticas das IMFs obtidas dos dados do estimador de torque na entrada de energia do motor de indução da máquina ferramenta operando com usinagem com cortes contínuo e interrompido.

2. O apêndice B contém os gráficos relativos aos módulo, fases e frequências instantâneas dos sinais analíticos da IMFs obtidas dos dados do dinamômetro Kistler nas condições de corte contínuo e interrompido.

3. O apêndice $C$ contém as IMFs extraídas dos dados do estimador de torque para as situações de corte contínuo e interrompido.

4. O apêndice D contém as IMFs extraídas dos dados do dinamômetro Kistler para as situações de corte contínuo e interrompido.

5. O apêndice $E$ contém os resultados da aplicação da transformada de wavelet aos dados do estimador de torque e do dinamômetro nas duas situações abordadas,ou seja a de passe contínuo e a interrompido.

Para a análise dos dados obtidos via HHT, tomou-se como referência, a análise espectral realizada no capítulo 4 para a condição da força de corte, que é a mais significativa das forças analisadas e está bastante relacionada com o torque eletromagnético do motor de indução. Vamos iniciar com os resultados obtidos na situação de usinagem com corte contínuo e passe com profundidade de $0,5 \mathrm{~mm}$.

\subsection{Relações entre o espectro (FFT) e a HHT dos dados do dinamômetro}

\subsubsection{Usinagem com corte contínuo e UCP de 0,5mm}

A região de interesse, baseada nos dados apresentados na figura 5-1(a) apresentou, sob a análise do modo de decomposição empírico (EMD), entre seis e sete funções de modo intrínseco (IMF) cujas funções analíticas estão relacionadas com o espectro obtido na mesma situação e mostrado na figura 5 - 
2 com a supressão da componente média para evidenciar as componentes oscilatórias.

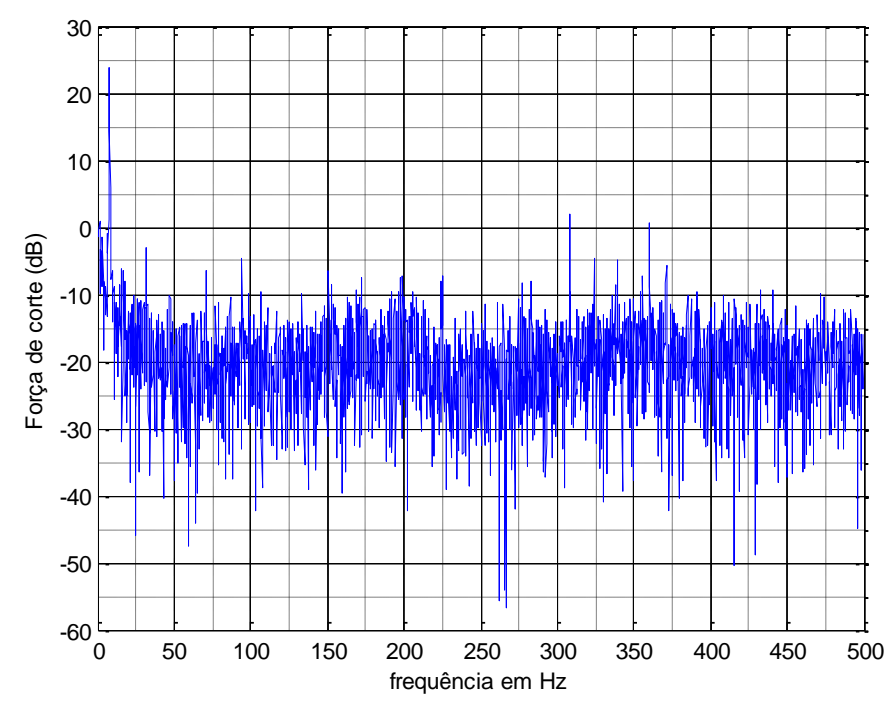

Figura 5-2 Espectro do sinal do dinamômetro Kistler com o torno executando ucp de $0,5 \mathrm{~mm}$ sem a presença da componente de frequência média

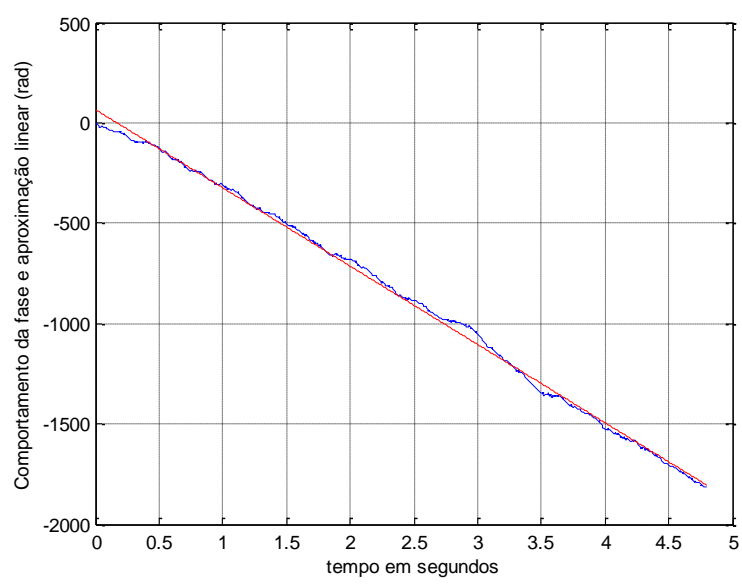

Figura 5-3 Inversão de fase do sinal analítico da primeira IMF devido as componentes da mesma terem frequências maiores que $1 / 4$ da frequência de amostragem (fmédia $=-62 \mathrm{~Hz}$ )

A IMF de frequência mais alta contém um grupo de frequências cujos valores podem ser observados por inspeção diretamente da figura 5-3, e ocorrem entre as frequências 300 a $375 \mathrm{~Hz}$, o fato dessas frequências estarem localizadas acima do valor de um quarto da frequência de amostragem provoca uma inversão na fase do sinal analítico, gerando uma frequência média negativa de modo que o valor real da frequência média passa a ser complemento para a metade da frequência de amostragem, ou seja $500 \mathrm{~Hz}$ 
para o caso em pauta. Assim se a frequência média for $-62,05 \mathrm{~Hz}$, o valor real da mesma é 500-62,05 = 437,95Hz, isso é mostrado na figura 5-2. As análises relativas a essa IMF são descartadas nesse trabalho.

Do espectro da figura 5-1 observam-se algumas componentes oscilatórias estacionárias acima de $300 \mathrm{~Hz}$ cujo espectro é evidenciado na figura 5-4(b) para a observação do detalhe do sinal nesta região espectral. A figura 5-4(b) indica a presença de uma componente do sinal com $360 \mathrm{~Hz}$, que podemos inferir que seja um efeito das $5^{\underline{a}}$ e $7^{\underline{a}}$ harmônicas da corrente elétrica que aparecem como vibração mecânica sobre a usinagem. Já a componente fixada em $308 \mathrm{~Hz}$ é um efeito mecânico da usinagem que pelo valor e intensidade parece ser o efeito de quebra de cavaco mencionado como um fenômeno periódico por Ferraresi (Ferraresi,1977). Como já discutido acima, esse grupo não é detectado pela metodologia de geração da HT utilizada nesse trabalho, outras componentes de menor módulo aparecem, mas tudo indica que são interações dessas duas componentes principais.

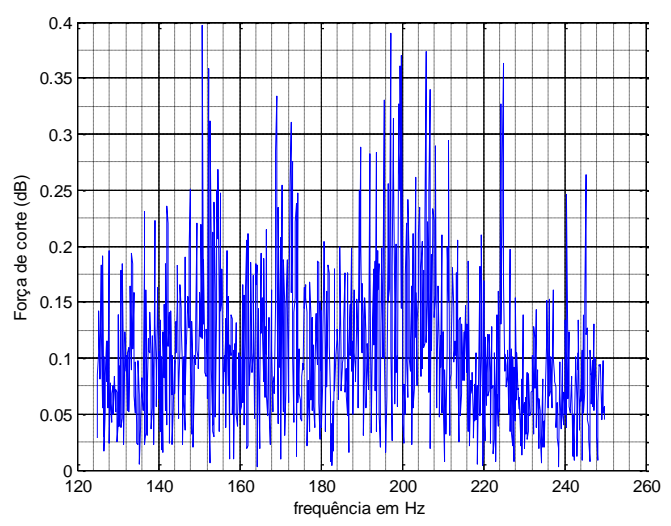

(a)

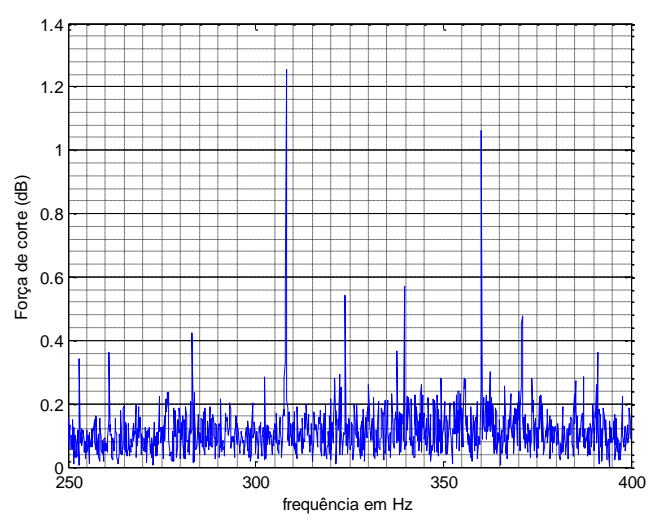

(b)

Figura 5-4 Espectros locais de algumas componentes mais evidentes nas regiões de frequências mais altas. O caso (a) é detectado na IMF-1.

A figura 5-4(a) possui um grupo de frequências correspondentes a IMF1, lembrando que descartamos a primeira IMF devido a inversão de fase, 0 valor médio detectado pela IMF-1 correspondente a esse grupo é $128,9 \mathrm{~Hz}$, como indica a tabela 5-1 e a frequência máxima determinada numericamente a partir da inclinação máxima da curva de fase do sinal analítico é $223,9 \mathrm{~Hz}, 0$ que corresponde aproximadamente a banda do sinal mostrado na figura 5-4(a). 
A IMF-2, de acordo com a tabela 5-1, corresponde a uma faixa de frequências entre 79 e $150 \mathrm{~Hz}$ e seu espectro é mostrado na figura 5-5(a), mas corresponde a um grupo de baixa energia, ou de componentes com pequena influência sobre a força de corte. Já a IMF-3 corresponde a uma oscilação da máquina ferramenta que aparece na força de corte com nível $360 \mathrm{Hzde}$ força muito pequeno, sendo seu grupo espectral mostrado na figura 5-5(b).

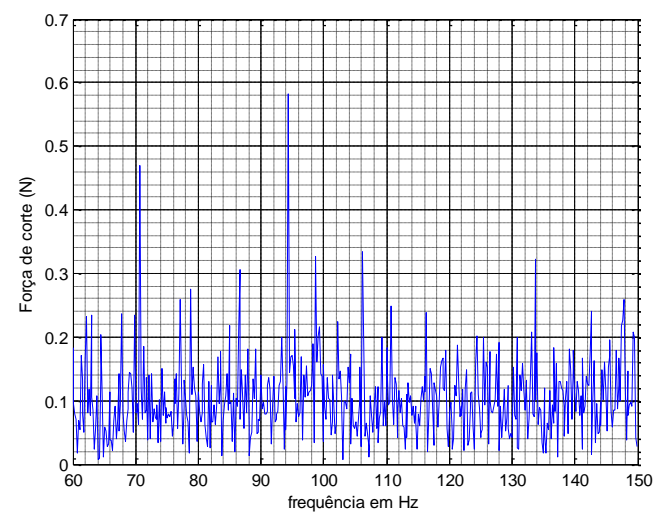

(a)

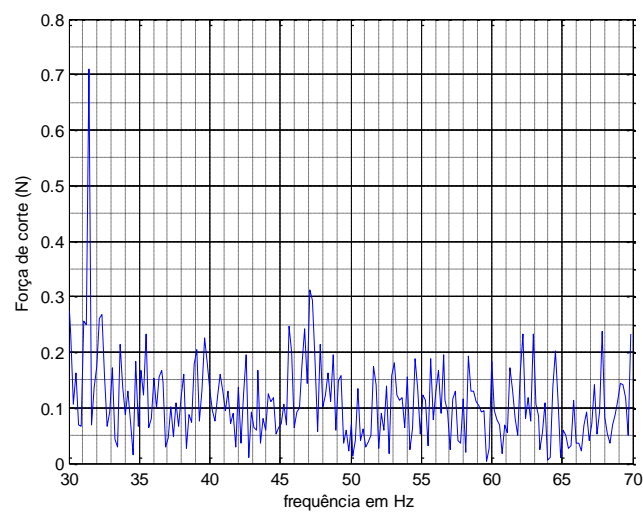

(b)

Figura 5-5 Espectros locais referentes as IMF-2(a) e IMF-3(b)

A IMF-4 possui uma parcela apreciável do conteúdo oscilatório da usinagem, o seu grupo possui frequência média $7,56 \mathrm{~Hz}$ e módulo $16,20 \mathrm{~N}$ e seu espectro é mostrado na figura 5-6, que também mostra o espectro da parte mais baixa dos grupos correspondentes as IMF-5 e IMF-6.

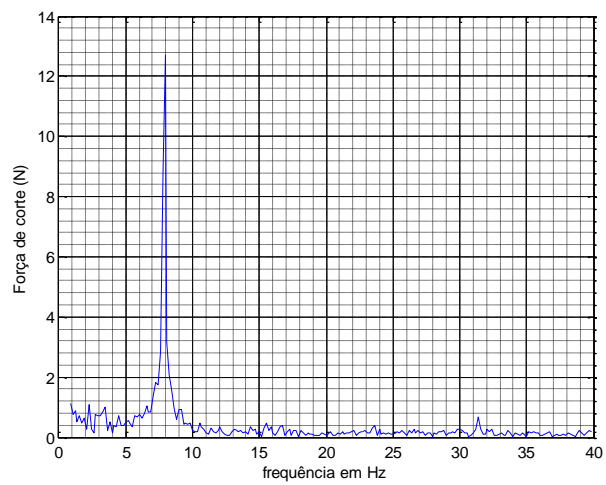

Figura 5-6 Parcela de baixas frequências do espectro da força de corte

Um dado interessante, relaciona os módulos da força de corte obtidos da IMF-4 com o observado na figura 5-6. Na IMF-4 temos $16,2 \mathrm{~N}$ e no espectro temos aproximadamente $13 \mathrm{~N}$, se considerarmos que o dado do espectro 
corresponde a apenas uma componente e o da IMF a um grupo de componentes pode-se inferir que, em uma versão estacionária, a força total associada a cada IMF corresponde a força total do grupo de componentes que a constitui, e isso pode se estender para o torque ou qualquer outro tipo de sinal sob análise.

A tabela 5-1 corresponde as seis IMFs detectadas a partir dos dados do dinamômetro mostrados na figura 5-1(a).

Tabela 5-1: Características da HHT do sinal de torque com corte contínuo e passe de $0,5 \mathrm{~mm}$

\begin{tabular}{|c|c|c|c|c|}
\hline IMF & $\begin{array}{c}\text { Fase (linearizada) } \\
\text { (radianos) }\end{array}$ & $\begin{array}{c}\text { Frequência } \\
\text { (média) }(\mathrm{Hz})\end{array}$ & $\begin{array}{c}\text { Frequência } \\
\text { máxima } \\
\text { (média) }(\mathrm{Hz})\end{array}$ & $\begin{array}{c}\text { Força de } \\
\text { corte } \\
\text { (média) }(\mathrm{N})\end{array}$ \\
\hline 1 & $\psi(t)=814,69 t+30,4$ & 129,66 & 237,34 & 3,02 \\
\hline 2 & $\psi(t)=500,53 t+30,44$ & 79,66 & 163,05 & 1,81 \\
\hline 3 & $\psi(t)=206,48 t+47,81$ & 32,86 & 92,58 & 1,62 \\
\hline 4 & $\psi(t)=47,720 t+5,340$ & 7,59 & 28,06 & 16,97 \\
\hline 5 & $\psi(t)=17,230 t-4,644$ & 2,74 & 26,15 & 1,64 \\
\hline 6 & $\psi(t)=6,969 t+1,369$ & 1,10 & 3,11 & 2,23 \\
\hline
\end{tabular}

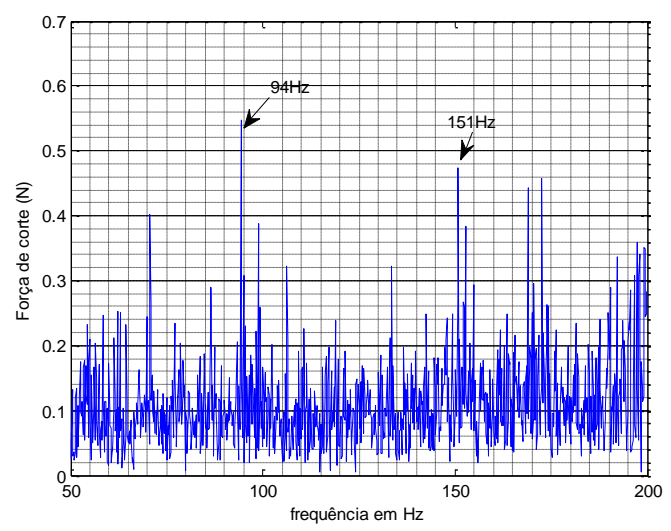

Figura 5-7 Espectro da região detectada pela HHT nas IMFs 3 e 4

As figuras 5-7 e 5-8 (a) e (b) permitem uma comparação visual entre as regiões espectrais correspondentes as IMF-1 e IMF-2 com os resultados da análise do sinal analítico correspondente a ambas, de modo que a componente espectral de $94 \mathrm{~Hz}$ na figura 5-7 está associada ao grupo de frequências da IMF-2 mostrado na figura 5-8(b). Enquanto que a componente de $151 \mathrm{~Hz}$ está associado ao grupo de componentes detectado pela IMF-1 e mostrado na figura 5-9(a). As figuras 5-9(a) e 5.9 (b) correspondem aos módulos das IMF 1 e 2 . 


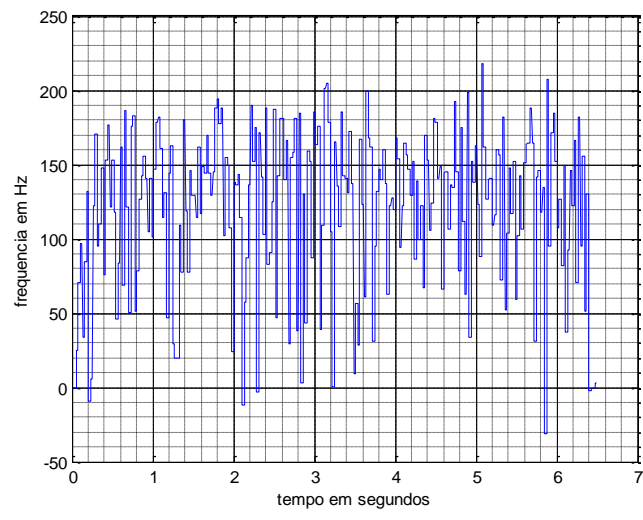

(a)

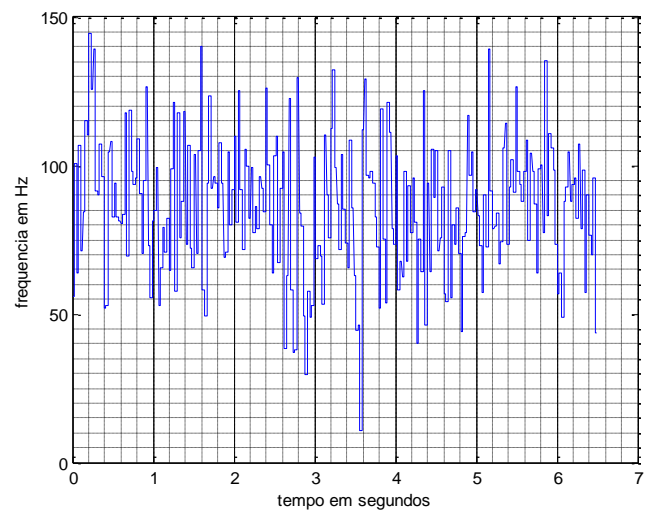

(b)

Figura 5-8 Frequências das IMF-1 (a) e IMF-2 (b) em função do tempo

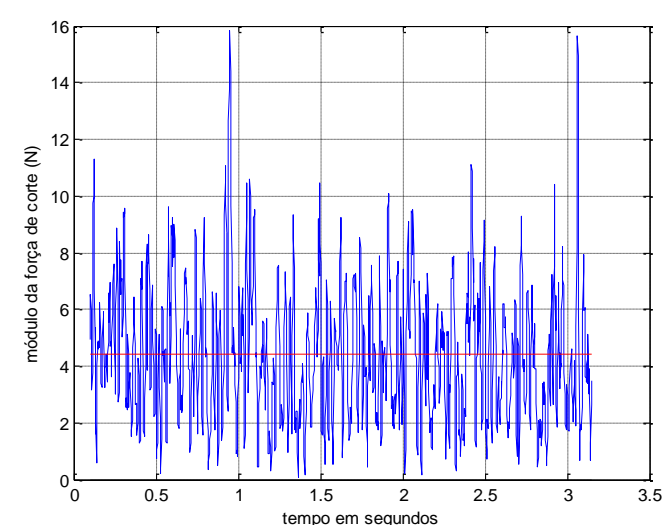

(a)

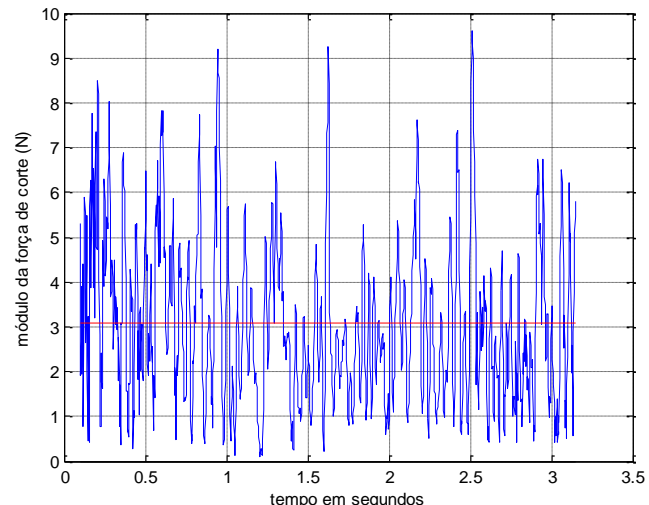

(b)

Figura 5-9 Módulos das IMF-1 (a) e IMF-2 (b) em função do tempo

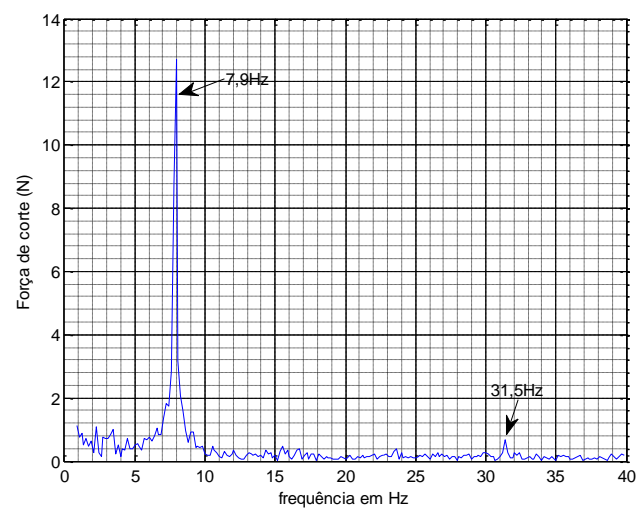

Figura 5-10 Espectro da região detectada pela HHT nas IMFs 3 e 4

A mesma análise realizada acima pode ser aplicada as IMFs 3 e 4, cujo conteúdo espectral é mostrado, mais uma vez, na figura 5-10 e os conteúdos de frequência são mostrados na figura 5-11(a) para o grupo da IMF-3 e na 
figura 5-11(b) para o grupo da IMF-4. O comportamento do grupo da IMF-3 é mais caótico porque em função do baixo carregamento da máquina ferramenta, suas oscilações naturais ou "livres" predominam, enquanto que o grupo de componentes da IMF-4 é muito mais consistente e os picos que ocorrem são relativos a eventos transitórios presentes no processo de usinagem.

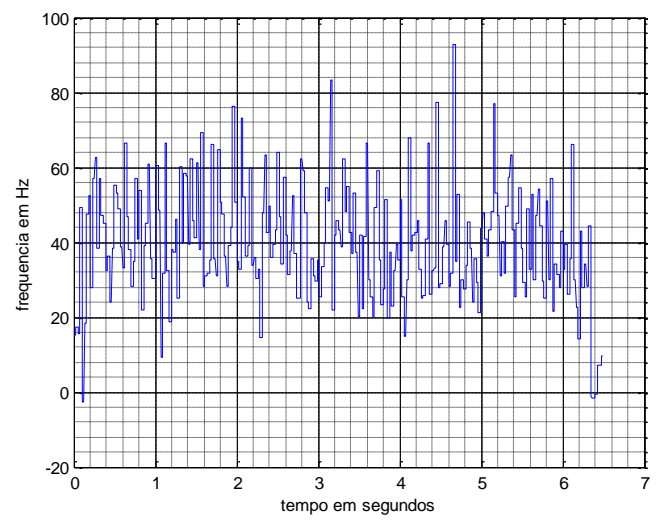

(a)

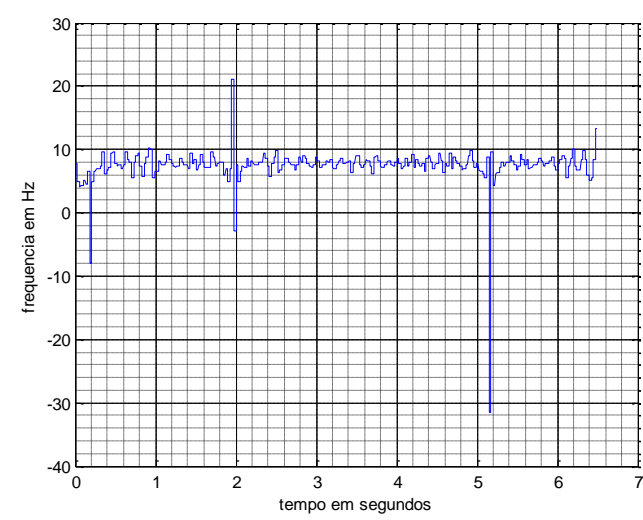

(b)

Figura 5-11 Frequências das IMF-3 (a) e IMF-4 (b) em função do tempo

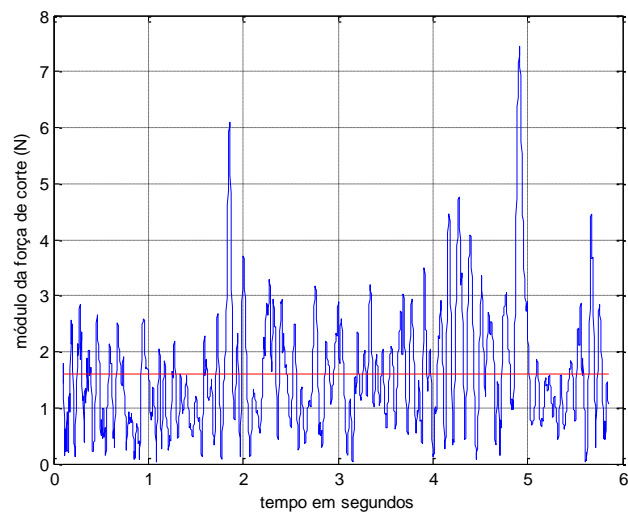

(a)

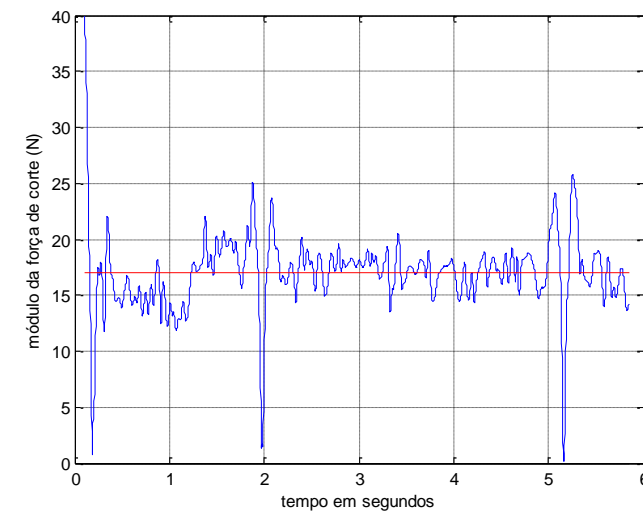

(b)

Figura 5-12 Módulos das IMF-3 (a) e IMF-4 (b) em função do tempo

As figuras 5-12 (a) e (b) correspondem aos módulos das IMF-3 e IMF-4, pode-se perceber em uma comparação entre as figura 5-11(a) e 5-12(a) que uma forte queda na frequência próxima a $1,8 \mathrm{~s}$ acarretou um pico positivo no módulo dessa IMF, e o mesmo ocorre com a IMF-4 quando um pico negativo em aproximadamente 2 segundos acarreta um pico positivo de frequência no mesmo instante do tempo. Em uma relação de causa e efeito fica claro que a 
variação da força do processo de usinagem, indicada no módulo, provocou as variações correspondente na frequência.

O conteúdo espectral correspondente as IMFs 5 e 6 é mostrado na figura 5-13 e as frequências correspondentes a essas IMFs são mostradas nas figuras 5-14 (a) e (b), assim como os módulos estão nas figuras 5-15 (a) e (b).

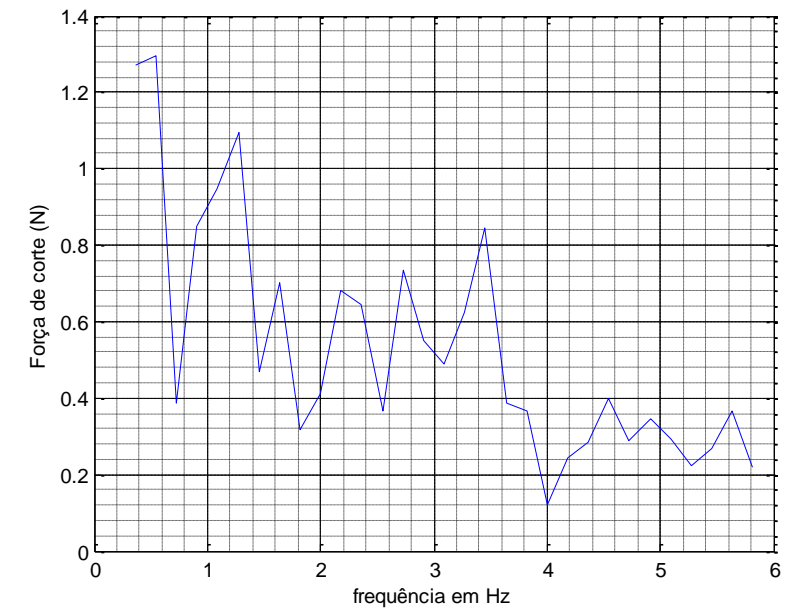

Figura 5-13 Conteúdo espectral relativo as IMFs 5 e 6

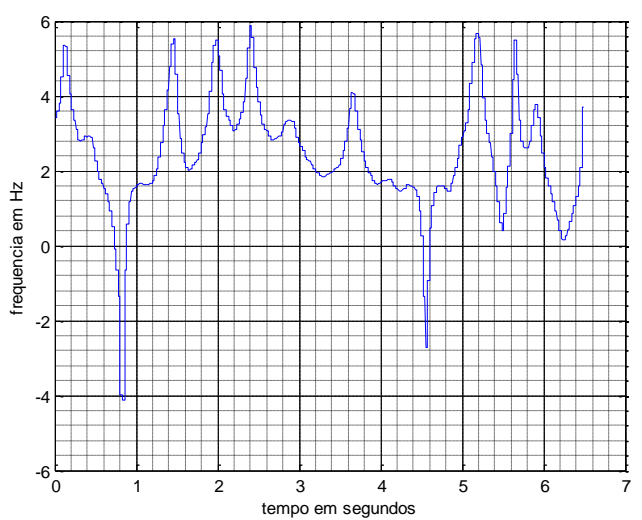

(a)

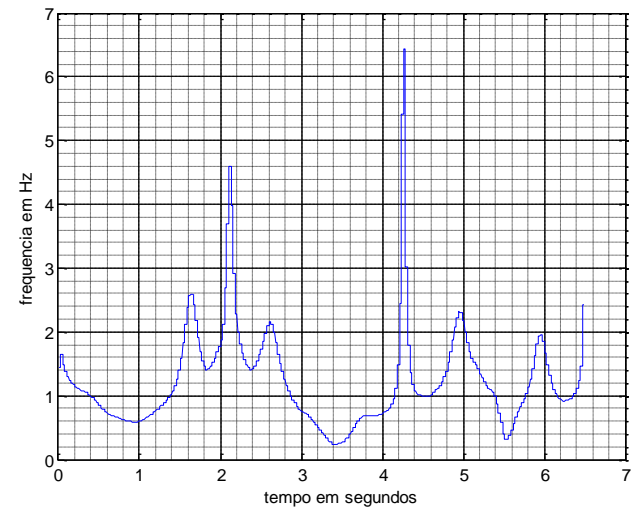

(b)

Figura 5-14 Frequências das IMF-5 (a) e IMF-6 (b) em função do tempo 


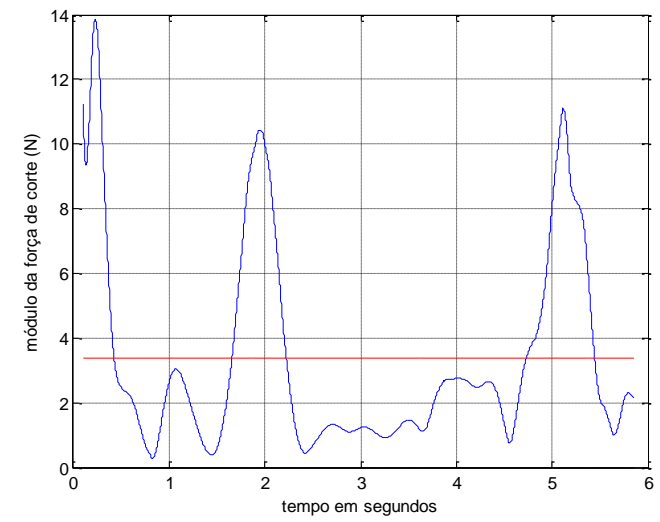

(a)

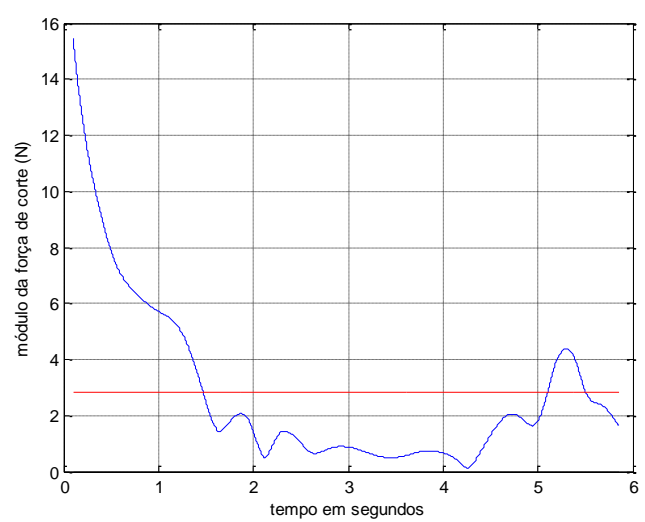

(b)

Figura 5-15 Módulos das IMF-5 (a) e IMF-6 (b) em função do tempo

Uma correlação de causa e efeito entre as componentes de frequência e módulo, para as IMFs 5 e 6, torna-se quase impossível devido a baixa velocidade e valor em que essa componente ocorre, além do que os efeitos laterais devido as splines são bastante evidentes principalmente nos módulos.

O conjunto de gráficos relativo aos resultados obtidos nesse item, estão disponíveis no apêndice $\mathrm{C}$ deste trabalho.

\subsubsection{Usinagem com corte contínuo e passe de 1,0mm}

Uma análise espectral dos dados da força de corte obtida pelo dinamômetro é mostrada na figura 5-16 onde a escala logarítmica permite perceber a relevância do conjunto de frequências entre $150 \mathrm{~Hz}$ e $225 \mathrm{~Hz}$ e entre $300 \mathrm{~Hz}$ e $400 \mathrm{~Hz}$ que são analisadas em detalhes nas figuras 5-17 (a) e (b), respectivamente, esse último caso não será analisado aqui usando a HHT devido ao efeito de inversão de fase da HHT já discutido.

A análise espectral do conjunto de frequências superiores, mostrado na figura 5-18(b) indica uma forte componente local de $340 \mathrm{~Hz}$ com módulo igual a $1,25 \mathrm{~N}$, com bandas laterais de $308 \mathrm{~Hz}$ e $372 \mathrm{~Hz}$ com módulos aproximados de $0,9 \mathrm{~N}$ e portanto trata-se de uma componente com modulação em amplitude que pode ser descrita pela expressão $(1,25+0,9 \cos (2 \pi 32 t)) \cos (2 \pi 340 t)$ e sua origem é mecânica, como no caso de usinagem com passe de $0,5 \mathrm{~mm}$ foi detectada uma componente de origem mecânica de $308 \mathrm{~Hz}$, aparentemente 
sem banda laterais, essa componente parece um progressão daquela sob condições de um passe de maior profundidade e energia.

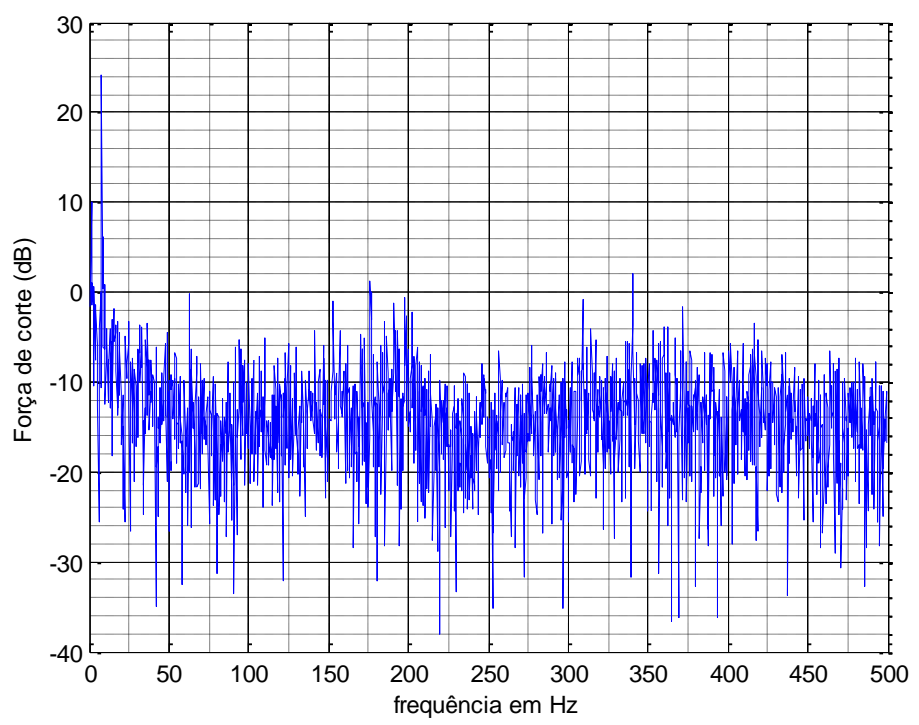

Figura 5-16 Espectro total dos dados da figura 5-1(b) (passe de 1,0mm)

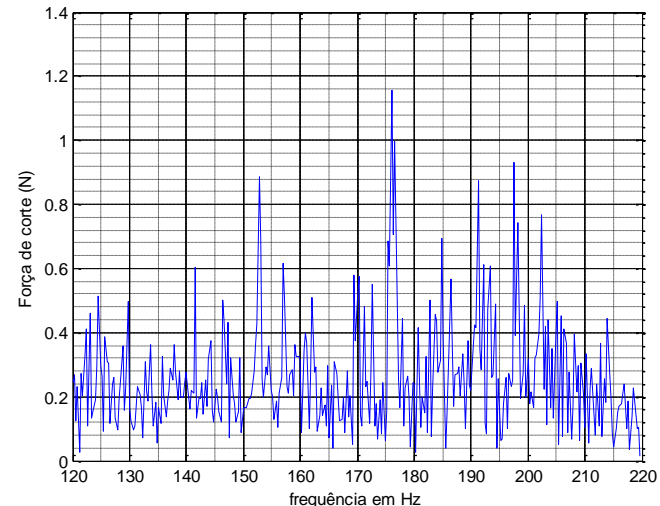

(a)

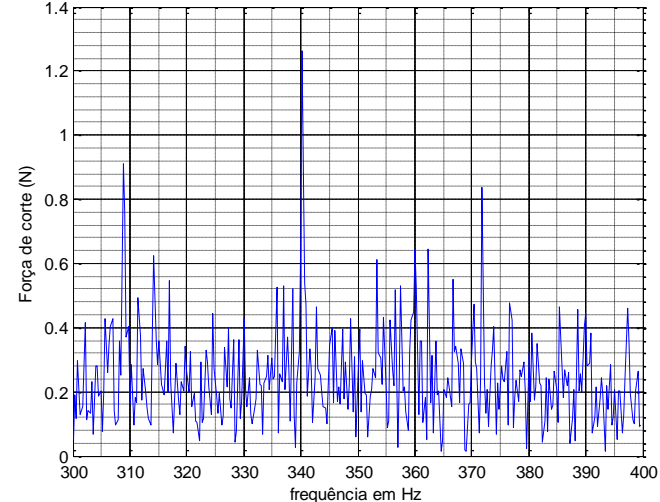

(b)

Figura 5-17 Regiões espectrais com oscilações estacionárias relevantes

A componente dominante local com frequência de $176 \mathrm{~Hz}$ sem bandas laterais que pode ser vista na figura 5-17(a) está no grupo da IMF-1, mostrado na tabela 5-2 e já detectada na situação do passe anterior como ocorreu uma concentração maior de energia nessa componente, a frequência média da IMF1 se aproximou da mesma, mas como o conjunto de componentes espectrais de módulo localmente significativo é denso não ocorre um identidade mais específica entre o valor médio da frequência média relativa a IMF-1 que é $131 \mathrm{~Hz}$ com a da componente espectral dominante com $176 \mathrm{~Hz}$. 
Tabela 5-2: Características da HHT do sinal de torque com corte contínuo e passe de $1,0 \mathrm{~mm}$

\begin{tabular}{|c|c|c|c|c|}
\hline IMF & $\begin{array}{c}\text { Fase (linearizada) } \\
\text { (radianos) }\end{array}$ & $\begin{array}{c}\text { Frequência } \\
\text { (média) }(\mathrm{Hz})\end{array}$ & $\begin{array}{c}\text { Frequência } \\
\text { máxima } \\
\text { (média)(Hz) }\end{array}$ & $\begin{array}{c}\text { Força de corte } \\
\text { (média) }(\mathrm{N})\end{array}$ \\
\hline 1 & $\psi(t)=813,36 t+15,27$ & 129,45 & 249,18 & 4,36 \\
\hline 2 & $\psi(t)=446,02 t+5,76$ & 70,98 & 234,06 & 2,82 \\
\hline 3 & $\psi(t)=156,25 t+30,63$ & 24,86 & 138,71 & 7,04 \\
\hline 4 & $\psi(t)=46,225 t+4,49$ & 7,35 & 26,57 & 14,87 \\
\hline 5 & $\psi(t)=13,37 t-6,54$ & 2,12 & 4,49 & 6,66 \\
\hline 6 & $\psi(t)=3,698 t+0,690$ & 0,59 & 3,65 & 8,11 \\
\hline
\end{tabular}

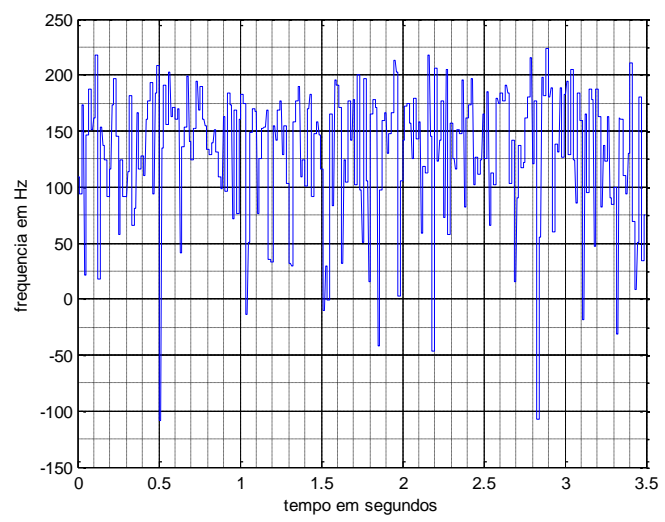

(a)

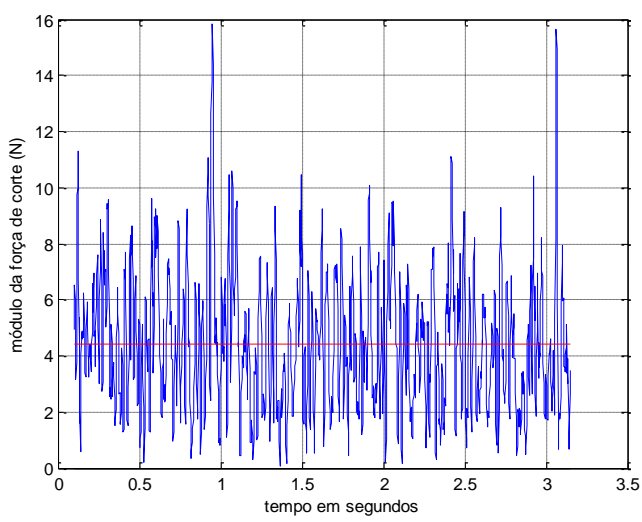

(b)

Figura 5-18 Frequência (a) e módulo (b) da IMF-1

As figuras 5-17(a) correspondente ao conteúdo espectral local e as figuras 5-18(a) e (b) permitem relacionar a IMF-1 e o conteúdo espectral detectado pela FFT.

A figura 5-19 mostra o espectro local das regiões detectadas pelas IMFs 2 e 3 onde existe uma predominância acentuada em alguns módulos presentes na IMF-3 em relação aos módulos da IMF-2, principalmente com relação a componentes de $63 \mathrm{~Hz}$ presente na IMF-3, as figuras 5-20(a), (b) trazem as frequências relativas a ambas IMFs respectivamente, assim como as figuras 520(c) e (d) trazem os respectivos módulos. 


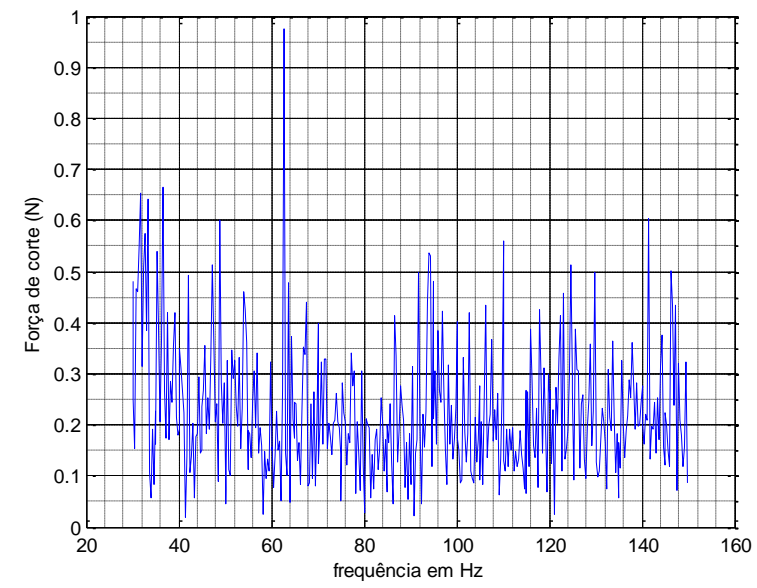

Figura 5-19 Conteúdo espectral correspondente as IMFs 2 e 3

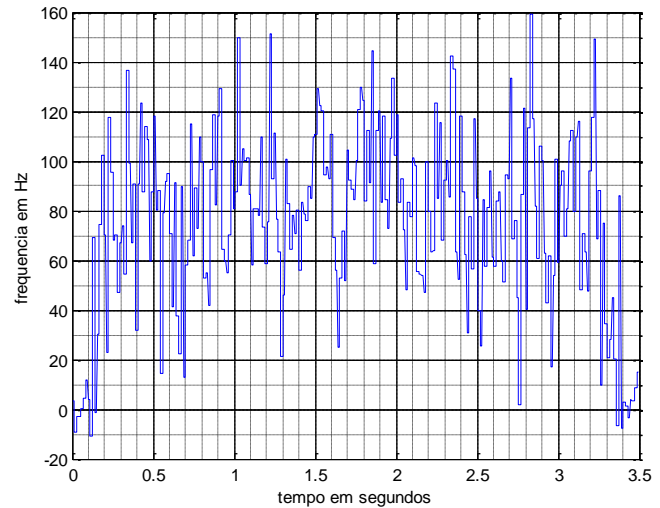

(a)

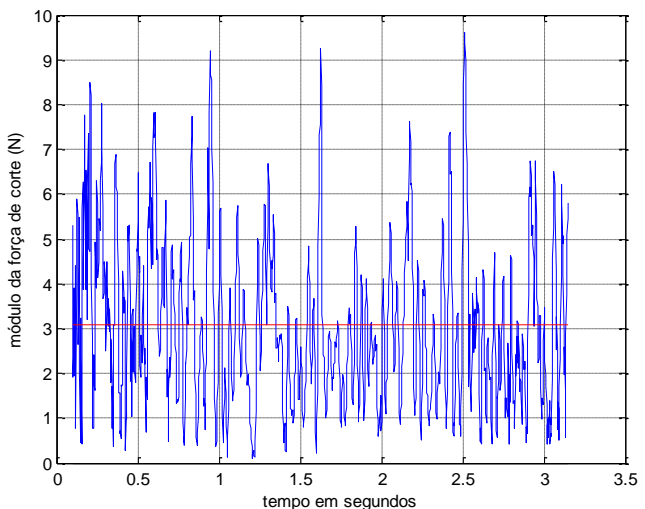

(c)

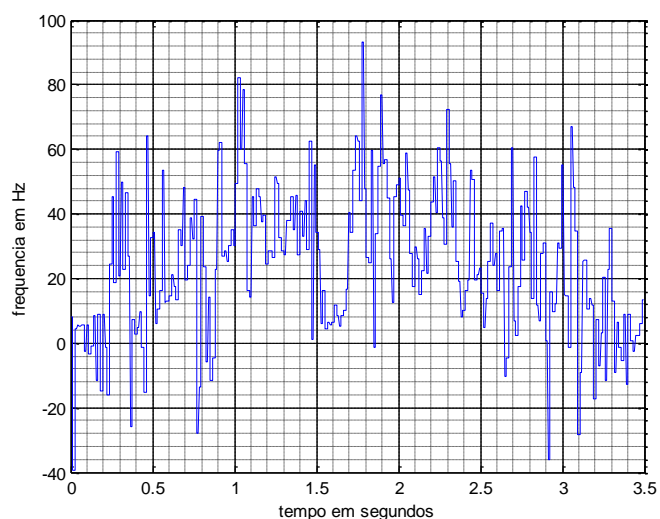

(b)

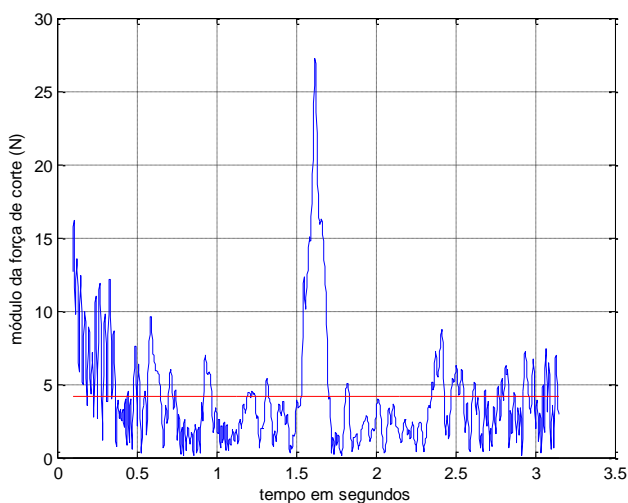

(d)

Figura 5-20 Frequência (a) e módulo (c) da IMF-2, frequência (b) e módulo (d) da IMF3

A figura 5-21 mostra o conteúdo espectral correspondente aos grupos das IMFs 4 e 5 onde a componente espectral dominante total em termos 
vibratórios é a componente de $7,9 \mathrm{~Hz}$ com módulo de $16 \mathrm{~N}$ e as figuras $5-22$ (a) e (b) trazem as frequências relacionadas as IMF-4 e IMF-5.

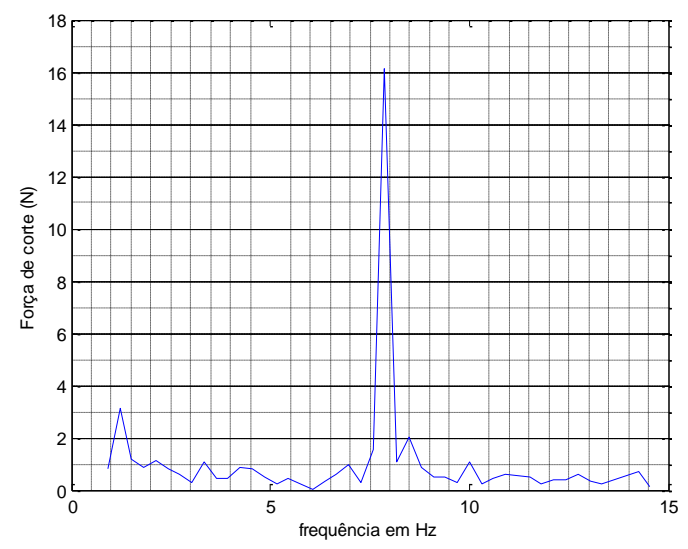

Figura 5-21 Espectro parcial das componentes relacionadas as IMFs 4 e 5

A figura 5-22 (a) mostra o comportamento da frequência em função do tempo e a 5-13(b) o comportamento do módulo em função do tempo onde é possível verificar por inspeção alguns efeitos transitórios no módulo, por exemplo o que ocorre no instante 2 segundos, acarreta um efeito imediato na frequência em um instante próximo.

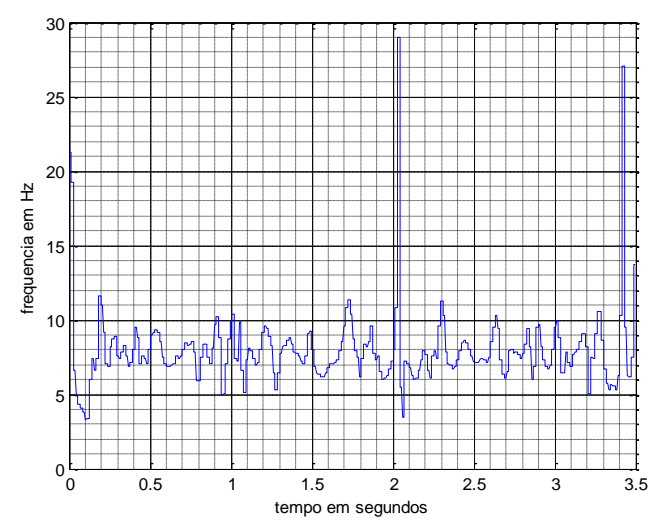

(a)

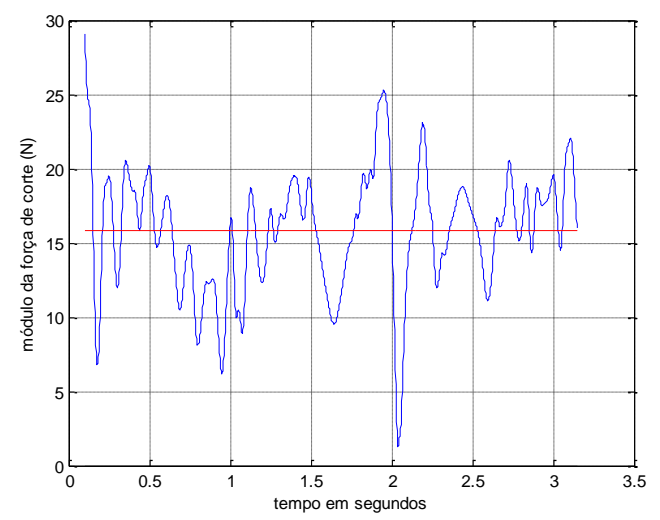

(b)

Figura 5-22 Frequência (a) e módulo(b), da IMF-4

A figura 5-23 mostra os mesmos efeitos da figura 5-22 com uma velocidade menor, já que as componentes relacionadas com a IMF-5 tem frequência mais baixa e módulo que varia mais lentamente. 


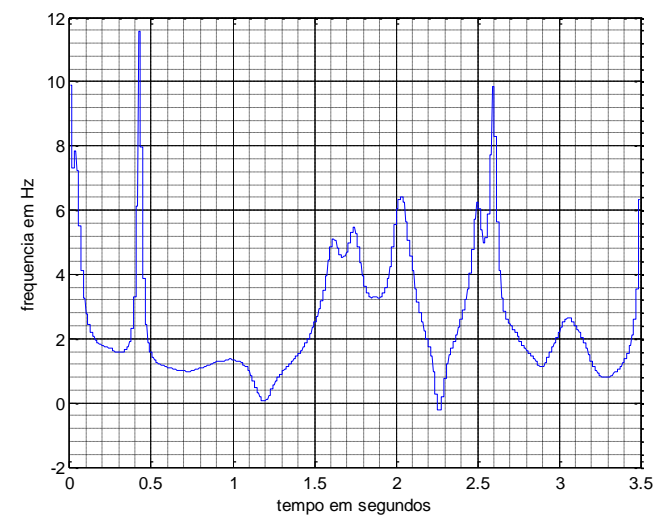

(a)

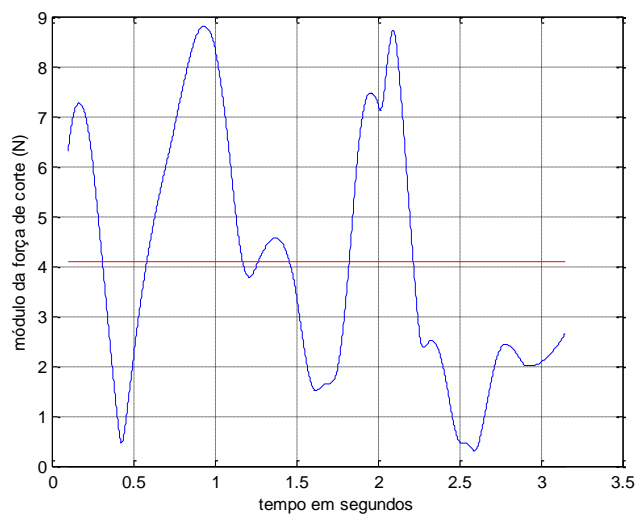

(b)

Figura 5-23 Frequência (a) e módulo(b), da IMF-5

Uma consequência dessa afirmação pode ser vista na figura 5-24 onde o perfil da força de corte apresenta nitidamente uma oscilação de aproximadamente $1,5 \mathrm{~Hz}$.

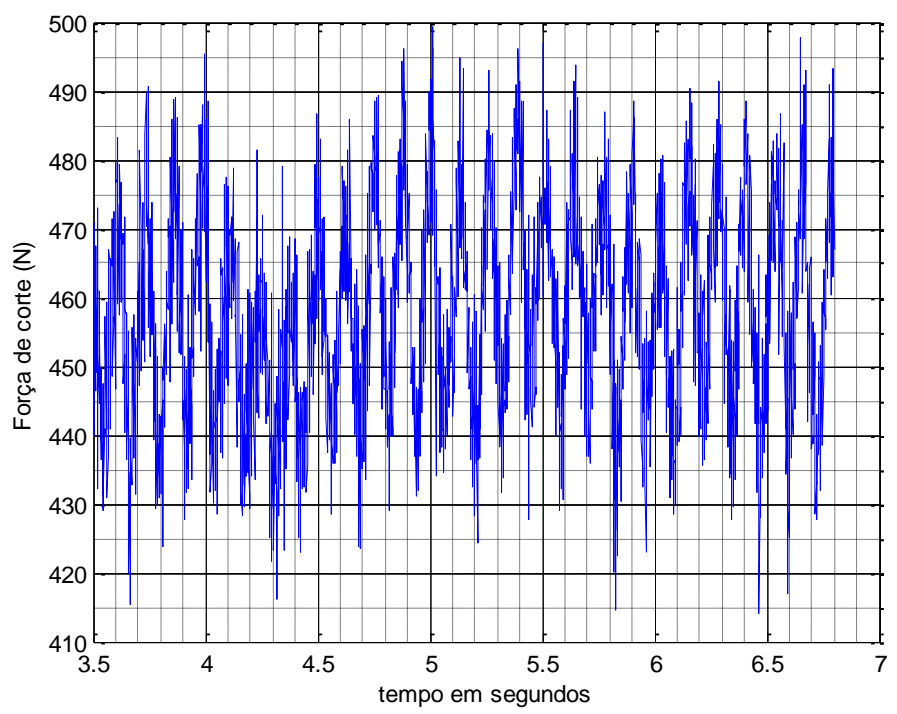

Figura 5-24 - Perfil da força de corte no passe de 1,0mm de profundidade

\subsubsection{Usinagem com corte contínuo e passe de 1,5mm}

O espectro completo dos dados do dinamômetro para a condição de corte contínuo com profundidade de 1,5mm é mostrado na figura 5-25 e podese observar do mesmo que ocorrem diversas componentes vibratórias nesse processo. O grupo de frequências mais altas ocorre entre $275 \mathrm{~Hz}$ e $375 \mathrm{~Hz}$, de 
modo que detalhamos esta região do espectro na figura 5-26(a), outro grupo de interesse ocorre entre $150 \mathrm{~Hz}$ e $200 \mathrm{~Hz}$ de modo que também este grupo está detalhado na figura 5-26(b).

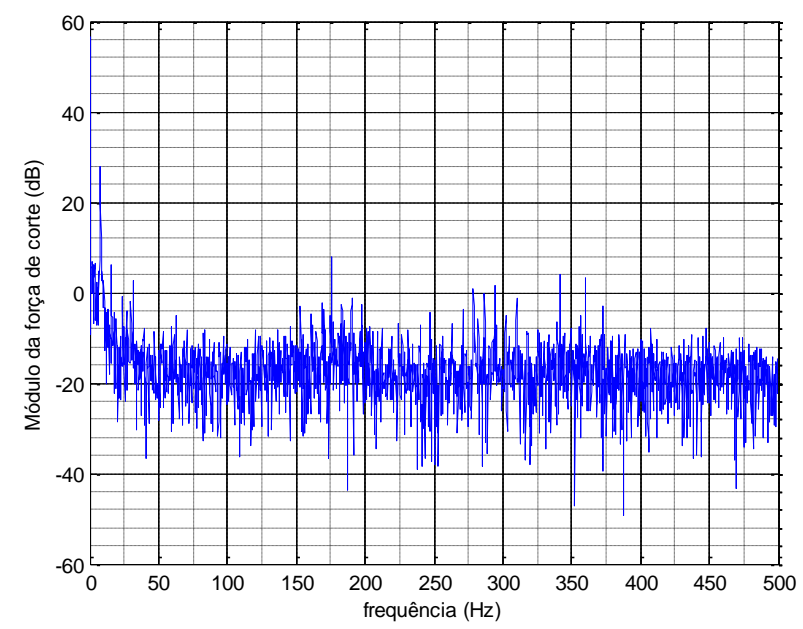

Figura 5-25 Espectro completo dos sinais da força de corte do dinamômetro

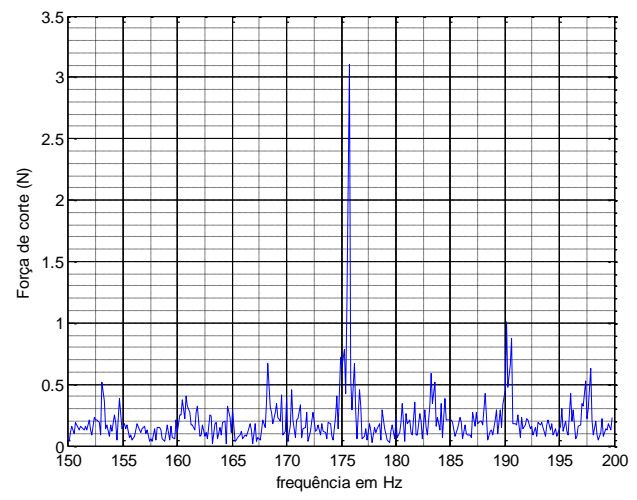

(a)

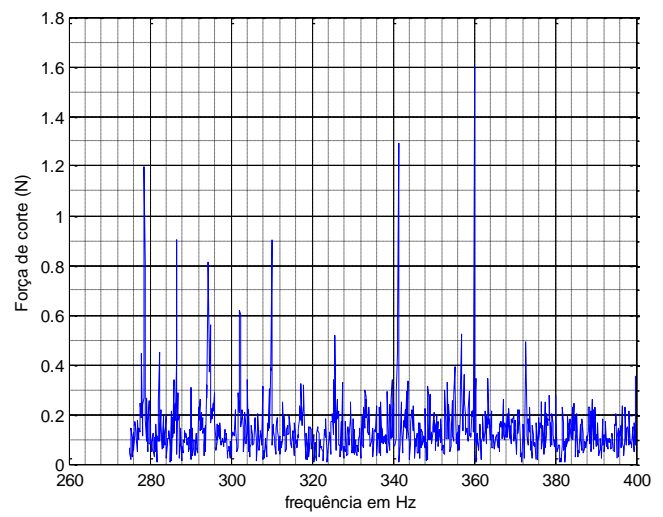

(b)

Figura 5-26 Espectros parciais com as componentes dominantes locais.

Os espectros locais mostrados nas figuras 5-26 (a) e (b) indicam que o aumento do carregamento da máquina ferramenta com um passe de esforço maior força as componentes vibratórias para seus limites sobressaindo as frequências das componentes forçadas. Nota-se no espectro entre 280 e $400 \mathrm{~Hz}$ que as componentes vibratórias associadas a usinagem e já discutidas com possível ação de quebra de cavacos entre $280 \mathrm{~Hz}$ e $340 \mathrm{~Hz}$ estacionam em módulo, porém a componente de $360 \mathrm{~Hz}$ associada a corrente de fase distorcida de alimentação do motor trifásico aumenta em módulo, o que é 
facilmente compreendido, já que o aumento da corrente de fase traz consigo um aumento das distorções associadas a $5^{\underline{a}}$ e $7^{\text {a }}$ harmônicas.

A componente vibratória relativa a IMF 1 e mostrada na tabela 5-3, continua com seu valor em $175 \mathrm{~Hz}$ mas seu módulo aumenta em $162 \%$ e a frequência e o módulo do sinal analítico correspondente a IMF de seu grupo é mostrada na figura 5-27 (a) e (b).

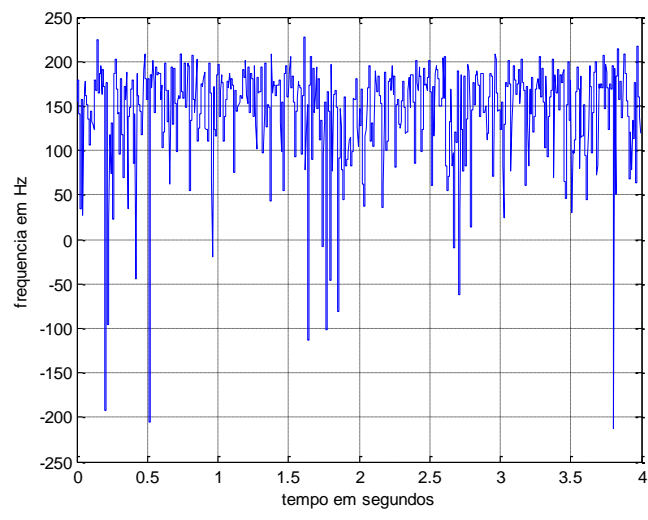

(a)

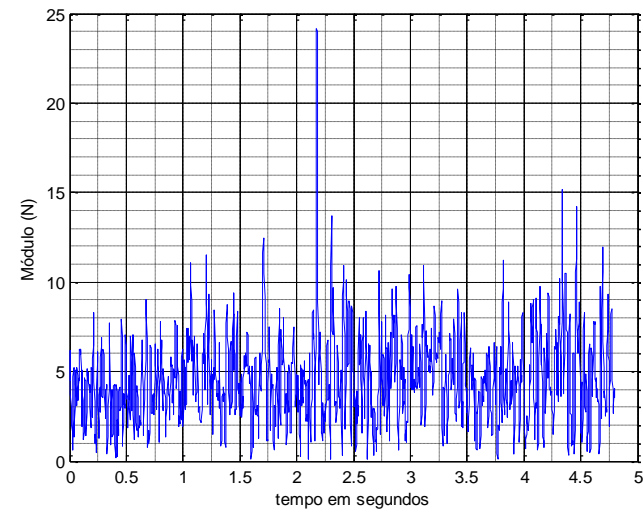

(b)

Figura 5-27 Frequência (a) e módulo(b), da IMF-1 do passe contínuo de 1,5mm

Tabela 5-3 Características da HHT do sinal de torque com corte contínuo e passe de $1,5 \mathrm{~mm}$

\begin{tabular}{|c|c|c|c|c|}
\hline IMF & $\begin{array}{c}\text { Fase (linearizada) } \\
\text { (radianos) }\end{array}$ & $\begin{array}{c}\text { Frequência } \\
\text { (média) } \mathrm{Hz})\end{array}$ & $\begin{array}{c}\text { Frequência } \\
\text { máxima } \\
\text { (média)(Hz) }\end{array}$ & $\begin{array}{c}\text { Força de } \\
\text { corte } \\
\text { (média) }(\mathrm{N})\end{array}$ \\
\hline 1 & $\psi(t)=897,28 t+8,096$ & 142,80 & 222,55 & 4,26 \\
\hline 2 & $\psi(t)=481,23 t+17,96$ & 76,59 & 157,41 & 2,45 \\
\hline 3 & $\psi(t)=92,96 t-41,83$ & 14,79 & 105,03 & 26,21 \\
\hline 4 & $\psi(t)=6,722 t-8,28$ & 5,84 & 25,55 & 12,51 \\
\hline 5 & $\psi(t)=15,95 t-0,59$ & 2,53 & 60,28 & 3,37 \\
\hline 6 & $\psi(t)=7,136 t+0,201$ & 1,13 & 6,67 & 2,90 \\
\hline 7 & $\psi(t)=3,937 t-4,269$ & 0,632 & 6,40 & 6,44 \\
\hline
\end{tabular}

A figura 5-28 mostra o conteúdo espectral local relativo a IMF-2 que tem uma frequência dominante de aproximadamente $70 \mathrm{~Hz}$, enquanto que as figuras 5-29(a) corresponde a frequência em função do tempo e 5.29(b) o módulo da função analítica do mesmo sinal. 


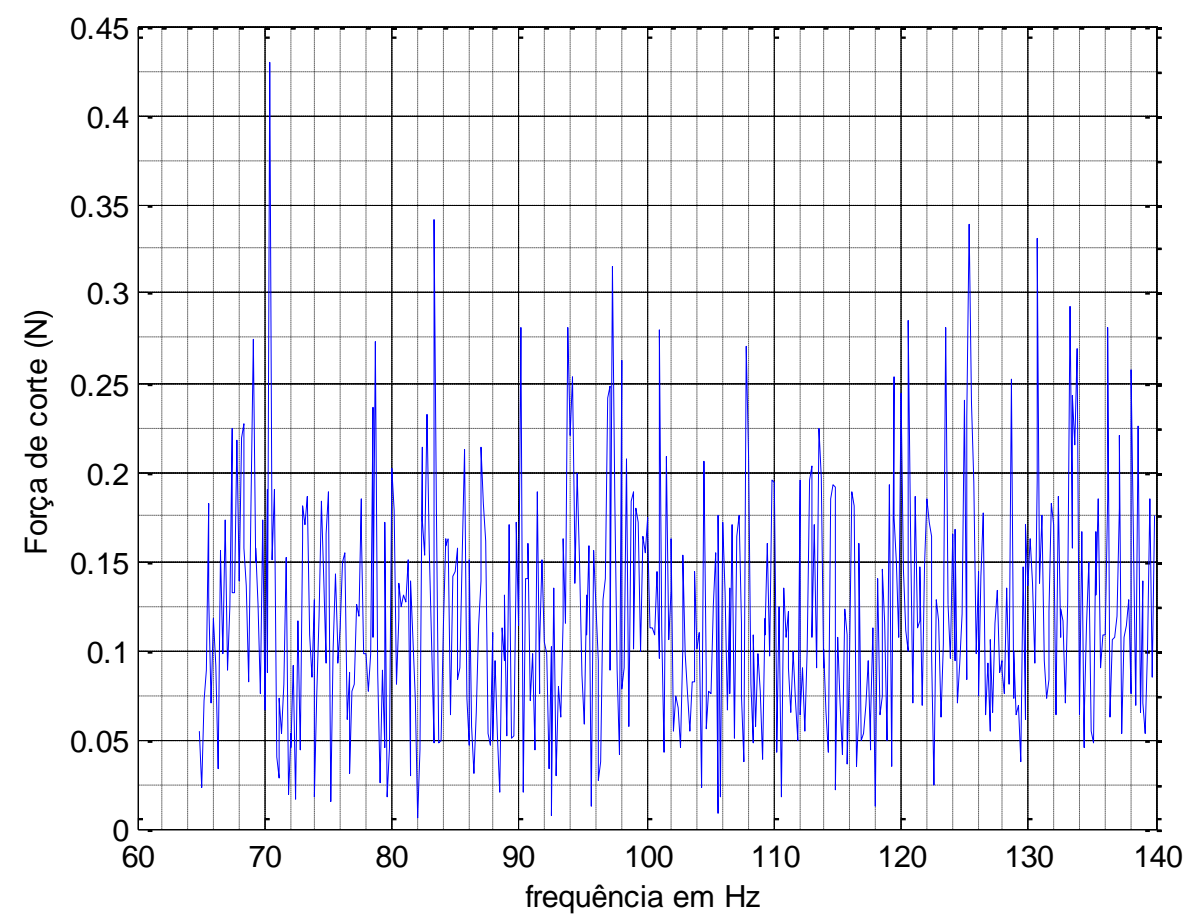

Figura 5-28 Espectro relativo ao grupo da IMF-2

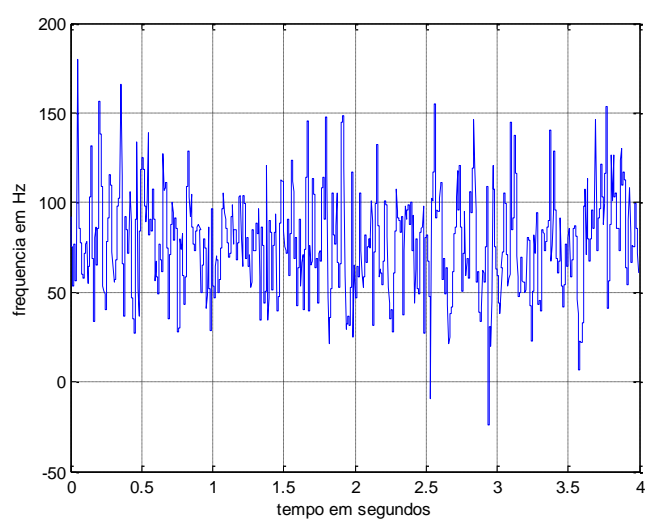

(a)

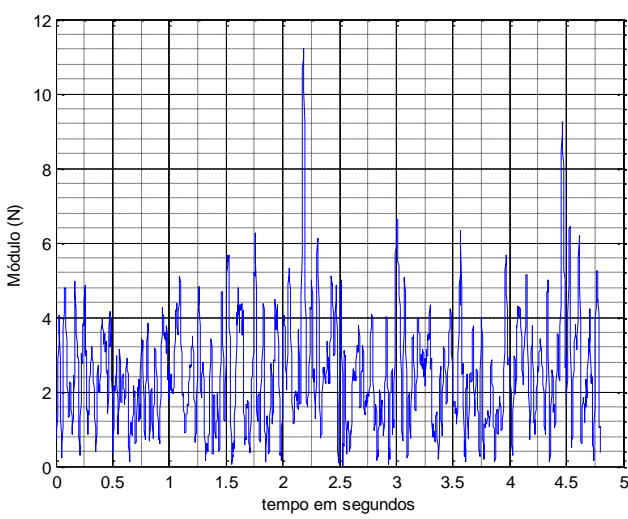

(b)

Figura 5-29 Frequência (a) e módulo(b), da IMF-2 do passe contínuo de 1,5mm

A figura 5-30 mostra o conteúdo espectral relativo as IMFs 3 e 4 que é a região da grande componente vibratória de $7,9 \mathrm{~Hz}$ com $28,5 \mathrm{~N}$ de módulo. Observa-se do mesmo espectro uma pequena componente de $15,7 \mathrm{~Hz}$ com módulo de $2 \mathrm{~N}$ e uma esmaecida componente de $31,5 \mathrm{~Hz}$ com módulo de 1,2N. 


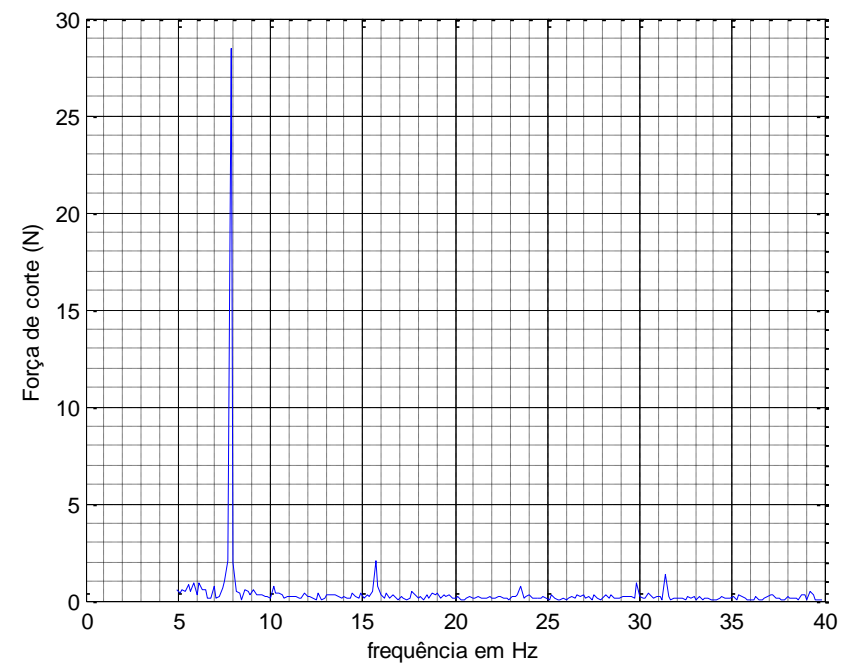

Figura 5-30 Espectro parcial das baixas frequências com a componente dominante vibratória dominante de todo o espectro.

As fases relativas as IMFs 3 e 4 são mostradas nas figuras 5-31 (a) e (b), e verificamos um comportamento de saturação extremado nas bordas inicial e final, o que indica escassez de pontos e falhas no mecanismo de splines que dificulta a interpolação cúbica nessas partes dos dados, o que automaticamente leva a diminuição do intervalo de análise de modo a comportar apenas a região onde ocorre um deslocamento linear da fase sem as saturações que ocorrem nas bordas.

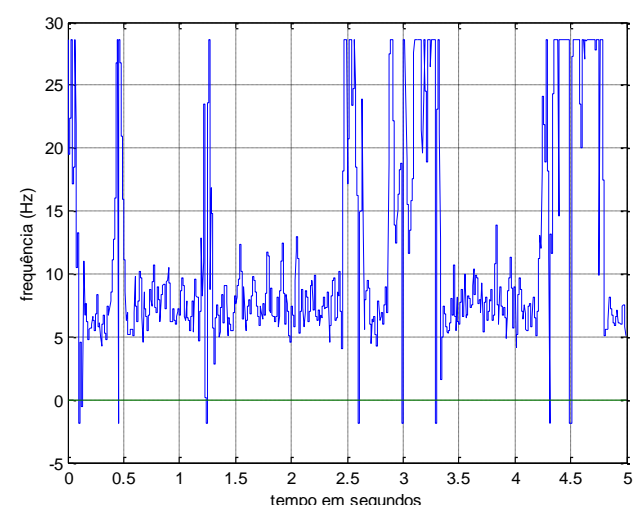

(a)

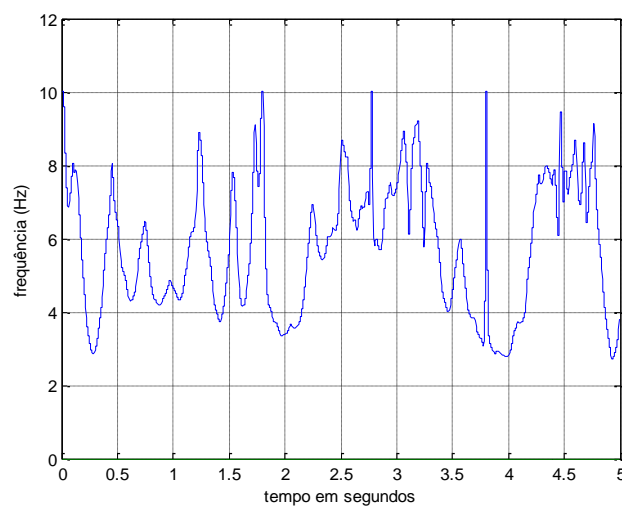

(b)

Figura 5-31 Frequências relativas as IMF-3 (a) e IMF-4 (b) 


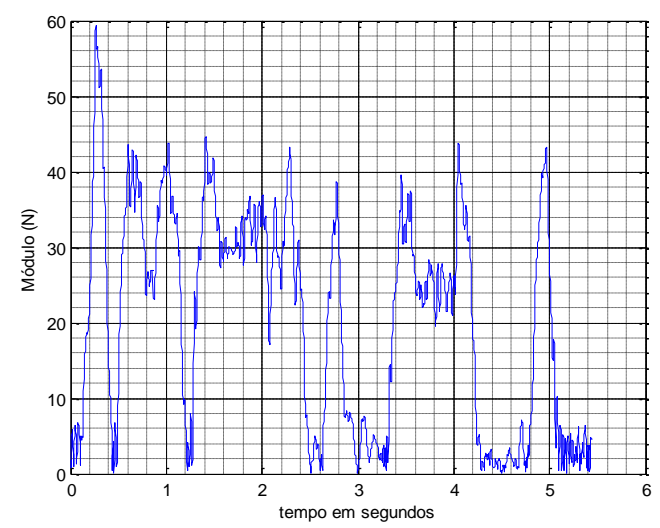

(a)

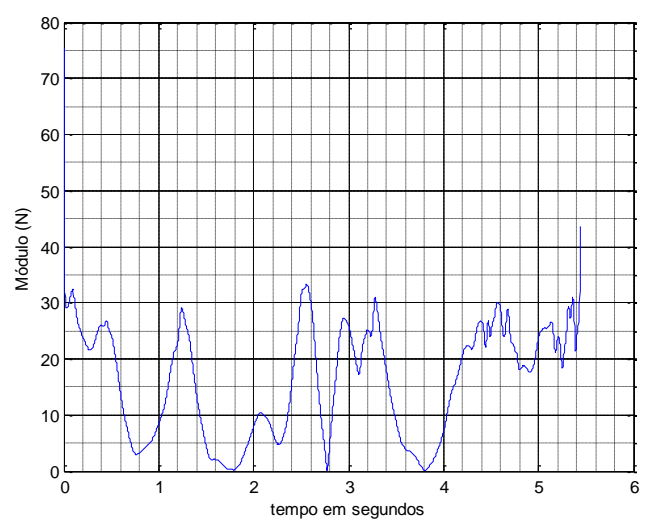

(b)

Figura 5-32 Módulos relativos as IMF-3 (a) e IMF-4 (b)

Das figuras 5-31 (a) e (b) relativas as frequências e as figuras 5-32(a) e (b) relativas aos módulos da IMF-3, percebemos que essa componente é bastante vibratória com variações de módulo de usinagem de quase 40N, assim como grande variação de frequência.

Os gráficos relativos a transformada de Hilbert-Huang dos dados do dinamômetro com a máquina ferramenta operando com corte contínuo estão no apêndice $\mathrm{C}$ desse trabalho.

\subsection{Análise espectral e com a HHT da operação de usinagem com $\mathrm{Cl}$}

As características da usinagem com corte interrompido são basicamente as mesmas com corte contínuo, o material em usinagem tem as mesmas propriedades físicas e as dimensões geométricas as quais se adiciona dois rasgos simétricos longitudinais ao corpo de prova, cada um dos quais tem largura de $10 \mathrm{~mm}$ e profundidade de $15 \mathrm{~mm}$, como o passe mais profundo tem apenas $1,5 \mathrm{~mm}$, a ferramenta perde totalmente o contato com a peça quando percorre esses dois vãos da peça gerando assim a interrupção da usinagem.

As figuras 5-33 (a), (b) e (c) mostram os perfis de usinagem interrompida executado nesse experimento. 


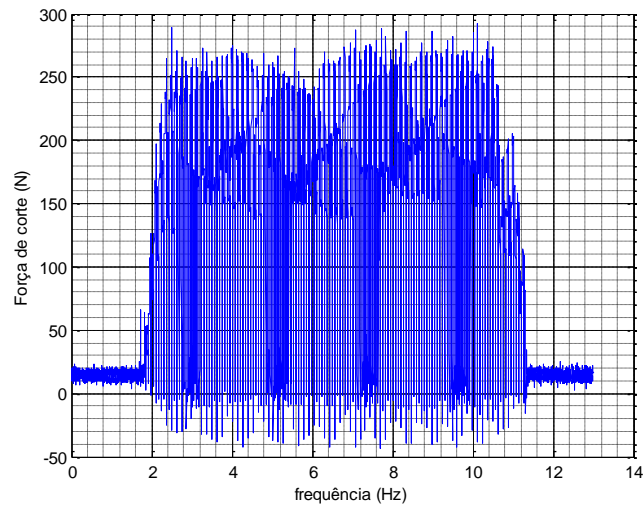

(a)

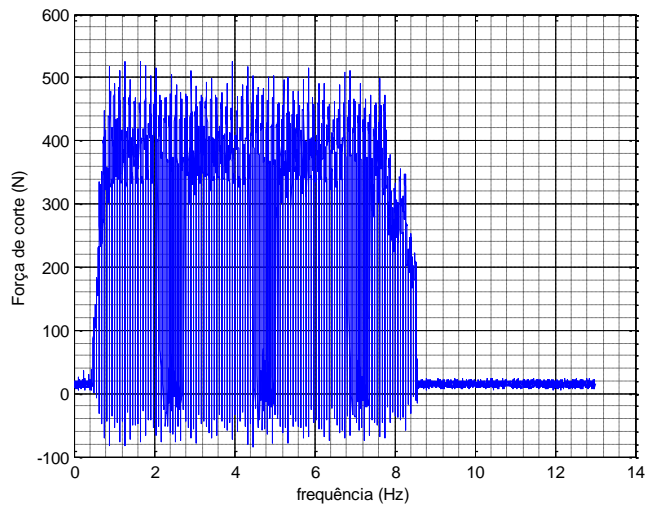

(b)

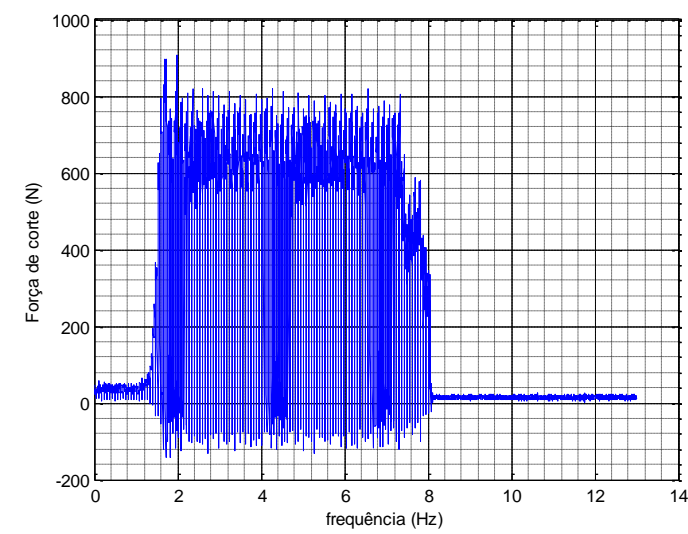

Figura 5-33 Perfis das forças de corte para os passes de 0,5mm(a), 1,0mm(b) e $1,5 \mathrm{~mm}(\mathrm{c})$

\subsubsection{A usinagem com $\mathrm{Cl}$ como um fenômeno de modulação com amplitude modulada (AM)}

No trabalho já realizado relativo ao corte contínuo, observamos uma componente dominante presente em todos os testes realizados com frequência de $7,8 \mathrm{~Hz}$ que pela sua frequência em relação a velocidade de rotação do eixo árvore do torno que é de 49,582 $\mathrm{rad} / \mathrm{s}$ (passe de $0,5 \mathrm{~mm}$ ) indica que esta componente está intimamente ligada ao efeito de rotação de usinagem. A inserção de dois rasgos longitudinais simétricos no corpo de prova deve gerar um fenômeno vibratório com o dobro da frequência de rotação o que deve gerar um efeito de modulação com 0 sinal de baixa frequência $(7,8 \mathrm{~Hz})$ modulando o sinal devido a, interrupção de corte da ferramenta e gerando assim uma trepidação controlada. O processo de corte interrompido funciona 
como uma portadora de AM com a forma mostrada na figura 5-34 onde $T_{1}=10,11 \mathrm{~ms}$ e $T_{c}=\frac{2 \pi}{2 * 49,582}=63,36 \mathrm{~ms}$.

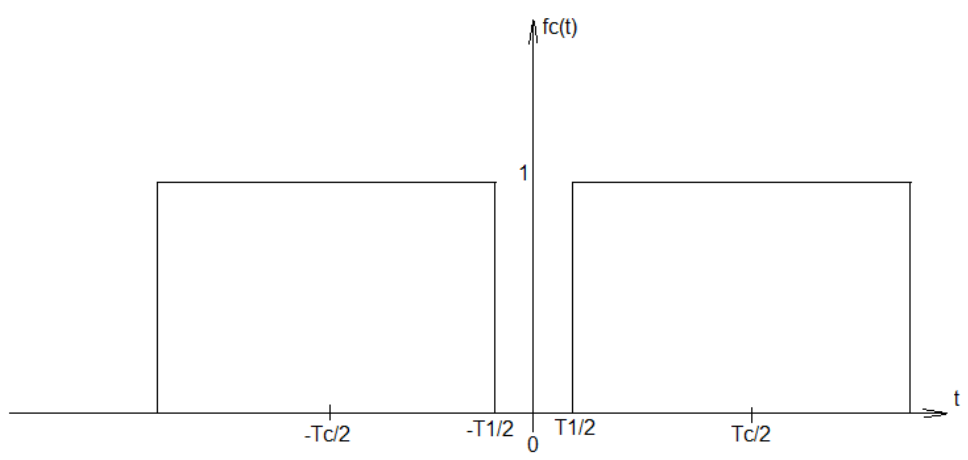

Figura 5-34 Forma da onda representativa da trepidação vinculada a usinagem com corte interrompido.

A partir dos dados fornecidos obtém-se a representação do sinal da onda portadora como uma série temporal pela aplicação da série de Fourier, onde os coeficientes das componentes podem ser calculados pela expressão (5.1),

$$
a_{n}=-\frac{2}{n \pi} \operatorname{sen}\left(n * 49,582 * T_{1}\right)
$$

O que permite calcular a expressão da portadora mostrada em (5.2).

$$
f_{c}(t)=0,5-0,3059 \cos (99,164 t)-0,2683 \cos (198,33 t)-
$$

$0,2117 \cos (297,49 t)-0,1444 \cos (396,65 t)-\cdots$

Por sua vez a força de corte com a vibração de $7,8 \mathrm{~Hz}$ adicionada a componente média de corte e operando como sinal modulante é dada pela expressão (5.3). Esse dado foi extraído do caso de corte interrompido com passe de $0,5 \mathrm{~mm}$ de profundidade.

$$
f_{m}(t)=178,5+50,6 \cos (49,582 t)
$$

Aplicando a operação de modulação em amplitude dada pela equação (5.4).

$$
f(t)=\left(1+f_{m}(t)\right) * f_{c}(t)
$$


Os sinais da trepidação modulada e da modulante natural do sistema de usinagem estão representados na figura 5.35 (a) e (b) respectivamente. A figura 5-36 mostra o resultado da modulação em função do tempo em 5.25(a) e o espectro do sinal resultante em 5.35(b).

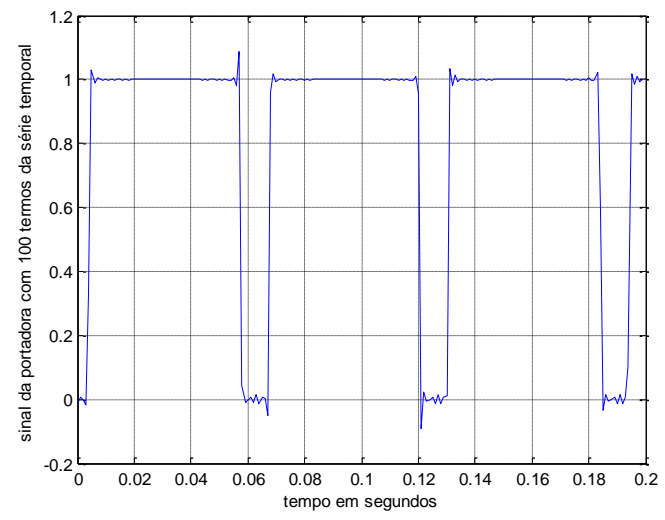

(a)

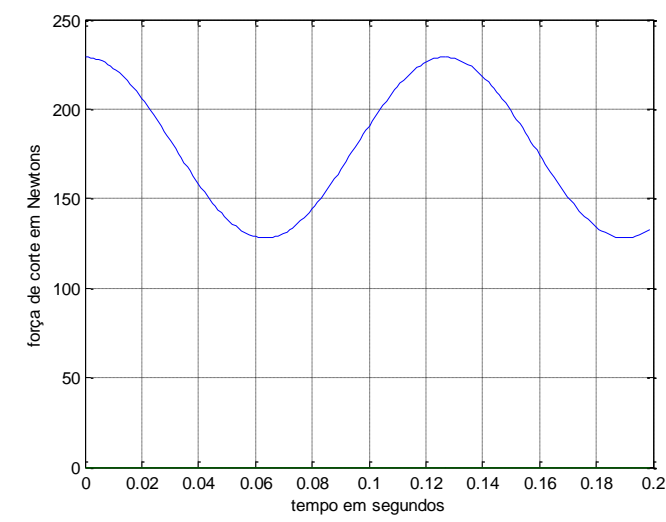

(b)

Figura 5.35 Portadora relativa a trepidação (a) e modulante da força de corte (b)

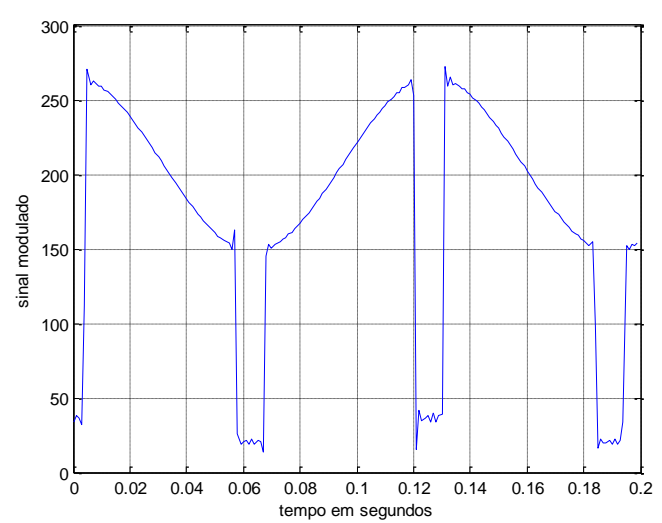

(a)

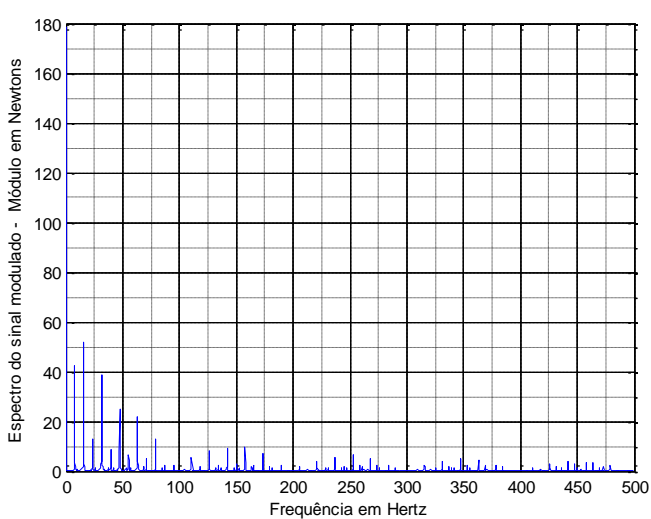

(b)

Figura 5-36 Sinal modulado (a) e espectro do sinal modulado

A figura 5-37 corresponde ao sinal obtido pelo dinamômetro para a situação de corte interrompido e passe de $0,5 \mathrm{~mm}$ para uma comparação com o espectro obtido matematicamente na figura 5-36(b). Notam-se algumas diferenças, mas é importante salientar que existem outras vibrações que afetam o sistema real e que não foram modeladas matematicamente. 


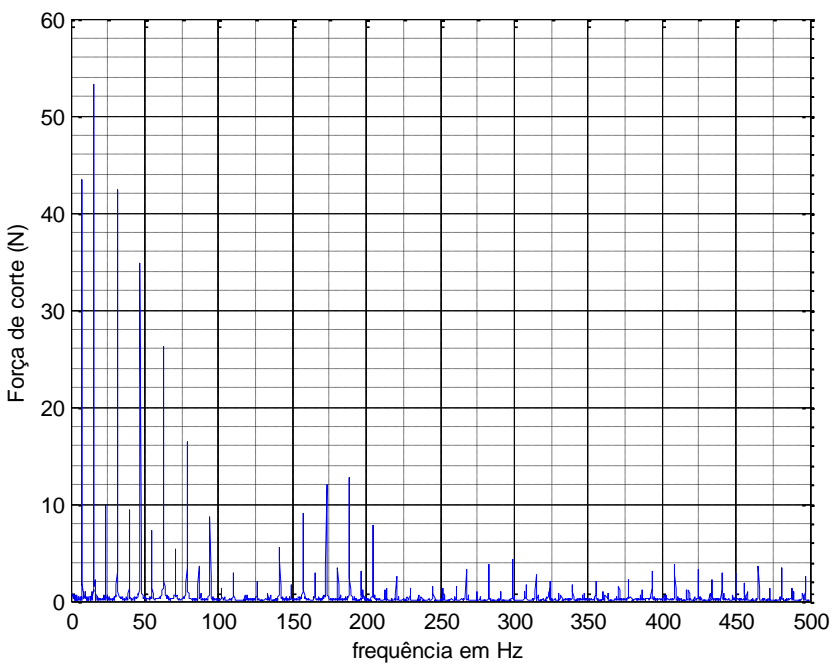

Figura 5-37 Espectro real da operação com corte interrompido com passe de 0,5 mm

Tabela 5-4: Relação entre as componentes encontradas no processo de usinagem e no processo de modulação

\begin{tabular}{|c|c|c|c|c|}
\hline $\begin{array}{c}\text { Componente } \\
\text { espectral }\end{array}$ & $\begin{array}{c}\text { Corte } \\
\text { interrompido } \\
0,5 \mathrm{~mm}\end{array}$ & $\begin{array}{c}\text { Modulação em } \\
\text { amplitude }\end{array}$ & $\begin{array}{c}\text { Frequência } \\
(\mathrm{Hz})\end{array}$ & $\begin{array}{c}\text { Erro em } \\
\text { relação ao } \\
\text { caso real }\end{array}$ \\
\hline a1 & 43,1 & 42,48 & 7,9 & $1,4 \%-$ \\
\hline a2 & 52,9 & 51,7 & 15,8 & $2,2 \%$ \\
\hline a3 & 10,9 & 12,56 & 23,6 & $-15,2 \%$ \\
\hline a4 & 42,10 & 38,75 & 31,5 & $7,9 \%$ \\
\hline a5 & 9,2 & 7,5 & 39,4 & $18,5 \%$ \\
\hline a6 & 34,7 & 27,2 & 47,3 & $21, \%$ \\
\hline
\end{tabular}

A tabela 5-4 mostra as relação numéricas entre as componentes medidas no processo real de corte com passe interrompido com profundidade de $0,5 \mathrm{~mm}$ e o processo de modulação para o caso ideal. Os erros aumentam a medida de outros processos vibratórios não participantes da modelagem que interferem nas componentes simuladas. 


\subsubsection{Análise espectral (FFT) e com a HHT da operação de $\mathrm{Cl}$ com UCP de $0,5 \mathrm{~mm}$}

O espectro mostrado na figura 5-38 apresenta uma série de componentes de módulos relevantes abaixo de $100 \mathrm{~Hz}$ e novamente um outro grupo entre $125 \mathrm{~Hz}$ e $225 \mathrm{~Hz}$. O primeiro grupo é resultado direto da modulação não linear introduzida pela usinagem com corte interrompido onde todas as componentes harmônicas geradas tanto pela interrupção como início súbito da usinagem periodicamente introduz no sistema de usinagem, o segundo grupo também é decorrente disso, porém é reforçado pela presença de uma vibração de origem mecânica de $176 \mathrm{~Hz}$ já existente nas operações de usinagem em vazio, mas bastante ampliada pelo efeito do corte interrompido, já que é bastante pequena na situação de passe contínuo de $0,5 \mathrm{~mm}$, passa a $1,2 \mathrm{~N}$ para o caso de passe contínuo de $1,0 \mathrm{~mm}$, mas aqui com passe de $0,5 \mathrm{~mm}$ interrompido aumenta para $12 \mathrm{~N}$ e traz consigo componentes laterais de igual monta, ou seja é modulada em amplitude tanto pela componente de $7,9 \mathrm{~Hz}$ com e mais intensamente pela componente de $15,8 \mathrm{~Hz}$ e todo 0 conjunto de harmônica que acompanha esta.

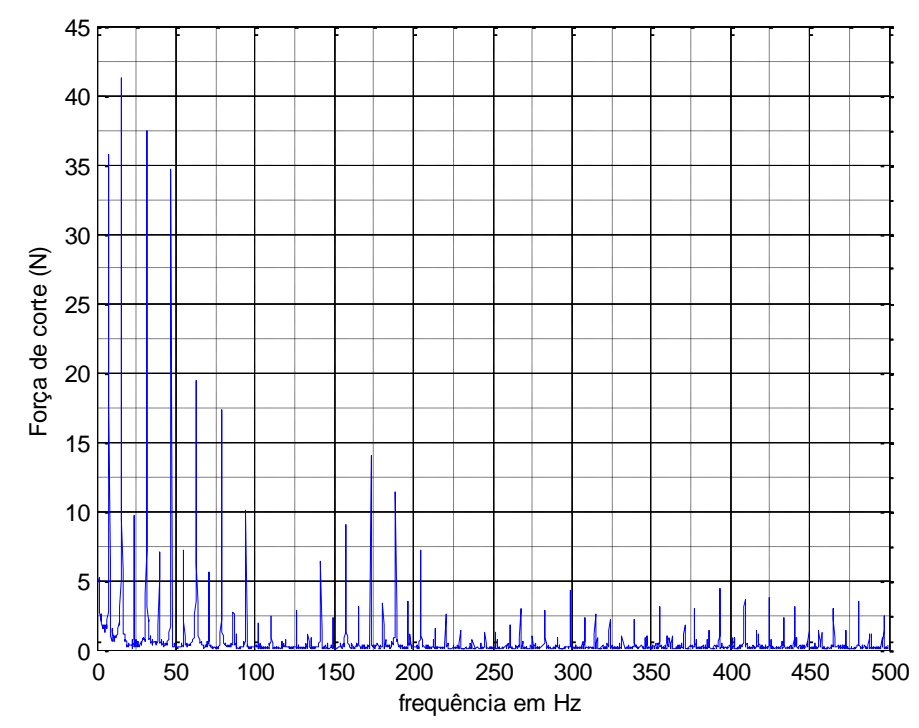

Figura 5.38 Espectro da usinagem com $\mathrm{Cl}$ e ucp 0,5mm com supressão da componente média

A tabela 5-5 traz as características do sinal analítico obtido das IMFs do sinal mostrado na figura 5-33(a), nota-se da tabela que a pouca concentração 
de componentes próximas a frequência de corte interrompido não indica claramente que essa componente é dominante no processo, a componente média mais próxima é a da IMF-5 com $11,35 \mathrm{~Hz}$, que é mostrada com módulo é frequência na figura 5-39 (a) e (b).

O módulo da IMF-5 reflete claramente a situação de corte interrompido, mas a variação da frequência não é tão grande, a não ser pelos picos que também ocorrem em condições de corte contínuo.

Tabela 5-5 Características da HHT do sinal de torque com corte interrompido e passe de $0,5 \mathrm{~mm}$

\begin{tabular}{|c|c|c|c|c|}
\hline IMF & $\begin{array}{c}\text { Fase (linearizada) } \\
\text { (radianos) }\end{array}$ & $\begin{array}{c}\text { Frequência } \\
\text { (média) } \mathrm{Hz} \text { ) }\end{array}$ & $\begin{array}{c}\text { Frequência } \\
\text { máxima } \\
\text { (média) }(\mathrm{Hz})\end{array}$ & $\begin{array}{c}\text { Força de } \\
\text { corte } \\
\text { (média) }(\mathrm{N})\end{array}$ \\
\hline 1 & $\psi(t)=637,52 t-73,18$ & 101,46 & 201,59 & 21,7 \\
\hline 2 & $\psi(t)=437,61 t+5,87$ & 69,65 & 151,78 & 34,15 \\
\hline 3 & $\psi(t)=298,02 t-0,273$ & 47,43 & 118,41 & 51,31 \\
\hline 4 & $\psi(t)=145,28 t-2,481$ & 23,12 & 50,62 & 52,87 \\
\hline 5 & $\psi(t)=71,25 t-1,920$ & 11,35 & 44,26 & 44,18 \\
\hline 6 & $\psi(t)=33,27 t-6,618$ & 5,29 & 10,75 & 15,96 \\
\hline 7 & $\psi(t)=15,67 t+5,473$ & 2,49 & 8,57 & 3,75 \\
\hline
\end{tabular}

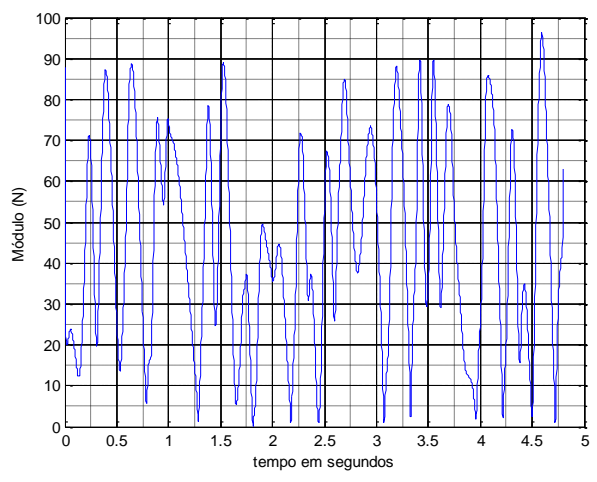

(a)

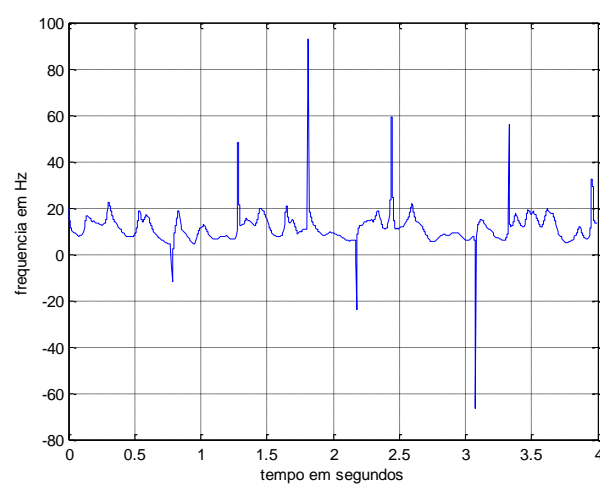

(b)

Figura 5-39 Módulo da IMF-5 (a) e frequência da IMF-5 (b)

Embora a componente de frequência média mais próxima seja efetivamente a correspondente a IMF-5, a tabela 5-5 mostra que existe muita concentração de esforços nas componentes relativas as IMF-3 e IMF-4. Isso é explicado pelo fato da máquina ter formatação antiga e o conjunto estimulado 
por uma situação de corte interrompido faça outras componentes vibratórias se evidenciarem, no caso a que consome mais esforço é a correspondente a IMF4, cujas componentes de módulo e frequência são mostrados nas figuras 540 (a) e (b).

A figura 5-40(a) mostra como a variação do módulo dessa IMF é intenso refletindo o efeito de usinagem que passa da operação em vazio para com esforço e vice-versa onde o módulo passa de praticamente zero para quase $150 \mathrm{~N}$ e esse fenômeno também é observado na análise da IMF-3.

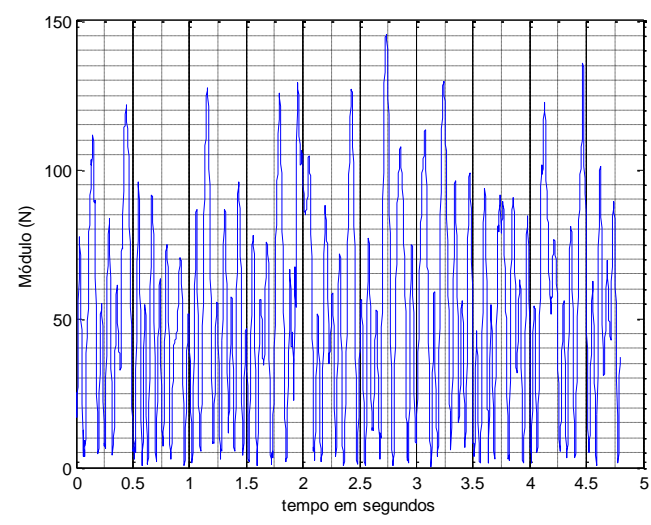

(a)

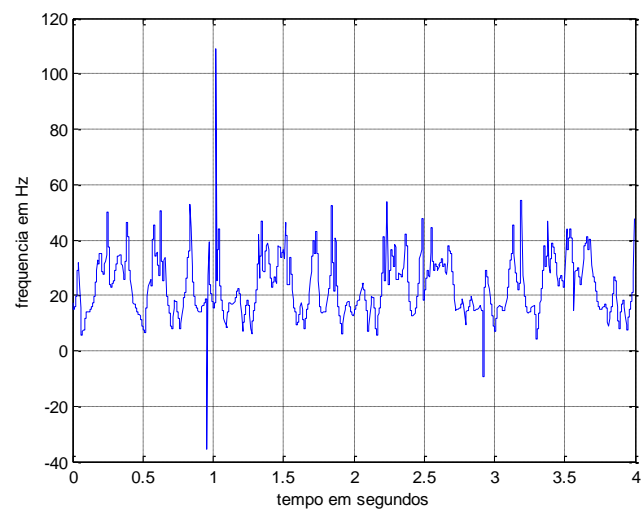

(b)

Figura 5-40 Módulo da IMF-4 (a) e frequência da IMF-4 (b)

Embora não seja relevante para esse trabalho é interessante a observação do espectro das IMF 4 e 5 lembrando que o efeito da aplicação da FFT nessas IMFs somente possa apresentar frequências abaixo de $250 \mathrm{~Hz}$ devido as limitações do método de obtenção da HHT. Isso é feito nas figuras 541 (a) e (b). Dessa figura é possível perceber que as IMFs representam um grupo de componentes estacionárias que é possível verificar pelos espectros apresentados, além das componentes não estacionárias que somente podem ser visualizadas pela aplicação da HT no sinal analítico gerado por essas IMFs.

As figuras 5-42 (a) e (b) mostram a concentração das forças vibratórias médias em função das frequências média e máximas das IMFs e mostram que a "banda passante" dos sinais vibratórios de intensidade relativamente grande se concentra em uma gama de frequências relativamente pequena, o que 
caracteriza a máquina ferramenta, como era esperado, como um dispositivo passa baixas em termos de resposta em frequência.

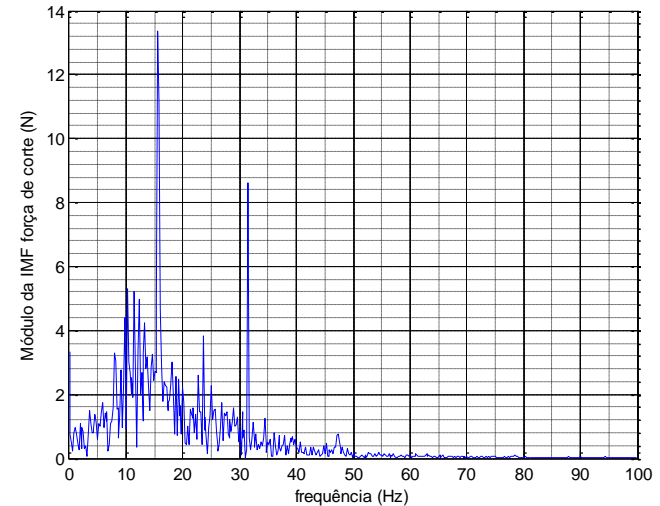

(a)

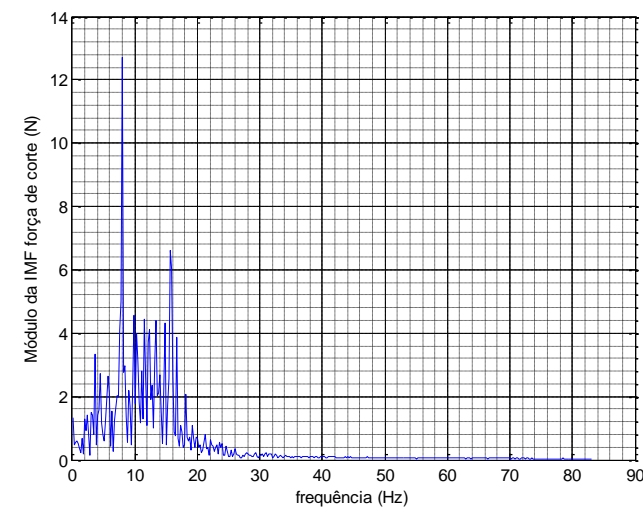

(b)

Figura 5-41 Espectros da IMF-4 (a) e da IMF-5 (b) com Cl e UCP de 0,5mm

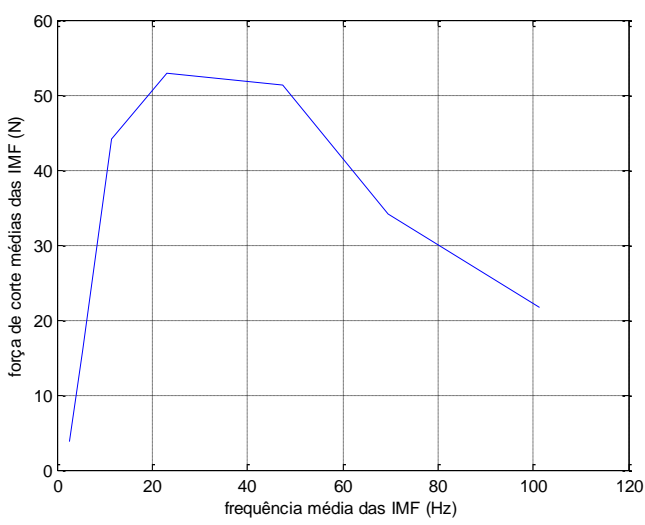

(a)

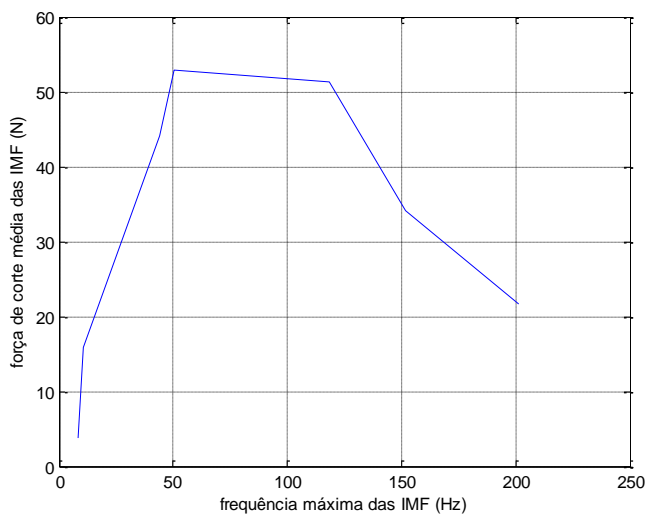

(b)

Figura 5-42 Relação entre os valores médios das forças de corte e a frequência média das IMFs (a) e com relação as frequências máximas das IMFs(b)

\subsubsection{Análise espectral (FFT) com a HHT da operação com Cl e UCP de $1,0 \mathrm{~mm}$}

A figura 5-43 apresenta o espectro total da força de corte para a situação de corte interrompido com passe de profundidade $1,0 \mathrm{~mm}$, nota-se um substancial aumento da componente portadora, mas não da componente modulante o que é ,explicado pelo fato da componente modulante ter origem mecânica natural da relação usinagem e máquina ferramenta e que aparece em todas as situações de usinagem, porém a componente de $15,9 \mathrm{~Hz}$ 
correspondente a situação de corte interrompido gera um componente forçada, praticamente sintonizando o conjunto usinagem máquina ferramenta nessa componente, assim como aumentando todas suas componentes harmônicas conforme demonstra a equação (5.2) e (5.3) com um razoável aumento da componente média da força que é a componente que esta sendo "chaveada".

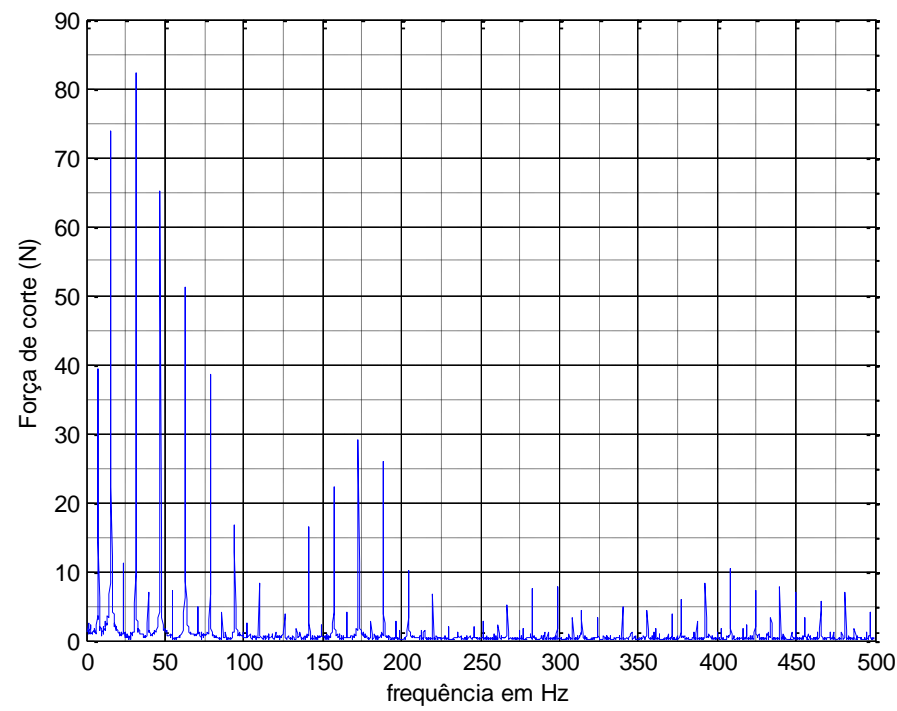

Figura 5-43 Espectro do sinal do dinamômetro para a situação de Cl e UCP de $1,0 \mathrm{~mm}$.

Tabela 5-6 Características da HHT do sinal de torque com corte interrompido e passe de $1,0 \mathrm{~mm}$

\begin{tabular}{|c|c|c|c|c|}
\hline IMF & $\begin{array}{c}\text { Fase (linearizada) } \\
\text { (radianos) }\end{array}$ & $\begin{array}{c}\text { Frequência } \\
\text { (média) } \mathrm{Hz})\end{array}$ & $\begin{array}{c}\text { Frequência } \\
\text { máxima } \\
\text { (média)(Hz) }\end{array}$ & $\begin{array}{c}\text { Forca de } \\
\text { corte } \\
\text { (média) }(\mathrm{N})\end{array}$ \\
\hline 1 & $\psi(t)=820,45 t+9,907$ & 130,58 & 200,57 & 35,33 \\
\hline 2 & $\psi(t)=617,42 t-9,419$ & 98,26 & 182,97 & 43,96 \\
\hline 3 & $\psi(t)=398,29 t+10,19$ & 63,39 & 145,39 & 67,38 \\
\hline 4 & $\psi(t)=288,48 t+10,96$ & 45,91 & 113,47 & 85,91 \\
\hline 5 & $\psi(t)=174,05 t+6,57$ & 27,70 & 88,13 & 87,23 \\
\hline 6 & $\psi(t)=89,184 t+2,366$ & 14,19 & 27,57 & 82,42 \\
\hline 7 & $\psi(t)=42,09 t-2,739$ & 6,70 & 12,65 & 25,96 \\
\hline
\end{tabular}

A tabela 5-6 apresenta os resultados do uso da HHT sobre a situação do passe de 1,0mm e corte interrompido e demonstra que a intensidade da componente de $15,8 \mathrm{~Hz}$ começa a predominar a detecção com concentração da 
força de corte nessa componente estacionária, mas é a IMF-5 que chama a atenção já que a concentração do esforço de vibração é mais intenso nessa IMF o que enseja um detalhamento do grupo de frequência em seu entorno utilizando a FFT, isso é mostrado na figura 5-44.

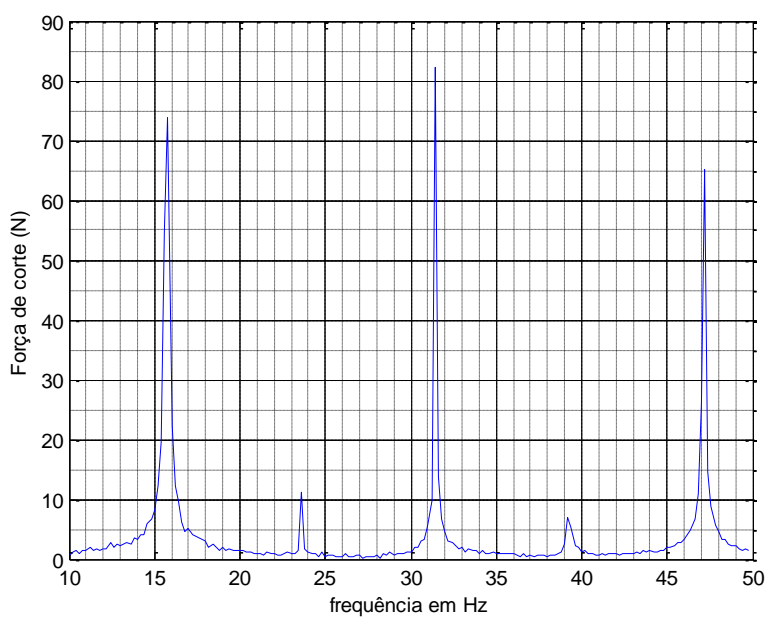

Figura 5-44 Composição da IMF-5

Em termos de componentes estacionária, a IMF-5 possui uma componente central em $31,5 \mathrm{~Hz}$ que é uma vibração mecânica da máquina ferramenta, modulada em amplitude pelas componentes correspondentes ao corte interrompido de $15,8 \mathrm{~Hz}$, componentes laterais maiores na figura 5-44, e pela componente de $7,8 \mathrm{~Hz}$, correspondente aos pico laterais menores e mais próximos da componente de $31,5 \mathrm{~Hz}$. A composição do módulo e da frequência instantânea correspondente a essa IMF são mostrados nas figura 5-45 (a) e (b).

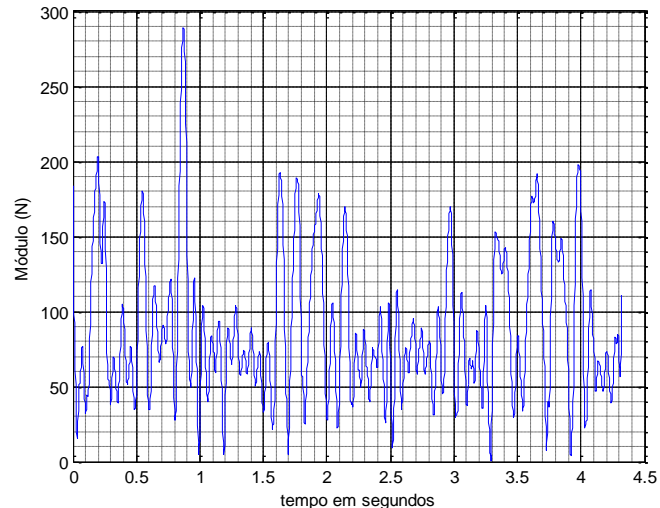

(a)

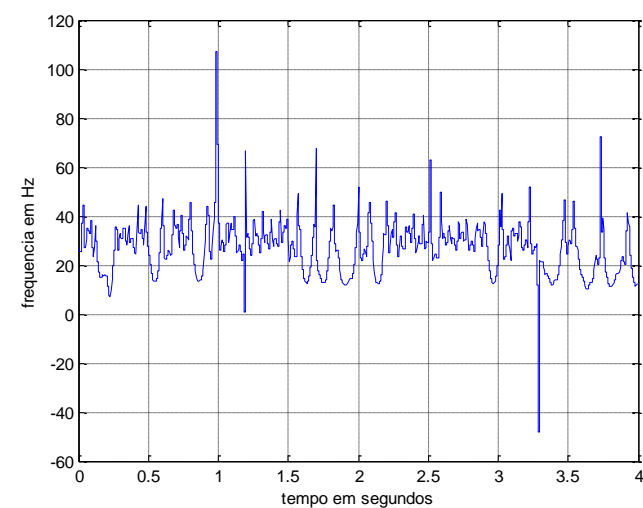

(b)

Figura 5-45 Módulo da IMF-5 (a) e frequência da IMF-5 (b) 
A expressão matemática da modulação em amplitude do espectro mostrado na figura 5-44 é dado na expressão (5.5).

$$
f(t)=[1+11 \cos (2 \pi 7,8 t)+74 \cos (2 \pi 15,8 t)] 82 \cos (2 * \pi * 31,5 t)
$$

As figuras 5-46 (a) e (b) mostram a a relação entre as frequências das IMFs e os módulos médios da força de corte para o caso de usinagem com corte interrompido e passe de $1,0 \mathrm{~mm}$ de profundidades e praticamente não difere da situação do caso anterior mostrado nas figura 5-46 (a) e (b).
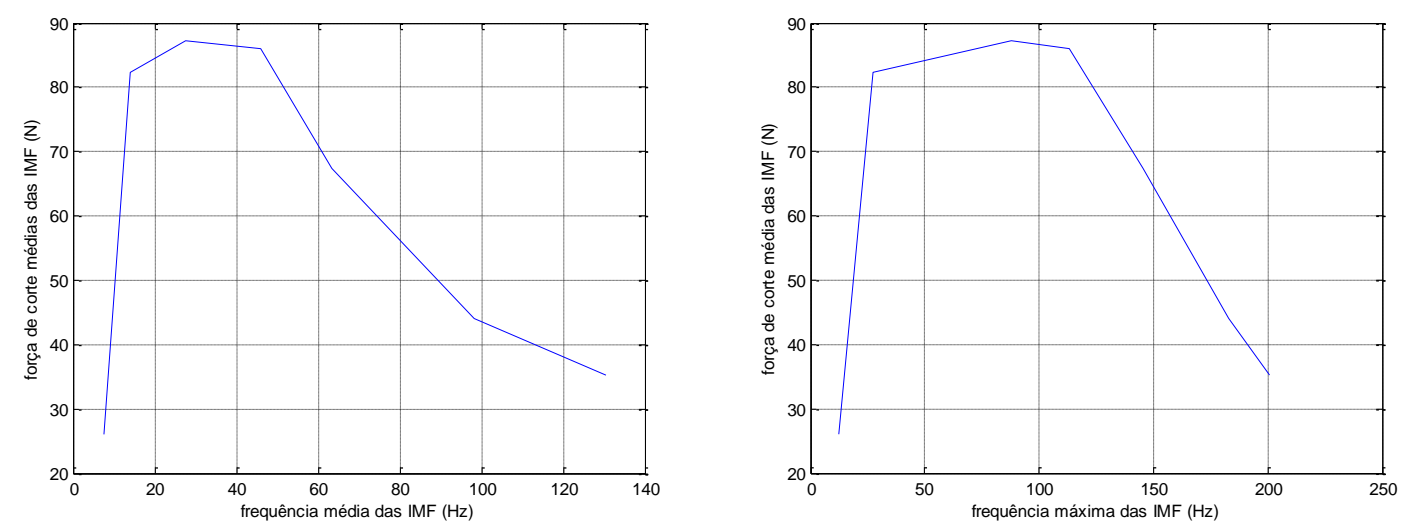

Figura 5-46 Relação entre os valores médios das forças de corte e a frequência média das IMFs (a) e com relação as frequências máximas das IMFs(b) para o caso de corte interrompido com passe de $1,0 \mathrm{~mm}$.

\subsubsection{Análise espectral (FFT) com a HHT da operação com $\mathrm{Cl}$ e UCP de}

\section{$1,5 \mathrm{~mm}$}

Ao contrário do caso anterior, não é necessário observar a tabela 5-7, para verificar que existe uma componente estacionária de grande amplitude próximo a $30 \mathrm{~Hz}$ como se observa no espectro da figura 5-47. A tabela 5-7 também mostra uma grande concentração de esforços vibratórios nas IMFs $4 \mathrm{e}$ 5. Com o aumento do esforço de corte interrompido, a máquina ferramenta passa a vibrar com mais intensidade alargando se espectro vibratório geral e concentrando componentes vibratórias em posições do espectro onde ocorre algum tipo de ressonância. A posição vibratória de $31,5 \mathrm{~Hz}$ já havia sido detectada no caso do passe de $1,0 \mathrm{~mm}$, mas com o aumento da profundidade do passe a concentração de esforços nessa componente fica bastante maior 
que a própria componente originária do estado vibratória em $15,8 \mathrm{~Hz}$ e beira a $150 \mathrm{~N}$ o que acarreta fadiga e coloca em risco componentes mecânicos da máquina ferramenta.

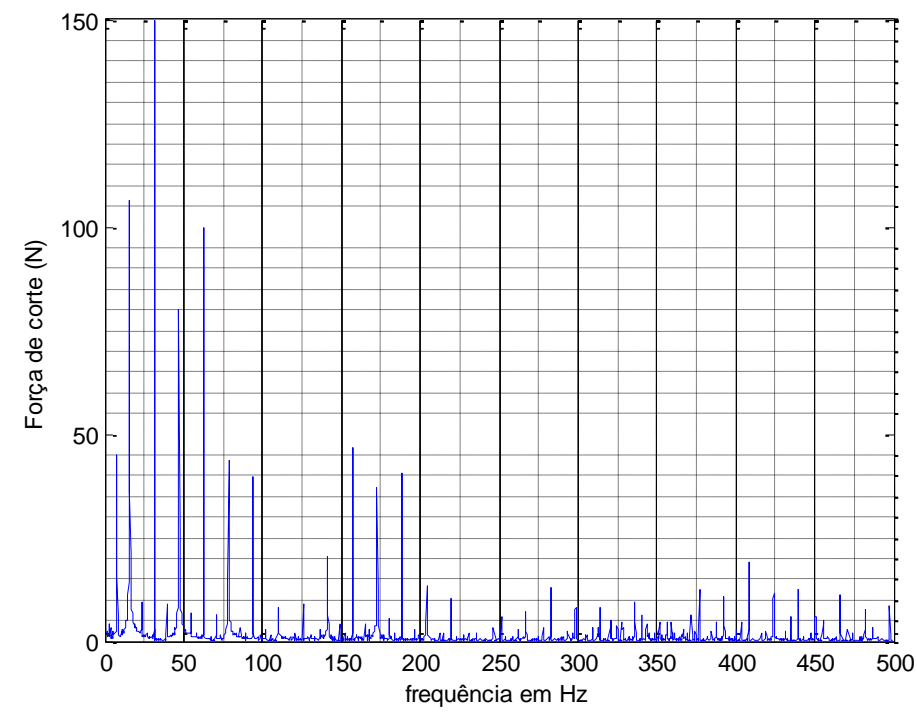

Figura 5-47 Espectro do sinal do dinamômetro para a situação de $\mathrm{Cl}$ e ucp de $1,5 \mathrm{~mm}$

O espectro da figura 5-46 mostra os detalhes da composição local do espectro total da figura $5-48$ com a componente de $31,5 \mathrm{~Hz}$ atuando com maior força vibratória do espectro e gerando harmônicas que superpõem a componente vibratória de $15,8 \mathrm{~Hz}$ que tem origem na usinagem com corte interrompido.

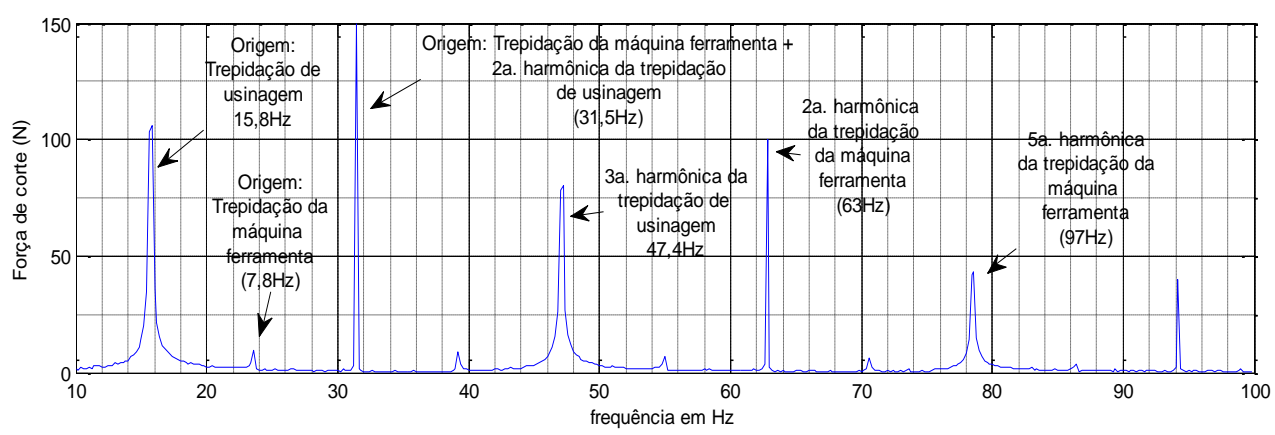

Figura 5-48 Espectro do sinal do dinamômetro para a situação de $\mathrm{Cl}$ e ucp de $1,5 \mathrm{~mm}$

A tabela 5-7 mostra como as IMFs de números 2 a 5 apresentam elevado módulo vibratório, denotando que todo o conjunto de frequências é afetado com a elevação dos esforços exigidos pela máquina na situação dessa 
usinagem e como ela afeta quase todos as componentes do espectro da máquina da análise realizada. As figuras 5-49 (a) e (b) mostram os efeitos do corte interrompido com passe de 1,5mm sobre a IMF-2. Deve-se observar que não só a variação do módulo é extensa, mas também a variação da frequência dessa IMF.

Tabela 5-7 Características da HHT do sinal de torque com corte interrompido e passe de $1,5 \mathrm{~mm}$

\begin{tabular}{|c|c|c|c|c|}
\hline IMF & $\begin{array}{c}\text { Fase (linearizada) } \\
\text { (radianos) }\end{array}$ & $\begin{array}{c}\text { Frequência } \\
\text { (média) } \mathrm{Hz})\end{array}$ & $\begin{array}{c}\text { Frequência } \\
\text { máxima } \\
\text { (média)(Hz) }\end{array}$ & $\begin{array}{c}\text { Forca de } \\
\text { corte } \\
\text { (média) }(\mathrm{N})\end{array}$ \\
\hline 1 & $\psi(t)=737,75 t-7,91$ & 117,41 & 196,70 & 70.94 \\
\hline 2 & $\psi(t)=537,57 t+1,930$ & 85,56 & 178,16 & 120,0 \\
\hline 3 & $\psi(t)=311,49 t+3,74$ & 49,57 & 114,89 & 94,86 \\
\hline 4 & $\psi(t)=193,37 t-0,196$ & 30,77 & 48,29 & 128,83 \\
\hline 5 & $\psi(t)=94,757 t-0,366$ & 15,08 & 21,72 & 146,96 \\
\hline 6 & $\psi(t)=46,879 t-7,666$ & 7,46 & 12,71 & 29,29 \\
\hline 7 & $\psi(t)=16,889 t-1,313$ & 2,68 & $20, .88$ & 9,0 \\
\hline
\end{tabular}

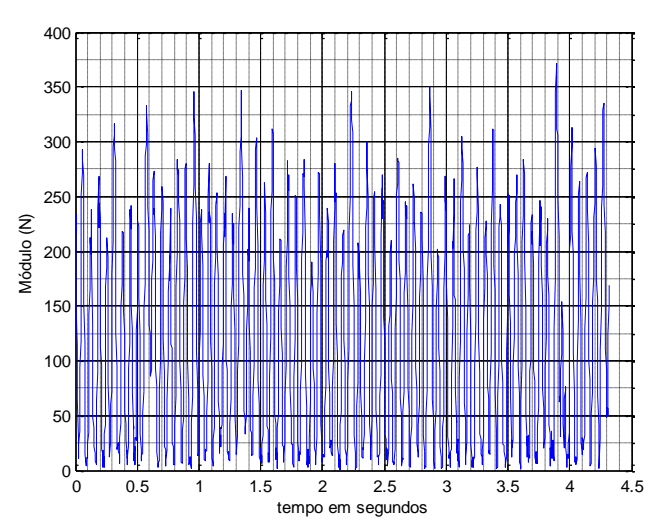

(a)

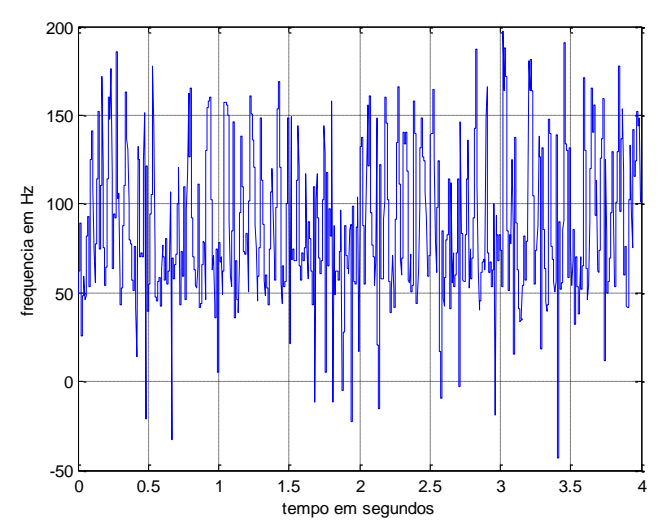

(b)

Figura 5-49 Módulo da IMF-2 (a) e frequência da IMF-2 (b)

As figuras 5-50 (a) e (b) mostram o mesmo que a figura anterior com relação ao módulo e a frequência da IMF-3, mas tanto as oscilações do módulo como as da frequência são bem menores como se pode verificar nas figuras 550 (a ) e (b).

A componente de $31,5 \mathrm{~Hz}$ tem o maior módulo como se verifica no espectro da figura 5-46 e isso também se verifica nas IMFs relacionadas a 
mesma como se verifica na figuras 5-50 (a) e (b) onde o módulo apresenta menos variações assim como a frequência que se situa em uma faixa mais estreita de variação o que corrobora a concentração de esforço mostrado no espectro.

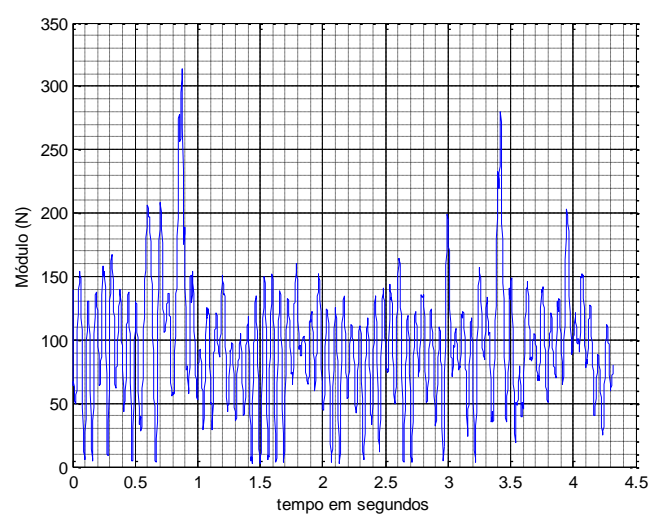

(a)

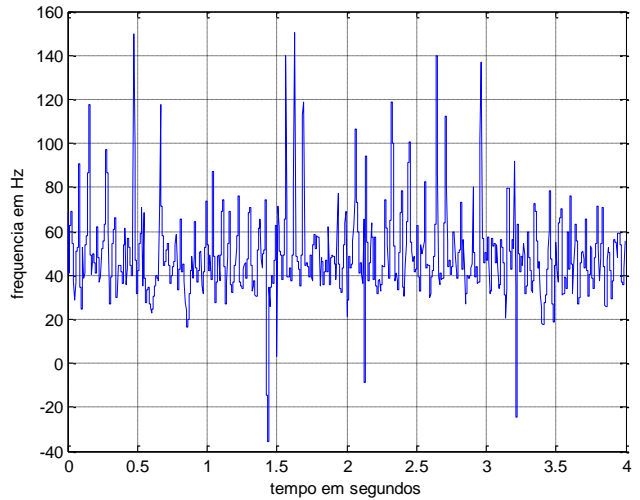

(b)

Figura 5-50 Módulo da IMF-3 (a) e frequência da IMF-3 (b)

O mesmo efeito observado com a componente de $31,5 \mathrm{~Hz}$ também pode ser observado com a componente de $15,8 \mathrm{~Hz}$ cuja IMF é a de número 5 e que pelo mesmo motivo concentra forte componente vibratória como mostram as figuras 5-51 (a) em (b) com menor gama de variação no módulo e a frequência variando menos em torno do valor médio.

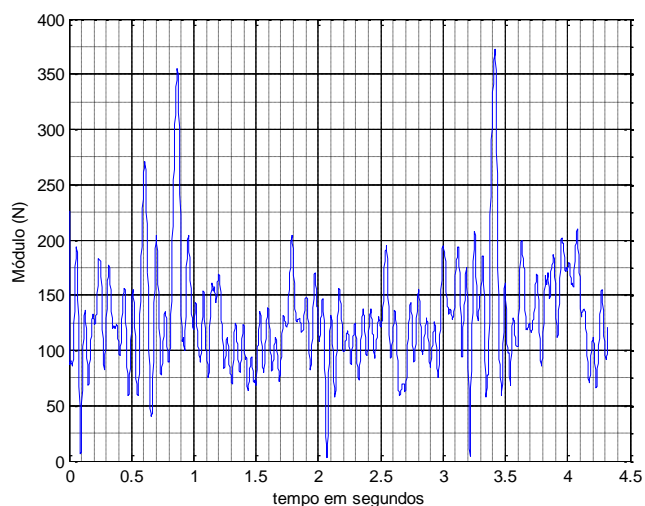

(a)

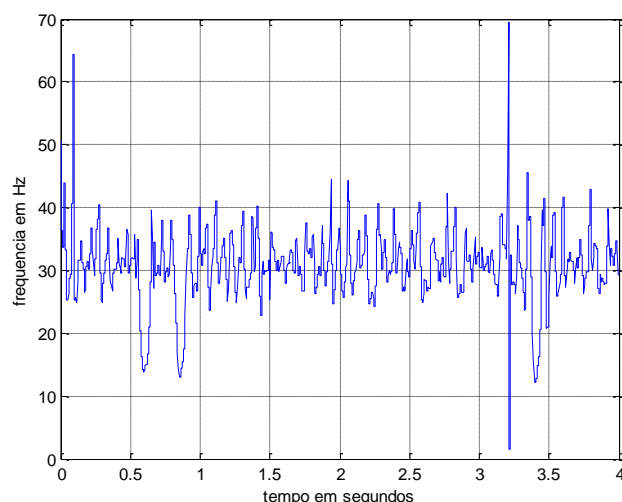

(b)

Figura 5-51 Módulo da IMF-4 (a) e frequência da IMF-4 (b) 


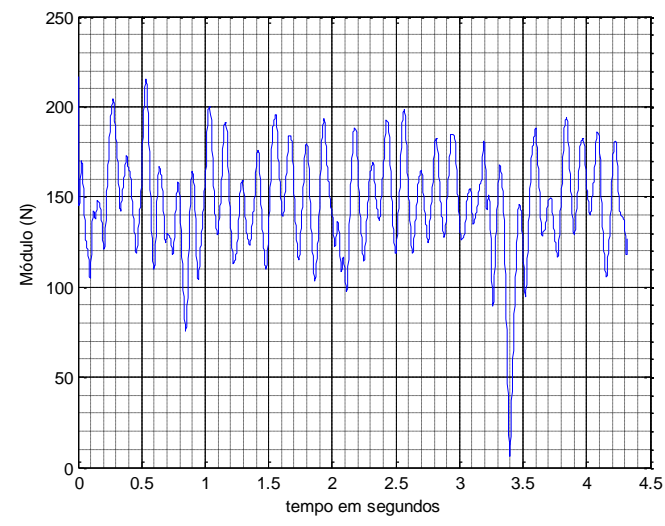

(a)

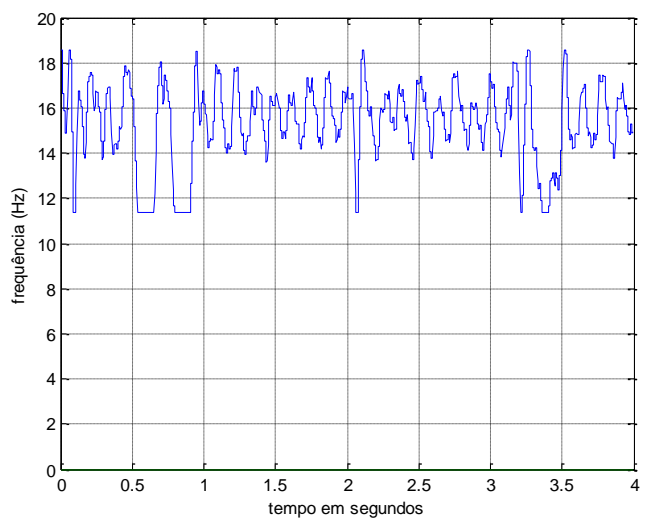

(b)

Figura 5-52 Módulo da IMF-5 (a) e frequência da IMF-5 (b)

As figuras 5.53 (a) e (b) mostram as relações entre a força de corte e a frequência média e máxima do sinal analítico de cada IMF obtida respectivamente. Como consequência do perfil das respostas das figura podemos concluir que a aplicação do método da HHT limita a resposta de análise do sinal da ferramenta em temos de $\mathrm{Fs} / 4$, ou $250 \mathrm{~Hz}$ como mostra efetivamente a figura 5.53(b).

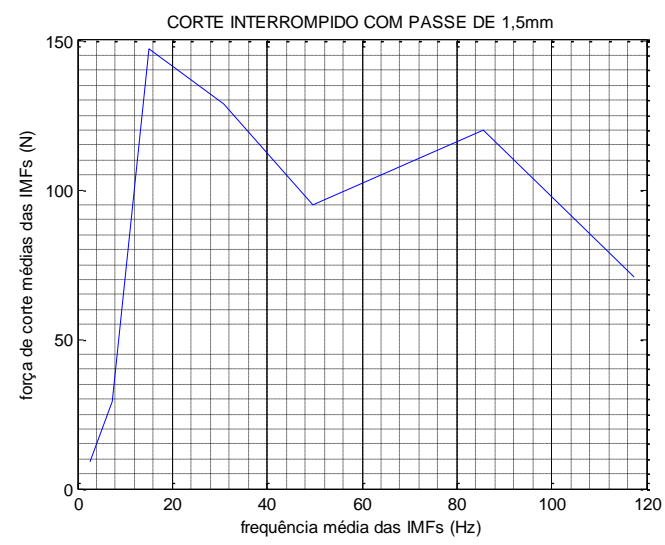

(a)

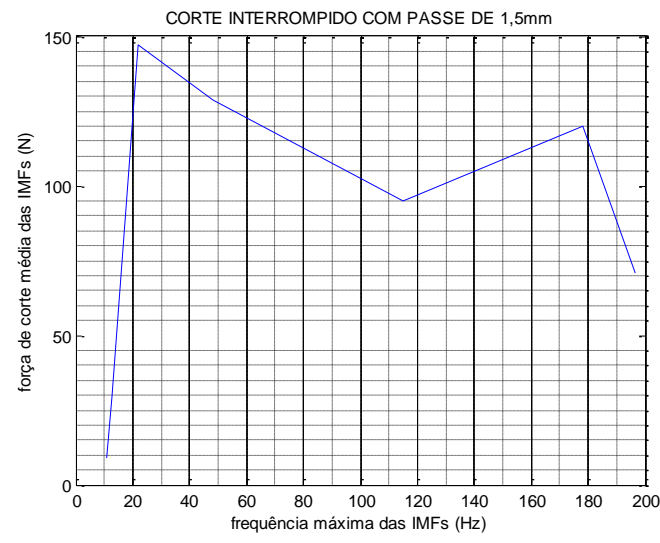

(b)

Figura 5-53 Relação entre os valores médios das forças de corte e a frequência média das IMFs (a) e com relação as frequências máximas das IMFs(b) para o caso de corte interrompido com passe de $1,5 \mathrm{~mm}$

\subsection{Análise pela aplicação da transformada de wavelet}

A estrutura da informação obtida pela aplicação da transformada de wavelet sobre os dados do dinamômetro é mostrada na figura 5.54 , onde os 
coeficientes da esquerda de cada nó mantém a informação de baixa frequência, ou do nível de aproximação (A), inclusive da componente média, enquanto os coeficientes do lado direito de cada nó mantém a informação das frequências mais altas ou de detalhe (D), onde o nível da componente média é eliminado.

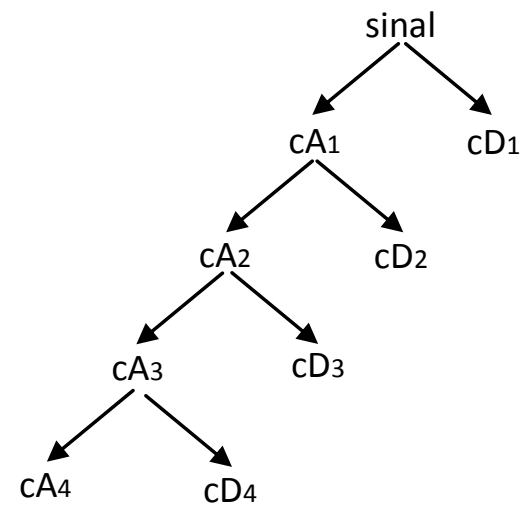

Figura 5.54 Estrutura de decodificação do sinal pela wavelet utilizada

O algoritmo da transformada de wavelet aplica uma operação de convolução utilizando a wavelet mãe 'db4', (adotada nesta análise) sobre o sinal de cada nó e sub-amostra este resultado por um fator 2 gerando assim o sinal resultante do nó subsequente. O sinal recuperado em cada nó pela operação inversa, contém a informação desejada sobre a composição do sinal neste nível.

\subsubsection{A WT do sinal de corte contínuo com UCP de $0,5 \mathrm{~mm}$}

Os resultados da aplicação da transformada de wavelet aos dados do dinamômetro estão no apêndice $F$ deste trabalho. As informações que obtemos a partir dos coeficientes de aproximação, permitem a observação dos sinais superpostos ao nível médio do sinal de força de corte, que no caso sob análise contém a sempre presente oscilação de $7,8 \mathrm{~Hz}$ até o nível de aproximação 4 , onde percebe-se a presença de componentes moduladoras de frequências inferiores a $7,8 \mathrm{~Hz}$ com se verifica na figura $5.55(\mathrm{a})$.

A figura 5.55(b) mostra a forma das componentes moduladoras de baixa frequência, inclusive seu aparentemente comportamento aleatório presente no coeficiente de aproximação 7, na cor preta na figura 5.55(b). Essa oscilação, 
com certeza não é aleatória, mas é decorrente da aceleração e desaceleração das massas acionadas em função da solicitação de esforços no passe de 0,5mm não gerar uma componente forçante contínua, o que limitaria a banda de passagem, ou a faixa de oscilação da força de corte para frequências mais próximas de um valor central, que devido ao desbalanceamento de massas, já observado, é de aproximadamente $7,8 \mathrm{~Hz}$.

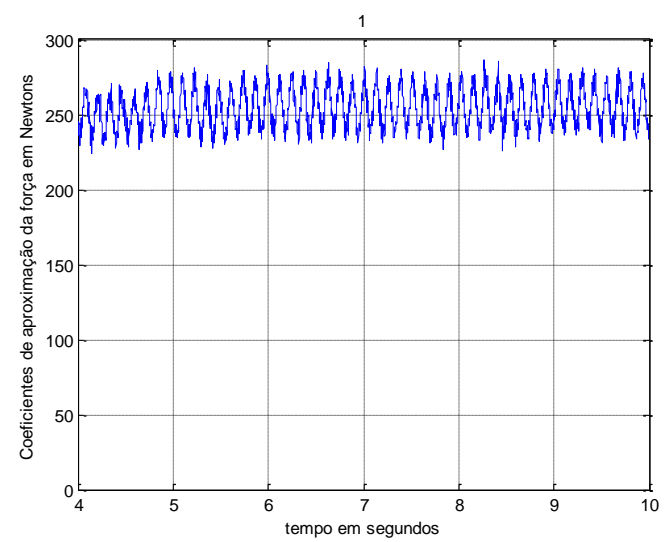

(a)

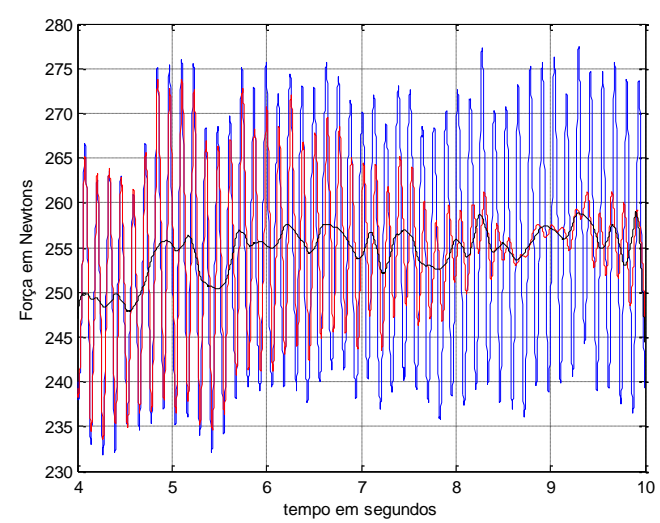

(b)

Figura 5.55 Coeficiente de aproximação 4 (a) e a superposição dos coeficientes de aproximação 5,6 e 7 (b) para $\mathrm{Cl}$ de $0,5 \mathrm{~mm}$

\subsubsection{Wavelet do sinal de corte contínuo com passe de 1,0mm}

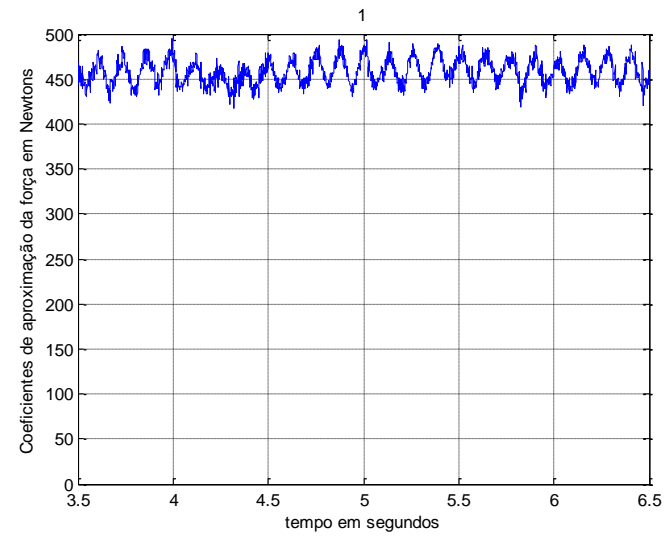

(a)

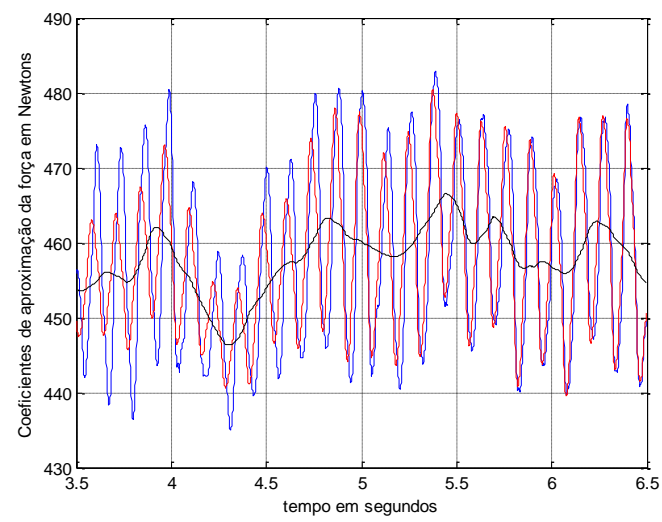

(b)

Figura 5.56 Coeficiente de aproximação 4 (a) e a superposição dos coeficientes de aproximação 5, 6 e 7 (b) para o corte contínuo de 1,0 mm 
As figuras 5.56 (a) e (b) mostram o efeito da aplicação da transformada de wavelet utilizando os coeficientes de aproximação, a figura 5.56(a) mostra a recuperação do coeficiente de aproximação $\mathrm{cA} 1$ utilizando com referência 0 nível 0 da força de corte. Já a figura 5.56(b) mostra as recuperações dos coeficientes de aproximação cA5, cA6 e cA7, superpostos na mesma figura. Observam-se os mesmos efeitos já mencionados na análise da figura 5.55(b).

\subsubsection{A WT do sinal de corte contínuo com passe de $1,5 \mathrm{~mm}$}

As figuras 5.57 (a) e (b) mostram os mesmos sinais já mostrados nas figura 5.55 e 5.56 (a) e (b) para o caso de corte com passe de $1,5 \mathrm{~mm}$. Observa-se nas figuras 5.57, que a oscilação que modula a componente de $7,8 \mathrm{~Hz}$ provoca um nível de flutuação menor na oscilação de $7,8 \mathrm{~Hz}$, o que indica que a componente forçada sintoniza as oscilações da máquina ferramenta em uma faixa mais próxima da oscilação dominante de $7,8 \mathrm{~Hz}$.

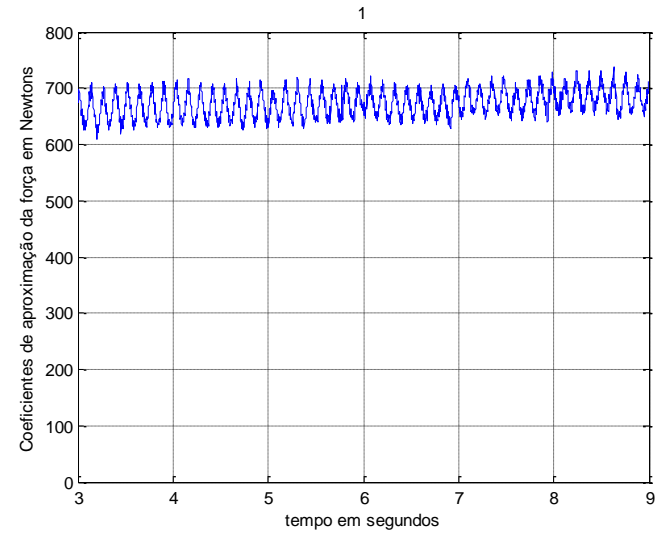

(a)

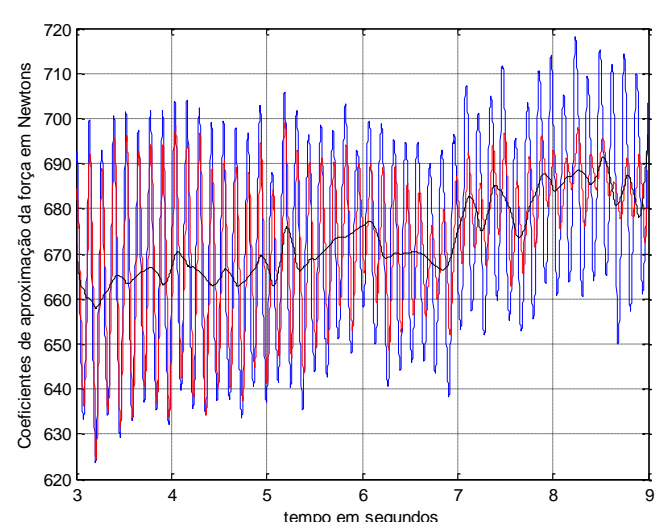

(b)

Figura 5.57 Coeficiente de aproximação 4 (a) e a superposição dos coeficientes de aproximação 5, 6 e 7 (b) para o corte contínuo de 1,5mm

\subsection{A transformada de wavelet e o EMD}

Com o objetivo de relacionar os sinais obtidos com a transformada de wavelet e a HHT, na forma do seu algoritmo de extração de modos EMD escolhemos a situação do passe com corte contínuo de $1,5 \mathrm{~mm}$ para efetuar algumas considerações. 
Como é muito difícil comparar os sinais resultantes da aplicação direta dos algoritmos, vamos trabalhar com a aplicação da FFT sobre o resultado de cada fase dos processos efetuados. Para o EMD existe um único processo de extração dos modos oscilatórios do sinal, já a transformada de wavelet opera com dois modo, o de aproximação que corresponde a informação de baixa frequência do sinal e o de detalhe que corresponde a informação de alta frequência do sinal. Vamos definir o modo de detalhe para a comparação porque consideramos que o mesmo é mais rico em conteúdo que o modo de aproximação e lembrado inclusive que a HHT tem a limitação no fato que a HT do valor médio ser zero e portanto o sinal analítico do valor médio é igual ao valor médio do próprio sinal. Como o valor médio não varia no tempo o método de interpolação cúbica (splines cúbicas) falha e portanto o EMD falha.

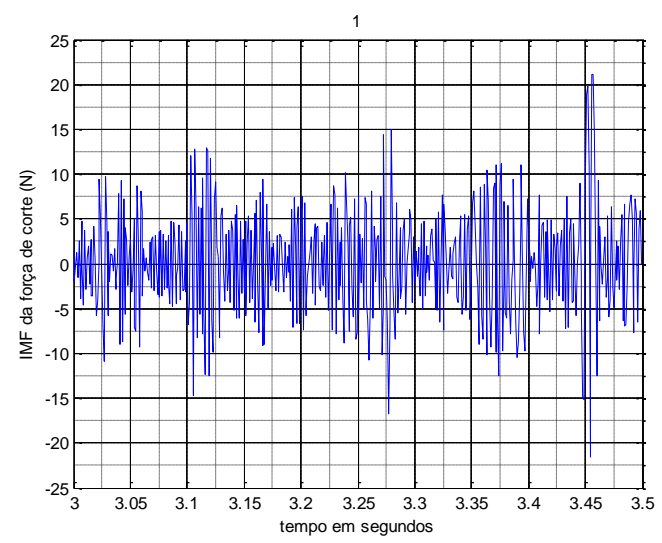

(a)

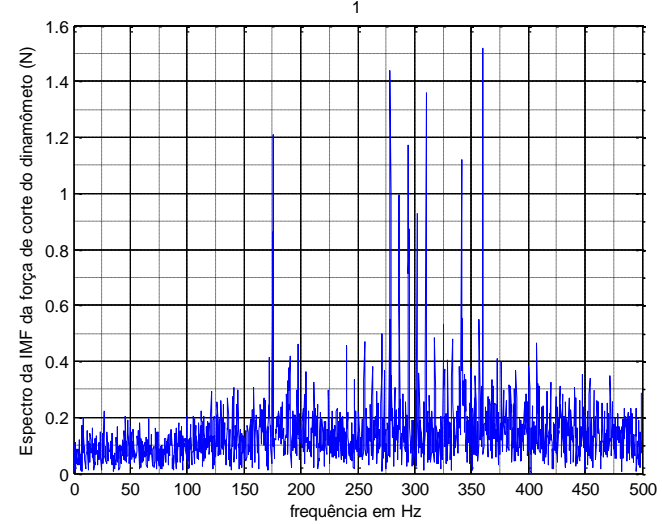

(c)

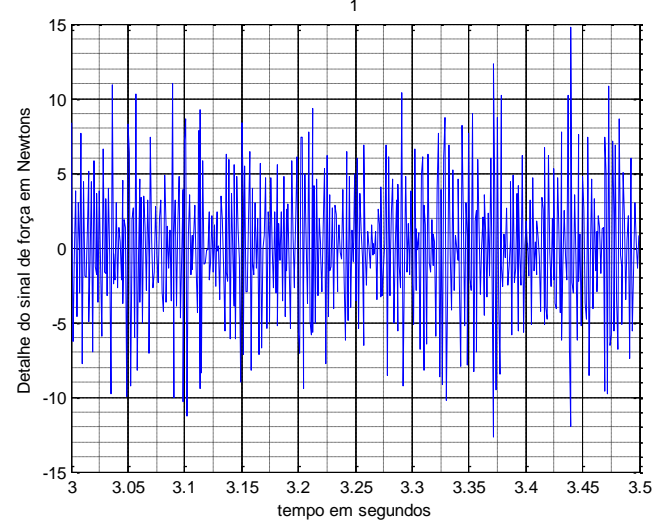

(b)

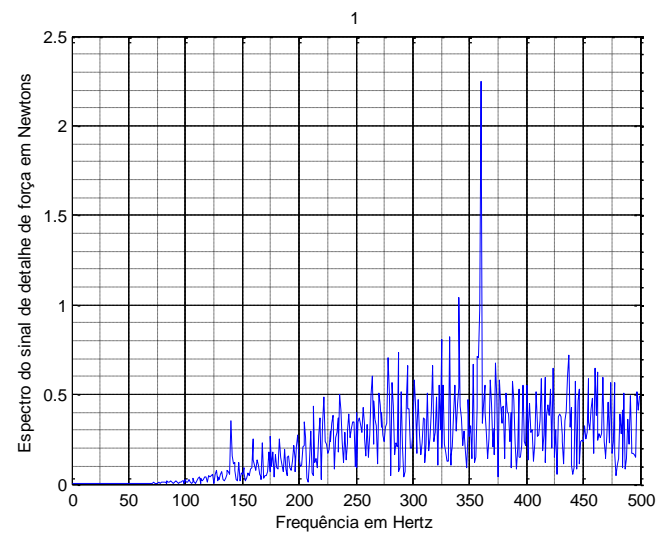

(d)

Figura 5.58 Os sinais da IMF-1 da força de corte e seu espectro (a) e (c) e os sinais de detalhe cD1 e seu espectro em (b) e (d). 
A figura 5.58(c) mostra claramente que a IMF-1 é composta de um conjunto de frequências, além da componente de $360 \mathrm{~Hz}$ que tem origem nas interações do motor de indução com a rede elétrica, ela acusa um conjunto de componentes entre 275 e $310 \mathrm{~Hz}$ que parece ter origem na usinagem, uma vez que este conjunto de componentes altera sua posição com a profundidade do passe. A IMF-1 acusa também uma componente de $175 \mathrm{~Hz}$ que tem origem aparente na máquina ferramenta, já que é evidenciada também, em outras análises já realizadas. A figura 5.59(d) enfatiza apenas a componente de $360 \mathrm{~Hz}$ e o conjunto de frequências a $300 \mathrm{~Hz}$, porém de forma bastante tênue em relação a IMF.

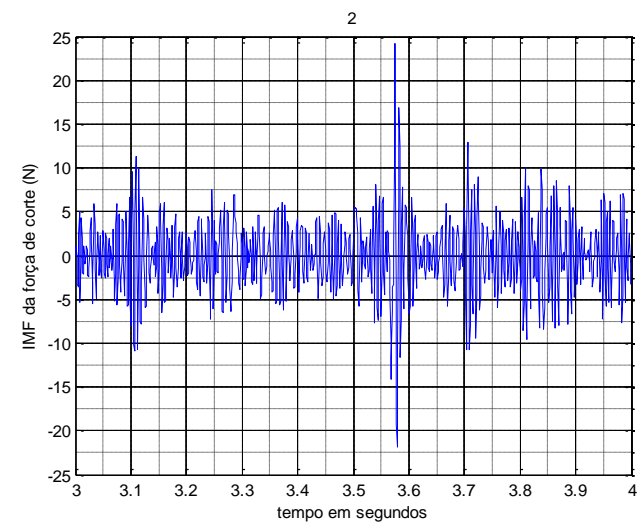

(a)

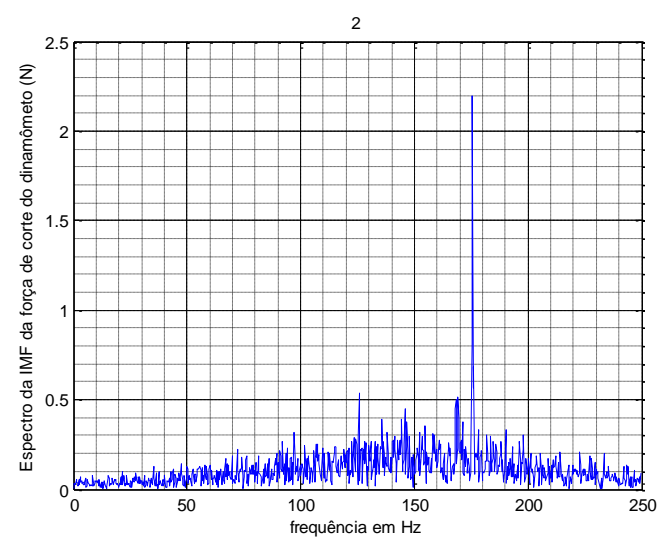

(c)

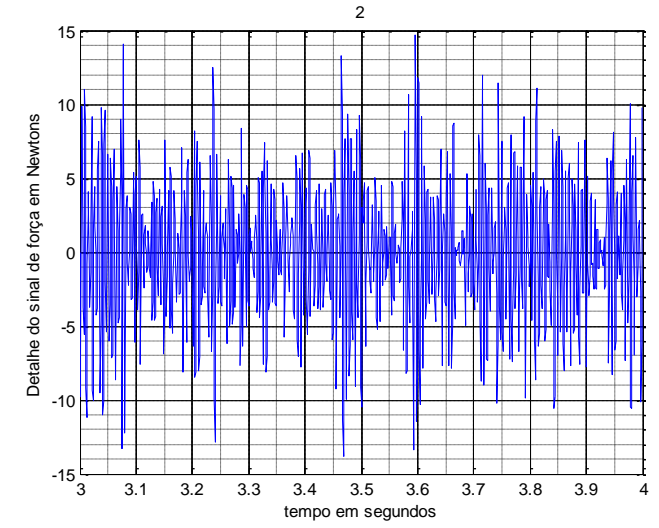

(b)

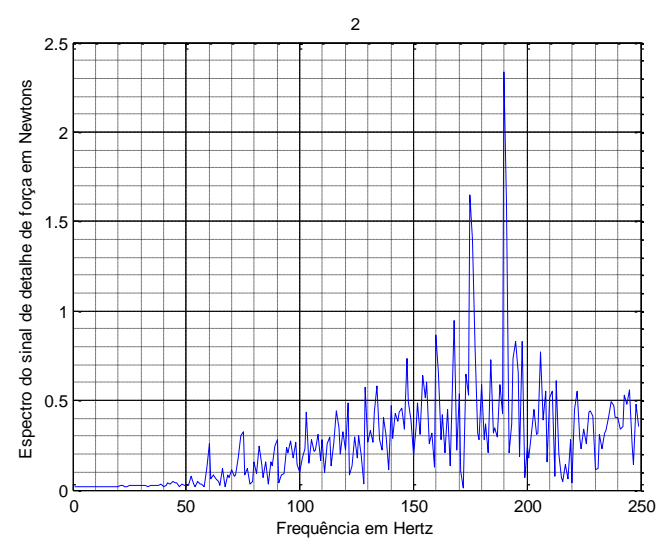

(d)

Figura 5.59 Os sinais da IMF-2 da força de corte e seu espectro (a) e (c) e os sinais de detalhe cD2 e seu espectro em (b) e (d)

Os casos apontados nas figuras 5.59 mostram que a IMF-2 apresenta uma forte componente de $175 \mathrm{~Hz}$ que aparece também no detalhe do espectro local mostrado na 5.26(a), ou seja é uma componente estacionária detectada 
também pela FFT. A mesma componente aparece no detalhe do espectro cD2, na figura 5.59(d), mas acompanhada de uma componente de maior amplitude de $190 \mathrm{~Hz}$ e não é um caso de modulação em amplitude, já que a componente de $175 \mathrm{~Hz}$ não é acompanhada de uma componente de $205 \mathrm{~Hz}$ a direta da componente de $190 \mathrm{~Hz}$.

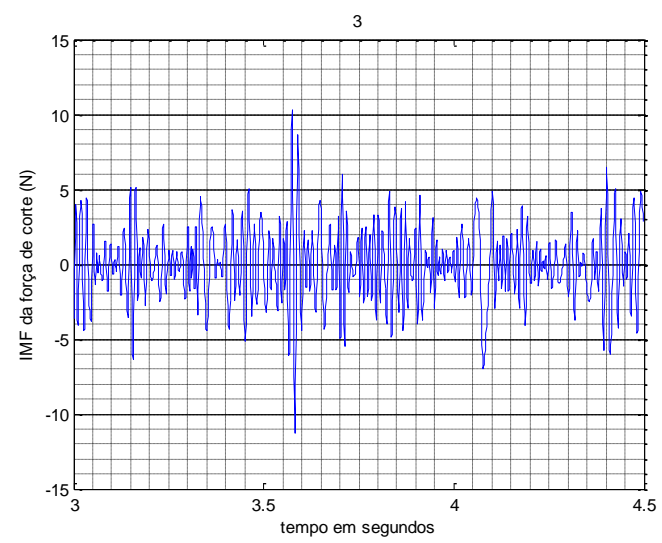

(a)

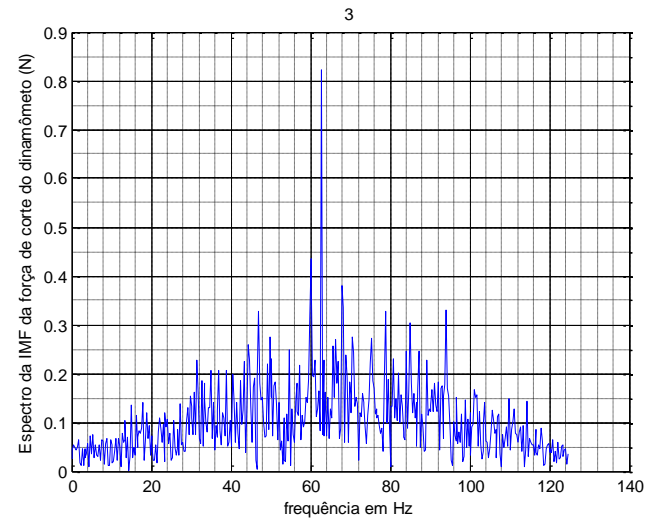

(c)

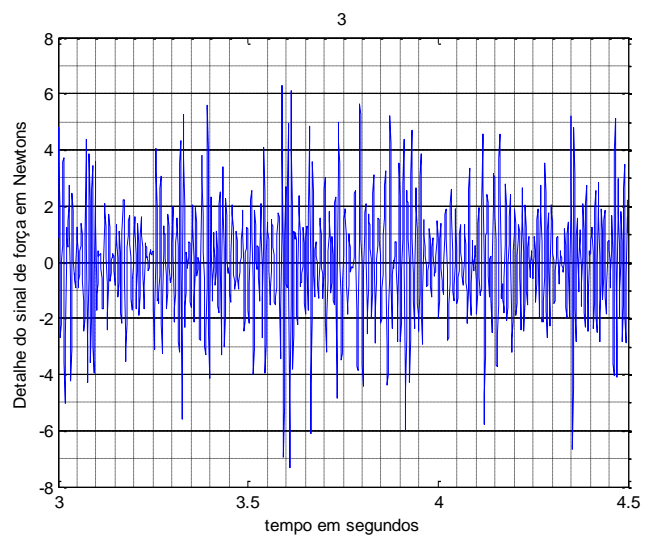

(b)

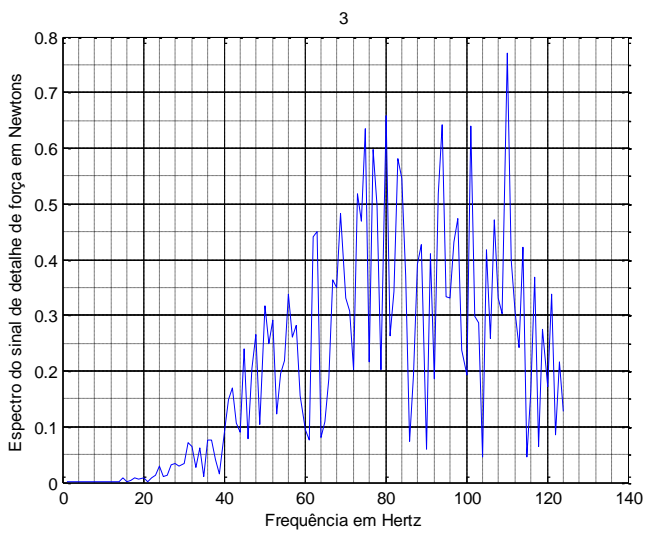

(d)

Figura 5.60 Os sinais da IMF-3 da força de corte e seu espectro (a) e (c) e os sinais de detalhe $c D 3$ e seu espectro em (b) e (d) respectivamente

As figuras 5.60 (a) a (d) mostram a IMF-3 e o coeficiente de detalhe cD3. 0 espectro da IMF-3 mostrado na figura 5.60(c), indica uma componente de valor absoluto relativamente grande no espectro local com aproximadamente $63 \mathrm{~Hz} \mathrm{com}$ módulo de $0,82 \mathrm{~N}$, existem duas componentes laterais à componente de $63 \mathrm{~Hz}$, mas não estão equidistantes da mesma e portanto não caracterizam uma oscilação de AM. O espectro da cD3, mostrado na figura 5.60(d), apresenta também a mesma componente, porém com módulo de $0,45 \mathrm{~N}$, com um conjunto de componentes de 
módulo duas vezes maior na região de frequências imediatamente maior a direta, sendo que ocorre uma componente dominante no espectro da cD3 na frequência de $110 \mathrm{~Hz}$.

As figuras 5.61 (a) a (d) mostram os sinais relativos a IMF-4 e ao sinal de detalhe cD4. Observa-se que a IMF-4 não detecta o pequeno grupo de componentes em torno de $31,5 \mathrm{~Hz}$, mas o detalhe mostrado em vermelho na figura $5.61(\mathrm{c})$ indica a presença do mesmo como uma oscilação secundária extremamente esmaecida. O espectro da IMF4 indica que a componente de $8 \mathrm{~Hz}$ domina absoluta sobre este grupo relativo a IMF-4 e mostrado na figura 5.61(c). O sinal de detalhe cD4 indica que na faixa de sua existência uma componente de aproximadamente $31,5 \mathrm{~Hz}$ com módulo de $0,59 \mathrm{~N}$ como aponta a figura $5.61(d)$.

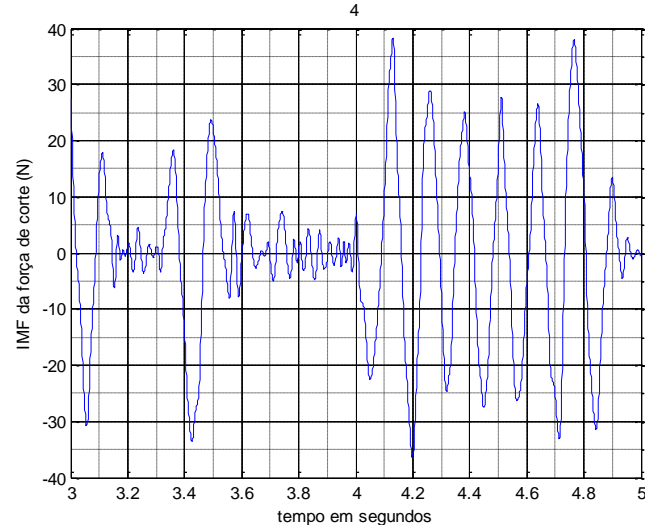

(a)

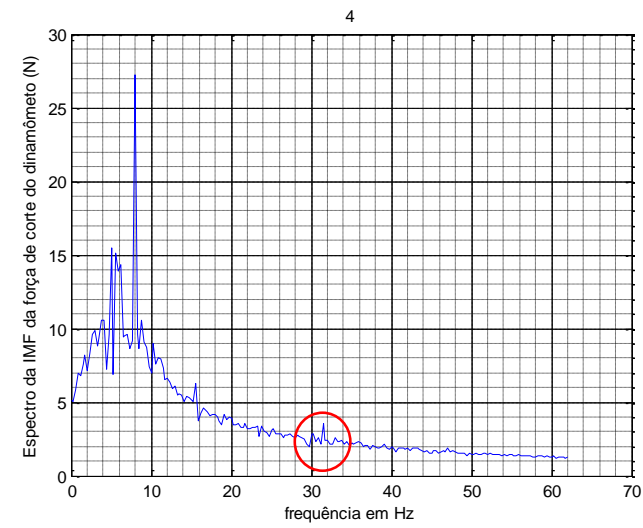

(c)

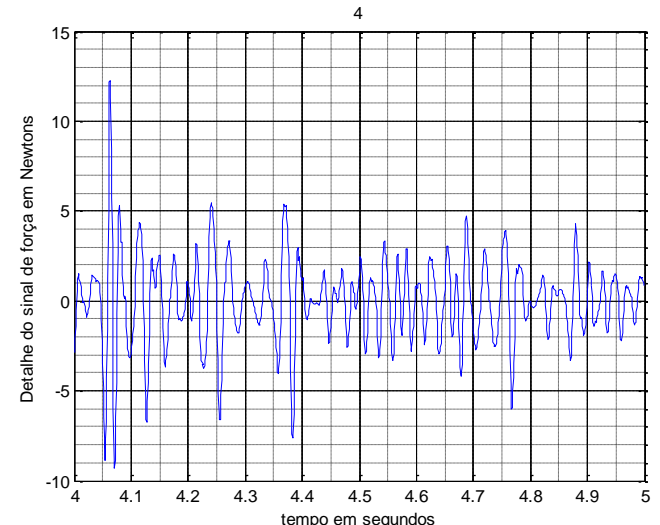

(b)

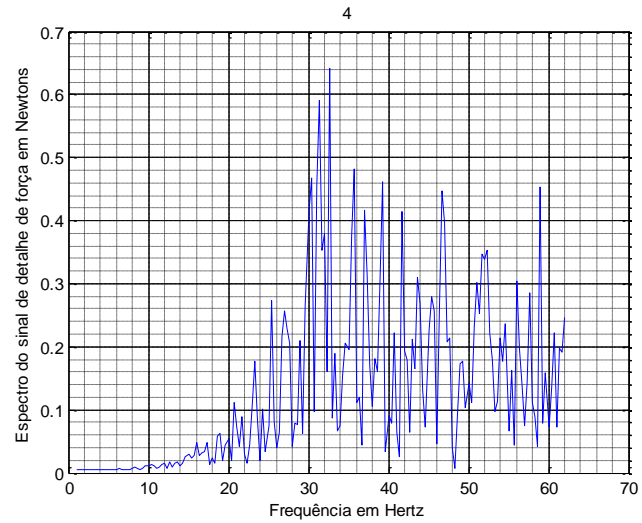

(d)

Figura 5.61 Os sinais da IMF-4 da força de corte e seu espectro (a) e (c) e os sinais de detalhe cD4 e seu espectro em (b) e (d) 
As figuras 5.62 são relativas a IMF-5 e a cD5 e indicam claramente que não existe correspondência alguma entre as IMFs e as cDs da transformada de wavelet, uma vez que o espectro da IMF-5 está relacionado a uma componente de frequência muito baixa com módulo máximo em torno de 5,5 a $6 \mathrm{~Hz}$ e apresenta um conteúdo lateral estacionário, mas com indefinição de componentes, exceto em uma região muito próxima a $5 \mathrm{~Hz}$, quando aparece uma lacuna de componente similar a situação de um filtro rejeita faixa de apenas uma unidade de frequência. $O$ espectro da CD5 apresenta uma componente dominante em torno de $23,5 \mathrm{~Hz}$ com módulo de $2,5 \mathrm{~N}$ e uma componente menor de $15,8 \mathrm{~Hz}$ e módulo de $1,1 \mathrm{~N}$ com certeza conectada a componente de $16 \mathrm{~Hz}$ que esta sendo gerada por desequilíbrio de massas girantes na máquina ferramenta.

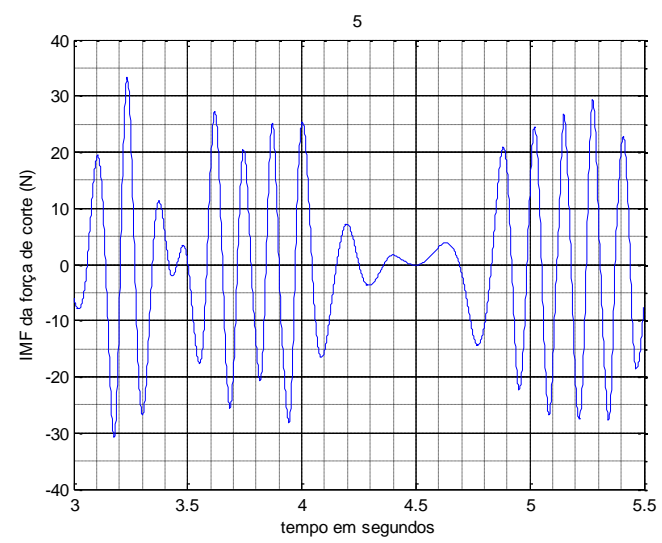

(a)

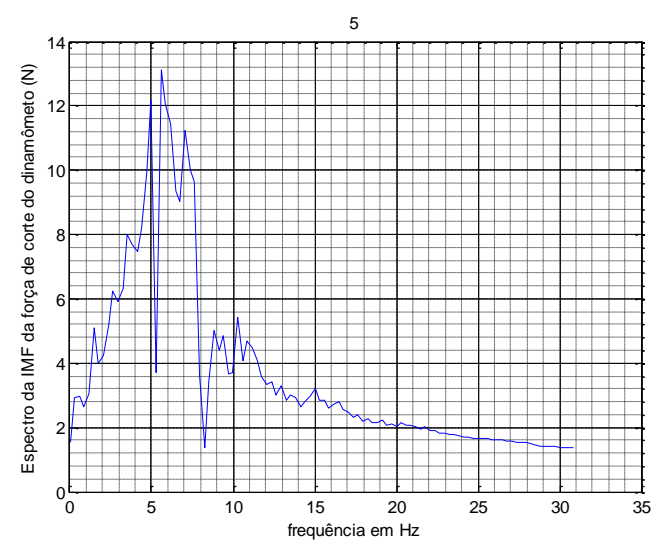

(c)

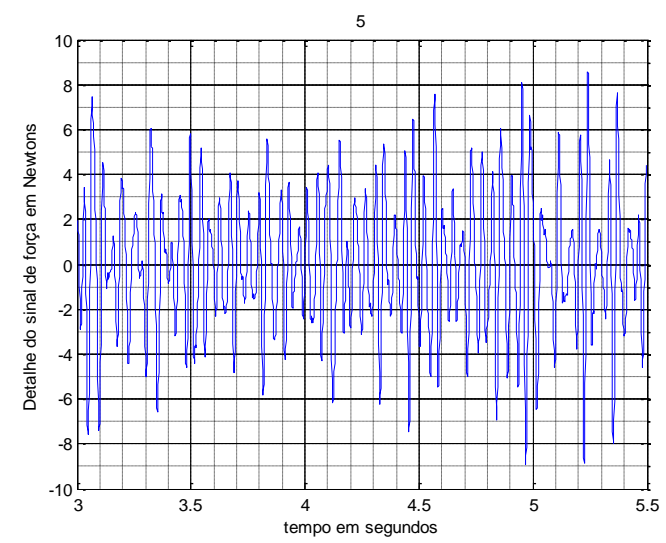

(b)

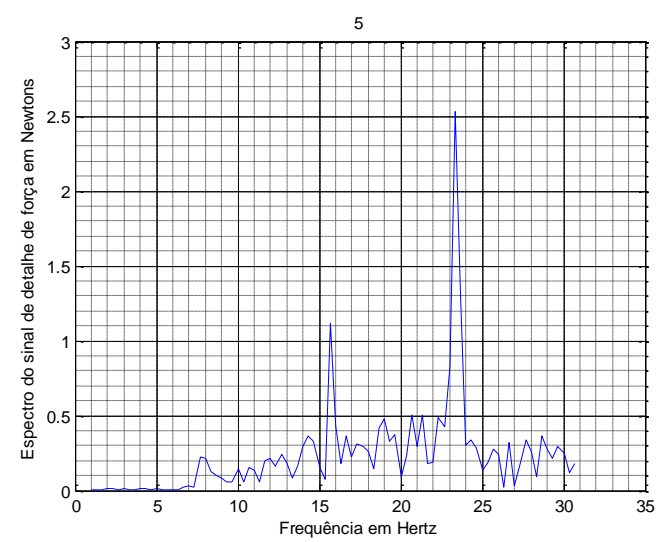

(d)

Figura 5.62 Os sinais da IMF-5 da força de corte e seu espectro (a) e (c) e os sinais de detalhe cD5 e seu espectro em (b) e (d) 


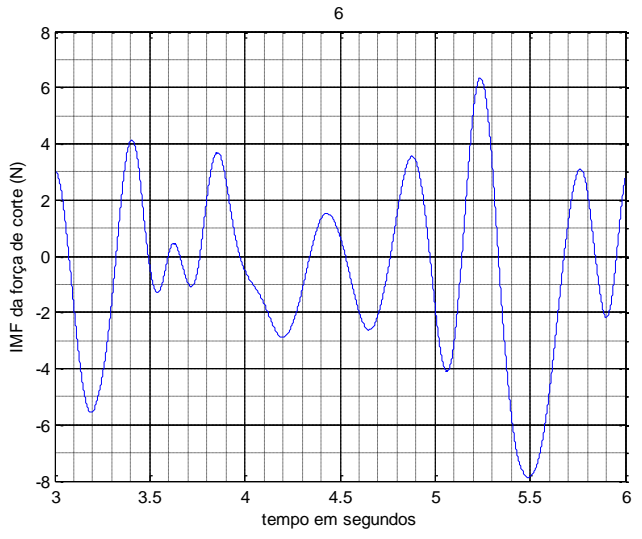

(a)

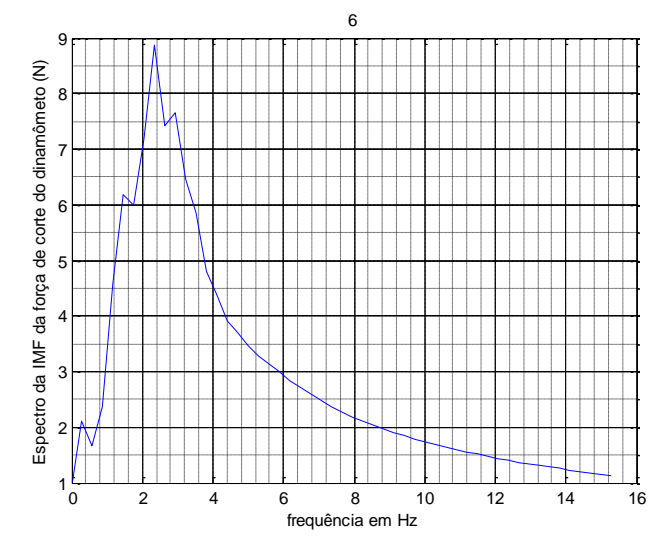

(c)

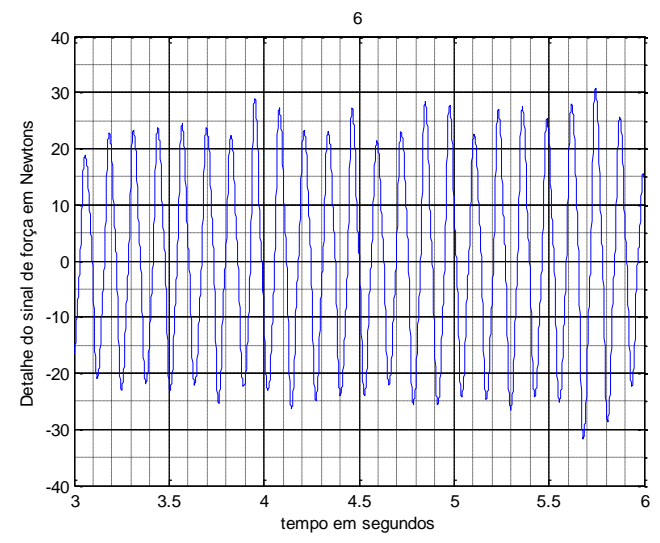

(b)

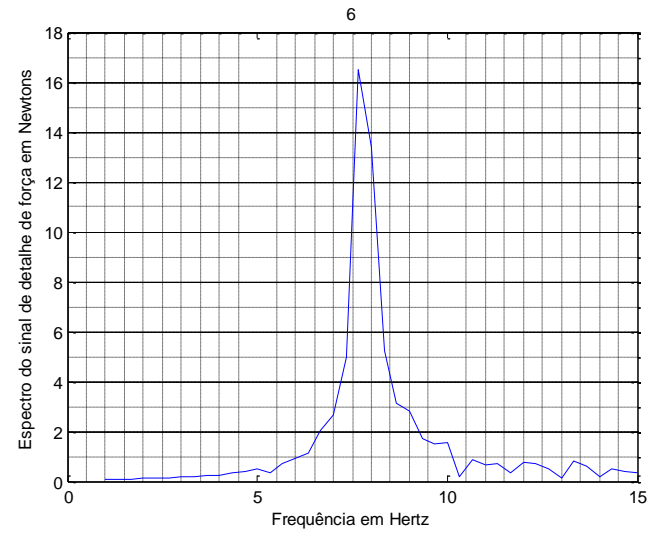

(d)

Figura 5.63 Os sinais da IMF-6 da força de corte e seu espectro (a) e (c) e os sinais de detalhe cD6 e seu espectro em (b) e (d)

As figuras 5.63 (a) a (d) são relativas a IMF-6 e a cD6 e novamente confirmam que não existe correspondencia alguma entre as IMFs e as cDs da transformada de wavelet, uma vez que o espectro da IMF-6 está, novamente relacionado a uma componente de frequência muito baixa com módulo máximo em torno de $2,2 \mathrm{~Hz}$ com conteúdo lateral estacionário, mas com indefinição de componentes. O espectro da cD6 apresenta a componente de $8 \mathrm{~Hz}$ com módulo de $16,5 \mathrm{~Hz}$ e corresponde a componente dominante do espectro da IMF-4. A magnitude do módulo desta componente mascára outras componentes que pertençam a seu entorno, mas oberva-se que existem composições laterais que geram pequenos lóbulos laterais contíguos a componente central de $8 \mathrm{~Hz}$, o que confere credibilidade ao sinal mostrado na 
figura 5.57(b) que mostra que esta componente é modulada por componentes que oscilam de forma aparentemente aleatória em seu entorno.

Pouco se pode afirmar com relação as componentes de frequência muito baixa que acompanham o sinal da IMF-7 e da cD7. O espectro da IMF-7 mostrado na figura 5.64 (c) identifica um pico em $0,6 \mathrm{~Hz}$ com módulo de $6,2 \mathrm{~N}$, mas com componentes laterais totalmente incorporadas em um entorno contínuo, enquanto que o espectro da cD7 mostra um pico em $3 \mathrm{~Hz}$ com módulo de $3,45 \mathrm{~N}$.

É importante salientar que após uma determinada frequência os coeficientes de detalhe passam a ser os coeficientes de aproximação com a exclusão da componente média, nos casos aqui analisados, isso ocorre para as componentes de frequência superior a $7,8 \mathrm{~Hz}$.

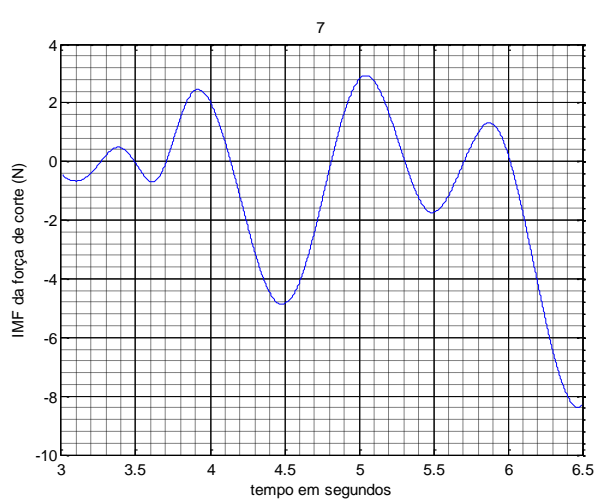

(a)

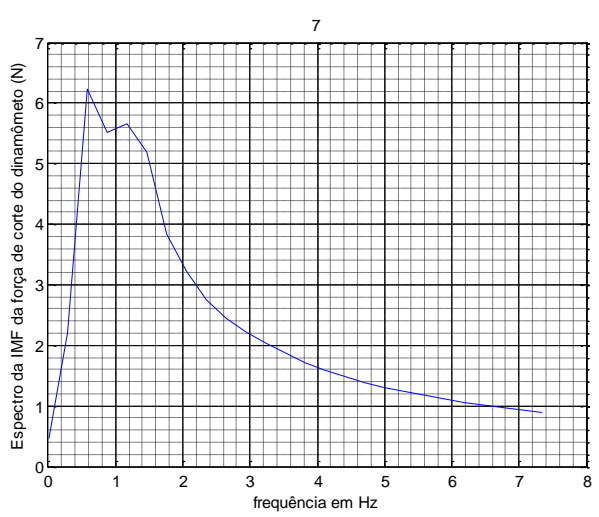

(c)

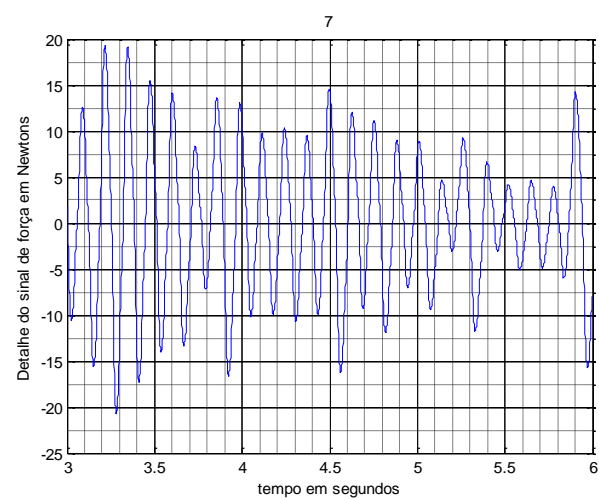

(b)

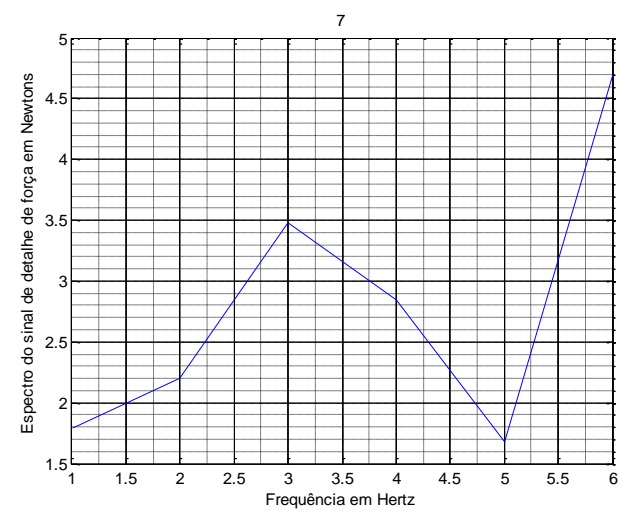

(d)

Figura 5.64 Os sinais da IMF-7 da força de corte e seu espectro (a) e (c) e os sinais de detalhe cD7 e seu espectro em (b) e (d). 


\subsection{As relações entre a HT e as IMFs obtidas pelo EMD}

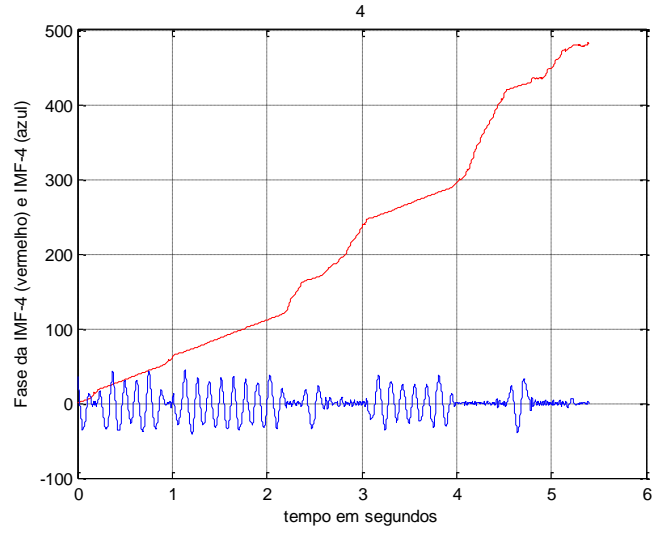

(a)

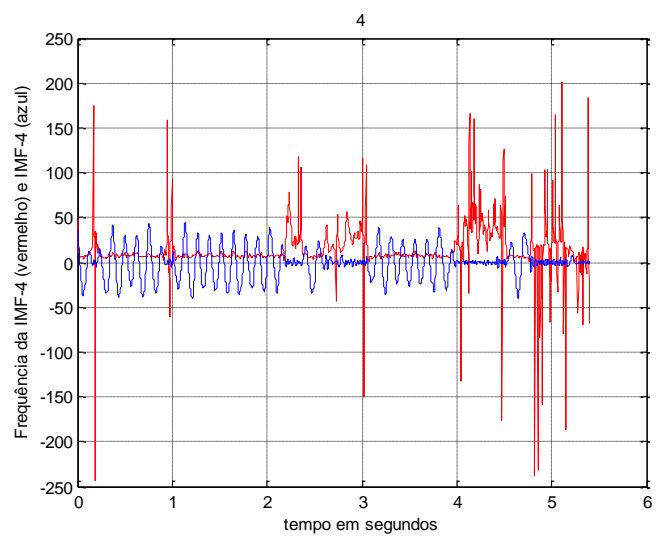

(c)

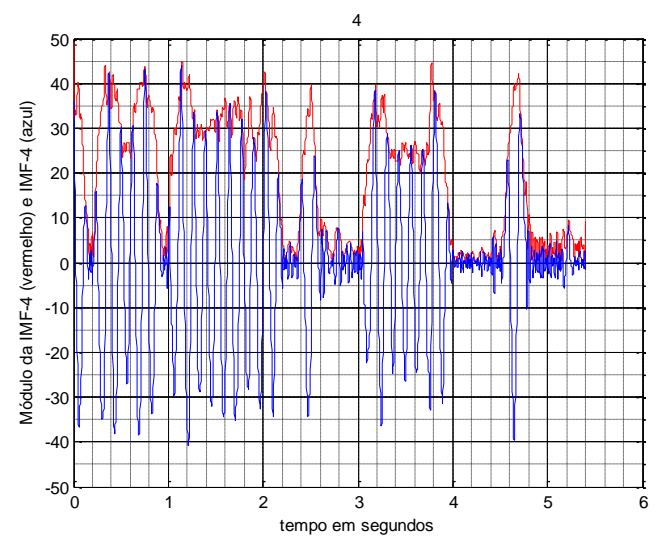

(e)

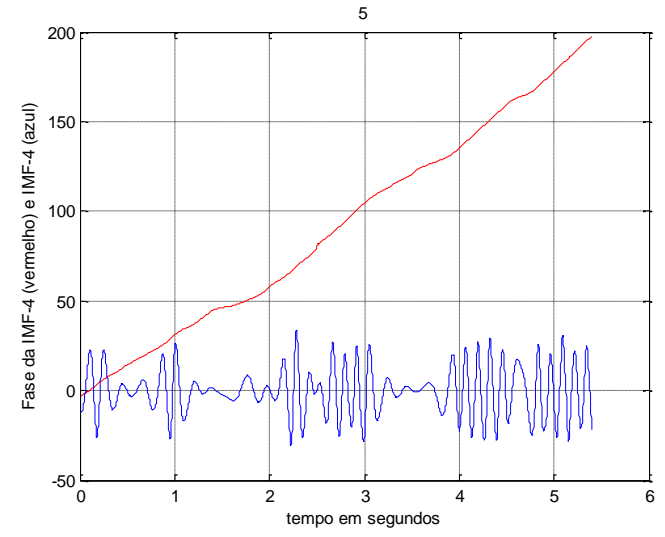

(b)

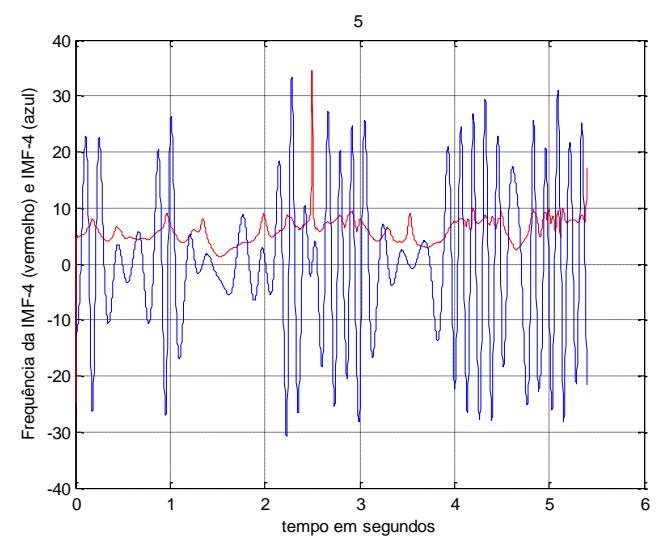

(d)

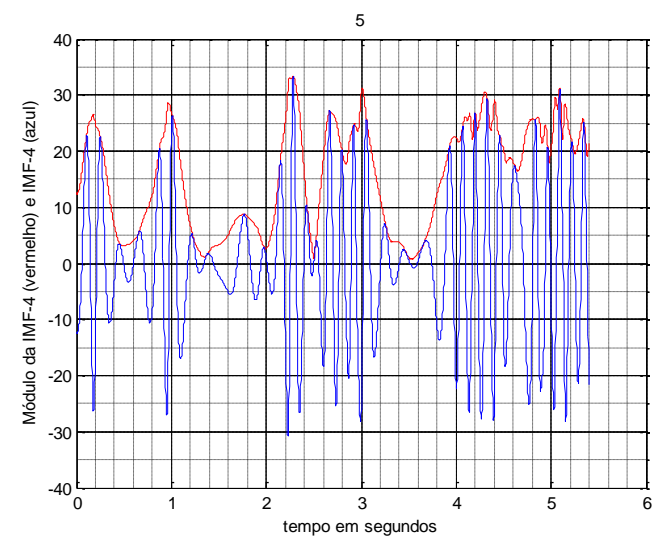

(f)

Figura 5.65 As IMFs 4 (a), (c) e (e) e 5 (b), (d) e (f) e os módulos, fases e frequências de seus respectivos sinais analíticos 
Após o processo de peneiramento feito pelo algoritmo do EMD, as IMFs resultantes são processadas pelos algoritmos relativos a HT que geram os módulo e as fases do sinal analítico a partir desta última obtemos o comportamento das frequências do objeto de estudo.

Para obter uma referência relativa ao significado físico das relações entre essas componentes, optou-se por uma demonstração relativa ao corte contínuo e passe de $1,5 \mathrm{~mm}$, a partir do qual colocou-se no mesmo gráficos as IMFs relacionadas com um determinado sinal analítico e as respectivas fases, frequências e módulos como são mostrados nas figuras 5.65 (a) a (f).

Uma inspeção visual da figura 5.65 (e) mostra que a componente vibratória de aproximadamente $8 \mathrm{~Hz}$ predomina em boa parte do período de aquisição do sinal, na média a frequência cai para cerca de $5,84 \mathrm{~Hz}$, a mesma componente vibratória ocorre na figura 5.65 (d) porém o perfil mantém uma regularidade menor que a do caso da figura 5.65(e), o que torna sua frequência média menor, em torno de $2,5 \mathrm{~Hz}$.

\subsection{Conclusões do capítulo 5}

No capítulo 5 procurou-se realizar uma correlação entre a curva de fase oriunda dos sinais analíticos das IMFs em busca de componentes estacionárias dominantes, que são definidas por uma curva de fase bem-comportada, no sentido de linearidade. A aplicação do método dos mínimos quadrados permite determinar, via coeficiente angular da reta equivalente, a frequência dominante local. Esta componente local, nesta condição especial, tem uma correspondência espectral a componentes espectrais isoladas no espectro obtido pela FFT.

Quando ocorrem grupos de componentes relativamente próximas no espectro da IMF correspondente deixa de representar a energia de uma única componente e passa a representar o conjunto de componentes e o valor da frequência média da mesma pode ficar bastante longe da região de acomodação que define a componente dominante real.

Tendo em vista o comportamento das IMFs e as HTs de seus respectivos sinais, observou-se: 
- Quando as fases apresentam um comportamento regular, tendendo a uma reta na maior parte de sua faixa de existência, existe uma componente estacionária correspondente à frequência obtida do valor do coeficiente angular da reta, no espectro de frequências da FFT.

- Quando a curva de fase torna-se irregular, isso indica que ocorre modulação de algum tipo na frequência, aqui a $\mathrm{HHT}$ é proficiente na determinação de comportamentos não lineares com a detecção de modulações imprevisíveis por outros métodos.

- As distorções laterais apresentadas nos extremos das curvas (retas) de fase estão relacionadas com o método de interpolação cúbica via splines, e são inevitáveis nos extremos inicial e final do arquivo de dados, principalmente quando o número de ordem da extração da IMF é alto em função da rarefação dos pontos de máximos e mínimos.

- A medida que as IMFs são extraídas dos dados originais, ocorre redução nos pontos de máximos e mínimos dos dados resultantes. Essa diminuição provoca distanciamento entre os pontos de pico das envoltórias superior e inferior e aumenta a distorção que ocorre devido às splines nos extremos das IMFs seguintes. Ou seja, as IMFs de menor frequência sofrem maiores distorcões que as de maior frequência.

- A curva de fase sofre flutuações em torno de seu comportamento geométrico local, que pode até ser linear, porém o efeito derivativo amplifica quaisquer pequenas oscilações pelo valor frequência de amostragem, o que impõe variações significativas no comportamento da frequência obtida diretamente pela derivada numérica da fase. Para o caso dos sinais do dinamômetro que opera com uma frequência de amostragem de $1000 \mathrm{~Hz}$, a derivada numérica simples multiplica quaisquer variações da fase por 500, o que torna o perfil da frequência em função do tempo, em alguns casos quase inelegível. Optou-se por dividir a curva de fase em pequenos trechos de reta (100 ou 200 trechos) para, a partir dos coeficientes angulares de cada trecho, obter a frequência correspondente. Este método permitiu a determinação de uma frequência "máxima" associada a cada curva de fase. 
Em termos de comparações com os resultados das aplicações da FFT aplicadas ao mesmo conjunto de dados, objetivou-se:

- Procurar a presença de componentes estacionárias nas IMFs como método de verificação de consistência do algoritmo do EMD.

- Uma vez obtida as componentes estacionárias, procurou-se estabelecer sua origem mecânica ou elétrica. A componente elétrica sabidamente existente no espectro é a de $360 \mathrm{~Hz}$, relacionadas as distorções de $5^{\mathrm{a}} \mathrm{e}$ $7^{\mathrm{a}}$ provocadas pela distorção da corrente do motor de indução e que aparecem no processo de usinagem via oscilação no corte da ferramenta. Isso pode ser verificado em quase todos os espectros das IMFs e também nas da transformada de wavelet.

Com relação as IMFs e as transformadas de wavelet, procurou-se não fazer uma comparação já que se tratam de ferramentas distintas de análise de sinais baseadas em princípios completamente diferentes.

Uma comparação direta entre a HHT e a transformada de wavelet é mais difícil ainda, já que o método utilizado para obtenção do sinal analítico gera uma faixa de análise espectral abaixo de $250 \mathrm{~Hz}$ para o caso de amostragem de $1000 \mathrm{~Hz}$. Utilizando os resultados do último item do atual capítulo podemos inferir:

- Não existe correspondência direta entre o EMD e os processos de obtenção dos coeficientes de aproximação ou detalhe, gerados pela transformada de wavelet.

- A transformada de wavelet utiliza um processo onde a faixa de análise de sua componente de aproximação ou de detalhe ocorre sempre na metade da situação de aproximação ou detalhe anterior, enquanto que o EMD busca o grupo de maior energia, de frequência menor que o da última IMF detectada. Se houver apenas duas componentes relevantes e relativamente separadas, apenas duas IMFs serão detectadas, se estiverem muito próximas, apenas uma será detectada. A resolução de frequências do EMD é um de seus pontos fracos. 
Para finalizar essa conclusão é importante salientar o exemplo final da seção 5.6 onde se procurou estabelecer a relação entre as IMFs e os módulos, fase e frequências de suas respectivas $\mathrm{HT}$, onde o poder da HHT se apresenta com toda a sua força, indicando uma modulação da componente de $8 \mathrm{~Hz}$ que é feita por uma componente aparentemente aleatória que gera componentes de alta frequências, mas de módulo muito pequeno como pode ser visto em uma comparação entre as figuras 5.65 (c) e (e). 
A análise dos dados de torque do estimador de torque utilizando a HHT e a WT

\subsection{Estratégias utilizadas para a análise dos sinais do estimador de torque}

As figuras 6.1 (a) a (d) exibem os perfis dos torques estimados em várias situações operacionais da máquina ferramenta em ensaios de corte contínuo partindo da situação em vazio e entrando em contato com a peça a ser usinada, o que é indicado pela mudança do nível do torque, aumentando quase que bruscamente ou diminuindo da mesma forma, com exceção da figura 61(a) onde a máquina ferramenta opera em vazio em todo o tempo de teste. $\mathrm{A}$ motivação deste teste em vazio é a determinação das frequências de operação naturais da máquina ferramenta.

Os perfis exibidos nas figuras 6-1 (b) a (d), estão relacionados com esforços realizados pela máquina ferramenta para usinar um tarugo de $39,9 \mathrm{~mm}$ de diâmetro que já havia sido pré-usinado. O material do tarugo era de aço 52100 e a usinagem neste caso foi realizada em regime de corte contínuo com velocidade média de avanço da ferramenta de $100 \mathrm{~m} / \mathrm{min}$. A ferramenta utilizada para a usinagem era de metal duro nova e estava fixada com um ângulo de corte de $90^{\circ}$ em relação a peça em usinagem.

Os ensaios foram projetados para a realização de passes com $0,5 \mathrm{~mm}$, $1,0 \mathrm{~mm}$ e $1,5 \mathrm{~mm}$ progressivamente com duração total de 10 segundos, embora o teste efetivo seja realizado em 6 segundos de operação de usinagem, 0 
sincronismo com o sistema de aquisição foi realizado manualmente, de forma que nem sempre foi possível obter todos os seis segundos de aquisição relativas ao mesmo.

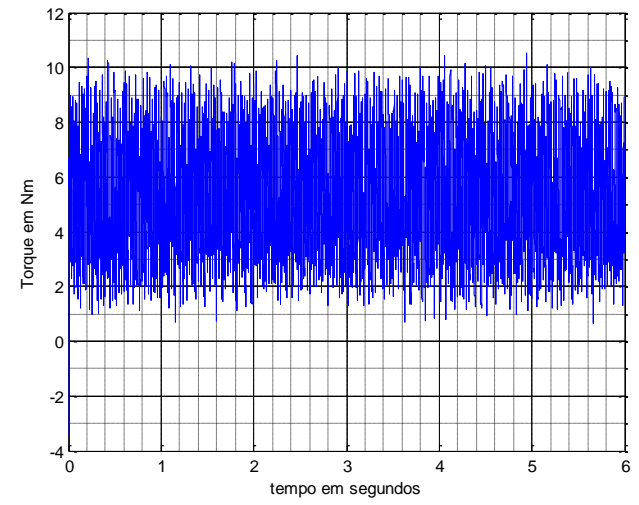

(b)

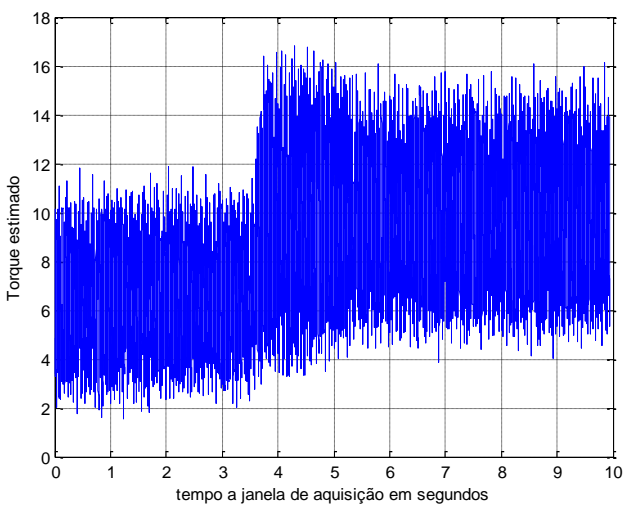

(c)

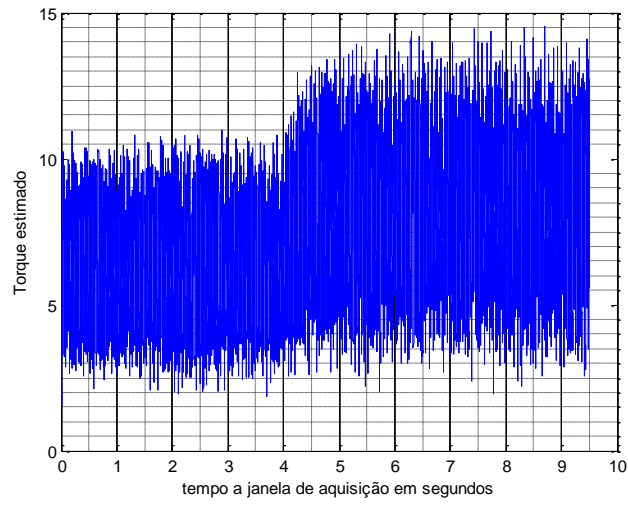

(b)

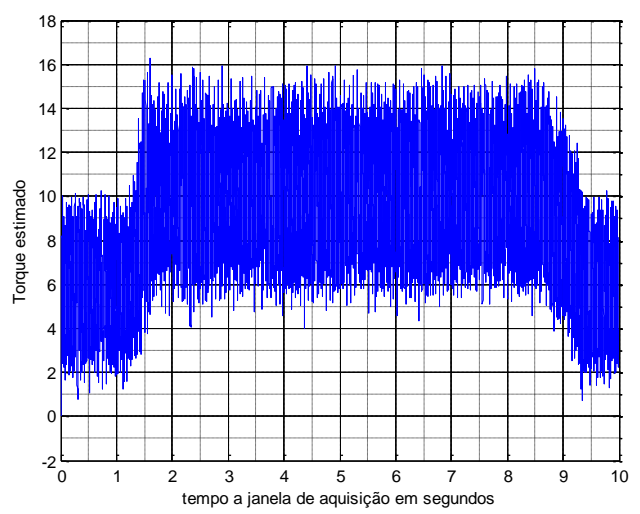

(d)

Figura 6.1 Perfis de torque eletromagnético estimados para as várias situações operacionais de carregamento do motor com torno executando operação com torque contínuo (a) torno em vazio tracionando o carro longitudinal, (b) torno executando passe de $0,5 \mathrm{~mm}$ de profundidade, (d) torno executando passe de $1,0 \mathrm{~mm}$ de profundidade, (d) torno executando passe de $1,5 \mathrm{~mm}$ de profundidade.

Todas as situações mencionadas são analisadas utilizando a transformada de Fourier, que foi utilizada como referência para o estudo das oscilações estacionárias e a transformada de Hilbert-Huang buscando informações mais detalhadas das operações de usinagem dentro do cenário experimental efetuado. Na parte final foi utilizada a transformada de wavelet como processo verificador da consistência da HHT dentro das limitações inerentes relacionadas a cada uma dessas transformadas. 
Como explanado anteriormente, a aplicação da HHT sofre dos efeitos laterais dentro do "quadro" de aquisição de dados, uma vez que o efeito das splines fica evidente principalmente nas baixas frequências quando o número de pontos do sinal residual fica menor em função do efeito de peneiramento que retira as componentes de maior frequência do quadro de análise o que aumenta os efeitos de borda nas extremidades das IMF de menor frequência.

\subsubsection{A determinação experimental da frequência máxima}

A frequência máxima foi obtida a partir da curva de fase do sinal, o intervalo de tempo de medição da fase do sinal analítico foi dividido em um número de partes iguais (100 nos testes iniciais) e foi aplicada a regressão linear a cada parte, obtendo-se assim os coeficientes angulares de cada parcela. $O$ coeficiente angular mais alto corresponde a frequência angular mais alta que compõe o sinal, desta forma a largura de banda aproximada de cada IMF foi determinada e por consequência a resolução de frequência do método.

\subsection{Relações entre o espectro e a HHT do torque eletromagnético estimado}

\subsubsection{Caso 1: Torno operando em vazio com tração do carro longitudinal}

Primeiramente analisou-se o sinal estimado de torque do motor do torno na situação de acionamento em vazio, tracionando apenas o carro longitudinal principal. O objetivo do teste é a verificação das oscilações livres presentes na máquina ferramenta. Devido aos redutores com engrenagens e sistemas de transmissão por correias, já eram esperadas algumas oscilações mecânicas da máquina ferramenta, mas admite-se inicialmente que o conjunto mecânico não tenha defeitos nesses componentes, assim como o motor de indução não possua defeitos mecânicos ou elétricos.

No início do processo de análise é fundamental estabelecer a banda de frequências que deve efetivamente compor o escopo da análise. Para uma primeira investida sobre este aspecto do problema, é fundamental ter uma ideia da composição espectral do sinal de torque eletromagnético estimado, o que é investigado na figura 6-2 onde, verifica-se que somente existem componentes 
de módulo em decibéis, mais elevados que $-40 \mathrm{~dB}$ somente abaixo da frequência de $1500 \mathrm{~Hz}$ o que reduz sensivelmente a região espectral a pesquisar.

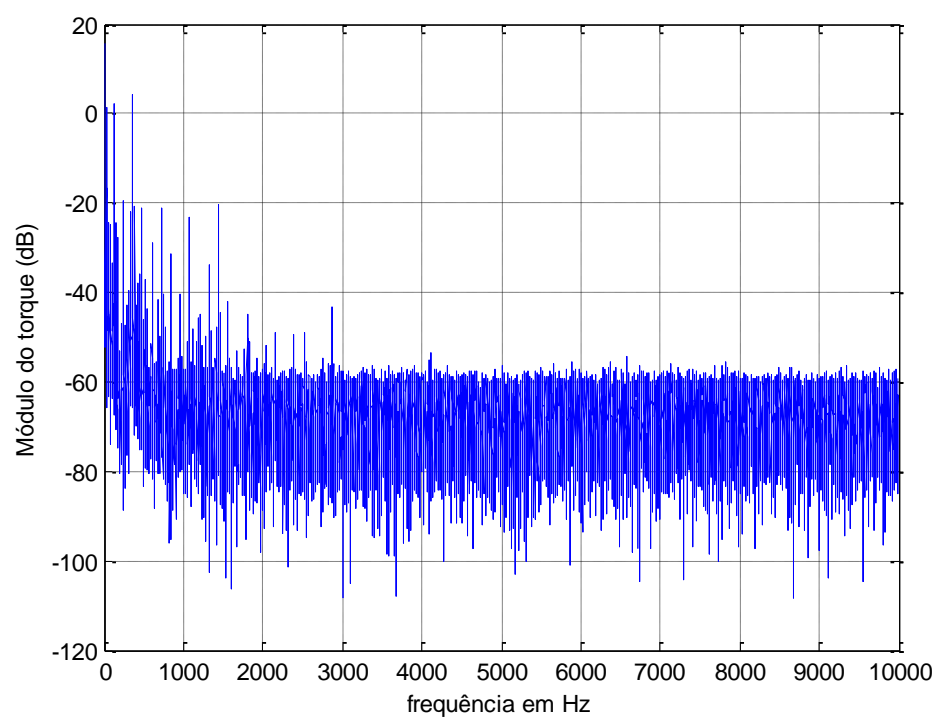

Figura 6.2 Espectro dos dados de torque do estimador

Uma vez definida a região espectral de aspecto mais relevante, observou-se também que as componentes maiores que $500 \mathrm{~Hz}$ tem valor módulo inferior a $-20 \mathrm{~dB}$, ou seja seus módulos são menores que $0,1 \mathrm{Nm}$, isso permite concluir que a informação obtida diretamente do motor de indução é de frequência muito baixa, o que confirma o pressuposto que o conjunto máquina ferramenta e motor de indução forma um filtro passa-baixas de frequência crítica relativamente baixa onde, devido a natureza elétrica do estimador de torque, algumas componentes elétricas assumem relevância na parte mais alta do espectro de frequências.

Tendo em vista a informação obtida acima, vamos limitar nossa investigação a faixa entre 0 e $1500 \mathrm{~Hz}$, levando em conta que o dinamômetro Kistler que fornece a contra parte desta experimentação, opera com frequência de amostragem de $1000 \mathrm{~Hz}$, ou seja gera um espectro máximo entre 0 e $500 \mathrm{~Hz}$, o estimador de torque opera com frequencia de amostragem de $20 \mathrm{kHz}$, que com a aplicação da FFT cai pela metade como mostra o espectro da figura 6.2. 


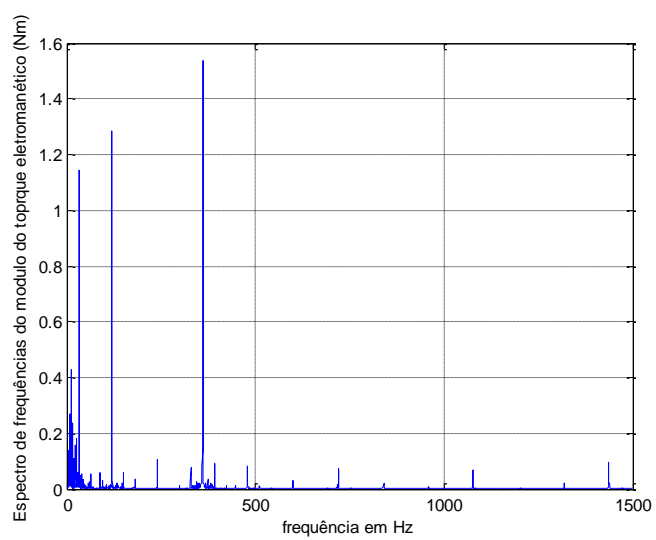

Figura 6.3 Composição espectral entre 1 e 1500Hz em vazio (sem a componente média )

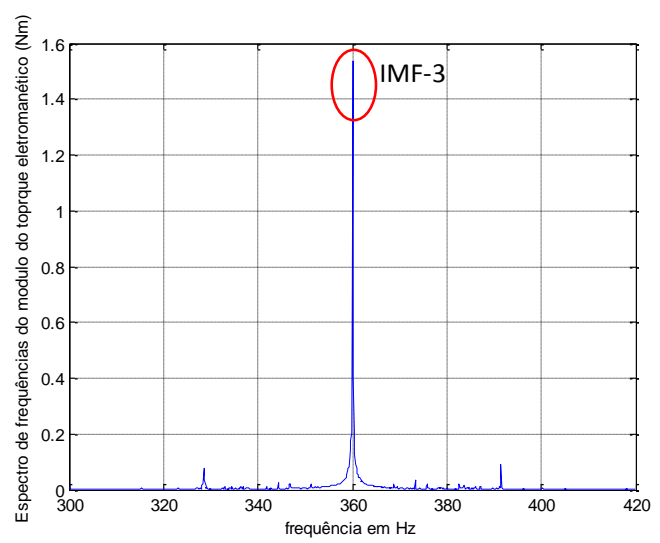

(a)

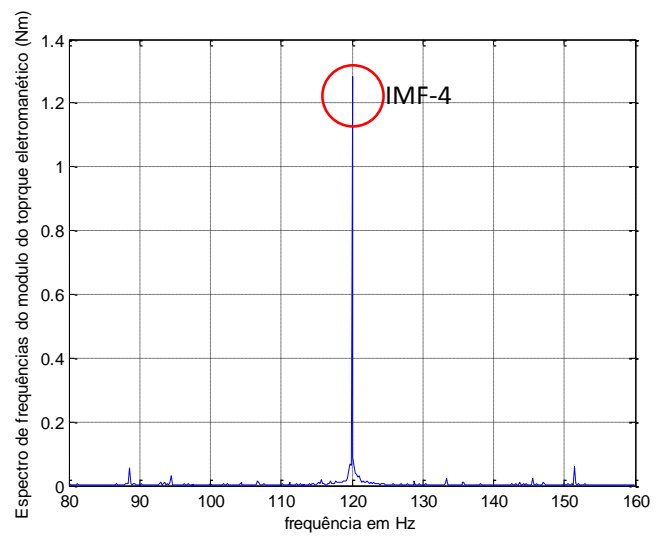

(b)

Figura 6.4 Detalhes do espectro da figura 6.3 indicando duas componentes estacionárias, uma de $360 \mathrm{~Hz}$ (a) e outra de $120 \mathrm{~Hz}$ (b)

O espectro mostrado na figura 6-3 indica claramente a presença de duas componentes de frequência relativamente altas em relação aos processos mecânicos, uma localizada em $360 \mathrm{~Hz}$ e relacionada a $5^{\text {a }}$ e $7^{\text {a }}$ harmônicas da corrente da rede elétrica que são efeitos típicos da não linearidade do motor de indução devido ao fenômeno de saturação do núcleo magnético, a outra componente ocorre em $120 \mathrm{~Hz}$ e tem origem no desequilíbrio das tensões de fase da rede trifásica que alimenta o motor de indução da máquina ferramenta. As figuras 6.4(a) e (b) mostram os detalhes dessas componentes. 


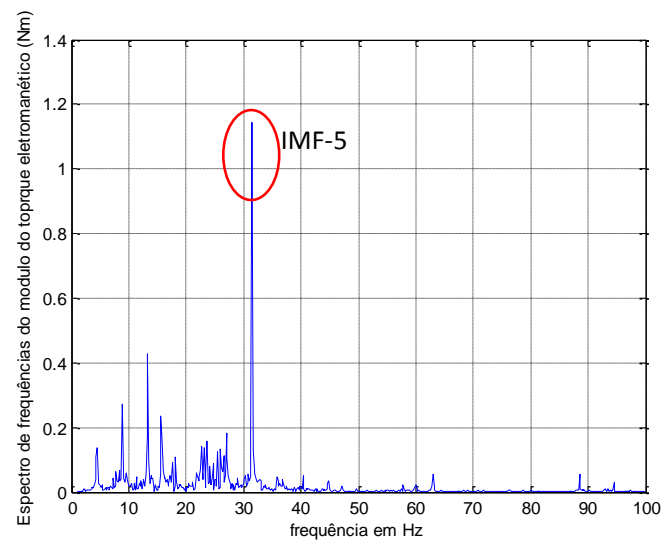

(a)

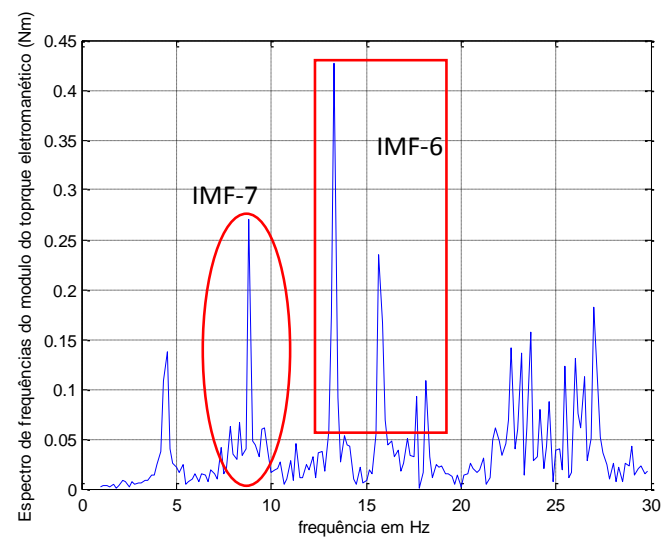

(b)

Figura 6.5 Espectros parciais com as componentes aparentemente mono-harmônicas de baixa frequência e as correspondentes IMFs.

As figuras 6.5(a) e (b) detalham os espectros das componentes abaixo de $100 \mathrm{~Hz}$, onde percebe-se claramente a presença de uma componente dominante de $31,5 \mathrm{~Hz}$ na figura 6.5 (a) é interessante observar-se que a velocidade do eixo árvore do torno na condição de vazio era 49,632 rad/s ou que a frequência de rotação da máquina era de $7,9 \mathrm{~Hz}$ e que $4 * 7,9=31,6 \mathrm{~Hz}$, assim essa componente esta relacionada a velocidade do torno. Por sua vez a figura 6.5 (b) mostra uma componente de $7,8 \mathrm{~Hz}$ totalmente relacionada com a velocidade do eixo árvore e outra de aproximadamente $16 \mathrm{~Hz}$ que é o dobro da frequência de rotação do mesmo eixo. A componente de $13 \mathrm{~Hz}$ com módulo 0,43N não encontra correspondente na velocidade do eixo árvore e consequentemente esta sintonizada com outros elementos mecânicos que compõem a máquina ferramenta. A tabela 6.1 lista as IMFs obtidas pela aplicação da HHT ao sinal da figura 6.1 e as figuras 6.5 (a) e (b) mostram uma possível relação entre as componentes estacionárias da HHT e o espectro.

A tabela 6-1 relaciona as IMFs detectadas pela aplicação da HHT aos mesmos dados que geraram as FFTs das figuras mostradas acima. As equações relativas a fase da função analítica foi obtido pela aplicação do método de regressão linear aos dados de fase em função do tempo de aquisição. As flutuações da frequência afetam o coeficiente angular da reta obtida pelo método dos mínimos quadrados, e que corresponde a frequência angular do sinal, de modo que a frequência média obtida não é exatamente a mesma obtida no espectro de frequências com o uso da FFT. 
Tabela 6.1: Características da HHT do sinal de torque em vazio

\begin{tabular}{|c|c|c|c|c|}
\hline IMF & $\begin{array}{c}\text { Fase (linearizada) } \\
\text { (radianos) }\end{array}$ & $\begin{array}{c}\text { Frequência } \\
\text { (média) }(\mathrm{Hz})\end{array}$ & $\begin{array}{c}\text { Frequência } \\
\text { máxima }(\mathrm{Hz})\end{array}$ & $\begin{array}{c}\text { Módulo } \\
\text { (médio) }(\mathrm{Nm})\end{array}$ \\
\hline 1 & $\psi(t)=10649 t-73,29$ & 1694,8 & 2245,5 & 0,047 \\
\hline 2 & $\psi(t)=11201,4 t-58,1$ & 1782,7 & 2137,0 & 0,11 \\
\hline 3 & $\psi(t)=2464,0 t+171,5$ & 392,1 & 541,9 & 1,5 \\
\hline 4 & $\psi(t)=916,06 t+79,82$ & 145,8 & 219,6 & 1,31 \\
\hline 5 & $\psi(t)=319,09 t+38,10$ & 50,78 & 89,00 & 1,15 \\
\hline 6 & $\psi(t)=134,5 t+6,35$ & 21,40 & 31,97 & 0,86 \\
\hline 7 & $\psi(t)=65,91 t+3,39$ & 10,49 & 15,09 & 0,497 \\
\hline 8 & $\psi(t)=27,13 t+1,41$ & 4,31 & 6,42 & 0,24 \\
\hline 9 & $\psi(t)=10,71 t-1,13$ & 1,70 & 2,25 & 0,074 \\
\hline
\end{tabular}

$\mathrm{O}$ algoritmo do EMD extrai primeiramente as componentes de maior energia com frequências mais altas e se desloca para as frequências mais baixas buscando sempre o próximo grupo de frequência mais baixa que tenha energia significativa, dentro da capacidade resolutiva do algoritmo. Existe uma aparente inconsistência da IMF-2 em relação a IMF-1 observada na tabela 6.1, isso decorre do fato das energias das componentes nesta região serem muito pequenas o que torna as duas primeiras fases detectadas quase iguais, mas existe uma componente dominante de energia bem superior na segunda região da decomposição, mas mesmo assim com pouca energia em relação as componentes dominantes de menor frequência.

Uma análise mais detalhada dos módulos e fase dos sinais oscilatórios de origem elétrica mostra que existe uma correspondência bastante grande tanto em módulo como em frequência com relação as valores obtidos dos sinais analíticos correspondentes como mostram as figuras 6-6 e 6-7 (a) e (b), onde a natureza intrínseca do estimador releva a presença de componentes estacionárias relativas ao motor e a rede elétrica.
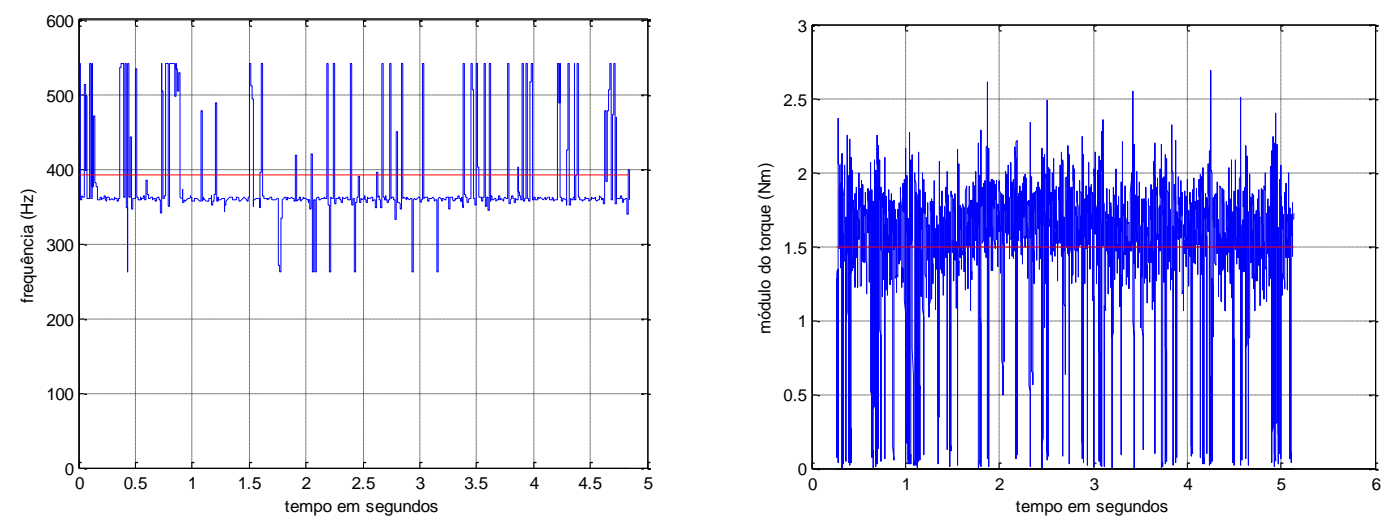
Figura 6.6 Frequência instantânea (a) e módulo (b) relativos a componente de $360 \mathrm{~Hz}$

As funções analíticas correspondentes as outras IMFs podem ser verificadas nos gráficos do apêndice $A$ sob índice faselMF0,5mm- $x$, frequencialMF0,5mm-x e módulolMF0,5-x, onde $x$ corresponde ao número da IMF analisada.

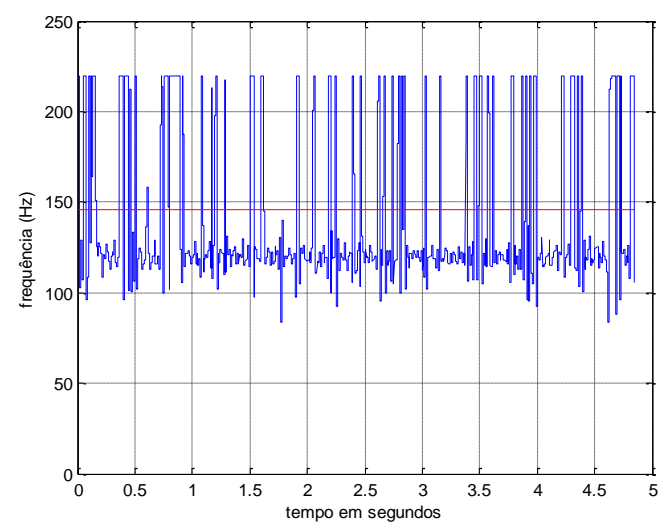

(a)

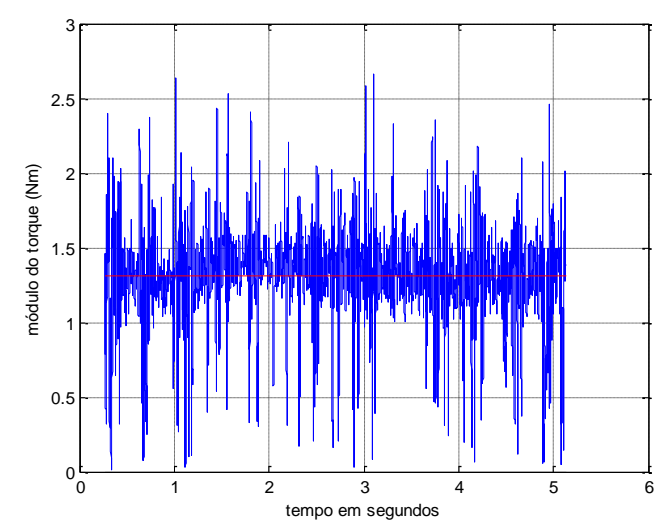

(b)

Figura 6.7 Frequência instantânea (a) e módulo (b) relativos a componente de $120 \mathrm{~Hz}$

A análise realizada explica a relação entre a parcela estacionária indicada pelo espectro de frequências do sinal e a realizada pela aplicação da HHT, com a diferença que a HHT mostra como as frequências variam em torno da frequência média, assim como o módulo de torque oscila em torno do valor médio que é medido na amplitude das componentes do espectro obtido pela FFT.

\subsubsection{Caso 2: Torno com UCP de $0,5 \mathrm{~mm}$ contínua}

Repetindo as ações do caso em vazio, obtemos primeiramente o espectro do torque entre 1 e $1500 \mathrm{~Hz}$. A componente média foi retirada do processo de análise para evidenciar as outras componentes de módulo muito menor, como é mostrado na figura 6-8. 


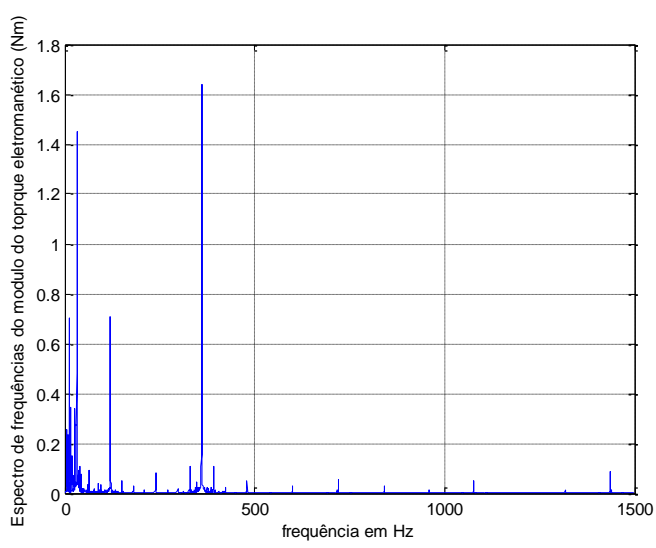

Figura 6.8 Espectro total do sinal do módulo do torque eletromagnético fornecido pelo motor de indução com o torno realizando UCP de $0,5 \mathrm{~mm}$

Sob condições de usinagem com passe de $0,5 \mathrm{~mm}$, o espectro modificase muito pouco em relação ao espectro do torque em vazio. A componente de $360 \mathrm{~Hz}$ aumenta ligeiramente, e a componente de $120 \mathrm{~Hz}$ sofre uma sensível atenuação o que indica que o aumento da absorção de corrente pelo motor de indução força a linha trifásica a operar com um desequilíbrio de fase menor, o que é mostrado nas figuras 6-9 (a) e (b), mas é o espectro de frequências mais baixas se altera bastante nesta condição.

Verificamos que a componente de $31,8 \mathrm{~Hz}$ aumenta sob esta nova condição indo de $1,18 \mathrm{Nm}$ em vazio para $1,48 \mathrm{Nm}$ na usinagem com passe de $0,5 \mathrm{~mm}$, ou seja, esta componente está presente no processo de usinagem, assim como a componente de $13,2 \mathrm{~Hz}$ que passa de $0,43 \mathrm{Nm}$ em vazio para 0,7 na situação do passe atual e a componente de $7,9 \mathrm{~Hz}$ que acompanha a de $13,2 \mathrm{~Hz}$ em tendência, as outras componentes diminuem seu valor e até desaparecem sob a condição forçada, o que indica que estas componentes são resultantes de oscilações livres dos processos mecânicos da máquina ferramenta. As figuras 6.10 (a) e (b) mostram o comportamento das componentes discutidas acima. 


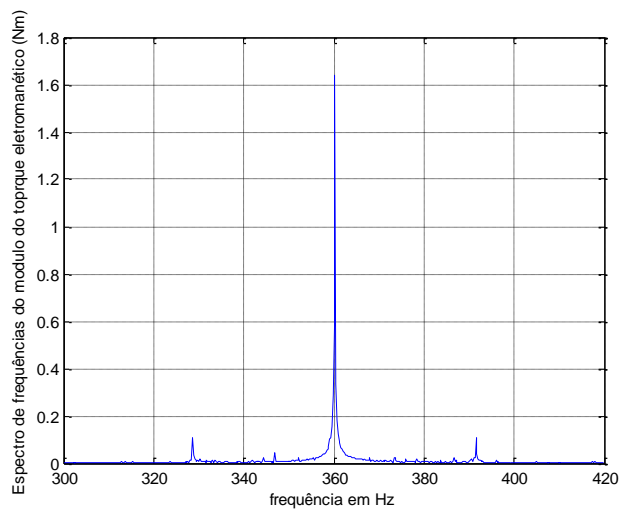

(a)

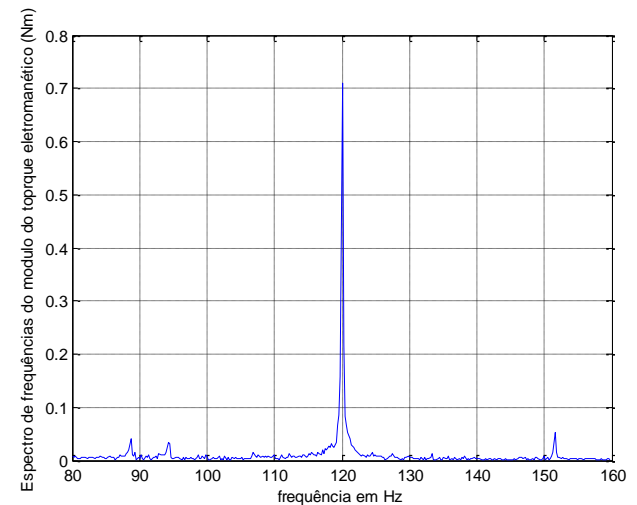

(b)

Figura 6.9 Espectros do torque estimado na condição de passe de $0,5 \mathrm{~mm}$ para o caso das frequências de $360 \mathrm{~Hz}$ (a) e $120 \mathrm{~Hz}$ (b).

Tabela 6.2: Características da HHT do sinal de torque com corte contínuo e passe de $0,5 \mathrm{~mm}$

\begin{tabular}{|c|c|c|c|c|}
\hline IMF & $\begin{array}{l}\text { Fase (linearizada) } \\
\text { (radianos) }\end{array}$ & $\begin{array}{l}\text { Frequência } \\
\text { (média) }(\mathrm{Hz})\end{array}$ & $\begin{array}{l}\text { Frequência } \\
\text { máxima }(\mathrm{Hz})\end{array}$ & $\begin{array}{l}\text { Módulo } \\
\text { (médio) }(\mathrm{Nm})\end{array}$ \\
\hline 1 & $\psi(t)=11295 t-125,8$ & 1797,6 & 2416 & 0,047 \\
\hline 2 & $\psi(t)=86003 t-637,0$ & 1368,8 & 1945,8 & 0,40 \\
\hline 3 & $\psi(t)=2180,6 t-98,44$ & 347,06 & 420,63 & 1,54 \\
\hline 4 & $\psi(t)=807,15 t-26,64$ & 128,46 & 165,3 & 0,85 \\
\hline 5 & $\psi(t)=219,62 t-9,51$ & 34,95 & 53,8 & 2,2 \\
\hline 6 & $\psi(t)=102,17 t-3,06$ & 16,26 & 22,38 & 1,09 \\
\hline 7 & $\psi(t)=51,78 t-8,75$ & 8,24 & 10,84 & 0,34 \\
\hline 8 & $\psi(t)=26,21 t-3,71$ & 4,17 & 8,78 & 0,29 \\
\hline 9 & $\psi(t)=7,73 t-5,35$ & 1,23 & 2,0 & 0,11 \\
\hline
\end{tabular}

A tabela 6-2 relaciona as IMFs detectadas pela aplicação da HHT aos mesmos dados que geraram as FFTs das figuras mostradas acima. As equações relativas a fase da função analítica foi obtido pela aplicação do método de regressão linear aos dados de fase em função do tempo de aquisição. Como no caso anterior, as flutuações da frequência afetam o coeficiente angular da reta obtida pelo método dos mínimos quadrados, e que corresponde a frequência angular do sinal, de modo que a frequência média obtida não é exatamente a mesma obtida no espectro de frequências com 0 uso da FFT. 


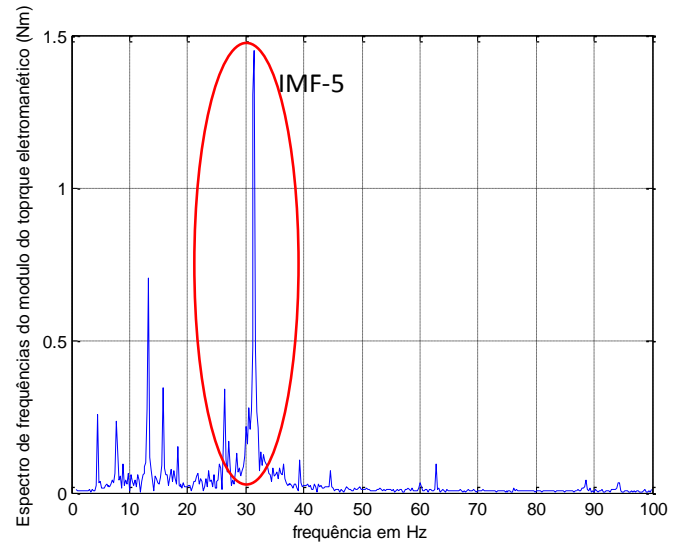

(a)

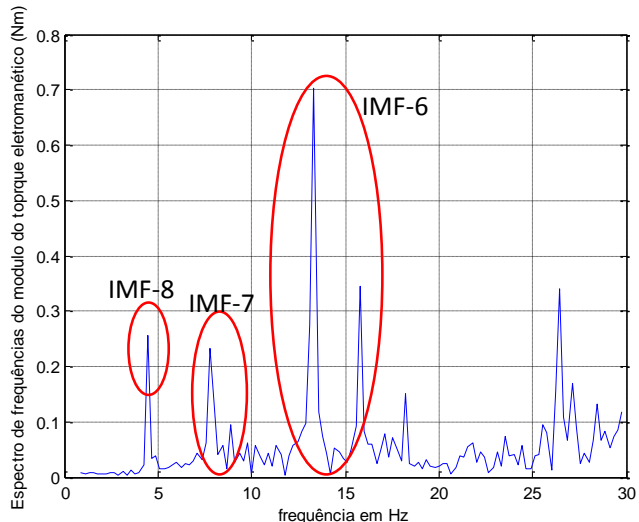

(b)

Figura 6.10 Espectros do torque estimado das componentes de baixas frequências para a situação de passe de com profundidade de corte de $0,5 \mathrm{~mm}$ e a associação com as IMFs da tabela 6.2.

Os valores mostrados na tabela 6-2 foram obtidos pela aplicação direta do método de regressão linear ao conjunto de dados de cada IMF após a aplicação da HT na IMF correspondente, porem nem sempre a função correspondente a fase do sinal analítico pode ser linearizada devido a muitos fatores, mas principalmente devido aos efeitos de bordas das splines utilizadas pelo processo do método de decomposição empírico (EMD), a largura de banda correspondente a diferença entre a frequência máxima e a frequência mínima obtida indiretamente do sinal de fase do sinal analítico de cada IMF também é calculada, os gráficos relativos as fases, frequências instantâneas e módulo instantâneos de cada sinal analítico obtidos a partir das IMFs está em anexo ao trabalho no apêndice $A$ sob índice faselMF0,5mm-x, frequencialMF0,5mm-x e móduloIMF0,5-x, onde x corresponde ao número da IMF analisada.

\subsubsection{Caso 3: Torno com UCP de 1,0mm contínua}

As ações realizadas para esta condição são fundamentalmente as mesmas dos casos anteriores, o espectro reduzido de frequencias do sinal da figura 6-1(c) é mostrado na figura 6-11 e o comportamento das componentes é bastante parecido com o caso anterior, com aumento do módulo da componente de $360 \mathrm{~Hz}$ e diminuição do módulo da componente de $120 \mathrm{~Hz}$, devido a um equilíbrio pontual observado no caso de passe com profundidade 
de $0,5 \mathrm{~mm}$ torna-se menos evidente com a componente de $120 \mathrm{~Hz}$ voltando a crescer com o aumento do carregamento do motor de indução. Os efeitos do carregamento da máquina ferramenta com passe de $1,0 \mathrm{~mm}$ são mostrados nas figura 6-12 (a) e (b).

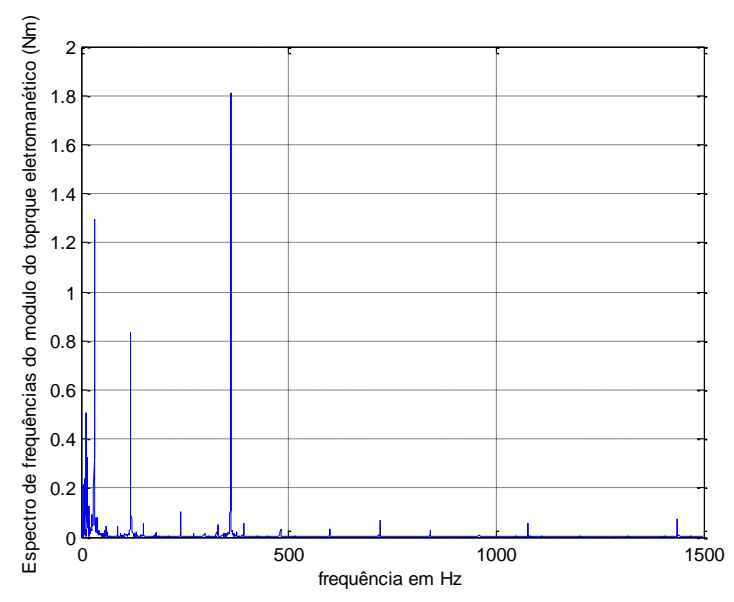

Figura 6.11 Espectro de frequências do sinal obtido pelo estimador de torque com a máquina ferramenta executando passe de $1,0 \mathrm{~mm}$

As interações mecânicas, assim como no caso do carregamento anterior, ocorrem nas frequencias mais baixas do espectro, abaixo da componente de $31,5 \mathrm{~Hz}$ como mostram as figuras 6-13 (a) e (b), com algumas frequências respondendo diretamente a solitação de torque da máquina ferramenta, nas operações de corte contínuo isso ocorre principalmente com as componentes entre $5 \mathrm{~Hz}$ e $13 \mathrm{~Hz}$.

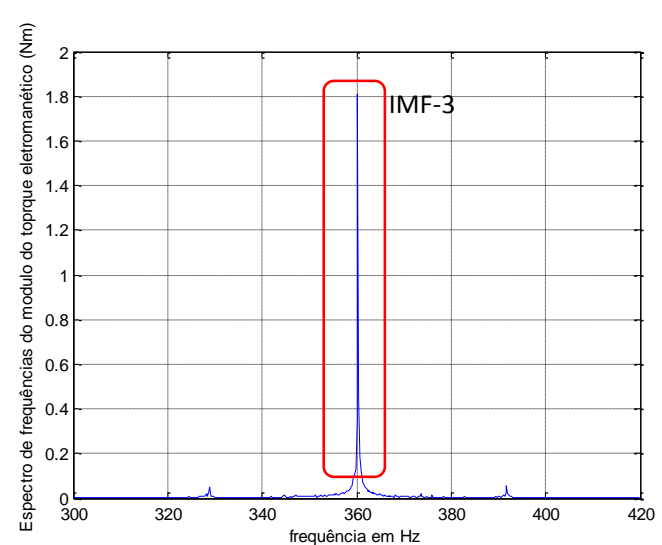

(a)

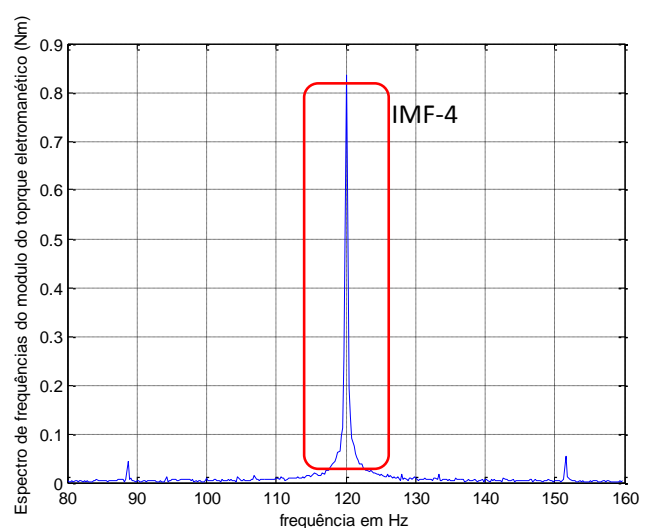

(b)

Figura 6.12 Espectros do torque estimado na condição de passe de 1,0mm enfatizando a componente de $360 \mathrm{~Hz}$ (a) e a componente de $120 \mathrm{~Hz}(\mathrm{~b})$ 


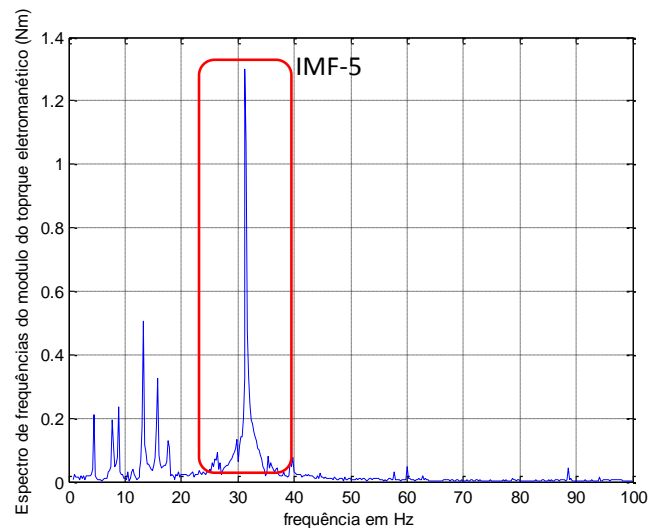

(a)

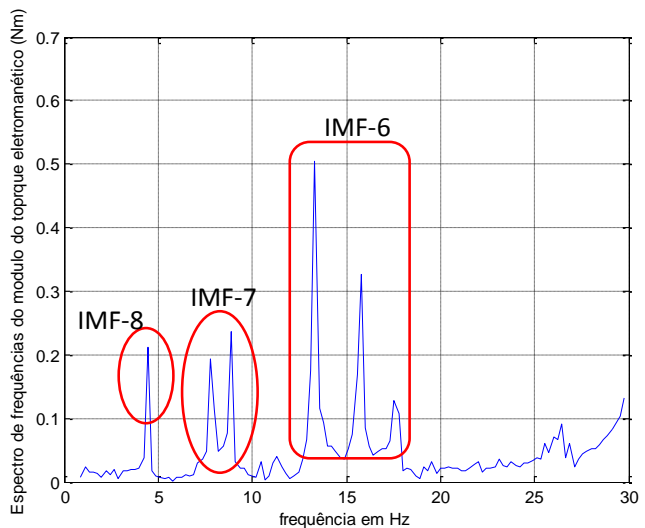

(b)

Figura 6.13 Espectros do torque estimado na condição de passe de $1,0 \mathrm{~mm}$ para as componentes de baixas frequências do torque

A tabela 6-3 mostra como as funções analíticas de cada IMF presente nesta situação responde. A IMF de frequencias mais alta pode ser ignorada em função do valor médio de seu módulo ser muito baixo. A componente de $617 \mathrm{~Hz}$ aparece apenas no contexto deste carregamento e parecer ser uma composição de componentes da IMF, pois não é visível no espectro da figura 6-11, como acontece com a componente de $1041 \mathrm{~Hz}$ obtida nas IMFs do caso de passe de $0,5 \mathrm{~mm}$. As outras componentes se repetem e se compõem com mudanças no valor médio obtida com o método de regressão linear, o que indica que sua composição não detectável pela análise espectral, isto pode ser verificado pelos gráficos das frequencias instantâneas das componentes de $37,11 \mathrm{~Hz}$ e e $16,62 \mathrm{~Hz}$ mostradas nas figuras 6.13 (a) e (b).

Tabela 6-3: Características da HHT do sinal de torque com corte contínuo e passe de $1,0 \mathrm{~mm}$

\begin{tabular}{|c|c|c|c|c|}
\hline IMF & $\begin{array}{c}\text { Fase (linearizada) } \\
\text { (radianos) }\end{array}$ & $\begin{array}{c}\text { Frequência } \\
\text { (média) }(\mathrm{Hz})\end{array}$ & $\begin{array}{c}\text { Frequência } \\
\text { máxima }(\mathrm{Hz})\end{array}$ & $\begin{array}{c}\text { Módulo } \\
\text { (médio) }(\mathrm{Nm})\end{array}$ \\
\hline 1 & $\psi(t)=11371 t+224,11$ & 1809,8 & 2339,9 & 0,046 \\
\hline 2 & $\psi(t)=9177,5 t+974,0$ & 1460,6 & 2072,2 & 0,30 \\
\hline 3 & $\psi(t)=2183,8+78,75$ & 347,56 & 417,62 & 1,70 \\
\hline 4 & $\psi(t)=792,5 t+14,802$ & 126,13 & 165,63 & 1,14 \\
\hline 5 & $\psi(t)=233,19 t-18,92$ & 37,11 & 53,90 & 2,07 \\
\hline 6 & $\psi(t)=104,45 t-0,335$ & 16,62 & 23,55 & 0,86 \\
\hline 7 & $\psi(t)=48,62 t-3,34$ & 7,74 & 10,90 & 0,37 \\
\hline 8 & $\psi(t)=26,12 t+1,68$ & 4,15 & 5,57 & 0,20 \\
\hline 9 & $\psi(t)=9,47 t+0,62$ & 1,50 & 2,00 & 0,085 \\
\hline
\end{tabular}




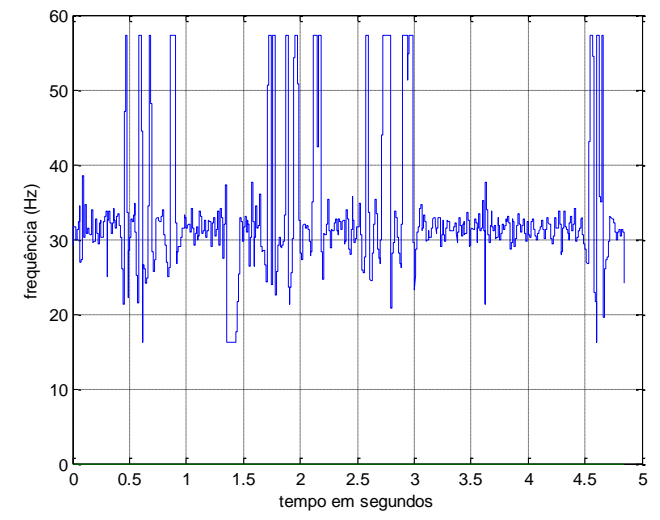

(a)

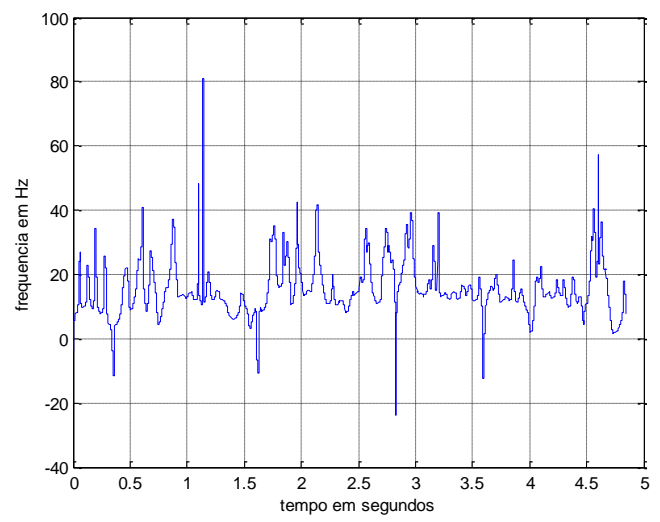

(b)

Figura 6.14 Frequências instantâneas do torque estimado na condição de passe de $1,0 \mathrm{~mm}$ para as componentes de baixas frequências do torque

A figura 6-14(a) mostra claramente que a componente média da frequência instantânea ocorre próxima a $31 \mathrm{~Hz}$ e não $37 \mathrm{~Hz}$ como indicado na tabela, isso reflete a composição complexa do sinal analítico de fase da IMF correspondente cujas variações rápidas da fase do snal analítico produzem picos bastante elevados na composição da frequência instantânea. O mesmo ocorre com a figura 6-14(b), o que pode ser corroborado pela figura 6-13(b), porem neste caso o método do EMD não possui capacidade de separar as duas componentes, mas o módulo da componente de frequência $16,61 \mathrm{~Hz}$ mostra uma soma dos dois sinais, ou seja a energia de ambos os sinais mostrados no espectro com $13,5 \mathrm{~Hz}$ com $0,51 \mathrm{Nm}$ e $16 \mathrm{~Hz}$ com $0,34 \mathrm{Nm}$, juntamente com outras componentes menos significativas próximas, está preservada na componente de $16,62 \mathrm{~Hz}$ cujo módulo é $0,86 \mathrm{Nm}$.

\subsubsection{Caso 4: Torno com UCP de 1,5mm contínua}

A situação relativa aos dados do estimador de torque com a máquina ferramenta operando um passe de $1,5 \mathrm{~mm}$ é semelhante aos dados das outras duas operações. A tabela 6.4 relaciona as componentes do sinal analítico das IMFs encontradas nesta situação e que são repetições dos outros casos com variações pontuais de módulo e frequência. 


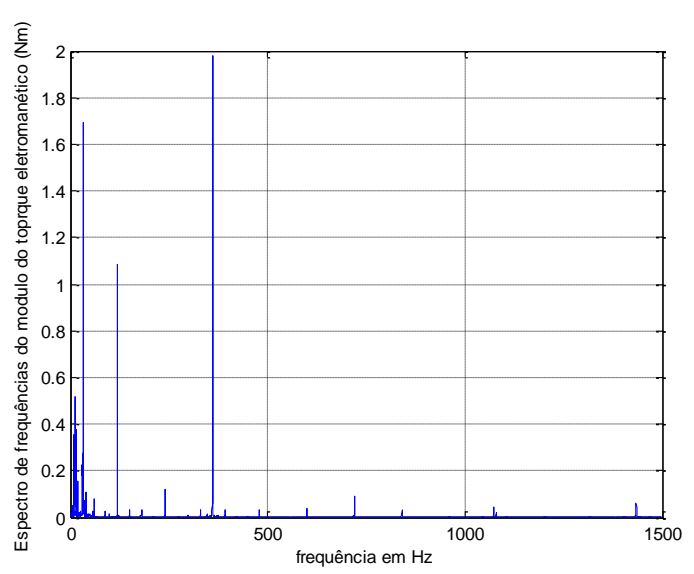

Figura 6.15 Composição espectral entre 1 e 1500Hz (sem a componente média)

A figura 6-15 mostra o espectro da parte plana do sinal mostrado na figura 6-1 (d), ou seja do sinal entre $2 \mathrm{~s}$ e $8 \mathrm{~s}$, que é a região onde ocorre efetivamente a usinagem na máquina ferramenta. A componente contínua ou de frequência zero foi eliminada para enfatizar as componentes oscilatórias.

Novamente as componentes oscilatórias mais evidentes acima da componente de $31,5 \mathrm{~Hz}$, são as componentes de $360 \mathrm{~Hz}$ e $120 \mathrm{~Hz}$ e acima dessas não ocorrem componentes estacionárias de módulo relevante. A situação das duas componentes citadas acima é mostrada na figura 6-16.

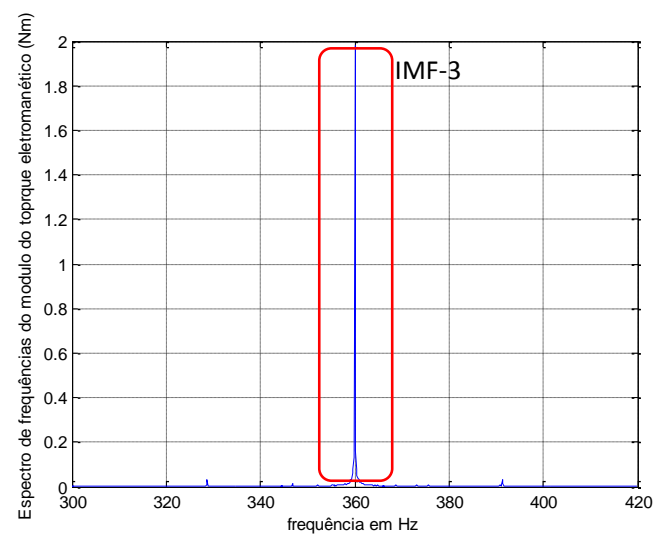

(a)

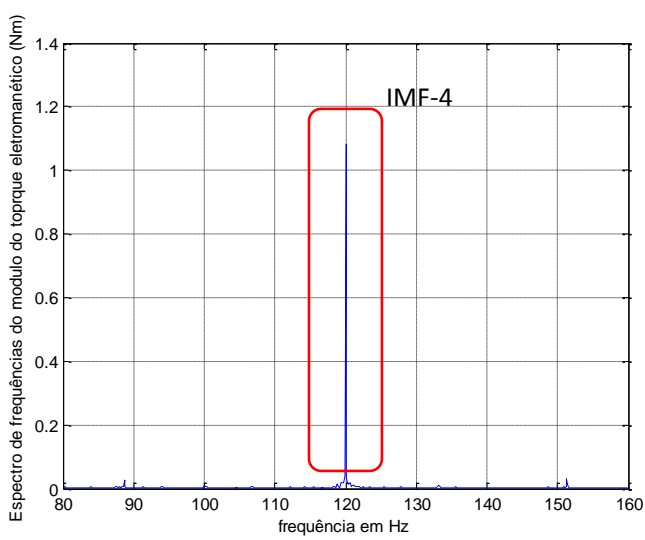

(b)

Figura 6.16 Espectros do torque estimado na condição de passe de 1,5mm enfatizando a componente de $360 \mathrm{~Hz}$ (a) e a componente de $120 \mathrm{~Hz}$ (b)

A componente de $360 \mathrm{~Hz}$ que tem origem na composição da $5^{\underline{a}}$ e $7^{\text {a }}$ harmônicas da corrente trifásica de entrada, aumenta porque a corrente aumenta com o aumento do carregamento do motor de indução, já o 
comportamento da componente de $120 \mathrm{~Hz}$ é algo dependente da linha de alimentação trifásica e neste caso, volta ao mesmo valor de módulo que o motor absorvia quando operando em vazio.

Os espectros mostrados nas figura 6-17 (a) e (b) evidenciam o comportamento das componentes do espectro abaixo de $100 \mathrm{~Hz}$ onde as componentes estacionárias que efetivamente atuam nos processos mecânicos estão abaixo de $31,5 \mathrm{~Hz}$, como já verificado anteriormente. A componente de $31,5 \mathrm{~Hz}$ é uma das componentes mais acentuadas do espectro geral e é interessante observar que todas as componentes relevantes de baixa frequência tem frequência inferior ao valor dessa componente, como pode ser verificado novamente nas figuras 6-17 (a) e (b).

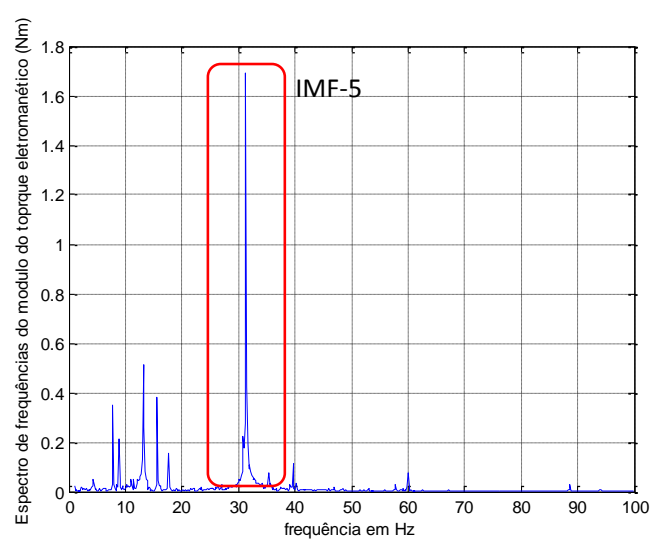

(a)

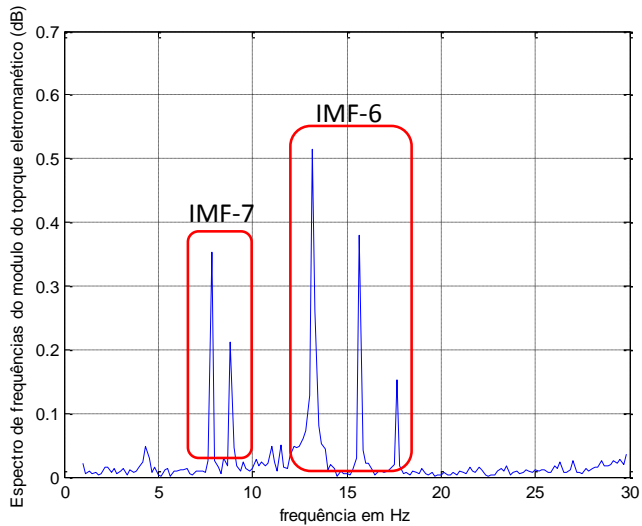

(b)

Figura 6.17 Espectros do torque estimado na condição de passe de 1,5mm para as componentes de baixas frequências do torque estimado

Um cruzamento de dados entre os valores dos espectros das figuras 6 17 (a) e (b) em relação a tabela 6-4 permite concluir que aparentemente algumas componentes espectrais não são detectadas pelo EMD, porém uma análise mais detalhada mostra que, embora o método do EMD não distinga frequências médias muito próximas, elas são contempladas na variação de frequências detectadas por esse método. Se tomarmos como exemplo as frequências de 8 e $9 \mathrm{~Hz}$ mostradas no espectro da figura 6-17 (b) e repetidas com detalhe na figura $6-18$, verificamos que as duas componentes estão presentes na componente de valor médio $7,81 \mathrm{~Hz}$ cuja frequência máxima é $34 \mathrm{~Hz}$, e tem sua composição em função do tempo mostrada na figura 6-19 (a). 
Outra característica importante reside no fato que a soma dos módulos (amplitudes) das duas componentes citadas é aproximadamente 0,2+0,35=0,55 e corresponde ao valor do módulo da componente de $7,81 \mathrm{~Hz}$ mostrado na tabela 6-4, portanto em termos de energia, as componentes obtidas pelo EMD estão de acordo com a identidade de Parseval. Assim uma comparação entre o espectro de frequências na faixa entre $5 \mathrm{~Hz}$ e $10 \mathrm{~Hz}$ da figura 6-18 é equivalente a decomposição em função do tempo da informação mostrada nas figuras 6-19 (a) e (b).

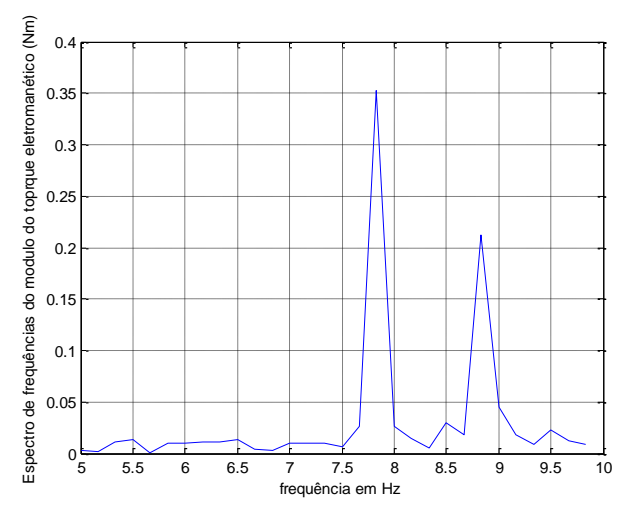

Figura 6.18 Parcela do espectro de baixa frequência do torque estimado correspondente a IMF-7

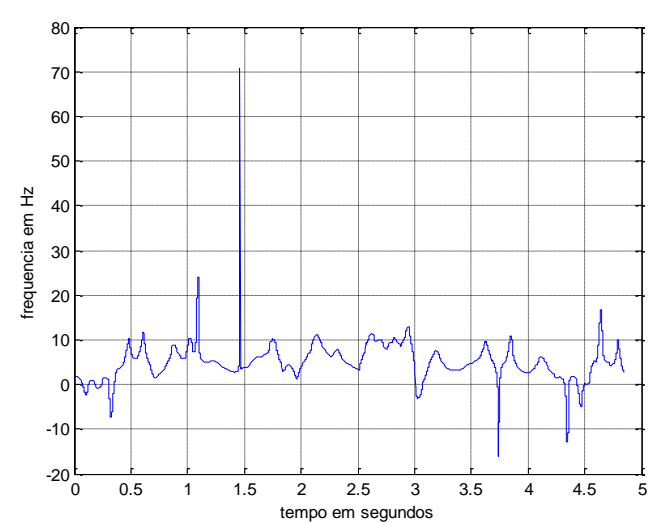

(a)

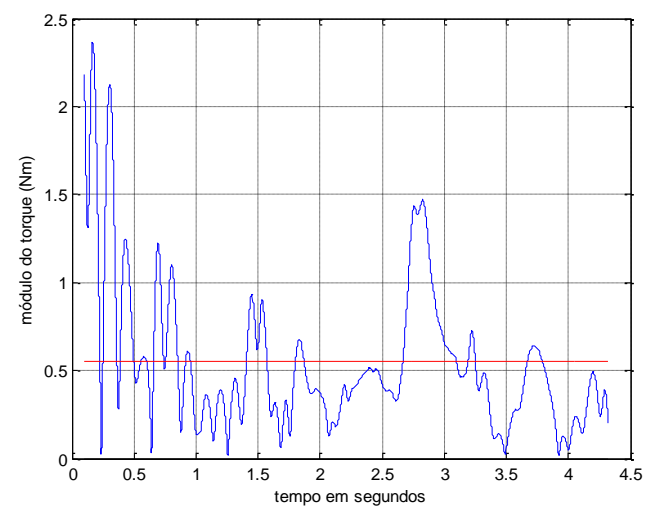

(b)

Figura 6.19 Decomposição dos sinais da figura 6-19 em função do tempo com a frequência em (a) e o módulo em (b). 


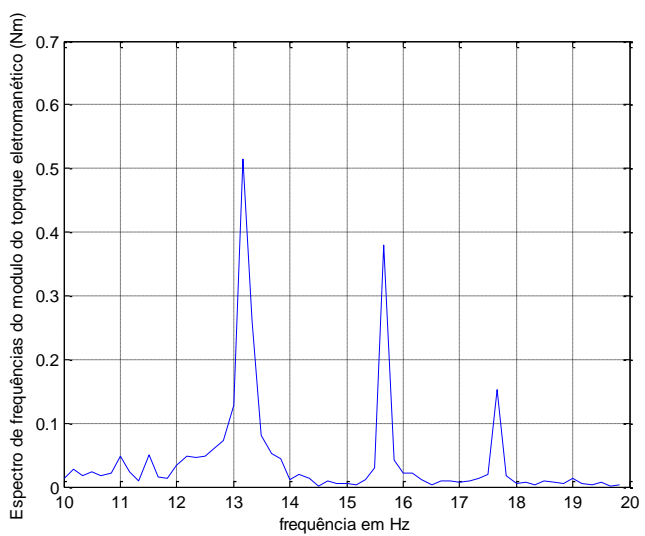

Figura 6.20 Parcela do espectro de baixa frequência correspondente a IMF-6
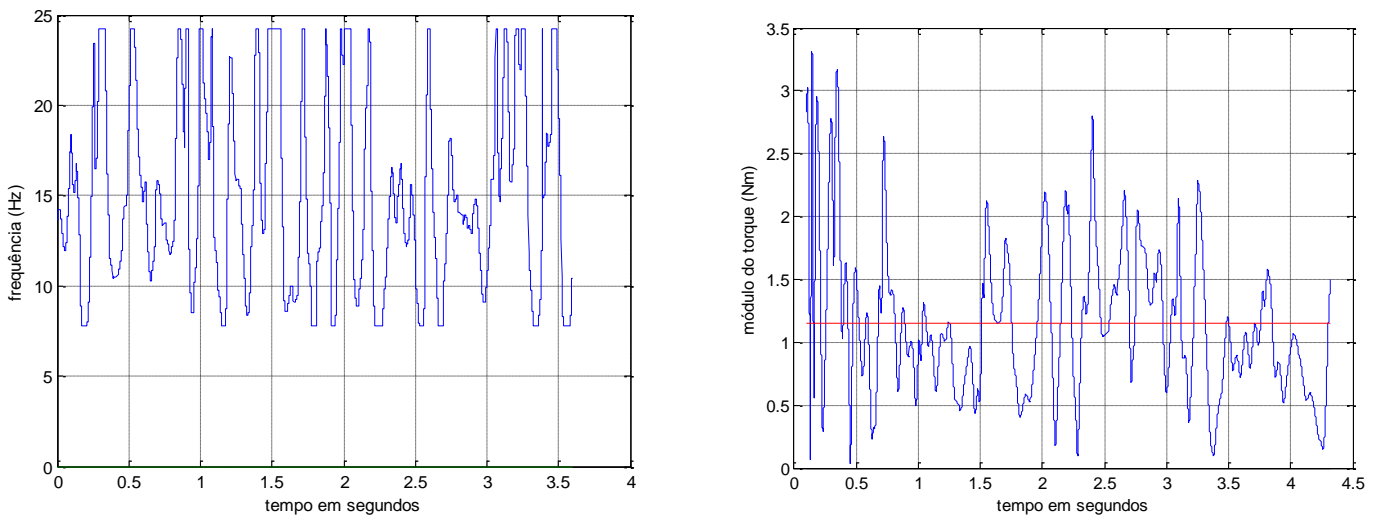

Figura 6.21 Frequência (a) e módulo (b) correspondentes ao espectro da figura 6-21 e a IMF-7

Novamente é possível verificar aproximação entre o valor médio do módulo obtido via FFT e o obtido pela análise relativa a EMD quando verificase que a soma dos módulos da figura 6-21 resulta em 1,15Nm e a tabela 6-4 indica o valor 1,14Nm como módulo do sinal analítico da IMF-6.

Tabela 6-4: Características da HHT do sinal de torque com corte contínuo e passe de $1,5 \mathrm{~mm}$

\begin{tabular}{|c|c|c|c|c|}
\hline IMF & $\begin{array}{c}\text { Fase (linearizada) } \\
\text { (radianos) }\end{array}$ & $\begin{array}{c}\text { Frequência } \\
\text { (média) }(\mathrm{Hz})\end{array}$ & $\begin{array}{c}\text { Frequência } \\
\text { máxima(Hz) }\end{array}$ & $\begin{array}{c}\text { Módulo (médio) } \\
(\mathrm{Nm})\end{array}$ \\
\hline 1 & $\psi(t)=11003 t-244,98$ & 1751,1 & 2242,0 & 0,046 \\
\hline 2 & $\psi(t)=8649,8 t-803,7$ & 1376,7 & 2012,3 & 0,4 \\
\hline 3 & $\psi(t)=2104,6 t-47,43$ & 334,96 & 417,41 & 1,73 \\
\hline 4 & $\psi(t)=739,93 t-15,49$ & 117,76 & 152,03 & 1,15 \\
\hline 5 & $\psi(t)=209,48 t-2,87$ & 33,34 & 47,28 & 1,76 \\
\hline 6 & $\psi(t)=87,61 t+1,992$ & 13,94 & 18,68 & 1,14 \\
\hline 7 & $\psi(t)=41,47 t-6,06$ & 6,60 & 9,45 & 0,55 \\
\hline 8 & $\psi(t)=20,83 t+0,88$ & 3,31 & 4,47 & 0,15 \\
\hline 9 & $\psi(t)=6,84 t+4,23$ & 1,08 & 1,86 & 0,069 \\
\hline
\end{tabular}


A inserção dos gráficos de fase, frequências e módulos dos sinais analíticos de todas as IMFs ocuparia um espaço muito grande neste capítulo, por isso decidiu-se que era melhor alocar esta informação em um apêndice específico para a mesma, e neste caso essas informações estão alocadas no apêndice $A$.

Os gráficos e dados que geraram a tabela 6-4 no apêndice A estão indexados da seguinte forma: "fase-IMF1,5mm-x" para as fases das funções analíticas, "frequência-IMF1,5mm- $x$ " para as frequências instantâneas e "módulo-IMF1,5mm-x" para os módulos, onde IMF1,5mm corresponde a IMF do passe de $1,5 \mathrm{~mm}$ de profundidade e $\mathrm{x}$ indica o número da IMF.

\subsection{Máquina ferramenta operando com usinagem de $\mathrm{Cl}$}

As figuras 6-23 (a) a (c) mostram os perfis dos sinais obtidos com o estimador de torque na situação de usinagem com corte interrompido nas condições:

- Passe com profundidade de 0,5mm - figura 6-22(a)

- Passe com profundidade de 1,0mm - figura 6-22(b)

- Passe com profundidade de 1,5mm - figura 6-22(c)

\subsubsection{Caso 1: Torno com Cl e UCP de 0,5mm}

Esta situação de usinagem é , basicamente idêntica a situação já descrita no caso 6.2.1, com a diferença que ao tarugo geometricamente semelhante ao anterior, foram introduzidos dois rasgos longitudinais simétricos, semelhantes a chavetas, de $10 \mathrm{~mm}$ de largura e $15 \mathrm{~mm}$ de profundidade como mostrado na foto da figura 6-22.

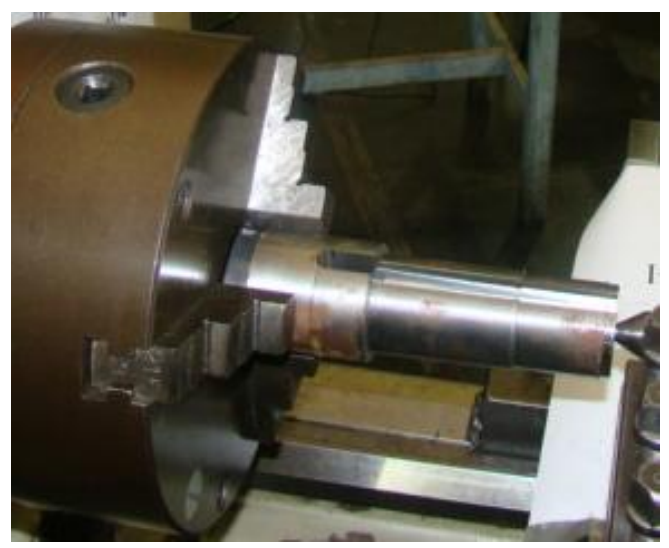

Figura 6-22 Tarugo utilizado para a usinagem com corte interrompido 


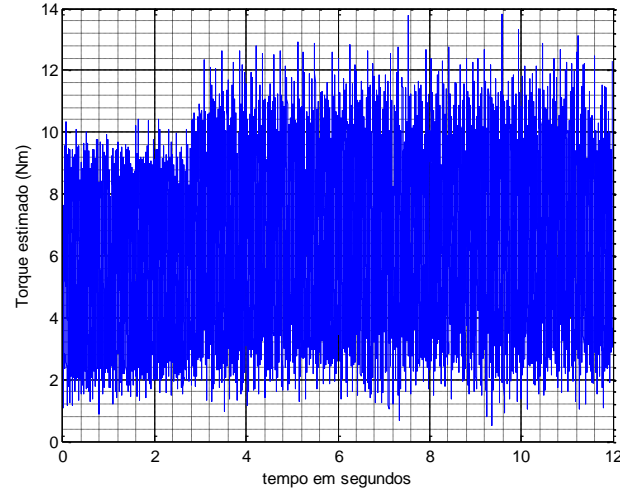

(a)

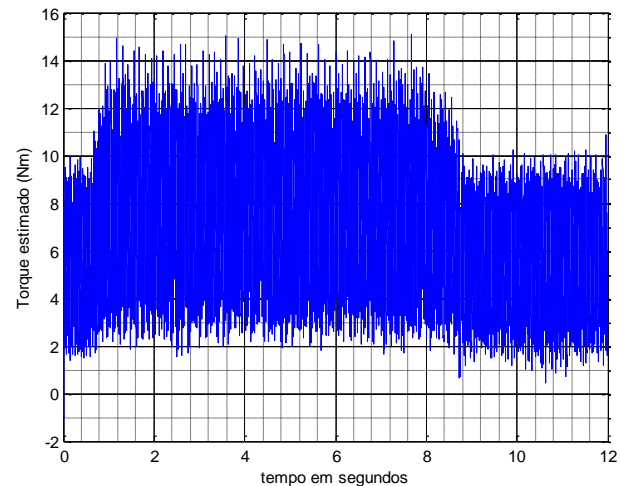

(b)

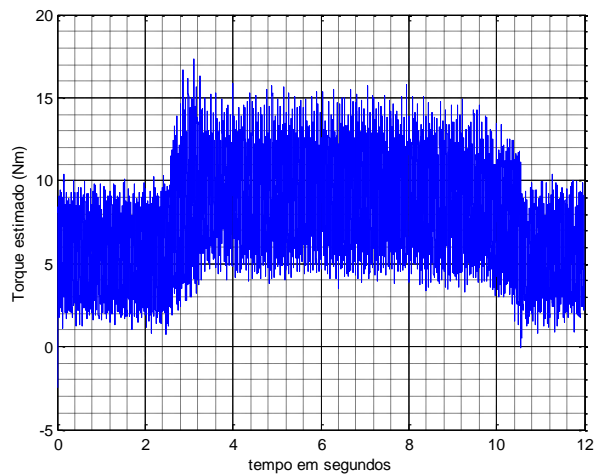

(c)

Figura 6-23 Perfis dos sinais do estimador de torque para usinagem com $\mathrm{Cl}$ e UCP de $0,5 \mathrm{~mm}(\mathrm{a}), 1,0 \mathrm{~mm}$ (b) $1,5 \mathrm{~mm}$ (c)

A figura 6-24 mostra o espectro limitado entre $1 \mathrm{~Hz}$ e $1500 \mathrm{~Hz}$, como nos casos anteriores retirou-se a componente contínua para enfatizar os módulos das componentes oscilatórias e vibratórias.

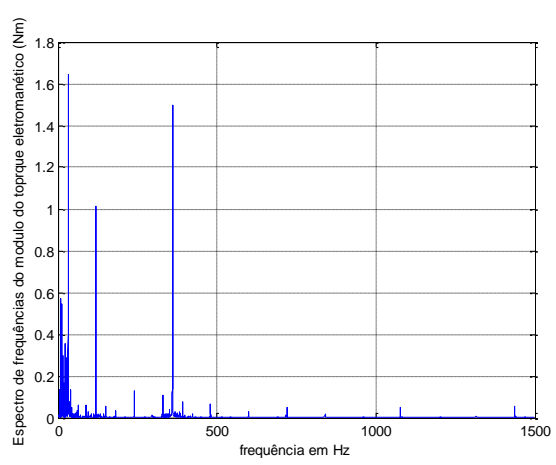

Figura 6-24 Espectro do torque estimado na região pesquisada sem a componente contínua para enfatizar os sinais vibratórios 
Observa-se na figura 6-25 que a maior parte das componentes com frequências maiores que $100 \mathrm{~Hz}$ se mantêm, mas que ocorrem alterações na região de baixas frequências do espectro com um aumento da componente de $31,5 \mathrm{~Hz}$ que passa de $1,45 \mathrm{Nm}$ para $1,65 \mathrm{Nm}$, o que indica que sob condições de corte interrompido a máquina ferramenta apresenta a tendência de aumentar sua componente vibratória dominante natural.

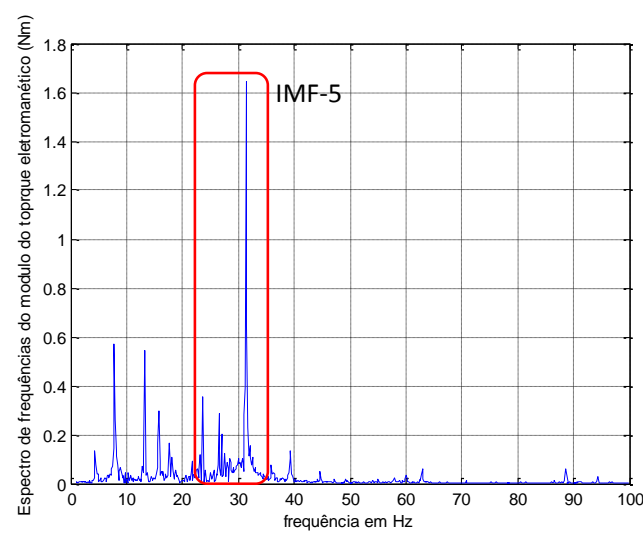

(a)

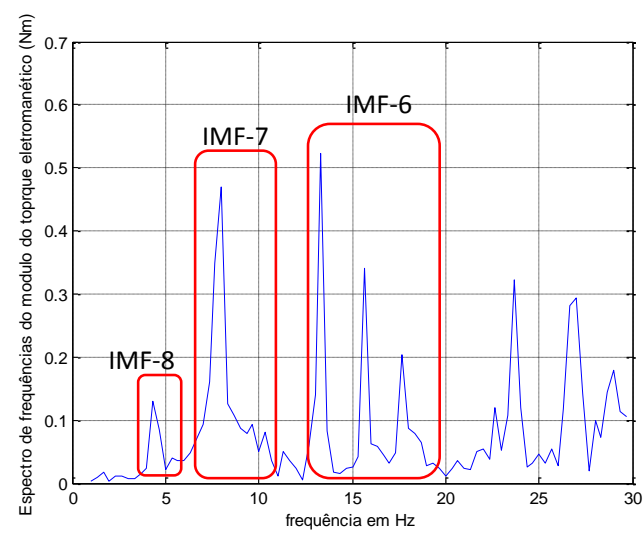

(b)

Figura 6-25 Espectro de baixa frequência do corte interrompido de 0,5mm abaixo de $100 \mathrm{~Hz}$ (a) e abaixo de $30 \mathrm{~Hz}$ (b).

A figura 6-25 indica também, que a componente de aproximadamente $8 \mathrm{~Hz}$ aumenta de forma expressiva, isso corresponde a uma coincidência entre a frequência natural de demanda de torque pela máquina, já verificada para a condição de corte contínuo. A frequência gerada pela situação de corte interrompido com o eixo árvore da máquina girando na velocidade de $49,582 \mathrm{rad} / \mathrm{s}$ ou $7,89 \mathrm{~Hz}$, e duas chavetas deslocadas simetricamente uma da outra gera um sinal de frequência $15,78 \mathrm{~Hz}$. Esta situação é desenvolvida com mais detalhe no capítulo 4 desse trabalho.

A tabela 6-5 mostra os resultados obtidos a partir da análise dos sinais analíticos relativos as nove IMFs obtidas a partir do sinal do estimador de torque para a situação de passe com corte interrompido com profundidade de $0,5 \mathrm{~mm}$. As frequências mais altas das IMFs 1 e 2, têm amplitudes muito pequenas e a indicação de $0,16 \mathrm{Nm}$ no módulo da IMF 2 é alta porque esta IMF sofre com picos de grande amplitude oriundos do sistema mecânico da máquina ferramenta e também do fator associado ao tempo de amostragem, 
que associado ao efeito derivativo do sinal gera um efeito multiplicador pelo seu inverso, esse efeito pode ser visto na figura 6.26(a).

Tabela 6-5: Características da HHT do sinal de torque com corte interrompido e passe de $0,5 \mathrm{~mm}$

\begin{tabular}{|c|c|c|c|c|}
\hline IMF & $\begin{array}{c}\text { Fase (linearizada) } \\
\text { (radianos) }\end{array}$ & $\begin{array}{c}\text { Frequência } \\
\text { (média) }(\mathrm{Hz})\end{array}$ & $\begin{array}{c}\text { Frequência } \\
\text { máxima(Hz) }\end{array}$ & $\begin{array}{c}\text { Módulo } \\
\text { (médio) }(\mathrm{Nm})\end{array}$ \\
\hline 1 & $\psi(t)=11163 t+21,61$ & 1776,6 & 2248,2 & 0,046 \\
\hline 2 & $\psi(t)=10041 t+708,1$ & 1598,0 & 2123,3 & 0,21 \\
\hline 3 & $\psi(t)=2277,0 t+51,00$ & 362,39 & 442,05 & 1,6 \\
\hline 4 & $\psi(t)=838,57 t+2,60$ & 133,46 & 177,47 & 1,09 \\
\hline 5 & $\psi(t)=255,12 t-13,71$ & $40,60]$ & 65,07 & 1,88 \\
\hline 6 & $\psi(t)=106,07 t-7,53$ & 16,88 & 24,32 & 1,14 \\
\hline 7 & $\psi(t)=47,59 t+1,62$ & 7,57 & 10,32 & 0,60 \\
\hline 8 & $\psi(t)=20,8 t+2,17$ & 3,31 & 6,25 & 0,18 \\
\hline 9 & $\psi(t)=5,198 t+4,22$ & 0,82 & 1,90 & 0,099 \\
\hline
\end{tabular}

A tabela 6-5 traz os resultados da investigação utilizando a HHT para cada IMF detectada nesta condição de usinagem com torque interrompido, nota-se, da mesma, que aparecem algumas componentes dentro da região de baixa frequência, notadamente a IMF, de número 5 com um grupo de frequências dominantes em torno de $40,6 \mathrm{~Hz}$.

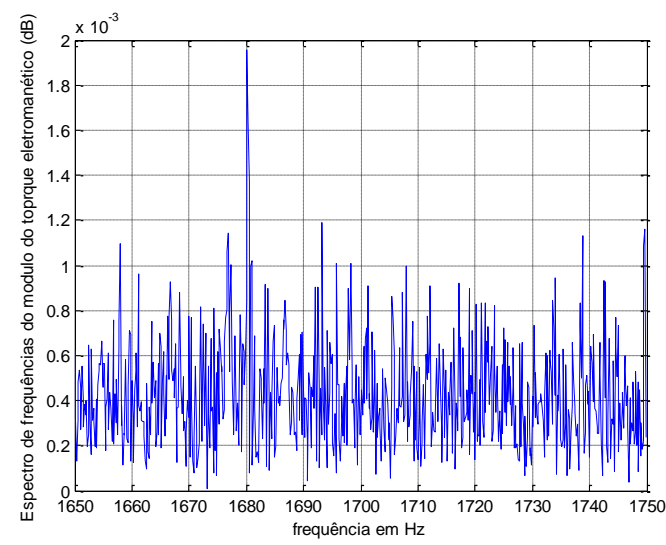

(a)

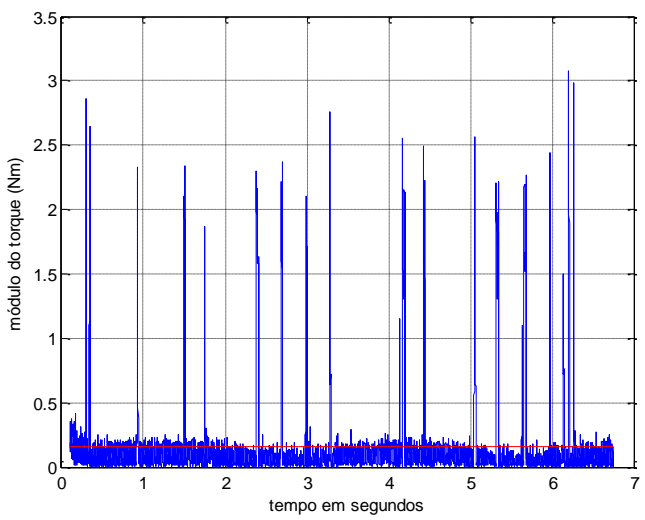

(b)

Figura 6-26 Detalhe do espectro do torque estimado com uma oscilação dominante local próxima a $1680 \mathrm{~Hz}$ (a) também detectada na IMF 2 cujo módulo é mostrado em (b)

As IMFs 3 e 4 são relativas as componentes com frequências de $360 \mathrm{~Hz}$ e $120 \mathrm{~Hz}$ como pode ser verificado nos gráficos correspondentes do apêndice A, enquanto que a IMF 5 está relacionada a componente vibratória natural da máquina ferramenta localizada, em termos estacionários em $31,5 \mathrm{~Hz}$ e cujas 
variações de frequência obtidas com a HHT podem ser verificadas na figura 627(a) enquanto que as variações de módulo podem ser verificadas em 2-27(b).

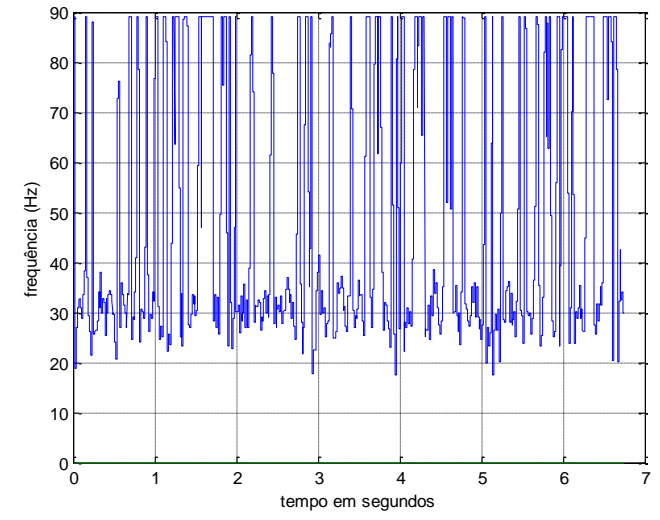

(b)

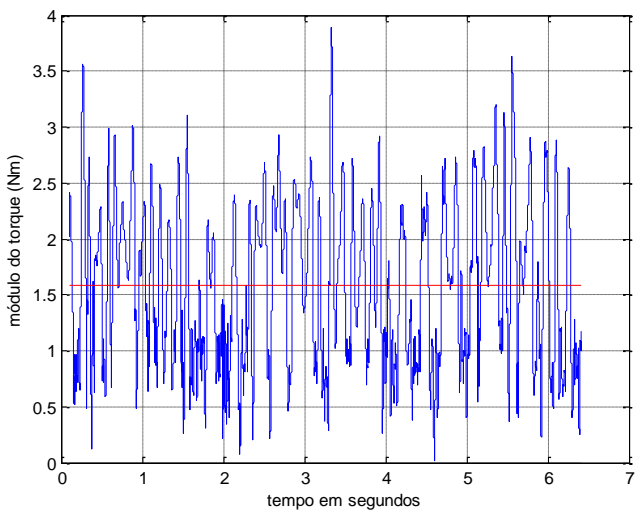

(b)

Figura 6-27 Frequência (a) e módulo (b) do sinal analítico da IMF 5 com UCP de $0,5 \mathrm{~mm}$ e $\mathrm{Cl}$

Observa-se da IMF 5 mostrada na figura 6-27(a) que a máquina ferramenta oscila com uma variação bastante grande de frequências que pelo método para determinação de largura de banda adotado nesse trabalho tem variação entre 0 e aproximadamente $136 \mathrm{~Hz}$, o sinal mostrado na figura relacionada está limitado ao valor médio mais ou menos o desvio padrão do sinal, por isso o limite máximo na figura é de aproximadamente $90 \mathrm{~Hz}$.

A IMF 6 corresponde a corresponde ao grupo formado pela componente da fundamental da componente modulada que ocorre em aproximadamente $16 \mathrm{~Hz}$, ou $2 * 49,582 /(2 * \pi)$, onde 49,582 é a velocidade do eixo árvore em radianos por segundo, enquanto que a IMF 7 corresponde ao grupo de frequências próxima a $8 \mathrm{~Hz}$, que funciona como uma componente modulante e tem módulo maior em virtude da concentração de energia vibratória neste grupo de componentes devido ao desbalanceamento mecânico da máquina feramenta.

A IMF 8 corresponde a componente de aproximadamente $4 \mathrm{~Hz}$ mostrada no espectro da figura 6-25(b) enquanto que a IMF mais alta com frequência de $2,22 \mathrm{~Hz}$ não aparece no espectro. 
Todos gráficos relativos aos processamentos dos sinais analíticos das IMFs obtidas utilizando o estimador de torque estão no apêndice A deste trabalho.

\subsubsection{Caso 2: Torno com $\mathrm{Cl}$ e UCP de 1,0mm}

De modo a manter os procedimentos já adotados anteriormente neste trabalho, analisamos primeiramente o espectro entre $1 \mathrm{e} 1500 \mathrm{~Hz}$, o que é mostrado na figura 6.28 onde observamos um ligeiro aumento do módulo da componente de $31,5 \mathrm{~Hz}$, a manutenção do valor do módulo da componente de $120 \mathrm{~Hz}$ e a diminuição do módulo da componente de $360 \mathrm{~Hz}$.

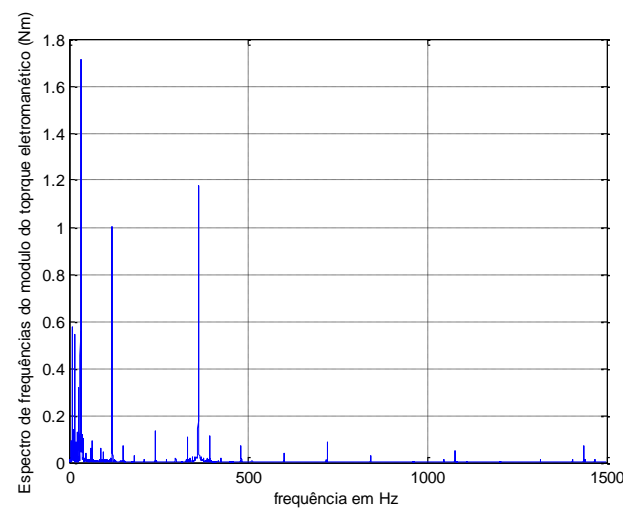

Figura 6.28 Espectro entre 1 e $1500 \mathrm{~Hz}$ com a máquina ferramenta usinando com $\mathrm{Cl}$ e UCP de $1,0 \mathrm{~mm}$

As figuras 6-29 (a) e (b) mostram os efeitos da situação de passe com profundidade de $1,0 \mathrm{~mm}$ sobre a parte das frequências mais baixas do espectro, onde observa-se uma forte diminuição da componente de $13,2 \mathrm{~Hz}$ assim como um aumento na componente de $15,8 \mathrm{~Hz}$, e como já esperado a vibração forçada tende a prevalecer principalmente quando ocorrem tão próximas .
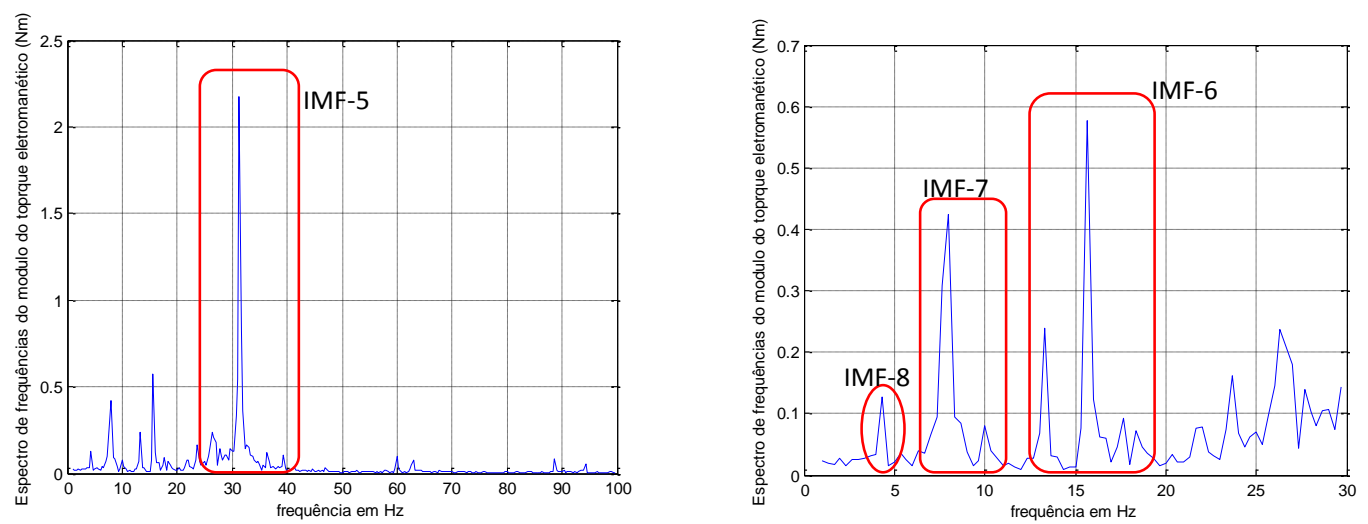
(a)

(b)

Figura 6-29 Detalhes da região de baixas frequências do espectro e suas respectivas IMFs

Tabela 6-6: Características da HHT do sinal de torque com corte interrompido e passe de $1,0 \mathrm{~mm}$

\begin{tabular}{|c|c|c|c|c|}
\hline IMF & $\begin{array}{c}\text { Fase (linearizada) } \\
\text { (radianos) }\end{array}$ & $\begin{array}{c}\text { Frequência } \\
\text { (média) }(\mathrm{Hz})\end{array}$ & $\begin{array}{c}\text { Frequência } \\
\text { máxima }(\mathrm{Hz})\end{array}$ & $\begin{array}{c}\text { Módulo (médio) } \\
\text { (Nm) }\end{array}$ \\
\hline 1 & $\psi(t)=9726,8 t+337$ & 1548,1 & 2105,4 & 0,045 \\
\hline 2 & $\psi(t)=12082 t-34,68$ & 1922,9 & 2360 & 0,11 \\
\hline 3 & $\psi(t)=2412,4 t-114,6$ & 383,93 & 485,14 & 1,73 \\
\hline 4 & $\psi(t)=896,76 t-59,57$ & 142,72 & 196,9 & 1,13 \\
\hline 5 & $\psi(t)=264,96 t-21,00$ & 42,17 & 71,66 & 2,30 \\
\hline 6 & $\psi(t)=115,66 t-1,27$ & 18,40 & 27,01 & 1,61 \\
\hline 7 & $\psi(t)=64,42 t-3,62$ & 10,26 & 14,40 & 0,89 \\
\hline 8 & $\psi(t)=27,80 t-7,26$ & 4,42 & 6,09 & 0,30 \\
\hline 9 & $\psi(t)=10,69 t-3,41$ & 1,70 & 2,76 & 0,14 \\
\hline
\end{tabular}

As ocorrências desse caso são semelhantes ao já relatado nos casos anteriores, e as IMFs, a partir da IMF 3 são muito parecidas.

A tabela 6-6 traz os valores relacionados as IMFs detectadas na situação de corte interrompido com passe de $1,0 \mathrm{~mm}$ de profundidade e os gráficos relativos a essa tabela estão localizados no apêndice A deste trabalho.

\subsubsection{Caso 3: Torno com $\mathrm{Cl}$ e UCP de $1,5 \mathrm{~mm}$}

O sinal obtido pelo estimador de torque para essa situação é mostrado na figura 6-23(c) e sua análise espectral é mostrada na figura 6-30 e novamente observamos mudanças nas componentes de frequências mais altas com diminuição das componentes de $31,5 \mathrm{~Hz}$ e $120 \mathrm{~Hz}$ e aumento da componente de $360 \mathrm{~Hz}$ em relação caso anterior.

A tabela 6.7 exibe os resultados das análises dos sinais analíticos da situação aqui estudada, onde novamente observa-se uma distorção da fase das componentes das IMF 1 e 2 . O baixo valor do módulo da IMF 1 indica que a mesma é insignificante no processo e que a IMF 2 corresponde ao mesmo caso estudado no item do caso 3 acima discutido, portanto os casos de interesse ocorrem a partir da IMF 3. 
A IMF 3 corresponde ao grupo de frequências associado a componente estacionária de $360 \mathrm{~Hz}$, enquanto que a IMF 4 corresponde ao grupo de frequências associado a componente estacionária de $120 \mathrm{~Hz}$.

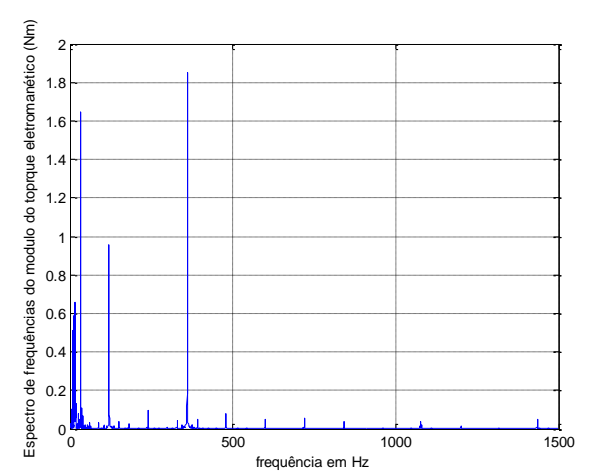

Figura 6-30 Espectro do sinal do torque estimado com a máquina ferramenta executando $\mathrm{Cl}$ e UCP de $1,5 \mathrm{~mm}$

O espectro da região de frequências entre 1 e $30 \mathrm{~Hz}$ é mostrada na figura 6-31 (a) e (b) onde observa-se um aumento na energia da componente de $15,8 \mathrm{~Hz}$, assim como uma recuperação na componente de $13,2 \mathrm{~Hz}$. A componente de $8 \mathrm{~Hz}$ novamente recebe sua companheira de $9 \mathrm{~Hz}$, presente também na situação de corte contínuo.

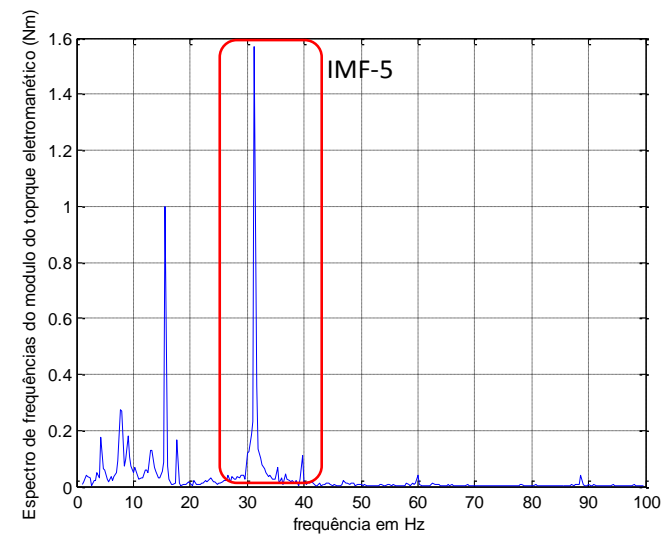

(a)

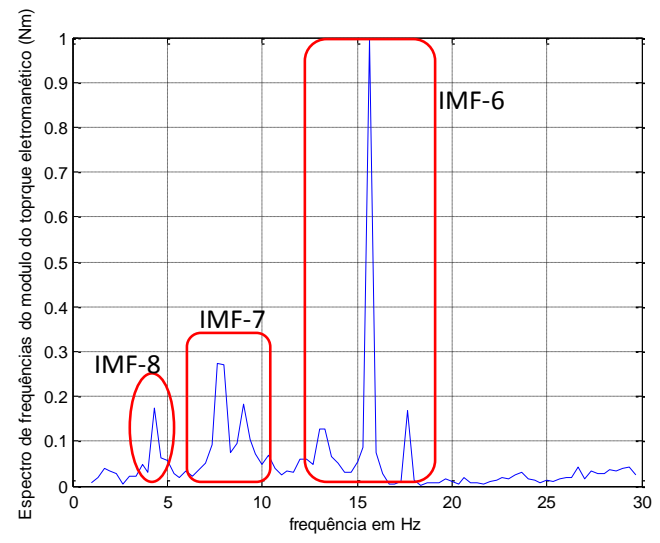

(b)

Figura 6-31 Espectro das baixas frequências (a) e seu detalhe com as componentes abaixo de $30 \mathrm{~Hz}$ e as IMFs correspondente.

Tabela 6-7: Características da HHT do sinal de torque com corte interrompido e passe de $1,5 \mathrm{~mm}$

\begin{tabular}{|c|c|c|c|c|}
\hline IMF & $\begin{array}{c}\text { Fase (linearizada) } \\
\text { (radianos) }\end{array}$ & $\begin{array}{c}\text { Frequência } \\
\text { (média) }(\mathrm{Hz})\end{array}$ & $\begin{array}{c}\text { Frequência } \\
\text { máxima(Hz) }\end{array}$ & $\begin{array}{c}\text { Módulo } \\
\text { (médio) }(\mathrm{Nm})\end{array}$ \\
\hline 1 & $\psi(t)=11023 t+189,24$ & 1754,3 & 2321,9 & 0,047 \\
\hline 2 & $\psi(t)=8355,3 t+150,87$ & 1329,8 & 1984,8 & 0,43 \\
\hline 3 & $\psi(t)=2056,5 t-10,38$ & 327,30 & 406,79 & 1,64 \\
\hline
\end{tabular}




\begin{tabular}{|c|c|c|c|c|}
\hline 4 & $\psi(t)=746,96 t+1,53$ & 118,88 & 147,69 & 1,16 \\
\hline 5 & $\psi(t)=216,36 t-7,45$ & 34,43 & 49,86 & 1,68 \\
\hline 6 & $\psi(t)=98,97 t+6,42$ & 15,75 & 21,32 & 0,95 \\
\hline 7 & $\psi(t)=43,58 t+2,77$ & 6,93 & 9,49 & 0,34 \\
\hline 8 & $\psi(t)=19,31 t+4,15$ & 4,15 & 4,61 & 0,10 \\
\hline 9 & $\psi(t)=8,667 t-3,25$ & 1,38 & 2,30 & 0,05 \\
\hline
\end{tabular}

Os sinais das IMFs superiores a $4^{\underline{a}}$ tem frequências médias bastante próximas as componentes dominantes do espectro, o que era esperado já que o aumento do carregamento cria uma condição vibratória forçada na frequência relativa a operação de usinagem, isso é evidente na figura 6-31(b) onde a componente de aproximadamente $16 \mathrm{~Hz}$ apresenta inclusive um aspecto de aumento de banda local dessa componente o que indica uma concentração de energia na mesma..

As figuras 6.32 (a) e (b) mostram os efeitos vibratórios da componente relativa a IMF-5 onde também se percebe a predominância da frequência de $31,5 \mathrm{~Hz}$ na figura $6.32(\mathrm{~b})$.

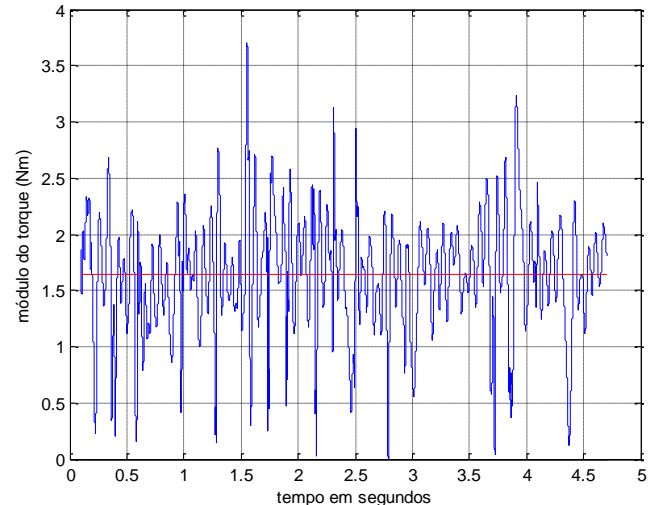

(a)

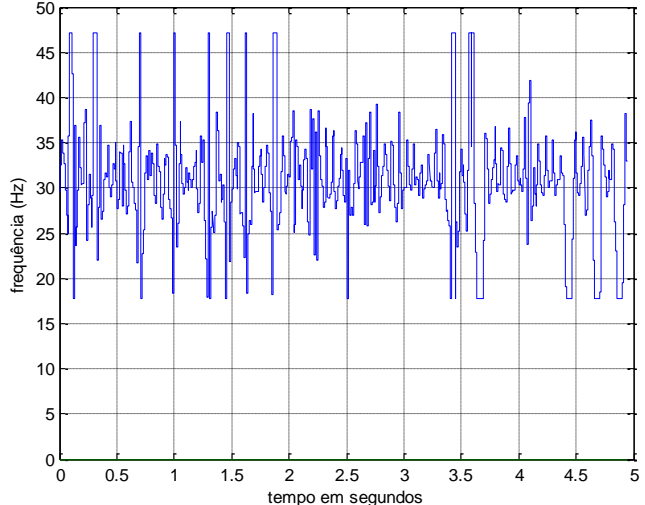

(b)

Figura 6-32 Módulo (a) e fase (b) da HHT da IMF-5
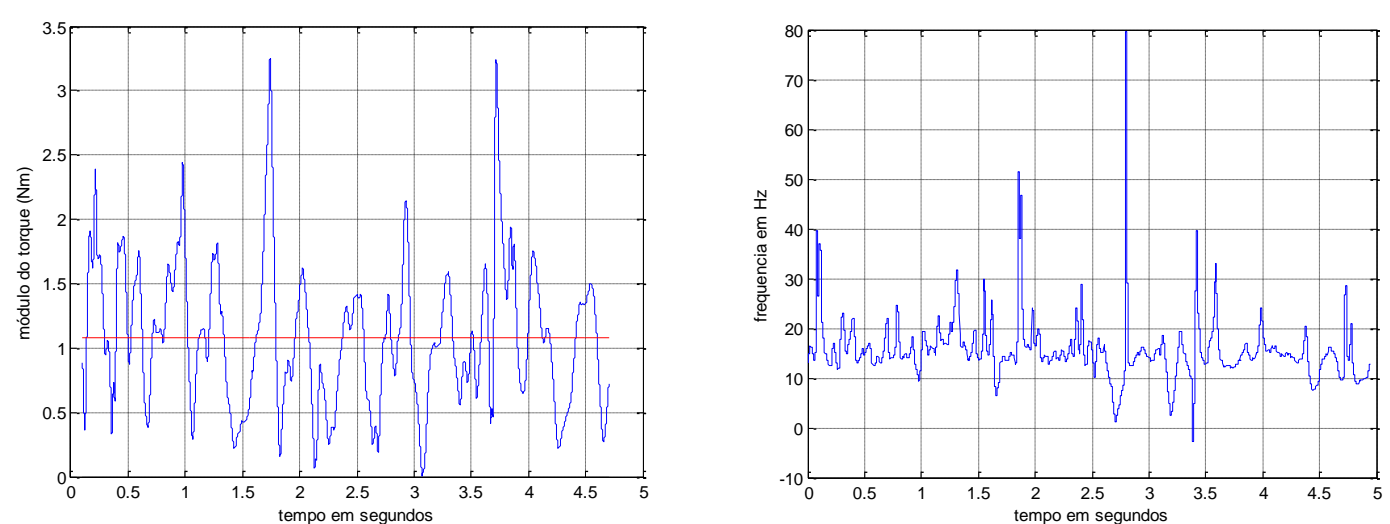
(a)

Figura 6.33 Módulo (a) e fase (b) da HHT da IMF-6

As figuras 6-33 (a) e (b) mostram os resultados da $\mathrm{HHT}$ relacionadas a IMF-6, o comportamento da frequência em torno de $15,8 \mathrm{~Hz}$ é evidente por inspeção da figura 6-33(b).

\subsection{Análise do cenário pela aplicação a WT}

Neste item procurou-se estabelecer uma relação entre as análises realizadas com a $\mathrm{HHT}$ e o mesmo processo realizado com a transformada de wavelet. O objetivo é estabelecer uma relação de consistência entre os dois algoritmos e utilizar a transformada de wavelet, já consagrada em muitas aplicações, para validar as observações feitas com a HHT.

Não houve nenhum objetivo de utilizar a transformada de wavelet como uma ferramenta de análise dos processos elétricos e mecânicos da máquina ferramenta, mas estabelecer uma relação do que a WT "vê" e o que a HHT "vê" e o porquê das diferenças entre as "visões".

O sinal escolhido para a realização da primeira observação foram as vibrações de $31,5 \mathrm{~Hz}$ e $8 \mathrm{~Hz}$, já detectadas pela FFT e pela $\mathrm{HHT}$, cujas componentes de aproximação e detalhe foram extraídas dos mesmos sinais já analisados pela FFT e pela HHT e as situações utilizadas para as observações foram:

- Máquina ferramenta operando em vazio

- Máquina ferramenta operando com corte contínuo e de passe de 1,5mm

- Máquina ferramenta operando com corte interrompido e passe de $1,5 \mathrm{~mm}$

A figura 6.34 (a) exibe a reconstrução do coeficiente de aproximação cA7 e a figura 6.34(b) a reconstrução do coeficiente de detalhe cD7 do torno operando em vazio onde é possível verificar por inspeção das figuras que a componente dominante na figura $6.32(\mathrm{a})$ tem aproximadamente $31,5 \mathrm{~Hz}$.

As figuras 6.35 (a) e (b) mostram os resultados obtidos pela HHT para as mesma situação descrita acima. 


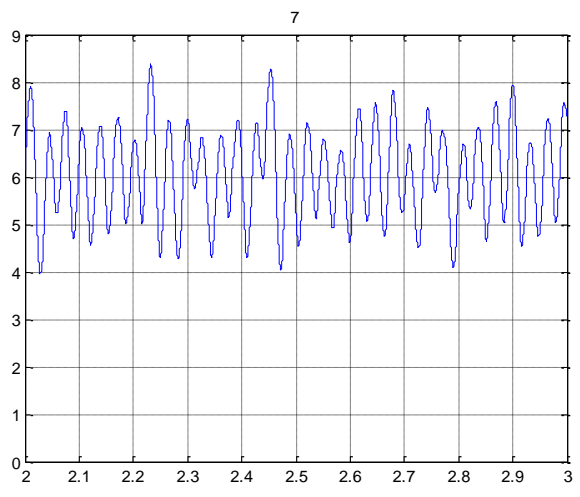

(a)

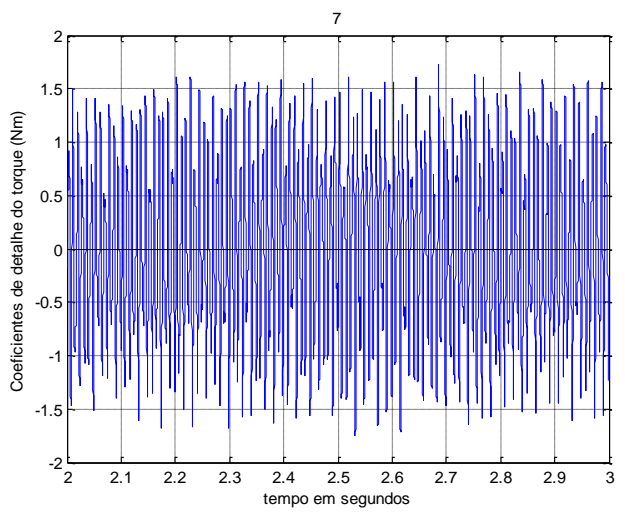

(b)

Figura 6.34 Coeficientes de aproximação cA7 (a) e de detalhe cD7 (b) com o torno em vazio

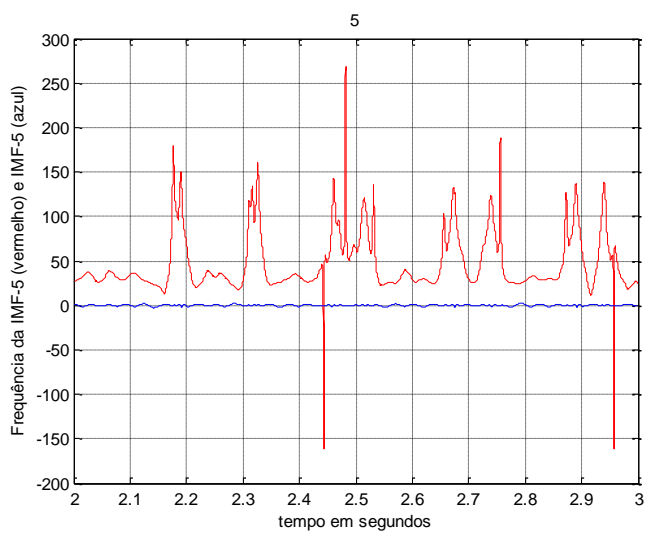

(a)

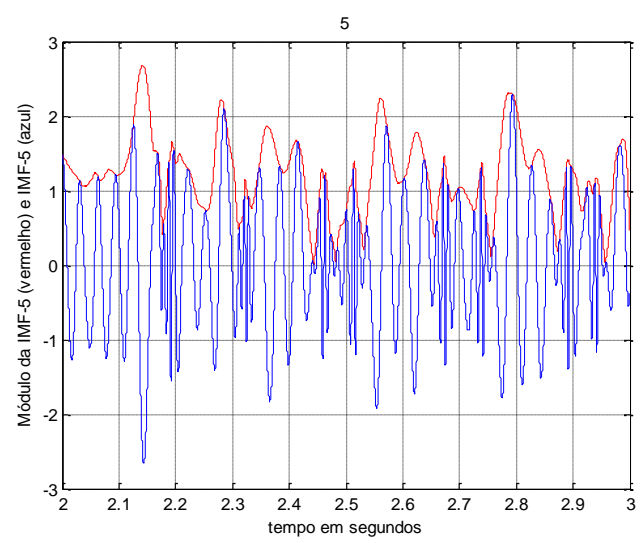

(b)

Figura 6.35 Frequência (a) e módulo (b) em função do tempo do sinal analítico da IMF6 juntamente com a IMF-5 com o torno em vazio

Um rápida comparação entre as formas do sinal de aproximação da WT, revela que além do valor médio do sinal, o efeito do filtro passa baixas da wavelet mãe permite a observação do sinal de $31,5 \mathrm{~Hz}$ e as flutuações de seu entorno enquanto que a alta frequência presente no coeficiente de detalhe indica o comportamento das componentes de alta frequência que compõem o cenário completo do sinal. A forma "harmoniosa" do sinal está relacionada a codificação de sub-banda inerente a WT.

A HHT relativa a frequência do sinal, vista na figura 6.35(a) apresenta um sinal mais tosco, uma vez que sua resolução é menor que a da WT, ou seja 
as componentes de seu entorno estão todas presentes, sejam as lineares ou não lineares, assim todas as perturbações presentes na fase do sinal analítico, são evidenciadas pelo filtro passa altas relacionado com a derivada da fase cujo efeito multiplicador dá extrema relevância aos detalhes da variação da frequência no tempo. O que se pode afirmar, é que a máquina ferramenta operando em vazio, nesse modo específico sofre bastante perturbação em sua componente de frequência.

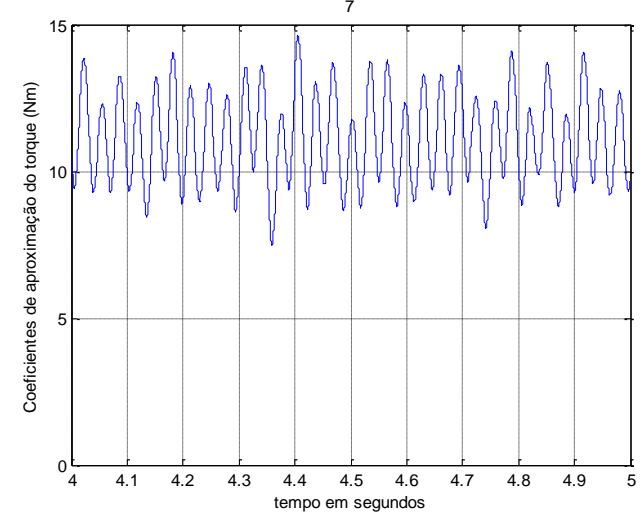

(a)

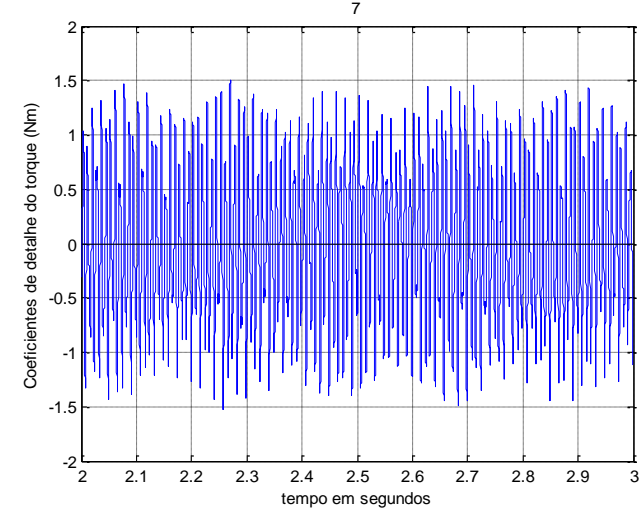

(b)

Figura 6.36 Coeficientes de aproximação cA7 (a) e de detalhe cD7 (b) do torno com corte contínuo e passe de $1,5 \mathrm{~mm}$

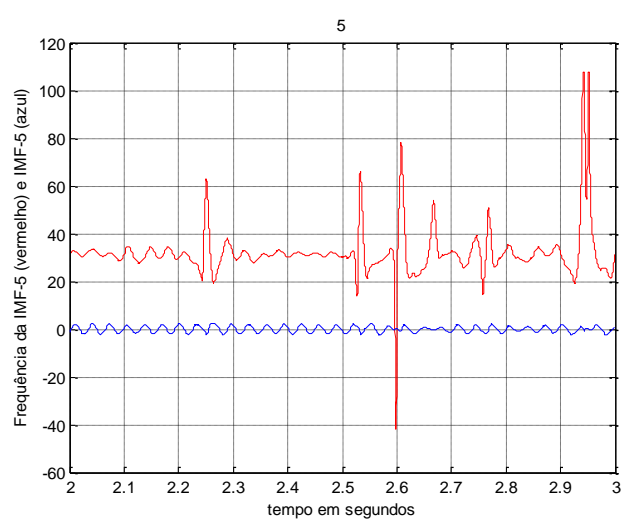

(a)

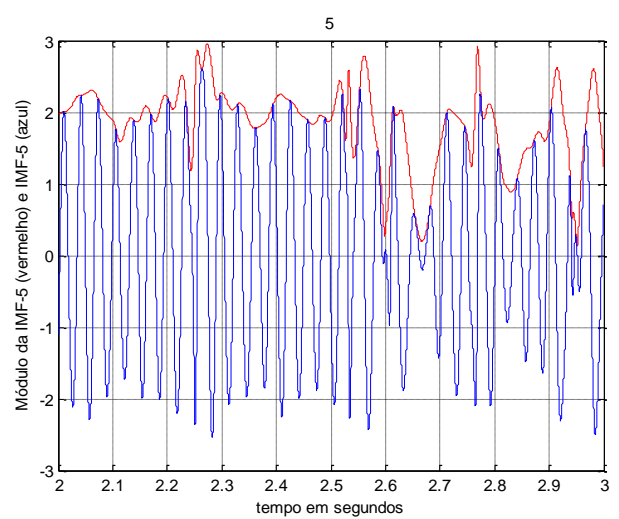

(b)

Figura 6.37 Frequência (a) e módulo (b) em função do tempo do sinal analítico da IMF5 com o torno executando passe contínuo de $1,5 \mathrm{~mm}$

A segunda situação abordada corresponde a operação da máquina ferramenta operando com corte contínuo e passe de $1,5 \mathrm{~mm}$ cujos resultados, 
relativos a WT, são exibidos nas figuras 6.36 (a) e (b) e relativos a HHT nas figuras 6.37 (a) e (b).

A informação contida nas componentes de aproximação e detalhe da WT não geram maiores informações sobre os fenômenos que estão sendo observados no torno que aqueles que ocorrem com a máquina ferramenta operando em vazio, exceto quanto ao módulo do torque aplicado pelo motor. Já a frequência observada pela HHT indica uma diminuição nos modos oscilatórios como se vê claramente na figura 6.37(a), assim como ocorre uma regularização no módulo do torque como se verifica na figura 6.37(b).

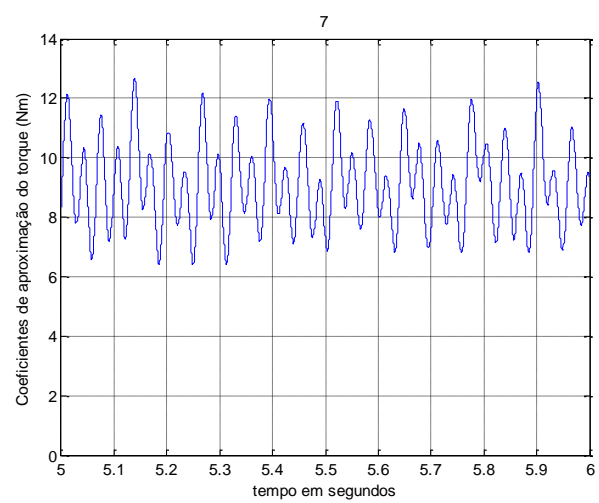

(a)

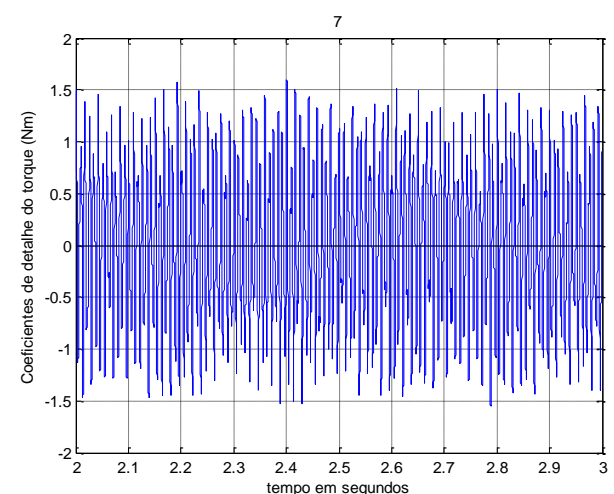

(b)

Figura 6.38 Coeficientes de aproximação cA7 (a) e de detalhe cD7 (b) com o torno operando com passe interrompido de $1,5 \mathrm{~mm}$

A terceira situação abordada leva em conta o torno operando com corte interrompido e passe de $1,5 \mathrm{~mm}$. Os resultados, para a $W T$, estão nas figuras 6.38 (a) e (b) e para a HHT nas figuras 6.39 (a) e (b).

Novamente observamos que a informação relacionada com a HHT apresenta maior riqueza de detalhes tanto no módulo quanto na frequência, na qual observa-se na figura 6.39(a), um aumento dos modos oscilatórios com flutuações mais frequentes e de maior variação de frequência que do caso com corte contínuo. Detalhes similares podem ser observados no torque, embora a informação do módulo do torque seja bastante similar ao do caso de corte contínuo. 


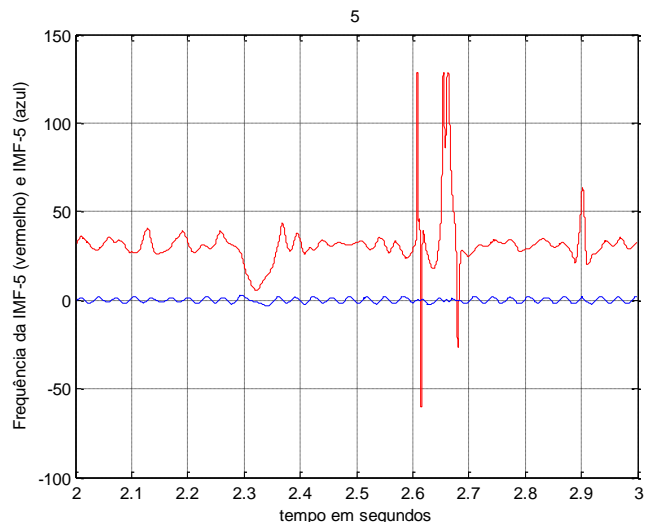

(a)

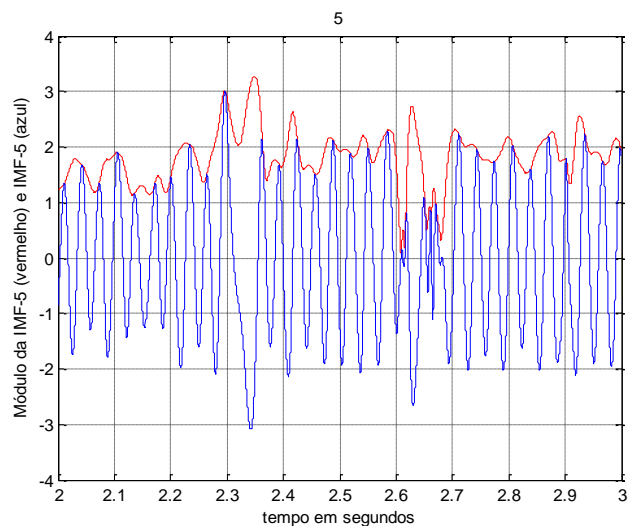

(b)

Figura 6.39 Frequência (a) e módulo (b) em função do tempo do sinal analítico da IMF5 com o torno executando corte interrompido de $1,5 \mathrm{~mm}$

\subsection{O comportamento das componentes estacionárias em função do carregamento}

O comportamento das componentes estacionárias detectadas varia de modo não uniforme com o carregamento, assim como algumas componentes diminuindo e posteriormente aumentado com o carregamento. Isto pode ser observado nas figuras 6.40 (a) e (b). A única componente que aumenta continuamente é a $360 \mathrm{~Hz}$.

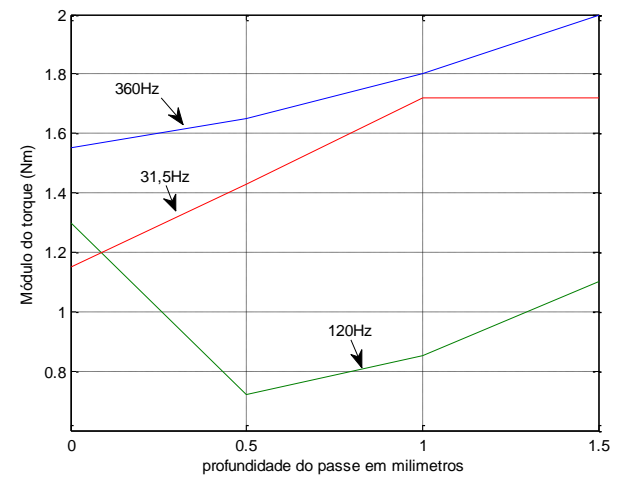

(a)

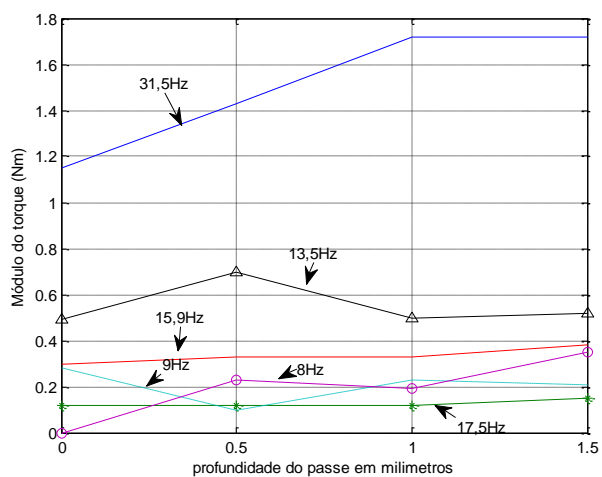

(b)

Figura 6-40 Comportamento do módulo espectral das componentes de frequências acima de $30 \mathrm{~Hz}$ em (a) e abaixo de $31,5 \mathrm{~Hz}$ (b) 


\subsection{Comparação entre os sinais de usinagem observados pela HHT nos dados do dinamômetro e do estimador de torque}

Finalmente comparou-se os perfis da força de corte e do torque convertido para força de corte por um fator que leva em conta o raio médio de usinagem, e o fator de transmissão de movimento, entre o eixo do motor e eixo árvore. A figura 6.41 (a) mostra o comportamento da frequência obtida do sinal analítico da IMF-3 do sinal do dinamômetro, enquanto que a figura 3.41(b) mostra a frequência obtida do sinal analítico do estimador de torque.

Observa-se que ambos sinais correspondem ao mesmo modo pela faixa de frequências que ambos ocupam, observa-se também que a dinâmica do sinal do dinamômetro é muito maior que a do estimador, o que já era esperado uma vez que o dinamômetro é um instrumento sintonizado para detectar esse sinal e está diretamente acoplado a ferramenta enquanto que o estimador de torque está medindo o torque de forma indireta com uma série de elementos mecânicos entre a ferramenta e o estimador de torque.

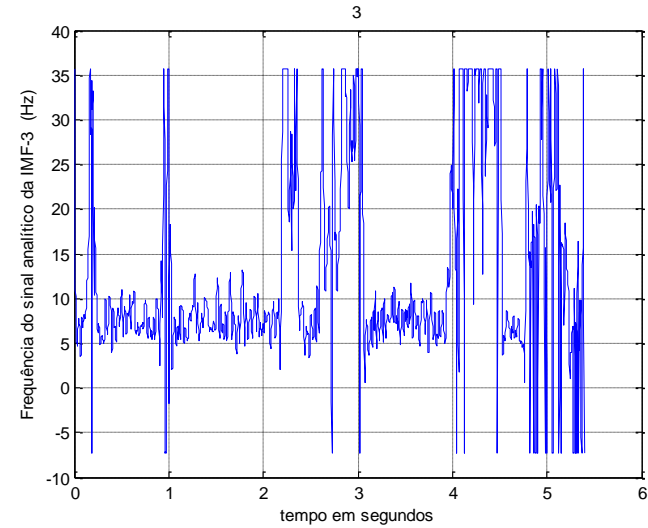

(a)

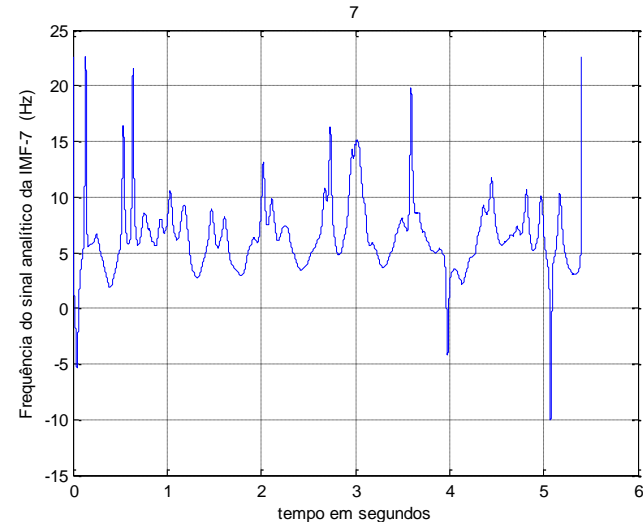

(b)

Figura 6-41 O sinal de frequência do sinal analítico da IMF-3 (a) e o sinal de frequência do sinal analítico da IMF-7 do estimador de torque

É importante observar que embora a resposta do estimador seja nitidamente mais lenta que a do dinamômetro, ela ainda é significativa e pode ser utilizada para a monitoração das baixas frequências presentes no sinal de torque.

As figura 6.41 (a) e (b) mostram os módulo dos sinais analíticos das IMFs relacionadas a força de corte do dinamômetro e a força equivalente 
oriunda do estimador de torque. Novamente observa-se uma dinâmica superior no caso do dinamômetro, assim como observa-se que o estimador tem uma resposta de frequência bem mais limitada.

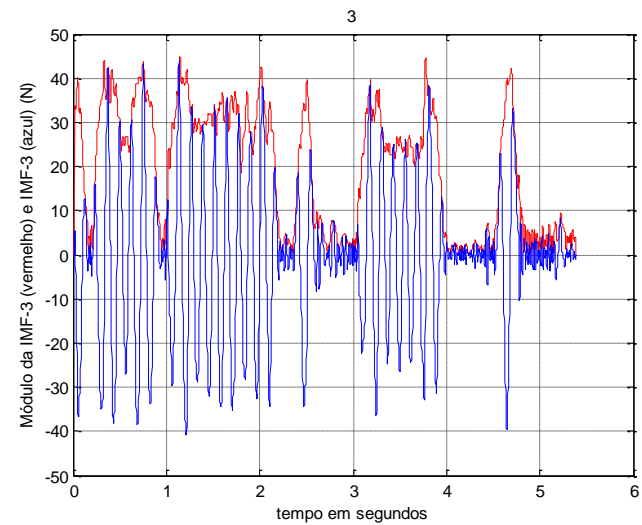

(a)

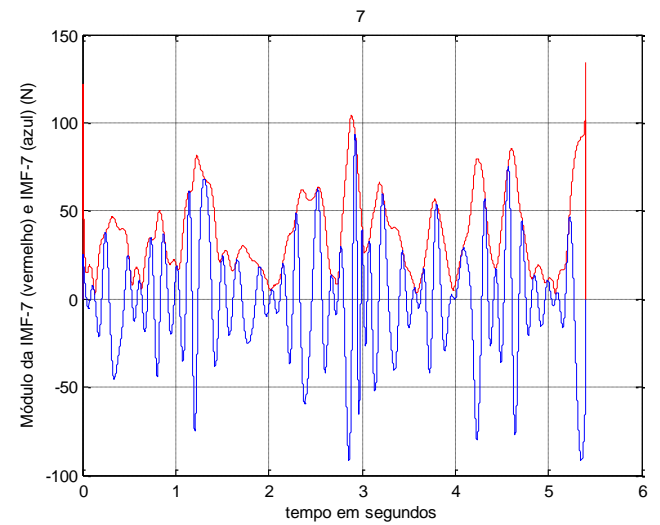

(b)

Figura 6-42 O sinal do módulo do sinal analítico da IMF-3 (a) e o sinal do módulo do sinal analítico da IMF-7 do estimador de torque

A análise realizada acima gera a impressão que o estimador de torque utilizado nos processos desse trabalho é limitado a operar em uma faixa de frequências muito baixa. Esta impressão é falsa, o que ocorre é que os componentes mecânicos da máquina ferramenta atenuam sobremaneira os sinais, como se houvesse uma cascata de filtros passa baixas entre 0 processo de usinagem e o motor de indução na forma de redutores de engrenagens, correias e mancais.

Como o estimador detecta colateralmente os efeitos da não linearidade do circuito magnético do motor assim como o desequilíbrio de fase da rede elétrica, é possível mostrar sua capacidade de resposta de frequências em frequências superiores a $720 \mathrm{~Hz}$. A figura 6.43 (a) mostra a resposta do estimador a componente de $360 \mathrm{~Hz}$ associada ao efeito de saturação magnética do motor na forma das componentes de $5^{\mathrm{a}}$ e $7^{\mathrm{a}}$ harmônicas, enquanto que a figura 6.43(b) mostra a resposta do estimador ao desequilíbrio de linha. É interessante observar que o torque do motor não é contínuo no sentido mais exato da palavra, mas ocorre de forma pulsada, pelo menos na situação de baixo carregamento utilizado com o passe contínuo de $1,5 \mathrm{~mm}$ de profundidade. 


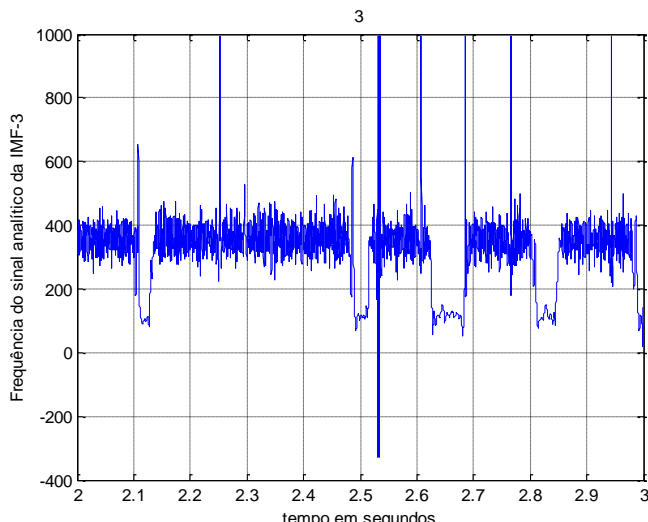

(a)

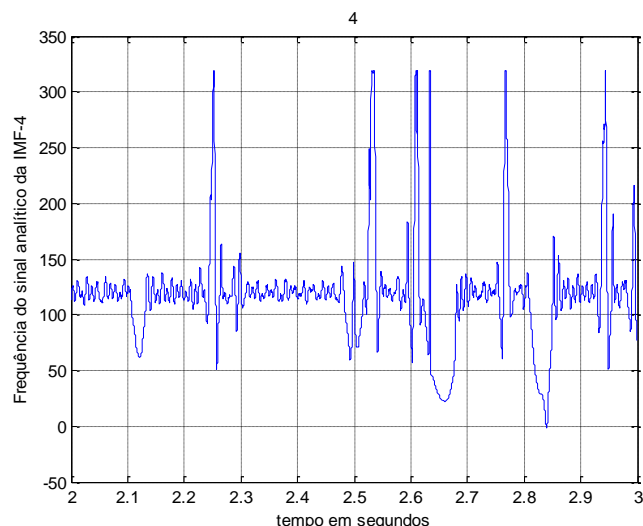

(b)

Figura 6-43 O módulo do sinal analítico da IMF-3 (a) e o módulo do sinal analítico da IMF-7 do estimador de torque

\subsection{Conclusões do capítulo 6}

As análises realizadas com os dados do estimador de torque são as mesmas realizadas com os dados do dinamômetro até para gerarem padrões comparativos entre os dois sinais. É importante salientar que o sincronismo entre os sistemas de aquisição foi realizado manualmente e portanto, colocar um sinal sobre o outro para procurar um padrão no tempo de teste é praticamente impossível, mesmo porque as respostas de frequência de ambos os métodos são completamente diferentes, uma vez que o dinamômetro é um instrumento e o motor de indução é um transdutor de energia elétrica para torque.

Diferentemente do dinamômetro, o estimador de torque está sujeito a todos os componentes mecânicos da máquina ferramenta e também de componentes estacionárias de origem elétrica que afetam a corrente e consequentemente a potência e daí o torque estimado, mas as revelações do estimador indicam alguns fatos interessantes, tais como:

- O torque fornecido pelo MIT não é contínuo, mas sofre pulsações, decorrentes do fato que o motor coloca energia nas massas girantes quando está em processo de aumento do escorregamento e consequentemente de torque. Uma vez que as massas em rotação se aproximam da velocidade síncrona da rede elétrica, essa energia rotativa passa a acionar os processos mecânicos e o MIT passa a 
operar como receptor de energia. Esse fenômeno não é periódico como fica demonstrado pela HHT.

- O desequilíbrio de fase sofre os efeitos do fenômeno explanado acima, assim a componente de $120 \mathrm{~Hz}$, diminui sensivelmente quando o motor esta recebendo energia das massas girantes.

- O fenômeno de corte não é contínuo, mas sofre perturbações que aparecem como surtos na frequência média, os surtos podem ter origem mecânica na própria máquina ferramenta ou metalúrgica com origem no fenômeno de usinagem. Isso poderia ser verificado em um torno mais novo e com menos desbalanceamento de massas, mas é nesse ponto que a HHT demonstra sua força quando utilizada com os dados do dinamômetro. Obviamente esta força decresce bastante quando o MIT é utilizado como sensor desse tipo de informação.

- As perturbações nos módulos do torque e da força de usinagem afetam o acabamento da superfície da peça, assim como o desgaste da ferramenta de corte. Em uma ou outra situação as análises realizadas pela HHT detectam as perturbações na força de corte. O fenômeno pode ser observado na figura 6.44 .

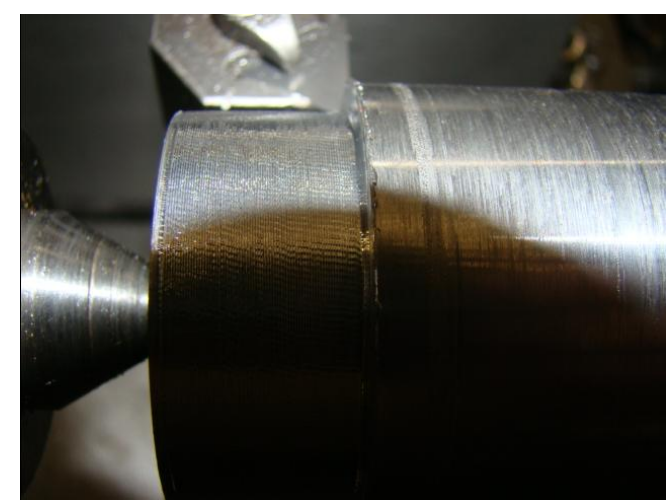

Figura 6.44 Rugosidades na superfície de uma peça usinada provocada pelas vibrações do módulo da força de corte. 


\subsection{Conclusão geral}

Algumas peculiaridades desse trabalho tornaram-no um tanto extenso, a parcela do trabalho que consumiu muito tempo e gerou muita informação, está relacionada com a HHT, cuja conceituação é basicamente empírica, o que levou a uma natural desconfiança dos resultados obtidos e consequentemente a uma intensa busca de verificação de consistência. Em decorrência disso, neste capítulo, procurou-se estabelecer as conexões entre todos os elementos abordados de forma sucinta procurando manter o cerne da pesquisa realizada com as conclusões finais de cada item pesquisado.

No capítulo 3, procurou-se estabelecer uma relação entre a potência ativa na entrada do motor de indução com a potência na aresta de corte da ferramenta operando na máquina ferramenta. Foi utilizado o algoritmo de busca de harmonia (HS) para realizar o processo de determinação dos parâmetros do motor e o processo foi dividido em dois estágios.

O primeiro estágio permite a determinação da constante de tempo do rotor, a indutância do estator e o coeficiente de dispersão total do fluxo magnético concatenado e o segundo estágio permite a determinação da indutância de magnetização. Como nos caso práticos adota-se $L_{r}=L_{s}$. 
Em uma primeira etapa, realizada com um aparato experimental em laboratório, os resultados foram bastante consistentes porque o motor de indução sofreu carregamento pleno dividido em dez etapas iguais e os erros de estimação de torque, potência e velocidade foram obtidos com porcentuais bastante aceitáveis.

Em uma segunda etapa, a estimação de torque foi confrontada com a força medida pelo dinamômetro Kistler, alguns resultados foram bons, mas o carregamento máximo da máquina realizado com a situação de corte contínuo com $1,5 \mathrm{~mm}$ de profundidade não gerou demanda de potência suficiente para uma conclusão mais definitiva sobre a aplicação do método. Os resultados obtidos são discutidos com mais detalhes na seção 3.9 do capítulo 3 .

No capítulo 4, a pesquisa concentrou-se no dados do dinamômetro Kistler com avaliação das forças de corte e de avanço sob a ótica estacionária do processo de corte e de avanço da ferramenta. Observou-se que a máquina vibra em algumas componentes relacionadas com a frequência de rotação do eixo árvore gerando harmônicas e sub-harmônicas da frequência relacionada com a rotação.

Foi observado também que existem componentes estacionárias não relacionadas diretamente a velocidade do eixo árvore, este é o caso da componente de $13 \mathrm{~Hz}$. Como o torno possui caixa Norton, provavelmente uma das combinações das engrenagens que a compõe gera esta componente.

No capítulo 4, utilizando os dados da operação com corte interrompido é possível fazer a modelagem dinâmica do processo de usinagem, tanto de corte como de avanço, isso não foi realizado porque desmontar o carro principal do torno para pesagem era impraticável, mas o método, baseado na resposta transitória da ferramenta no corte interrompido foi definido. As conclusões mais detalhadas sobre o capítulo 4 estão na seção 4.4 .

O capítulo 5 aborda a aplicação da transformada de Hilbert-Huang (HHT) aos mesmos dados utilizados no capítulo 4. Os fundamentos estacionários do capítulo 4 formam a base estacionária que corrobora os pontos de referência sobre os quais se apoiam as buscas iniciais de 
consistência. Observou-se que a fase do sinal analítico na maioria dos casos apresenta um comportamento linear e aplicando o método de regressão linear é possível determinar, através do coeficiente angular da reta ótima, um valor médio das componentes estacionárias em ação na IMF responsável pelo sinal analítico.

As flutuações no valor médio da reta determinada definem as variações da frequência do sinal sob análise, que podem sofrer oscilações locais bruscas, mesmo com pequenas variações de fase, devido ao efeito multiplicador do inverso do período de amostragem que é de 500 para o caso de amostragem com $1000 \mathrm{am} / \mathrm{s}$ e 10000 para o caso de $20000 \mathrm{am} / \mathrm{s}$. Adotou-se uma técnica para reduzir essas oscilações bruscas aumentando o $\Delta T$ para um número inteiro multiplicado pelos períodos de amostragem.

Ao final do capítulo 5, utilizou-se a transformada de wavelet (WT) para verificar a consistência das frequências observadas pela HHT, onde verificouse que a informação obtida pela $\mathrm{HHT}$, neste caso, apresenta uma riqueza maior de detalhes, para o método utilizado. O trabalho apresenta uma conclusão detalhada sobre os procedimentos do capítulo 5 na seção 5.7 .

O capítulo 6 repete as análises do capítulo 5 utilizando os dados do estimador de torque inserido na entrada de energia do motor elétrico com os resultados das análises utilizando a FFT, a WT e a HHT e finalmente conclui com uma comparação entre os dados obtidos a partir do dinamômetro e do estimador de torque para um mesmo modo oscilatório.

\subsection{Trabalhos futuros}

A aplicação da HHT abre um leque de pesquisa bastante amplo no que concerne aos fenômenos vibratórios associados aos sistemas aparentemente estacionários que até então eram analisados pela FFT e mais recentemente pela WT.

Dentro do escopo deste trabalho, a HHT pode ser utilizada na análise da usinagem de fresadoras com os mesmos objetivos aqui realizados. 
Outra aplicação da HHT ocorre na análise de ondas viajantes em barras longas para verificação de falhas na estrutura do material, tais como fissuras e trincas internas que pode ser utilizada na verificação da integridade dos eixos dos motores elétricos. 


\section{REFERÊNCIAS BIBLIOGRÁFICAS}

Anderson, P., Analysis of faulted power systems, The lowa State University Press, 1973

BALAN, C. The Monitoring of a Lathe Using Artificial Neural Network - part 2, SISOM 2007 and Homagial Session of the Commission of Acoustic, Bucarest 29-31 May

BARRET, P., Regimes transitoires des machines tournantes électriques,

Editions Eyrolles, 1982 Paris

BENBOUZID, M. H.; A review of induction motors signature as a medium for faults detection; IEEE Transactions on Industrial Electronics, Vol. 47, No 5, October 2000

Blaschke, F. The Principle of field orientation as opplied to the new TRANSVEKTOR closed-loop lontrol system for rotation-field machines, New York, IEEE Press, 1980.

BOSE, B. K., Power electronics and variable frequency drives, Technology and applications, IEEE Press, 1997

BROWNLEE, JASON; Clever Algorithms, First edition, Lulu 2011 (Licenced under Creative Commons)

CHEN, G., TONG, R., QIANG, B.; The Modeling and Simulation for Numerical Control Lathe's Feed System Based on MATLAB, Applied Mechanics and Material, Vol. 16-19, pp 328-333, 2009, doi:10.4028

DIMLA E. DIMLA S.; LISTER, P.M. On-line metal cutting tool condition monitoring I, Force and vibration análisis. International Journal of Machine Tools \& Manufacturing. Vol. 40, pp. 739-768, 2000.

DIMLA E., DIMLA Sr.; Sensor signals for tool-wear monitoring in metal cutting operations - a review of methods. International Journal of Machine Tools \& Manufacturing. Vol. 40, pp. 1073-1098, 2000.

DUGAN, R. C., McGranaghan, M. F., Santoso, S., Beaty, H. W., Electrical power system quality, McGraw-Hill, 2012 ISBN 978-0-07-176156-7 EBADI, A., MIRZAIE, M., GHOLAMIAN, S. A., Torque analysis of three phase induction motor under voltage unbalance using $2 \mathrm{~d}$ fem, International Jounal of Engineering Science and Technology, 3(2) 2011 
F. AL-BADOUR, F., SUNAR, M., CHEDED, L., Vibration analysis of rotating machinery using time-frequency analysis and wavelet techniques, Mechanical Systems and Signal Processing, Volume 25, Issue 5, August 2011

FAN, X., ZUO, M. J., Gearbox fault detection using Hilbert and eavelet packet transform, Mechanical Systems and Signal Processing 20 (2006)

FELDMAN, M.; Hilbert transforms applications in mechanical vibrations, Wiley, 2011.

FERRARESI. D. Fundamentos da usinagem dos materiais, São Paulo, Edgard Blücher, 1977. 751p

GEEM Z. W. (ed) Music-inspired Harmony Search algorithm, Springer Verlag Berlin, 2009

GEEM, Z. W., Recent advances in Harmony Search, Springer-Verlag Berlin, 2010

GOPI, E. S., Algorithms Collection for Digital Signal Processing Applications Using Matlab,Springer-Verlag Netherlands, 2007

GOSWAMI, J. C., CHAN A. K., Fundamentals of wavelets, John Wiley, 2011

HAHN, S. L., The Transforms and Applications Handbook, CRC Press LLC, 2000

HALSERMAN, D., LITTLEFIELD, B.; Matlab6, Prentice-Hall - São Paulo, 2003

HASSE, K. Drehzahlregelverfahren für schnelle umkehrantriebe mit Stromrichtergespeisten asynchron kurzschlußläufermotoren. Regelungs ProzessDatenverarbeitung, v. 2, p. 60-71, 1972.

HUANG, N., ATTOH-OKINE, N.; The Hilbert-Huang Transform in Engineering, Taylor \& Francis, 2005

HUANG, N.; On the Hilbert-Huang Transform Data Processing System Development, IEEE Aerospace Conference Proceedings, 2004

HUANG, X., CUI, H., WANG, Z., ZENG, Y., Mechanical fault diagnosis based on all-phase FFT parameters estimation, IEEE, ICSP2010 Proceedings

INGLE, V. K., PROAKIS, J. G.; Digital Signal Processing, Brooks/Cole Thomson, 2000

JEONG, Y.; CHO, D., Estimating cutting force from rotating and stationary feed motor currents on a milling machine, International Journal of Machine Tools and Manufacturing, 2002

JOETTEN, R; MAEDER, G., Control methods for good dynamic performance induction motor drives based on currents and voltages as measured quantities, IEEE Transactions on Industry Applications, Vol. IA 19, No 3, 1983

KAK, S. C., The discrete Hilbert transform, Procedings of IEEE, april 1970, pag. 585-586

KARANAYIL,B., RAHMAN, M. F., GRANTHAN, C.; Identification of motor parameters in industrial drives with artificial neural networks. Advances in 
Fuzzy Systems, Hindawi Publishing Corporation, Vol. 2009, pag. 10, doi:10.1155/2009/24809

KAZMIERKOWSKI, M, TUNIA, H.; Automatic Control of Conveter-Fed Drives, Elsevier, 1994

KRAUSE, P. C., WASYNCZUK, O., SUDHOFF, S. D., Analysis of Electrical Machines, IEEE Press, 1995

KUREK, A. et al; Diagnosis of induction motor using support vector machine, " $7^{\mathrm{TH}}$ International Workshop "Computational problems of electrical engineering" CPEE06, Lviv-Odessa 2006

LAUGHMAN, C., LEEB, S., NORFORD L.A, SHAW, S., ARMSTRONG, P.; Two-Step Method for Estimating the Parameters of Induction Machine Models, Mitsubishi Research Laboratories, TR2009-082, October 2009 LEE, S., HABETLER, T. G., HARLEY, R. G., GRITER, D. J., An evaluation of model-based stator resistance estimation for induction motor stator winding temperature monitoring, IEEE Transactions on Energy Conversion, Vol. 17, No. 1, March 2002

MAHDAVI, M., FESANGHARY, M., DAMANGIR, E., An Improved Harmony Search Algorithm for Solving Optimization Problems, Science Direct, Applied Mathematics and Computation, 188, 2007, pag. 1567-1579

MANNAN, M. A., BROMS, S., Monitoring and Adaptive Control of Cutting Process by Means of Motor Power and Current Measurements, Anals of CIRP, Vol. 38/1/1989, pag. 347-350

MARPLE JR. S.L, Computing the Discrete-Time Analytic Signal via FFT, IEEE Transaction on Signal Processing, VOL. 47, September 1999, pag. 26002603

MARQUES, J. R., Autocomissionamento de motores de indução sem uso de sensores eletromecânicos de velocidade, Tese de Mestrado, ITA, 2004 MEHALA, N.; Condition monitoring and fault diagnosis of induction motor using motor current signature analysis, 2010 (tese de doutorado) National Institute of Technology, Kurukshetra, India, 2010

NANGSUE, P. , PILLAY, C., CONRY, S. E.; Evolutionary Algorithms for Induction Motor Parameter Determination, IEEE Transaction on Energy Conservation, Vol. 14, No. 3, September, 1999

NEWLAND D. E.,; Mechanical vibration analysis and computation, Dover, 2006

ONG, CHEE-MUN; Dynamic simulation of electric machinery; Prentice-Hall PTR, 1998

OPPENHEIMER, A. V. \& SCHAFER, R. W., Discrete-time signal processing, Prentice Hall, 1999

PHILLIPS, C. L., PARR, J. M.;P; Signals, systems and transforms, PrenticeHall, 1999

RILLING, GABRIEL; Décompositions modales empiriques, Tese de doutorado, Université de Lyon, 2007 
ROY, N., PURKAIT, P., BHATTACHRYA, K., Application of wavelet and Fourier Transforms for vibration analysis of motor, IEEE Indcon 2005 COnference, Chennai, India, 11-13 Dec. 2005

Rucka, M., Damage detection in beams using wavelet transform on higher vibration modes, Journal of theorical and applied mechanics, 49, 2, pp. 399417, Warsaw 2011

SCHAUDER, C., Adaptive speed identification for vector control of induction motor without rotational transducers, IEEE Transactions on Industry Applications, Vol. IA 28, No 5, 1992

SEN, PARESH; Thyristor DC machines, John Wiley, 1981

Shin, H., Choi, J. Park H. Jang, S.; Vibration analysis and measurements through prediction of eletromagnetic vibration sources of permanent magnetic synchronous motor based on analytical magnetic field calculation, IEEE Transactions on Magnetics, Vol. 48, No. 11, November 2012

SILVA, de C. W., Vibration monitoring, testing and instrumentation, Taylor \& Francis, 2007

SLEMON, G. R.; STRAUGHEN, A. Eletric machines, Addison-Wesley Publishing Company, 1980

SOUZA, L., Avaliação dos efeitos dos parâmetros de usinagem e dos tratamentos térmicos no torneamento de três aços inoxidáveis autenísticos, 2006, Dissertação (Mestrado) - Escola Politécnica, Universidade de São Paulo, São Paulo, 2006

STEMMER, C. E., Ferramentas de corte I, Editora da UFSC, 2007

STRAFFORD, K. N. Indirect monitoring of machinability in carbon steels by measurement of cutting forces. Journal of Materials Processing Technology. V. 67. pp. 150-156, 1997.

THOMSON, D. RANKIN; DORREL, D. G., Online current monitoring to diagnose air-gap eccentricity in large three-phase induction motor industrial case histories verify predictions, IEEE Transactions on Energy Conservation, Vol. 14. No. 4 pp1372-1378, Dec 1999

TODORAN ET ALL, Discrete Hilbert transform numeric algorithms, Acta Eletrotehnica, pag. 485-490 Mediamira Science Publisher, 2009

TRZYNADLOWSKI, A. M., The field orientation principle in control of induction motor, Kluwer Academic Publishers, 1994

VAS, PETER, Parameter estimation condition monitoring, and diagnosis of electrical machine, Claredon Press, - Oxford 1993

WEIDONG, L.; MEHEFSKE C.; Detection of induction motor faults, Jounal of Vibrations and Control, February 2006, vol 12 No 2 165-188 doi: 10.1177/1077546306062097

YANG, B., Stress, strain, and structural dynamics, Elsevier Academic Press, 2005 
Apêndice A

Módulos, fases e frequências instantâneas obtidas a partir das funções analíticas das IMFs dos testes com estimador de torque.

Maquina ferramenta operando em vazio (tracionando o carro principal)

A1-Fases do sinal analítico em vazio

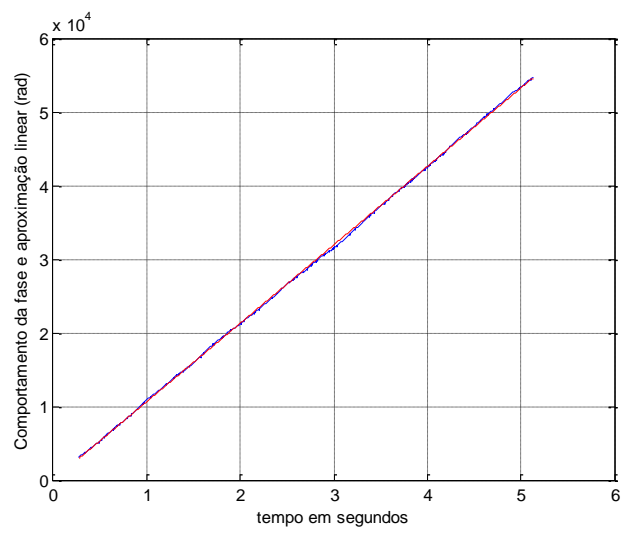

(Fase-vazio-IMF0,0-1)

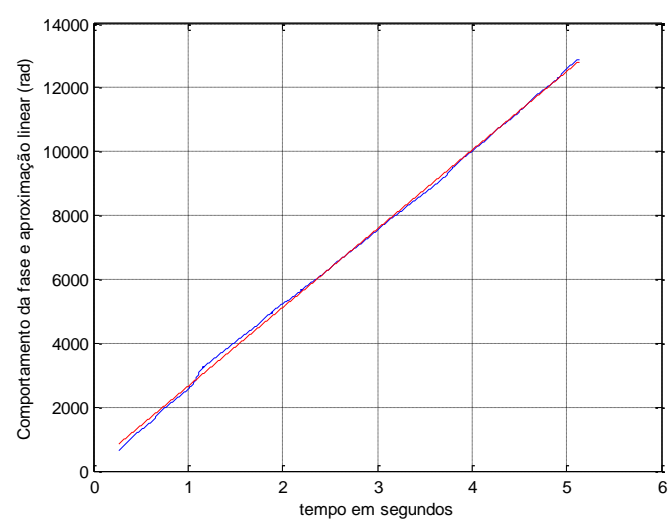

(Fase-vazio-Imf-3)

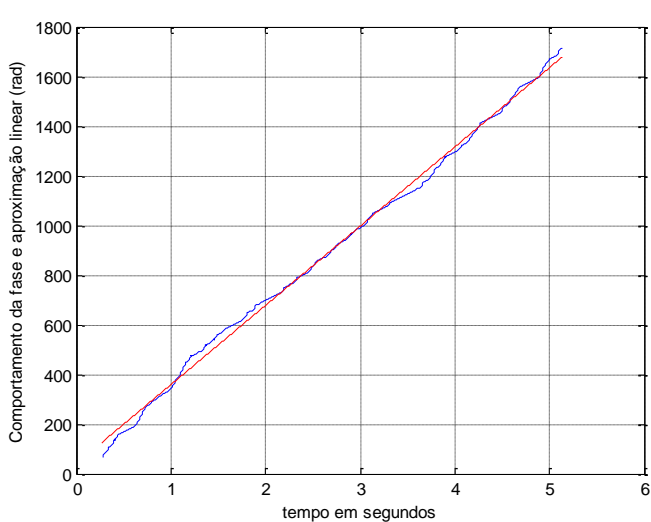

(Fase-vazio- Imf-5)

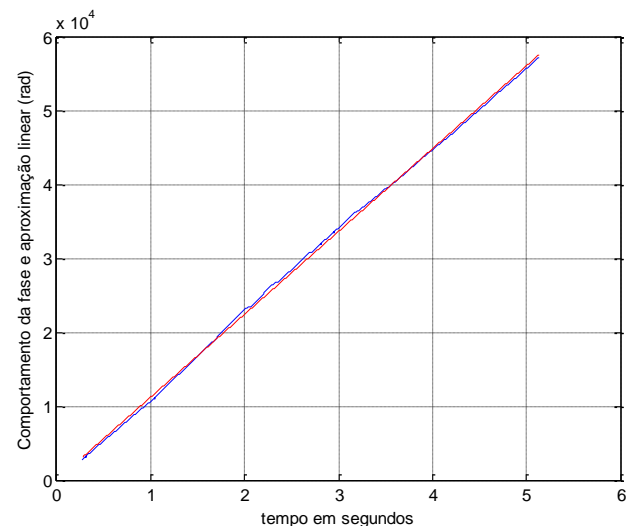

(Fase- vazio- Imf-2)

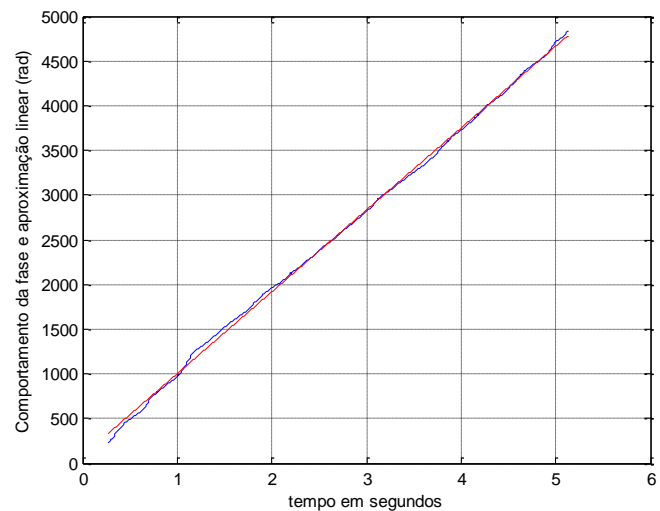

(Fase -vazio- Imf-4)

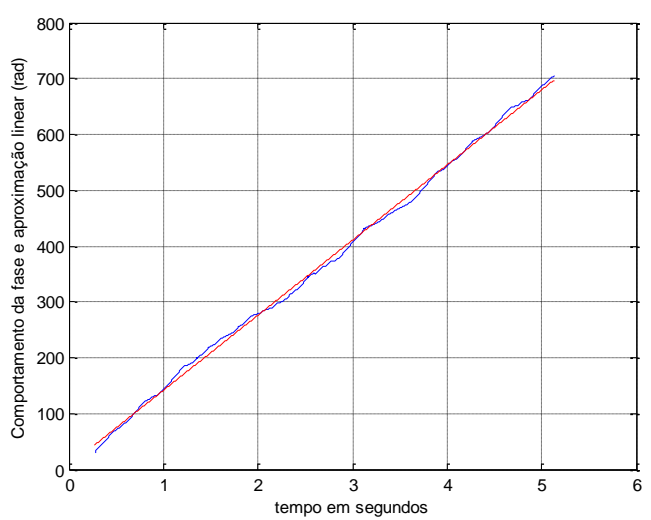

(Fase-vazio-Imf-6) 


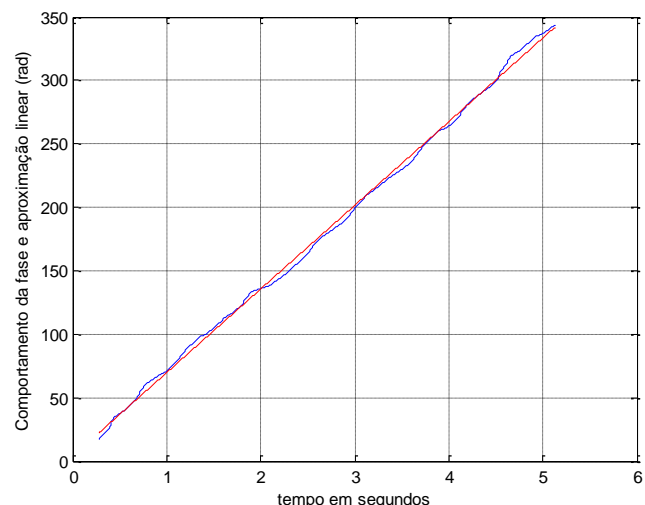

(Fase-vazio- Imf-7)

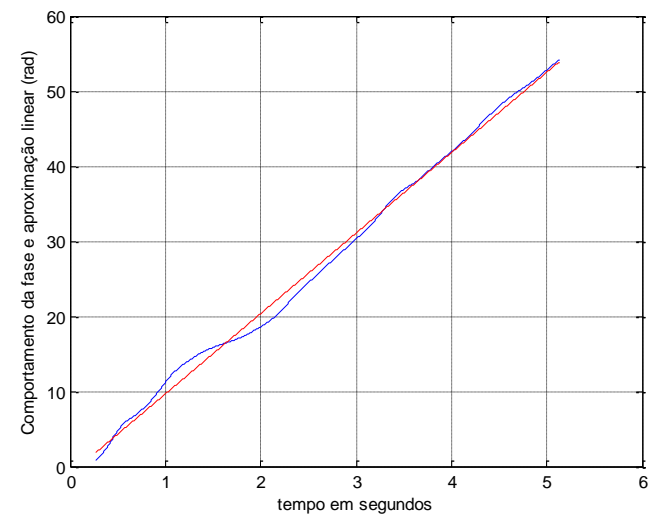

(Fase-vazio-Imf-9)

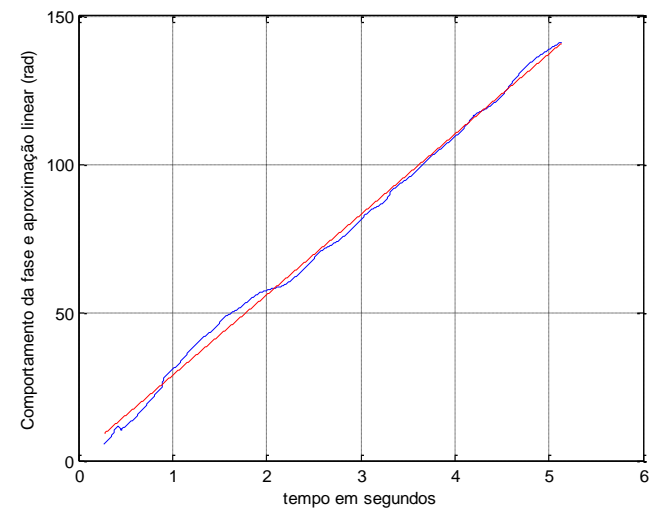

(Fase-vazio-Imf-8)

\section{A2-Frequências do sinal analítico em vazio}

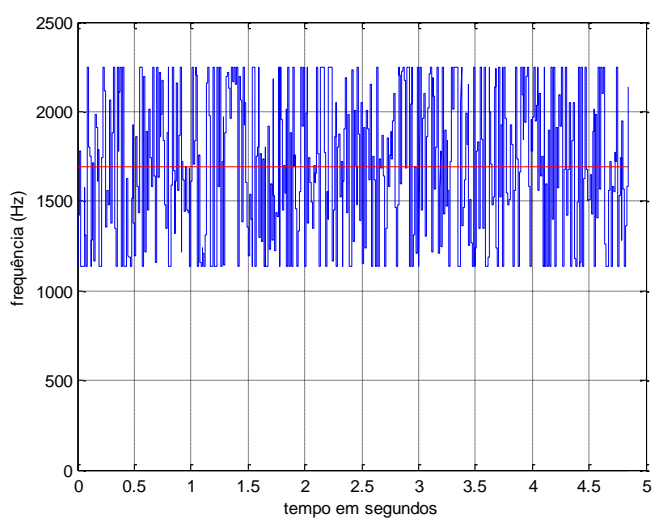

(Frequência-vazio-IMF-1)

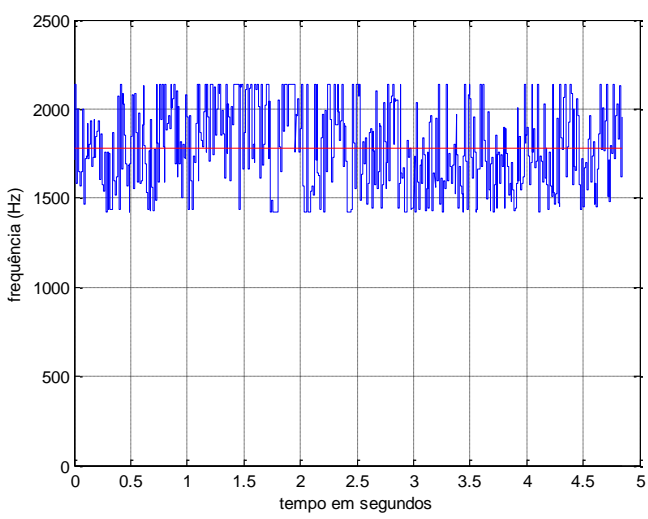

(Frequência-vazio-IMF-2) 


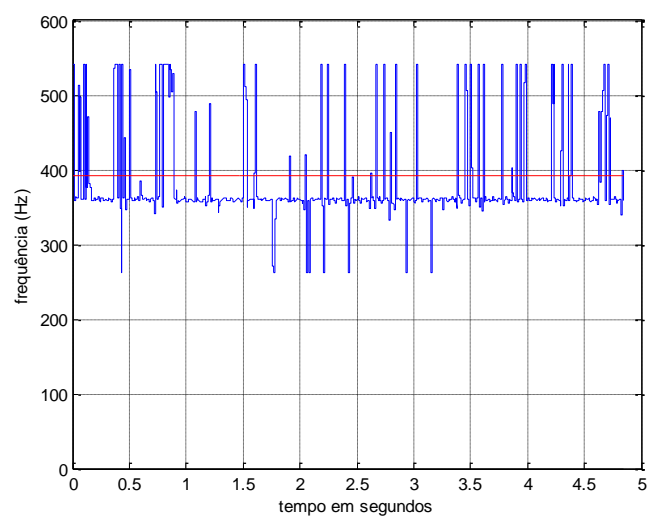

(Frequência-vazio-IMF-3)

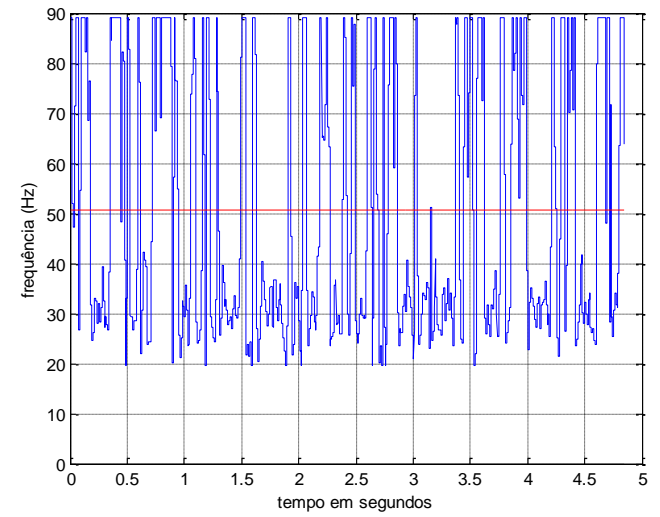

(Frequência-vazio-IMF-5)

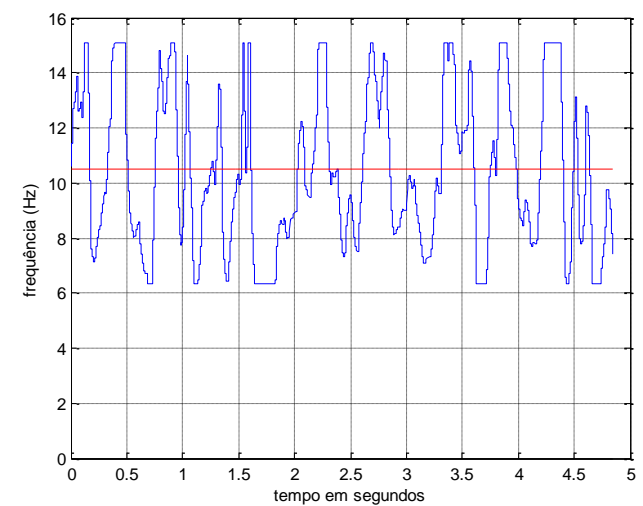

(Frequênciacia-vazio-IMF-7)

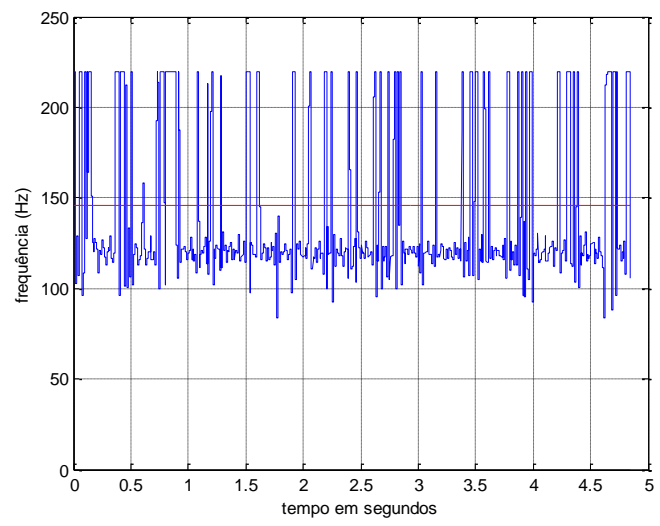

(Frequência-vazio-IMF-4)

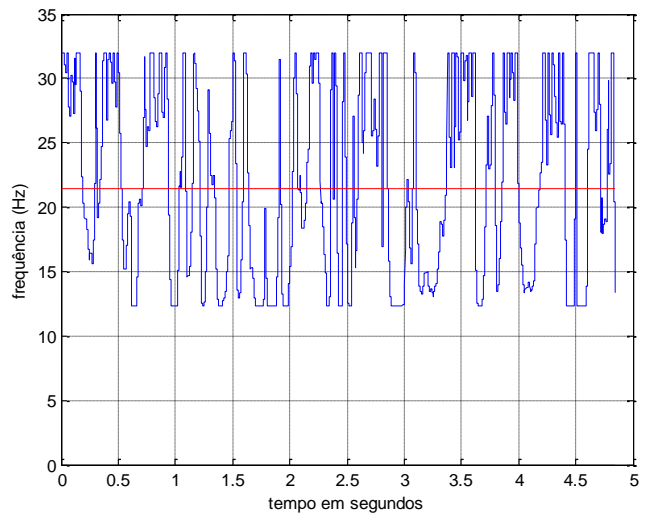

(Frequência-vazio-IMF-6)

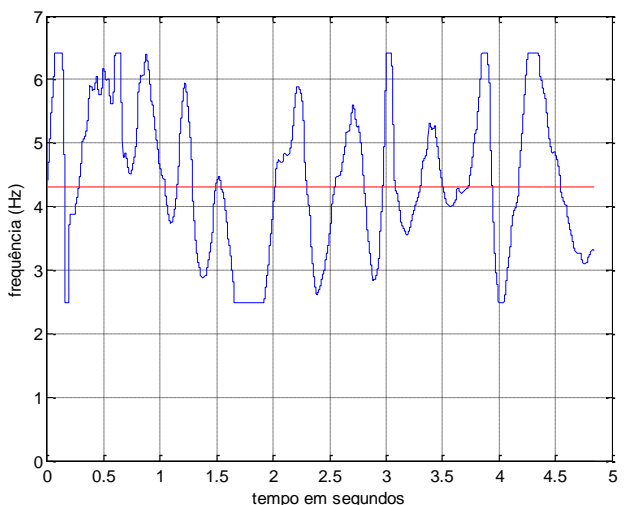

(Frequência-vazio-IMF-8) 


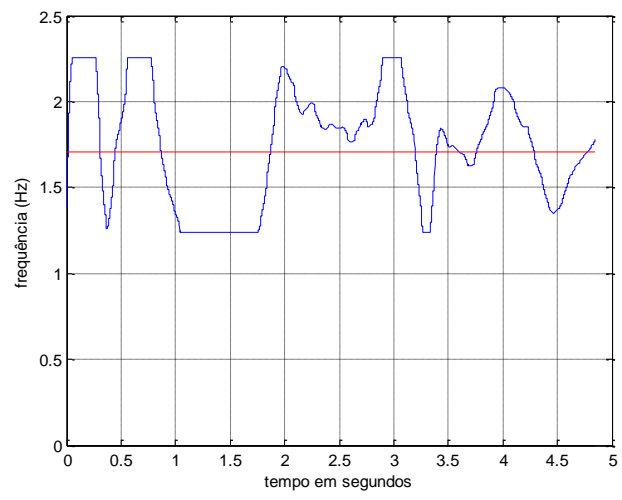

(Frequência-vazio-IMF-9)

\section{A3-Módulos do sinal analítico em vazio}

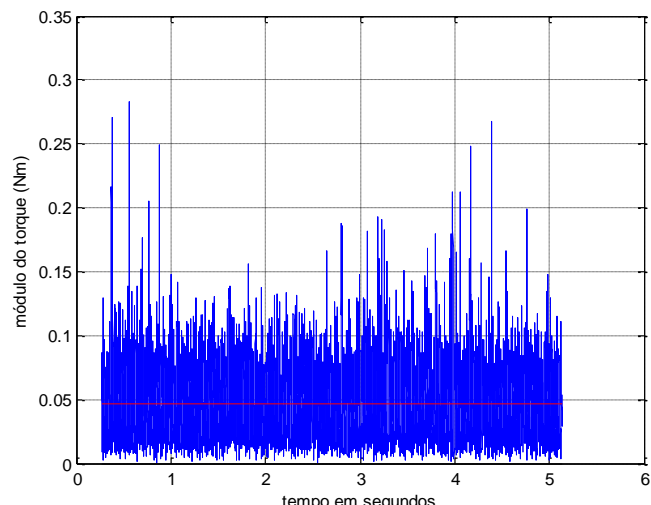

(Módulo-vazio-IMF-1)

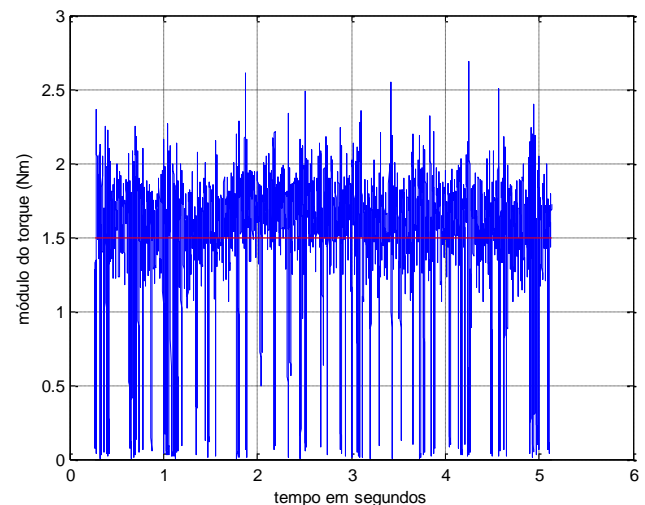

(Módulo-vazio-IMF-3)

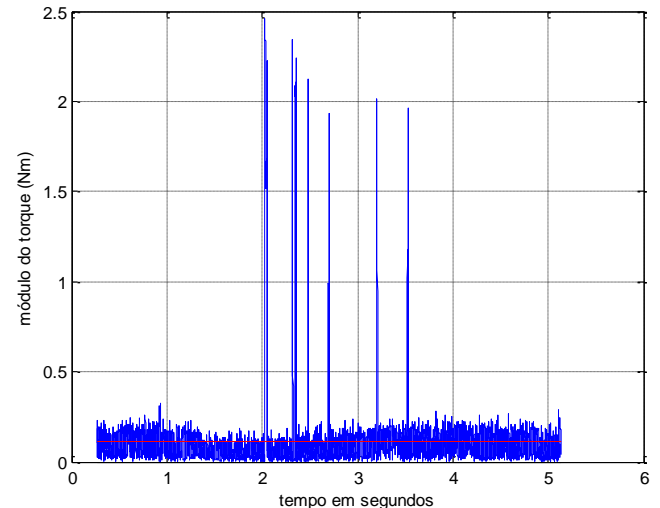

(Módulo-vazio-IMF-2)

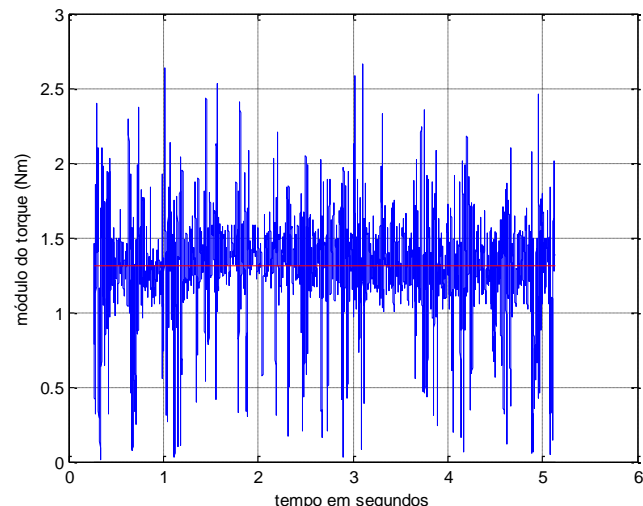

(Módulo-vazio-IMF-4) 


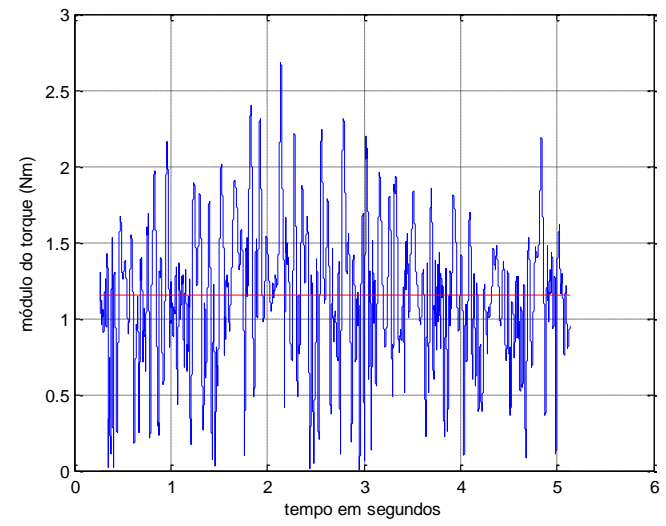

(Módulo-vazio-IMF-5)

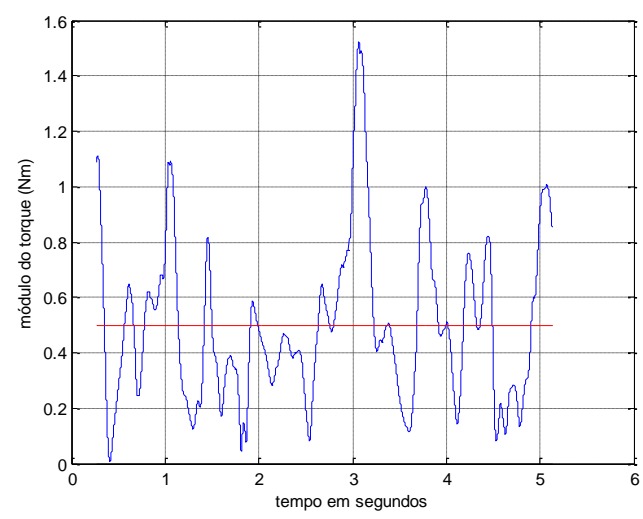

(Módulo-vazio-IMF-7)

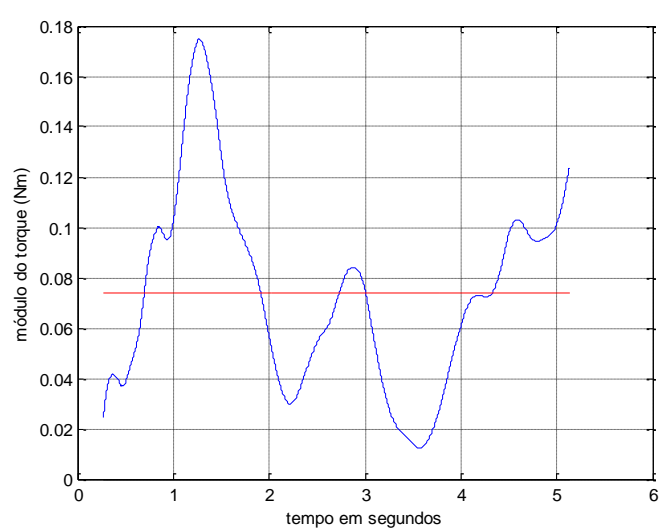

(Módulo-vazio-IMF-9)

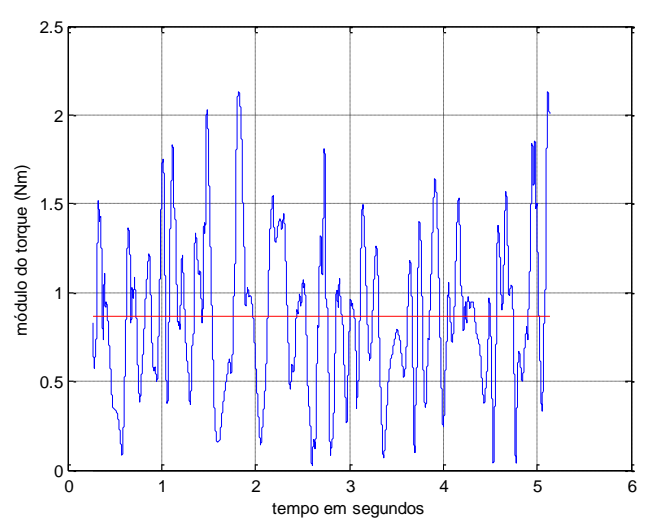

(Módulo-vazio-IMF-6)

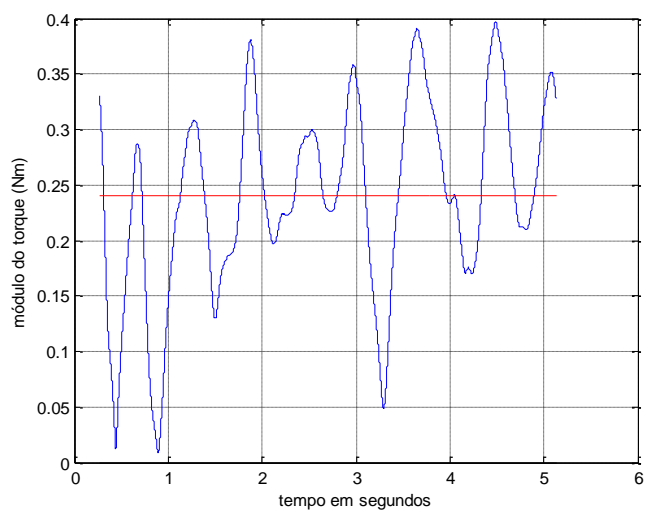

(Módulo-vazio-IMF-8) 


\section{A4- Fases sinal analítico da UCP de 0,5}

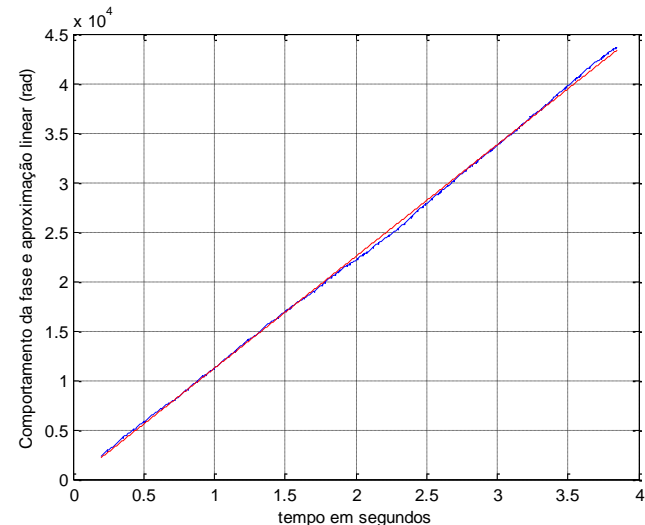

(fase-IMF0,5mm-1)

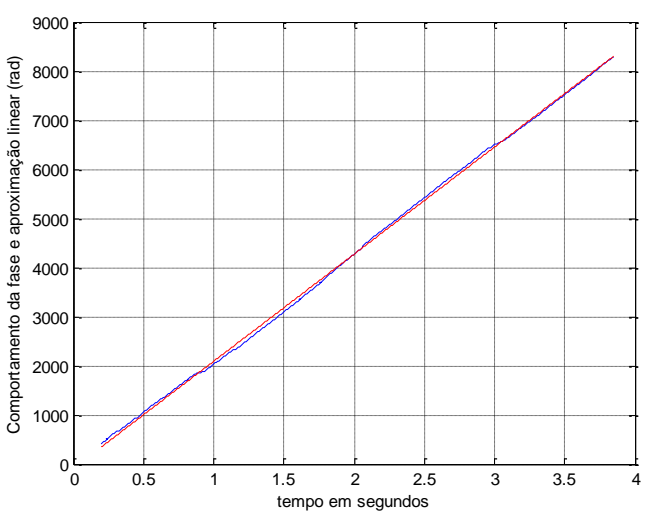

(fase-IMF0,5mm-3)

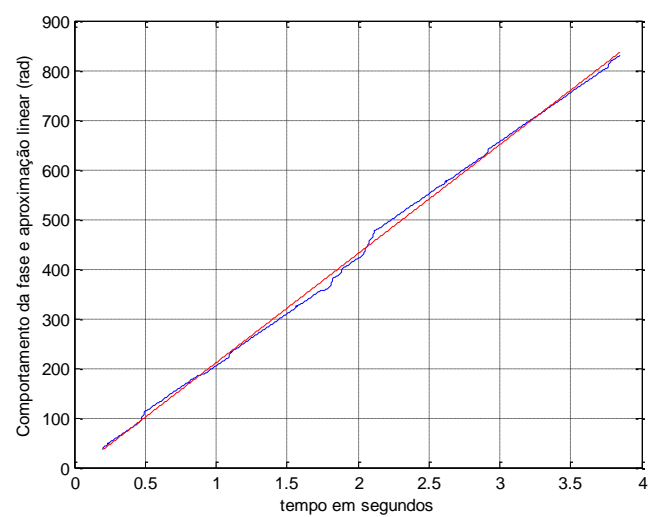

(fase-IMF0,5mm-5)

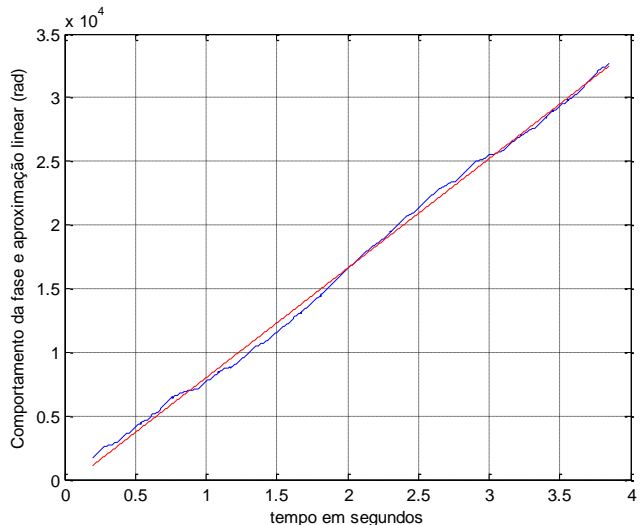

(fase-IMF0,5mm-2)

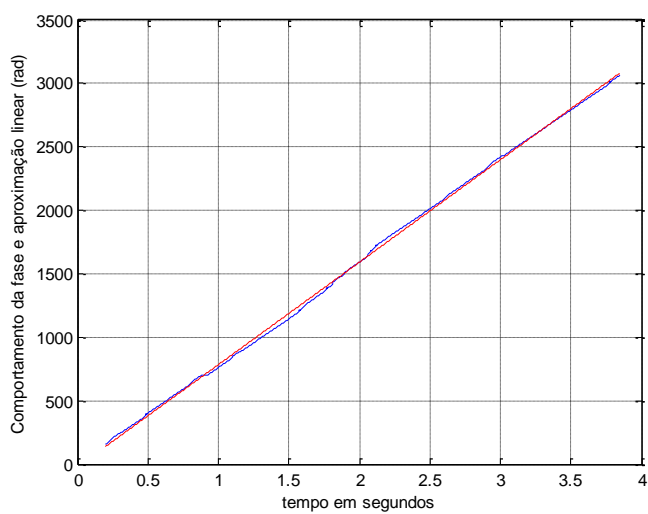

(fase-IMF0,5mm-4)

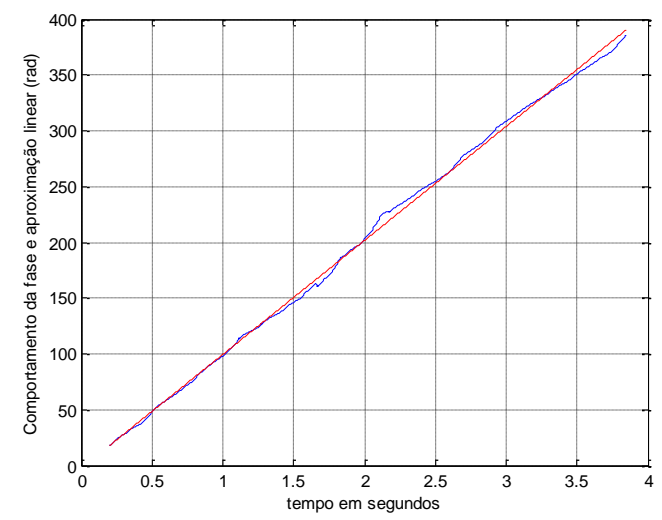

(fase-IMF0,5mm-6) 


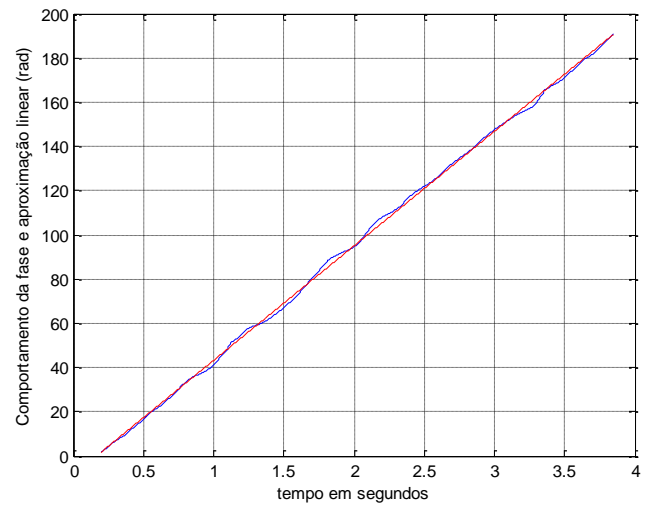

(fase-IMF0,5mm-7)

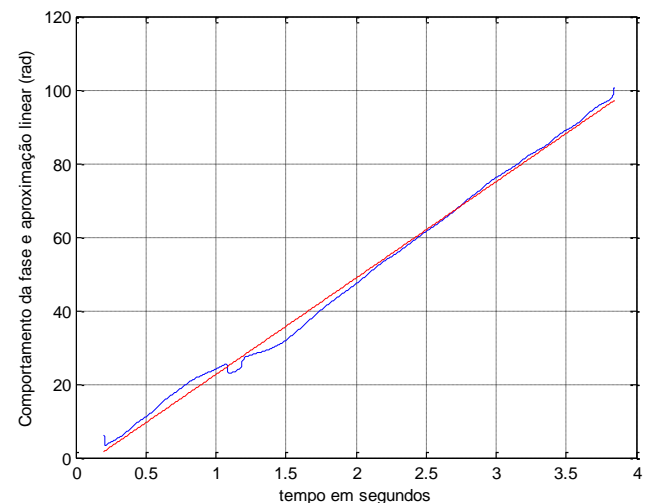

(fase-IMF0,5mm-8)

\section{A5-Frequências do sinal analítico da UCP de 0,5mm}

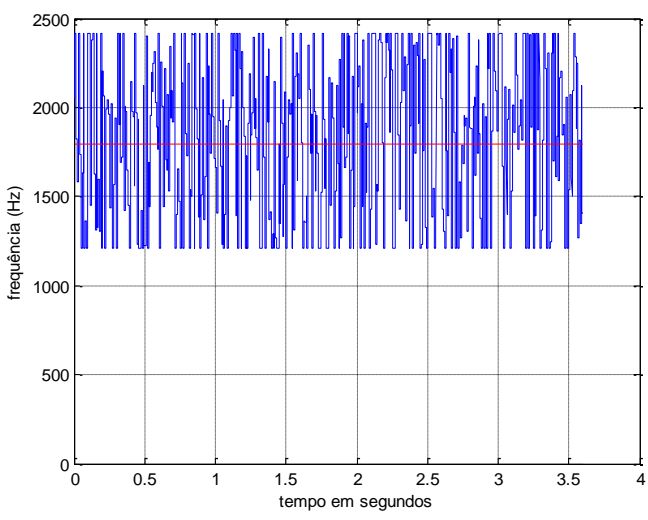

(frequência-IMF0,5mm-1)

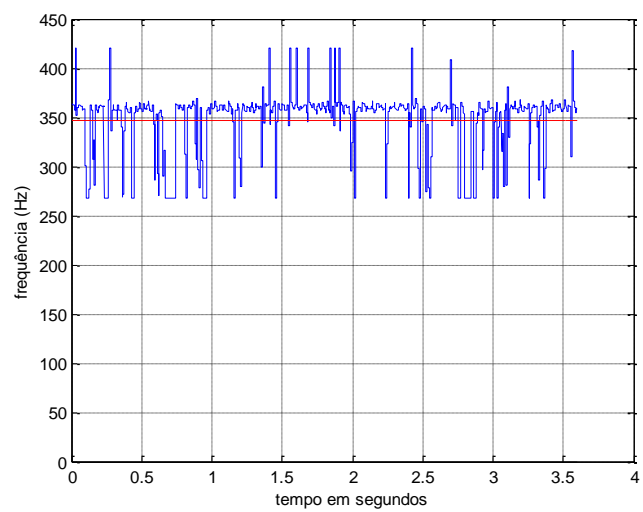

(frequência-IMF0,5mm-3)

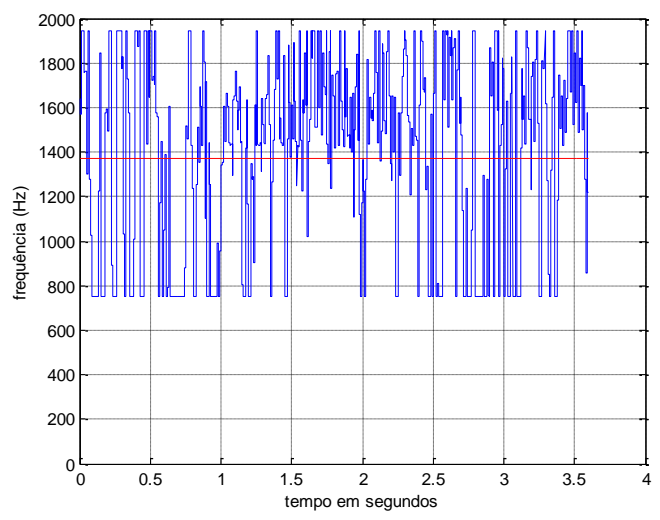

(frequência-IMF0,5mm-2)

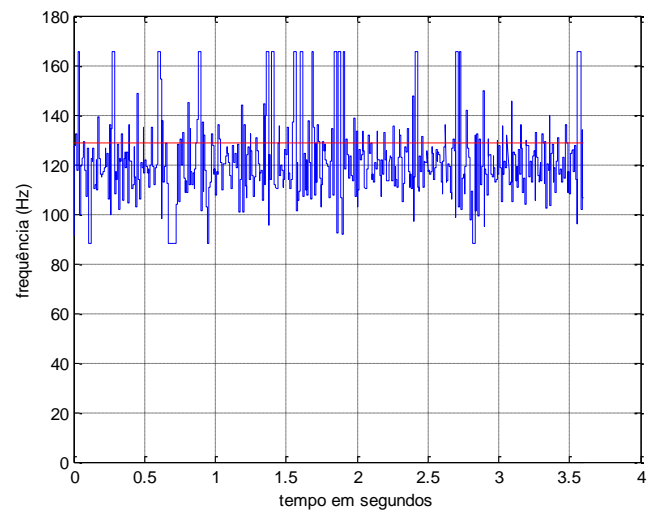

(frequência-IMF0,5mm-4) 


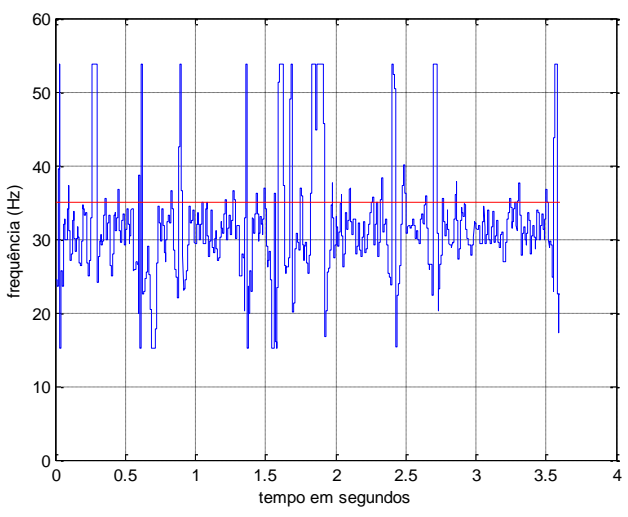

(frequência-IMF0,5mm-5)

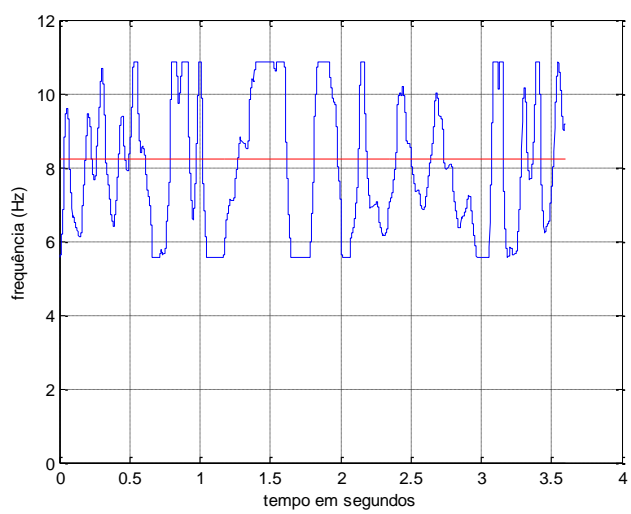

(frequência-IMF0,5mm-7)

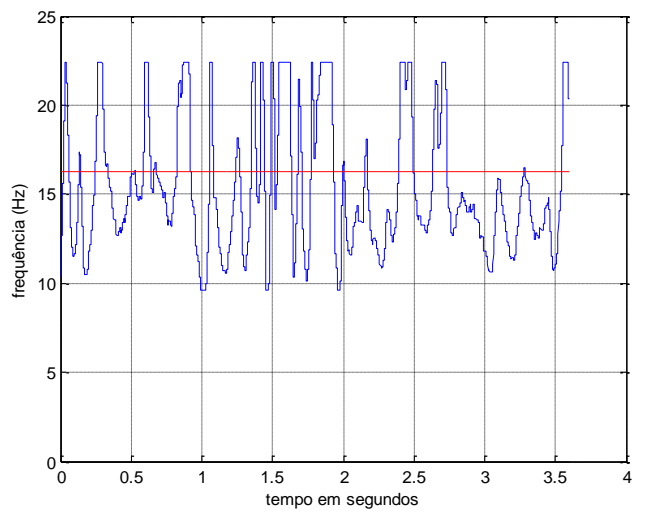

(frequência-IMF0,5mm-6)

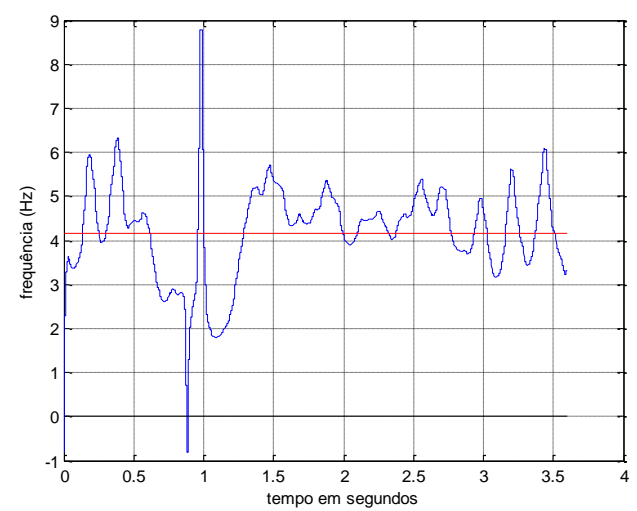

(frequência-IMF0,5mm-8)

\section{A6- Módulos do sinal analítico com UCP de 0,5mm}

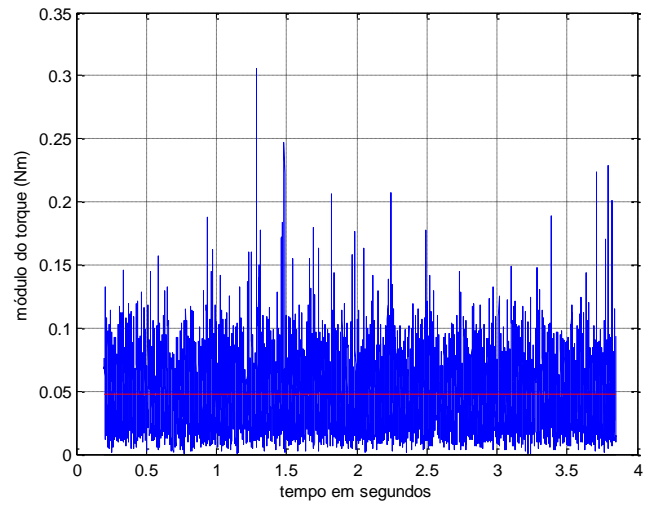

(módulo-IMF0,5mm-1)

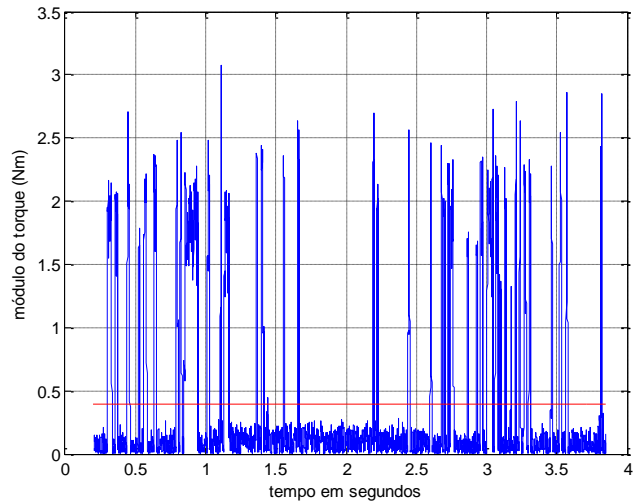

(módulo-IMF0,5mm-2) 


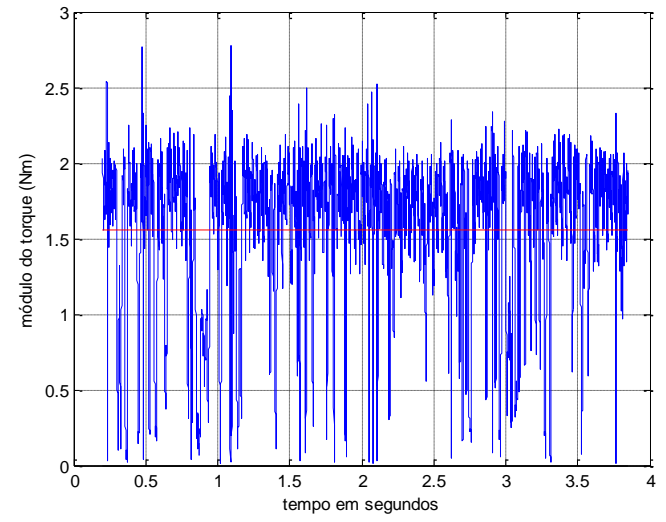

(módulo-IMF0,5mm-3)

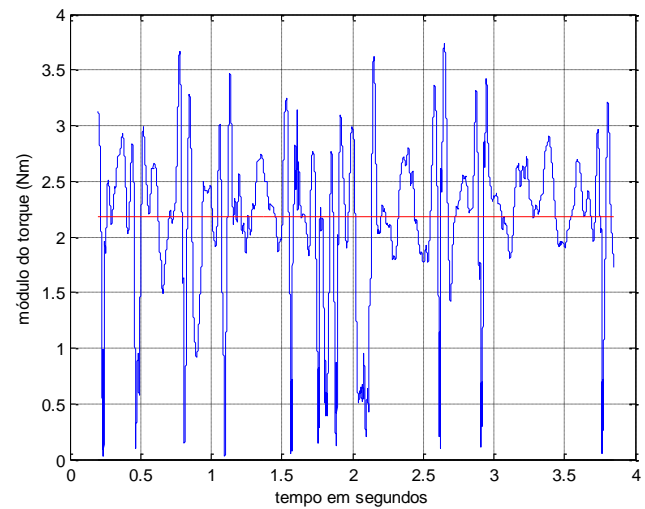

(módulo-IMF0,5mm-5)

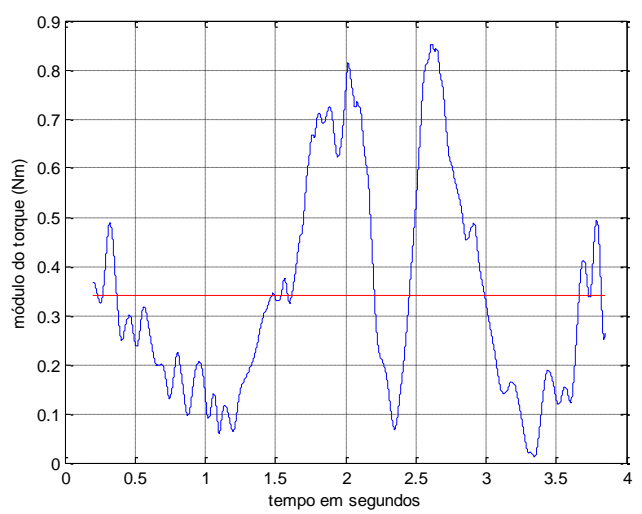

(módulo-IMF0,5mm-7)

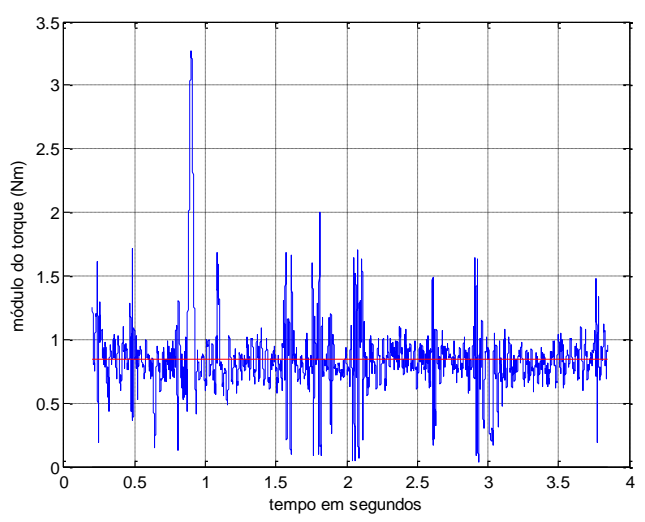

(módulo-IMF0,5mm-4)

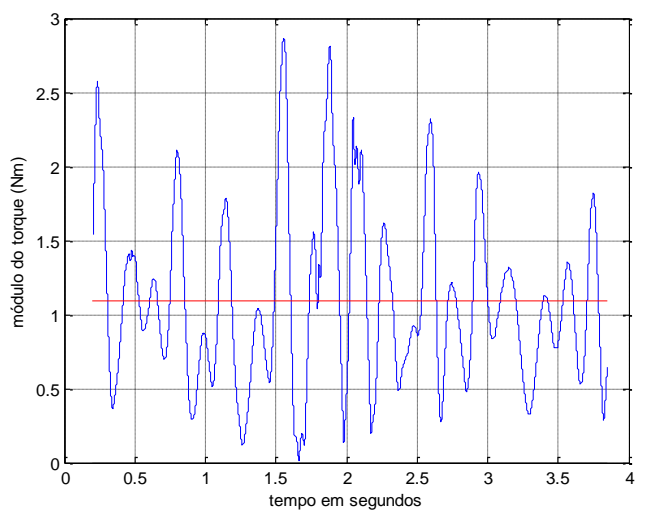

(módulo-IMF0,5mm-6)

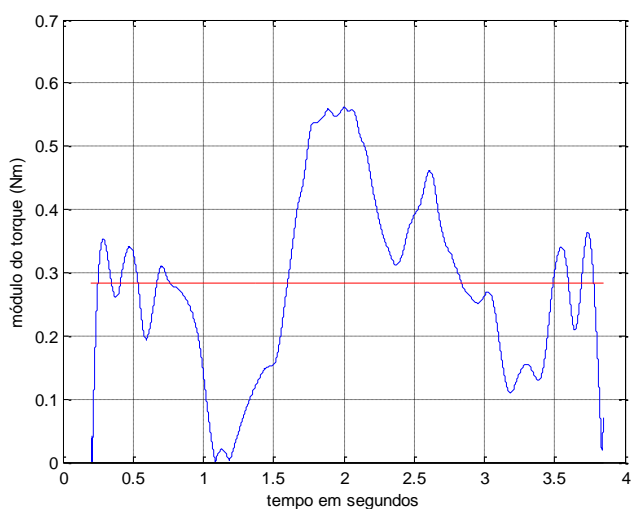

(módulo-IMF0,5mm-8) 


\section{A7- Fases do sinal analítico com UCP de 1,0mm}

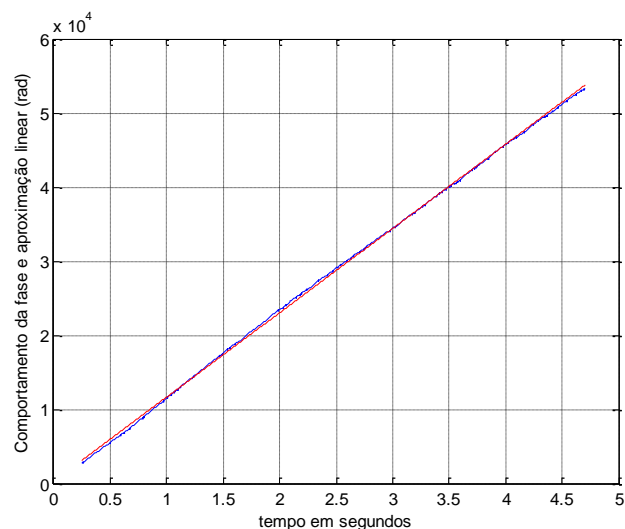

(fase-IMF1,0mm-1)

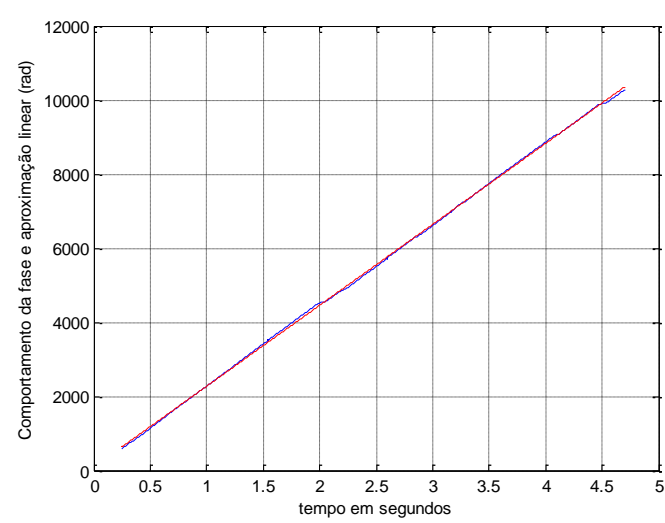

(fase-IMF1,0mm-3)

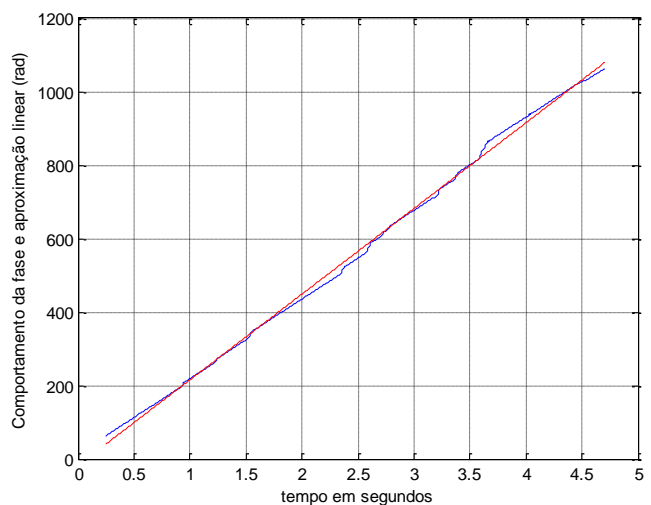

(fase-IMF1,0mm-5)

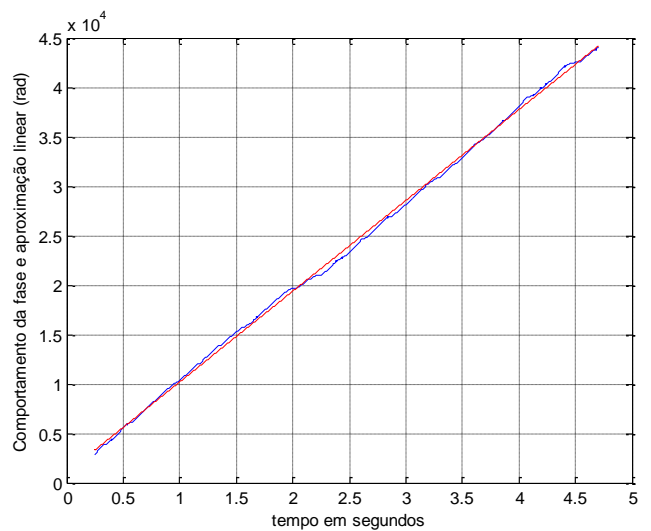

(fase-IMF1,0mm-2)

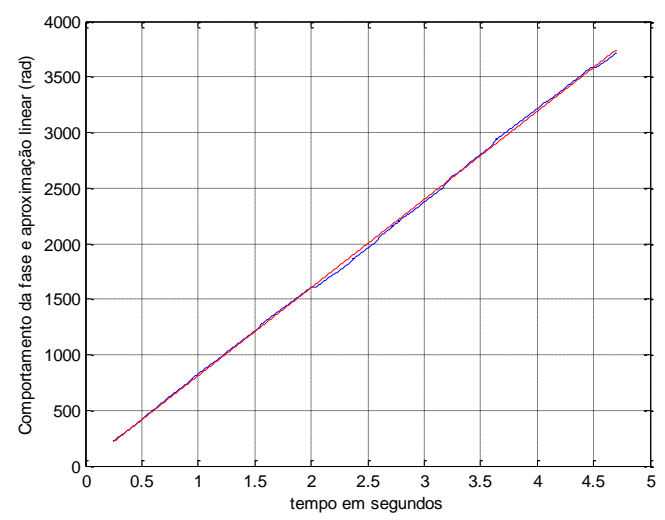

(fase-IMF1,0mm-4)

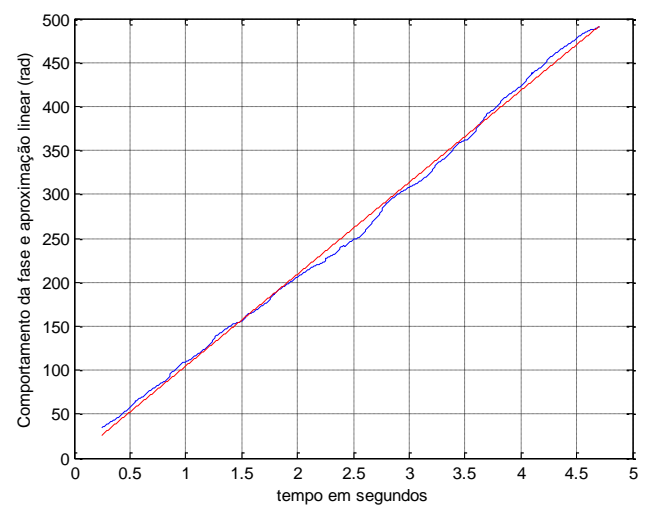

(fase-IMF1,0mm-6) 


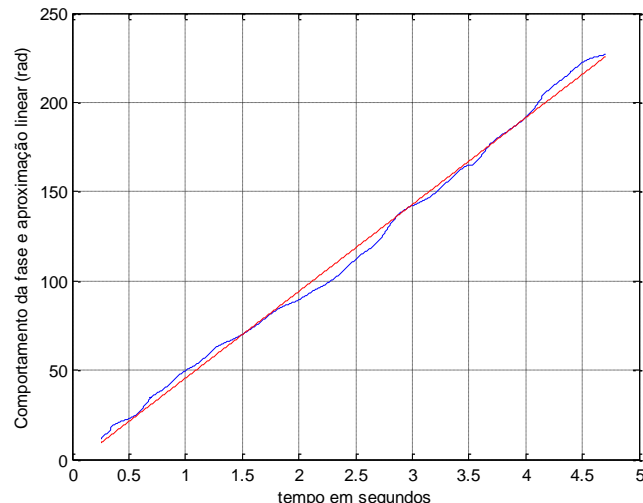

(fase-IMF1,0mm-7)

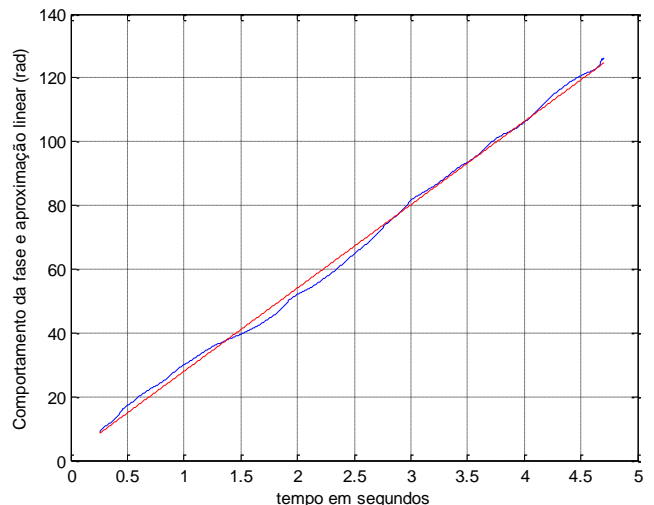

(fase-IMF1,0mm-8)

\section{A8- Frequências sinal analítico com UCP de 1,0mm}

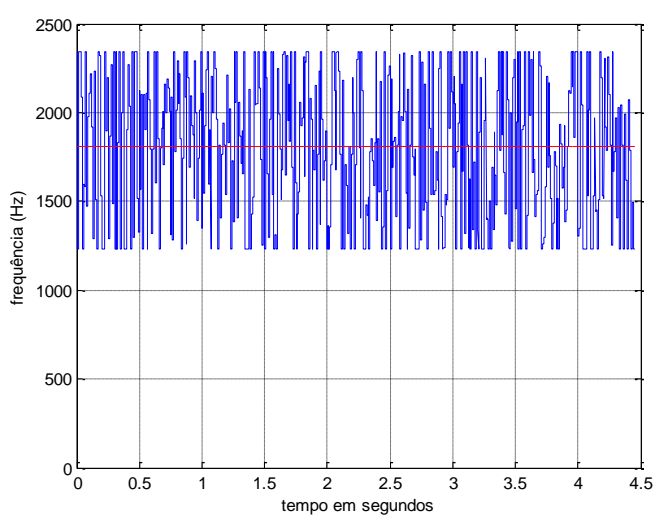

(frequência-IMF1,0mm-1)

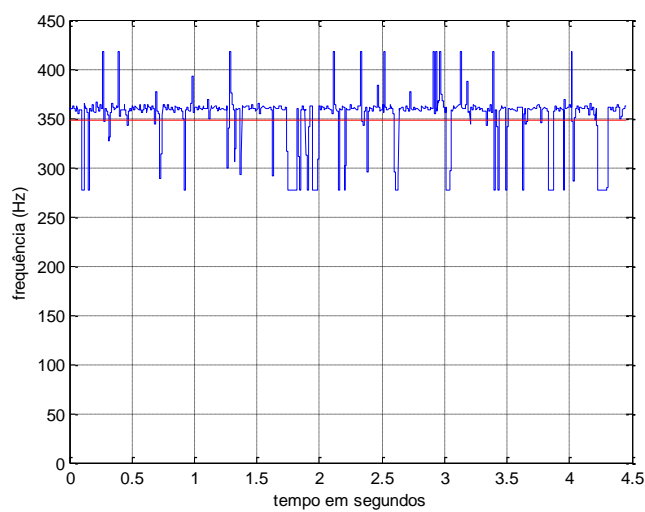

(frequência-IMF1,0mm-3)

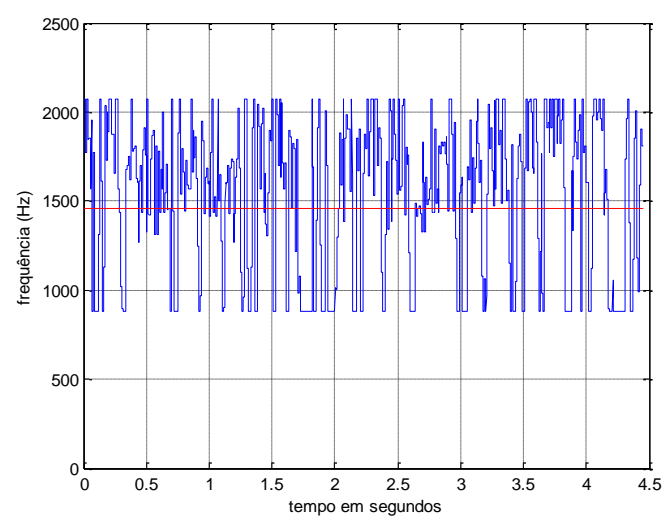

(frequência-IMF1,0mm-2)

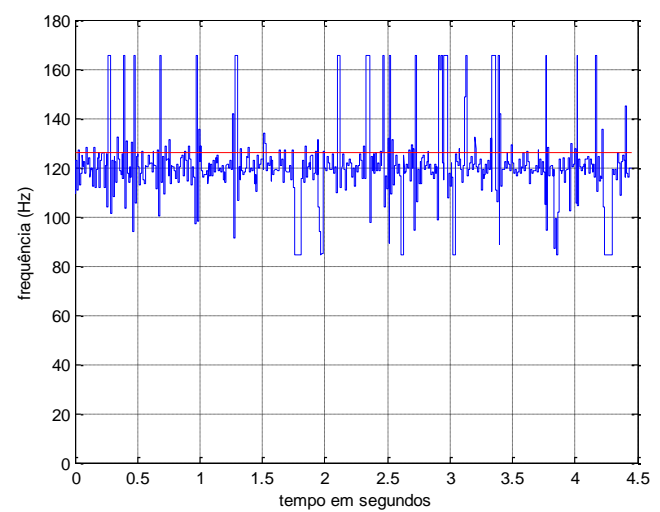

(frequência-IMF1,0mm-4) 


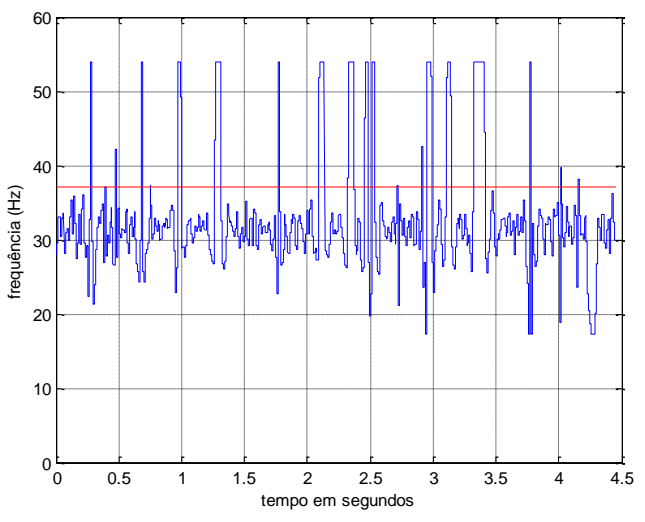

(frequência-IMF1,0mm-5)

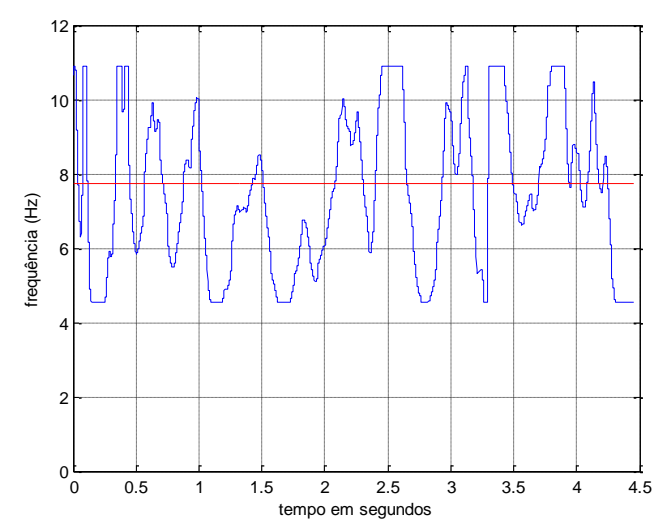

(frequência-IMF1,0mm-7)

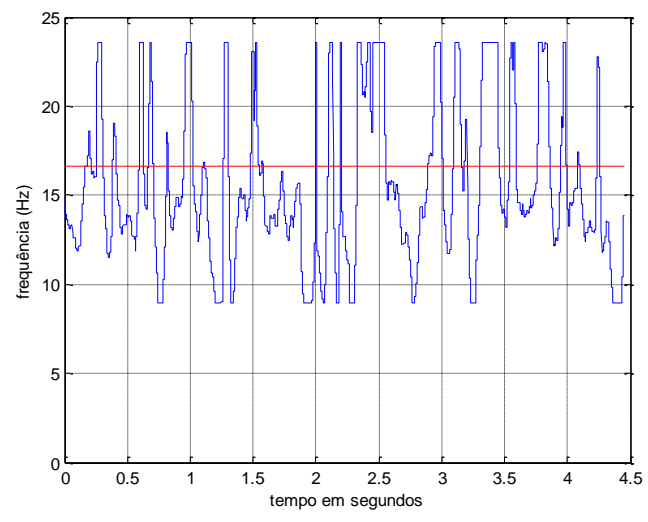

(frequência-IMF1,0mm-6)

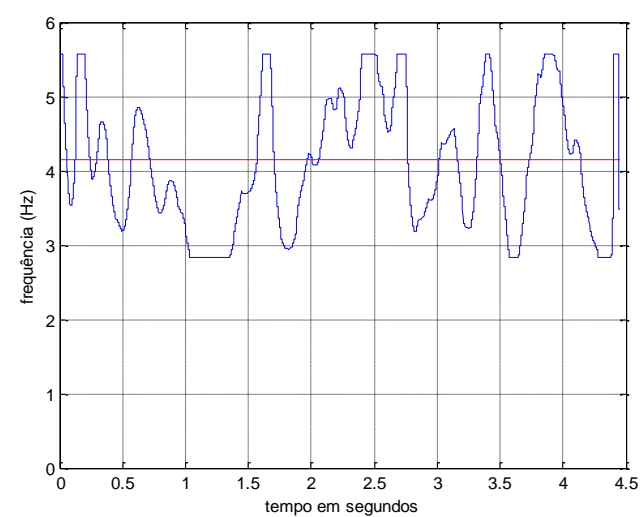

(frequência-IMF1,0mm-8)

\section{A9- Módulos do sinal analítico com UCP de 1,0mm}

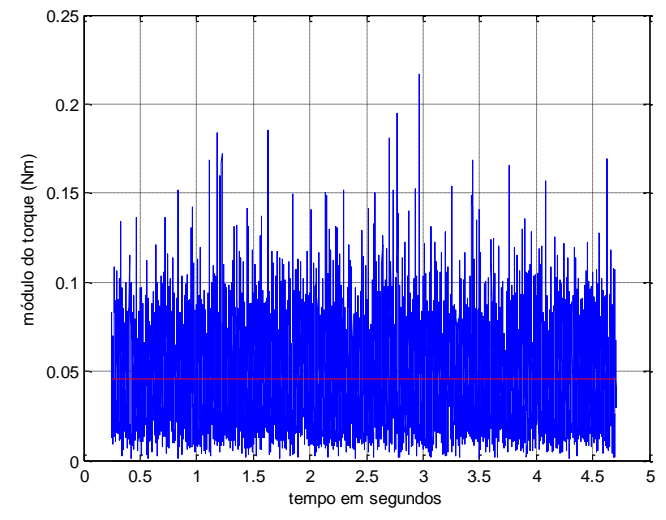

(módulo-IMF1,0mm-1)

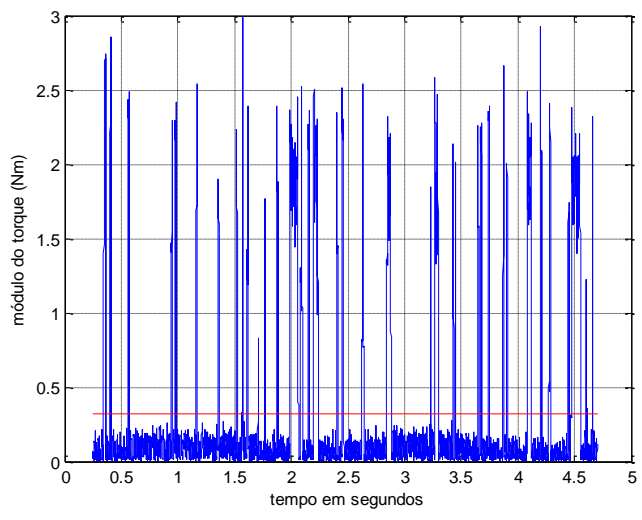

(módulo-IMF1,0mm-2) 


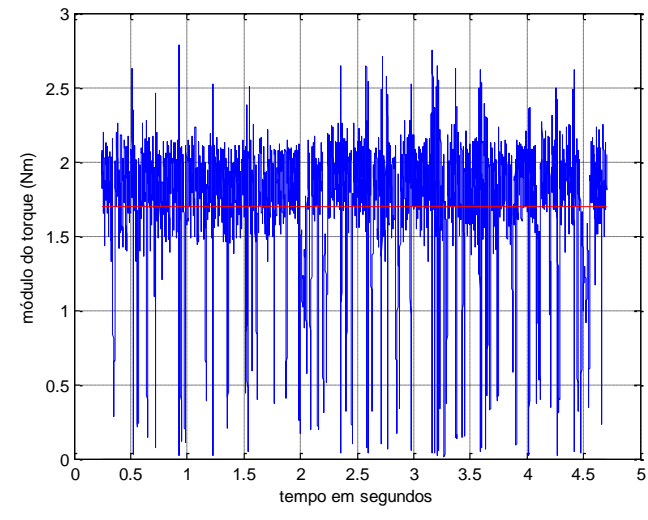

(módulo-IMF1,0mm-3)

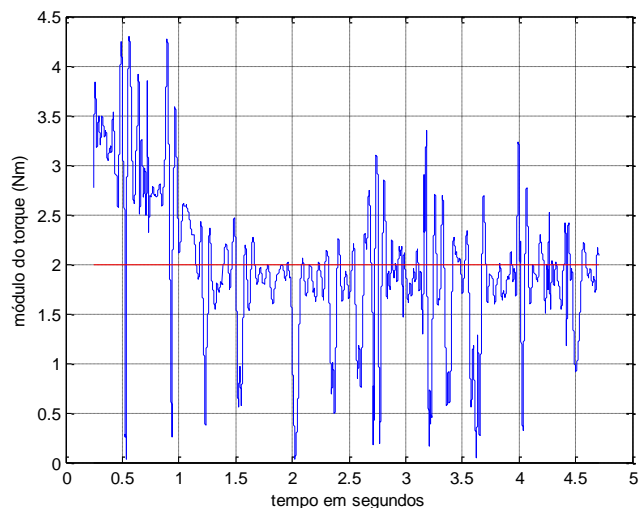

(módulo-IMF1,0mm-5)

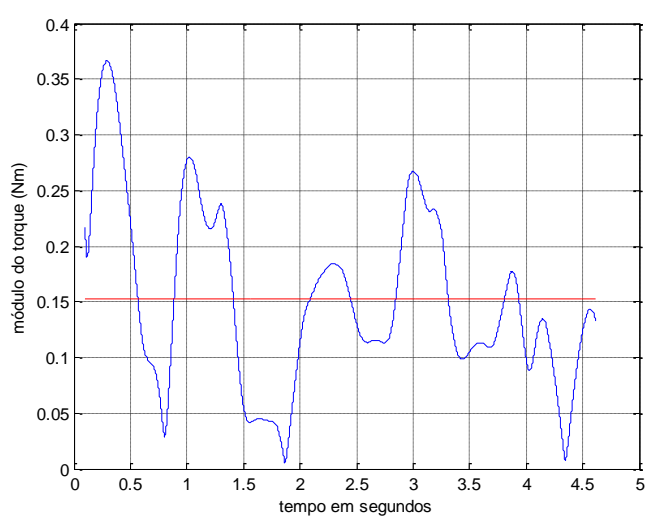

(módulo-IMF1,0mm-7)

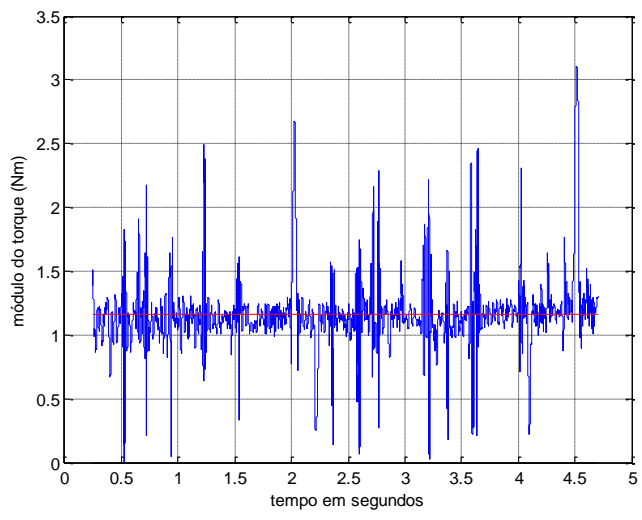

(módulo-IMF1,0mm-4)

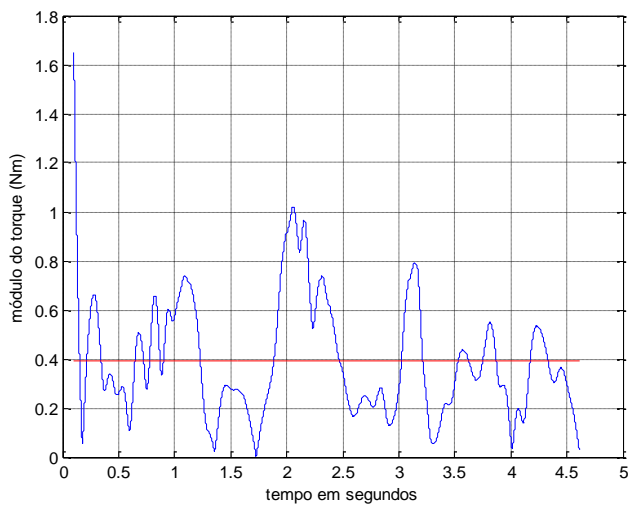

(módulo-IMF1,0mm-6)

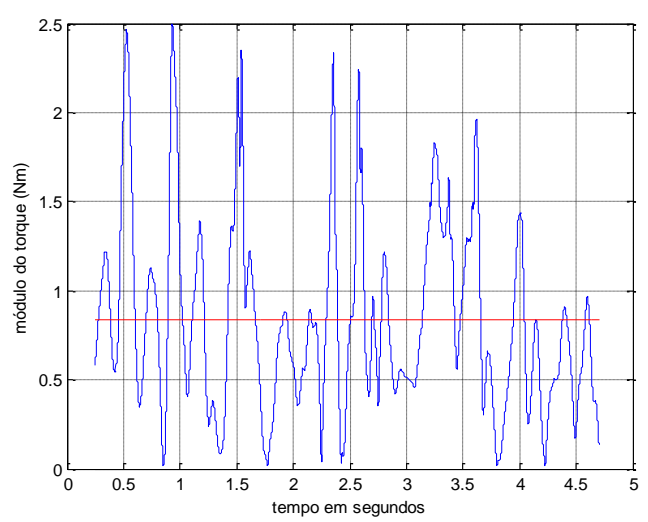

(módulo-IMF1,0mm-8) 


\section{A10- Fases do sinal analítico com UCP de 1,5mm}

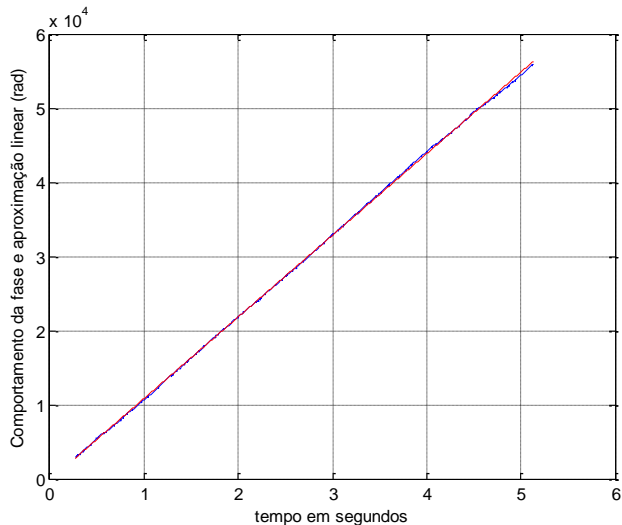

(fase-IMF1,5mm-1)

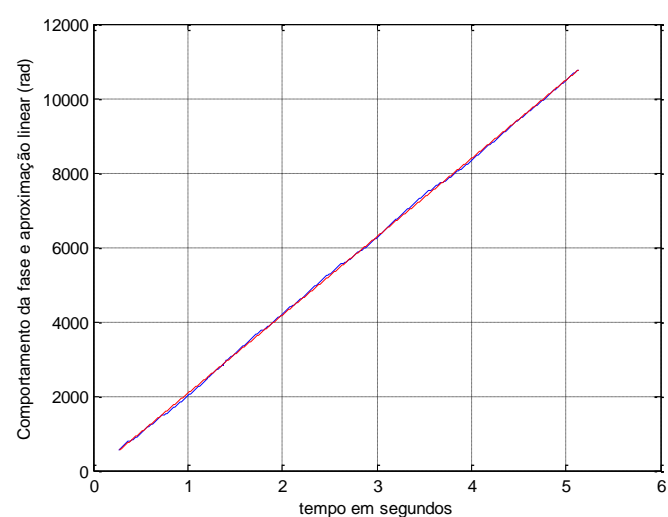

(fase-IMF1,5mm-3)

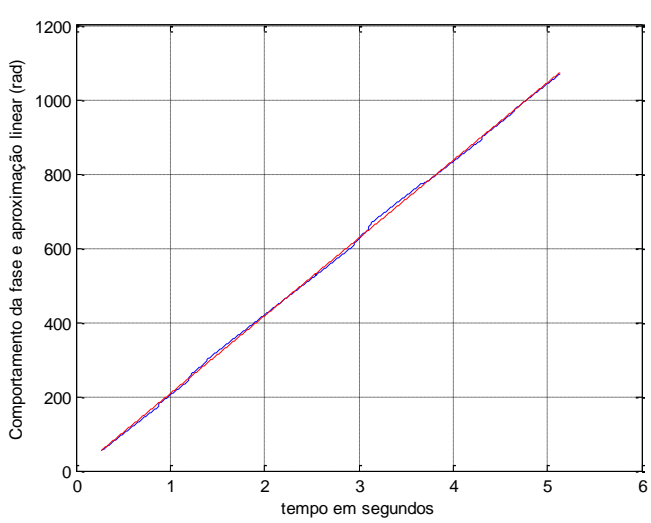

(fase-IMF1,5mm-5)

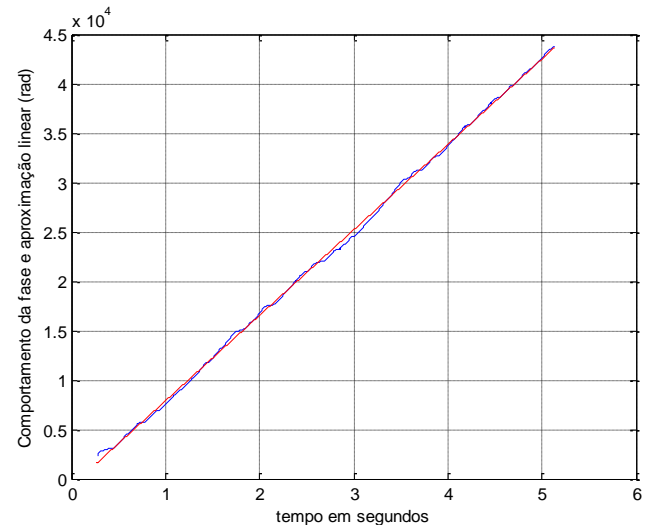

(fase-IMF1,5mm-2)

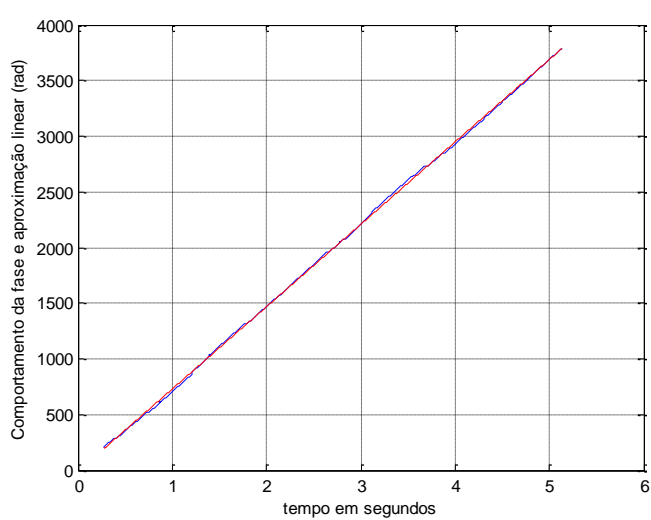

(fase-IMF1,5mm-4)

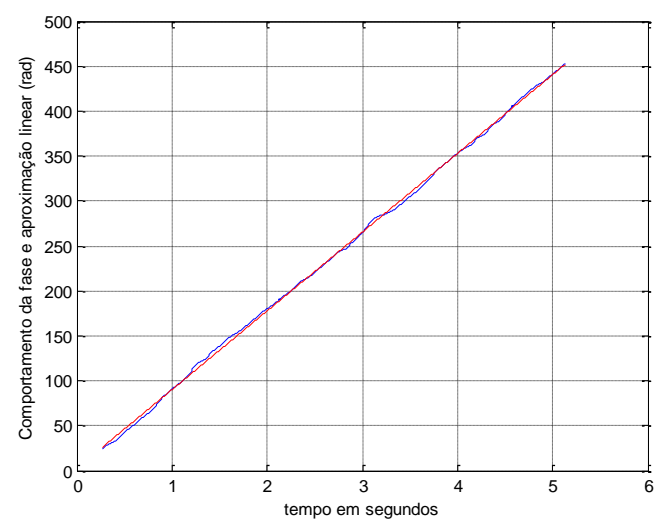

(fase-IMF1,5mm-6) 


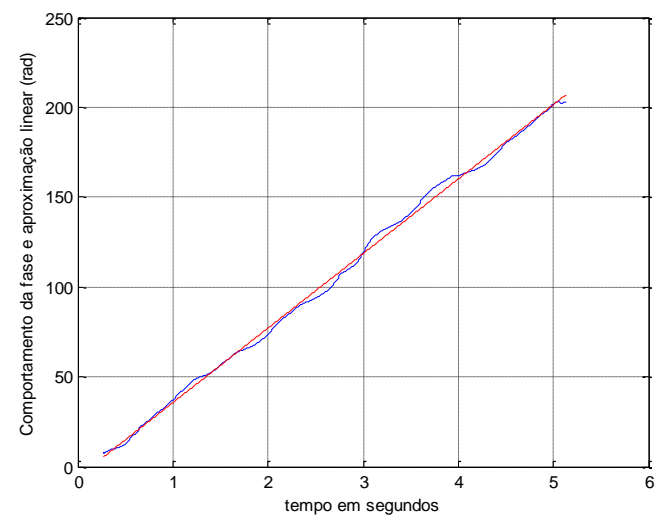

(fase-IMF1,5mm-7)

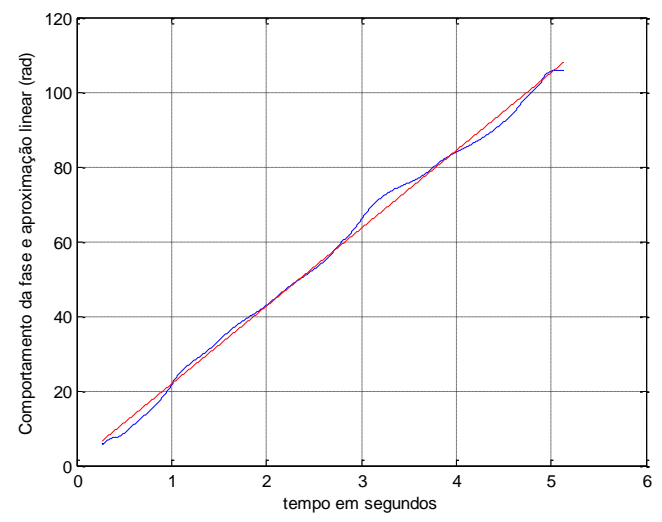

(fase-IMF1,5mm-8)

\section{A11- Frequências do sinal analítico com UCP de 1,5mm}

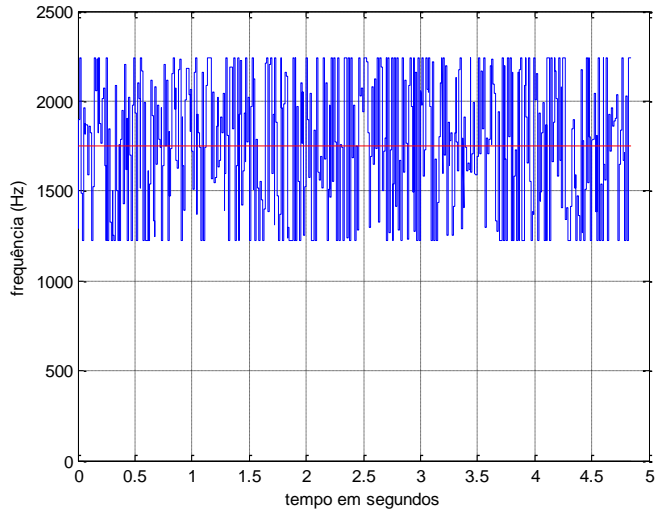

(frequência-IMF1,5mm-1)

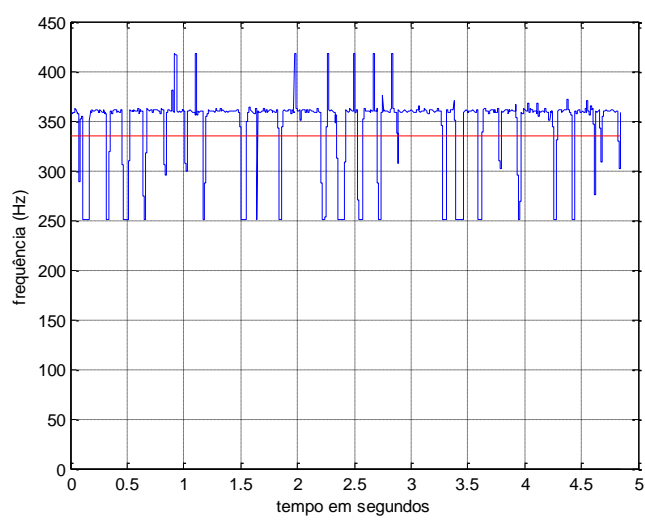

(frequência-IMF1,5mm-3)

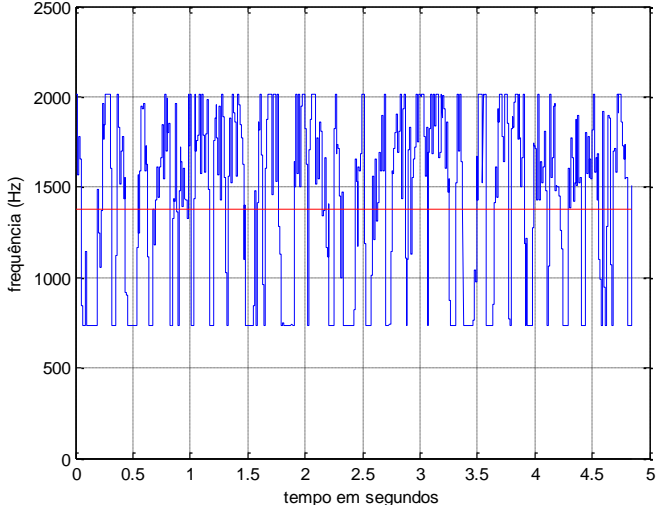

(frequência-IMF1,5mm-2)

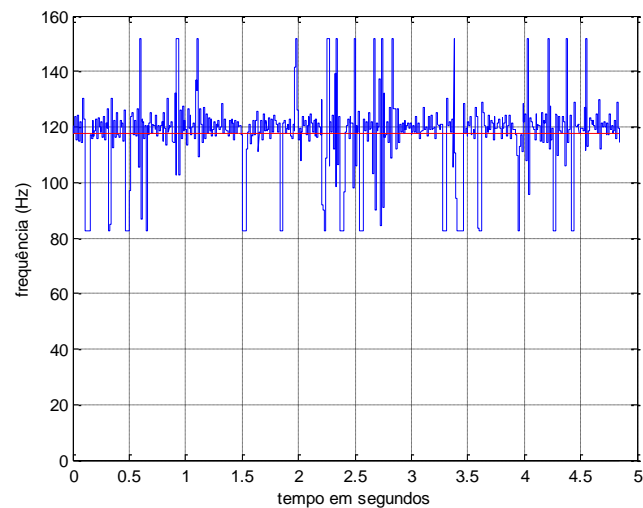

(frequência-IMF1,5mm-4) 


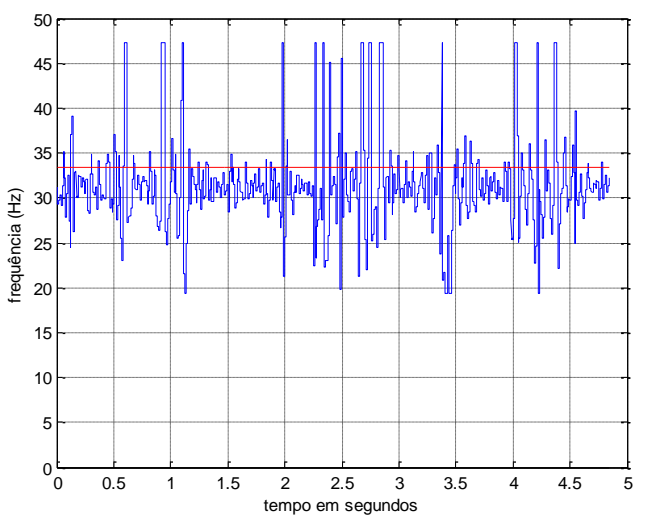

(frequência-IMF1,5mm-5)

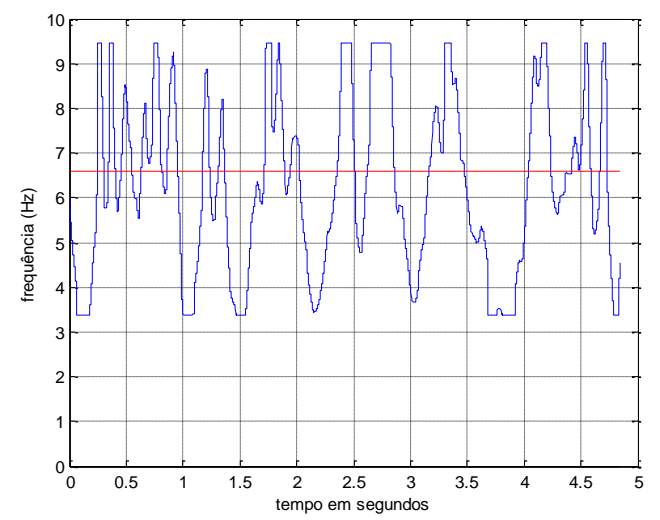

(frequência-IMF1,5mm-7)

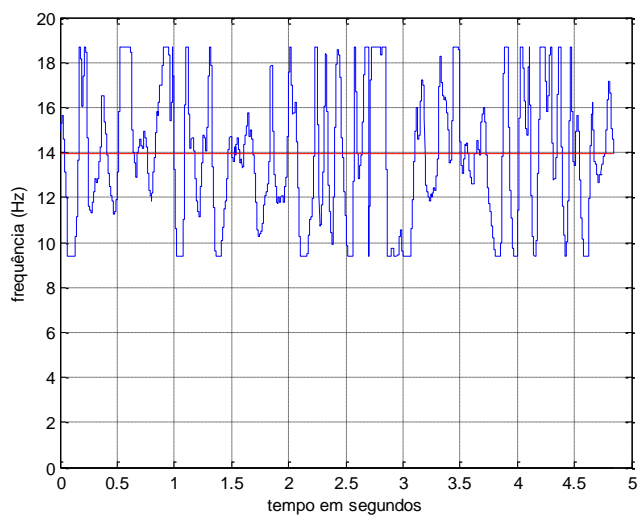

(frequência-IMF1,5mm-6)

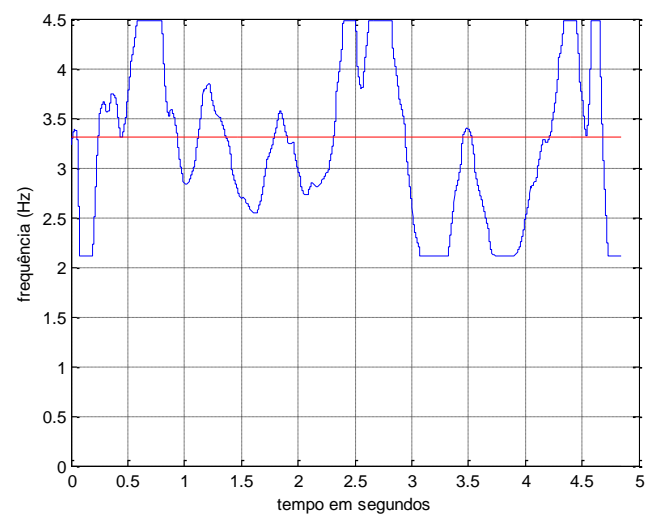

(frequência-IMF1,5mm-8)

\section{A12- Módulos do sinal analítico com UCP de 1,5mm}

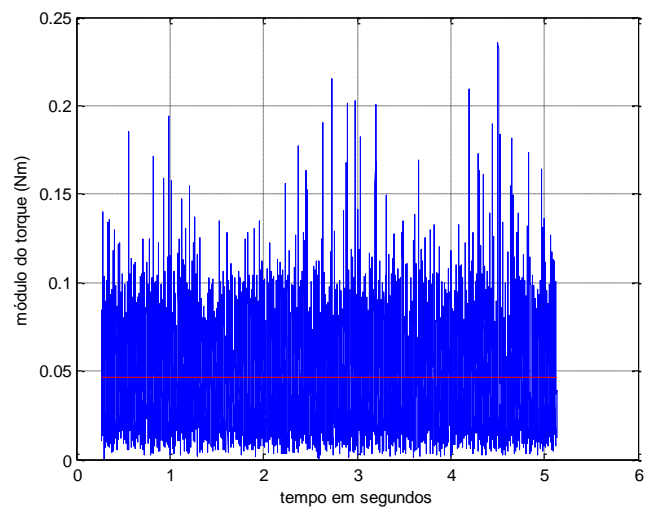

(módulo-IMF1,5mm-1)

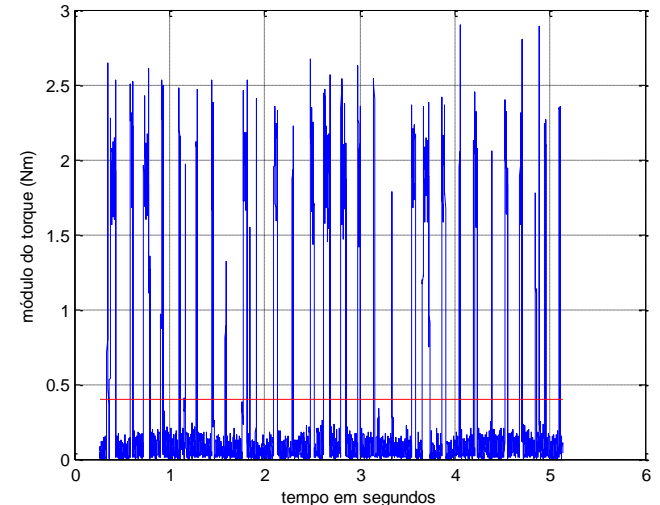

(módulo-IMF1,5mm-2) 


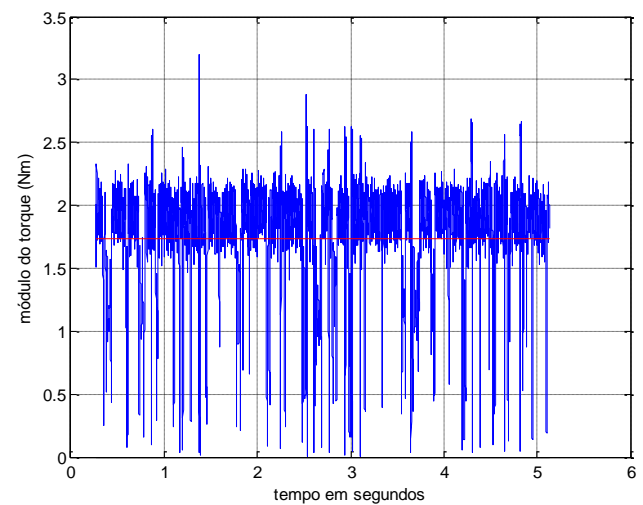

(módulo-IMF1,5mm-3)

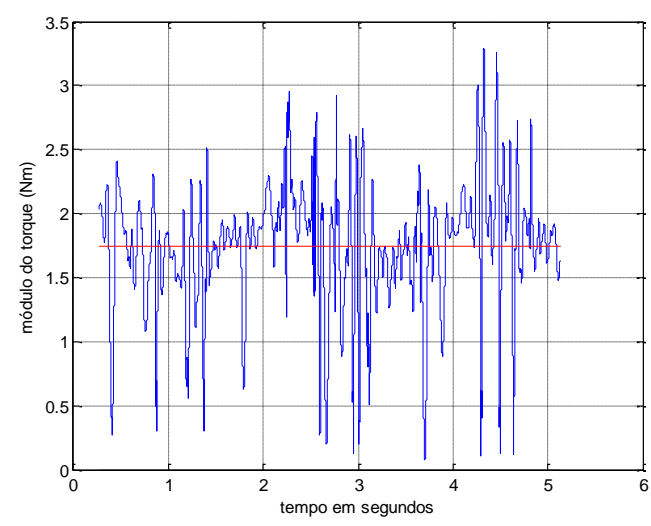

(módulo-IMF1,5mm-5)

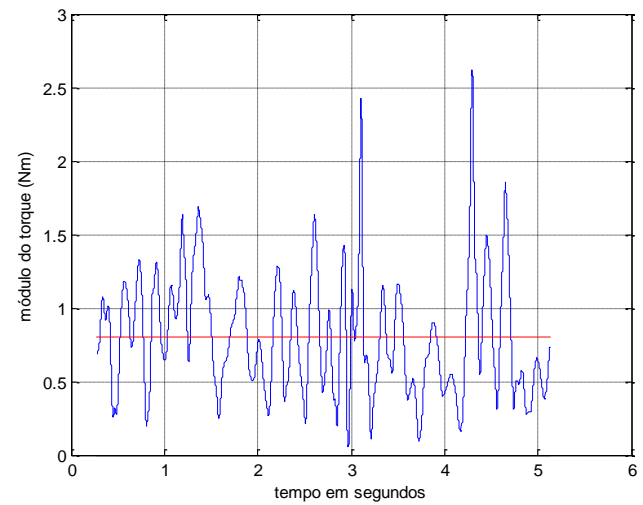

(módulo-IMF1,5mm-7)

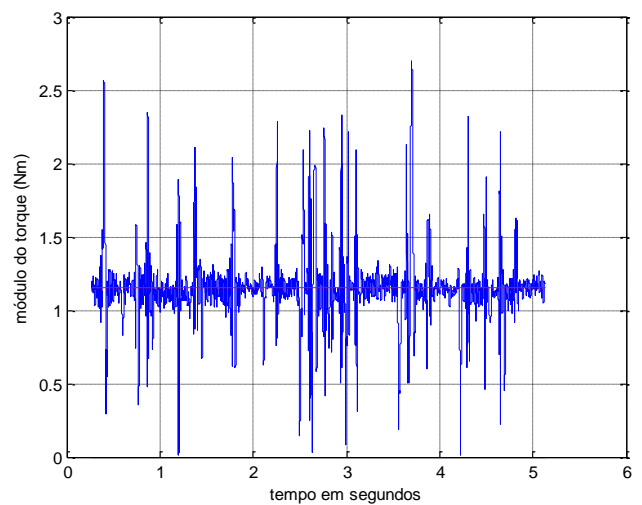

(módulo-IMF1,5mm-4)

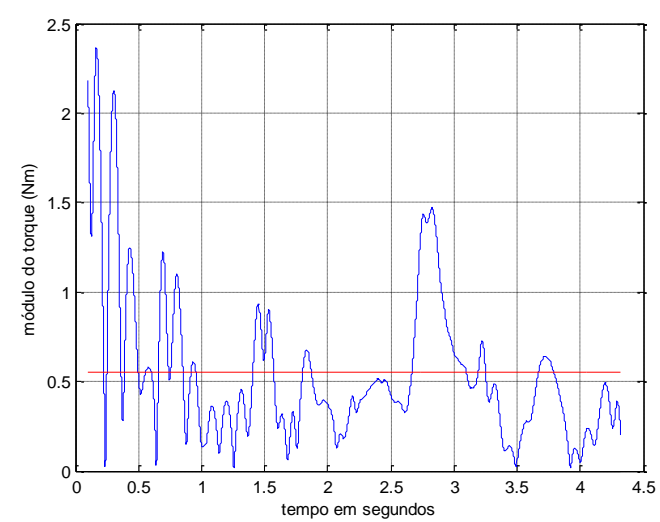

(módulo-IMF1,5mm-6)

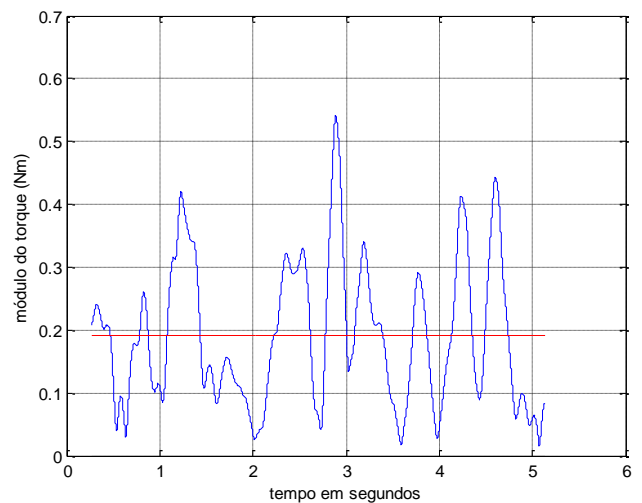

(módulo-IMF1,5mm-8) 


\section{Usinagem Interrompida}

\section{A14- Fases do sinal analítico de $\mathrm{Cl}$ com UCP de $0,5 \mathrm{~mm}$}

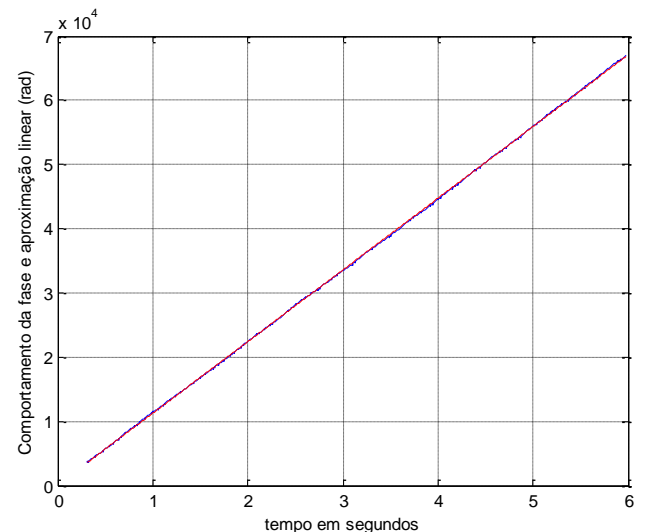

(fase-IMF0,5mm_int-1)

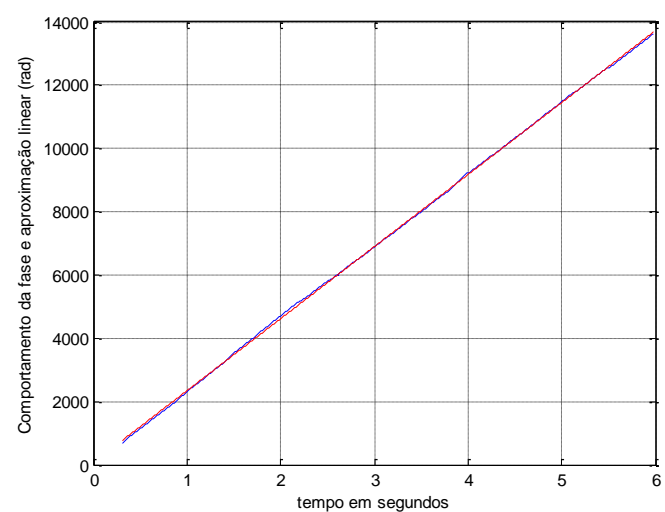

(fase-IMF0,5mm_int-3)

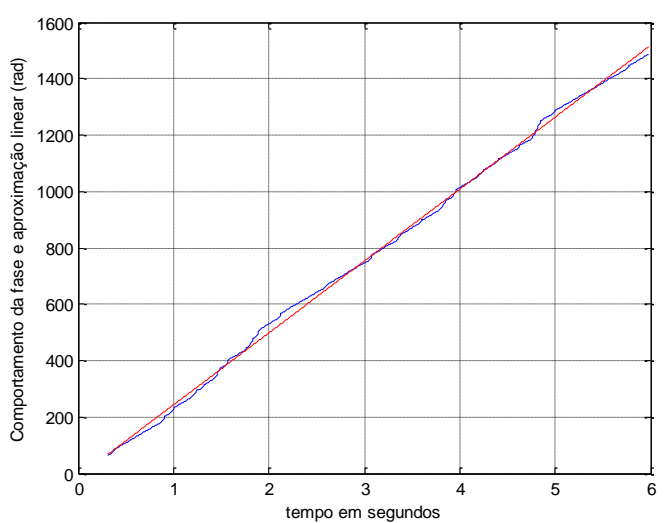

(fase-IMF0,5mm_int-5)

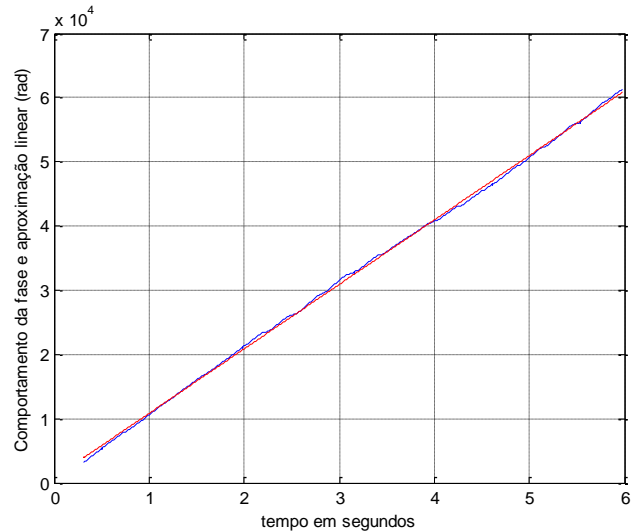

(fase-IMF0,5mm_int-2)

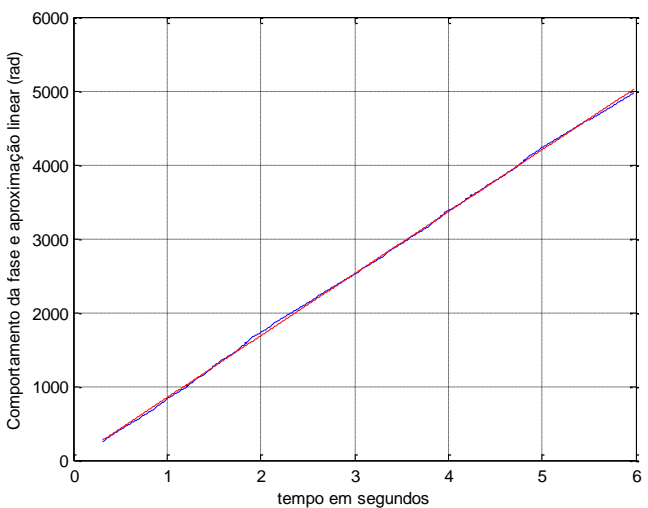

(fase-IMF0,5mm_int-4)

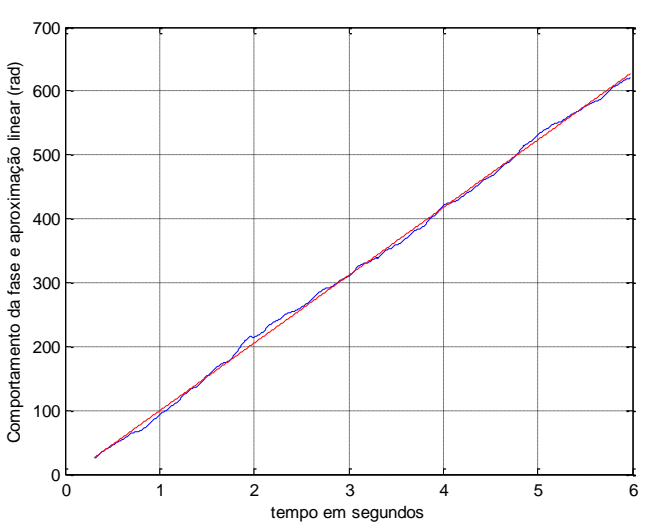

(fase-IMF0,5mm_int-6) 


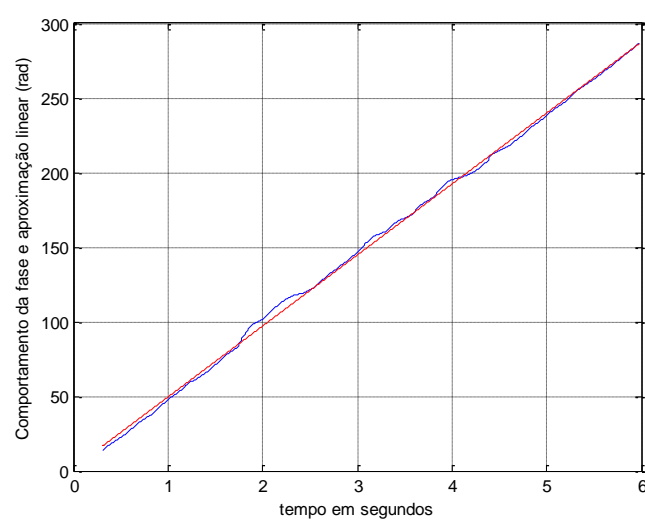

(fase-IMF0,5mm_int-7)

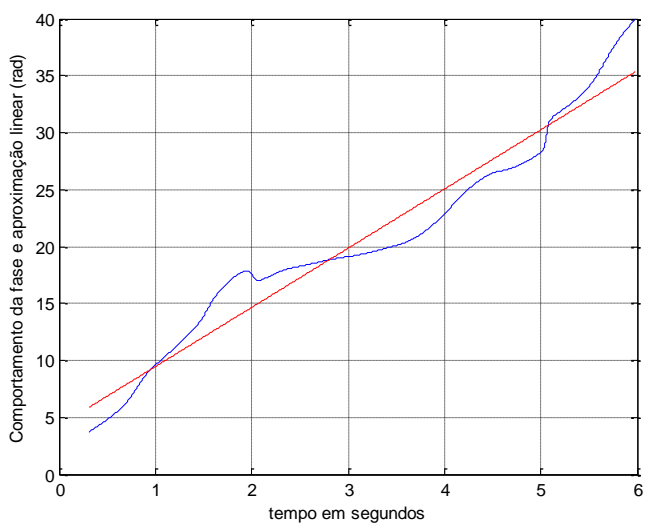

(fase-IMF0,5mm_int-9)

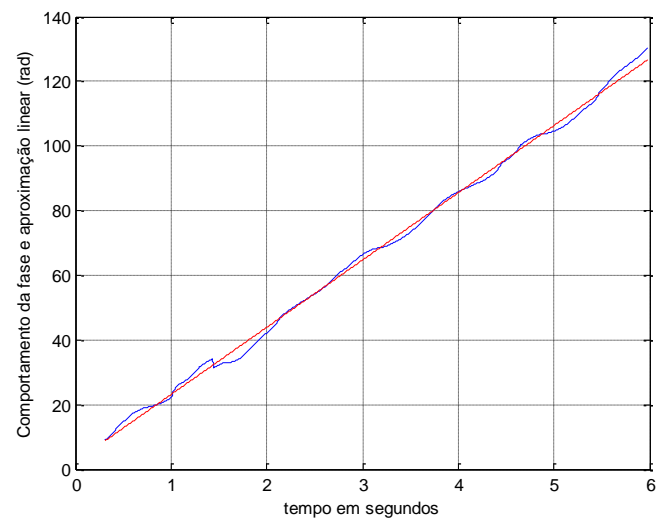

(fase-IMF0,5mm_int-8)

\section{A15- Frequências do sinal analítico de $\mathrm{Cl}$ com UCP de $0,5 \mathrm{~mm}$}

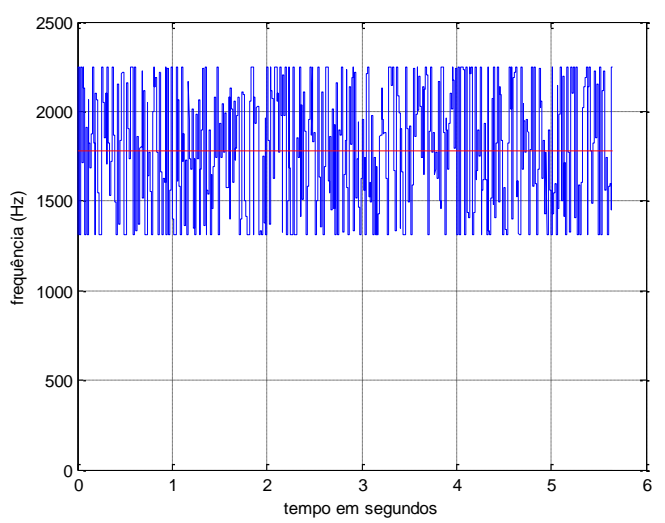

(frequência-IMF0,5mm_int-1)

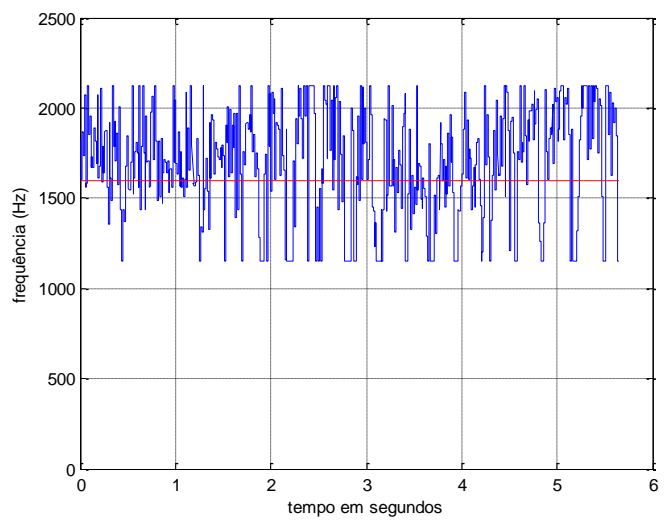

(frequência-IMF0,5mm_int-2) 


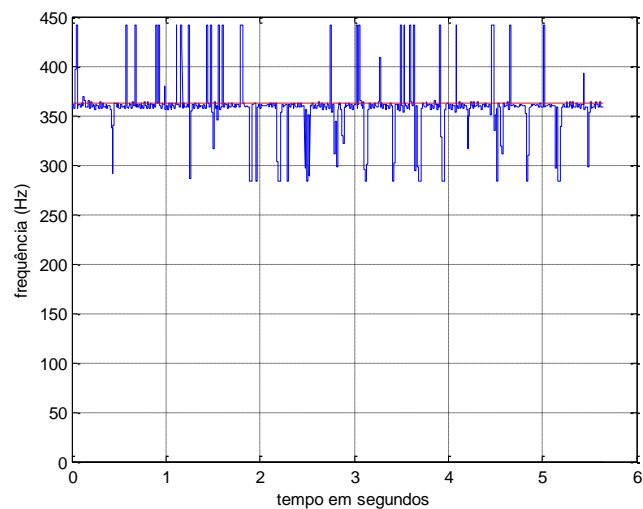

(frequência-IMF0,5mm_int-3)

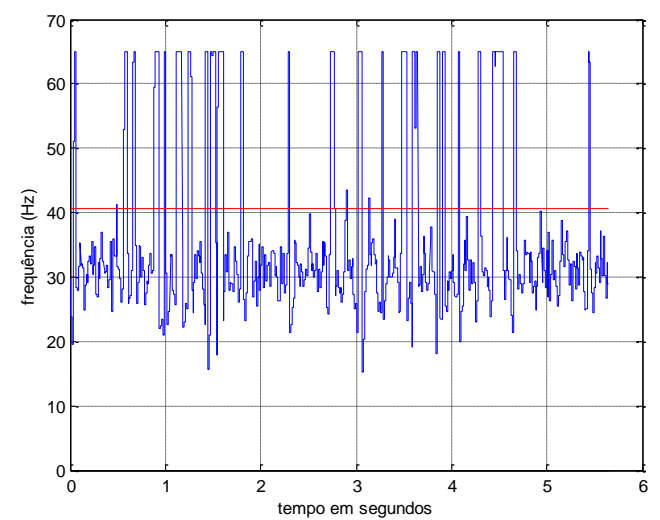

(frequência-IMF0,5mm_int-5)

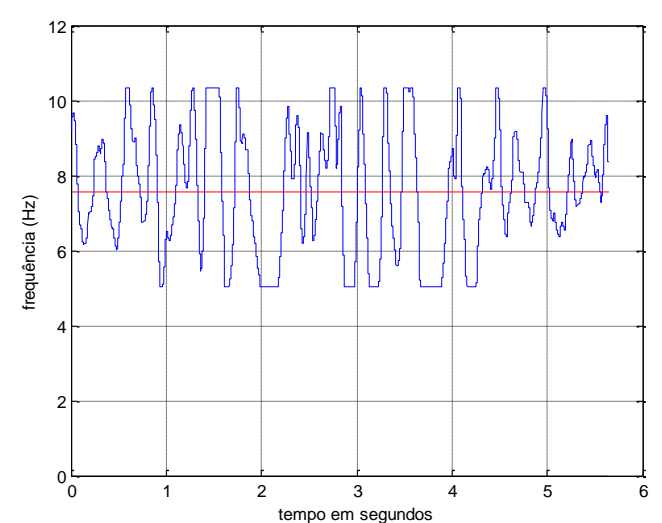

(frequência-IMF0,5mm_int-7)

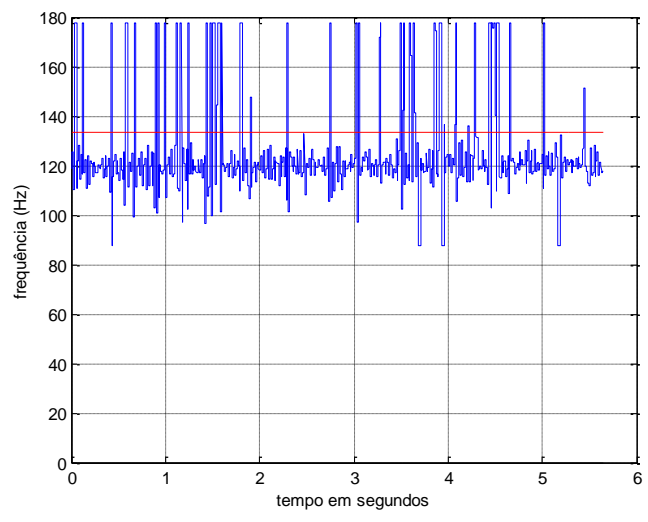

(frequência-IMF0,5mm_int-4)

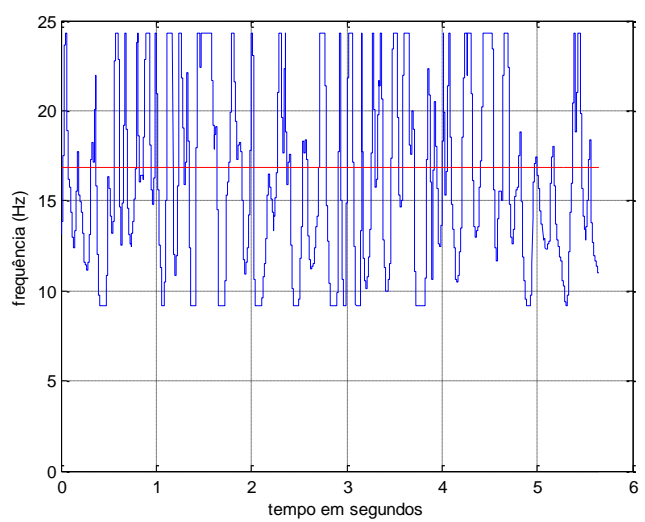

(frequência-IMF0,5mm_int-6)

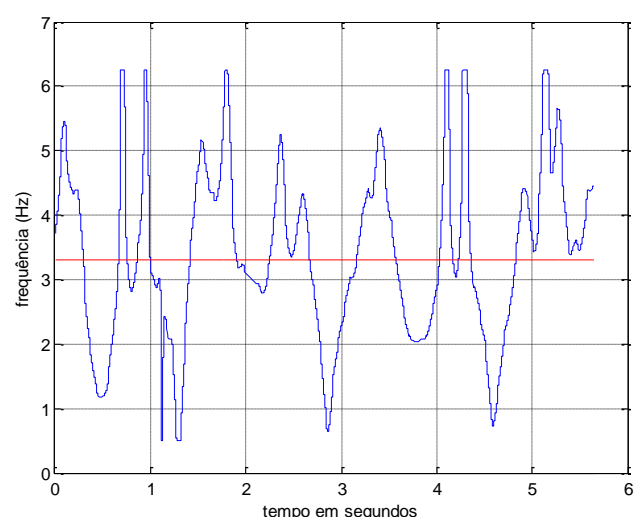

(frequência-IMF0,5mm_int-8) 


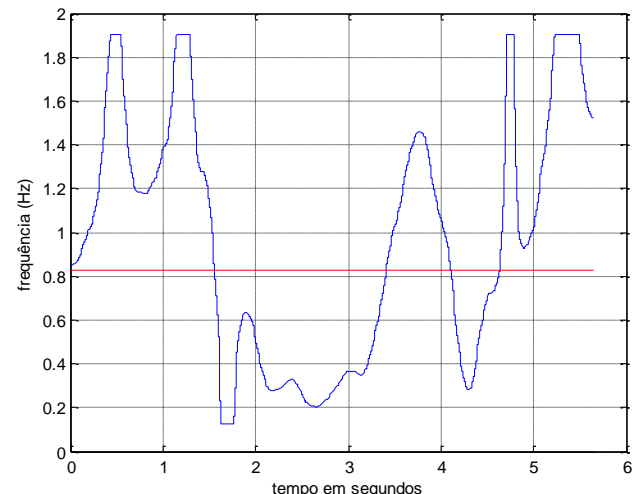

(frequência-IMF0,5mm_int-9)

\section{A16- Módulos do sinal analítico de Cl com UCP de 0,5mm}

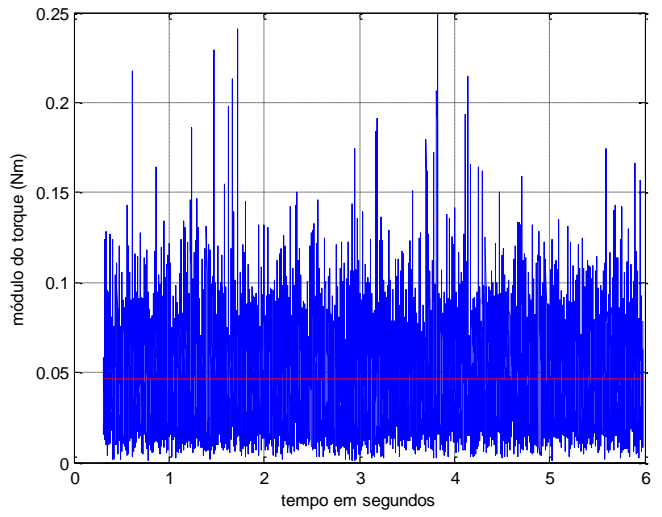

(módulo-IMF0,5mm_int-1)

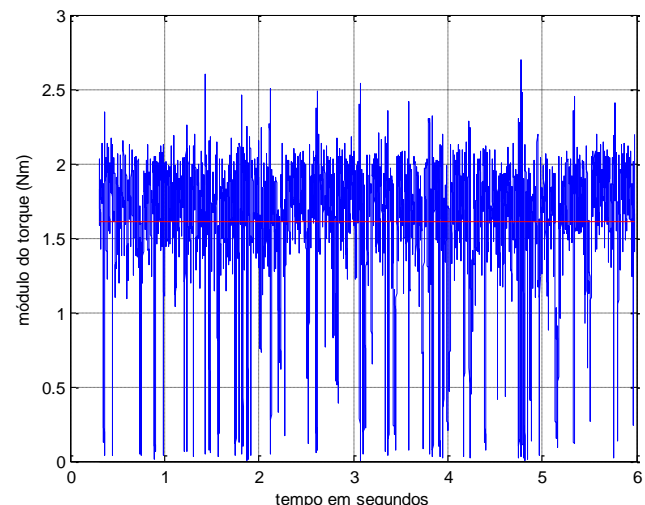

(módulo-IMF0,5mm_int-3)

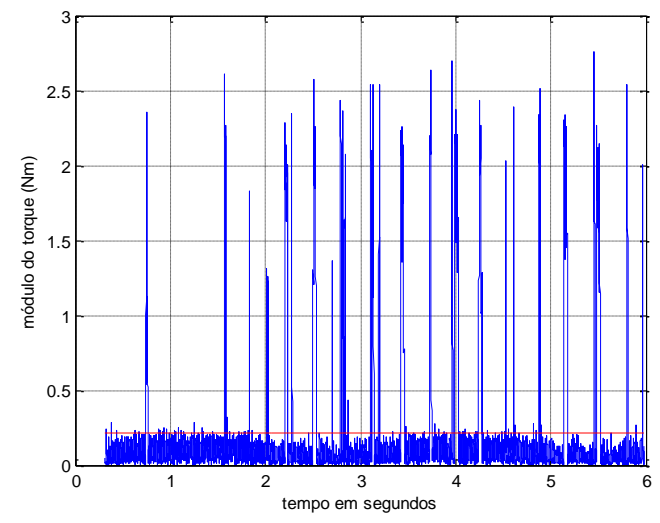

(módulo-IMF0,5mm_int-2)

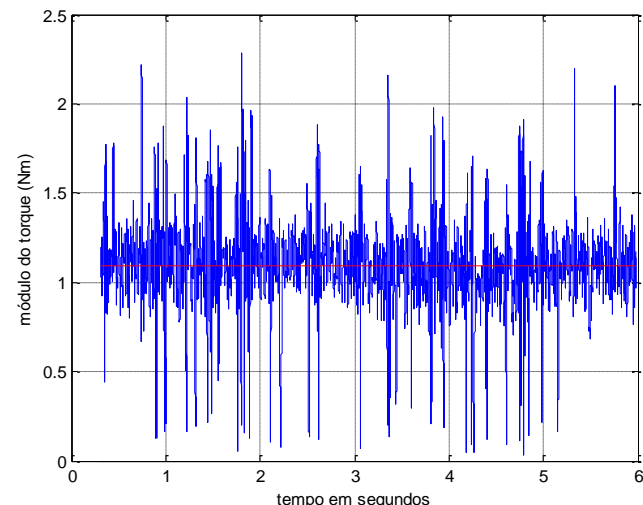

(módulo-IMF0,5mm_int-4) 


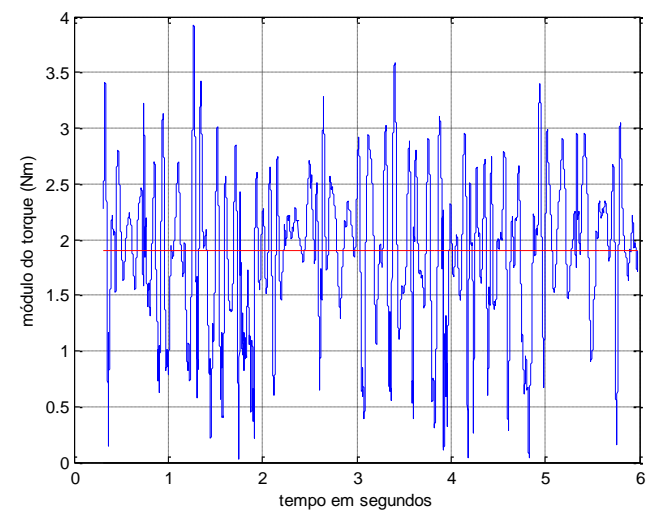

(módulo-IMF0,5mm_int-5)

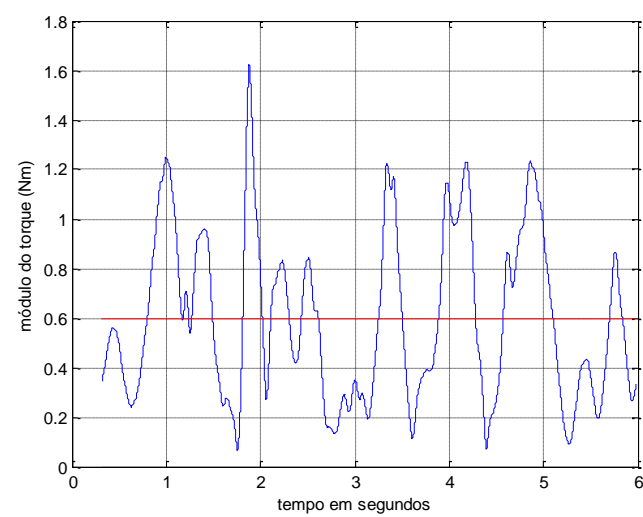

(módulo-IMF0,5mm_int-7)

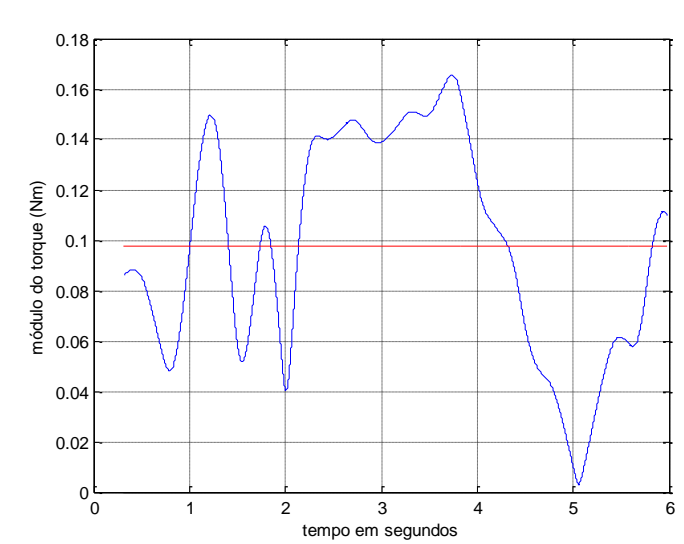

(módulo-IMF0,5mm_int-9)

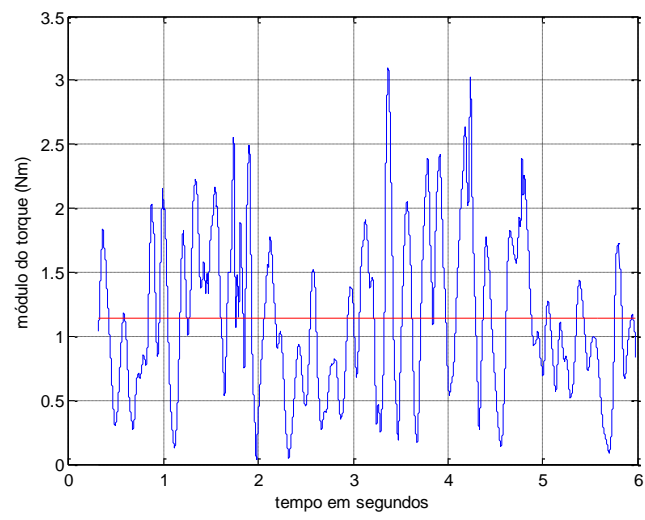

(módulo-IMF0,5mm_int-6)

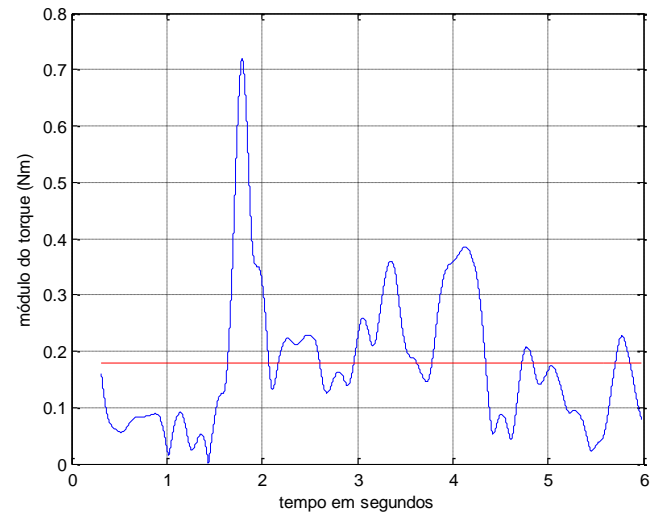

(módulo-IMF0,5mm_int-8) 


\section{A17- Fases do sinal analítico de Cl com UCP de 1,0mm}

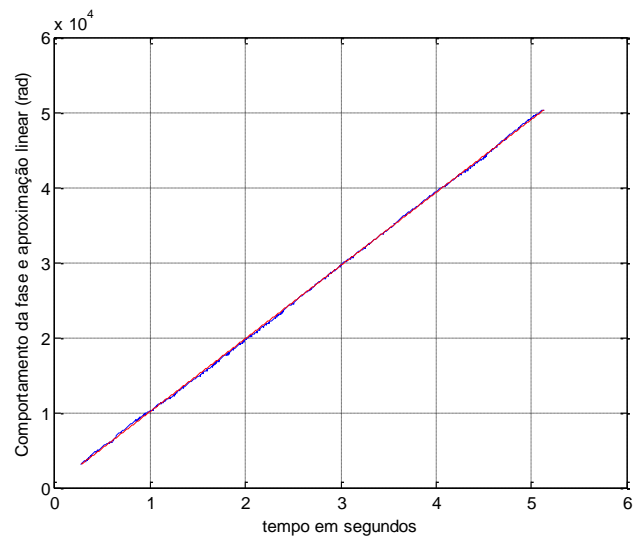

(fase-IMF1,0mm_int-1)

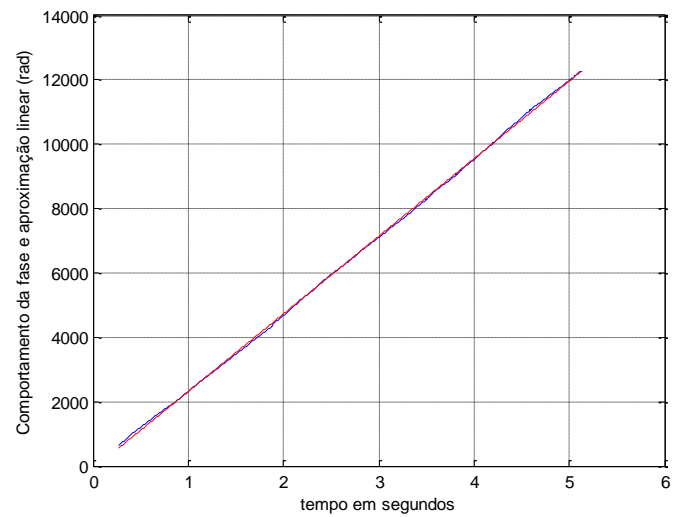

(fase-IMF1,0mm_int-3)

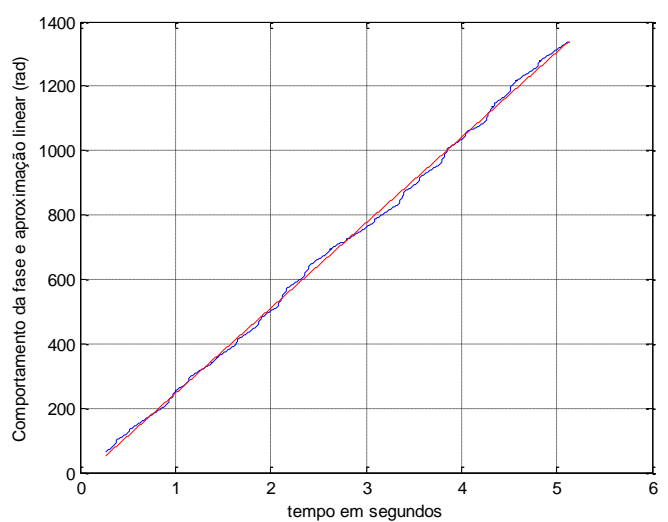

(fase-IMF1,0mm_int-5)

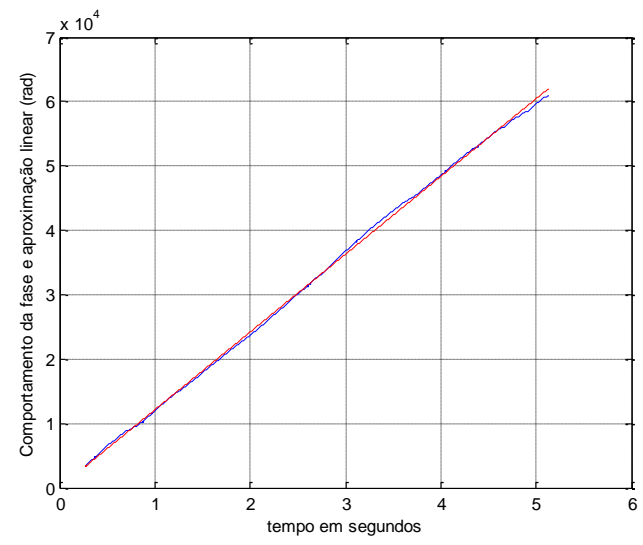

(fase-IMF1,0mm_int-2)

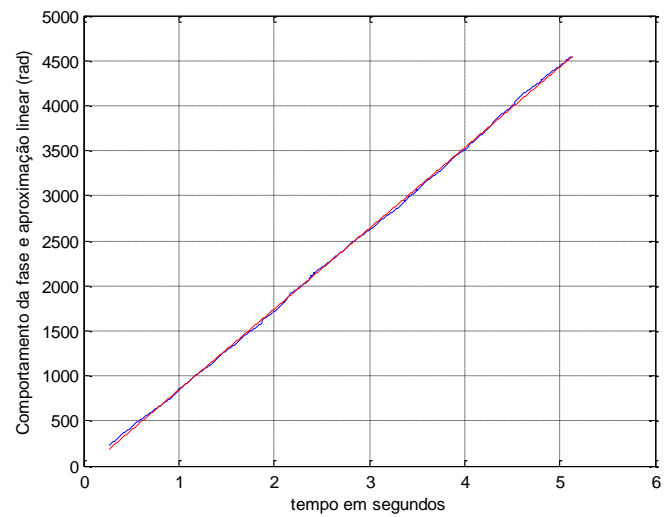

(fase-IMF1,0mm_int-4)

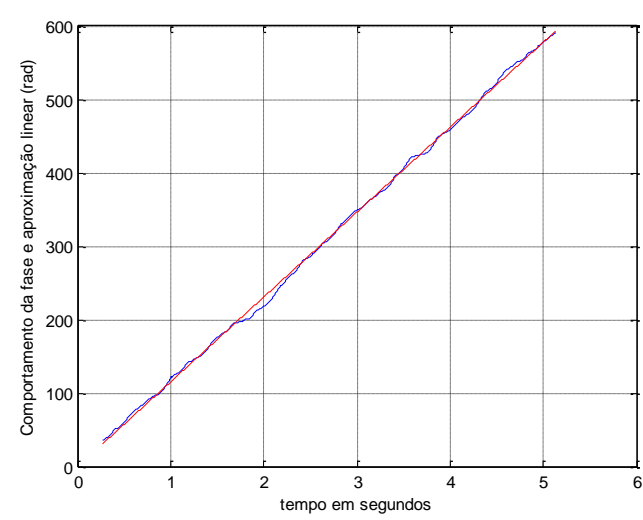

(fase-IMF1,0mm_int-6) 


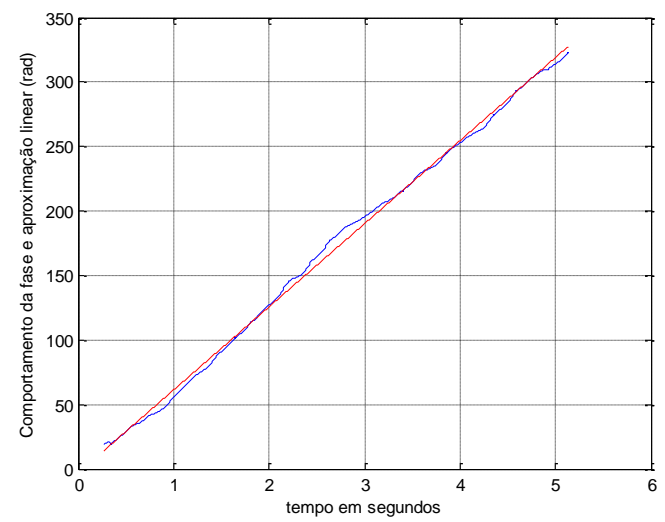

(fase-IMF1,0mm_int-7)

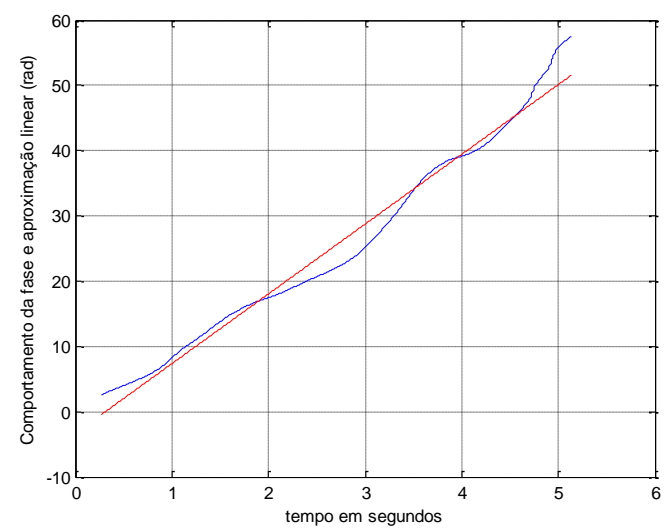

(fase-IMF1,0mm_int-9)

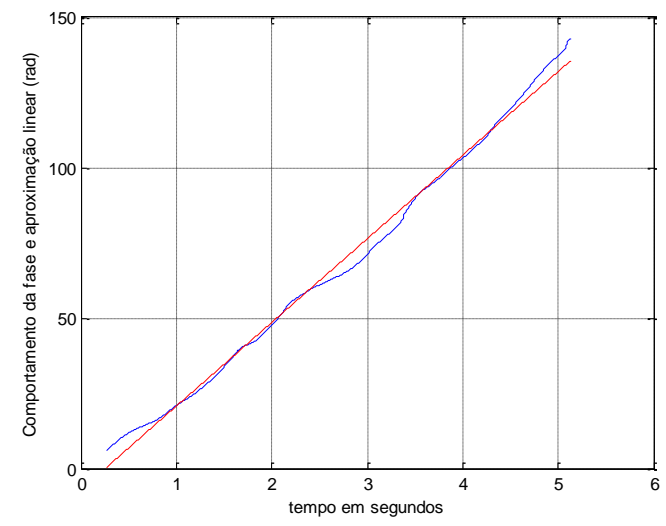

(fase-IMF1,0mm_int-8)

\section{A18- Frequências do sinal analítico de $\mathrm{Cl}$ com UCP de 1,0mm}

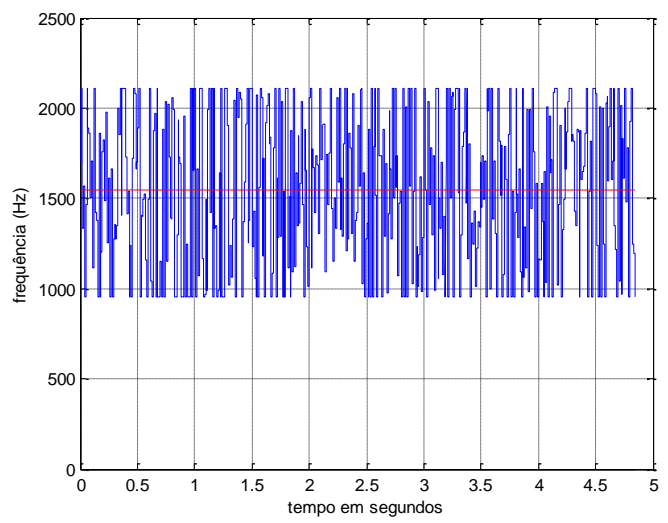

(frequência-IMF1,0mm-1)

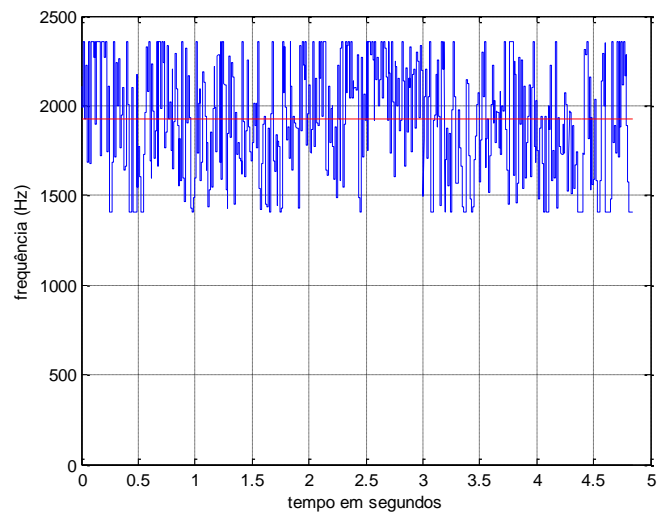

(frequência-IMF1,0mm-2) 


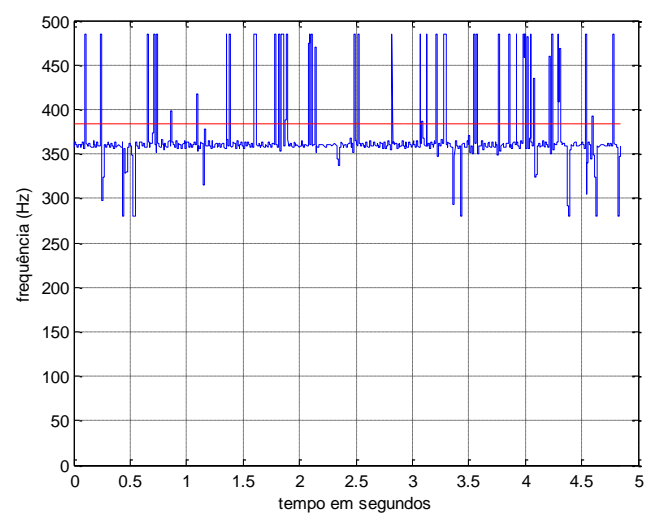

(frequência-IMF1,0mm-3)

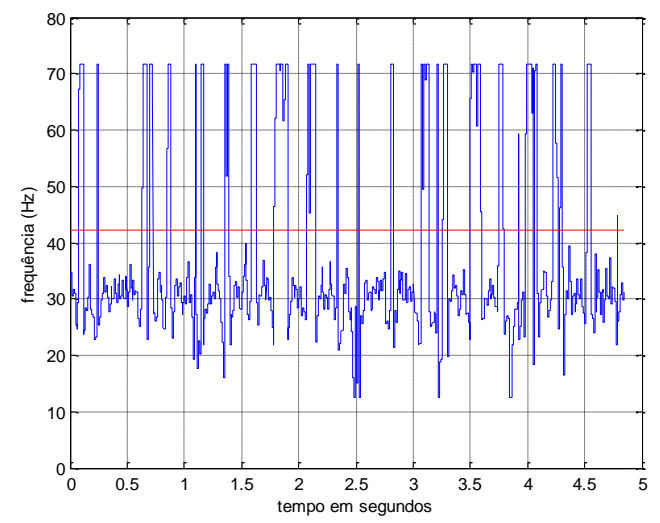

(frequência-IMF1,0mm-5)

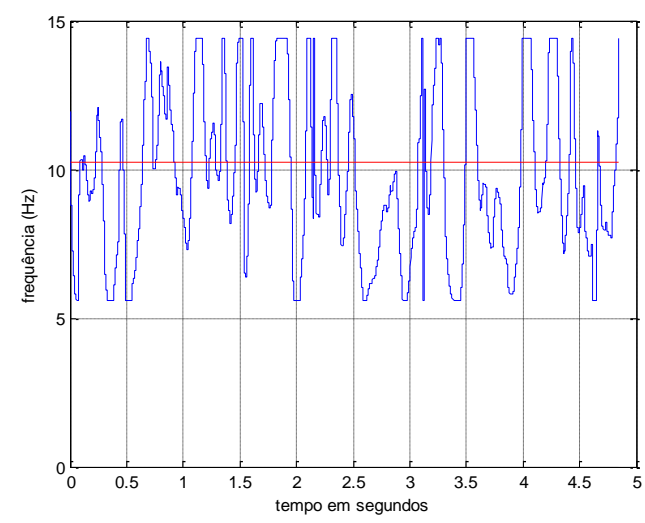

(frequência-IMF1,0mm-7)

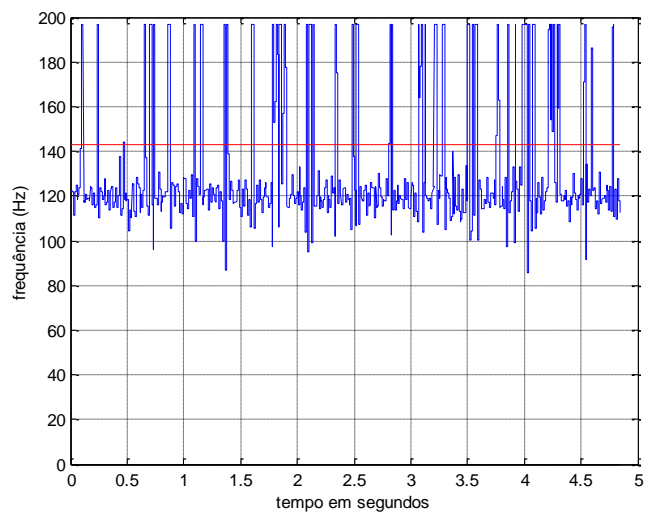

(frequência-IMF1,0mm-4)

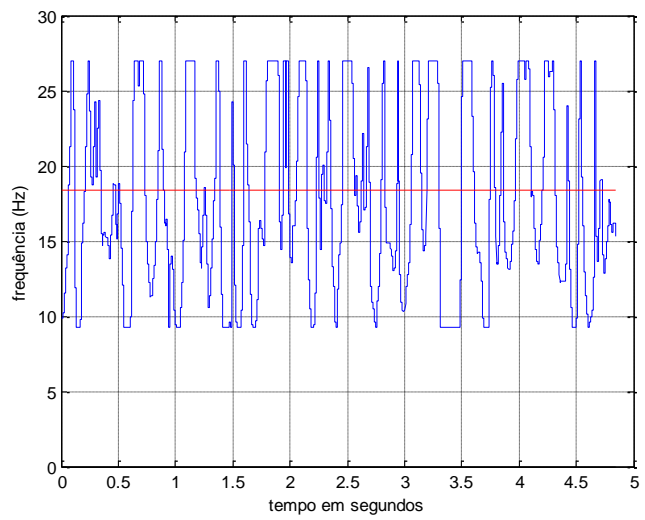

(frequência-IMF1,0mm-6)

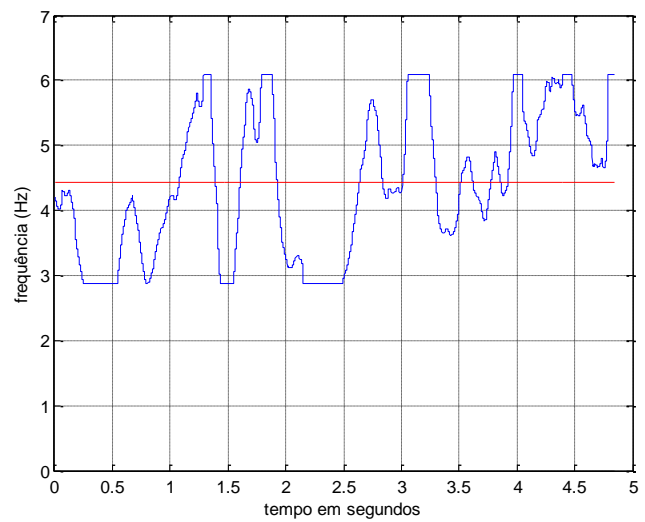

(frequência-IMF1,0mm-8) 


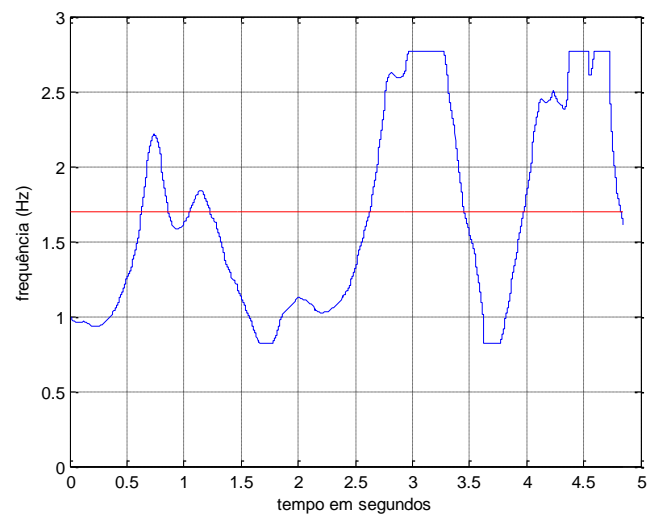

(frequência-IMF1,0mm-9)

\section{A19- Módulos do sinal analítico de Cl com UCP de 1,0mm}

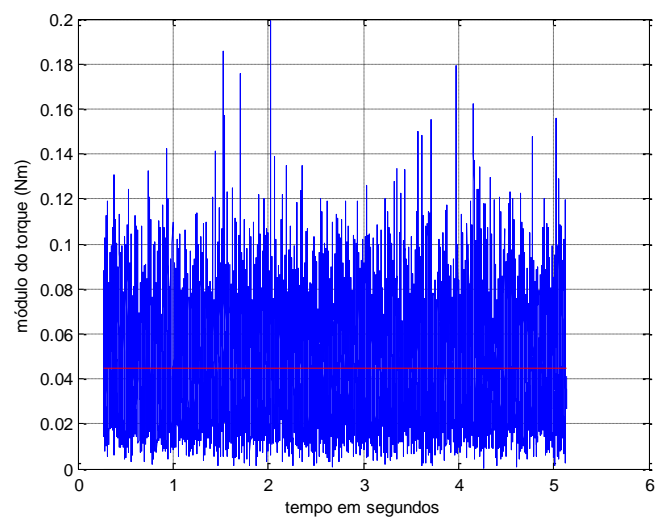

(módulo-IMF1,0mm-1)

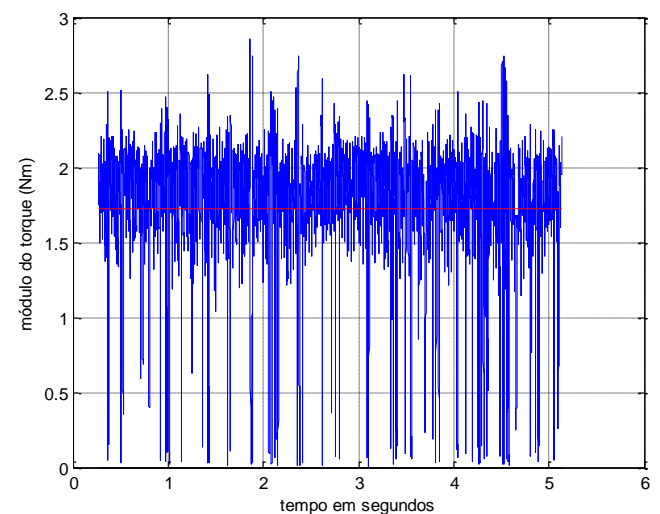

(módulo-IMF1,0mm_int-3)

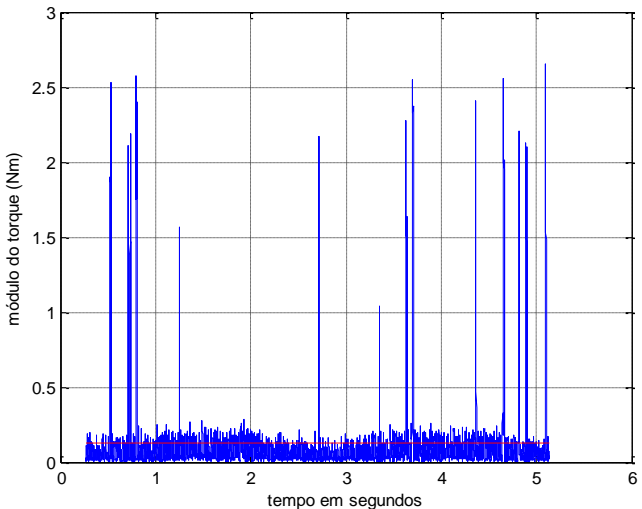

(módulo-IMF1,0mm-2)

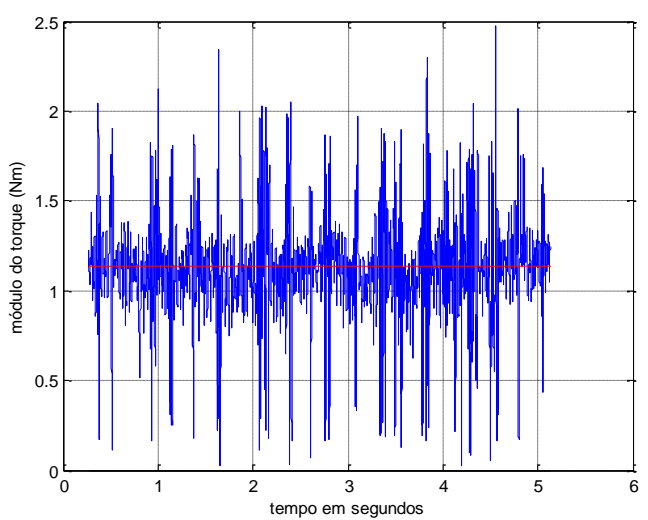

(módulo-IMF1,0mm_int-4) 


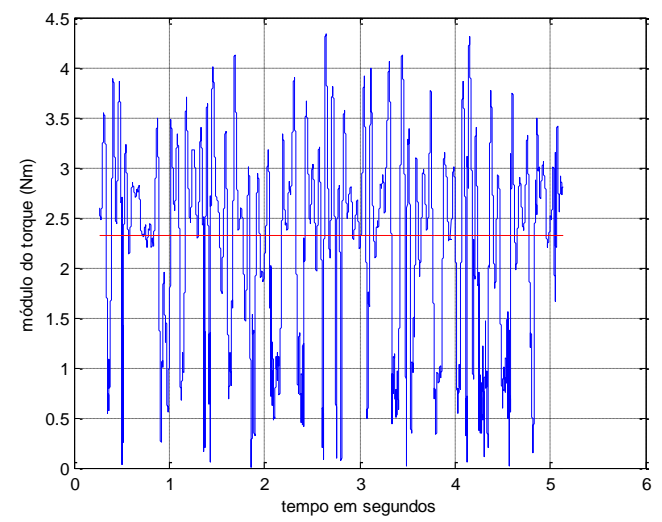

(módulo-IMF1,0mm_int-5)

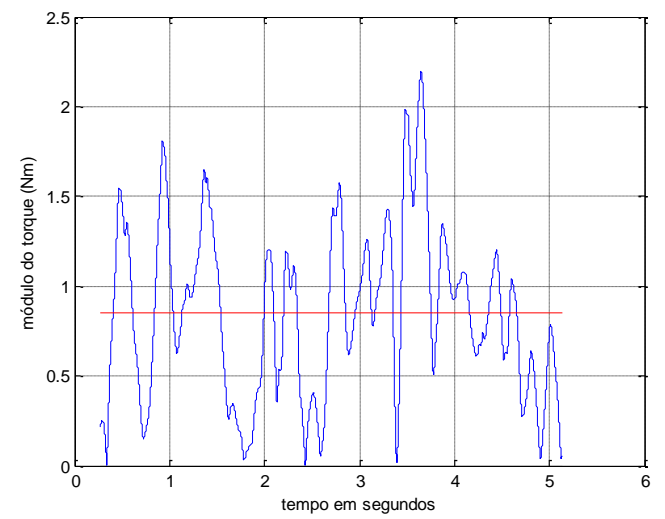

(módulo-IMF1,0mm_int-7)

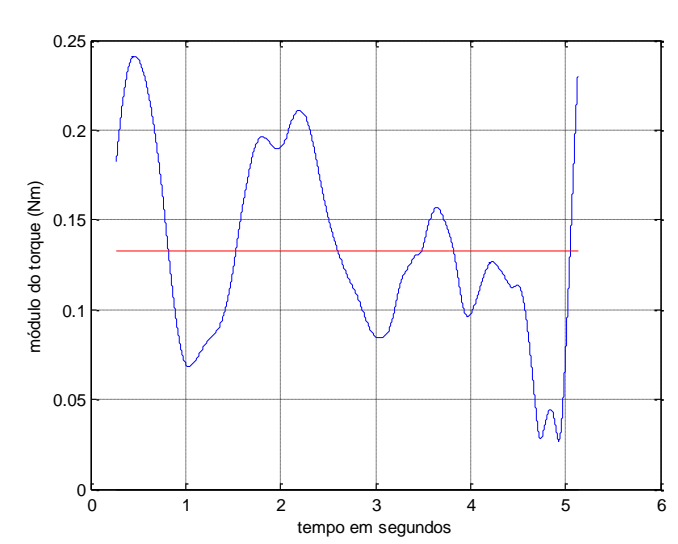

(módulo-IMF1,0mm_int-9)

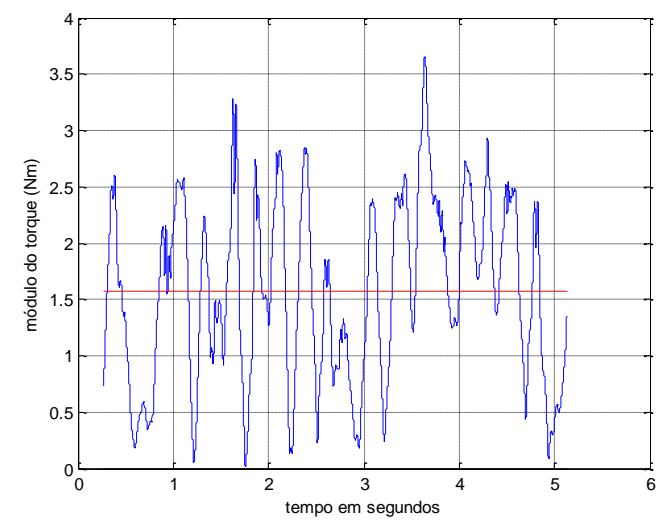

(módulo-IMF1,0mm_int-6)

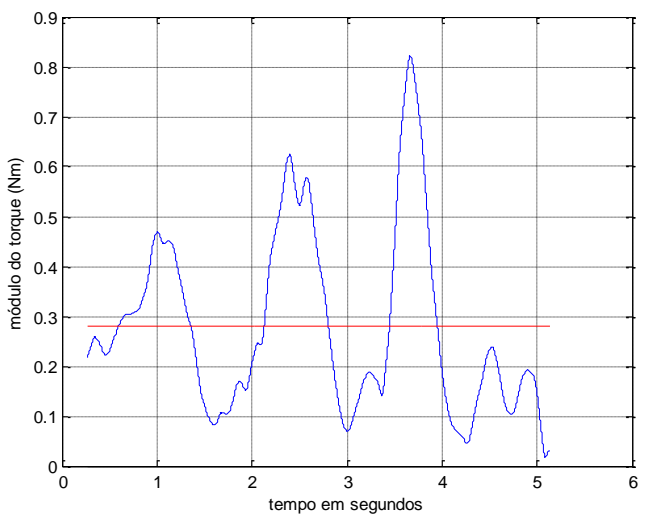

(módulo-IMF1,0mm_int-7) 


\section{A20- Fases do sinal analítico de $\mathrm{Cl}$ com UCP de 1,5mm}

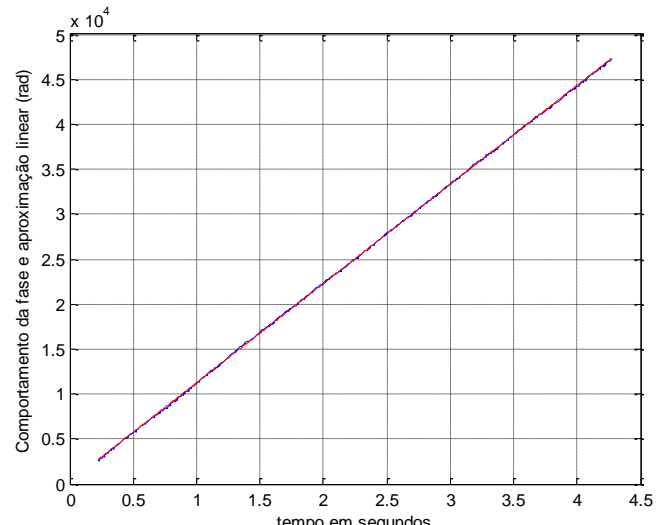

(fase-IMF1,5mm_int-1)

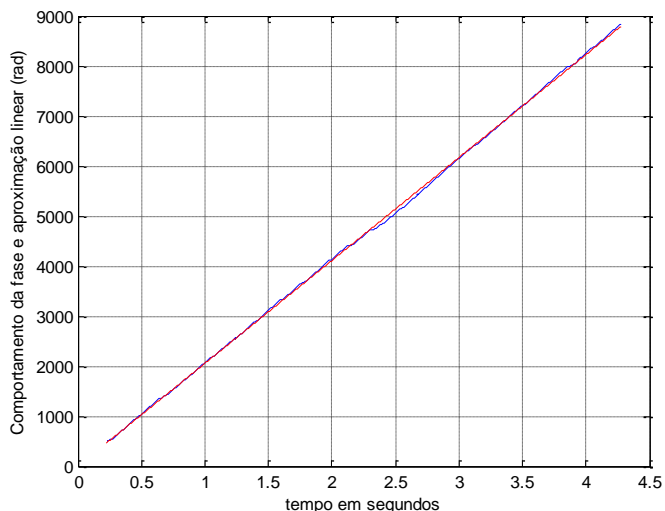

(fase-IMF1,5mm_int-3)

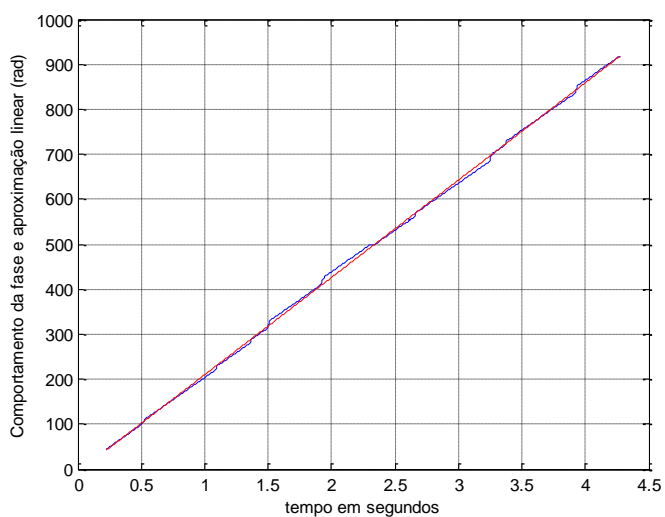

(fase-IMF1,5mm_int-5)

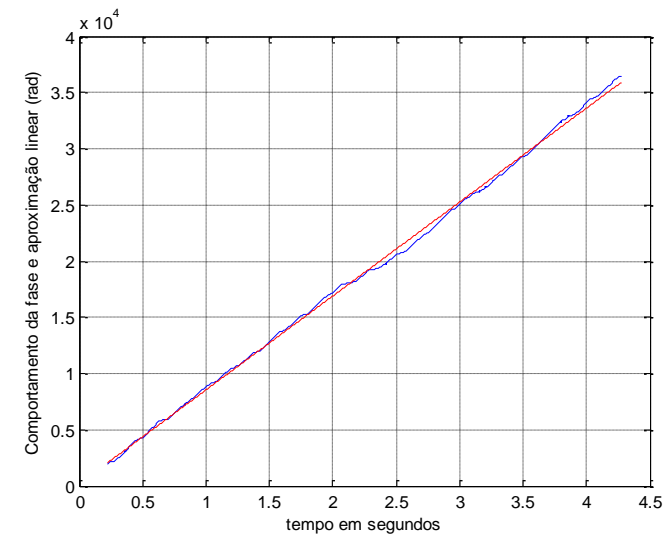

(fase-IMF1,5mm_int-2)

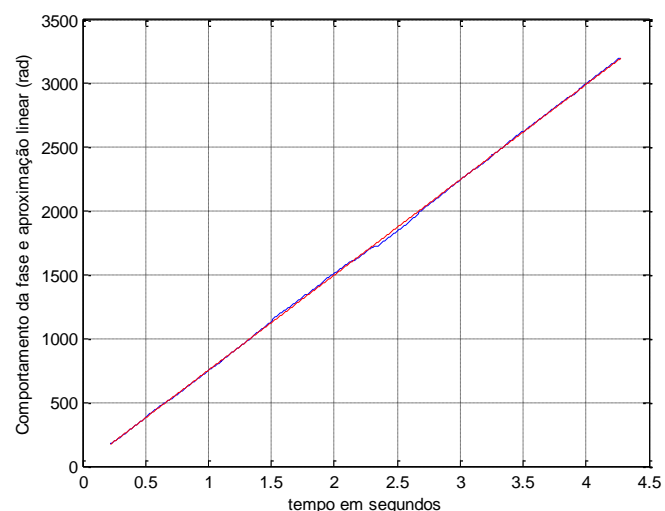

(fase-IMF1,5mm_int-4)

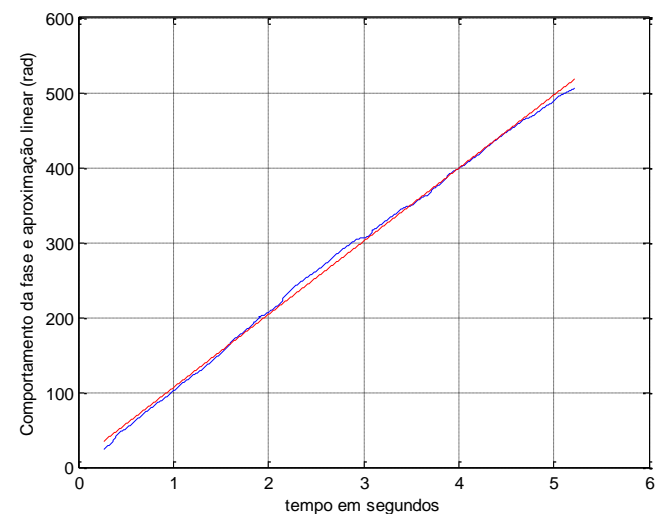

(fase-IMF1,5mm_int-6) 


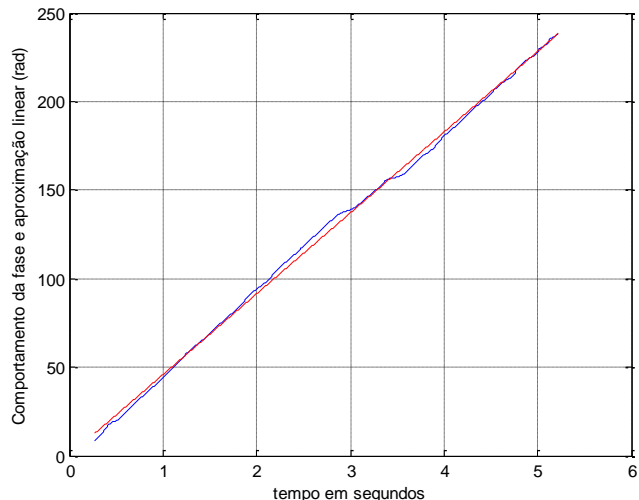

(fase-IMF1,5mm_int-7)

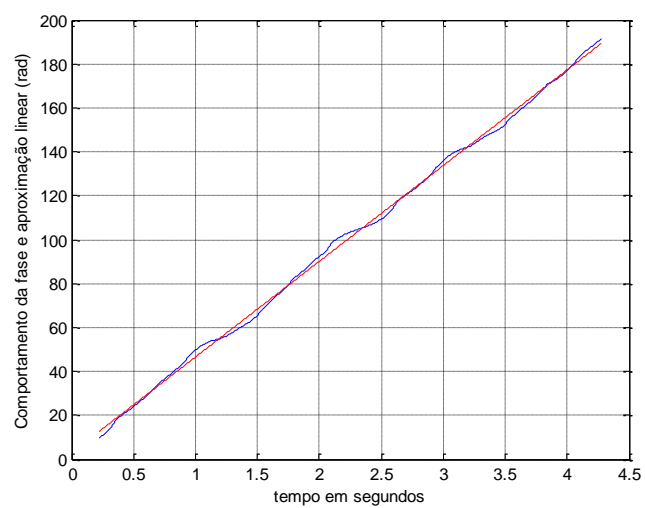

(fase-IMF1,5mm_int-9)

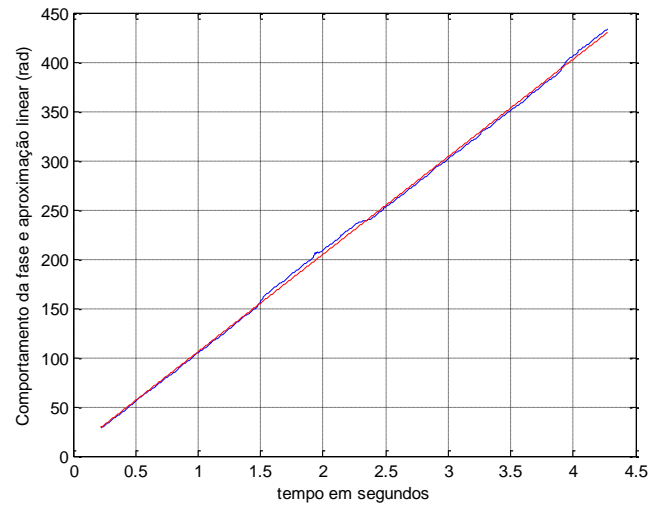

(fase-IMF1,5mm_int-8)

\section{A21- Frequências do sinal analítico de $\mathrm{Cl}$ com UCP de 1,5mm}

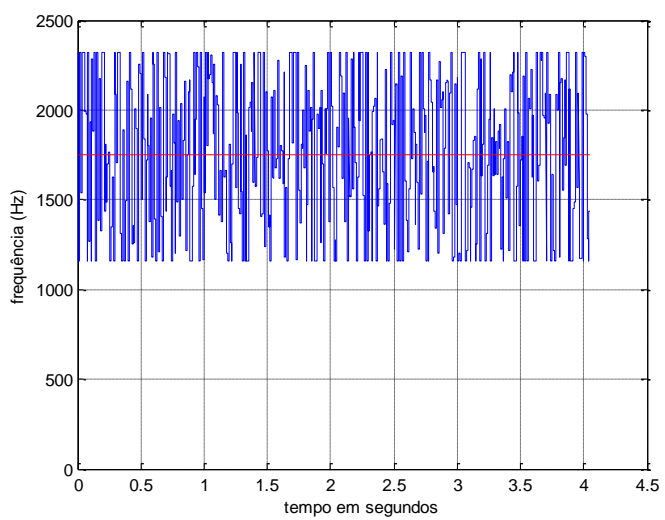

(frequência-IMF1,5mm_int-1)

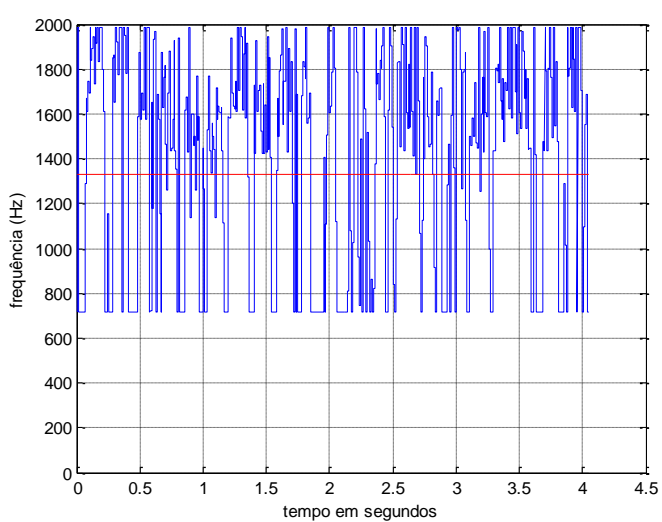

(frequência-IMF1,5mm_int-2) 


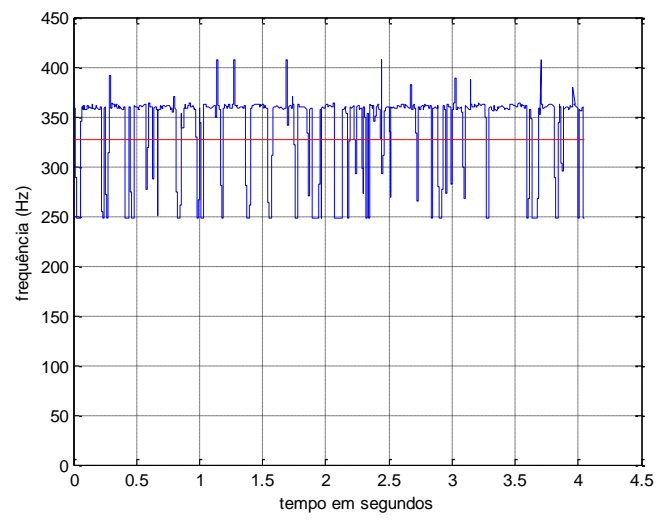

(frequência-IMF1,5mm_int-3)

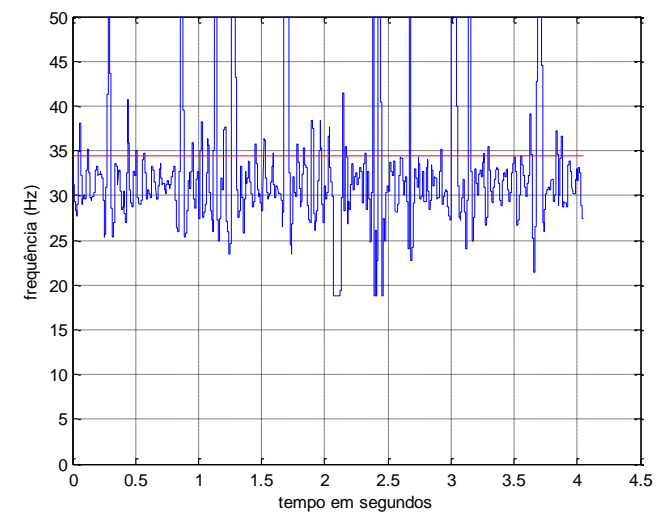

(frequência-IMF1,5mm_int-5)

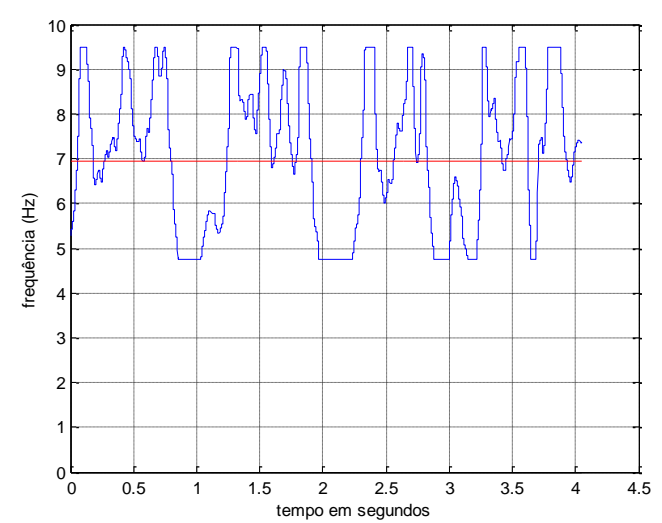

(frequência-IMF1,5mm_int-7)

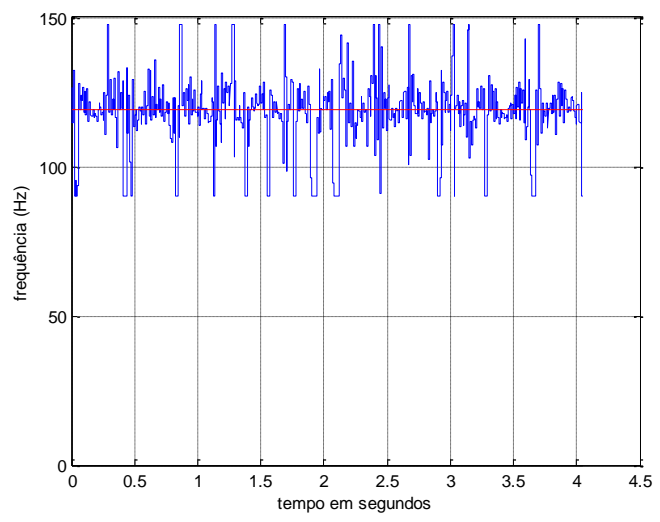

(frequência-IMF1,5mm_int-4)

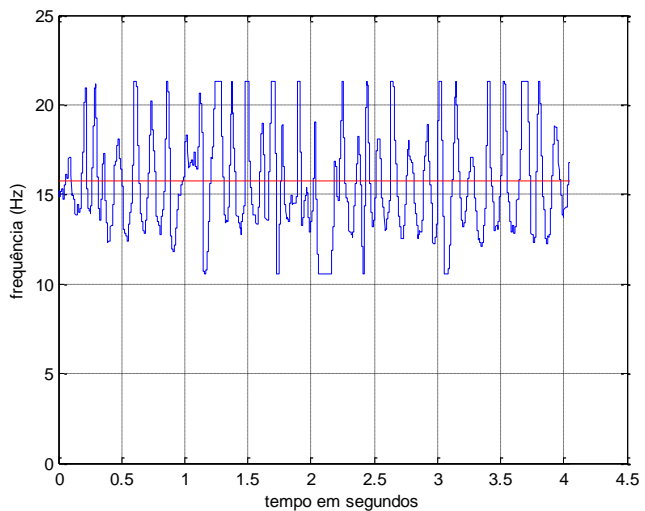

(frequência-IMF1,5mm_int-6)

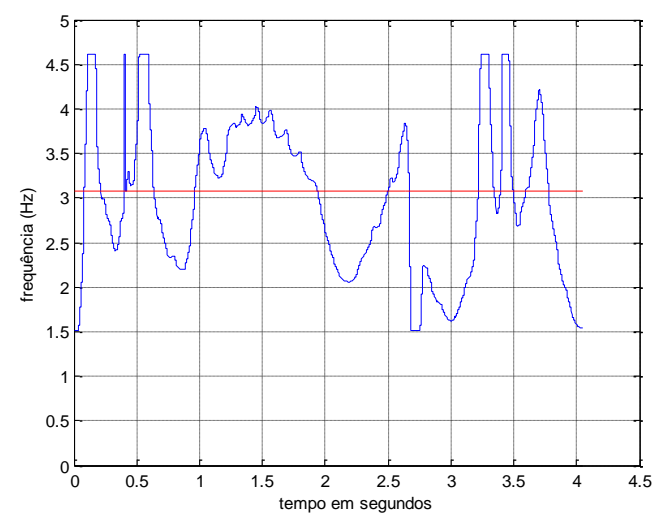

(frequência-IMF1,5mm_int-8) 


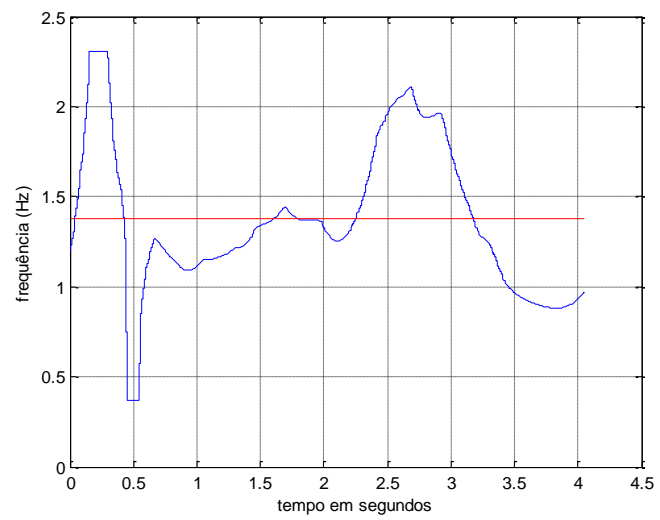

(frequência-IMF1,5mm_int-9)

\section{A22- Módulos do sinal analítico de Cl com UCP de 1,5mm}

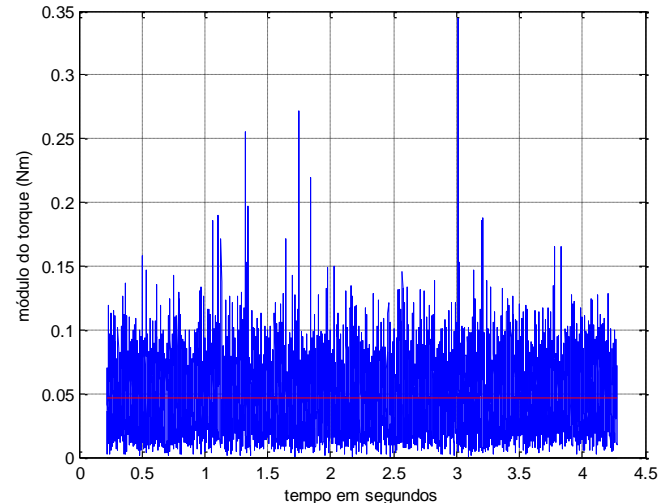

(módulo-IMF1,5mm_int-1)

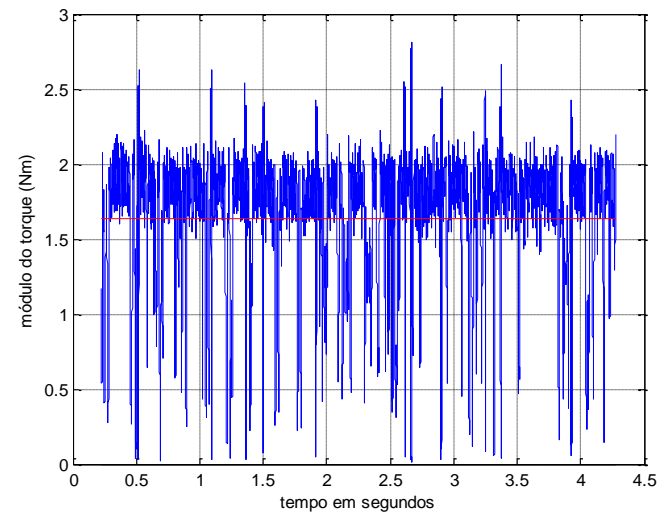

(módulo-IMF1,5mm_int-3)

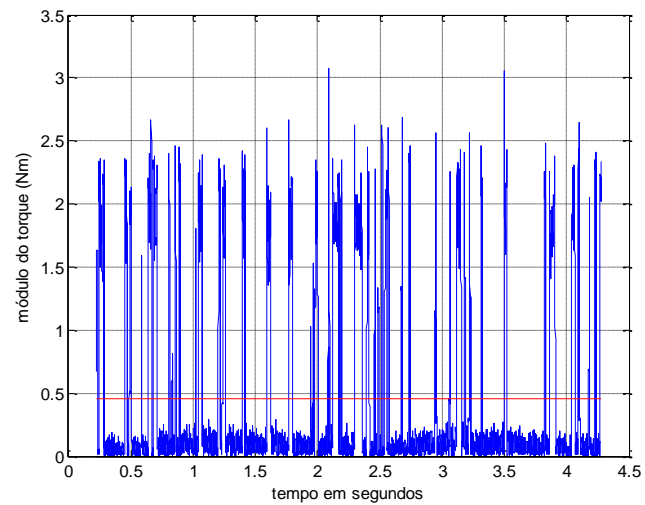

(módulo-IMF1,5mm_int-2)

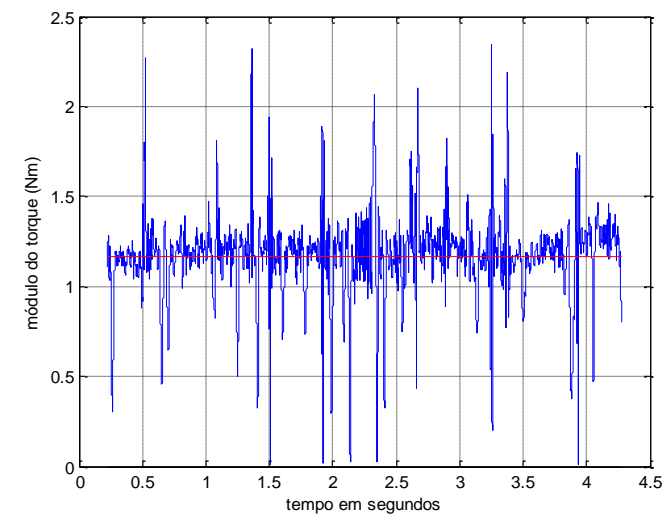

(módulo-IMF1,5mm_int-4) 


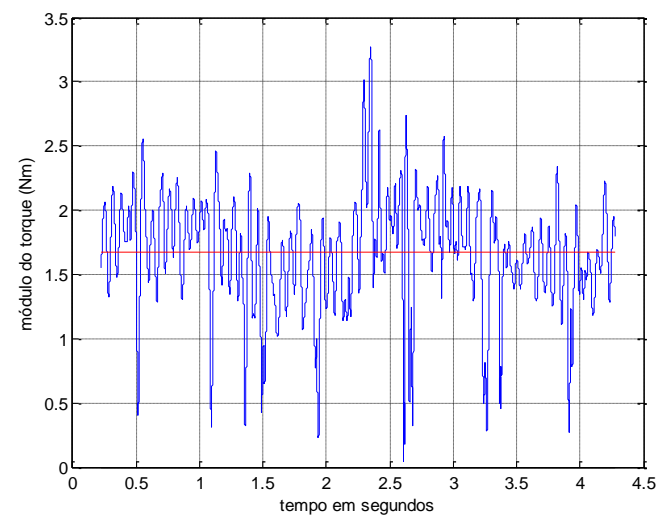

(módulo-IMF1,5mm_int-5)

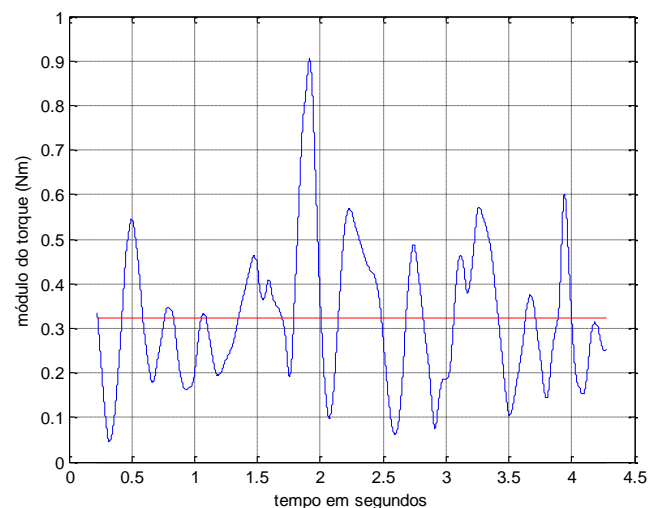

(módulo-IMF1,5mm_int-7)

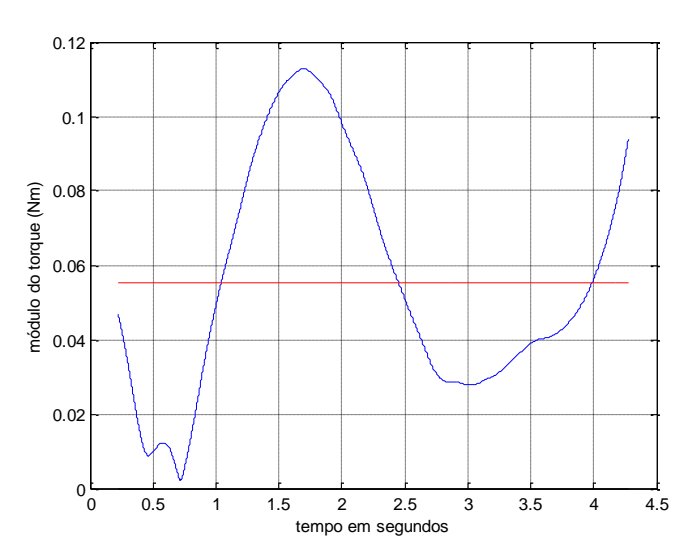

(módulo-IMF1,5mm_int-9)

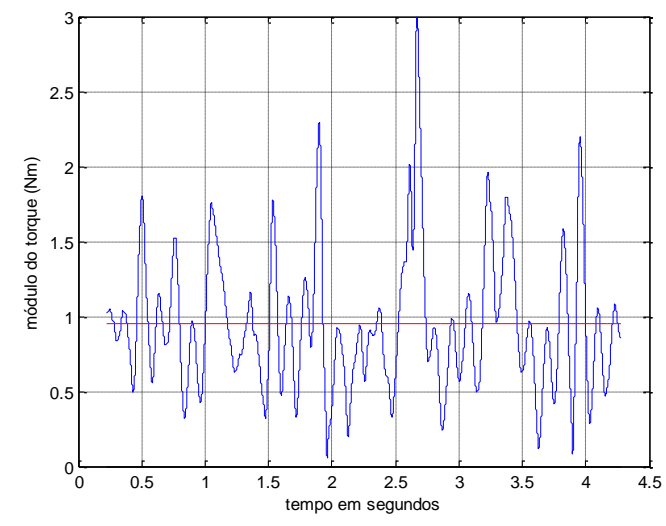

(módulo-IMF1,5mm_int-6)

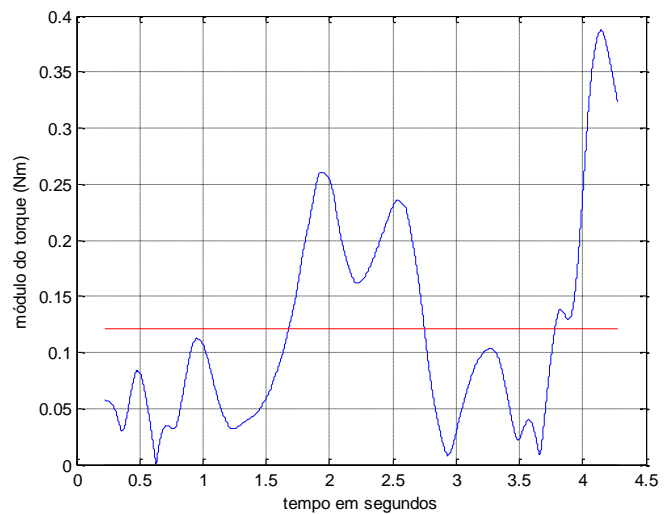

(módulo-IMF1,5mm_int-8) 
Apêndice B

Processamento dos dados obtidos com o DINAMÔMETRO Kistler usando a HHT

B1- Fases do sinal analítico com UCP de $0,5 \mathrm{~mm}$

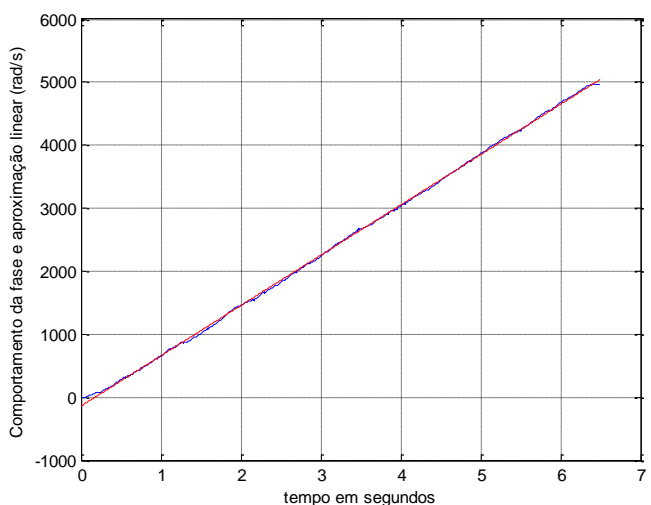

(fase-IMF0,5-1)

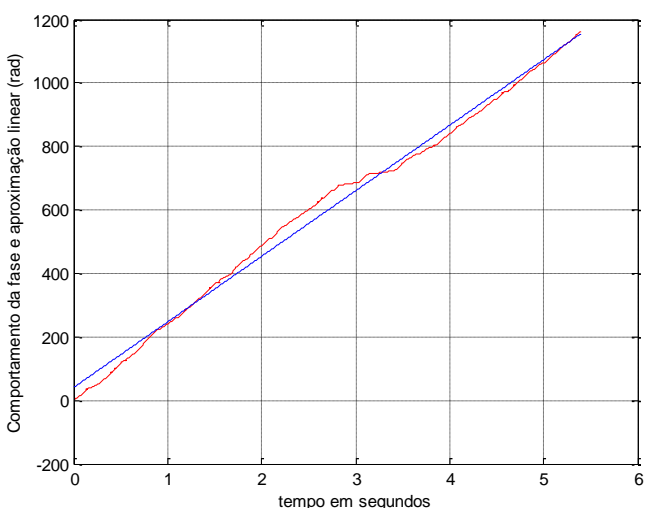

(fase-IMF0,5-3)

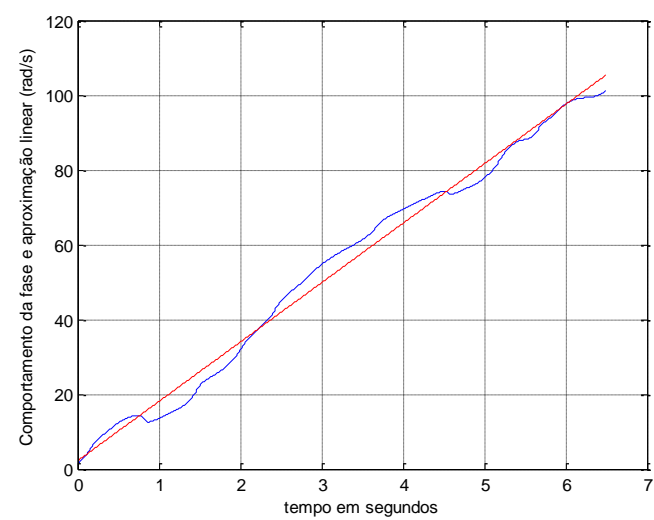

(fase-IMF0,5-5)

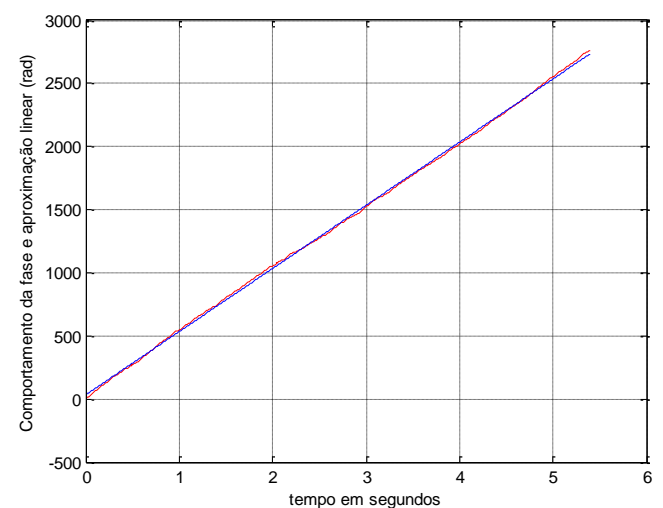

(fase-IMF0,5-2)

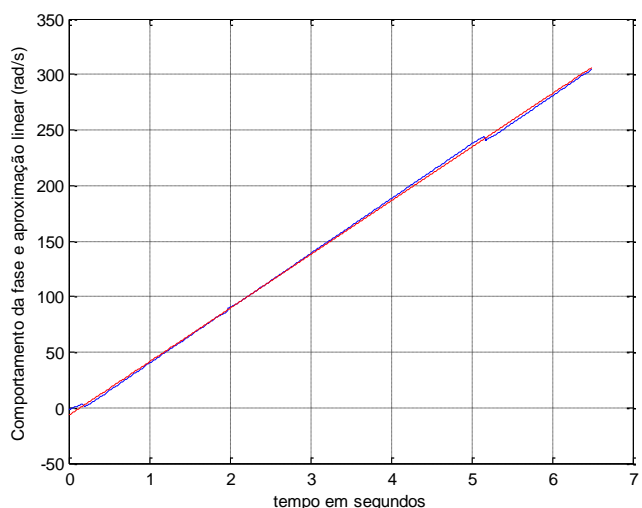

(fase-IMF0,5-4)

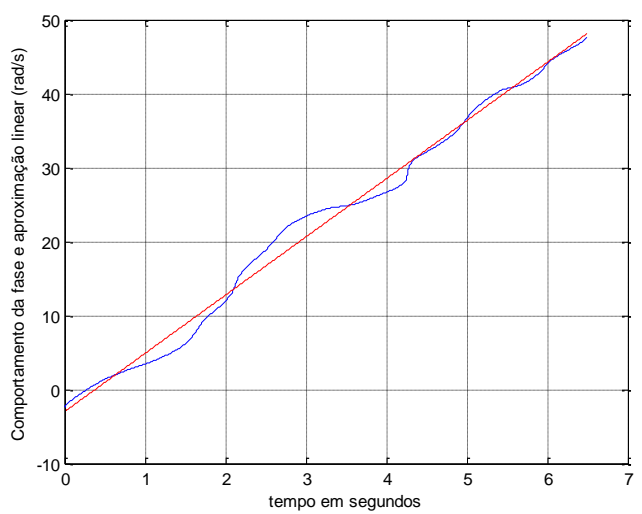

(fase-IMF0,5-6) 


\section{B2- Frequências do sinal analítico com UCP de $0,5 \mathrm{~mm}$}

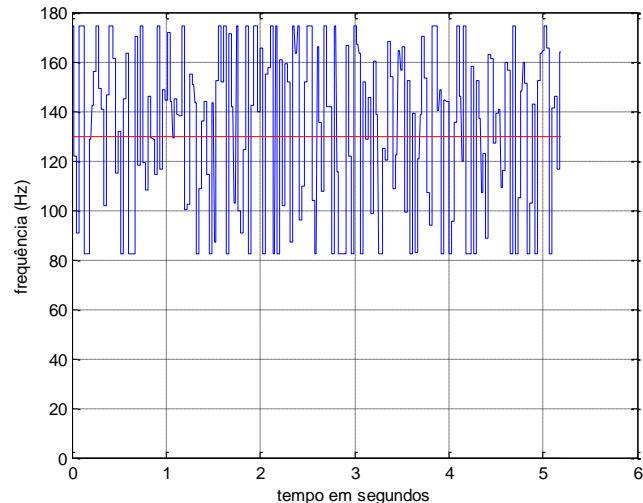

(frequência-IMF0,5-1)

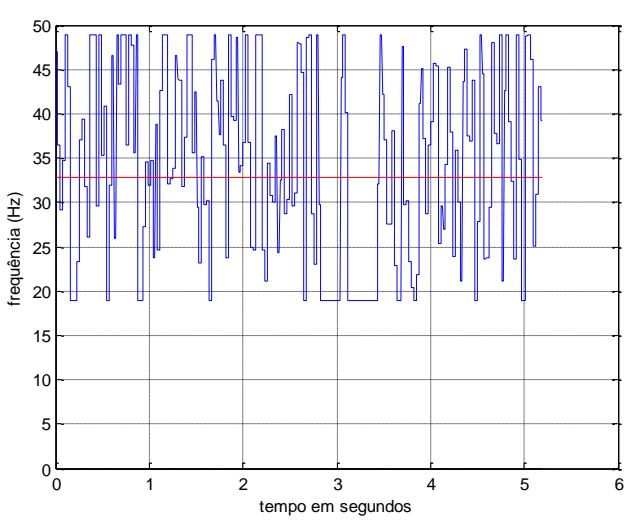

(frequência-IMF0,5-3)

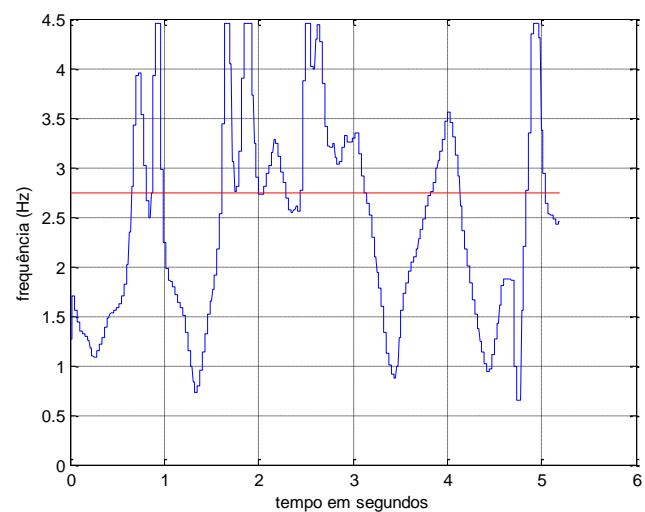

(frequência-IMF0,5-5)

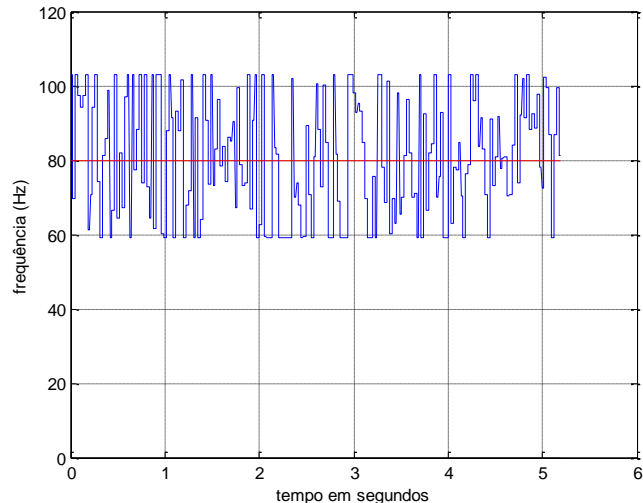

(frequência-IMF0,5-2)

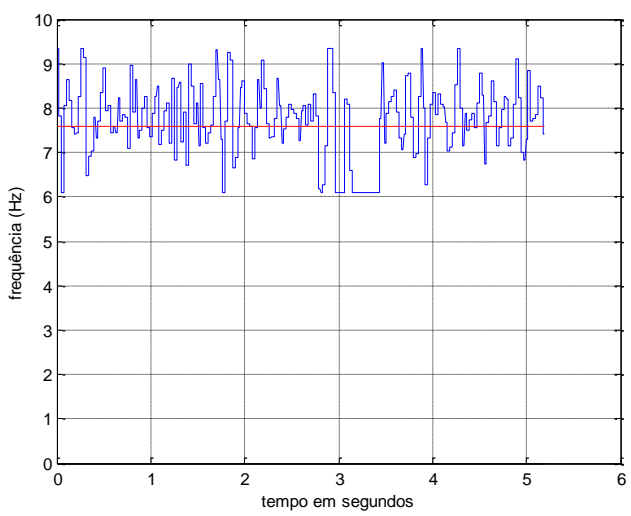

(frequência-IMF0,5-4)

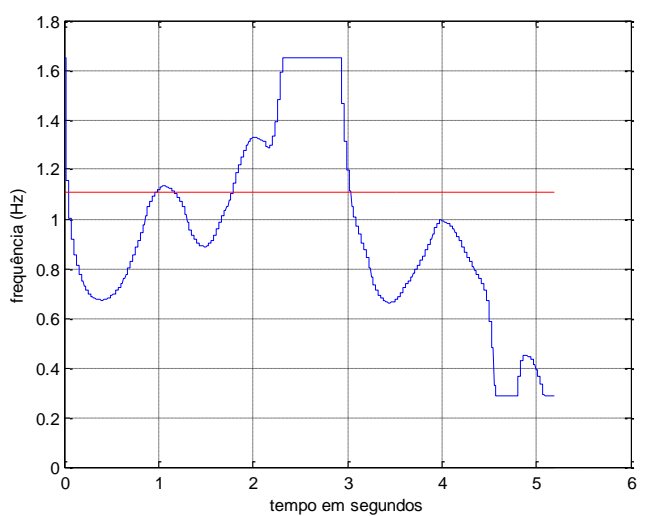

(frequência-IMF0,5-6) 


\section{B3- Módulos do sinal analítico com UCP de $0,5 \mathrm{~mm}$}

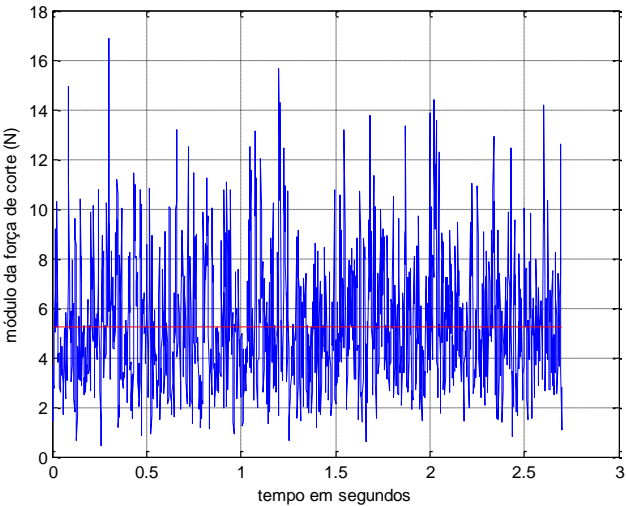

(módulo-IMF0,5-1)

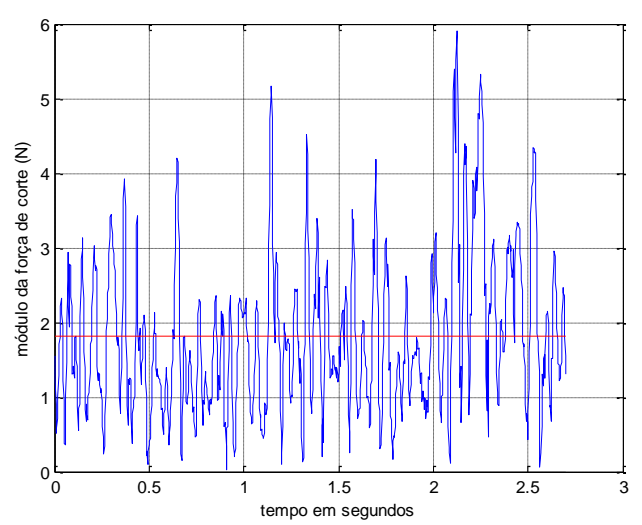

(módulo-IMF0,5-3)

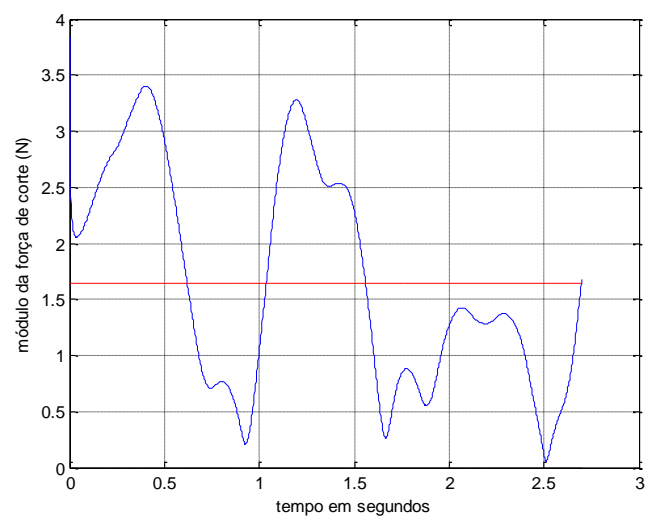

(módulo-IMF0,5-5)

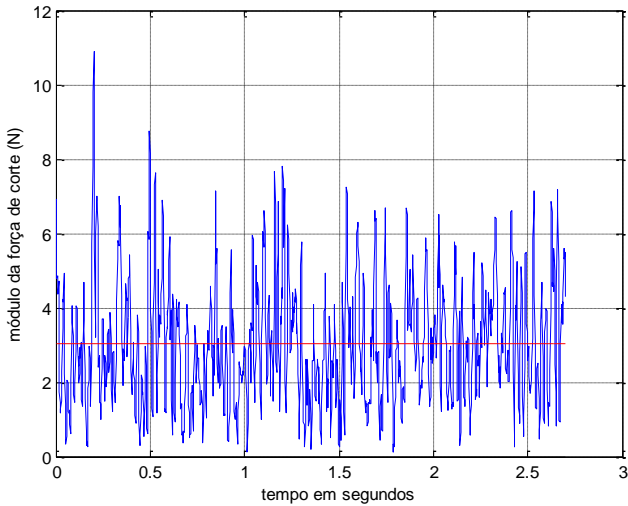

(módulo-IMF0,5-2)

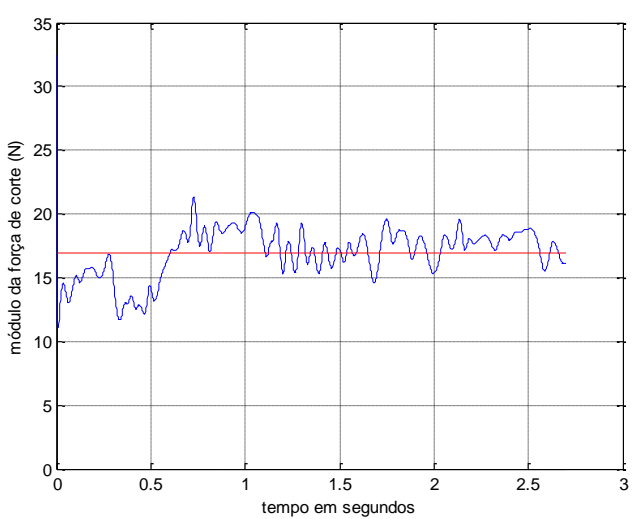

(módulo-IMF0,5-4)

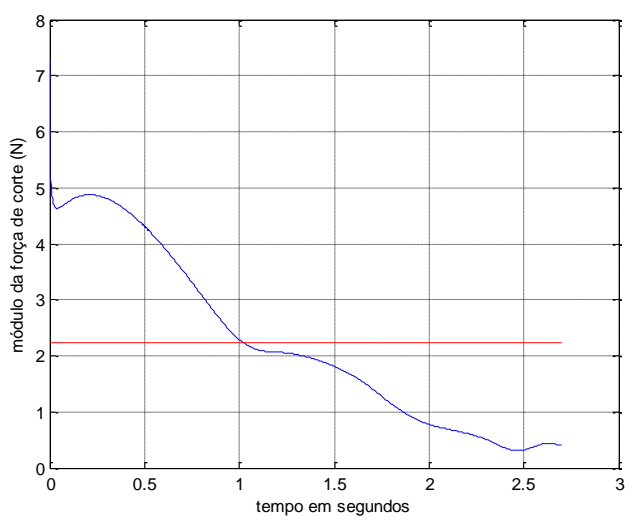

(módulo-IMF0,5-6) 


\section{B4- Fases do sinal analítico com UCP de 1,0mm}

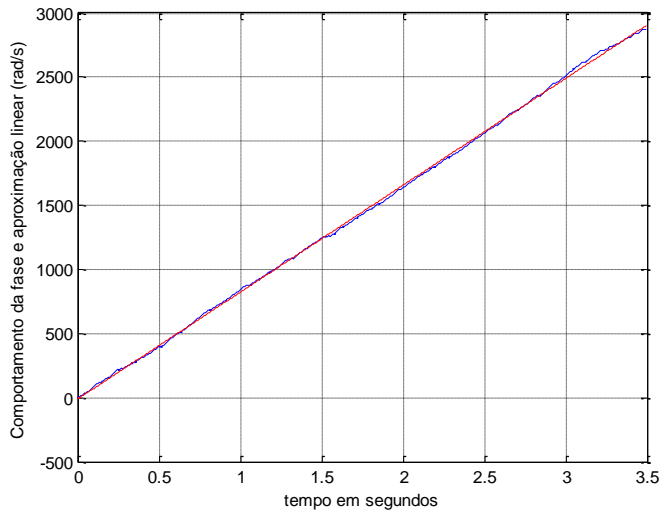

(fase-IMF1,0-1)

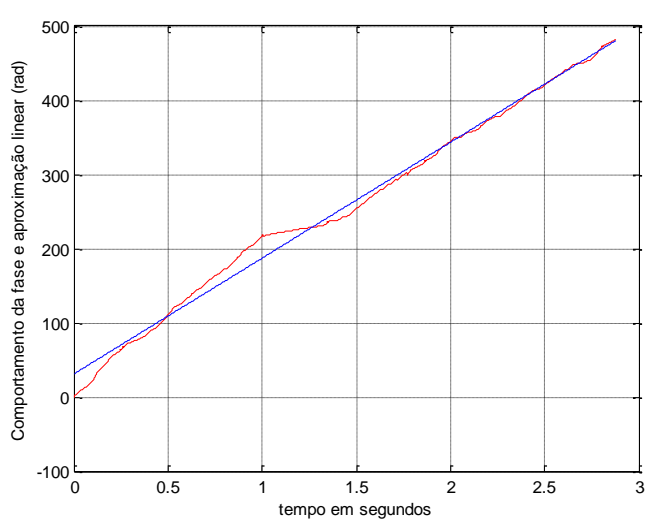

(fase-IMF1,0-3)

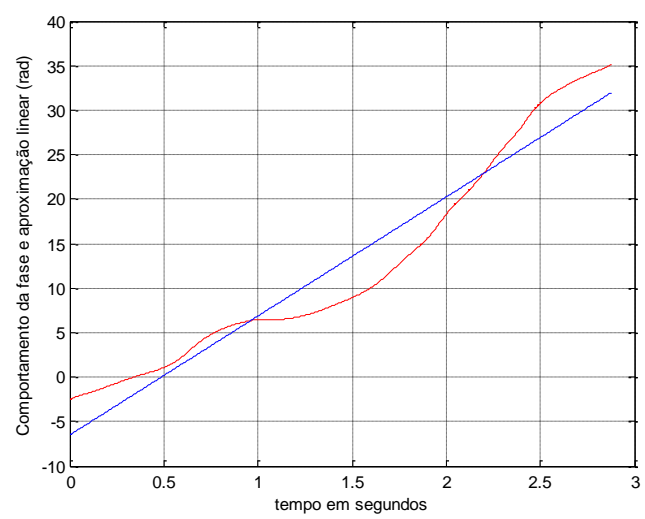

(fase-IMF1,0-5)

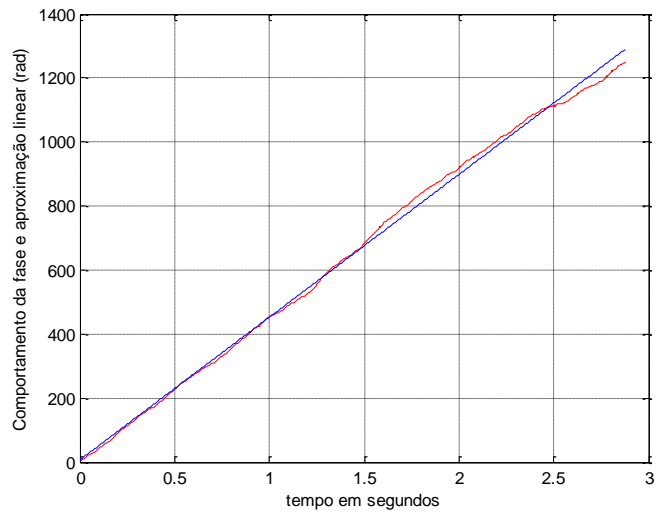

(fase-IMF1,0-2)

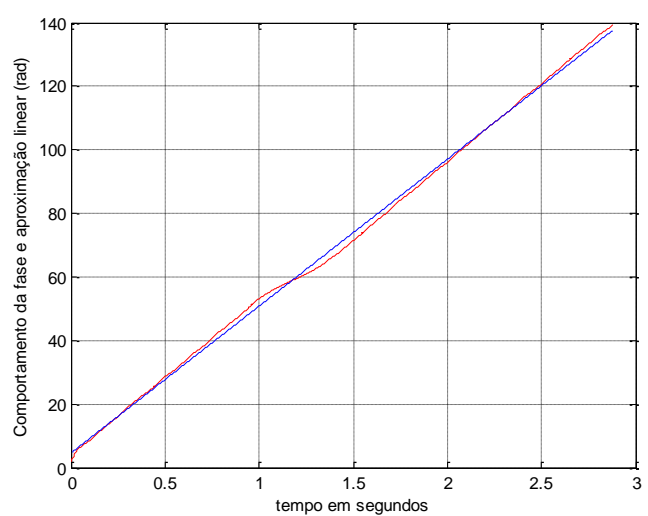

(fase-IMF1,0-4)

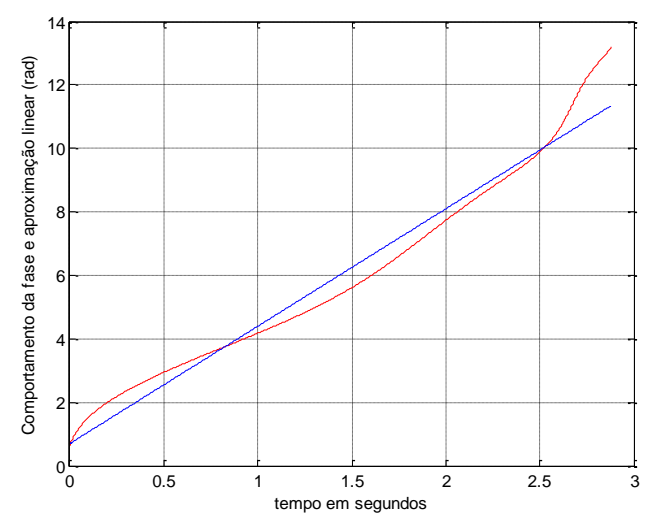

(fase-IMF1,0-6) 
B5- Frequências do sinal analítico com UCP de 1,0mm

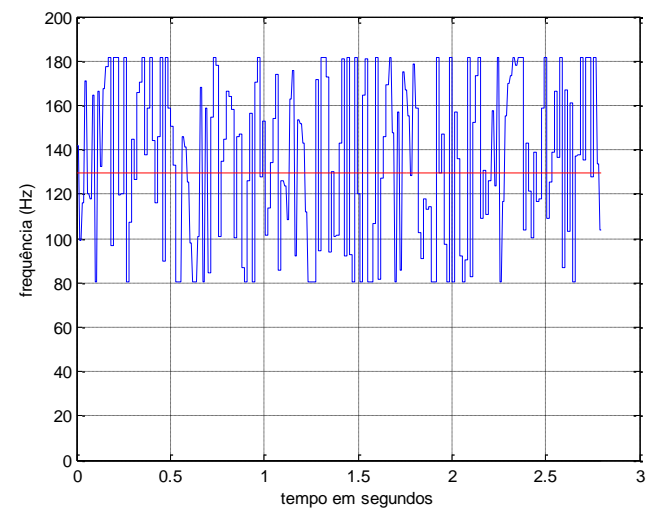

(frequência-IMF1,0-1)

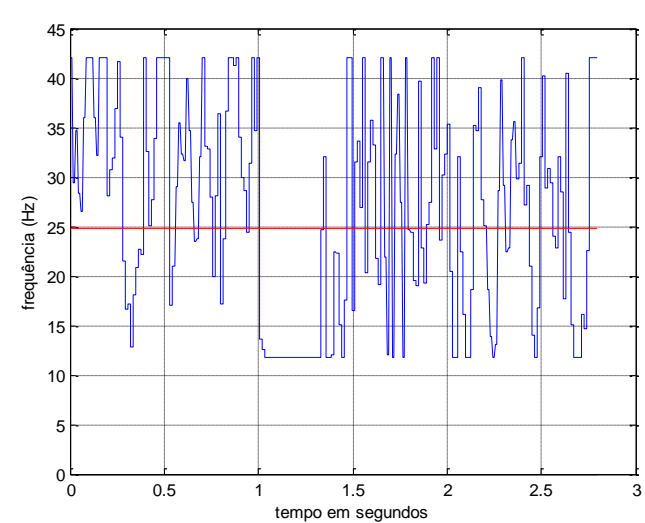

(frequência-IMF1,0-3)

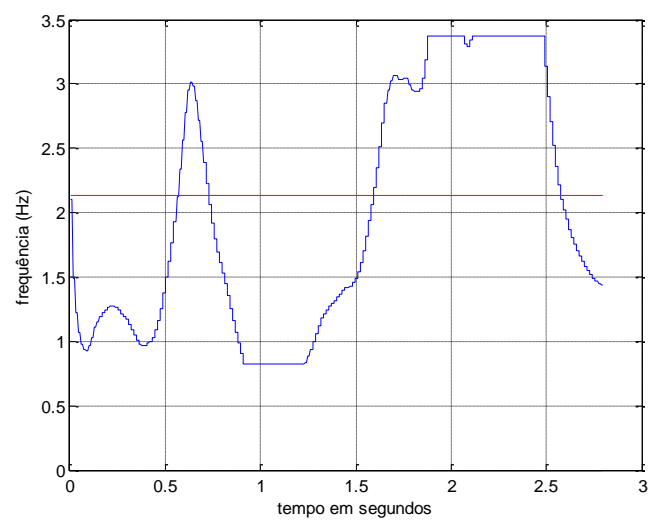

(frequência-IMF1,0-5)

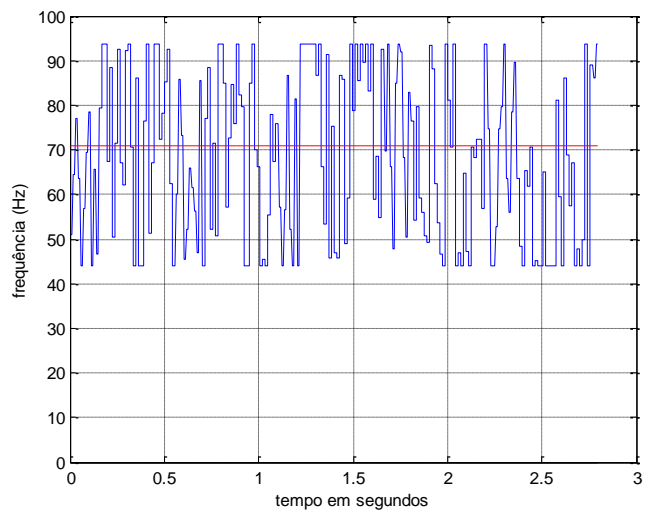

(frequência-IMF1,0-2)

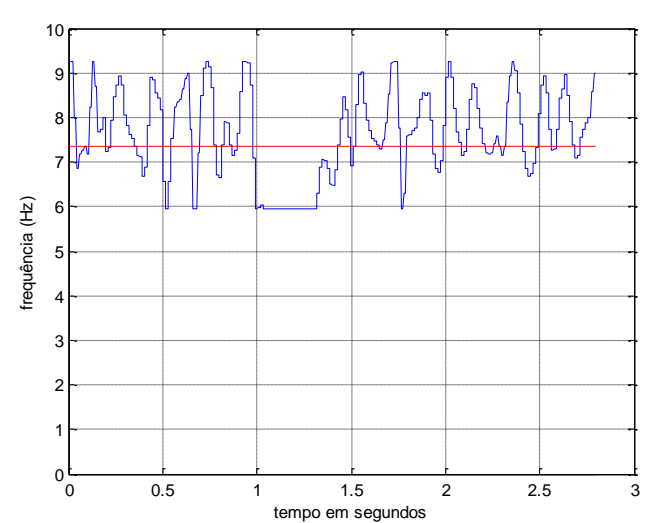

(frequência-IMF1,0-4)

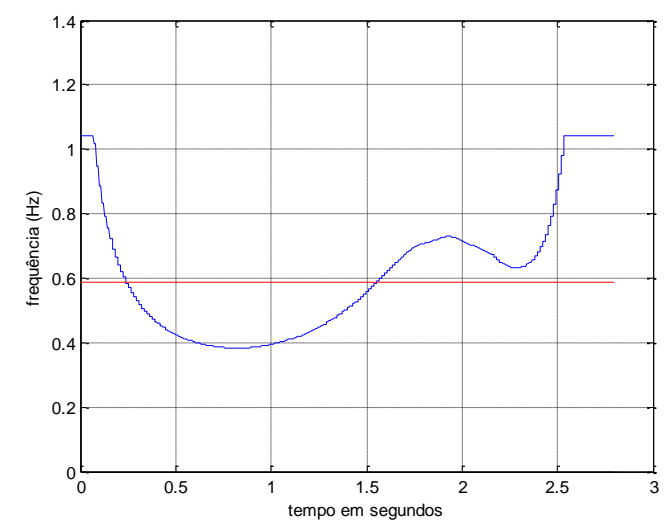

(frequência-IMF1,0-6) 
B6- Módulos do sinal analítico com UCP de 1,0mm

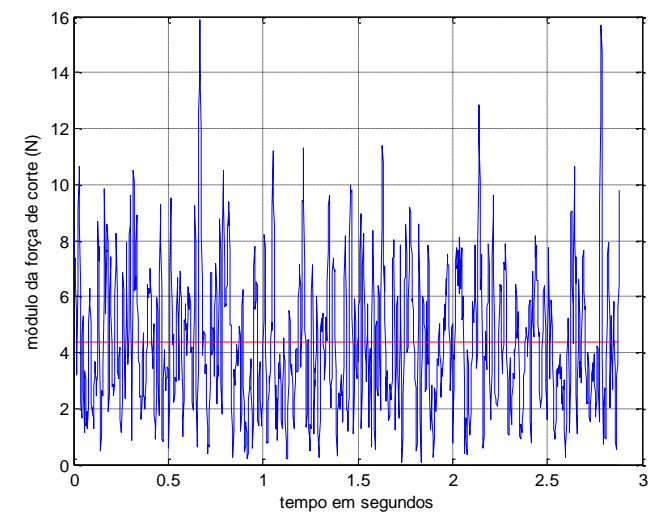

(módulo-IMF1,0-1)

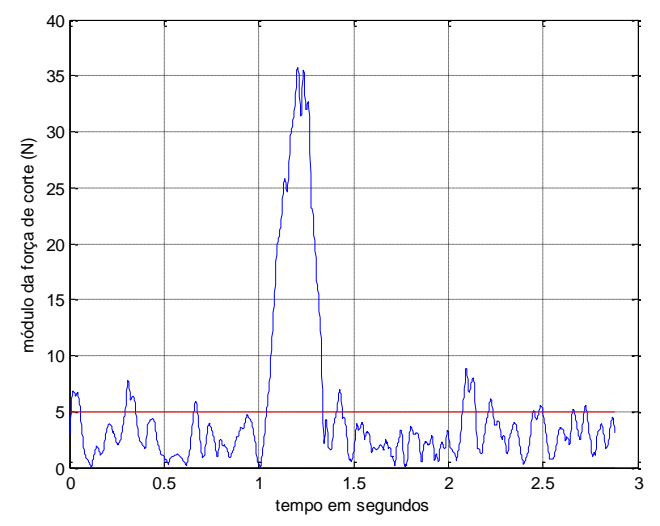

(módulo-IMF1,0-3)

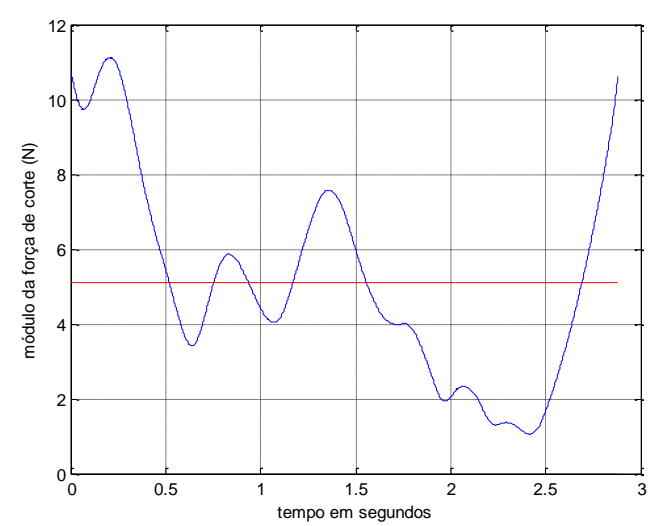

(módulo-IMF1,0-5)

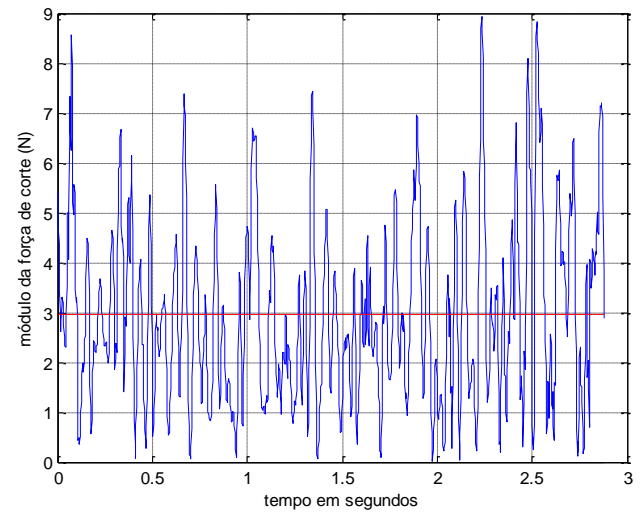

(módulo-IMF1,0-2)

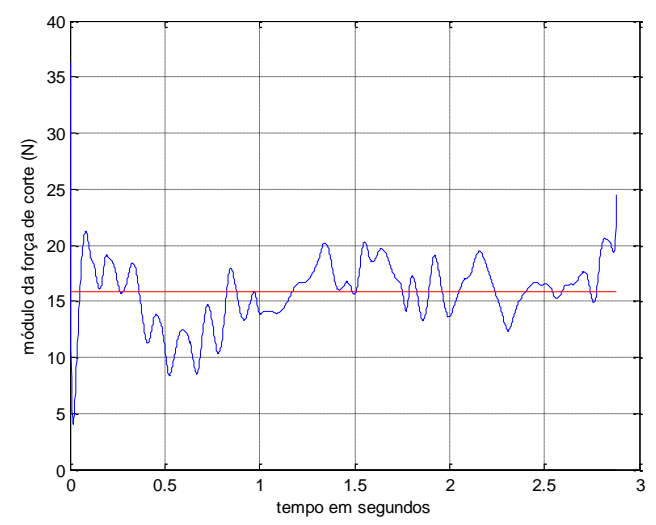

(módulo-IMF1,0-4)

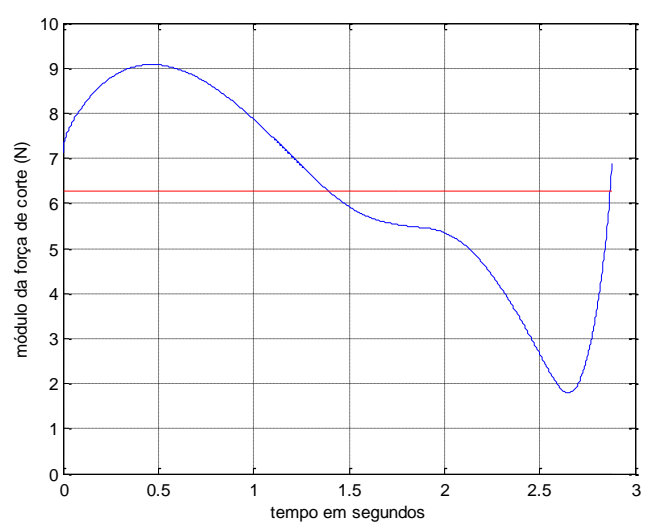

(módulo-IMF1,0-6) 


\section{B7- Fases do sinal analítico com UCP de 1,5mm}

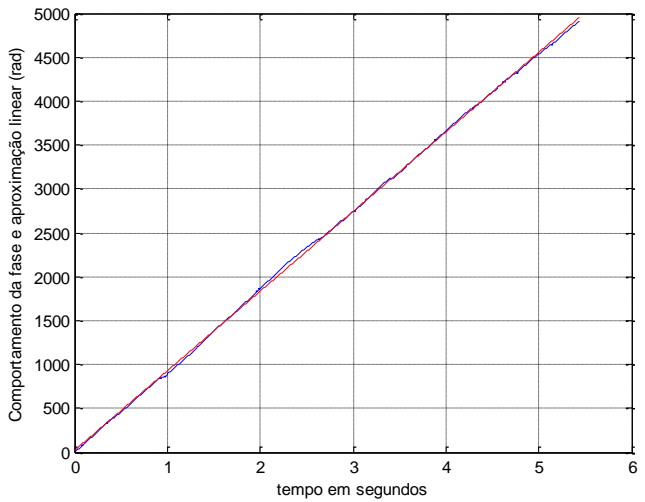

(fase-IMF1,5-1)

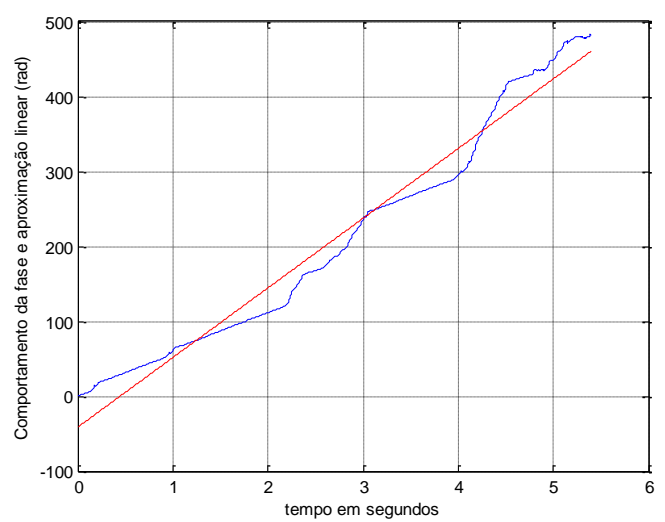

(fase-IMF1,5-3)

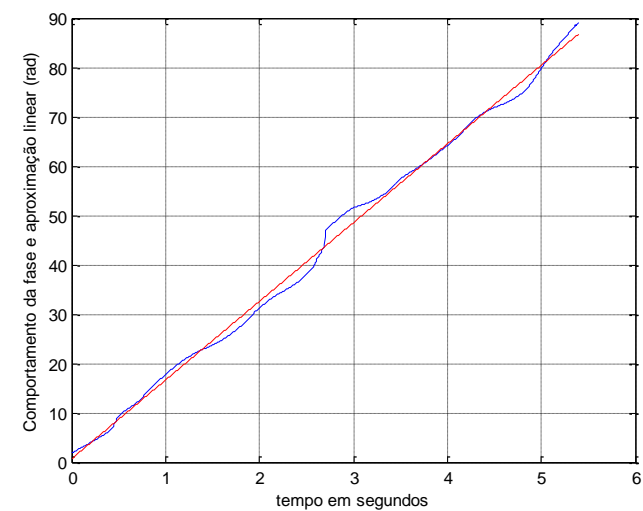

(fase-IMF1,5-5)

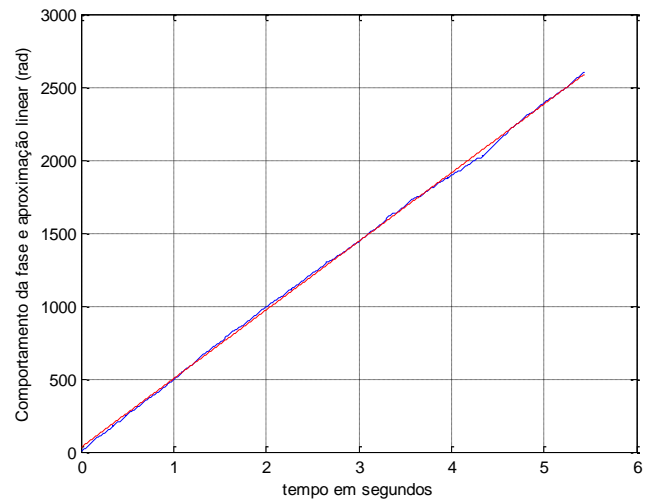

(fase-IMF1,5-2)

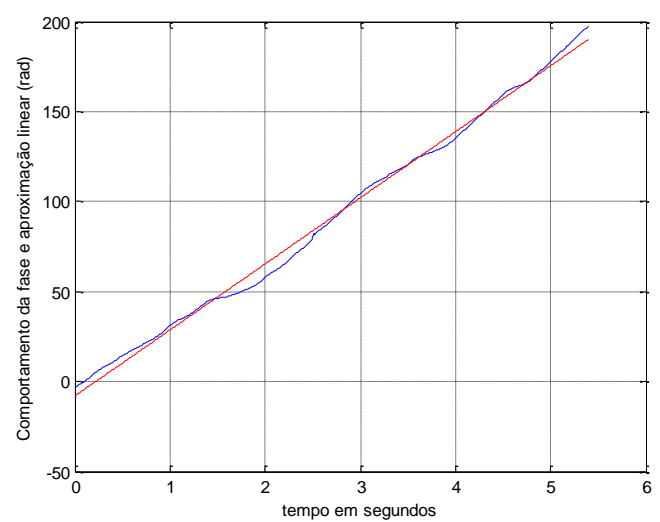

(fase-IMF1,5-4)

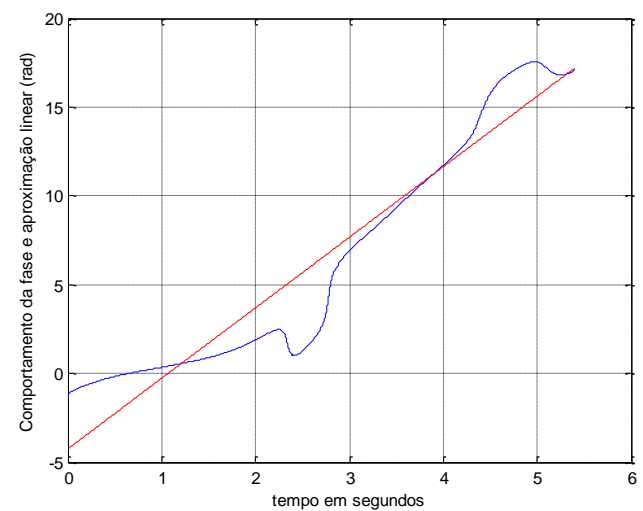

(fase-IMF1,5-6) 


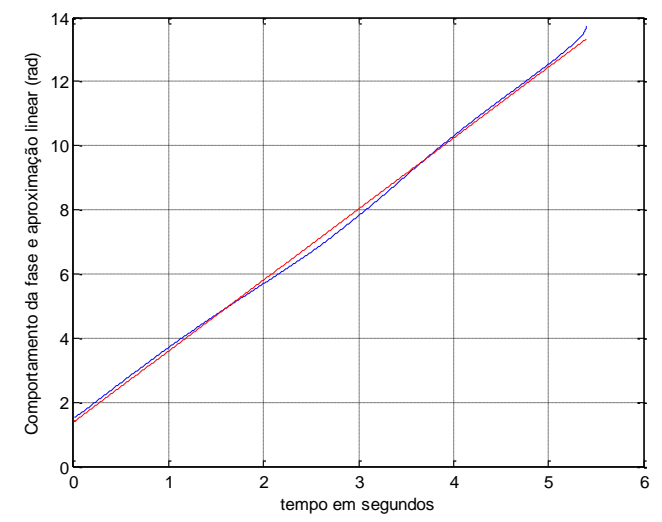

fase-IMF1,5-7)

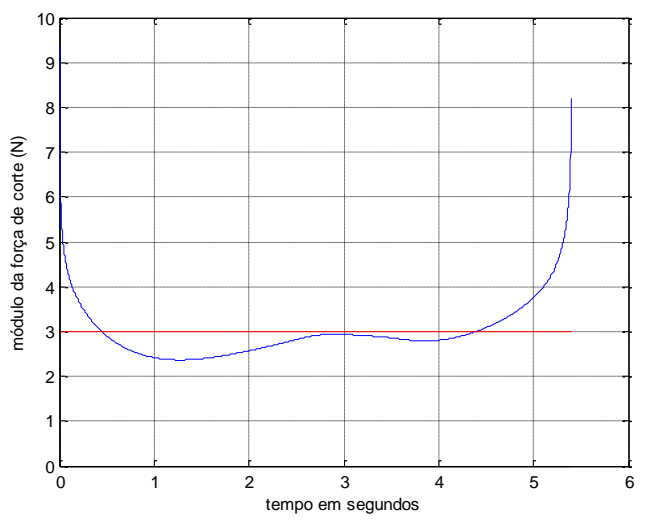

(fase-IMF1,5-8)

B8- Frequências do sinal analítico com UCP de 1,5mm

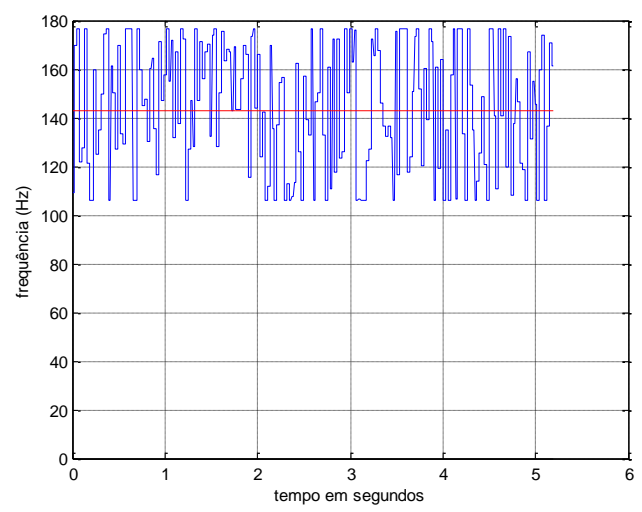

(frequência-IMF1,5-1)

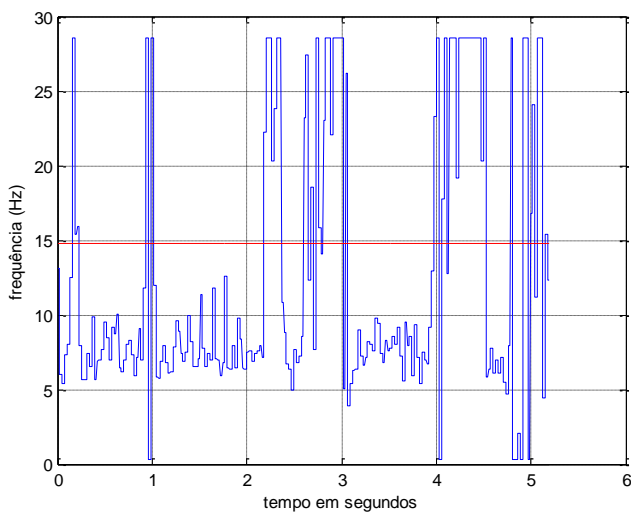

(frequência-IMF1,5-3)

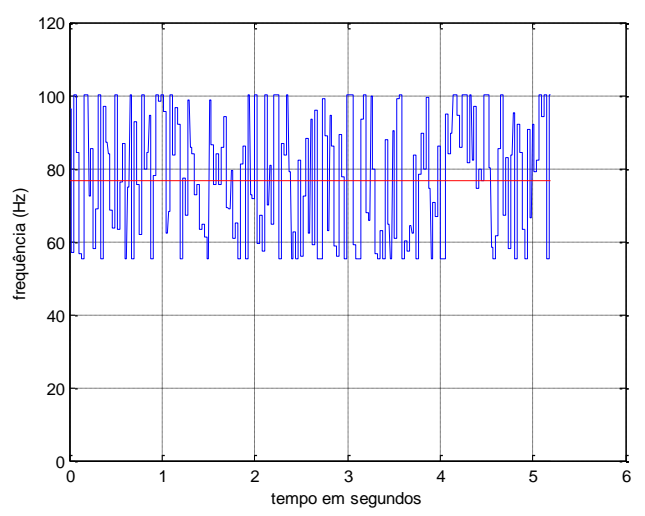

(frequência-IMF1,5-2)

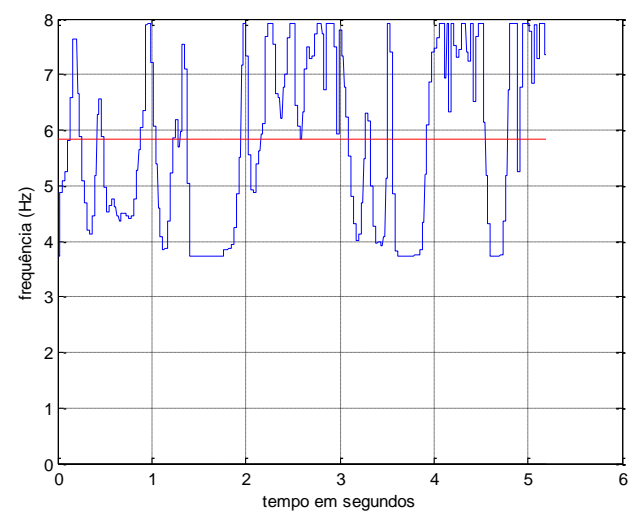

(frequência-IMF1,5-4) 


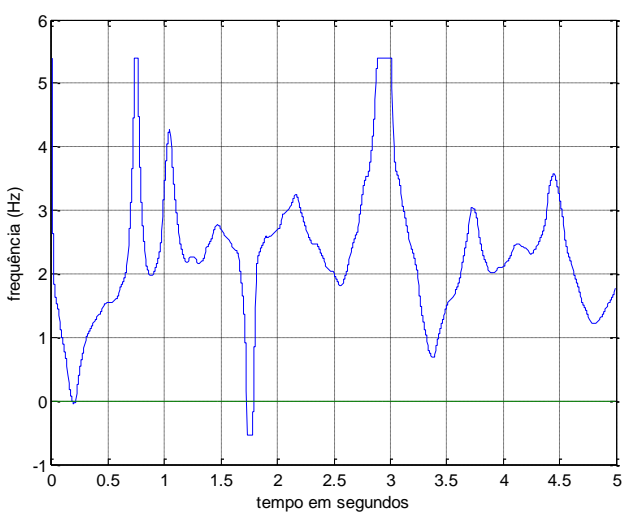

(frequência-IMF1,5-5)

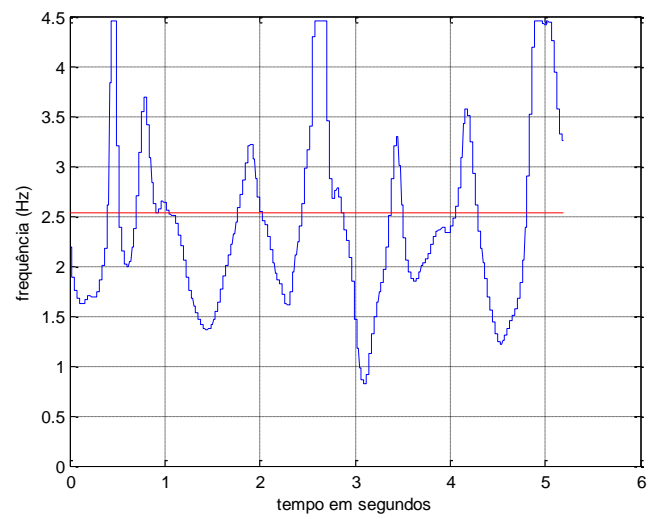

(frequência-IMF1,5-7)

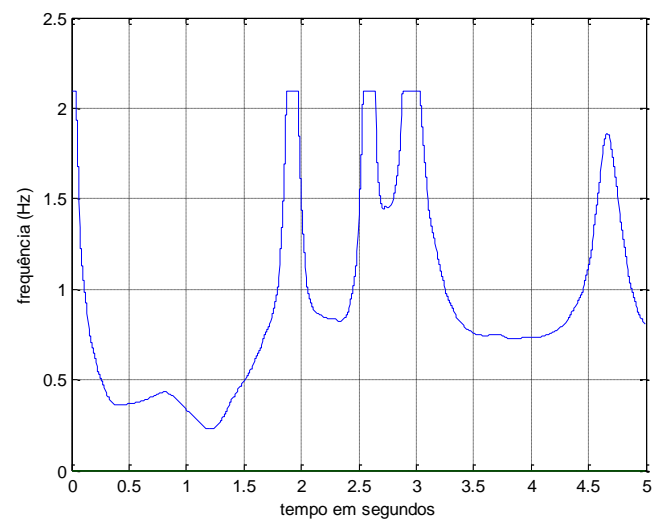

(frequência-IMF1,5-6)

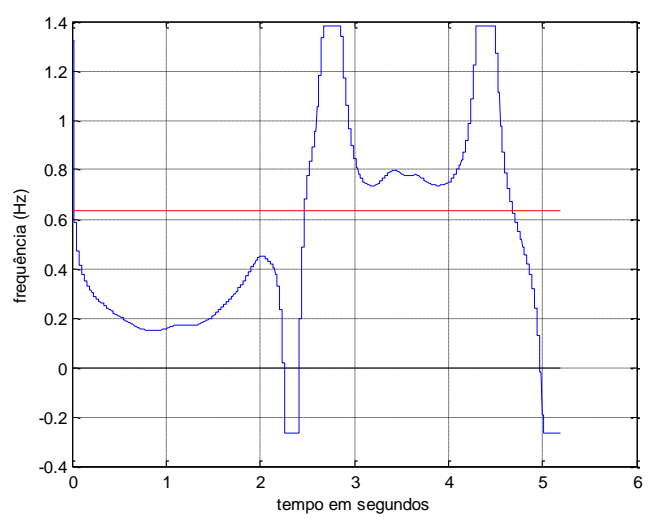

(frequência-IMF1,5-8)

\section{B9- Módulos do sinal analítico com UCP de 1,5mm}

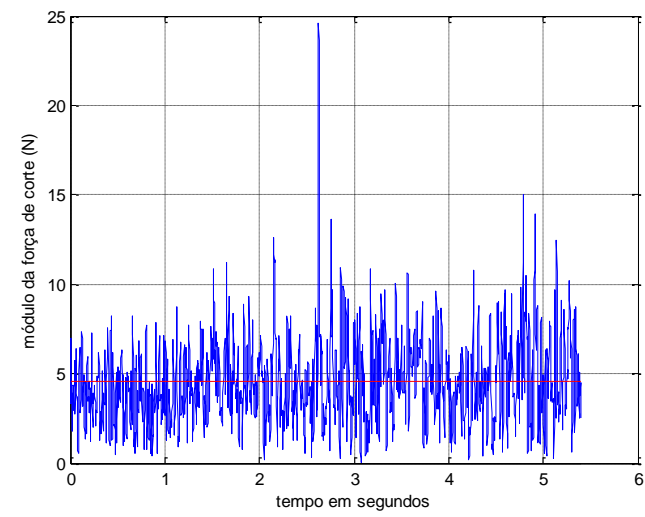

(módulo-IMF1,5-1)

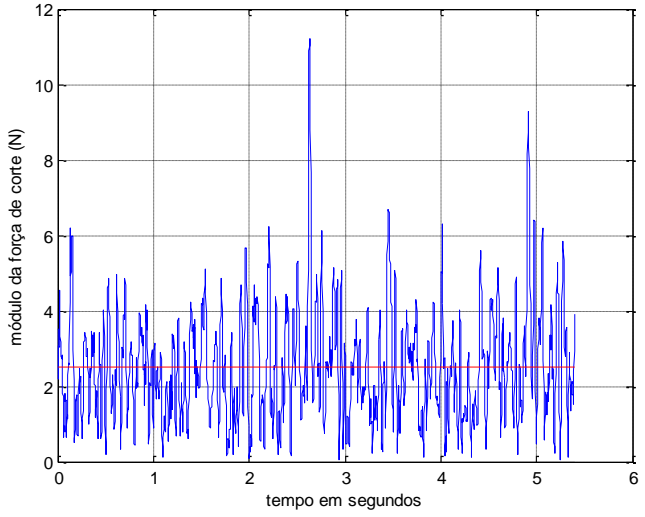

(módulo-IMF1,5-2) 


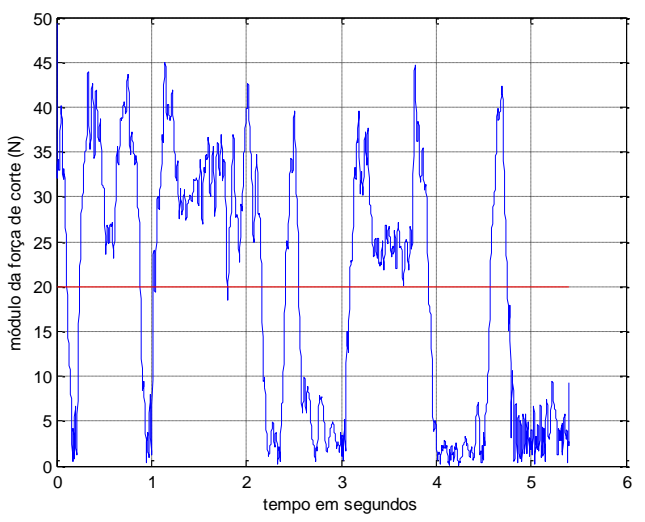

(módulo-IMF1,5-3)

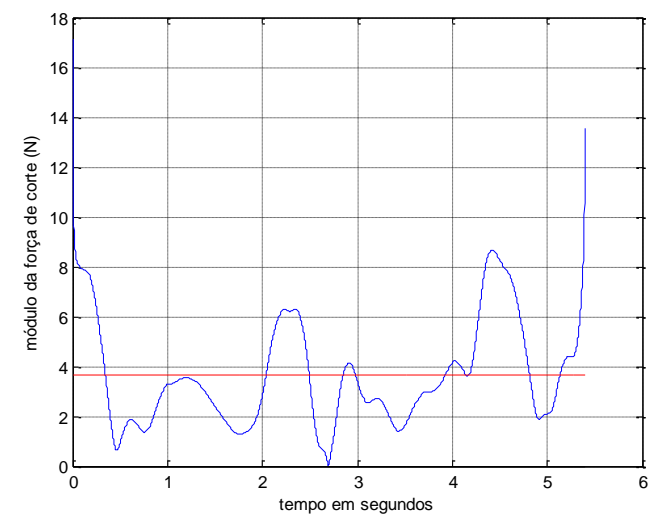

(módulo-IMF1,5-5)

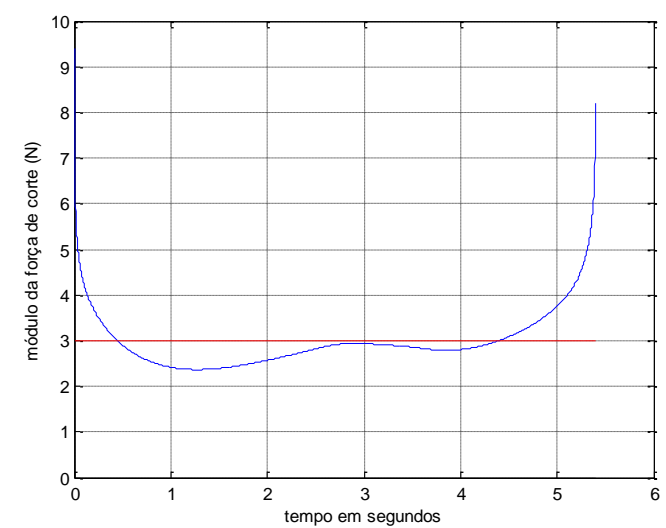

(módulo-IMF1,5-7)

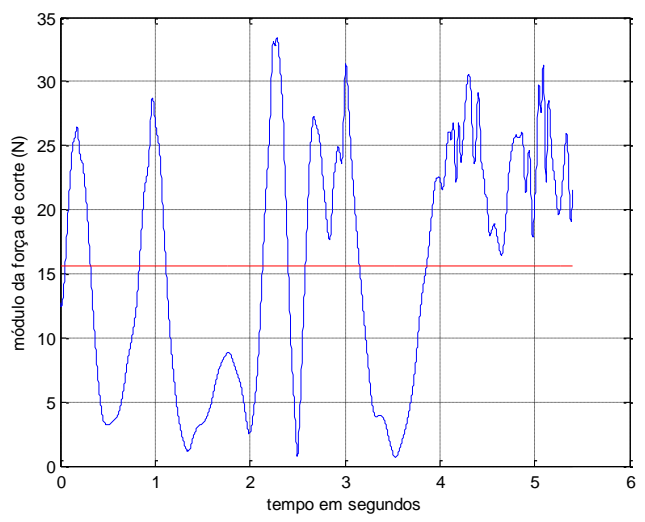

(módulo-IMF1,5-4)

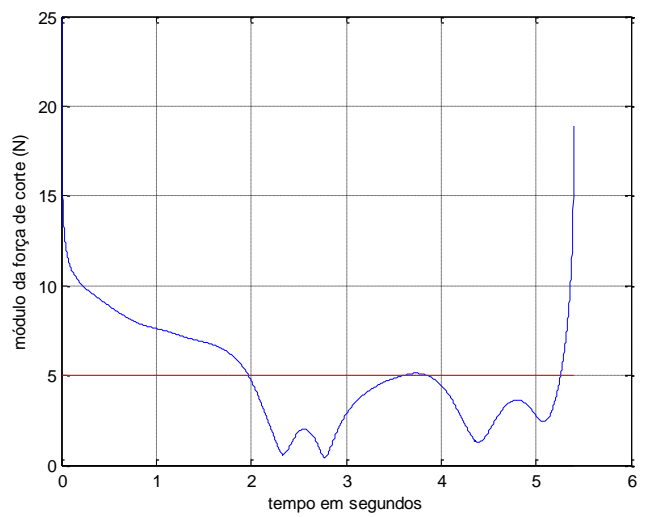

(módulo-IMF1,5-6) 


\section{USINAGEM COM CORTE INTERROMPIDO MEDIDA COM DINAMÔMETRO}

\section{B10- Fases do sinal analítico de $\mathrm{Cl}$ com UCP de $0,5 \mathrm{~mm}$}

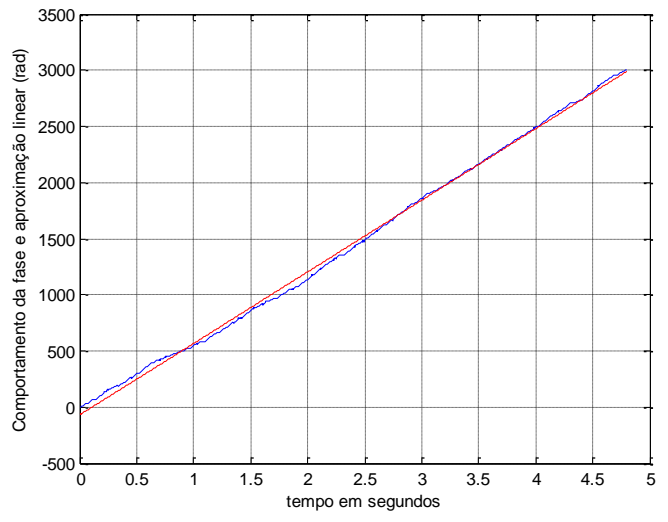

(fase-IMF0,5mm_int-1)

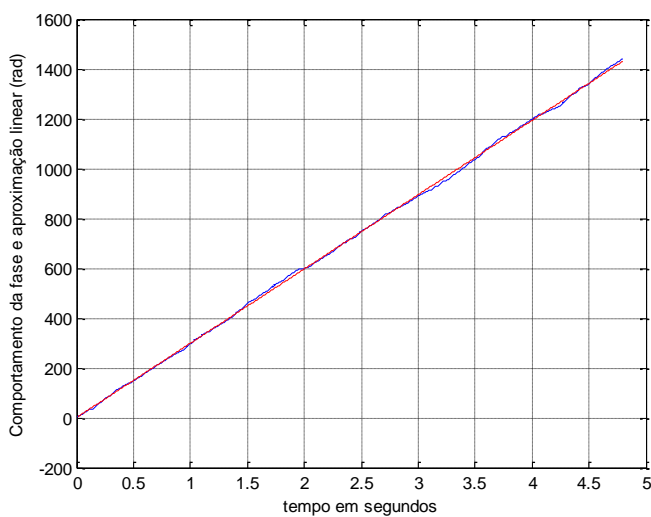

(fase-IMF0,5mm_int-3)

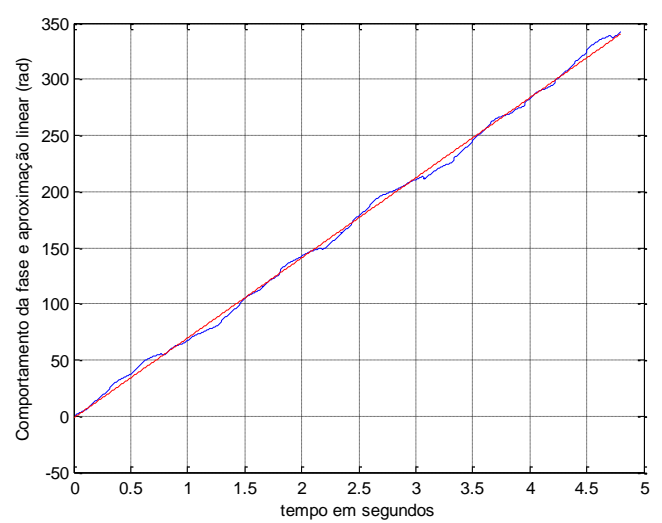

(fase-IMF0,5mm_int-5)

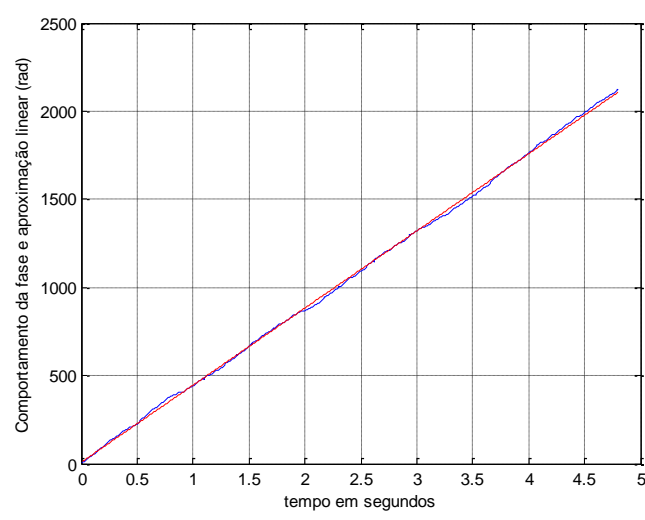

(fase-IMF0,5mm_int-2)

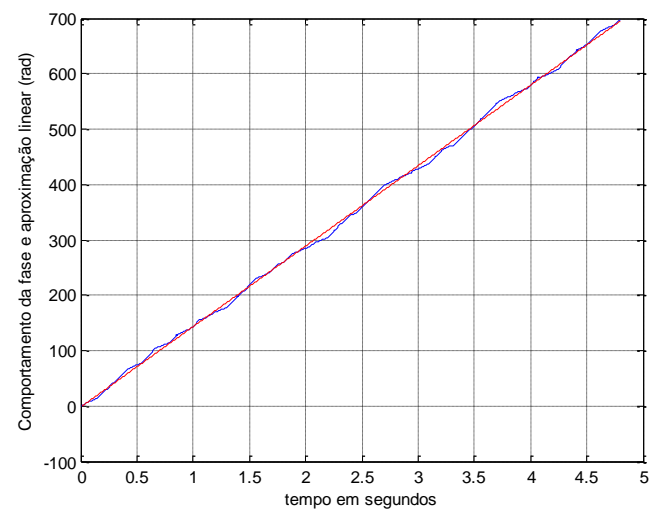

(fase-IMF0,5mm_int-4)

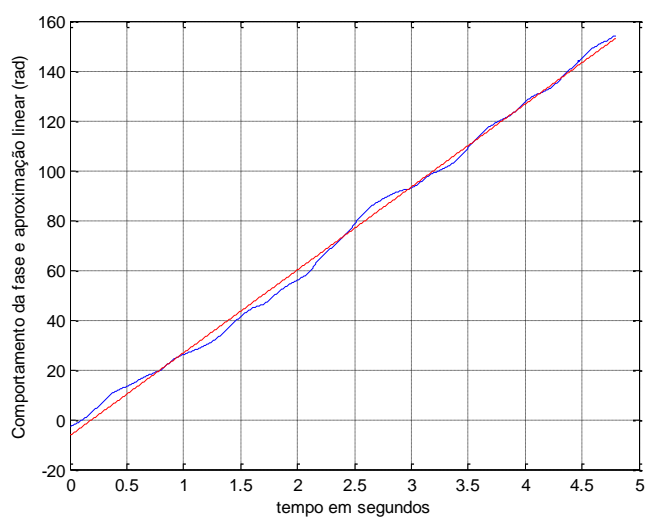

(fase-IMF0,5mm_int-6) 


\section{B11- Frequências do sinal analítico de $\mathrm{Cl}$ com UCP de $0,5 \mathrm{~mm}$}

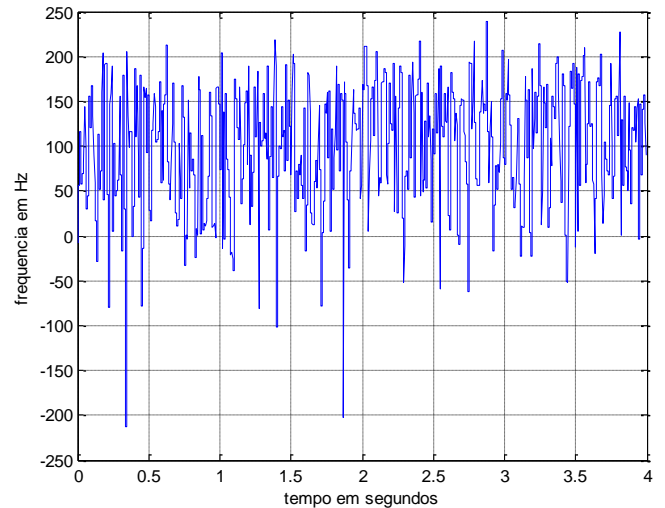

(frequência-IMF0,5mm_int-1)

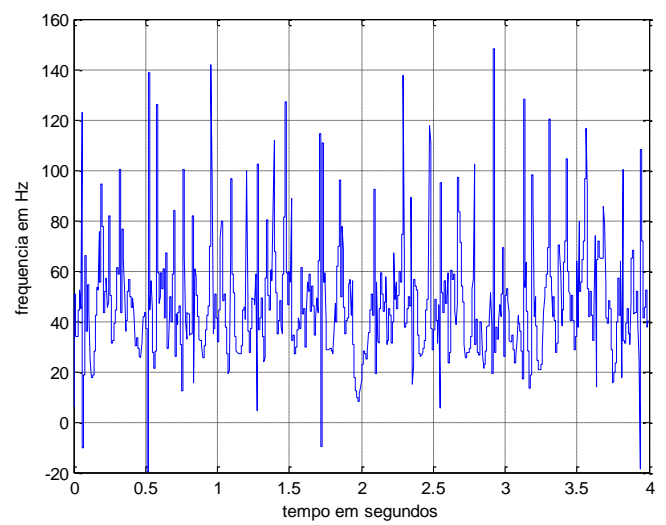

(frequência-IMF0,5mm_int-3)

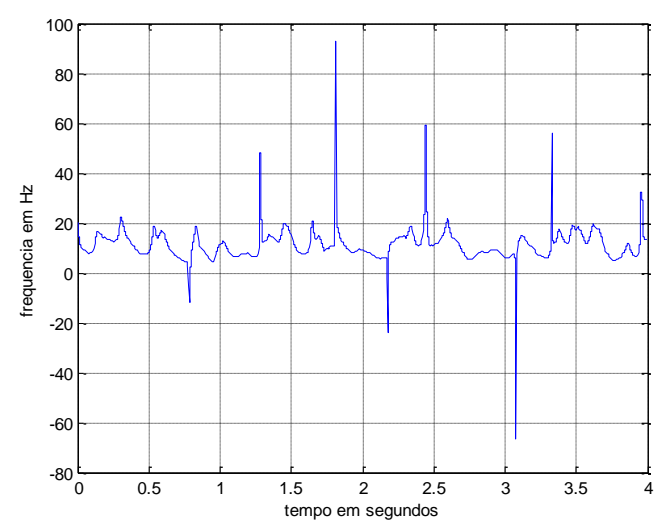

(frequência-IMF0,5mm_int-5)

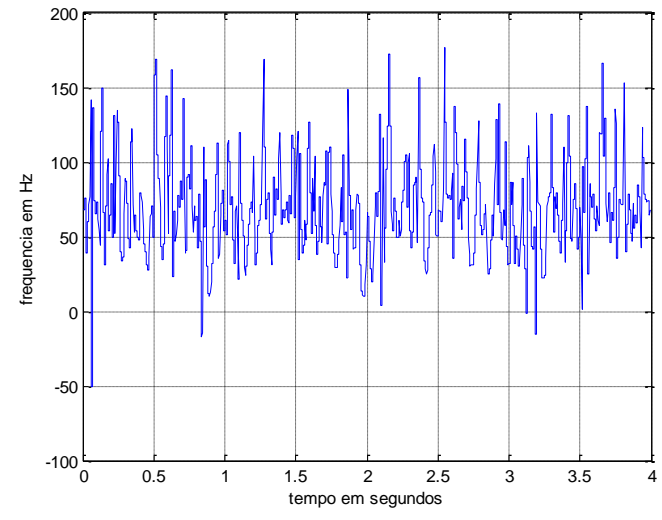

(frequência-IMF0,5mm_int-2)

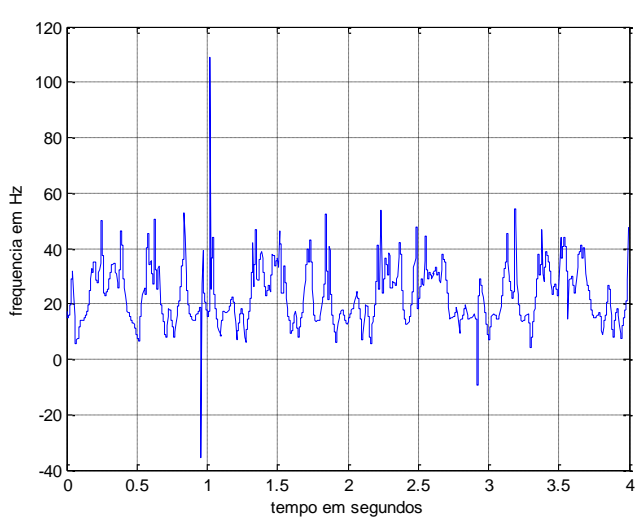

(frequência-IMF0,5mm_int-4)

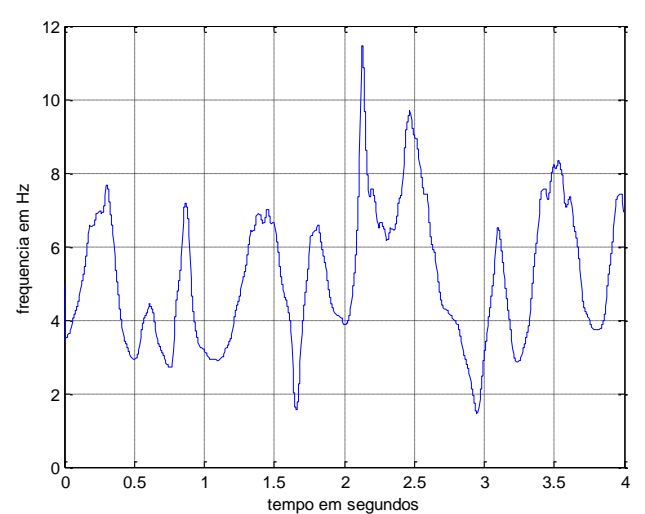

(frequência-IMF0,5mm_int-6) 
B12- Módulos do sinal analítico de $\mathrm{Cl}$ com UCP de 0,5mm

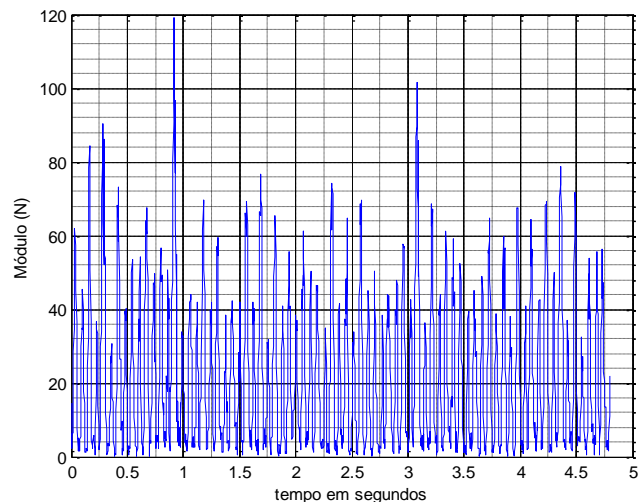

(Módulo-IMF0,5mm_int-1)

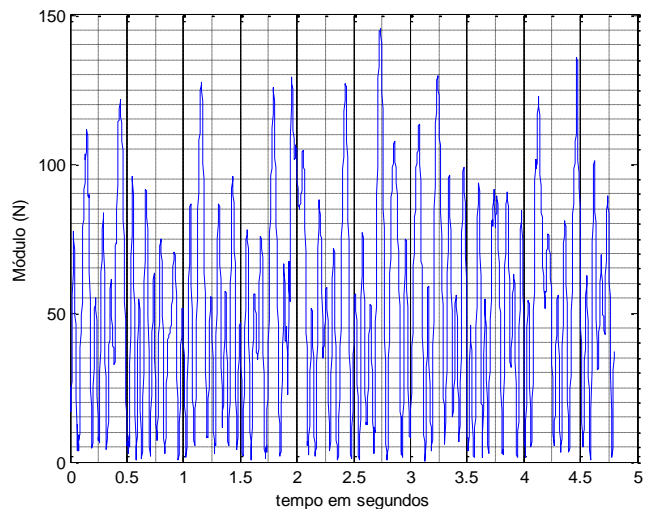

(Módulo-IMF0,5mm_int-3)

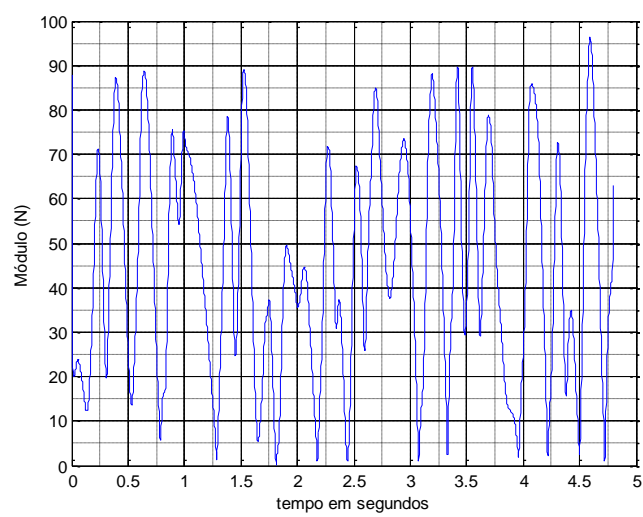

(Módulo-IMF0,5mm_int-5)

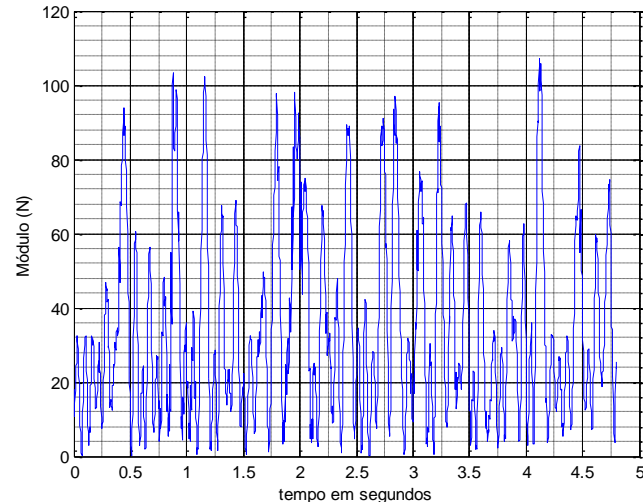

(Módulo-IMF0,5mm_int-2)

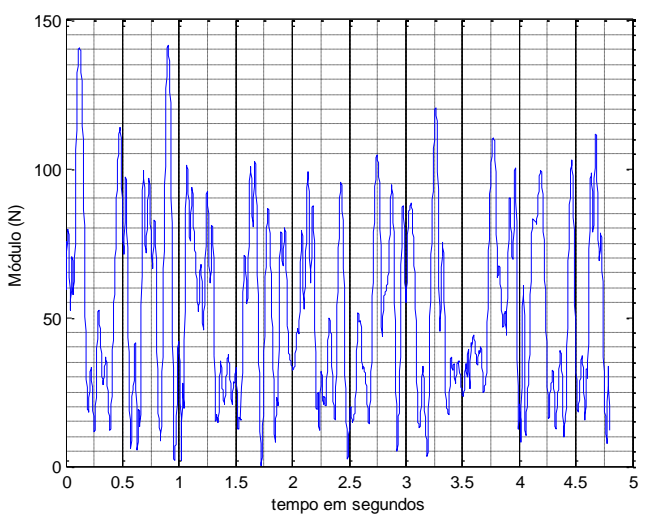

(Módulo-IMF0,5mm_int-4)

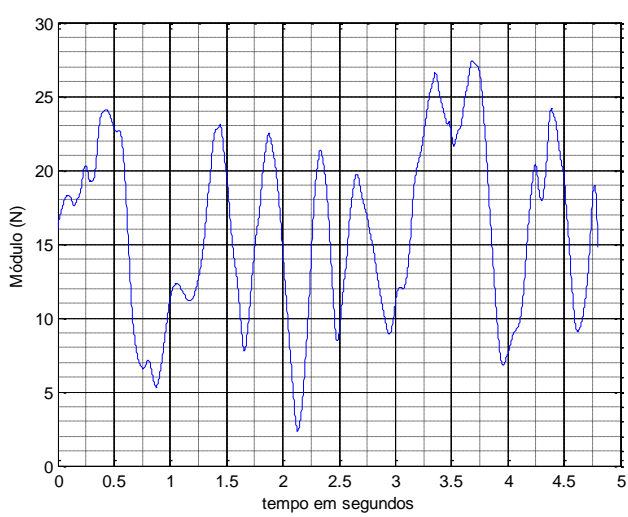

(Módulo-IMF0,5mm_int-6) 
B13- Fases do sinal analítico de $\mathrm{Cl}$ com UCP de 1,0mm

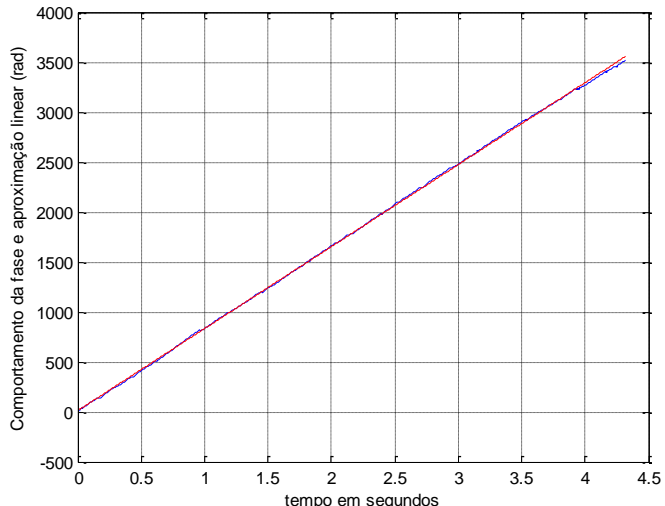

(fase-IMF1,0mm_int-1)

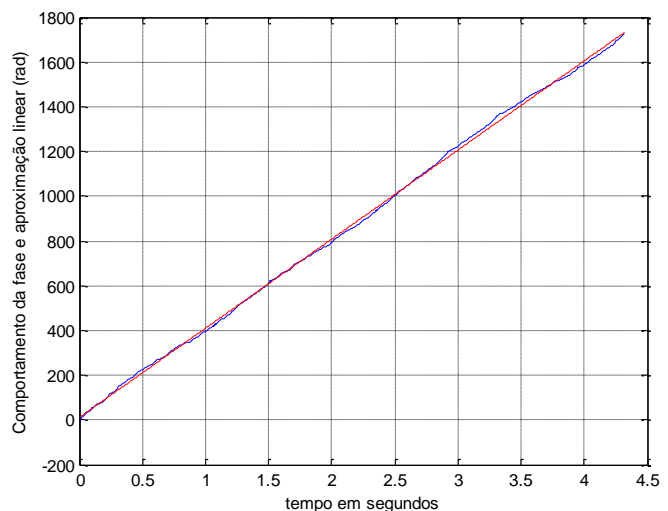

(fase-IMF1,0mm_int-3)

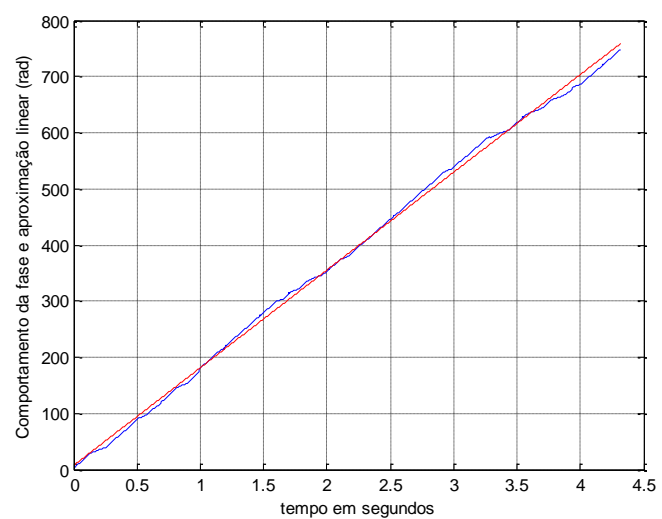

(fase-IMF1,0mm_int-5)

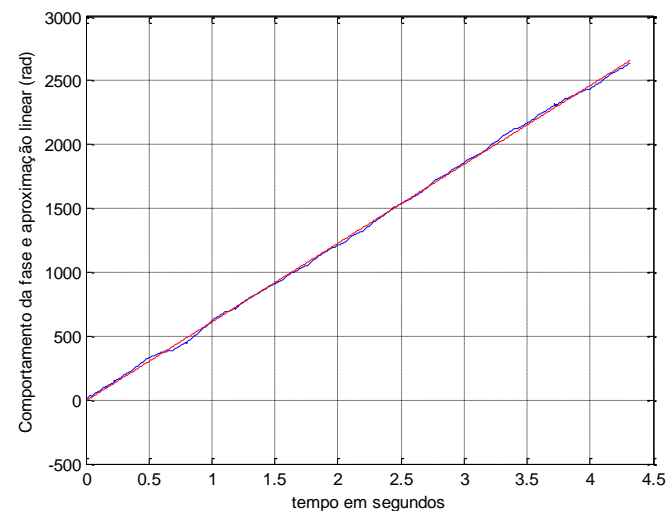

(fase-IMF1,0mm_int-2)

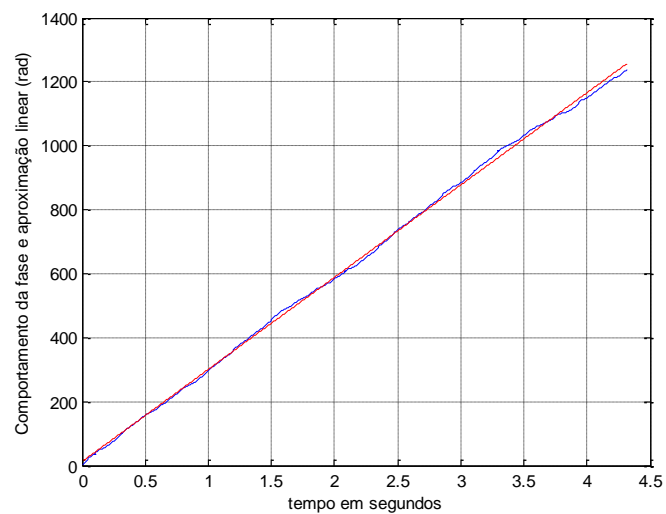

(fase-IMF1,0mm_int-4)

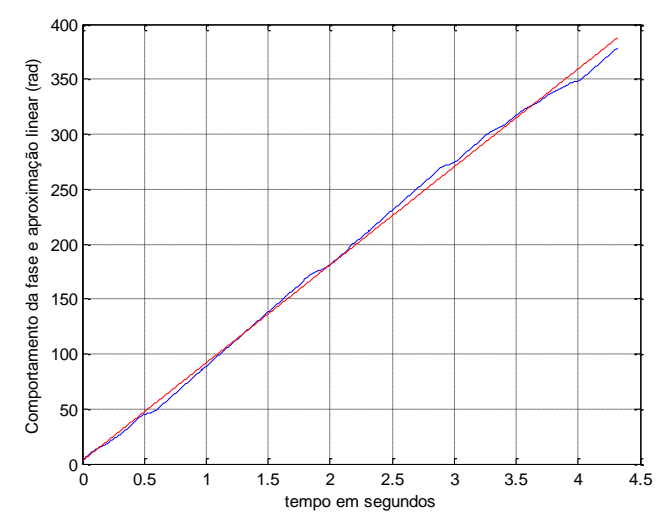

(fase-IMF1,0mm_int-6) 


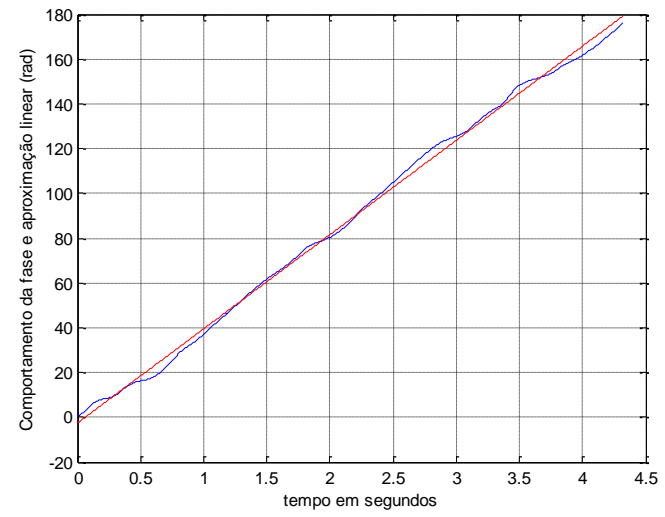

(fase-IMF1,0mm_int-7)

\section{B14-Frequências do sinal analítico de $\mathrm{Cl}$ com UCP de 1,0mm}

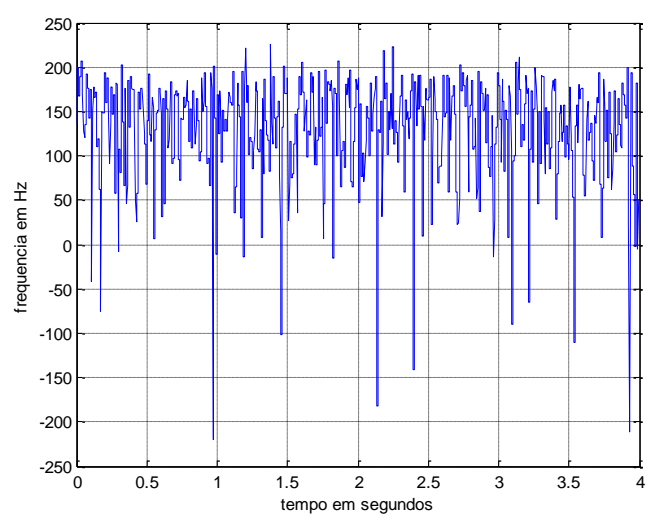

(frequência-IMF1,0mm_int-1)

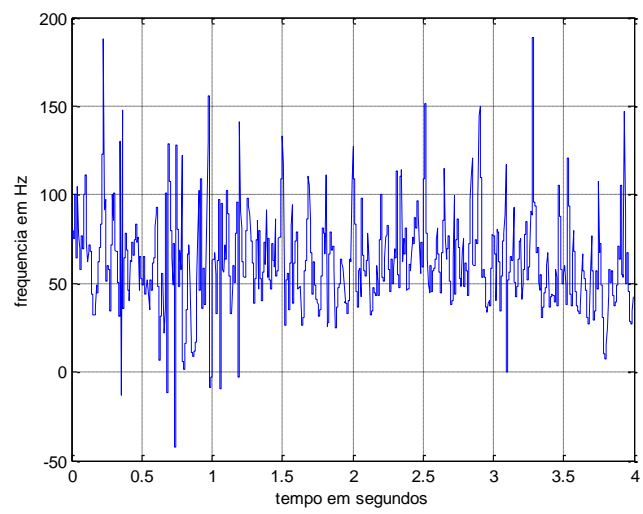

(frequência-IMF1,0mm_int-3)

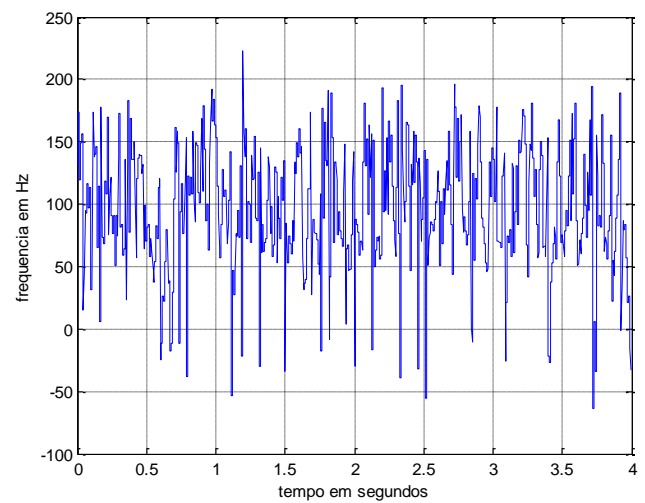

(frequência-IMF1,0mm_int-2)

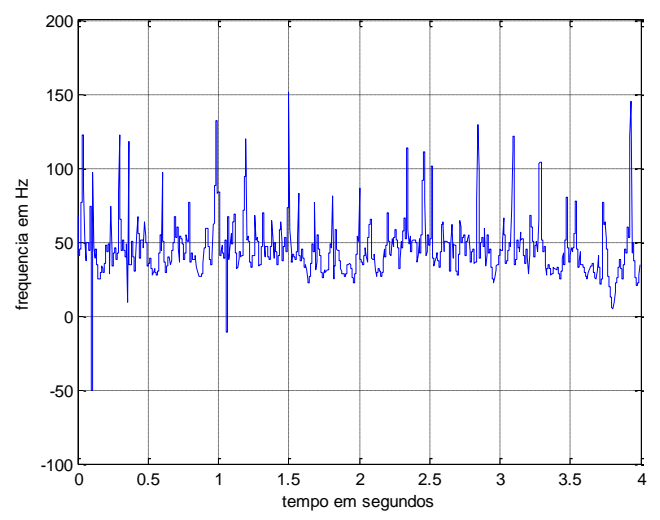

(frequência-IMF1,0mm_int-4) 


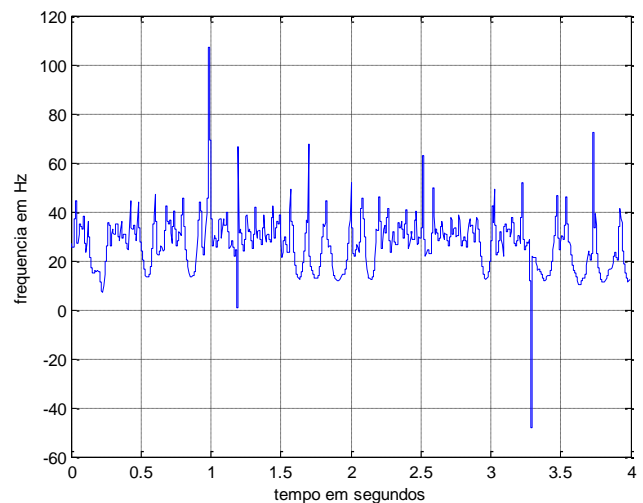

(frequência-IMF1,0mm_int-5)

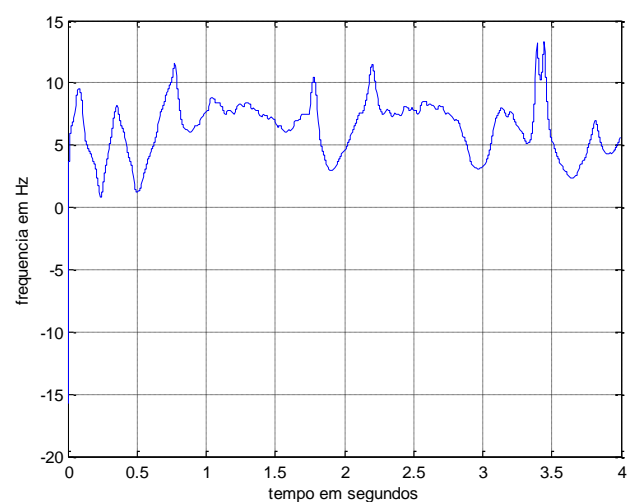

(frequência-IMF1,0mm_int-7)

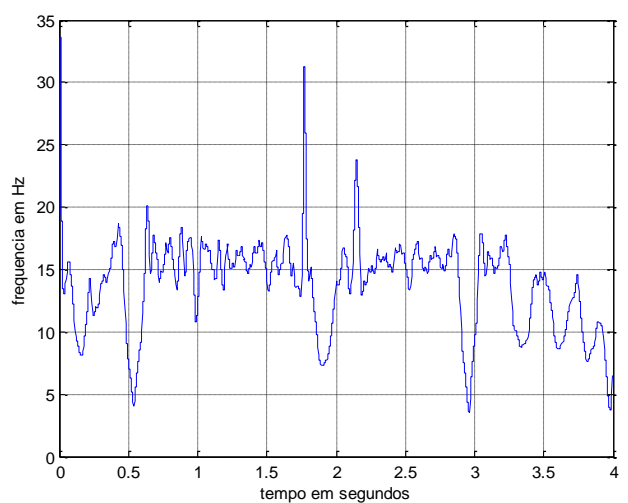

(frequência-IMF1,0mm_int-6)

\section{B15-Módulos do sinal analítico de Cl com UCP de 1,0mm}

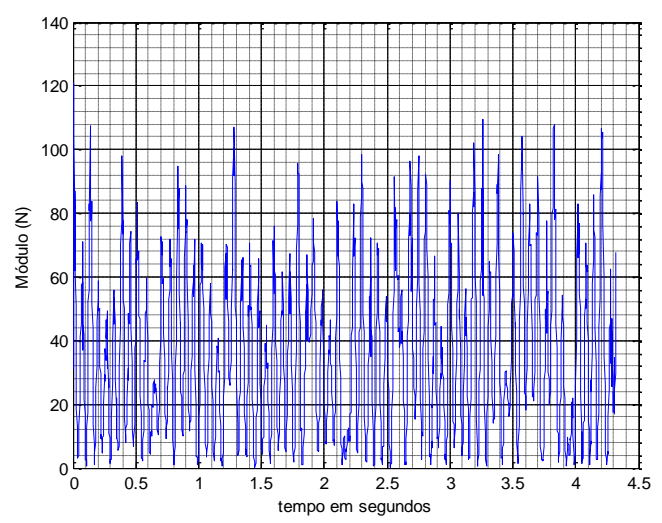

(Módulo-IMF1,0mm_int-1)

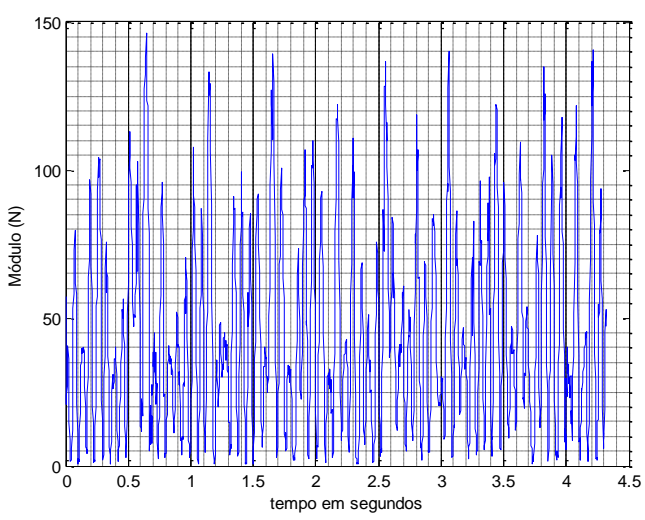

(Módulo-IMF1,0mm_int-2) 


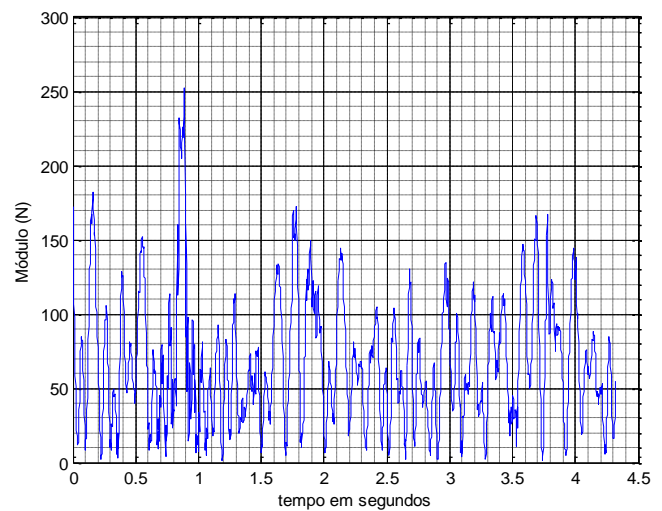

(Módulo-IMF1,0mm_int-4)

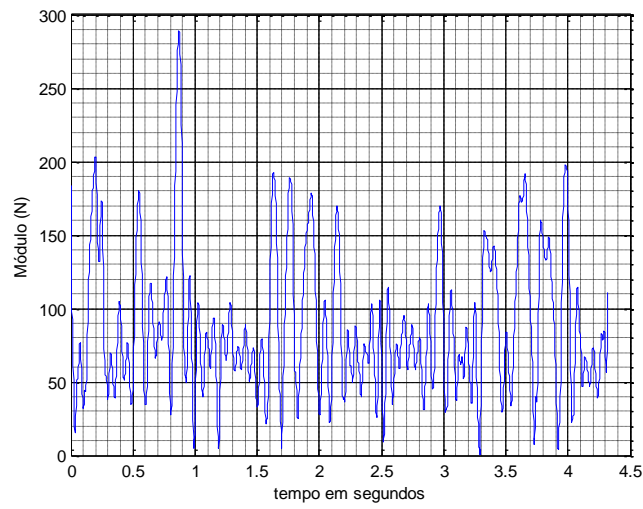

(Módulo-IMF1,0mm_int-5)

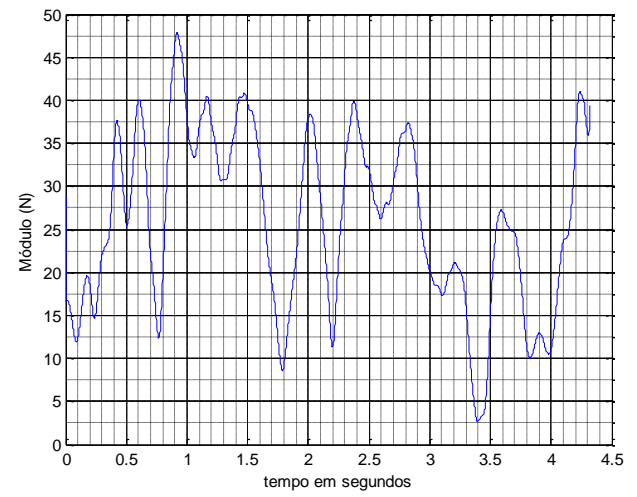

(Módulo-IMF1,0mm_int-7)

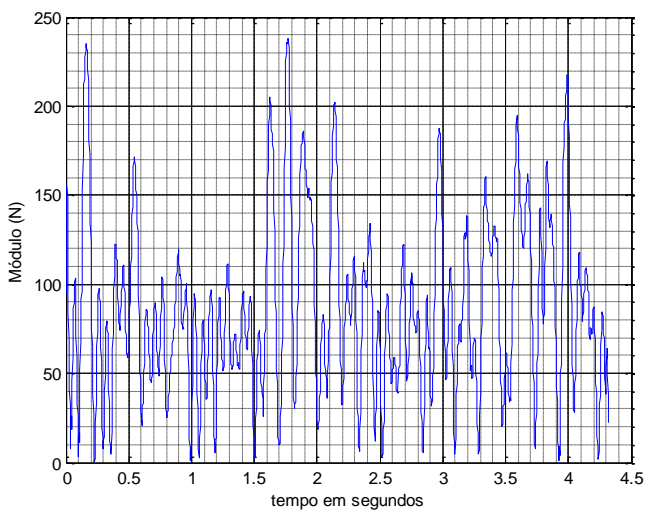

(Módulo-IMF1,0mm_int-5)

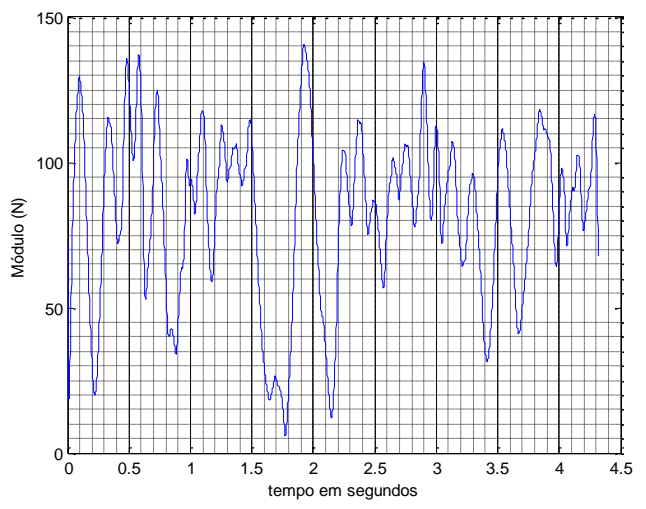

(Módulo-IMF1,0mm_int-6) 


\section{B16- Fases do sinal analítico de $\mathrm{Cl}$ com UCP de $1,5 \mathrm{~mm}$}

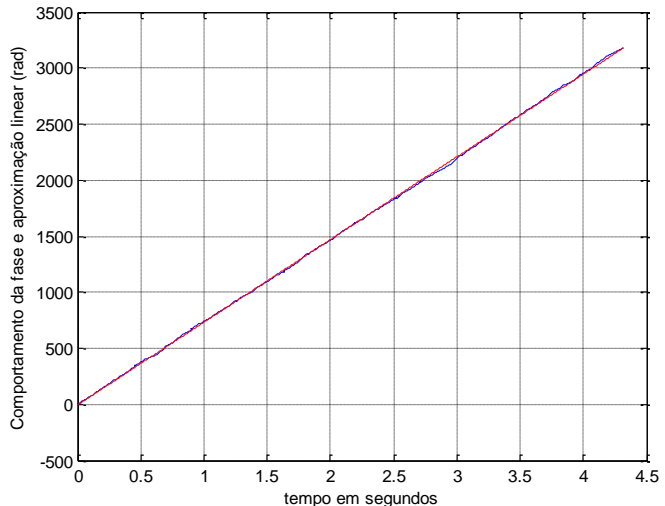

(fase-IMF1,5mm_int-1)

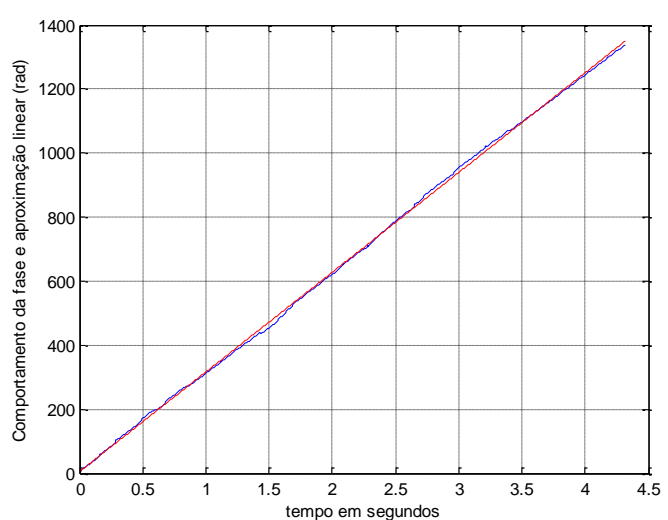

(fase-IMF1,5mm_int-3)

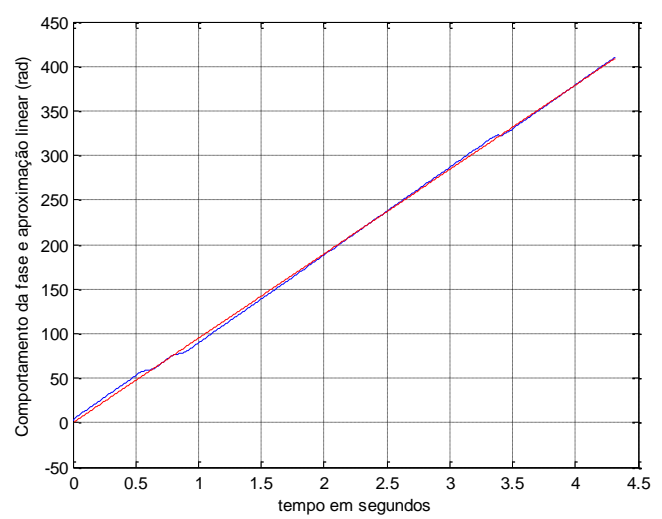

(fase-IMF1,5mm_int-5)

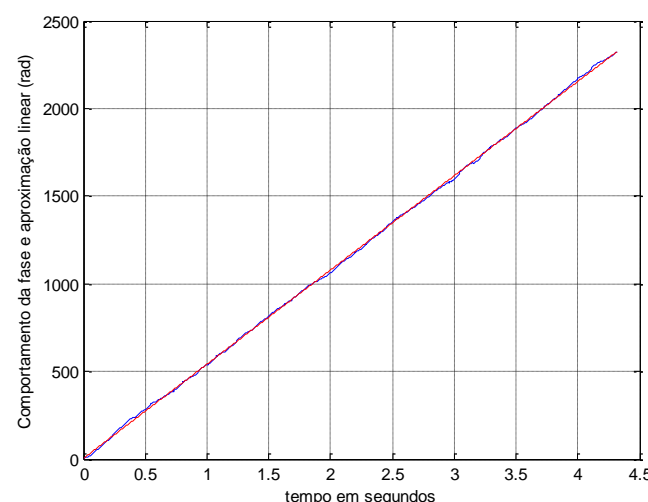

(fase-IMF1,5mm_int-2)

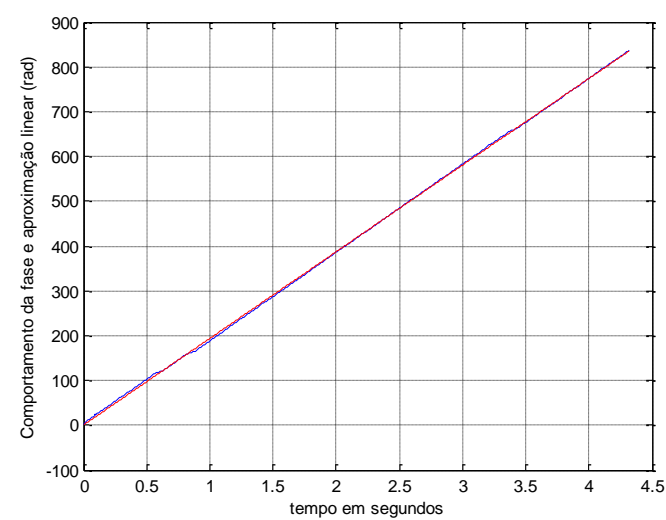

(fase-IMF1,5mm_int-4)

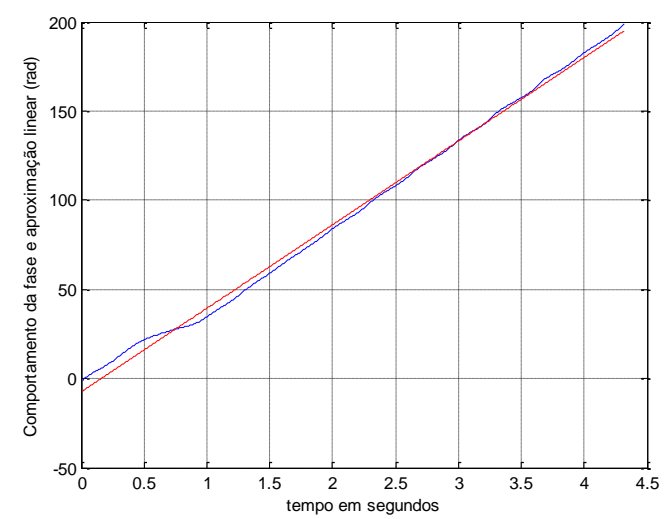

(fase-IMF1,5mm_int-6) 


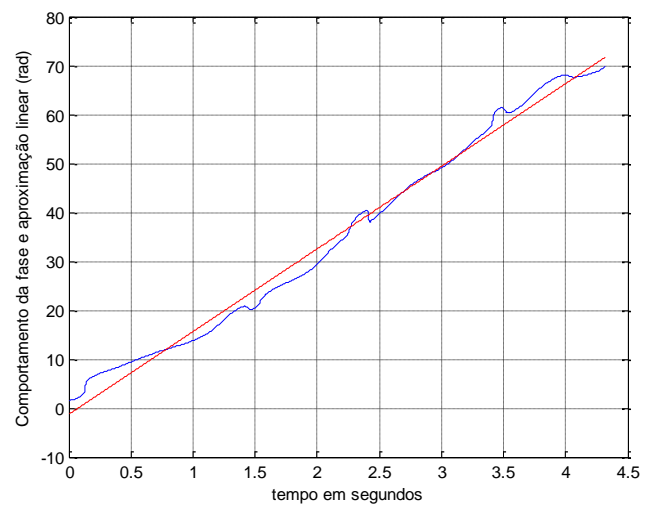

(fase-IMF1,5mm_int-7)

\section{B17- Frequências do sinal analítico de $\mathrm{Cl}$ com UCP de 1,5mm}

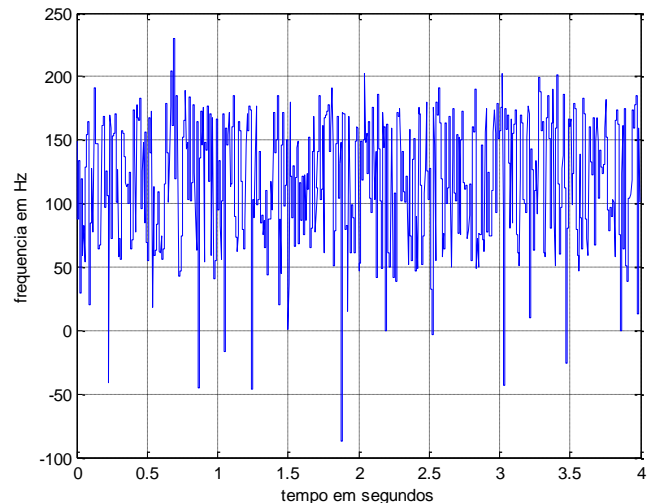

(frequência-IMF1,5mm_int-1)

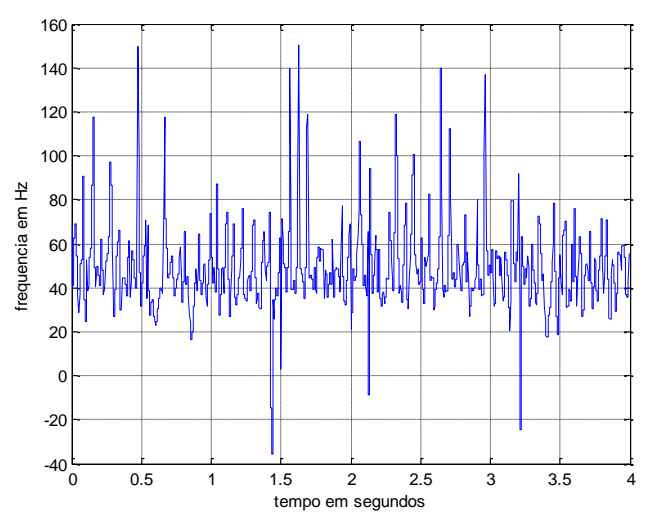

(frequência-IMF1,5mm_int-3)

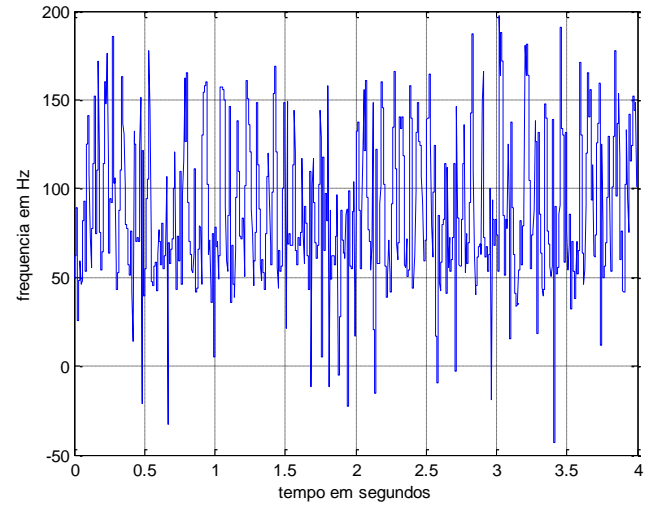

(frequência-IMF1,5mm_int-2)

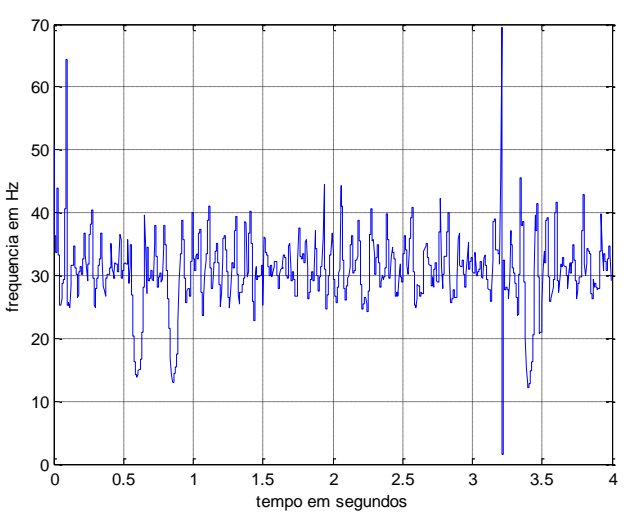

(frequência-IMF1,5mm_int-4) 


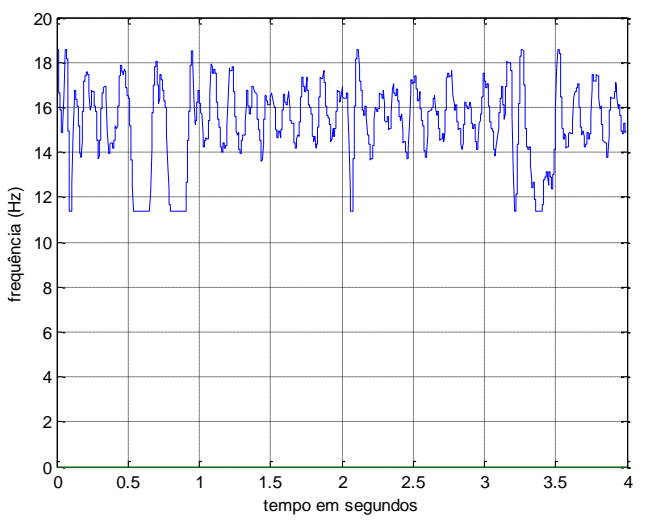

(frequência-IMF1,5mm_int-5)

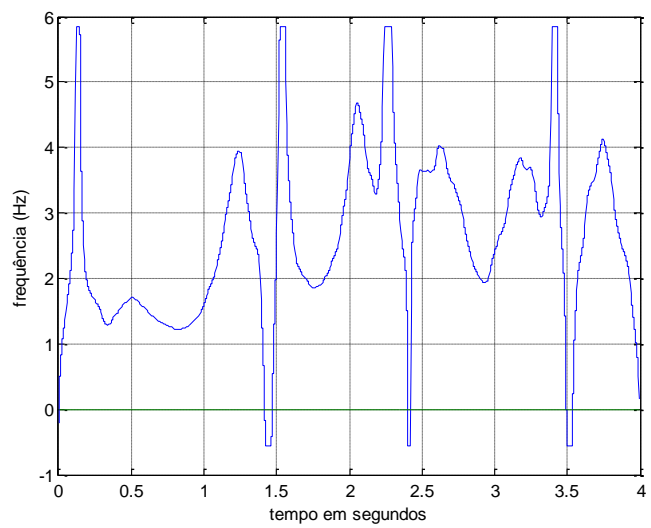

(frequência-IMF1,5mm_int-7)

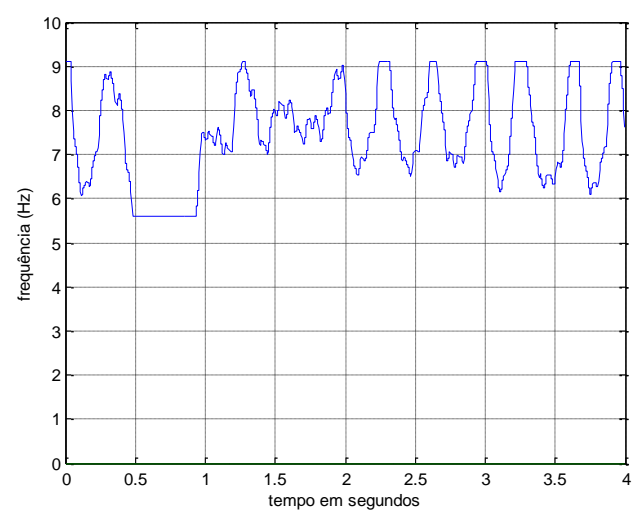

(frequência-IMF1,5mm_int-6)

\section{B18- Módulos do sinal analítico de Cl com UCP de 1,5mm}

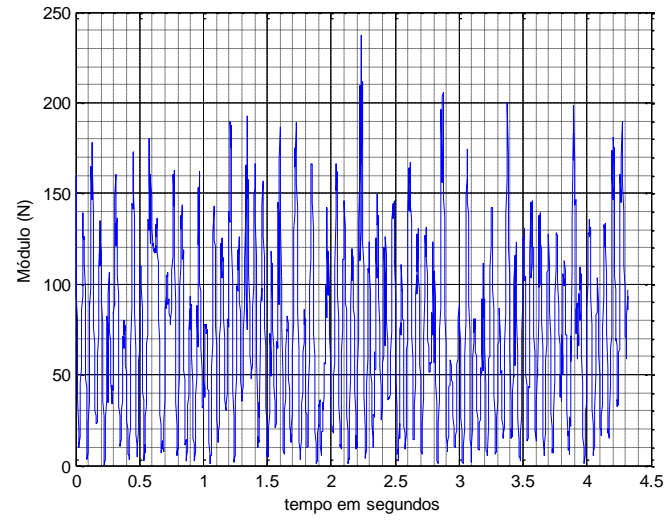

(Módulo-IMF1,5mm_int-1)

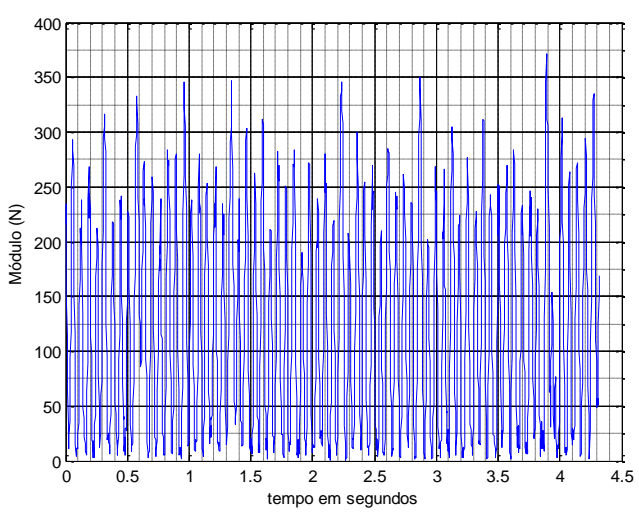

(Módulo-IMF1,5mm_int-2) 


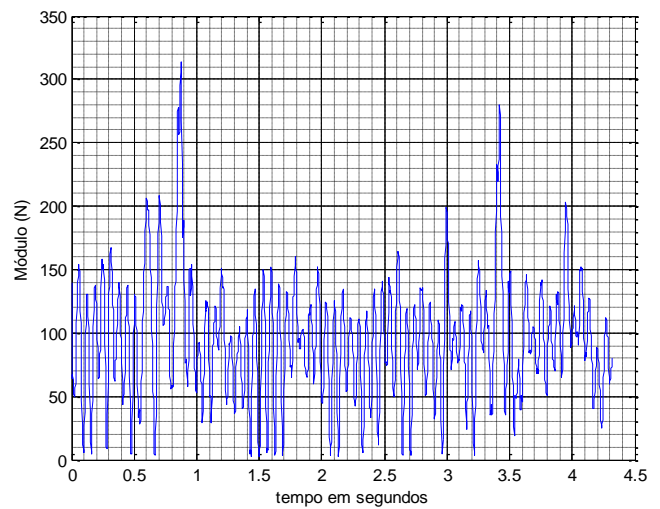

(Módulo-IMF1,5mm_int-3)

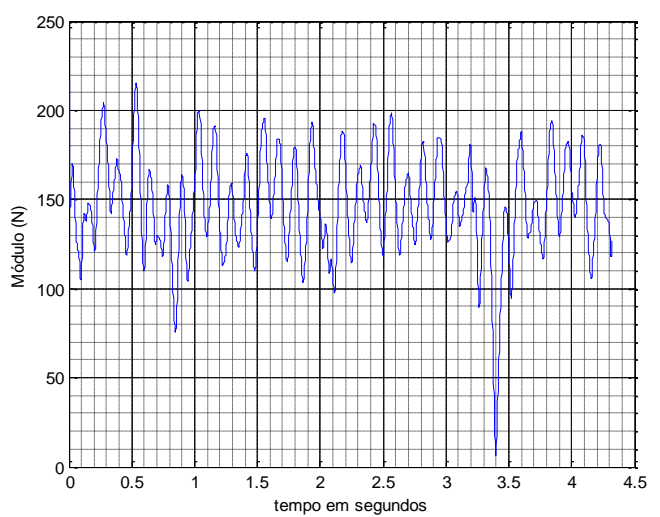

(Módulo-IMF1,5mm_int-5)

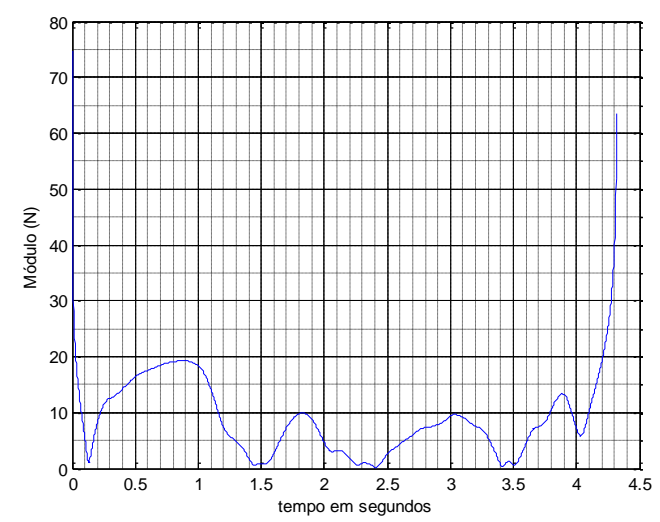

(Módulo-IMF1,5mm_int-7)

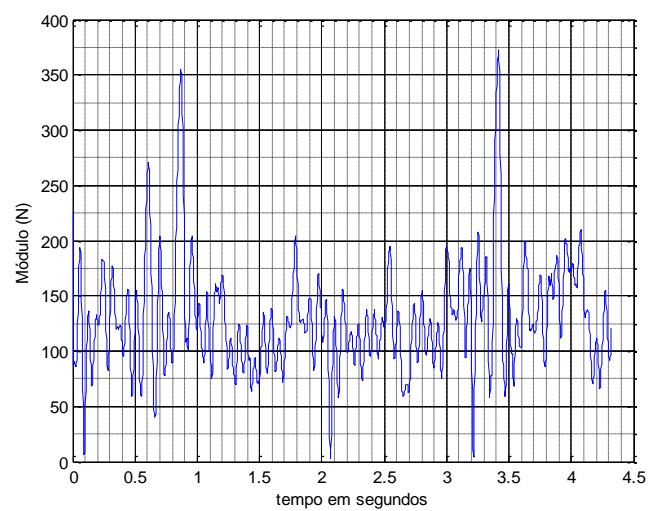

(Módulo-IMF1,5mm_int-4)

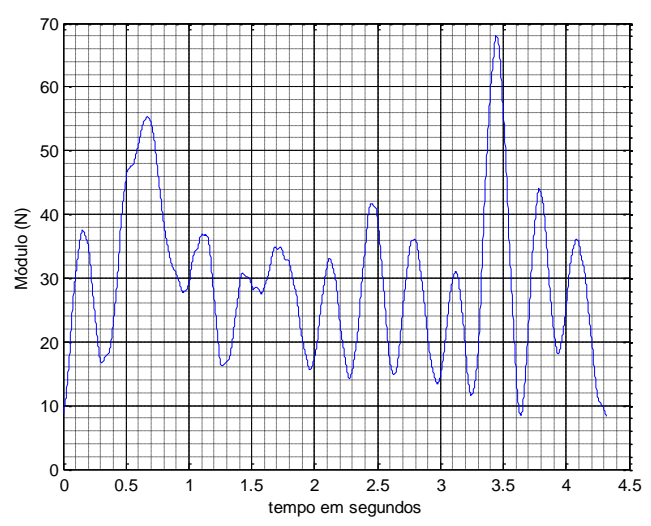

(Módulo-IMF1,5mm_int-5) 
Apêndice C

C1- As IMFs dos dados do estimador de torque para UCP de $0,5 \mathrm{~mm}$
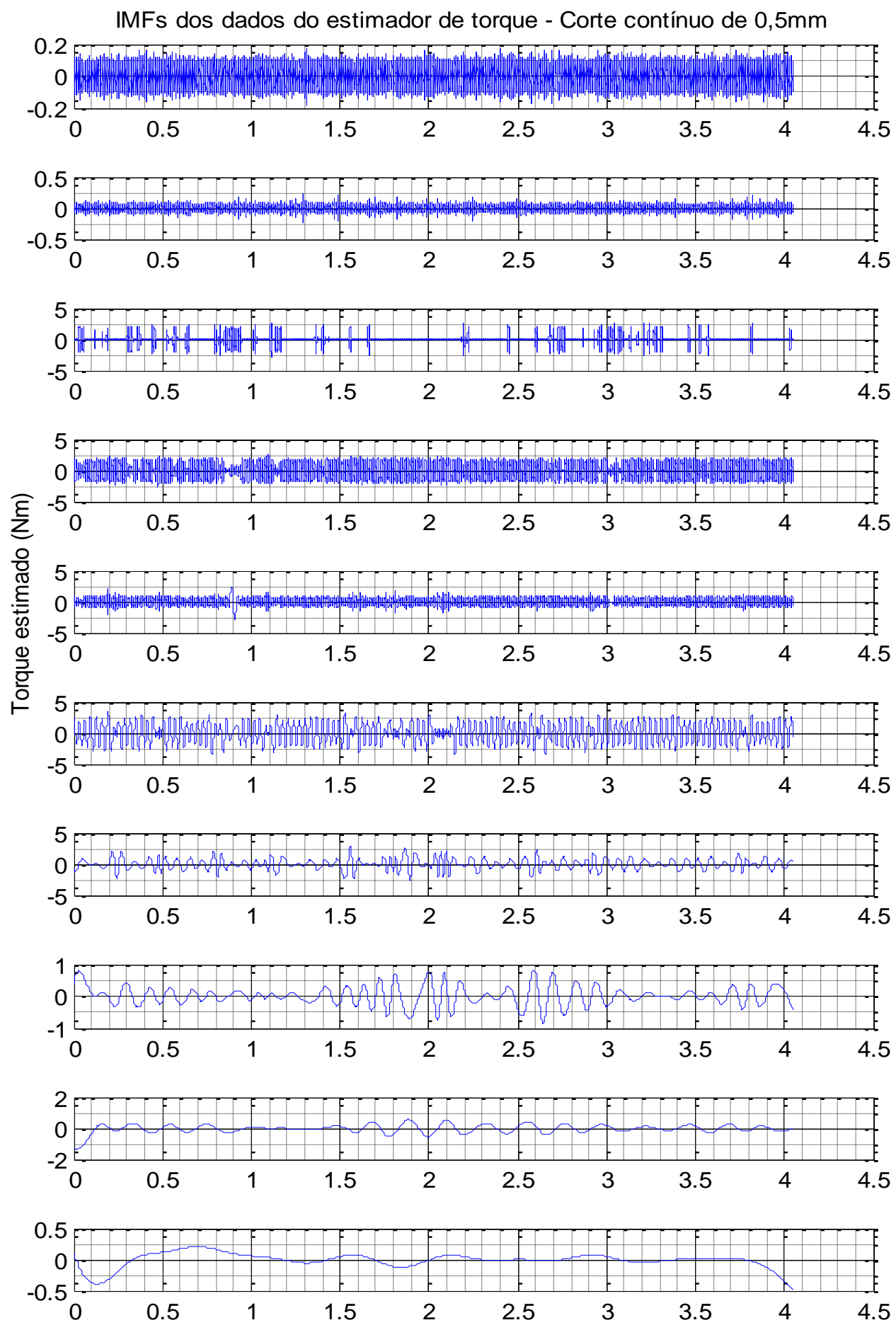
C2- As IMFs dos dados do estimador de torque para UCP de $1,0 \mathrm{~mm}$
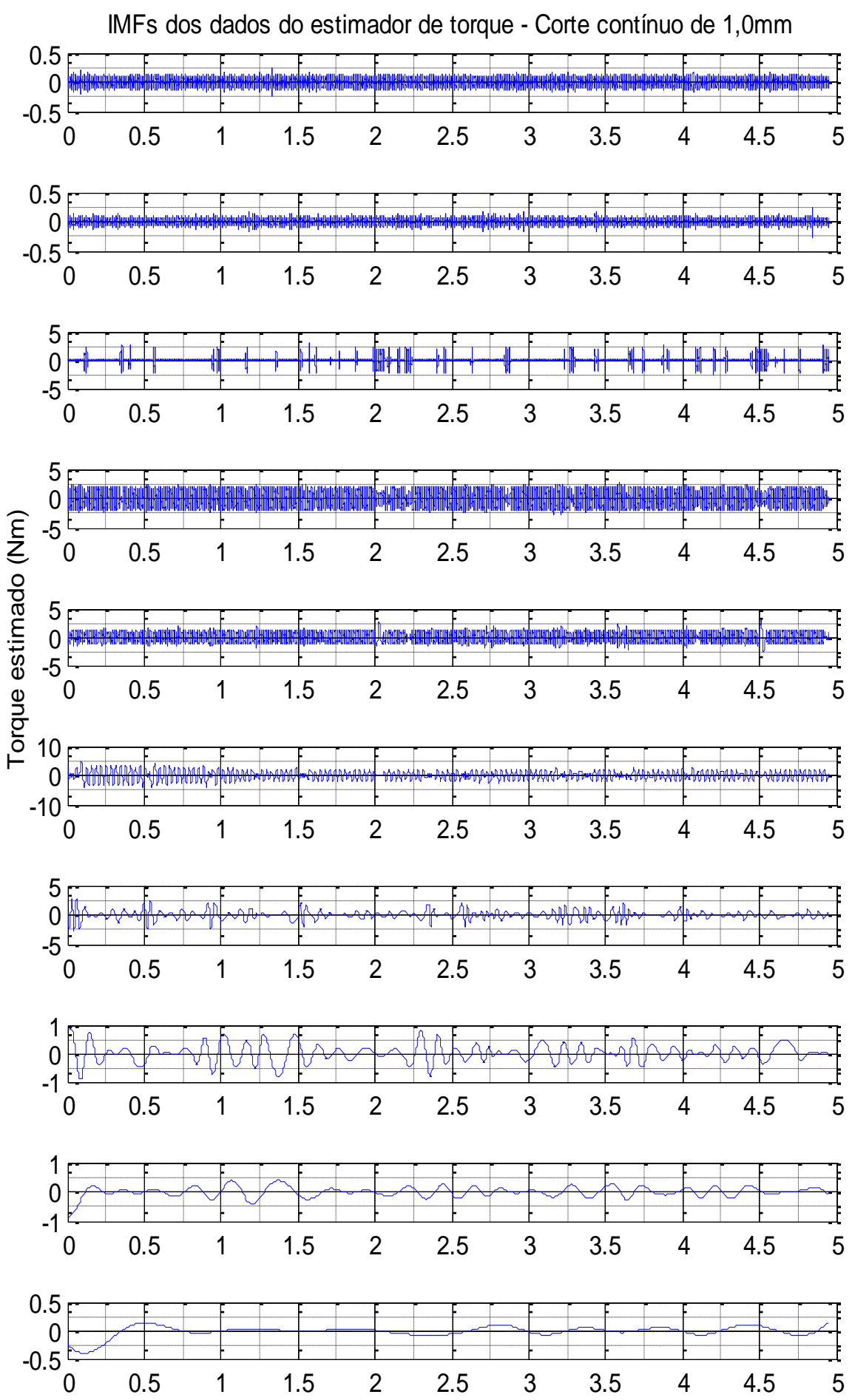
C3- As IMFs dos dados do estimador de torque para UCP de $1,5 \mathrm{~mm}$
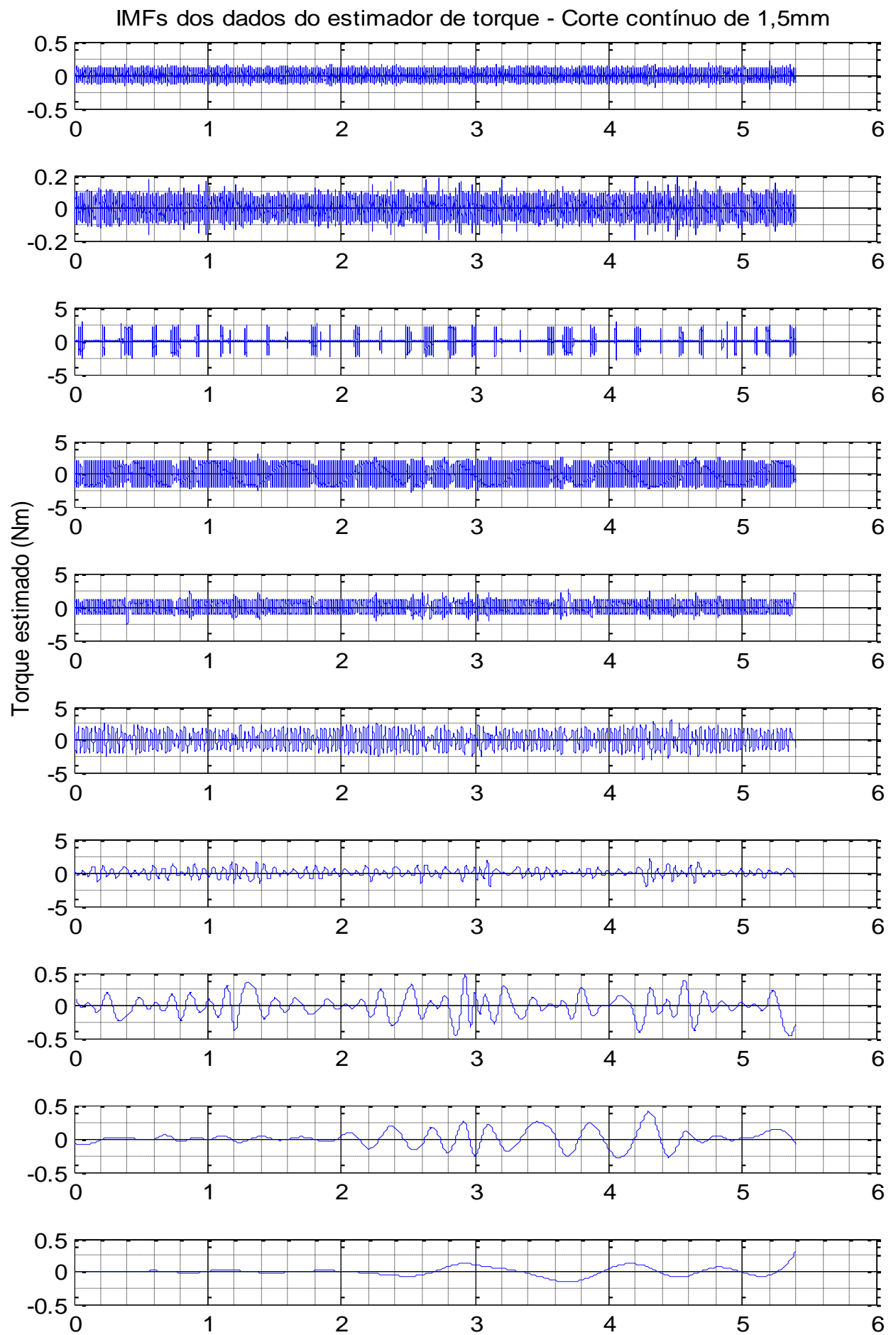


\section{Corte Interrompido}

C4- As IMFs dos dados do estimador de torque para $\mathrm{Cl}$ e UCP de $0,5 \mathrm{~mm}$
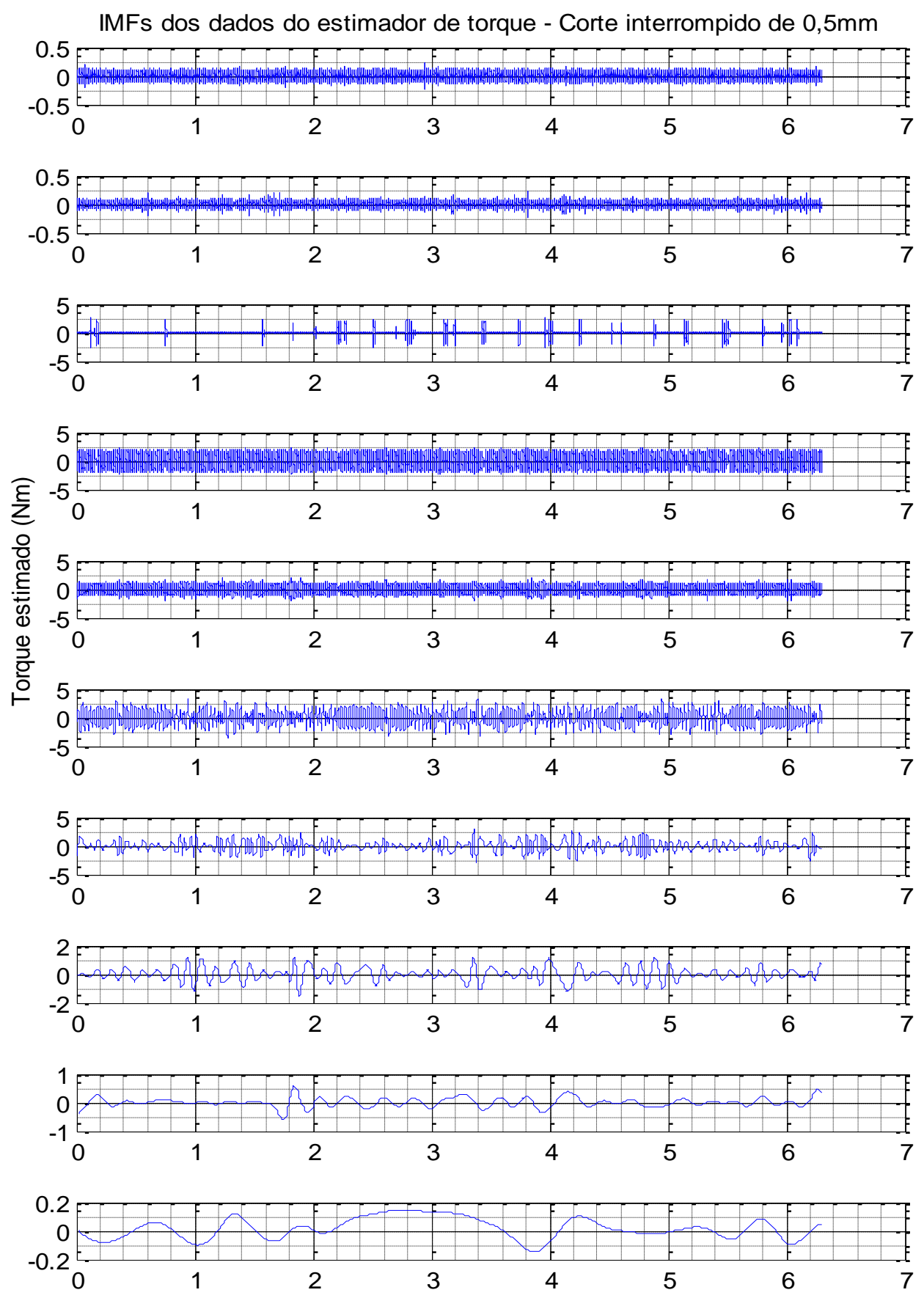
C5- As IMFs dos dados do estimador de torque para $\mathrm{Cl}$ e UCP de $1,0 \mathrm{~mm}$
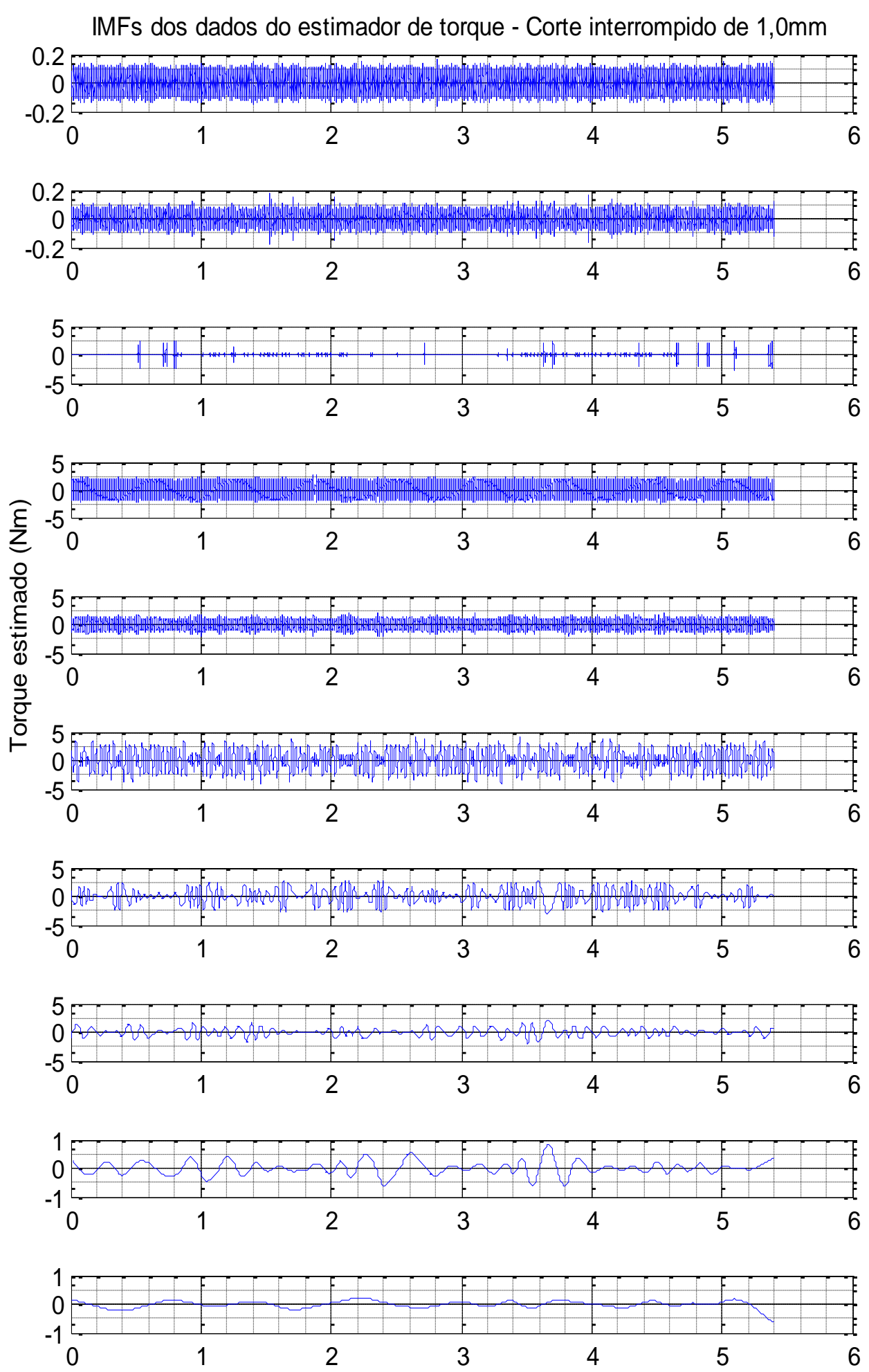
C6- As IMFs dos dados do estimador de torque para $\mathrm{Cl}$ e UCP de $1,0 \mathrm{~mm}$
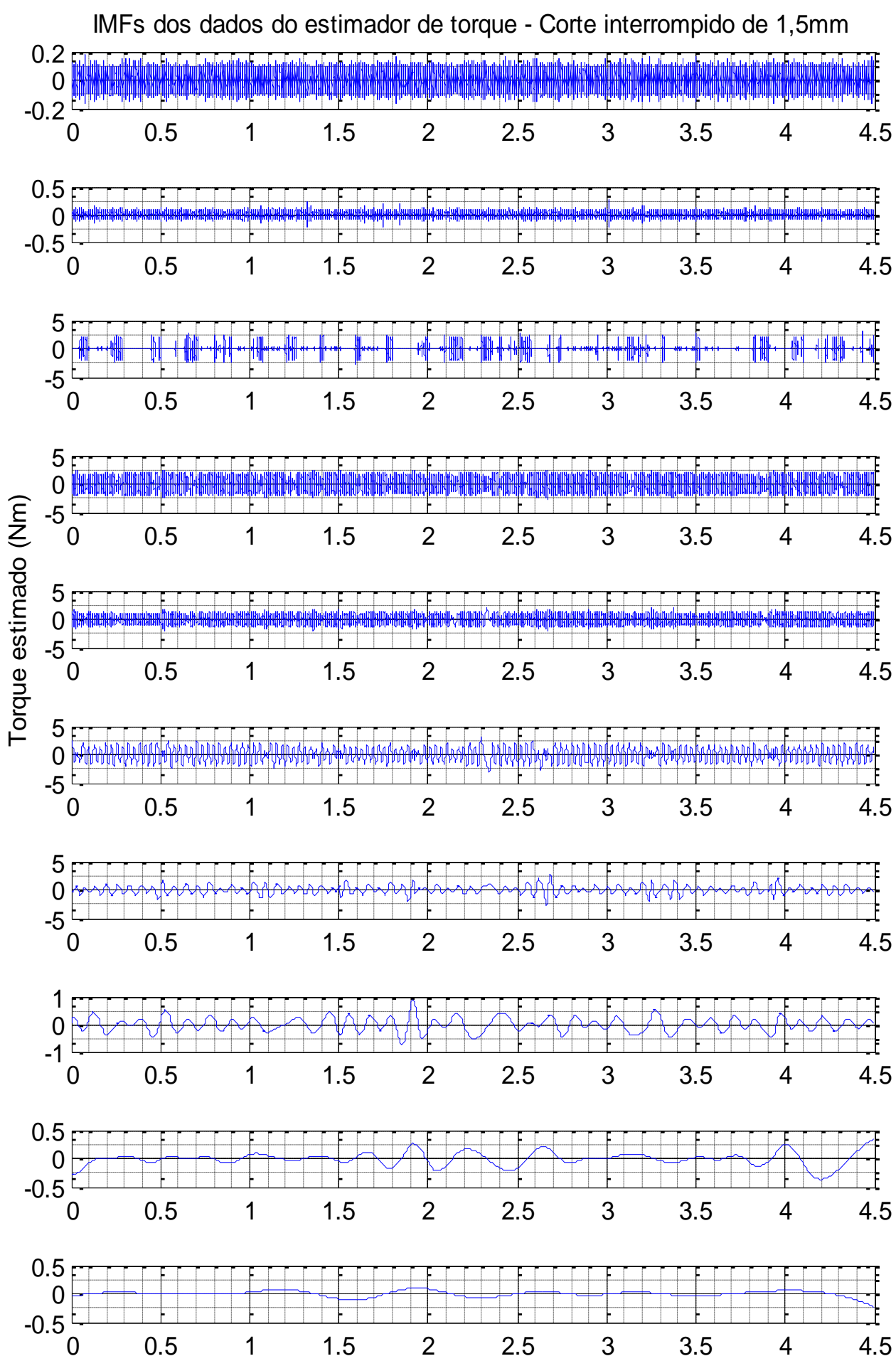
Apêndice D

D1- As IMFs dos dados do dinamômetro Kistler com UCP de 0,5mm
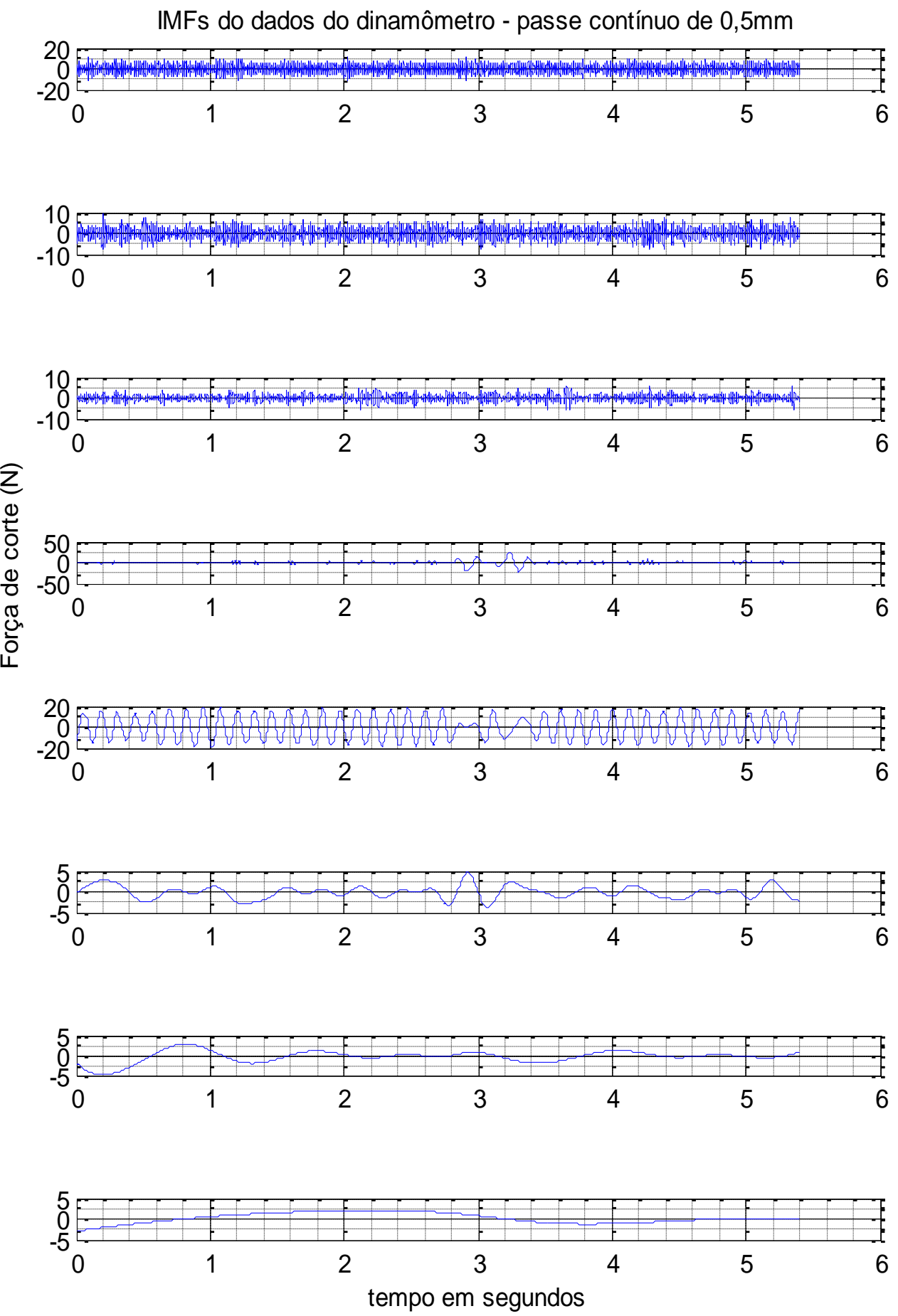
D2- As IMFs dos dados do dinamômetro Kistler com UCP de 1,0mm
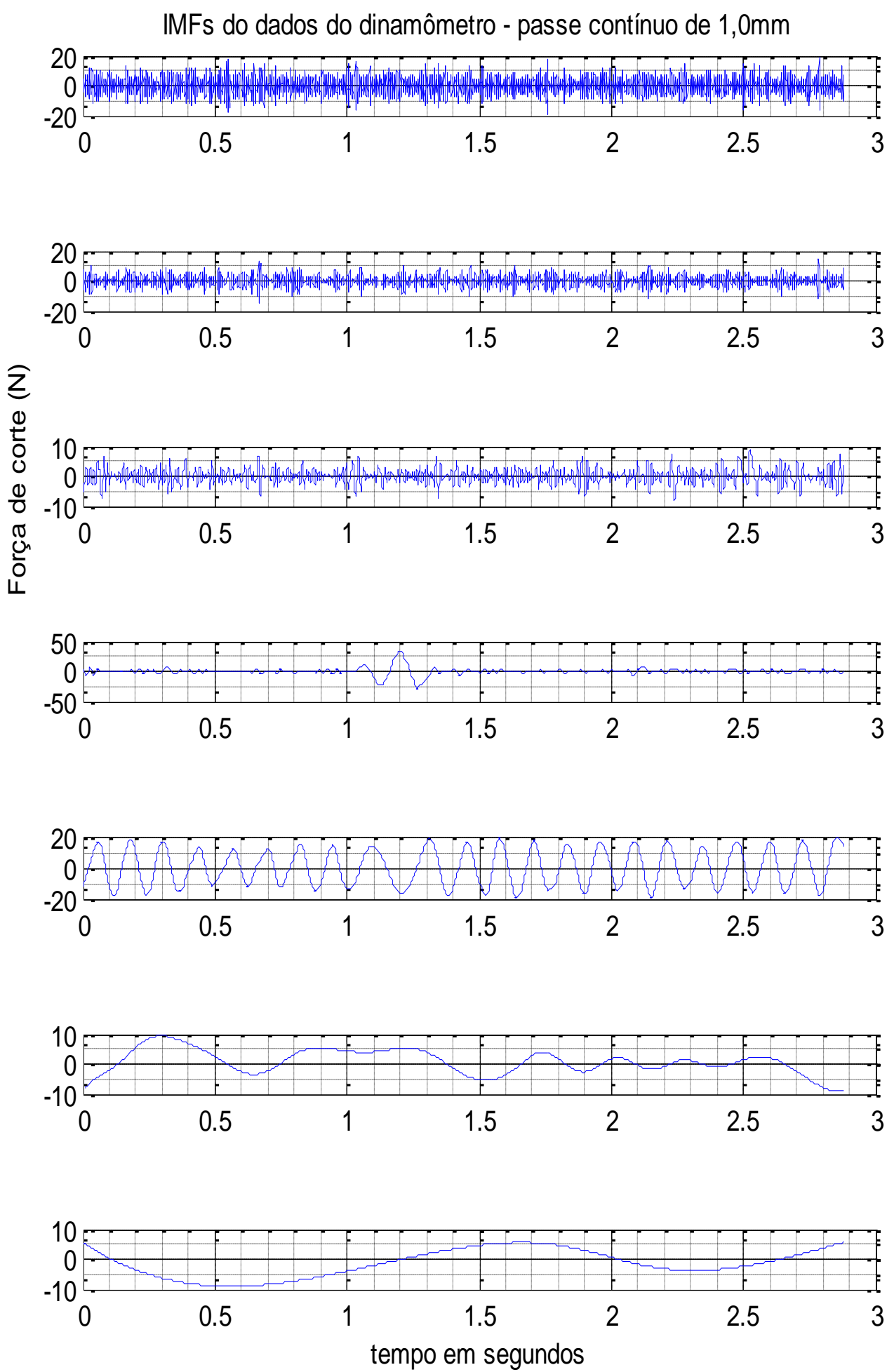
D3- As IMFs dos dados do dinamômetro Kistler com UCP de 1,5mm
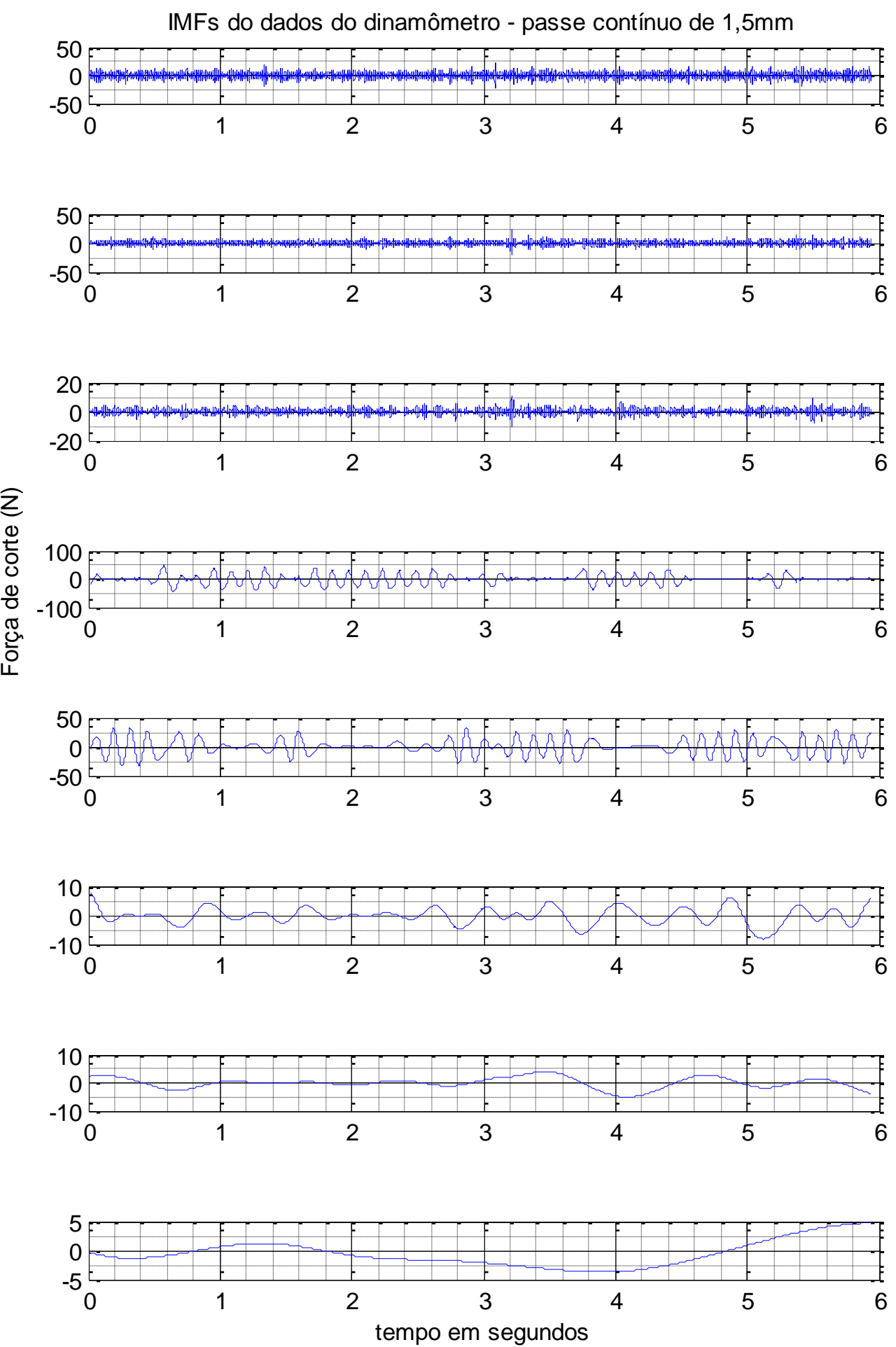


\section{Corte interrompido}

\section{D4- As IMFs dos dados do dinamômetro Kistler com Cl e UCP de 0,5mm}

IMFs do dados do dinamômetro - passe interrompido de $0,5 \mathrm{~mm}$
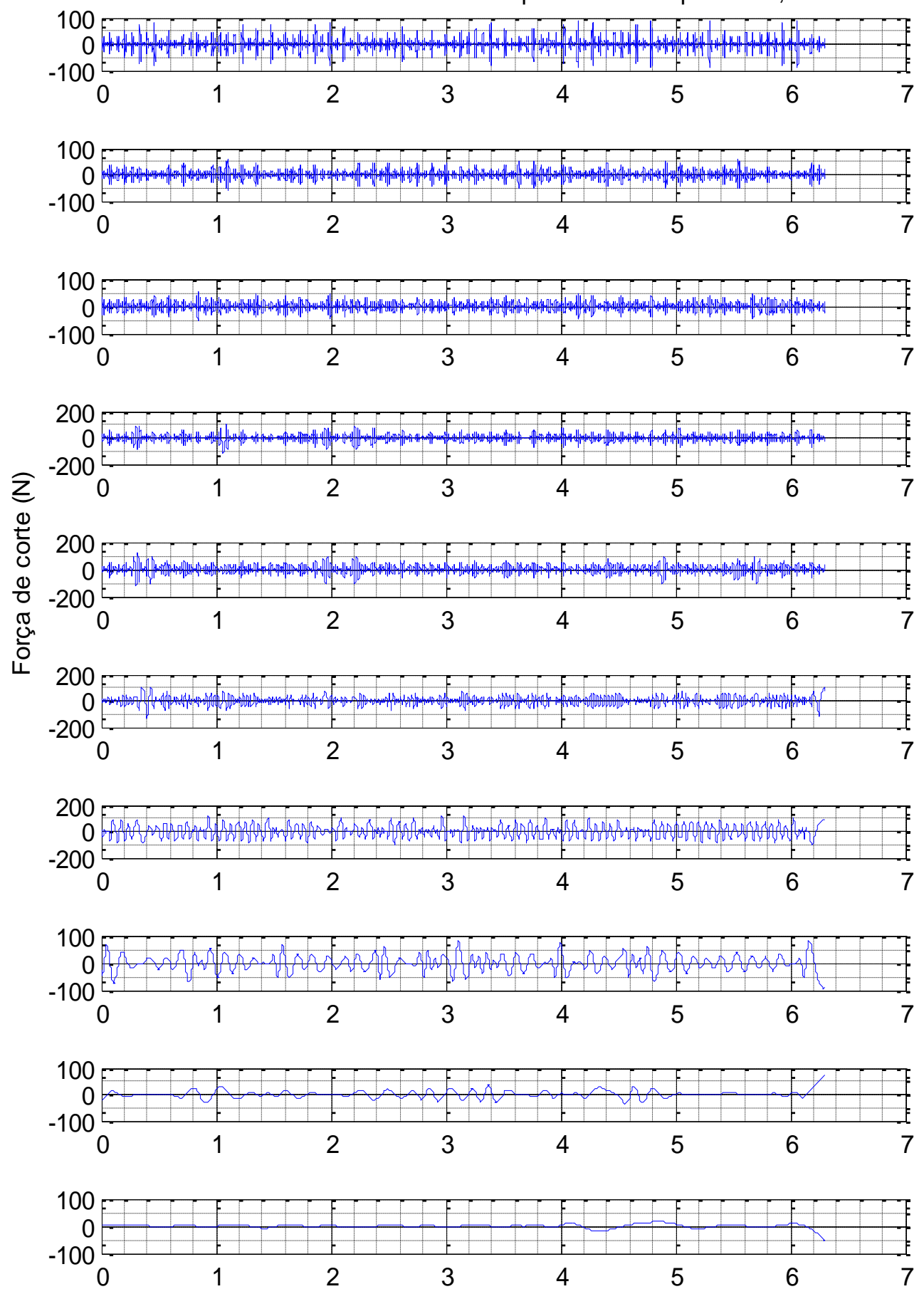
D5- As IMFs dos dados do dinamômetro Kistler com Cl e UCP de 1,0mm
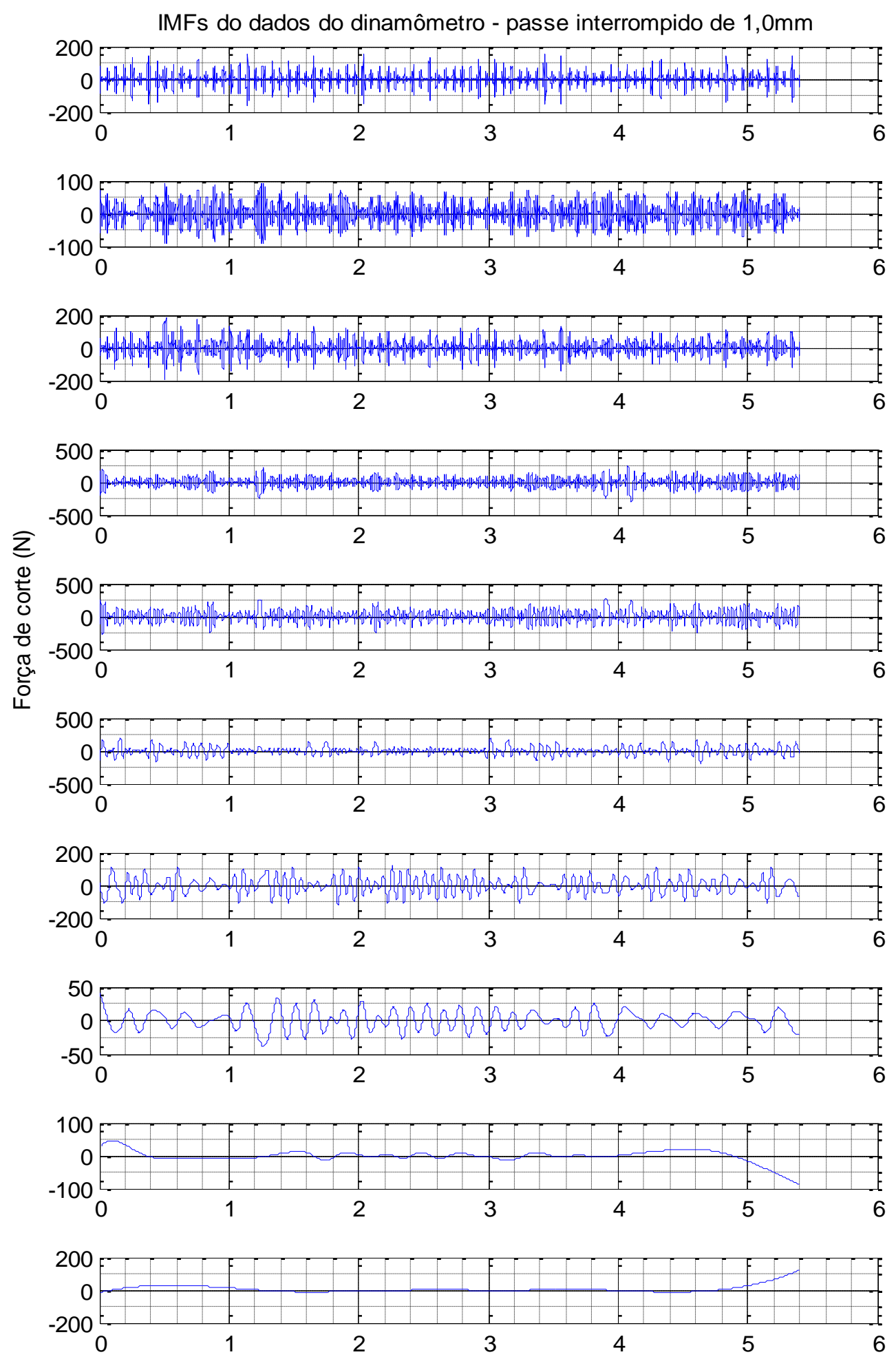
D6- As IMFs dos dados do dinamômetro Kistler com Cl e UCP de 1,5mm

IMFs do dados do dinamômetro - passe interrompido de 1,5mm
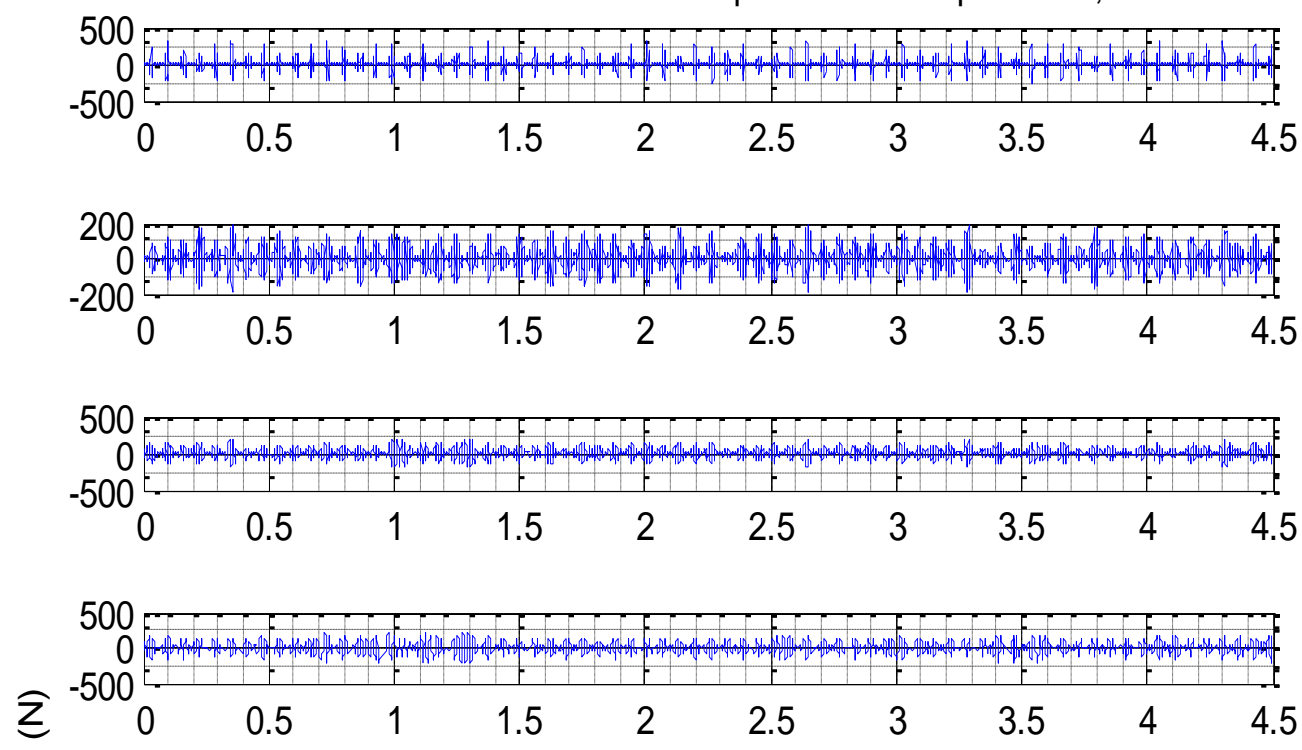

咅
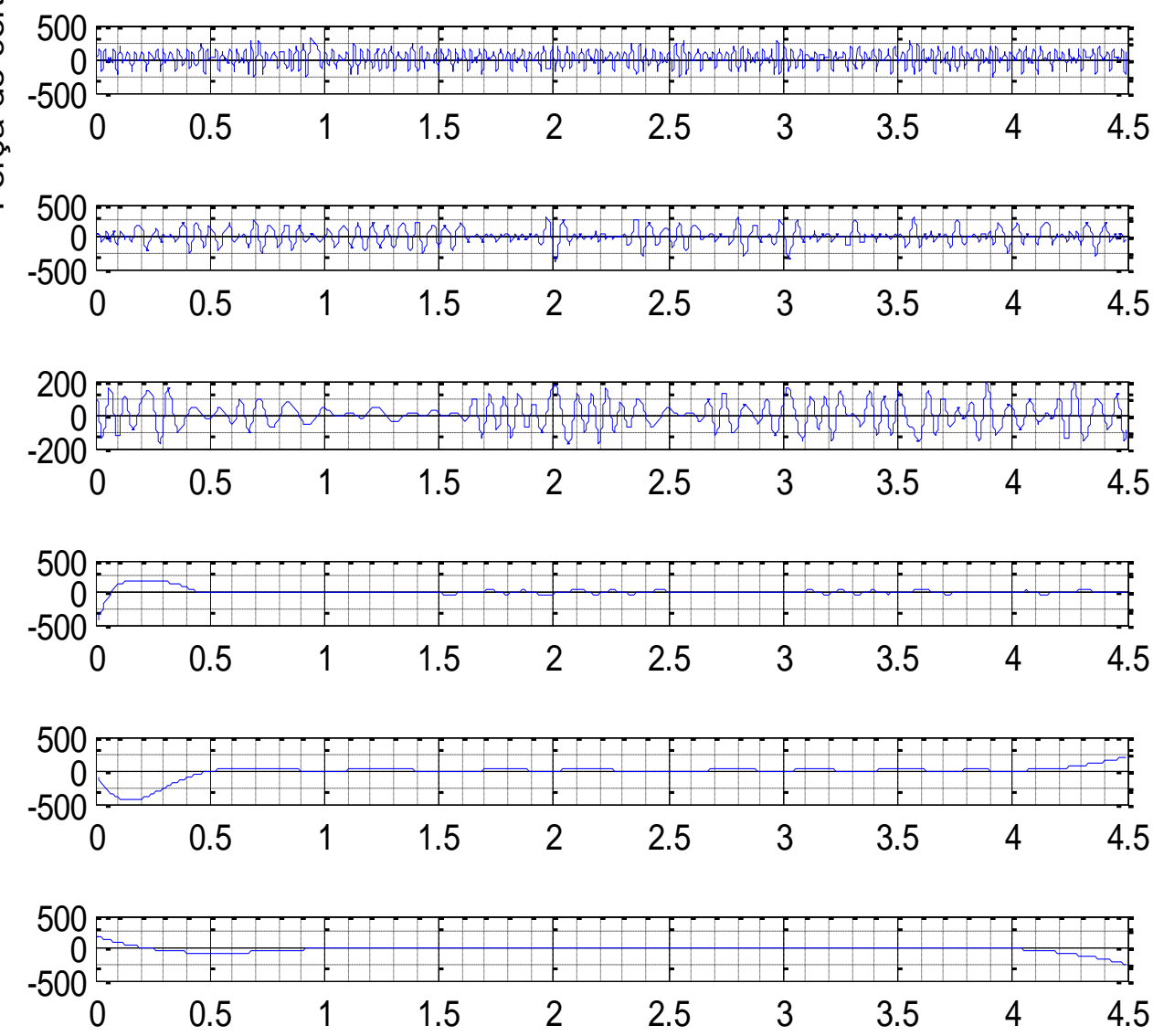


\section{Apêndice $E$}

\section{Resultados da análise pela transformada de wavelet}

\section{ESTIMADOR DE TORQUE}

E1- Coeficientes de aproximação - Torno operando em vazio
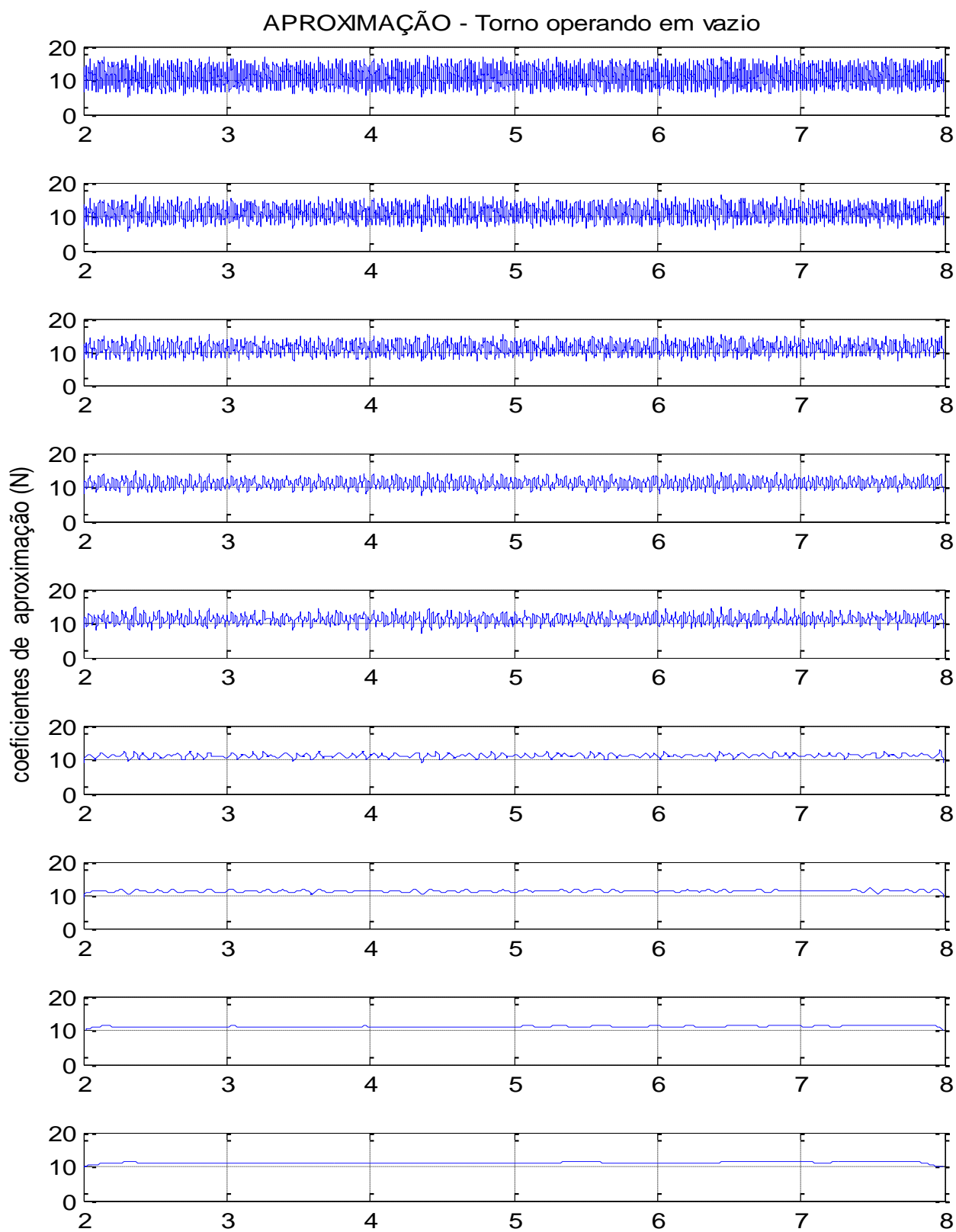
E2- Coeficientes de aproximação - Torno operando com UCP de 0,5mm
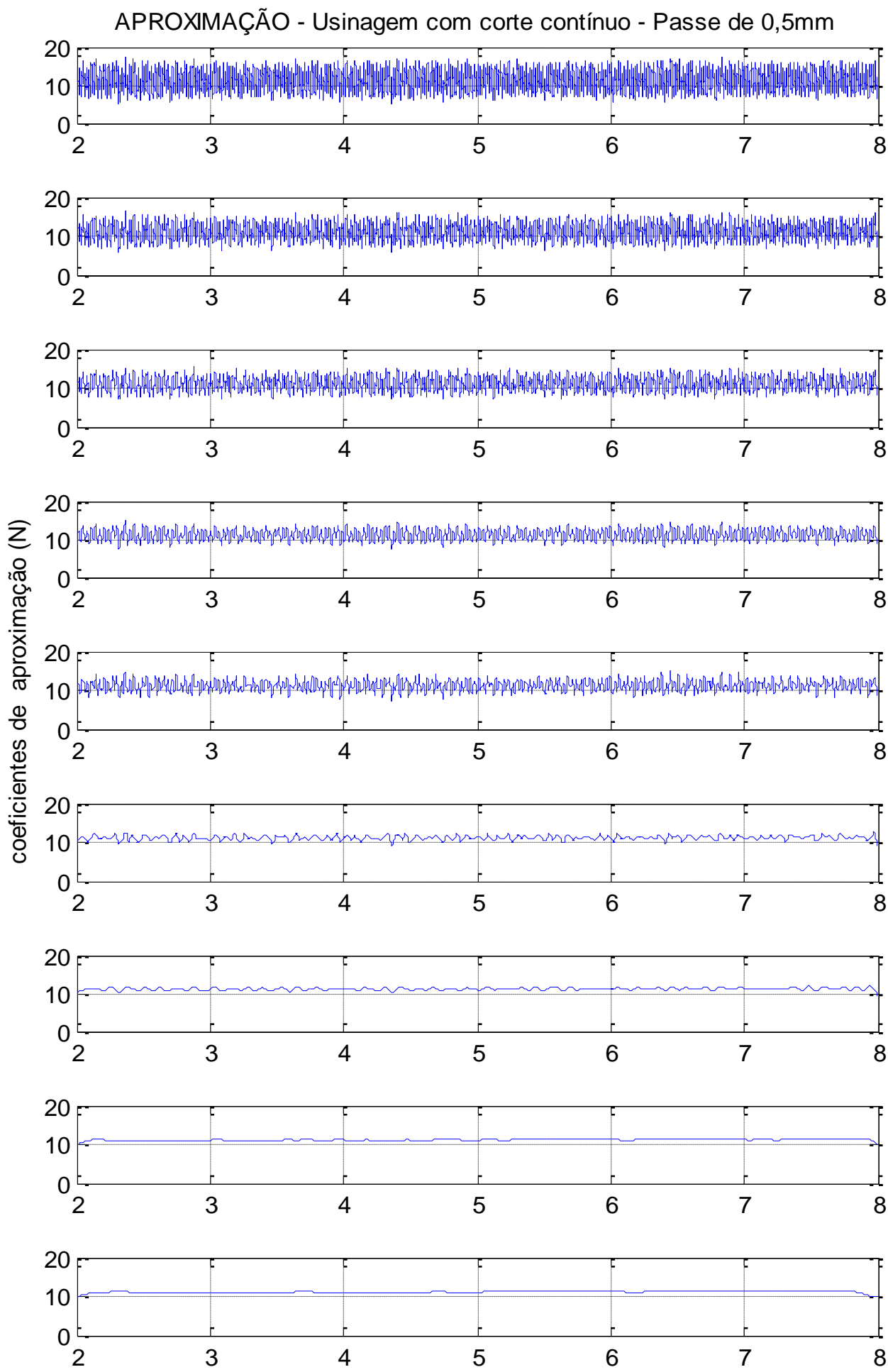
E3- Coeficientes de aproximação - Torno operando com UCP de 1,0mm
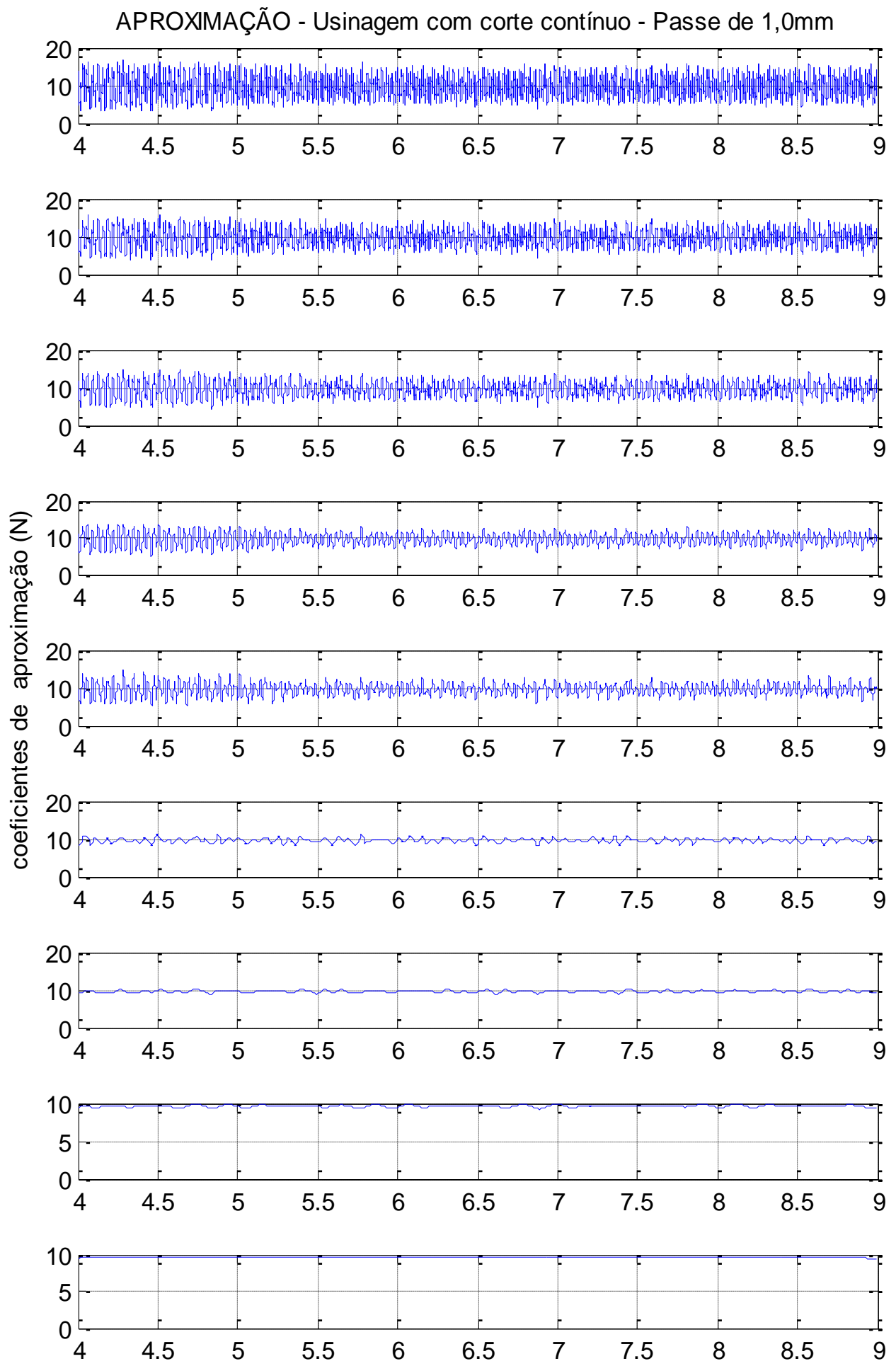
E4- Coeficientes de aproximação - Torno operando com UCP de 1,5mm
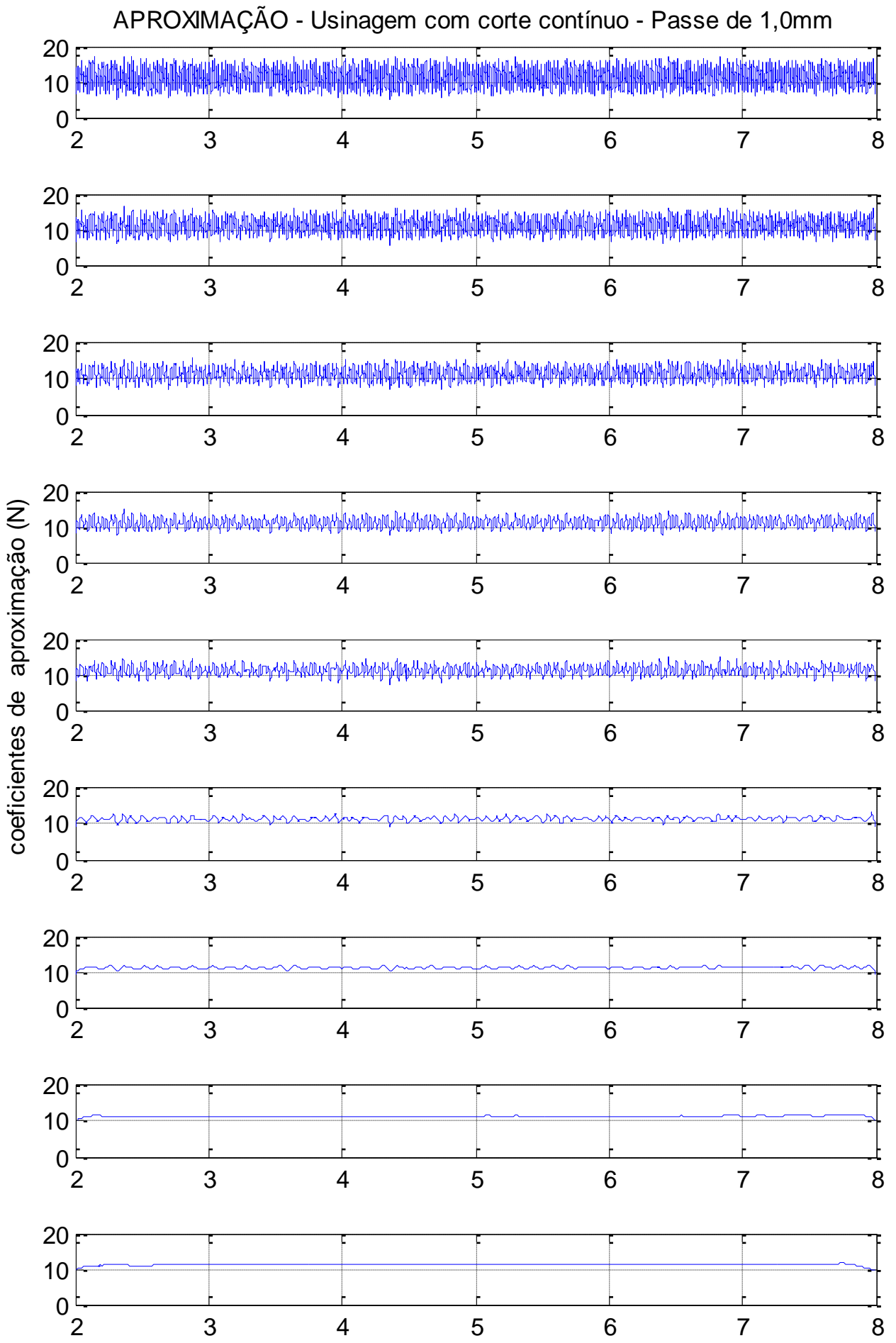
E5- Coeficientes de aproximação - Torno operando com Cl e UCP de 0,5mm

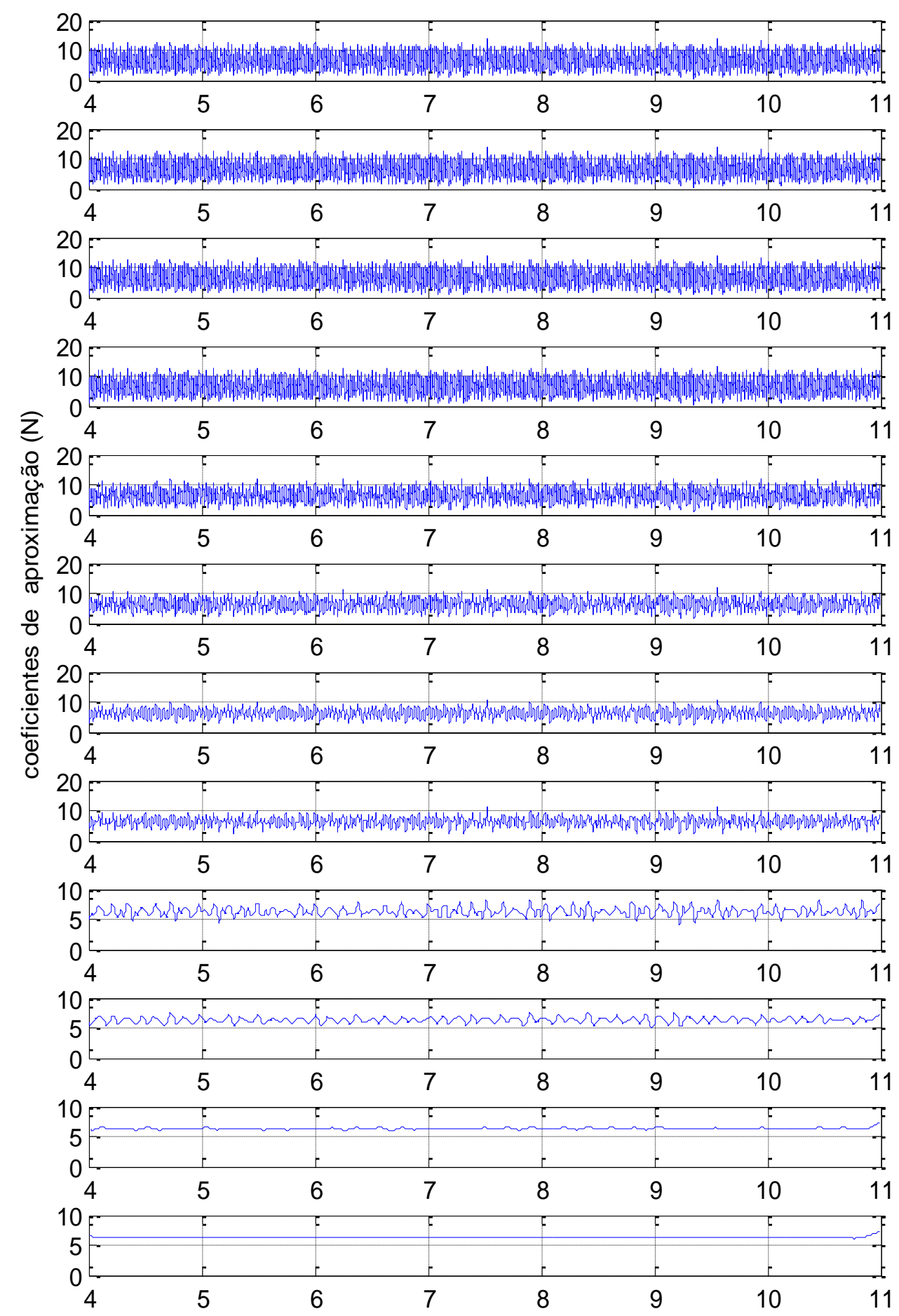


E6- Coeficientes de aproximação - Torno operando com Cl e UCP de 1,0mm

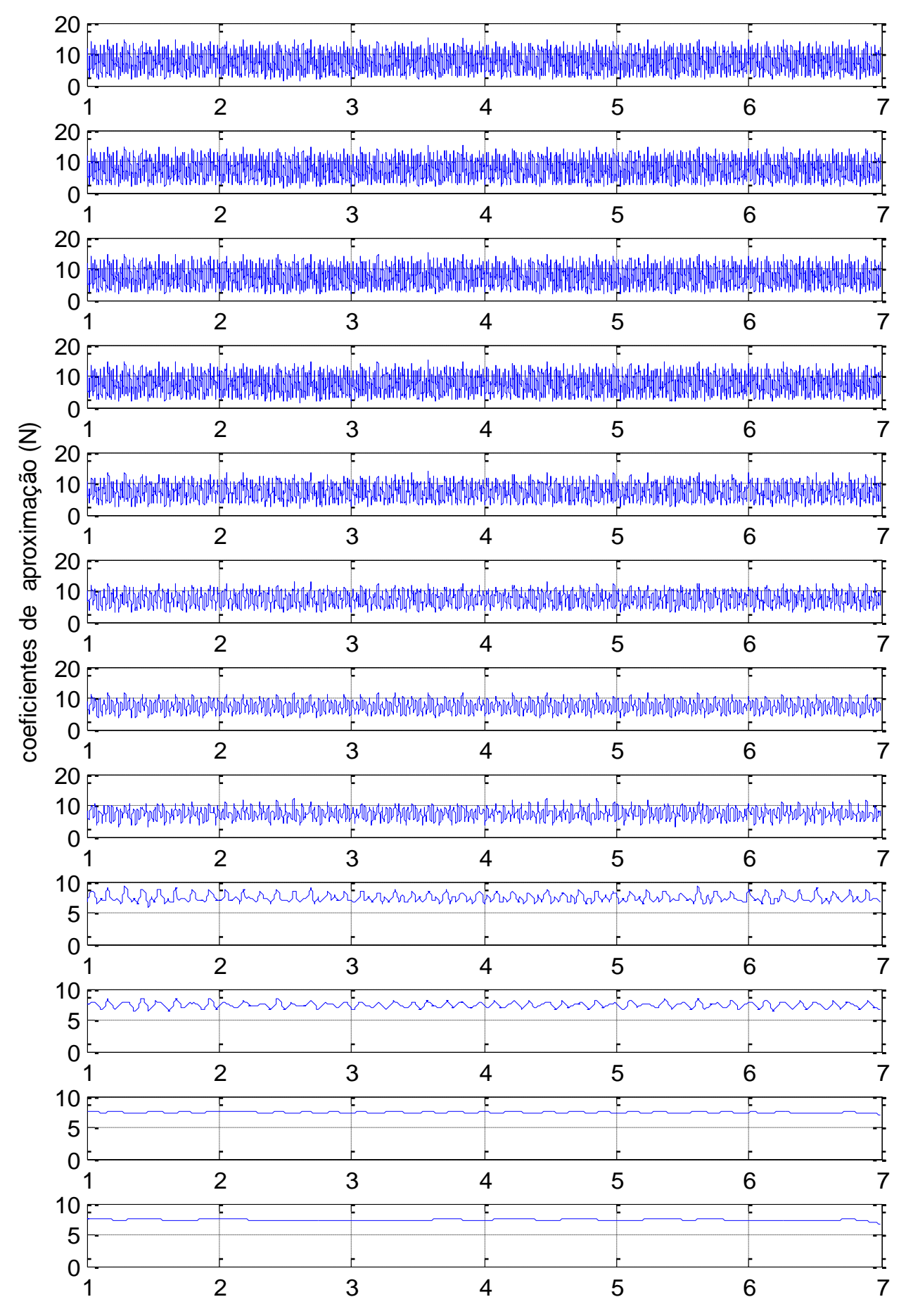


E7- Coeficientes de aproximação - Torno operando com Cl e UCP de 0,5mm

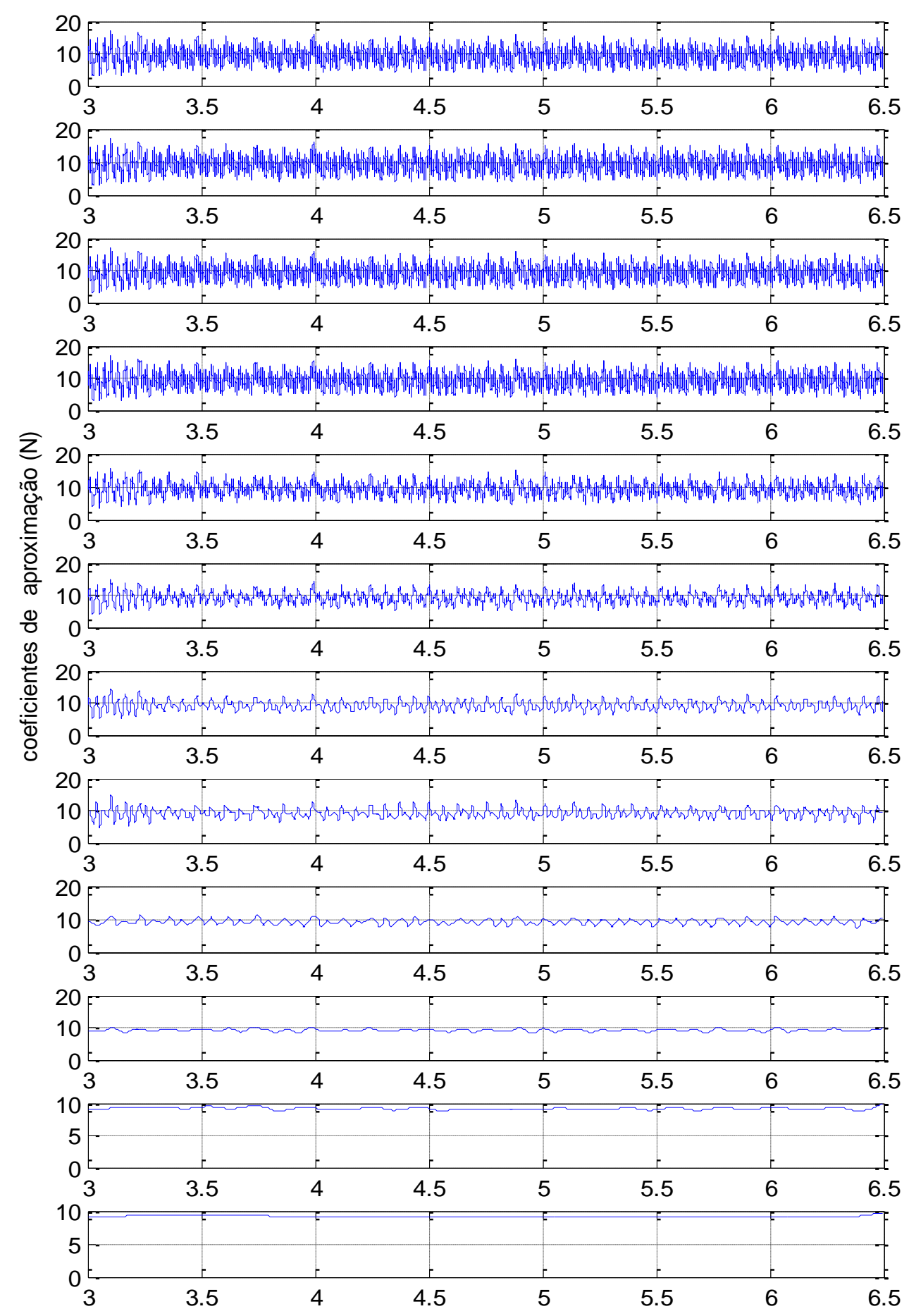


Apêndice $F$

Resultados da análise pela transformada de wavelet - DINAMÔMETRO

F1- Coeficientes de aproximação - Torno operando com UCP de 0,5mm
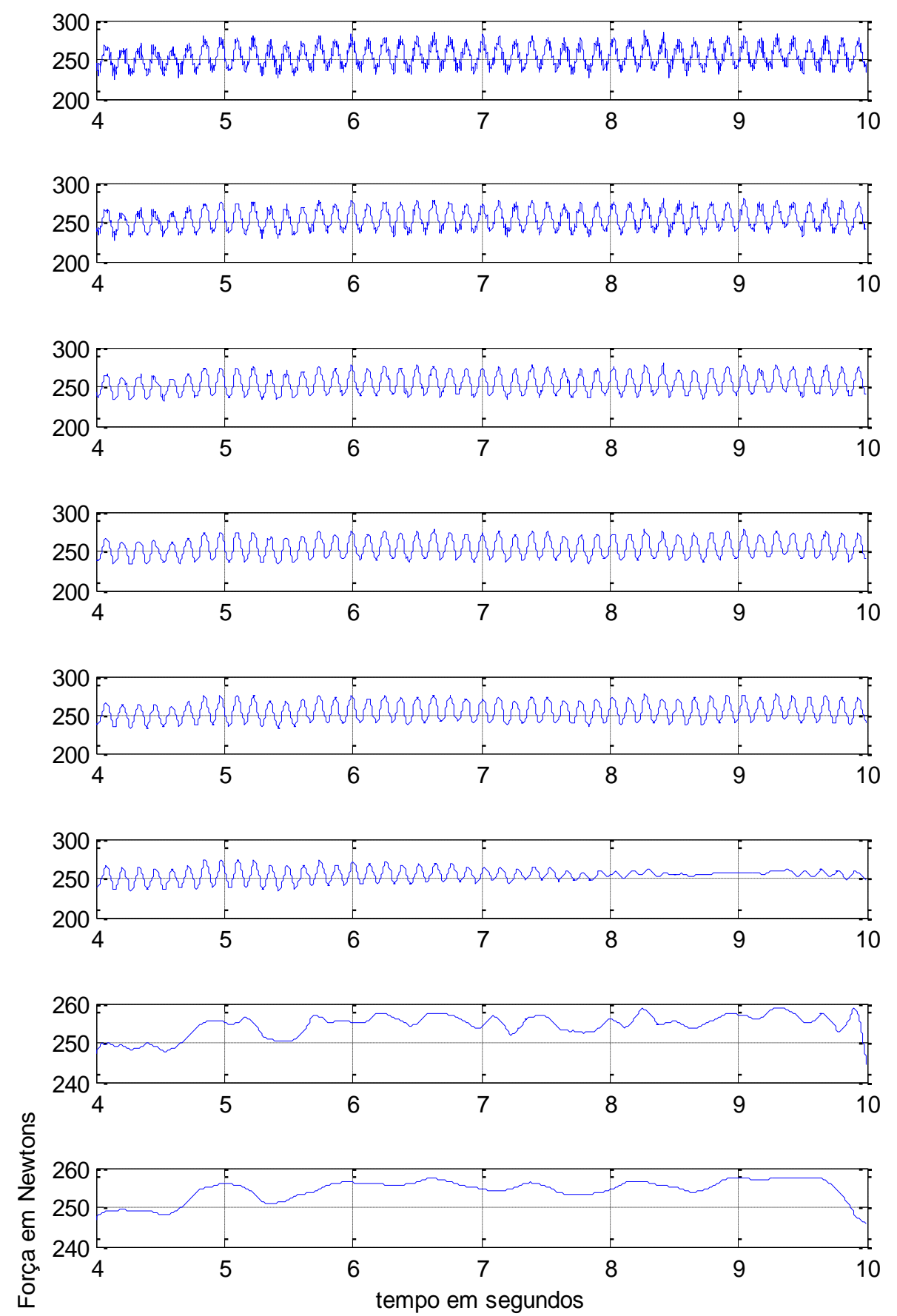
F2- Coeficientes de detalhe - Torno operando com UCP de 0,5mm
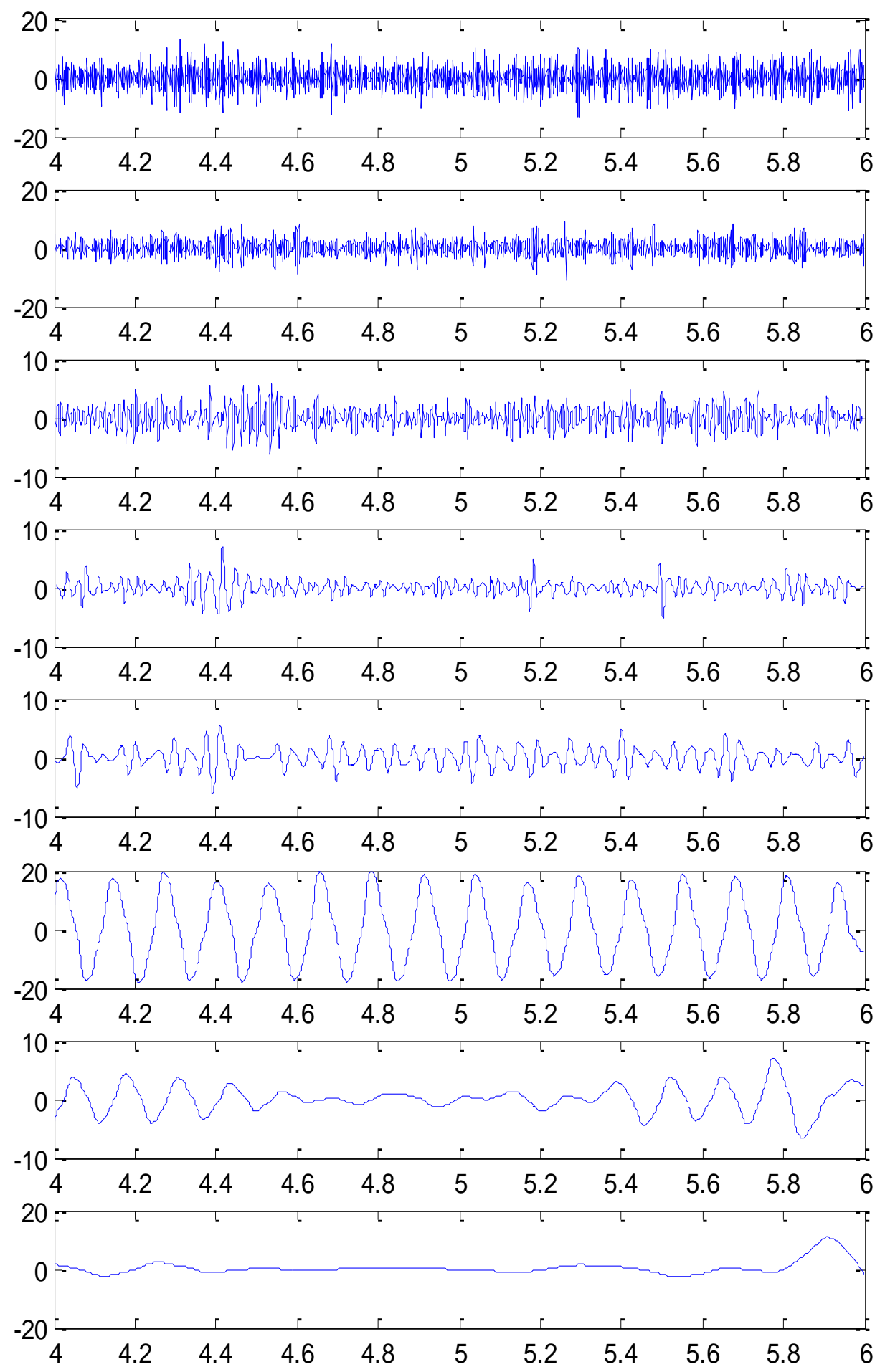
F3- Coeficientes de aproximação - Torno operando com UCP de 1,0mm
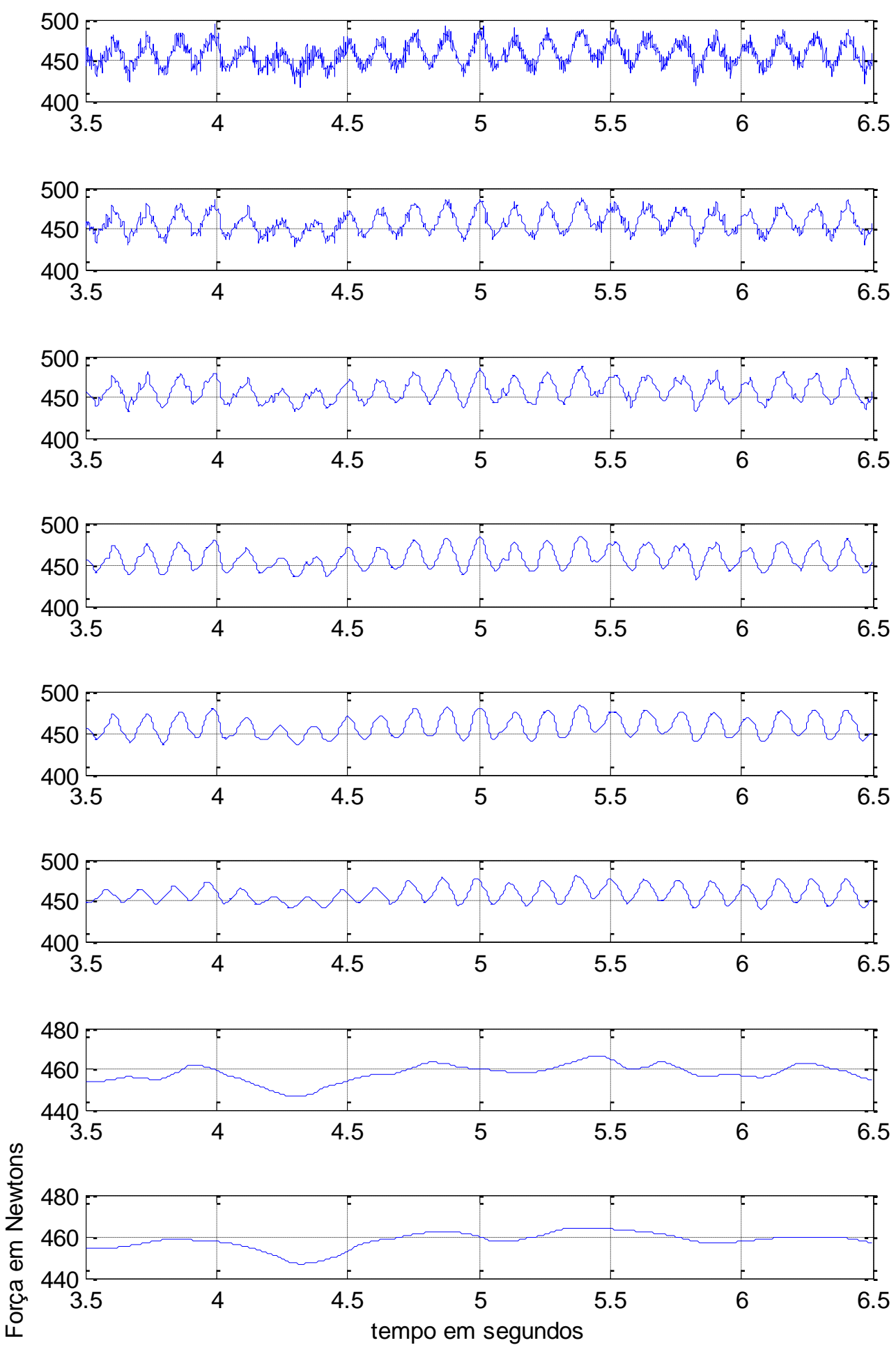
F4- Coeficientes de detalhe - Torno operando com UCP de 1,0mm
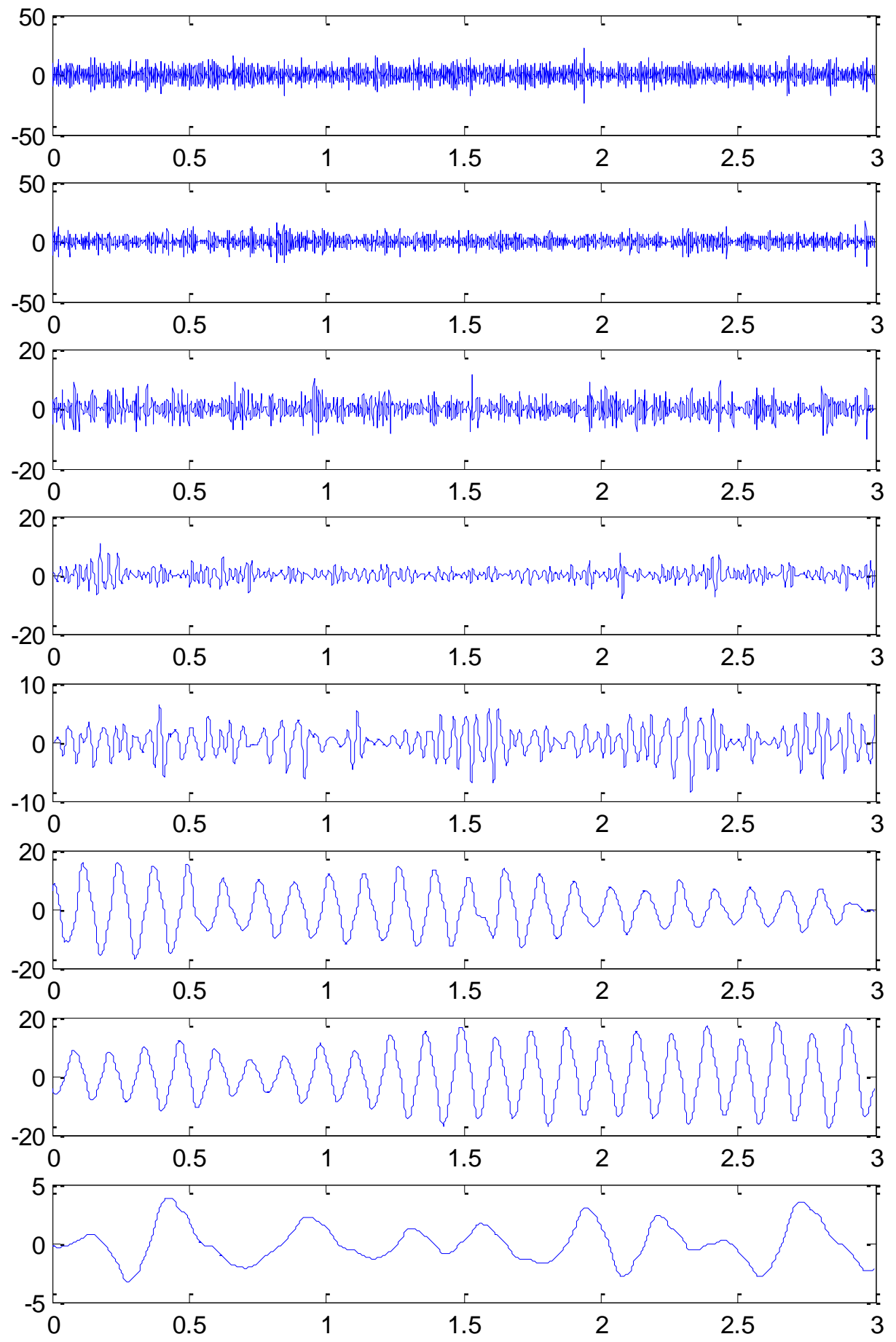
F5- Coeficientes de aproximação - Torno operando com UCP de 1,5mm
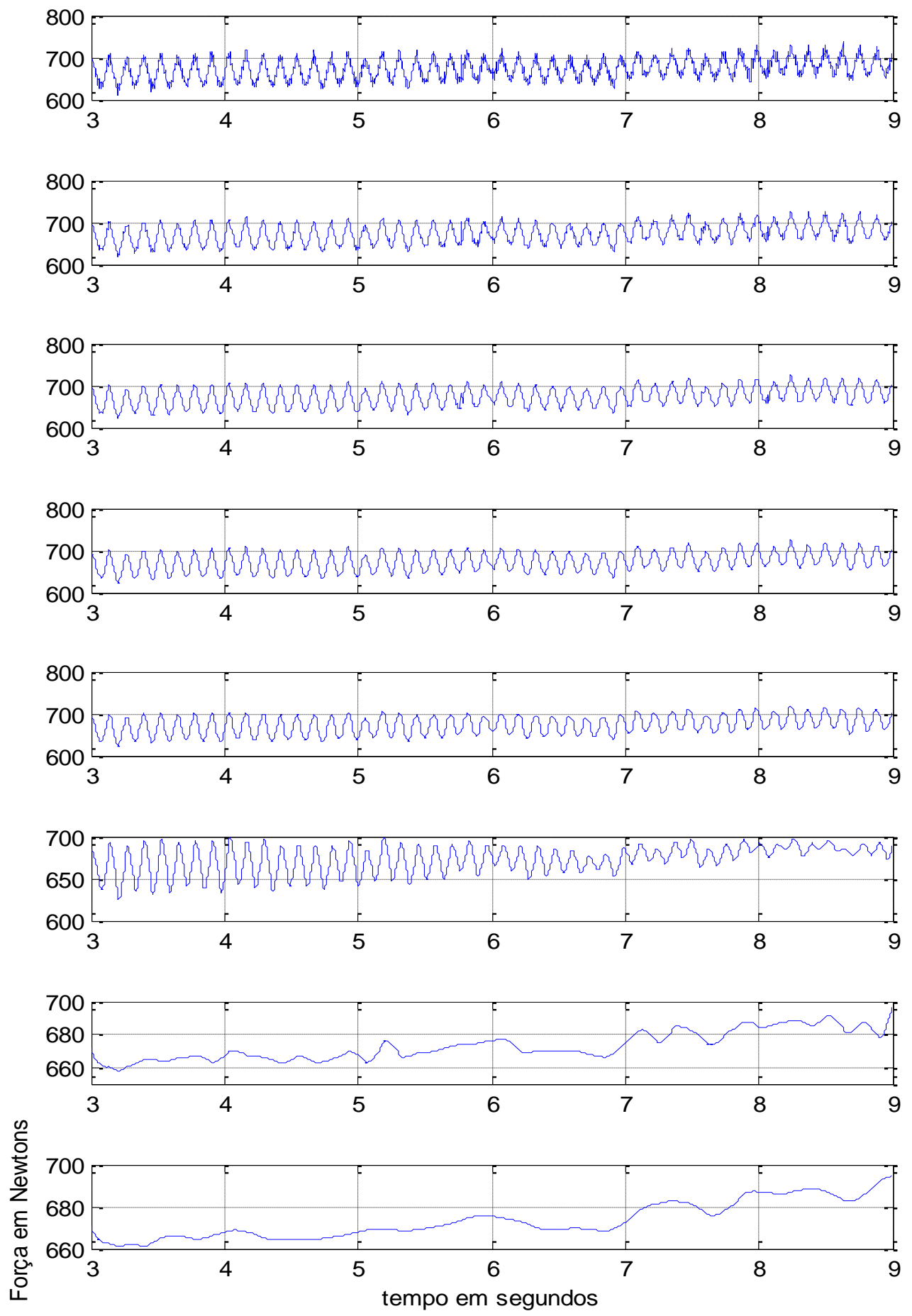
F6- Coef. detalhe - Torno operando com UCP de 1,5mm

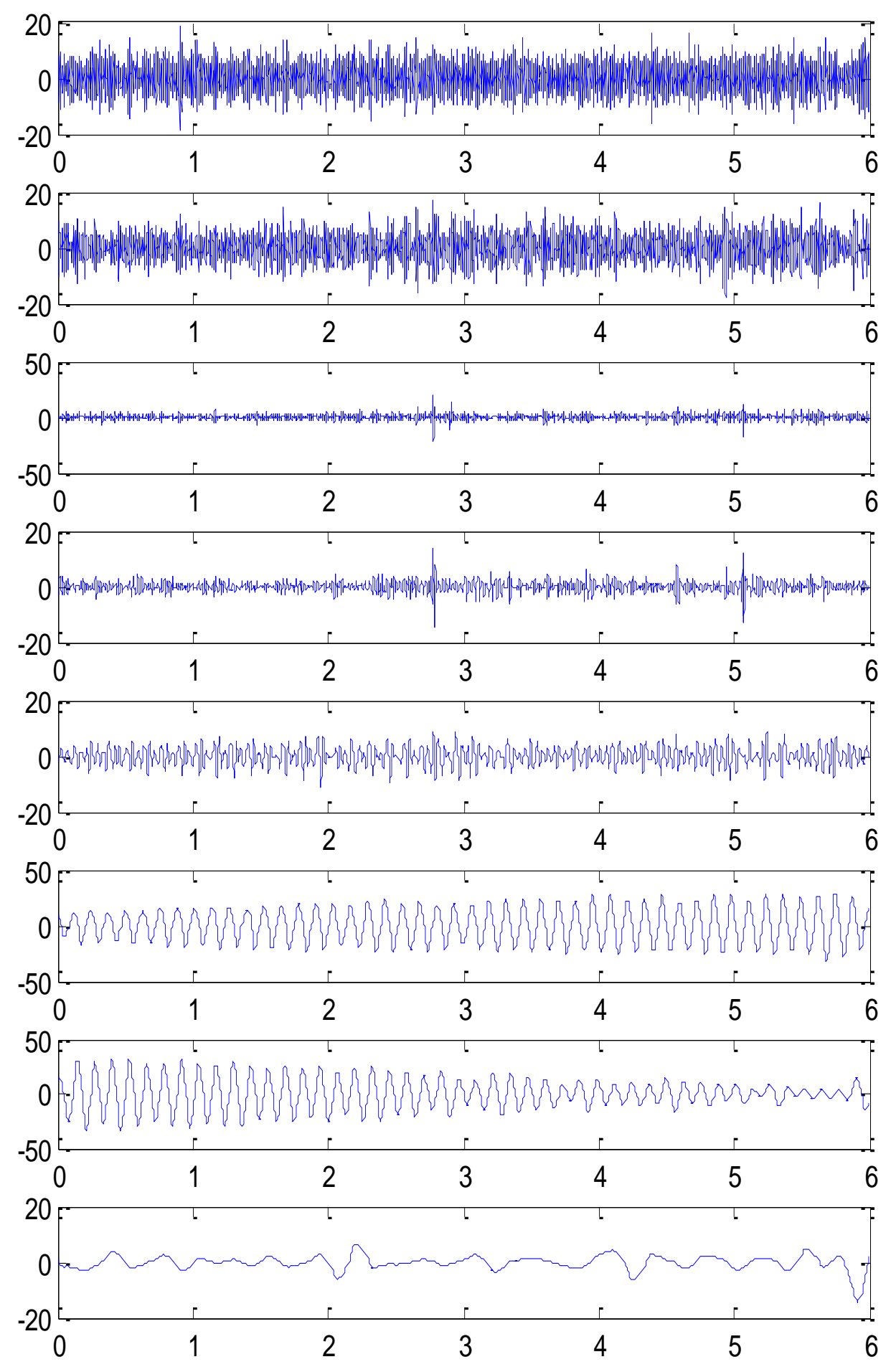


F7- Coeficientes de aproximação - Torno operando com Cl e UCP de 0,5mm
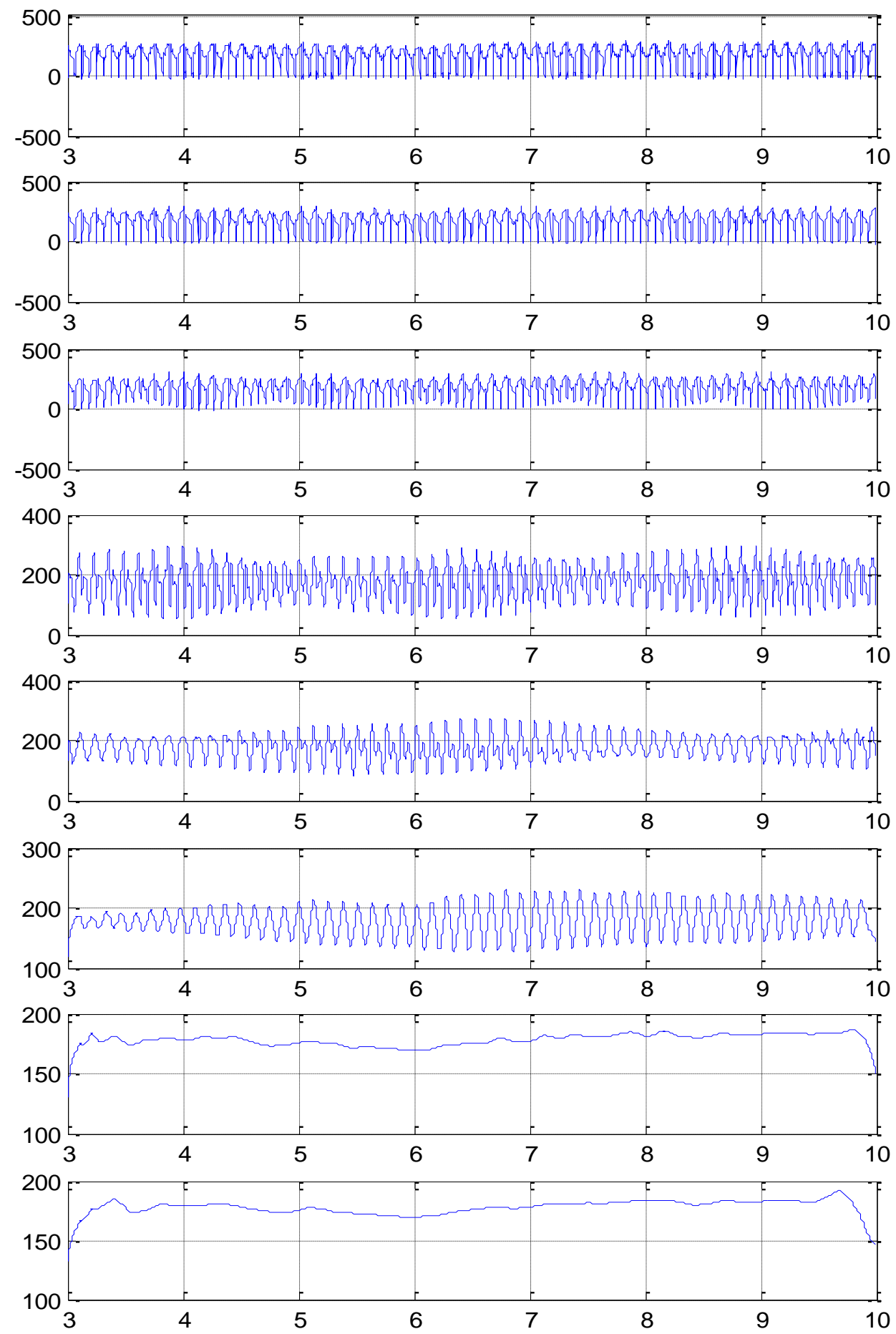
F8- Coeficientes de detalhe - Torno operando com Cl e UCP de 0,5mm
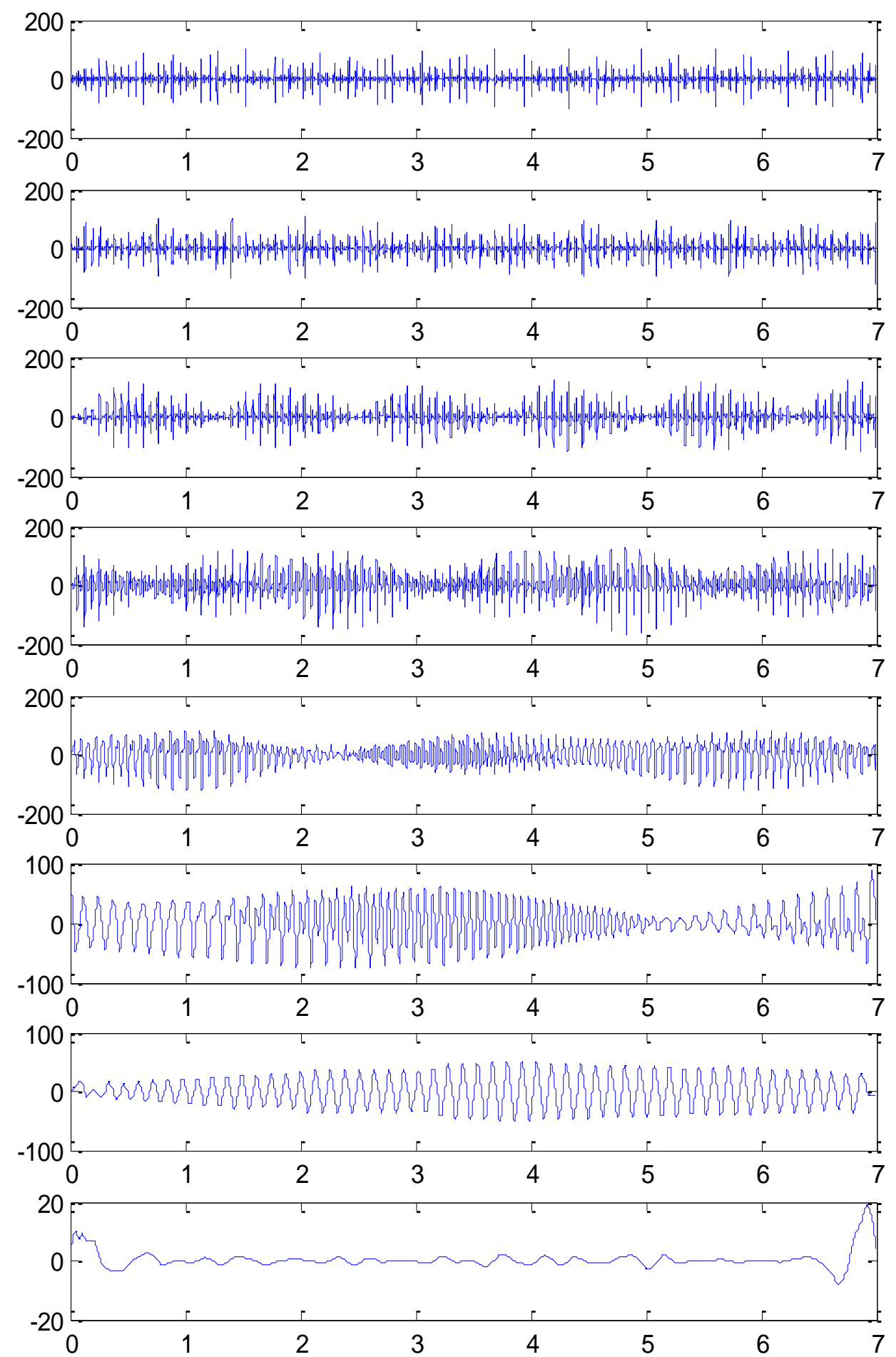
F9- Coeficientes de aproximação - Torno operando com Cl e UCP de 1,0mm
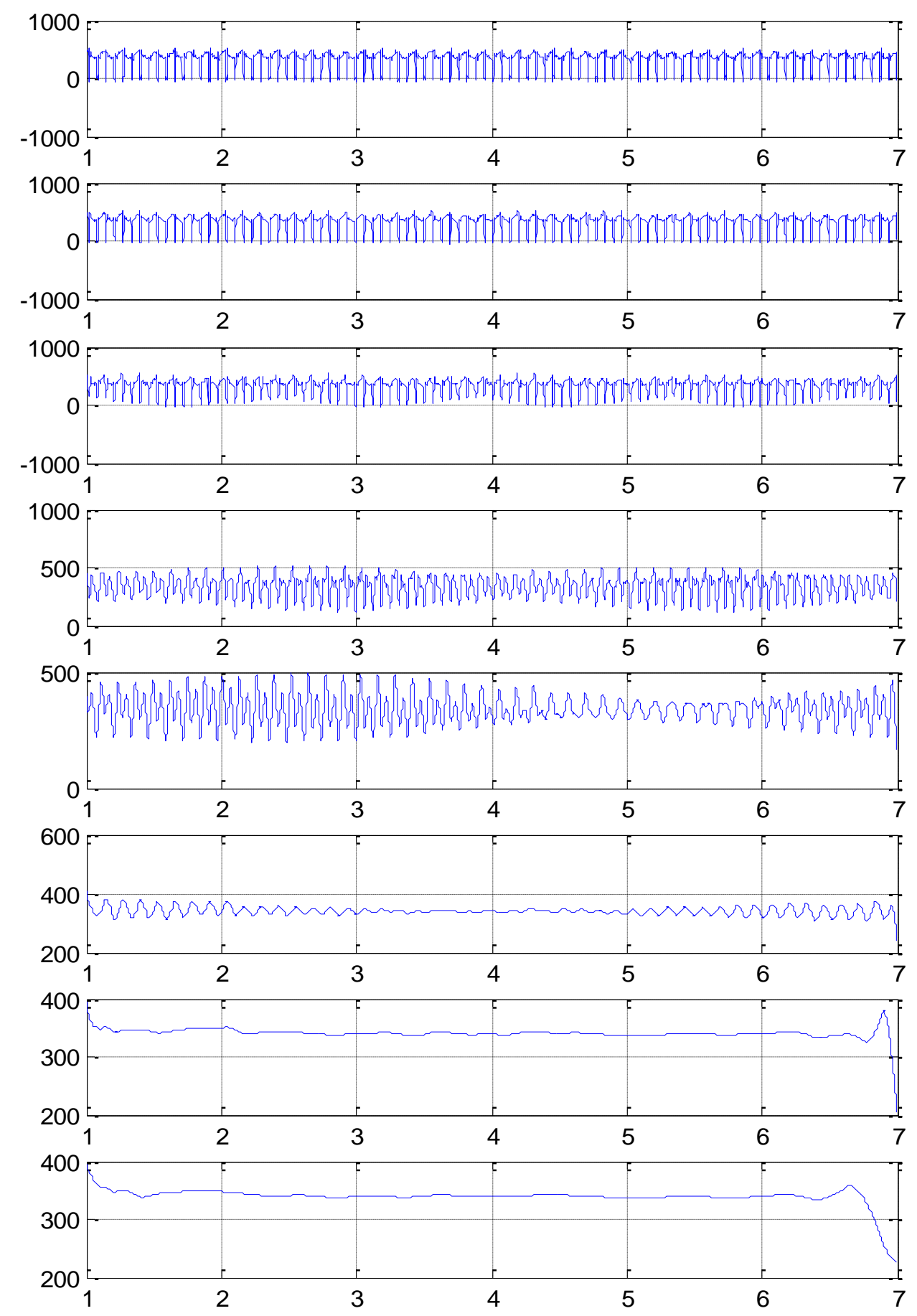
F10- Coeficientes de detalhe - Torno operando com Cl e UCP de 1,0mm

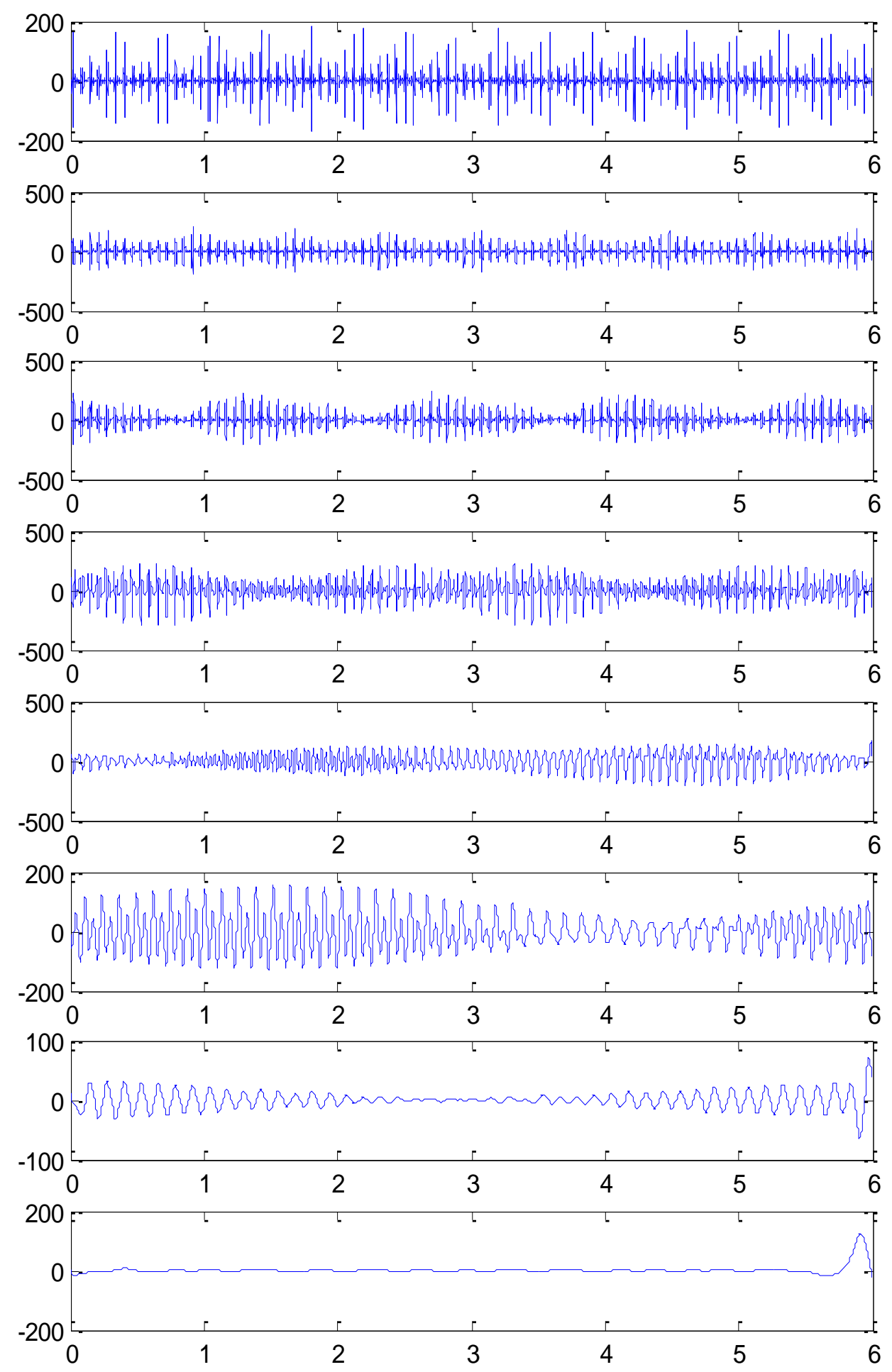


F11- Coeficientes de detalhe - Torno operando com Cl e UCP de 1,5mm
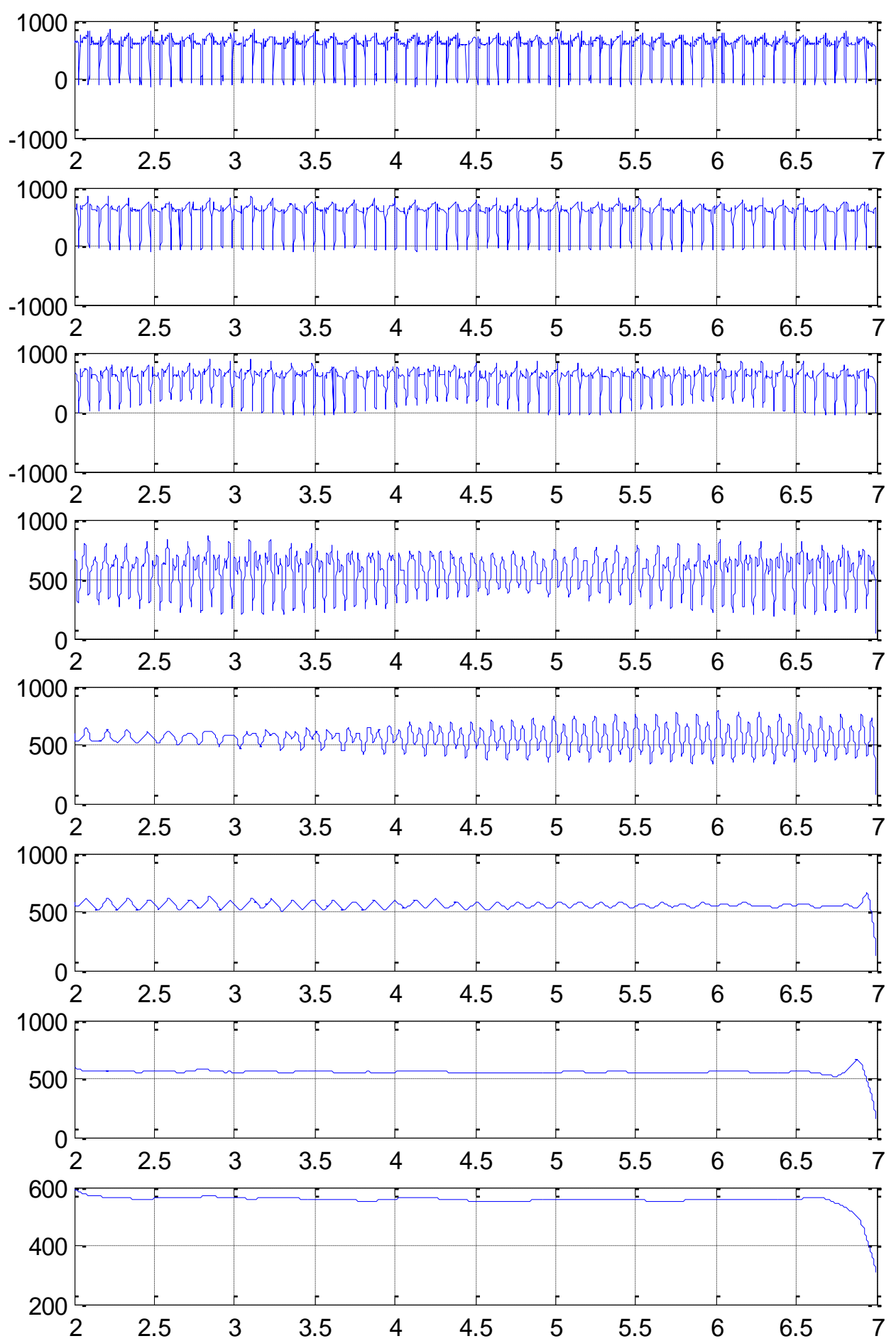
F12- Coeficientes de detalhe - Torno operando com Cl e UCP de $1,5 \mathrm{~mm}$

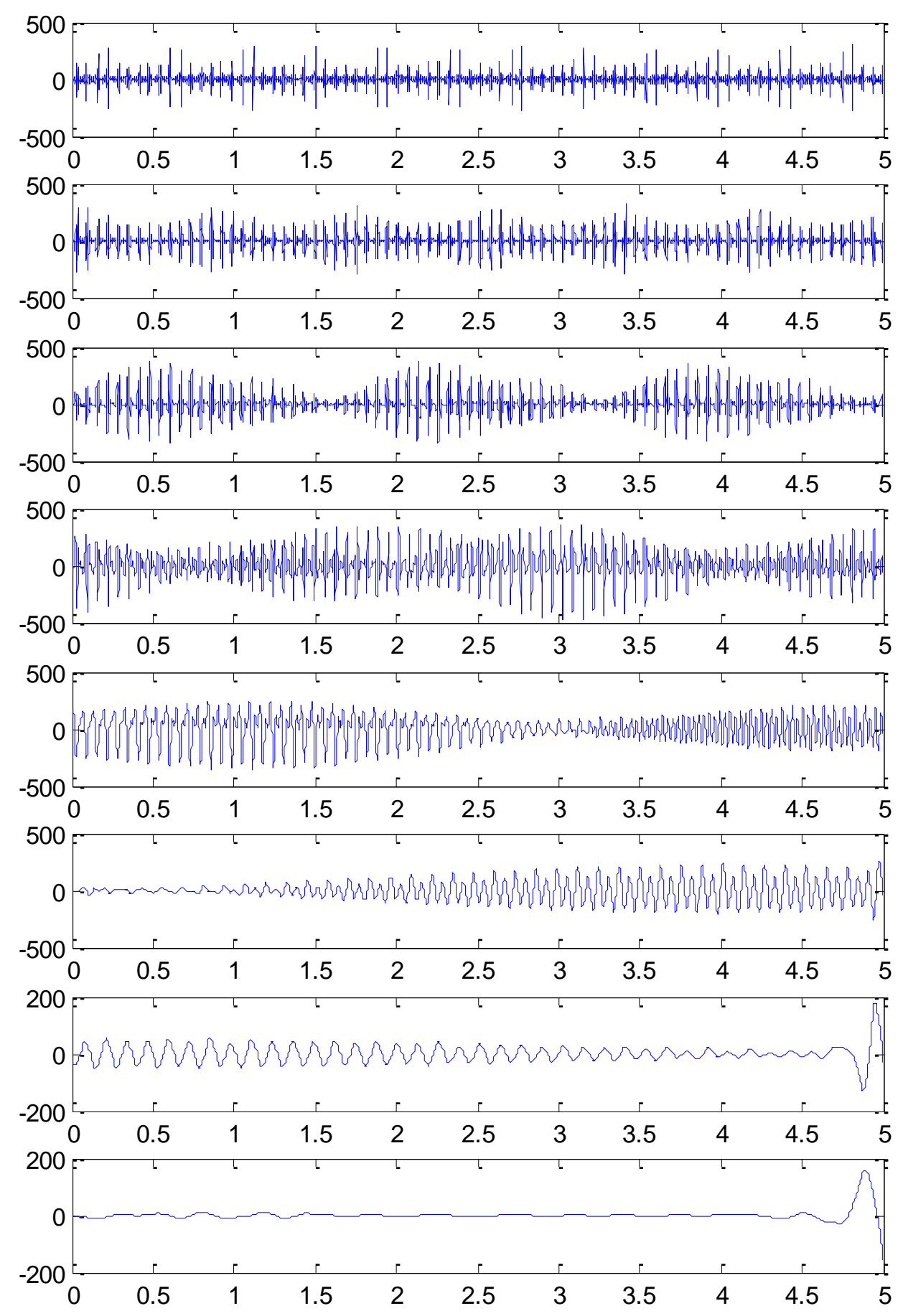

